\title{
EVALUATION OF THE RELIABILITY AND SENSITIVITY OF NDT METHODS FOR TITANIUM ALLOYS
}

McDonnell Aircraft Company

PREPARED FOR

Air force Materials Laboratory

JUNE 1974

DISTRIBUTED BY:

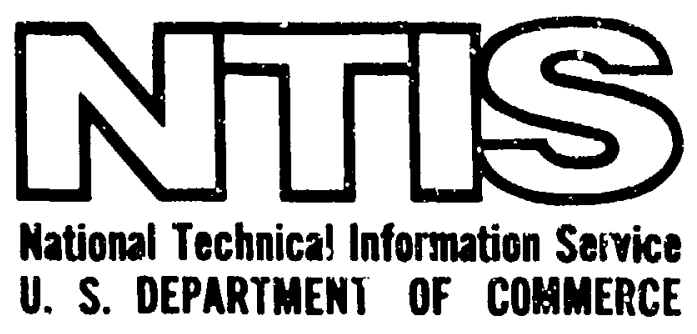




\section{NOTICE}

When Government dräwings, specifications, or other data are used for any purpose other than in connection with a definitely related Government procurement operation, the United States Government thereby incurs no responsibility nor any obligation whatsoever; and the fact that the government may have formulated, furnished, or in any way supplied the said drawings, specifications, or other data, is not to be regarded by implicatinn or otherwise as in any manner licensing the holder or any other person or corporation, or gonveying any rights or permission to manufacture, usg, or sell any patented invention that may in any /ay be reiated thereto.

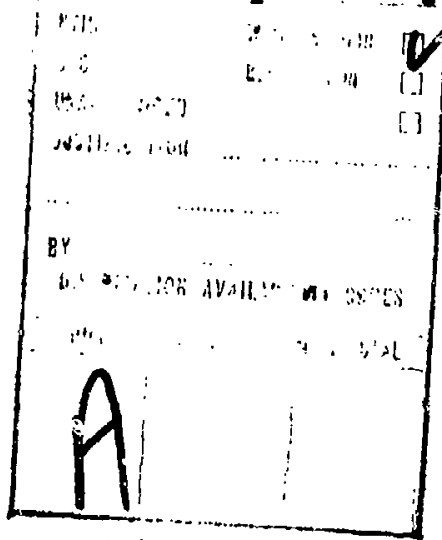

Copies of this report should not be returned unless return is required by security considerations, contractual obligations, or notice on a specific document.

AIR FORCE $/ 56780 / 15$ November $1974-450$ 
Unclassifled

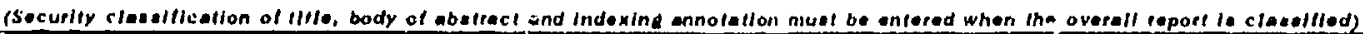

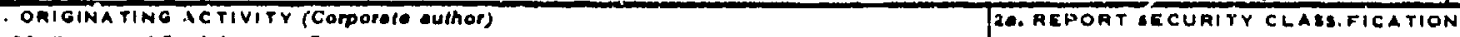
McDonne1l Alrcraft Co.

St. Louis, Mo. 63166

2b. CHOUP Unclassified

3. AEPONT TITLE

Evaluation of the Rellability and Sensitivity of NDT Methods for iitaniun Alloys

4. DESCRIPTIVE NOTE (rype of Peport and inclusivo deles)

Final Report, 1 May 1972 to 31 January 1974

5. AU THOA(s) (Fire? neme, middlo initial, leet name)

Robert. J. Lord

\begin{tabular}{|c|c|c|}
\hline $\begin{array}{l}\text { 6. AEPOAT OATE } \\
\text { June } 1974 \\
\end{array}$ & 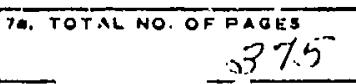 & 76. NO. OF HEFI \\
\hline O. CONTRACT OAGRANT NO. & \multicolumn{2}{|c|}{ Da. ORIGINATOR'SATPORT NUMBZH } \\
\hline $\begin{array}{l}\text { F33615-j2-C-1203 } \\
\text { b. PAOJeCr No. }\end{array}$ & \multicolumn{2}{|c|}{ AFM-TR-73-107 Vol II } \\
\hline 7351 & & \\
\hline c. & \multicolumn{2}{|c|}{ 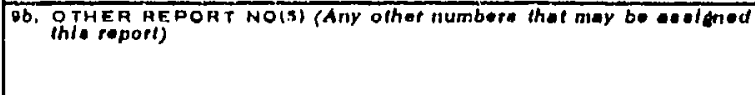 } \\
\hline
\end{tabular}

\begin{tabular}{|l|l|}
\hline 11. SUPPLEMENTARYNOTES & $\begin{array}{r}\text { 12. SPONSORING MILITAAY ACTIVITY } \\
\text { 11r Force Materials Laboratory } \\
\text { Wright-Patterson AFB, Oh10 } 45433\end{array}$ \\
\hline
\end{tabular}

The program objectives were to improve and to measure the detection capability of the penetrant, ulicrasonic, $x$-ray and eddy current methods. Several penetrant inspection purameters were investigated. The minimum penetrant dwell time required to detect a variety of discontinuities was found to be 10 minutes for water washable fluorescent penetrant and $20 \mathrm{minutes}$ for post-emulstflable fluoresrent penetrant. The minimum penetrant bleed-out time was 5 minutes for each. Ef ther dry powder and nonaqueous wet developer was fourd to be most effective. In u1trasonic inspection, contour sound entry surfaces signiflcantly affected Inspection for rad11 of curvature up to 4 inches. Near surface resolution was found to be affected by test frequency and sound entry surface cundition. It was also found that a significant difference in sound transmission characteristics can exist between the part to be inspected an? the reference standard used when inspecting titanium bar, plate, and Forgings In radlography, peneiraneters do not provide for a conisistent indication of thr. quality of a partlcular radlograph with the present thickness tolerances. During the detection capability portion of the program, it was determined that surface cracks with lengths of approximately 0.050 to 0.10 inch can be detected with a high probability in a production penetrant inspection. The probability of detection can be substantially increased by following a production penetrant inspection with a production surface wave and angle bean inspection, Also, the ef fectiveness of ultrasonic inspection of titantum ingot, billet, and forgings can be increased by using the shear wave as well as the longltudiral wave mode. The ultrasonic method was effective in detecting lype I alpina stabilized defects in titanium Ingot and billet as

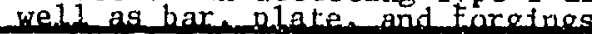

DD, FORM 1473

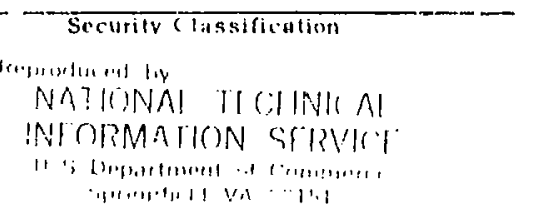




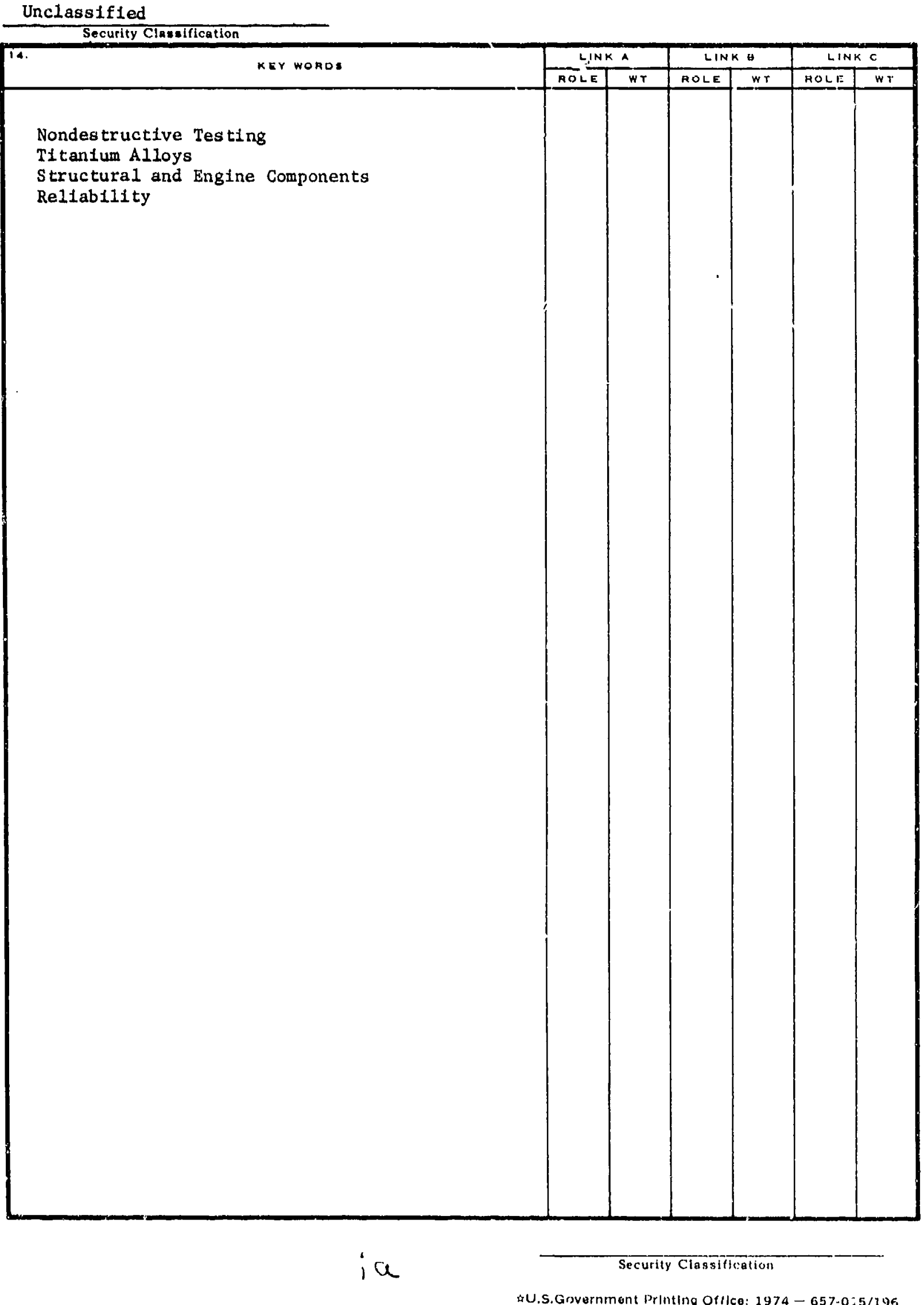

aU.S.Gevernment Printing Offlco: 1974-657-025/196 


\section{EVALUATION OF THE RELIABILITY AND SENSITIVITY OF NDT METHODS FOR TITANIUM ALLOYS}

Robert J. Lord

Approved for public release; distribution unlimited 
This Final Technical Report covers work perfnrmed under Contract F33615-72-C-1203 from 1 May 1972 to 31 January 1974. The work performed during the period 1 May 1972 to 28 February 1973 has previously been documented in AFML-TR-73-107. The work was performed under the direction of the Air Force Materials Laboratory, Wiright-Patterson Air Force Ease, Oh10, with Mr. James Holloway (AFML/LLP) as Project Engineer.

The work was performed by the McDonnell Aircraft Company, McDonnell Douglas Corporation, St. Louls, ilissourl, with the Aircraft Engine Group of the Ceneral Electric Company, Evendale, Ohio, acting as major subcontractor for the program. Mr. R. J. Juergeris of McDonnoll Alrcraft Corpany is the Program Managex. Mr. R. J. Lord of McDonnell Aircraft Company is the Principal investigator of the program and $\mathrm{Mr}$. H. Truscott of General Electric Company is the Principal Investigator for the engine portion of the program.

All of the Items compared in this report were comercial items that we we not develuped or manufactured to meet Government specifications, to with stand the testa to which they were subjected, or to operate as applied during this study. Any faflure to meet the objectives of this stuciy is no refiection on any of the commercial items discussed herein or on any manufacturer.

This report was subutted by the author in March 1974.

This technical report has been reviewed and is approved for fublication.

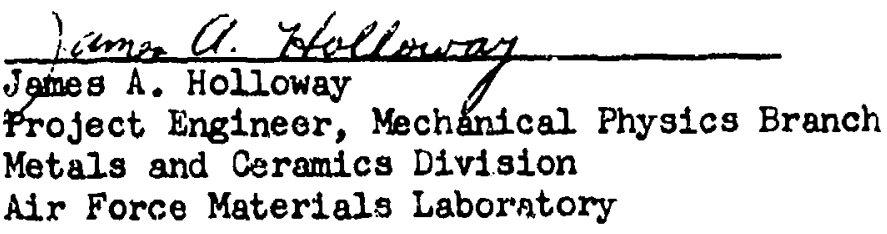

Dr. H. M. Burte

Chief, Mutals and Ceramics Division

Air Force Materials Laboratory 


\section{TABLE OF CONTENTS}

Section

Page

SUMMARY. . . . . . . . . . . . . . . . . . . . 1

INTRODUCIUN . . . . . . . . . . . . . . . . . . 2

IMPROVEYENT OF NONDESTRUCTIVE TESTING TECHNIQUES . . . . . . 3

1. Penetrant Method .................... . 3

a. Penetrant Systems ........ . . . . . 4

b. Specimen Fabrication .............. . 4

(1) Specimens With Tight Cracks......... . 5

(2) Specimens With Gross Cracks . . . . . . . . 5

(3) Porosity Specimens .......... . 7

c. Pre-Penetrant Drying. . . . . . . . . 8

(1) Water Wishable Penetrant System . . . . . . 8

(2) Post-Emulsifiable Penetrant System . . . . . 11

d. Penetrant Dlect-out Time . . . . . . . . . . II

(.1) Post-Emulsifiuble Penetrant System . . . . . 12

(2) Water Washable Penetrant System ........ 15

e. Fenetrant Dwell I'ime . . . . . . . . . 18

(1) Post-Emulsifiable Penetrant System . . . . . 20

(2) Water Washable Penet.rant System . . . . . . 23

f. Developer Effectiveness . . . . . . . . . . 25

(1) Post-Enulsifiable Penetrant System . . . . . 25

(2) Water Washable Penetrant System . . . . . 28

g. Emulsification Time . . . . . . . . . . 30

h. Water Washing Techniques . . . . . . . . . 35

(1) Post-Emulsifiable Penetrant System . . . . 35

(2) Water Washable Penetrant System . . . . . . 39

i. Vie::ing Jight Intensity . . . . . . . . . . . 45

(1) Test Procedure .. . . . . . . . . 45 
3. Effect of Mechanical Processing Prior To Penetrant Inspection .......... 54

k. Penetrant System Effectiveness . . . . . . 62

2. Radiographic Method .............. 64

a. Fabrication of Step Wedges .......... 64

b. Testing ............. 66

3. Ultrasonic Method . . . . . . . . . . 77

a. Surface Curvature Compensation ....... . 77

b. Near Surface Resolution ........... 103

(1) Specimen Fabrication .......... 203

(2) Testing of As-Received Material. . . . . 108

(3) l'esting of Machined Material . . . . . . . III

c. Sound Transmission Characteristics . . . . . 116

a. Effect of Surface Condition . . . . . . . . . 219

(1) Angle Beam Inspection-As-Rolled Plate . . . 219

(2) Straight Beam Inspection-Extrusion . . . . . 129

e. Inspection of Thin, Machined Parts . . . . . 130

(1) Pulse-E'cho ............. 130

(2) Reflector Plate Method ........... 132

(3) Ringing Method ........... 140

(4) Pitch-Catch ........... 140

f. Angle Beam Immersion T'esting of Plate . . . . . . 142 PROCESSING OF INGOI . . . . . . . . . . . . . 153

1. Ingot Melting . . . . . . . . . . . 154

2. Ingot Conversion to Billet, Bar,

Plate and Forgings ............ 158

3. Inspection of Irignt . . . . . . . . . . 170

a. Radiography ............. . . 170

b. Ultrasonic Inspection . . . . . . . . . . 170 
4. Inspection of 9 Inch Diameter Billet ........ 183

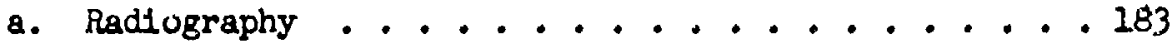

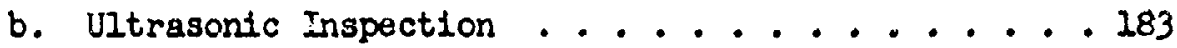

c. Macrootching and Anodic Etch ......... 189

5. Inspection of 6 Inch Diameter Blllet ........ 195

a. ULtrasonic Inspection ........... 195

b. Radiographic Inspection . . . . . . . 198

6. Correlation of Inspection Results ......... 203

7. Sumnary of NDT Results ............. 203

NDT Capability . . . . . . . . . . 205

1. Surface Connected Cracks ............ 205

a. Tension - Tension Fatigue Specimen Fabrication . . 205

b. Liquid Penetrant Tescing of Tension -

Tension Fatigue Specimens .......... 20

(1) Laboratory Inspection ......... . 207

(2) Production Inspection ............210

(3) Overhaul Inspection ...........212

c. Ultrasunlc Surface Wave Testing ........215

(1) Production Inspection ..........215

(2) Luboratory Inspection ........... 224

d. Ultrasunic Contact Angle Beam Testing . . . . . 226

(1) Production Inspection .......... 226

e. Overall. Production NDT Capability ....... 231

f. Laboratory Eddy Current Inspection . . . . . 232

8. Radiographic Inspection of Surface Cracks . . . . 237

h. Bending Fatigue Specimen Fabrication .......238

1. Liquid Penetrant Testing of Bending

Fatigue Specimens . . . . . . . . . 238

j. Radioactive Penetrant Testing ......... 242 
k. Eady current Inspection of Fastener Holes . . . . 244

1. Verification of Surface Crack Size . . . . . . 259

2. Porosity ................. . . 259

a. Ultrasonic Method . . . . . . . . . . . 259

b. Radiographic Method................. 266

c. Penetrant Methoa . . . . . . . . . . 266

3. Internal Cracks . . . . . . . . . . . . 268

a. Specimen Fabrication ............ 268

b. Ultrasonic Testing . . . . . . . . . . 270

c. Verification of Internal Crack Size . . . . . . 282

4. Segregates - Jet Engine Disk Porgings . . . . . . . 284

a. Radiographic Inspection ............ . 284

b. Penetrant Inspection . . . . . . . . . . 286

c. Ultrasonic Inspection . . . . . . . . . . 286

5. Segregates - Plate .. . . . . . . . . . 2 298

a. Ultrasonic Inspection . . . . . . . . . . . 298

b. Radiographic Inspection ... . . . . . . . 305

6. Segregates - Bar .............. 306

a. Utrasonic Inspection . . . . . . . . . 306

b. Radiographic Inspection . . . . . . . . . . 324

7. Segregates - Airframe Forgings . . . . . . . . 324

a. ULtrasonic Inspection ... . . . . . . . . 324

8. Metallographic Examination of Segregates

In Bar, Flate, and Forgings . . . . . . . . . . . 329

VI

CONCLUSIONS . . . . . . . . . . . . . . . . 348

VII

FECOMMFNDATIONS . . . . . . . . . . . . . 350

VIII

RFFERENCES .................................... 551 
LIS'I OF ILLUSTRATIONS

Figure

Title

Page

1

2

I'ixture for Stressing Specimens . . . . . . . . . . . 5

Shaker Table Test Set-Up . . . . . . . . . . . 6

Porosity in Hand Forged Billets . . . . . . . . . . . . 7

Photomicrographs uf Stress Corrosior. Cracks and Shake. Table Produced Cracks . . . . . . . . . . . . . . . . 8

Photomicrographs of Porosity . . . . . . . . . . . . .

Pre-penetrant Jxying T'est Program . . . . . . . . . . . 10

Test Plan for Penetrant Bleed-out Time Study (Postemulsifiable Penetrant System) . . . . . . . . . . . . 13

Hffectiveness of Vapor Degreasinf: Between Penetrant

Inspections . . . . . . . . . . . . . . . . . . 14

iffect of Penetrant Bleed-out Time (Post-emulsifiable

Penetrant System with Dry Powder Developed) . . . . . . . 17

Effect of Penetrant DwelJ. 'lime (Post-emulsifiable Penetrant 15 Minute Bleed-out l'ine) . . . . . . . . . . . . . . . .

Hffect of Penetrant Dweli Time (Water Washable Penetrant) . . 24

Relative lifrectiveness of Developer on Small Crack

Indications (Post-emulsifiable Penetrant - 20 Minutes

Dwel1 'l'ime - 15 Minutes Bleed-out Time) . . . . . . . 26

Relative liffectiveness of Developer for Detection of Gross

Cracks (Post-emulsifiable Penetrant - 20 Minutes Dwell lime -

15 Minutes Bleed-out Tine) .. . . . . . . . . . . . 27

Relative Effectiveness of Developer For Detection of Smaller,

Tighter Cracks (Water Washable Penetrant) . . . . . . . . .29

'Lest Plan for thulsification l'ime Stucly . . . . . . . . . . . . .

liffect of Limulsification Time (Post-emulsification Penetrant System - 20 Minutes Penetrant Dwell Time and 15 Minute

Penttrant Bleed-out 'I'ime) , . . . . . . . . . . . . 33

Degradation in Penetrant Indications Due to Overwashing (Post-emulsifiable Penetrant System) . . . . . . . . . 38 
LIST OF ILLUSTRATIONS (Continued)

Figure

Title

Page

18 Degradation in Fenetrant Indications Due to Overwashing

(Water Washable Penetrant Systen). . . . . . . . . . 41

19 Effect of Wate: Washing Time (Spray Washing - 40 PSI/

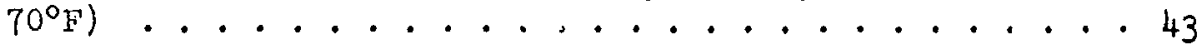

20

Luminosity Curves . . . . . . . . . . . . . 47

21 Brightriess Ratio as a Function of Visible Light and

Ultrariolet Light Intensity . . . . . . . . . . 49

22 Penetrant Indications Under Various Levels of Visible

Light iULtraviolet Light Level is 1000 Microwatts per:

$\mathrm{cm}^{2}$ ). . . . . . . . . . . . . . . . 50

23 Penetrant Indications Under Various Levels of Visible

Light (Untraviolet Light Level is 2000 Microwatts

per $\mathrm{cm}^{2}$ ). . . . . . . . . . . . . . . . 51

24 Brightness Ratio as a Function of Visible Light and

Ultraviolet Light Intensity (Fatigue Crack) . . . . . . . 55

Reprosentative Test Procedure . . . . . . . . . . 57

Effeci of Mechanical Processing Upou Fenetrant Indications

of Tight Cracks . . . . . . . . . . . . . . . 59

Effect of Mechanical Processing Upon Penetrant Indications

of Gross Cracks . . . . . . . . . . . . . . . 60

2E Radiographic Test Specimens . . . . . . . . . . 65

Test Specimens Arrangement . . . . . . . . . . . 67

Step Wedges with MIL-STD-453 Penetrameters . . . . . . . 69

Log Relative Exposure Used to Evaluate the Data . . . . 72

Convex Curvature Reference Standards . . . . . . . . . 78

Concave Curvature Reference Standards . . . . . . . 79

Concave Ultrasonic Specimens . . . . . . . . . . . . 80

Flat Surface Reference it idırd . . . . . . . . . . 31

Tests to Establish Difference in Sound Iransmission

Characteristics . . . . . . . . . . . . . . 84 
LIST OF ILLUSTRATIONS (Continued)

Fi.gure

Title

$\underline{\text { Page }}$

37

38

Typical Curves for Contour Surface Effect . . . . . . . 96

Variation in $\alpha B$ Difference as a Function of Search Unit and Ultrasonic Instrument (Titanium Specimens - 3/64 Inch Diameter Flat Bottom Hole - 3/4 Inch Metal Travel). . . . 9 97

40 Decibel Difference Between Flat Surface Response and Curved Surface Response as a Function of Radius and

Metal Iravel (3/4 Inch Diameter, $5 \mathrm{MHz}$, SII Search Unit). . 101

41 Die Forging Used for Near Surface Resolution Study . . . . 108

42 Near Surface Resolution Specimens - As-Rolled Plate . . . . 104

43 Near Surface Resolution Specimen Configuration ...... 105

44 Near Surface Resolution Specimens . . . . . . . . . . 107

45 Response from 3/64 Inch Diameter Flat Bottom Hole in 4 Inch Plate As-Rolled (3/4 Inch Diameter, $5 \mathrm{MHz}$, SIZ

Search Unit with 9 Inch Water Path) ......... 112

46

47

48

49

50

51

52

53

54

55

Relative Response Vs Metal TraveL... . . . . . . . 120

Relative Resnonse Vs Metal Iravel ............121

Angle Beam Test Specimen .............. . . 127

Test Specimen Configuration . . . . . . . . . . 131

Definition of Near Surface Resolution and Back Surface

Resolution ................. 133

Typical Cathode Ray Tube Displays for Pulse Echo Tests . . . 135

Increase in Resolution With $25 \mathrm{MHz}$ Test Frequency

(3/64 Irch Diameter Hole, .094 Inch Metal Travel) . . . . 136

Increased Resolution of Back Surface With Increased

T'est Frequency . . . . . . . . . . . . . 137

Reflection Plate Method .............. 133

Test Setup for Reflector Plate Tests . . . . . . . 133

Sound Entry Positions . . . . . . . . . . . . 243

First Melt Ingot . . . . . . . . . . . . . . 154

Seeds Used to Intentionally Produce Alpha Segregation . . . 156

Pattern for Sceding First Melt . . . . . . . . . 157 
LISI' OF ILLUSIRATIONS (Continued)

\begin{tabular}{|c|c|c|}
\hline Figure & Title & Page \\
\hline 60 & Final Melt Ingot . . . . . . . . . . . & . . 155 \\
\hline 61 & Expected Ingot Defects After Second Melt . . .... . & . . 159 \\
\hline 62 & Conversion of Ingot to 9 Inch Round Billet..... & . . . 160 \\
\hline 63 & Conversion of 9 Inch Billet From ingot Top ..... & ... 161 \\
\hline 64 & Conversion of 9 Inch Billet From Ingot Middle . . . & ... 162 \\
\hline 65 & Conversion of 9 Inch Billet From Ingot Bottom . . . & . . 162 \\
\hline 66 & Two Pieces of One and One-half Inch Thick Plate . . . & ... 163 \\
\hline 67 & Two-Inch Square Bar $\ldots \ldots \ldots$ & . . . 164 \\
\hline 68 & Airframe Forging . . . . . . . . . . . & ... 165 \\
\hline 69 & Jet Engine Disk Forgings . . . . . . . . . . & . . 166 \\
\hline 70 & Cross Section View of Jet Ingine Disk Forging ... & ... 166 \\
\hline 71 & Test Forging Simulating Airframe Component . . . . & . . . 167 \\
\hline 72 & $\begin{array}{l}\text { Schematic Showing Exposure Layout for Rediographic } \\
\text { Inspertion of Ingot . . . . . . . }\end{array}$ & $\cdots \cdot 171$ \\
\hline 73 & Arrangement fior Radiographic Inspection of Ingot . . & $\cdots 171$ \\
\hline 74 & Schematic Showing Axial and Circumferential Dimensions & s... 173 \\
\hline 75 & Ultrasonic Inspection of Ingot $\ldots \ldots$ & . . 175 \\
\hline 76 & Scan Plan for Ingot $\ldots \ldots \ldots$ & $\cdots 174$ \\
\hline 77 & Search Unit Acoustical Aralysis $\ldots \ldots$ & - 177 \\
\hline 78 & Sound Beam Path $\ldots \ldots \ldots$ & . 178 \\
\hline 79 & Ultrasonic Reference Standards for Ingot Inspection . & . . 179 \\
\hline 80 & $\begin{array}{l}\text { Schematic Showing } \text { Ixposure Layout for Radiographic } \\
\text { Inspection of } 9 \text { Inch Billet } . . . . . . .\end{array}$ & ... 3.34 \\
\hline 81 & $\begin{array}{l}\text { Spiral Scan During Ultrasonic Inspection of } 9 \text { Inch } \\
\text { Dianeter Billet } . . .\end{array}$ & . . \\
\hline $8 \%$ & 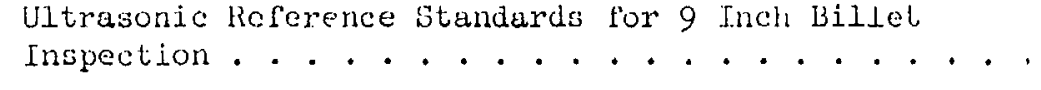 & \\
\hline
\end{tabular}




\section{LIST OF ILLUSTRATIONS (continued)}

Figure

83

84

85

86

87

88

89

90

91

y2

93

94

95

96

97

98

99

100

101

10:

10.3

104

Title

Page

Iypical Macroetohed Billet Surface From Seeded Infot . . . 191

Typical Mecroetched Surface in Commercial 9 Inch Billet . . 192

Discontinuity in 9 Inch Billet (1-2B) . . . . . . . 193

Ultrasonic Inspection Set-Up . . . . . . . . . . . I96

Ultrasonic Reference Standards for 6 Inch Billet

Inspection . . . . . . . . . . . . . . . . 199

Schematic Showing Exposure Layout for Radiographic

Inspection of 6 Inch Billet . . . . . . . . . . 198

Summery of NIT Results . . . . . . . . . . . 204

Fatigue Specimen ............. 206

Surface Wave Scanning ............. 218

Distance-Amplitude Correction (DAC) Curves for 3

Representative Technicians . . . . . . . . . . 219

Test Set.up Used to Measure Sound Transmission Differences . 227

Procedure for Distance - Amplitude Correction Curve . . . 229

Scan Plan for Contact Angle Beam T'esting . . . . . . . 228

Eady Current Sensitivity Standard . . . . . . . . 233

Configuration of Bending Fatigue Cracied Specimens . . . . 239

Specimen for 0.250 Diameter Holes . . . . . . . . 245

Specimen for 0.375 Diameter Holes . . . . . . . 246

Specjmen for 0.750 Diameter Holes . . . . . . . . 247

Secondary Cracks in Fastener Hole ........... 248

Titanium Eddy Current Sensitivity Standard . . . . . . 250

Scan Inde: Used During Eddy Current In pection . . . . . 249

Photogreph of Typical Fracture Surfices . . . . . . 252

$x 1:$ 


\section{IIST OF ILUUSTRATIONS (Continked)}

Figure

105

106

.207

108

109

110

111

112

113

114

116

117

118

119

1.20

121

122

123

124

126

Title

$\underline{\text { Page }}$

Cathode Ray Tube Presentation of Crack Response . . . . . 258

Photographs of Fracture Surface of Surface Cracks . . . . 261

Typical Porosity In Hand Forged Billets . . . . . . . 264

Penetrant Indications of Porosity . . . . . . . . . . 267

Diffusion Bonding of Internaliy Cracked Specimens . . . . . 269

Reference Standard . . . . . . . . . . . . ?72

Sound Beam Angle for Jet Engine Inspection of Internal

Cracks (Laboratory) . . . . . . . . . . . . . 273

Setup for Straight Bean l.mersion Testing of Internally

Cracked Specimens ............... . 278

Typical Responses from Internal Cracks During Straight

Beam Immersion Tests ............... 281

Photographs of Fracture Surface of Internal Iracks . . . 283

Radiography of Disk Forgings ............ . 285

Areas Machined on Disk Forg:ng . . . . . . . . . 287

Sound Beam Directions for Dfsk Forging Inspection . . . . . 289

Circumferential shear I spection . . . . . . . . . 290

Defect Location Summary for Engine Inspector A . . . . . .292

Defect Location Summary for Engine Inspector B . . . . . . 293

Total UItrasonic Indications From Engine lroduction

Inspections of Disk Forgings ............. . 294

Total Ultrasonic Indications from AFML Inspections of

Disk Forgings . . . . . . . . . . . . . . 297

High Noise Lerel In Plate After Subtractiun of $19 \mathrm{~dB}$. . . . 299

High Noise Level in Plate After Subtr cetion of $7 \mathrm{~dB} \ldots 299$

Scail Plan for Plate . . . . . . . . . . . . 301

Typical Response from Discontinuity in Plate . . . . . . 302 


\section{LIST OF ILLUSTRA'IIUNS (Continued)}

Figure

Witie

Page:

1.7 Location of Defects ir Plate A................. 304

1:3 Photographs of Cathode Ray Iube Presentation of Back Surface Response and Noise in Bar at Several Gain Levels " 307

129 Scan Plan for Bar . . . . . . . . . . . . . . . . . . . . . . .

130 Data Presentation . . . . . . . . . . . . . 310

131 Layout of Bars for UItrasonic Inspection . . . . . . . 310

132 Location of Defects in Bar . . . . . . . . . . . . 311

133 Sound Intry Points Used to Establish the DAC Curve . . . . 325

134 Scan Plan for Airframe Forkings . . . . . . . . . . 327

135 Ultrugonic Indications in Airframe lorgings . . . . . . . . 328

136 Photomicropraphs of Segregate in Plate A, Section 3

(Response was Greater 'hiain No. 5 Flat Bottom Iolc) . . . . ??

137 Photomicrographs of Segregates in Plate A, Section 17 (Response was Equal to a No. 2 Fat Bottom Hole) . . . . . 333

138 Thotomicrographs of Segregate in Plate A, Section 18 (Response was liqual to No. 2 lilat Bottom Hole) . . . . . . 334

139 Photomicrugrephs of Sigregate in Bar 1-2A2B, Section 1 (Response was Less Then No. 2 flat Bottum Hole) . . . . . 336

1h0 I'hotomicrographs of Segregate in Bar 1-2A2B, Section 6 (Reoponse was Équal to No. 2 Flat Bottom Hole) . . . . . . 337

1.41. Photomicrographs of Segregale in Bar 1-2A2H, Section 4 (Response was Greuter 'Than No. 5 Flat Bottom Hole) . . . . 338

142 Photomicrocraph of Uegregute in Bar 1-2A2E, Section 5 (Response was Equil to No, 2 llat Bottom llole . . . . . . 339

143 Typical Airframe Forging Microstructure . . . . . . . . . 340

Lhh Location of: Metallographic Cross Sections in Disk Forgings . . . . . . . . . . . . . . . . . 345

Lh) Discontinuities ln Disk forging . . . . . . . . . . 346

i!f Ihotomicrofraph of Discontinuity in in Disk forging

? (ive 'Tuble 98) . . . . . . . . . . . . 347 
LIST OF' TABLES

Table

Page

Minimum Bleed-out Time for Post-emulsifiable System . . . . . . . 16

2 Minimum Bleed-out Time for Water Washable Penetrant

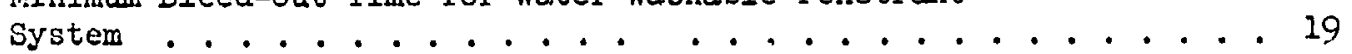

3 Minimum Penetrant Dwell Time (Post-emulsifiable Penetrant

System . . . . . . . . . . . . . . . . 20

4 Minimum Penetrant Dwell Time (High Sensitivity Water Washable

Penetrant System) .................... . 24

5 Relative Effectiveness of Developer Types (Post-emulsifiable

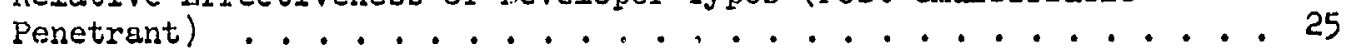

Relative EfPectiveness of Developer Iypes (Water Washable

Penetrant) .......................... 28

Effective Eulsification Range . . . . . . . . . . . . . 32

Water Washing Parameters . . . . . . . . . . . . . . . 36

Acceptable Washing Conditions (Post-emulsifiable Peneirant

System) . . . . . . . . . . . . . . . . . . . 37

.0 Acceptable Washing Conditions (Water Washable Penetrant

System) . . . . . . . . . . . . . . . . . . . 40

11

Washing Parameters .. . . . . . . . . . . . . . . . 44

Efferi of Remover Concentration on Indication Brightness . . . . . . 52

Effect of Wash Time on Indication Brightness . . . . . . . . . 52

Brightness Measurements Made on Tatigue Crack . . . . . . . . . 53

Effect of Mechanical Processing Prior to Penetrant Inspection . . . 58

Relative Effectiveness of Penetrant Systems . . . . . . . . . . 63

Exposure Condtions ................... 68

Contrast and Resolution as a Function of Kilovoltage

and Ihickness . . . . . . . . . . . . . . . . . . . 71

19 Comparison of Hilm Densities for Fxposures Under Same

Conditions Using Isovolt 400 and PG 300 X-Ray Machines. . . . . . $T^{4}$

Variation In Detemination in Radiographic Quality . . . . . . . 76 


\section{LIST OF TABLES (Continued)}

UItrasonic Instruments and Irarsducers Used for Curved

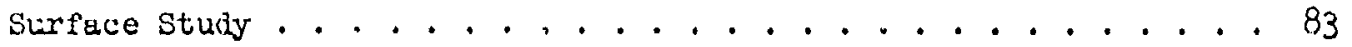

Response Ratio of Flat Surface Response $\left(I_{F}\right)$ to Curved Surface

Response $\left(I_{C}\right)$ - Titanium Specimens . . . . . . . . . . . 86

Response Ratio of Flat Surface Response $\left(f_{F}\right)$ to Curved Surface

Response $\left(I_{C}\right)$ - Aluminurn Specimens . . . . . . . . . . 93

Metal Trarely Used for Near Surface Resolution Study . . . . . . 106

Near Surface Resolution of As-Received Specimens (3/64 Inch

Diameter Flal Bcttom Hole Response) . . . . . . . . . . . . 110

Near Surface Resolution of As-Recaived specimens (5/64 Inch

Diameter Flat Bctton Hole Responise) . . . . . . . . . 110

Near Surface ikesolution of Machined Speciroens (3/64 Tnch

Diameter Flat Rotion Hole Response) ............. 114

Near Surface Resolution of Machired Specimens (5/64 Inch

Diamater Flut Botton liole Response) . . . . . . . . . . 115

Maximun Scan Index for Machined Sound lintry Surface

(Metal. Travels Are lndicated In Parenthesis) . . . . . . . . . . 127

Difference in Response Between PJ ite and Forgine And Aá'TM -

Iype Reference Stsndrrads . . . . . . . . . . . . . . . i28

Immersion Pulse Echo Testing . . . . . . . . . . . . . 134

I'est Results for Reflector Plate l'esting . . . . . . . . . . . 2 39

Results of Pitch-Catch l'ests . . . . . . . . . . . . . . 141

Ultresonic Noise During Angle Beam Immersion 'l'esting of'

2 Inch As-Rollea Plate . . . . . . . . . . . . . . . 144

Ultrasonic Noise During Angle Beam Immersion T'esting c $\mathbf{f}^{\prime}$

2 Inch Plate -125 RMs . . . . . . . . . . . . . . . 145

Ultrasonic Noise During Angle Bean Imnersion 'l'esting of

2 Inch Plate - 63 RMS ................ . . 146

Ultrasonic Noise During Angle Beam Immersion l'estine of 1 l,'2 Inch As-Rolled Plate . . . . . . . . . . . . . 147

Ultrasonic Noise During Angle Beam Immersion Jesting of

1 1/2 Inch Plate - 225 RMS 
LIST OF TABLES (Co:tinued)

Table

Page

39 Ultrasonic Noise During Angle Beam Immersion Testing of

1 I/2 Inch Plate $-6 \mathrm{~s}$ RMS ................... 149

40 Ultrasonic Noise During Angle Beam Imrersion Pesting of

1 Inch Plate - As-Rolled . . . . . . . . . . . . . . l . . . . . . .

41 Ultrasonic Noise Durirg Angle Beam Immersion Testing of

1 Inch Plate - $125 \mathrm{RMS}$. . . . . . . . . . . . . . 151

Ultrasonic Noise During Angle Beam Immersion 'Testing of

1 Inch Plate -63 RMS .................. . . 152

43

Ingot Inventory List . . . . . . . . . . . . . . . . 168

44 Comparison of Ingot Processing With Standard Practice . . . . . . 169

45 Kesults of Radiographic Inspection of Ingot . . . . . . . . 172

46 Equipment Used for Ingot Inspection . . . . . . . . . . . . 180

47 Number of Ultrasonic Indications in Ingot . . . . . . . . . . . 182

48 Resutis of Radiographic Insfection of 9 Inch Billet . . . . . 185

49 Equipment used for 9 Inch Billet Inspection . . . . . . . . . 186

5) Number of Ultrasonic Indications in 9 Inch Diameter Billet . . . 190

5]. Equipment Used to Ultrasonically Inspect 6 Inch Billet . . . . . 197

52 Number of Ultrasonic Indications in 6 Inch Dianeter Billet . . .200

53 Resul us of IRadiographic Inspection of 6 Inch Billet 1.-2A6 . . . . 201

54 Sompansen of Radiographic and Ultrasonic Indications in

6 Inch Billet l...2A6..................... . 202

55 Summary of Inspection Methods Used for Detection of

Surface Cracks ....................... 205

56 Parameters tor Surface Connected Cracks (Stress

liatio $=0.1)$. . . . . . . . . . . . . . . . 20s

$5 i$

Resulte of Iaboratory Peretrant Inspection of Surface

Cracks . . . . . . . . . . . . . . . . . . . . . 211

58 Results nf Production Penetrant Inspection of Surface

Cracks . . . . . . . . . . . . . . . . . . . . 213 
LIST OF TABLES (Continued)

$\underline{\text { Table }}$

Pege

59 Number of False Indications Production Penetrant

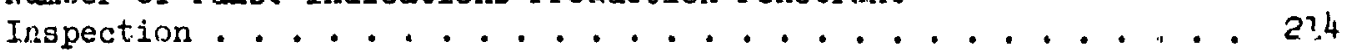

60

Comparison of Production Penetrant Inspectors . . . . . . . . 214

Results of Overhaul Penetrant Inspection . . . . . . . . . 216

62

Number of False Indications - Overhaul Penetrant Inspection . . . 217

63

Results of Production Surface Wave Ultrasunic Inspection . . . . . 220

64

Comparison of Penetrant and Surface Wave Test Results . . . . . ? ?21

65

Sumnary of Crac:: Detection Capabiljty of Surface Wave

Ultrasonics By Operator . . . . . . . . . . . . . 222

66

Cracks Detected from Both Sides of Specimen By Surface Weve

Ultiasnnics (Summation of 5 Cperators) ............ 223

Summary of False Indications - Ultrasonic Surface Wave . . . . . 224

Resilts of Laboratory Surface Wave Inspection . . . . . . . . 225

Results of Production Contact Angle Beam Inspection . . . . . . . 223

Cracks Detected From. Both Sides of Specimens By Contact

Angle Beam Ultrasonics (Summation of 2 Inspecturs) . . . . . . . 230

71

Eddy Current !'esi Results . . . . . . . . . . 235

72

Summary of Crack Detection Capability-Jaboratory

Eddy Current................. 236

73 Parameters for Surface Connected Cracks Made By

Bending Fatigue .. . . . . . . . . . . . . . . . . 238

74 Results of Engine Laboratory Penetrant Testing of

Surface Cracked Specimens (Results for Inspector $B$

Shown In Parenthesis) ... . . . . . . . . . . . . 2ill

75 Results of Ingine Production Penetrant Inspection

of Surface Cracked Specimens . . . . . . . . . . . . . . . c cl 


\section{LIST OF TABLES (Continued)}

Table

Page

$77 \quad$ Results of AFML Penetrant Inspection of Bending Fatigue

Surface Cracked Specimens ............... 243

78

Results of Radioactive Penetrant Testing ............ 244

79 Results of Eddy Current Irspention of Fastener Holes . . . . . 253

80 Sumary of Eddy Current Response Versus Maxdmure

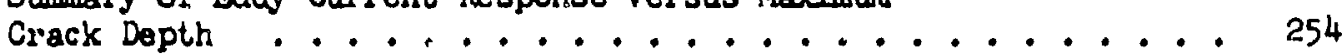

81 Eody Current Crack Response . . . . . . . . . . . 256

s2 Astual Size of Surface Cracks .............. 260

83 Porosity Dimeters ................ 267

84 Crack Lengths Before Bonding in Internaily Cracked

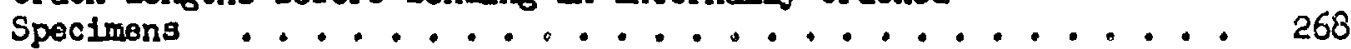

Q5 Sumary of U1trasonfe Testing of Internally Cracked

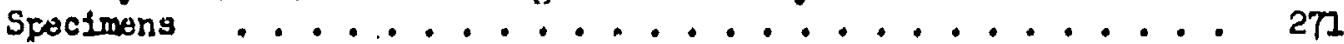

86 Jet Eingine Ultrasons: Inspection (Iaboratory) Results

for Internal cracks ................ 271

87 Results of Engine Production Straight Beam Immersion Tests . . . 275

88 Results of Engine Inmersion Angle Beam Tests . . . . . . 276

89 Result,s of AFML UItrasonic Inspections .......... 277

90 Ultrasontc Ingpection Results (A1rframe) for Internal Cracks . . 280

91 Jet Engine Manufacturer Laboratory Disk X-Ray Inspection

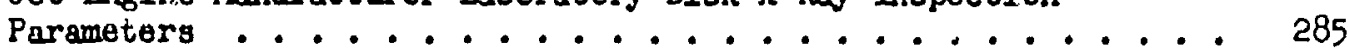

92 Sumary of UItrasontc Inspectiong of Disk Forgings . . . . . 289

93 Comparison of Total G.E. UItrasonic Indications With

Total AFML Ultrasonic Indicationg ............ 296

94 Sumnary of Stratght Beam Testing of Plate From

Ingot Bottom (Surface "A" Was the Sound Entry Surface) . . . . 303

95 Summary of Strafght Beam Testing of Plate From Ingot

Bottom (Surface "B" Was the Sound Entry Surface) ....... 304

96 Variation in Average Sound Transmission Characteristics

Between Bar and Reference Standards for $5 \mathrm{MHz}$ Stralght

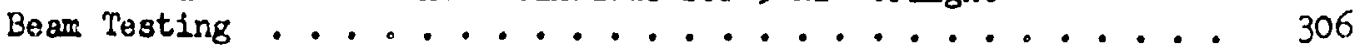

$x i x$ 
IST OF TABLES (ContInued:

Tabie

97 Dimonolons of Type I Alphe Stabllized Defocts . . . . . . 330

98 Compurison of threo Kethods Usod in Finding Defests for

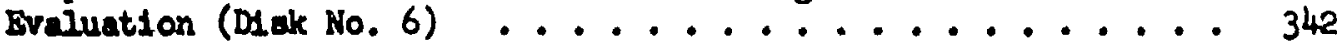

99 Comparison of Manual and Analog Scans for D1sk No. $7 \ldots \ldots$ 
SECTION I

SUMMARY

The results of the testing reported herein have emphasized the importance of controlling the significant parameters which inake up each nondestructive testing (NDT) methnd. In order to effectively inspect titanium by penetrant inspection, the penetrant dwell time, development time, water washing conditions, and inspection light intensity must all be chosen to effectively enhance the defect. detection capability of this method. Ultrasonic jispection of titanium was found to be affected by the internal structure and the physical configuration of the particular component undergoing inspection. Characteristics of the component such as surface finish, surface contrur, section thickness, and intemal structure car 8.1. Effect the ultrasonic 1.spection.

The capability of the NDT wethods for detecting flaws which occur in titanium was found to vary as a function of the chosen inspection method, the inspector, and the flaw size. Exceedingly snall surface cracks could be detected with production ultrasonic and penetrant inspections but not to a high degree of reliability. The capability of the ultrasonic method for detecting internal cracks in thick sections was found to be highly dependent upon the orientation. of the crack with respect to the sound beam. Small cracks oriented perpendicular to the sound beam can be detected, but, if the crack is oriented 45 dagrees to the sound beam, large cracks can go undetected. With this knowledge, proluction parts car, be more effectively inspected, knowing the likely orientation of expected flews and the most critical flaw orientations. For thin sections, the orientation of the flaw was found to have less effect.

Titanium melt defects, such as Iype I alpha stabilized areas, are detectable using production ultrasonic technjques, but, radiography seems to be ineffective. 


\section{SECTION II}

\section{INTRODUCTION}

The performance demands placed upon present day military aircraft are stringent. Advancements in the area of nondestructive test.ing (NVT) which parajlel new developuents in manufacturing technology can result in significant payoff. Improvements in the detection and evaluation of titanium defects by NDT can be made which can result in improved integrity and reliablitty of airframe and engine components.

The primary objectives of the program, then, were to improve nondestructive testing techniques which is discussed in Section III and to measure the capability and reproducibility of the improved nondestructive testing techniques for the evaluation of discontinuities occurring in titanium which $i$ 's iscussed in Section $V$ of this report. In addition, it was intended wo document NDT techniques presently used in industry and their shortcomtrigu.

The program was conducted using NDT methods and discontinuity types encountered in inspection of airframe and fet engine components. The NDT ruethods used were ultrasonics, penetrant, $X-r a y$, and eddy current. Discontinuitles which might occur in titanium components originate from two general gources. One source is associated with raw materials and ingot melting and includes discontinuities such as ingot pipe and alpha stabilized areas. Another source is component fabrication and includes discont nutities such as surface cracks, internal cracks, and porosity. All of the above discontinutties were utilized throughout the program.

The penetrant, radiographio, and ultrasonic methods were improved as discussed in subsections 1,2 and 3 of Section. III of this report. After the ND' improvement portion of the program was completed, the capability and reproducibility of the NDT methods were meesured with respect to surface cracks, porosity, internal crasks, and segregates as reported in subsections $1,2,3,4,5,6$, and 7 of Section $V$ of this report. The evaluation was divided into atrframe and jet engine inspections with laboratory, production, and overhaul inspections being included. Product forms inspected included bar, plate, and airframe and jet engine forgings. Following the nondestructive testing, the actual. size of the discontinufties was measured using selected destructive techniques such as inetallography. (See subsection 8 of Section V). 


\section{SECIION III}

\section{IMPROVEMENT OF NONDESTRUCTIVE TESTING TECHNIQUES}

A great deal needs to be learned about the variables of conventional NDT methods with regard to inspection of titanium hardware. The effect of several factors, such as complrx shapes encountered, is not sufficiently understood at this time. Also, the effect of surface structure upon an effective inspection needs investigation. The NDT methods commonly used for inspection of titanium hardware are ultrasonics, penetrant, $X-r a y$, and eddy current. Although these NDT methods are considered established crily limited work has been performed in investigating the pioduction process variables of the NDT methods as relater to detection of discontinuities in real components.

\section{PENETRANT METHÚD}

Pnicetrant inspection is heavily relied upon in the aircraft industry for the detection of surface connected discontinuities. For many aircraft components, penetrant inspection is the last inspection method used on the finish machined part prior to its installation in the aircraft. In some cases, it is the only inspection method used. Consequently, penetrant inspection is the final means used to guarantee that the subject component is "defect free". The penetrant method is of major importance in ensuring the integrity of titanium components.

In general, a penetrant inspection consists of:

(1) Preparation of the surfacas to be inspected

(2) Drying of the inspection surface

(3) Application of the penetrant

(4) Removal of excess penetrant

(5) Examination of the inspection surface.

The effectiveness of the penetrant inspertion is entirely dependent upon the penetrant entering the discontinuities and re-emerging for visual inspection. Any pre-penetrant process or any penetrant inspecison variable which reduces penetration and re-emercence of the penetrant can potentially reduce the effectiveness of the inspection. Ule of the factors which can affect the reliability and resolution limits of the inspection are:

(1) The effectiveness of the drying procedure prior to application of penetrant.

(2) The use or non-use of a developer

(3) The dwell time of the penetrant, enulsifier, and developer (if used). 
(4) Viewing ultraviolet light irtensity versus ambient white light intensity.

(5) The type of developer used ( $\mathrm{dry}$, nonaqueous wet, or aqueous wet)

(6) The technique used to remove excess penetrant

(7) Mechanical processing, such as shot peering, performed upon the inspection surface prior to the penetrant inspection.

(8) The proficiency of the inspectior

A test program was conducted in order to study several of the punetrant inspection variables. Loth gross cracks and small cracks were used in the program to measure the effect of such variables as penetrant dwell time and developer type.

a. Penetrant Systems

A large number of penetrant material systems are present." y marketed and used throughout the airframe and engine industries. These systems are characterized as color contrast (visible) dye penetrants (solvent removable and water washable) of several sensitivities, and fluorescent penetrants (solvent removable, water washable, and pust-emulsifiable) of several seinsitivities. The scope of the program to improve the penetrant method encompassed two penetrant systems which are considered representative of the systems in common use tuday. The chosen systems are:

Penetrant Type

Fluorescent

Post-Emulsifiable

Fluorescent Water Washable
Sensitivity

MIL-T.-25135, Group V when used with developer

Ecuivalent to MIL-I25135, Group VI penetrant when used with a devcioper
Manufacturer's Designation

Magnaflux ZL-2A penetrant, ZE-3 emulsifier, ZPX-437 nonaqueous wet developer, $\mathrm{ZP}-4$ dry powder developer, and $\mathrm{ZP}-13$ aqueous developer

Tracer-Tech P-133 penetrant, D499C nonaqueous wet developer, D493A dry developer, D492C aqueous developer

b. Specimen Fabrication

In a typical production penetrant inspection facility, a variety of srack sizes are encountered. Consequently, if a program is to be conducted on penetrant inspection variables, a variety of crack sizes should be used. Both gross cracks and small cracks were used in the study reported here. 


\section{(1) Specimens with 'I'ight Cracks}

Ti-6Al-4V blanks, $1 / 4 \times 2 \times 5$ inches, were cut to size und ground on one side. The blanks were ground to approximately 32. rms using a 60 grit whee? (12 inch dianeter $x 1$ inch wide), 2,000 rpm wheel speed, .002 to .003 inch downfeed, and approximately .100 inch crossfeed per pass. I'he workpiece was flooded with coolant during the process. After grinding, the specimens were bent in a fixture, as shown in Figure 1, to approximately $25 \%$ yield strenrth. The bent specimens were wetted with methanol and NaCl was appljod such that NaCl adhered to the specimen surface. 'Jhe stressed specimens were lowered into an anhydrous methanol-NaCl solution and :emained immersed until cracking occured in a few hours.

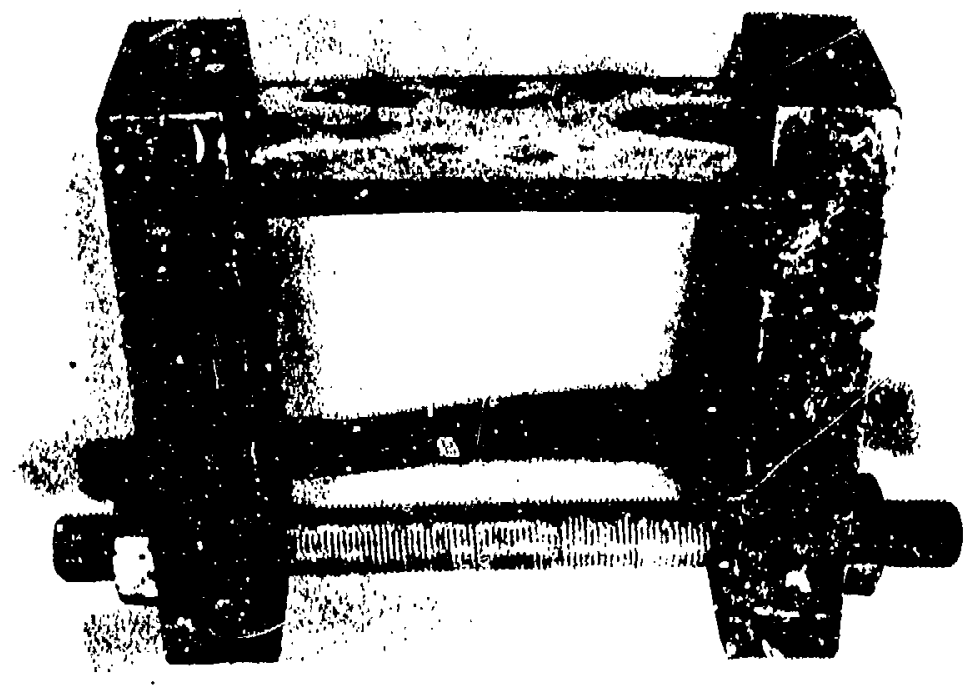

FIGURE 1

FIXTURE FOR STRESSING SPECIMENS

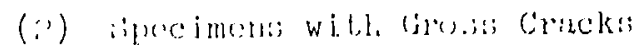

Biank' $1 / 4 \times 1 \times 6$ inches, were cut from $\mathrm{T} 1-6 \mathrm{AL}-4 \mathrm{~V}$ and a $3 \mathrm{aw}-$ cut notch was put into the $1 / 4 \times 6$ inch face to serve as a rack initiation site. Each specimen was cantilevered in a shaker table with a mass of 239 grams added near the frea end and was vibrated at its resonant frequency (approximately $550 \mathrm{~Hz}$ ). The crack growth was monitored optically until ine desired crack length $(1 / 4$ to $1 / 2$ inch) was obtyined. The test set-up is shown in Figure 2. The resulting cracks were propagated through the $1 / 4$ inch thickness and $1 / 4$ to $1 / 2$ inch into the $1 \times 6$ face (see Figure 2). The surface finish un the specimens was approximately $32 \mathrm{rms}$. 

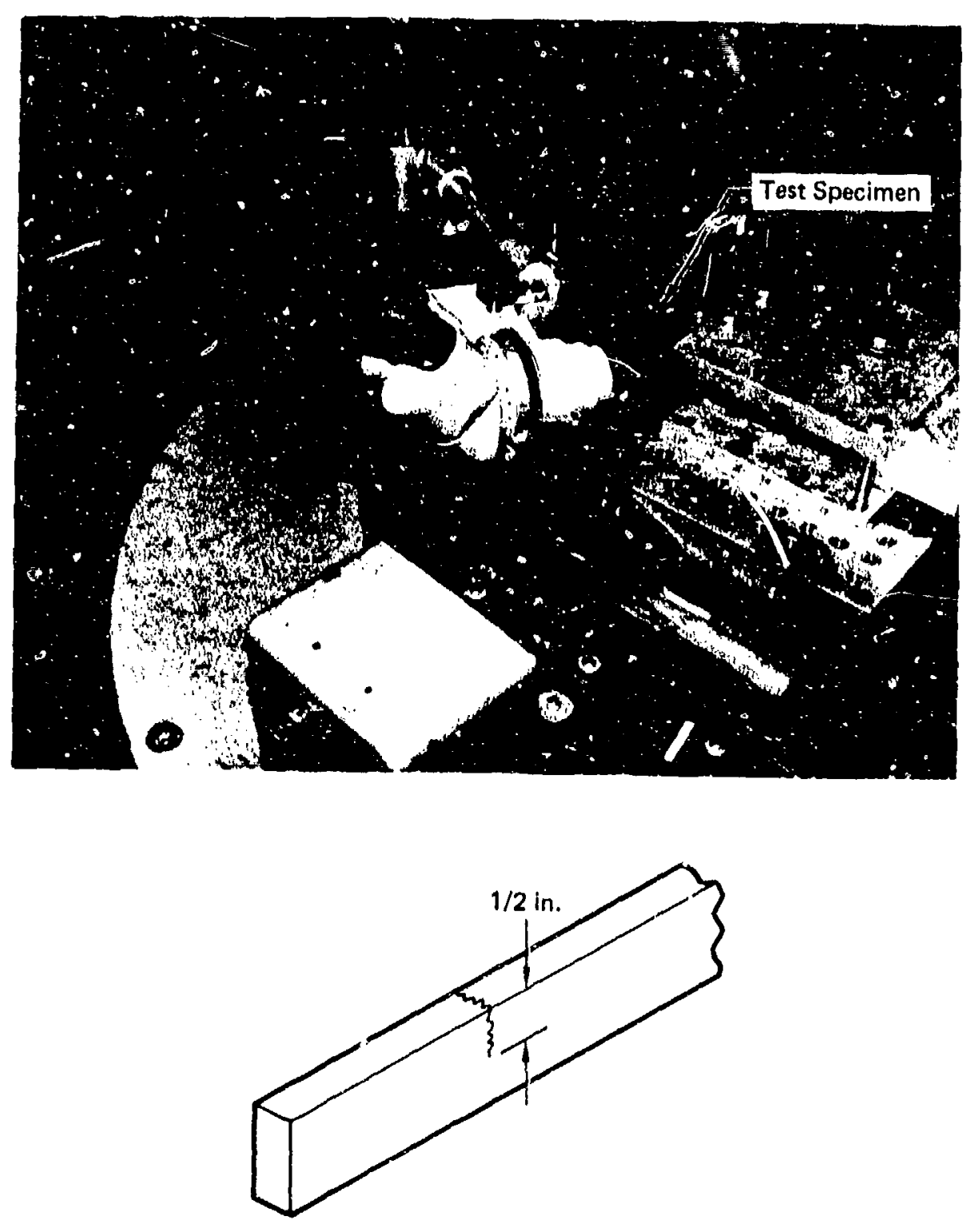

GP73.0284.41

FIGURE 2

SHAK.ER TABLE TEST SET-UP 


\section{(3) Porosity Specimens}

Several hand forged billets (Ti-6Al-6V-2Sn) containing porosity have reen collected during past internal programs. The porosity is dep'cted in Tigure 3 . Sections $1 / 4$ inch thick were cut from the billets, grownd rlat and etched, for use in the penetrant investigation.
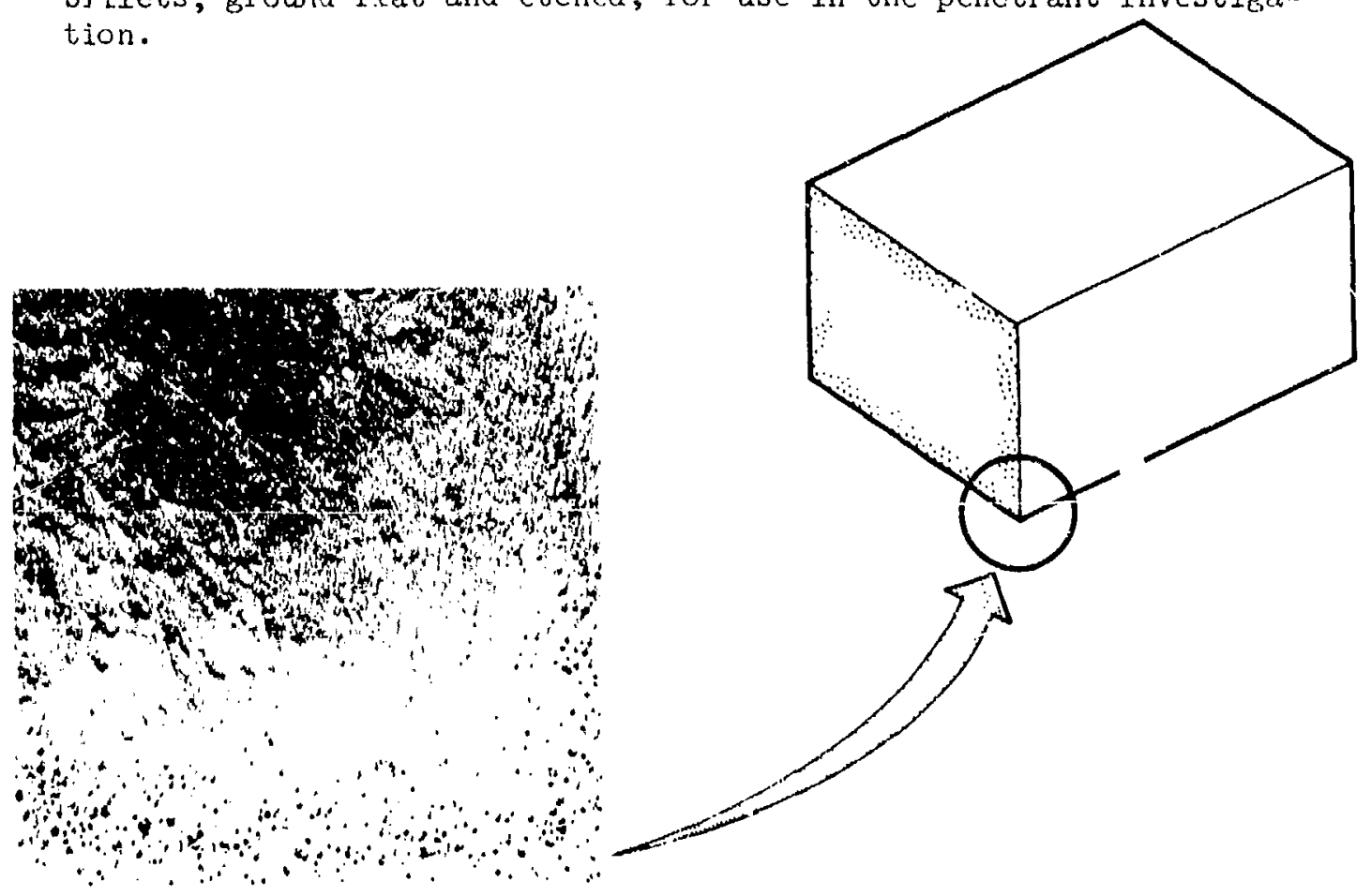

$2 \times$

FIGURE 3

POROSITY IN 'IAND FORGED BILLETS

Q. $14.0117 ! 40$

Photonicrographs of typical tight cracks, gross cracks, and porosity are shown in Figures 4 and 5 . As can be seen in Figure 4 , a wide range of crack sizes are represented by the tight cracks and gross cracks. The gross cracks had widthis at the surface of approximately .001 inch and depths of 0.2 .5 and 0.50 inch. Cracks of this size ure among those which have been encountered in production processes. For example, rolling cracks have been encountered with widths of approximately .001 inch. The width of the tight, uracks (at the surface) varied from .00016 to .0002 inch and the crack depth varied from .007 to .060 inch. Cracks this size have al:so been encountered in production processes such as forming. As shown in Figure 5, the porosity size varied considerably. The diameter of several pores was measured at high magnification and found to vary from .0005 to .0075 inch; the depths varied from .00? to .015 inch. 


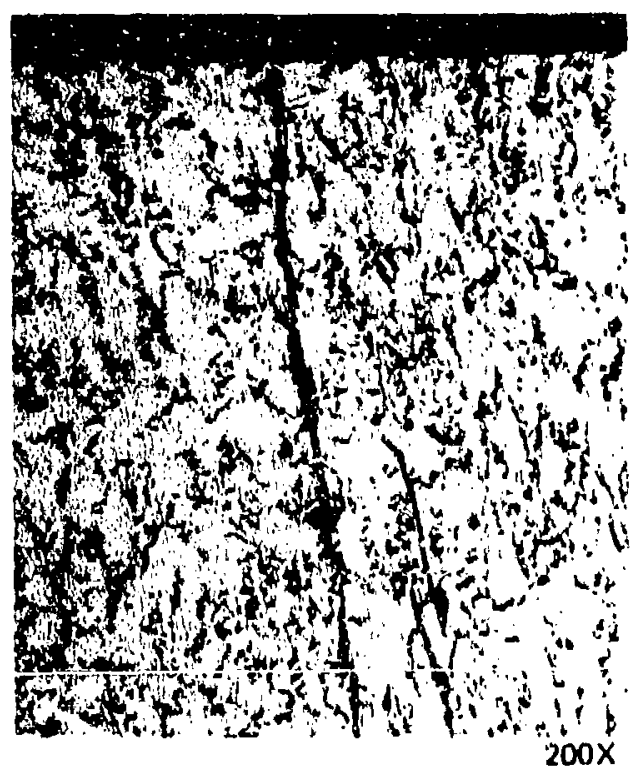

(Stress Corrosion)

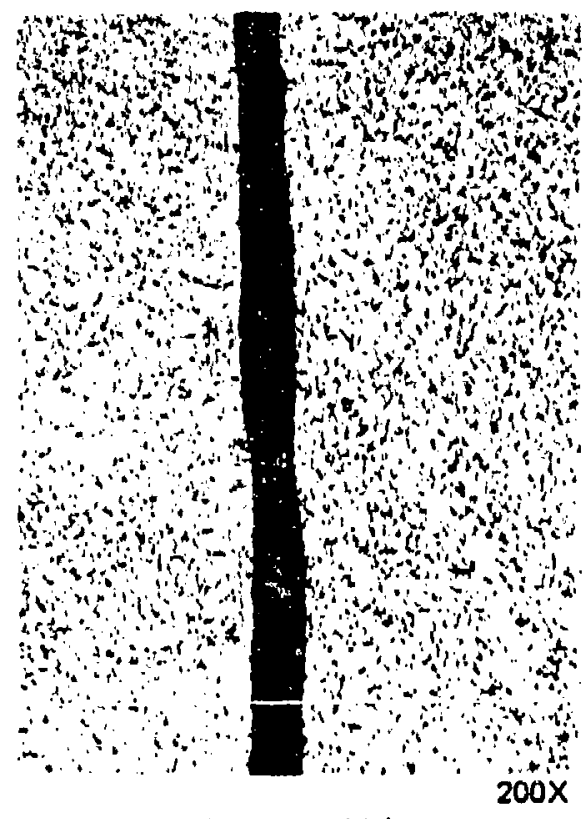

(Shaker Table)

0874.0117 .145

\section{FIGUAE 4 \\ PHOTOMICROGRAPHS OF STRESS CORROSION CRACKS AND SHAKER TABLE PRODUCED CRACKS}

\section{c. Pre-Penetrant Drying}

In the normal penetrant inspection sequence, the inspection surface is cleaned and dried prior to applying the penetrant. The purpose of the drying operation is to remove residual water and cleaning solution which may have become entrapped in the discontinuities. A number of dryine procedures are commonly used in industrial production penetrent inspection systems.

Several drying methuas were evaluated and compared to oven drying for 10 minites at $225^{\circ} \mathrm{fi}^{\prime}$ which was chosen as a typical adequate drying procedure. A flow chart is shown in Figure 6 to sunmarize the test program. It; should be noted that the same production cleaning method was used throughout the drying study.

\section{(1) Water Washable Penetrant Syst'm}

A high sensitivity fluorescent water washable penetrant was chosen for the investigation. Tracer-Tech P-133 penetrant, equivalent in sensirivity to a MIL-I-25135, Group V penetrant, was used alung witis Tracer-Tech D499C nonaqueous wet deveioper. 


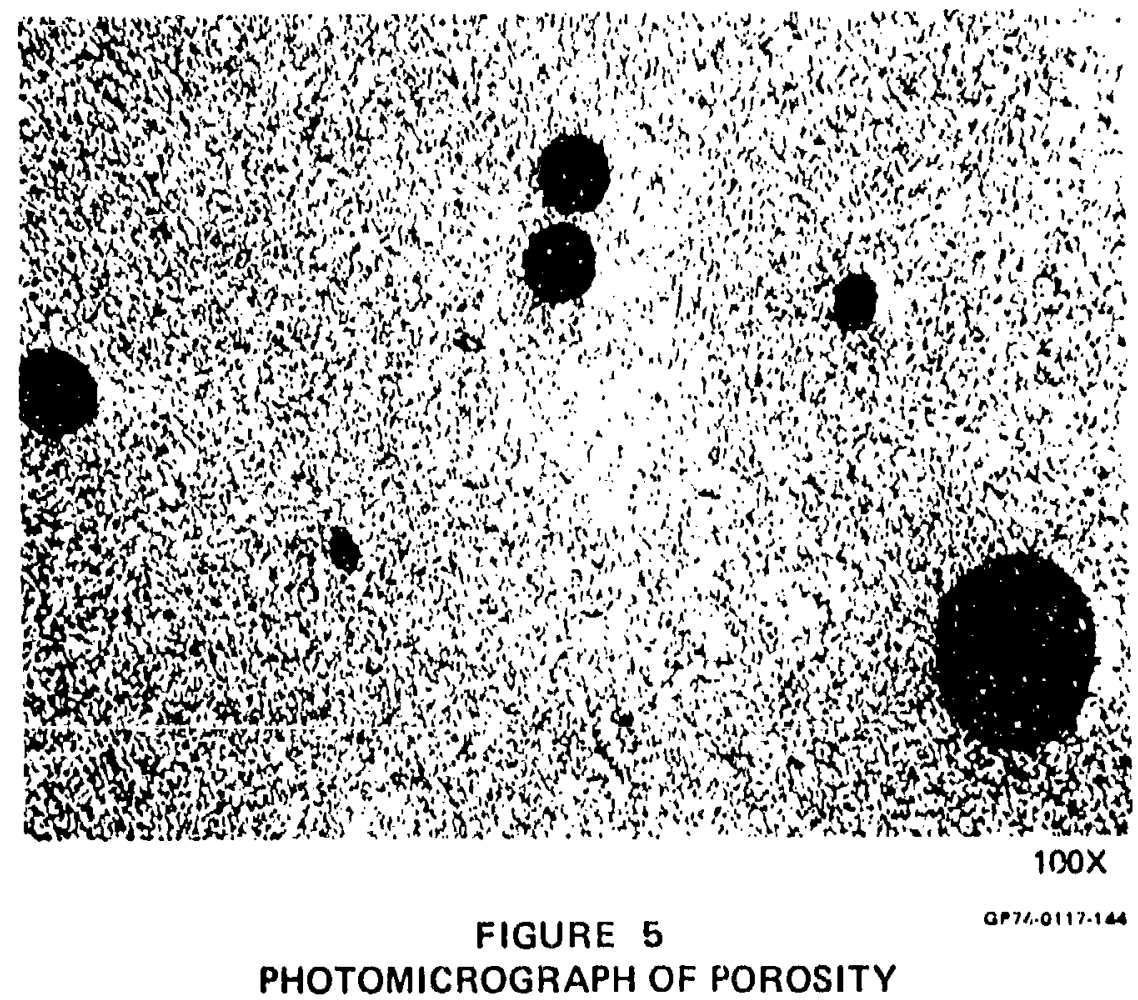




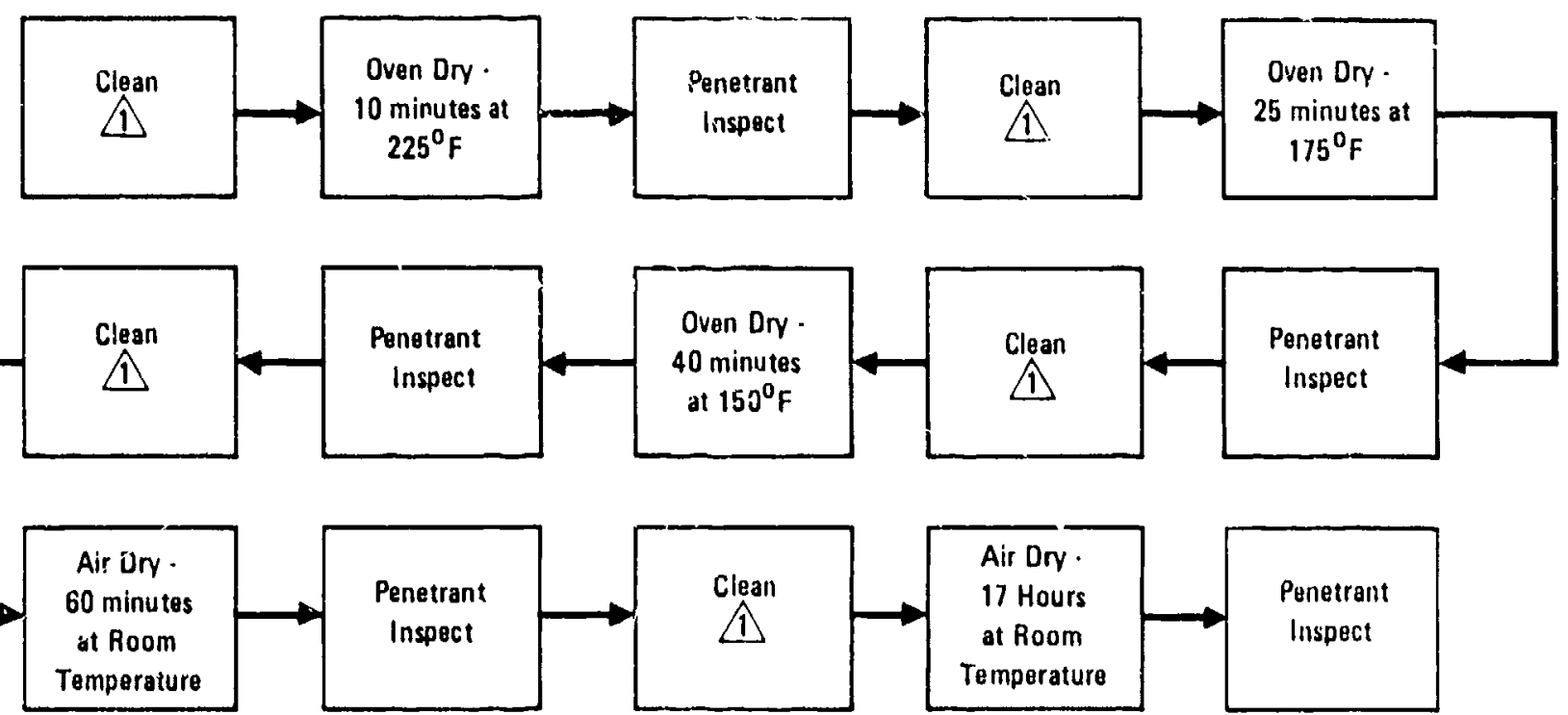

Aj Vapor degrease for 16 hours to remove residual pentetrant followad by normal production cieaning (alkaline cluan followed by acid pickle to remove 0.00005 inch and water rinsel.

FIGURE 6

PRE-PENETRANT DRYING TEST PROGPAM

Sever gross cracks (approximately .00.2 inch wide $x .25$ inch long) were used to study each drying condition. The specimens were completely immersed during penetrant dwell (10 minutes). Excess penetrant was washed from the specimons using a water spray nozzlo; the wash water temperature was approximately $90^{\circ} \mathrm{F}$ and the wash water pressure was approximately $40 \mathrm{psi}$. Fach specimen was washed until the specimen surface was visually clean under 200 minrowatts per $\mathrm{cm}^{2}$ of litraviolet light (approximetely 3.5 seconds). Next, the specimens were placed in a circulactig air sven at $170^{\circ} \mathrm{F}$ and dried until visually dry (15-20 minutes). Nonaqlieous wet jeveloper was applied to the cracks. After a development time of 1.5 minutes, the penctrant indications were photogrtiphed using the following parm leter's: approximately 1,000 microwat.ts per $\mathrm{cm}^{2}$ of ultraviolet light, 25 second exposure at $\mathrm{f} 9$, Royal ran lilm, Tiffen Yellow No. $\because$ filtox. An Ultraviolet Products, Inc. spot ultraviolet light was used to moduce the ultraviolet light. Fath drying procedure was compared to oven drying at $225^{\circ} \mathrm{F}$ for 10 minutes by directly comparing the photographs of the penetrant indications. The ultritviolet light intensity was measured with an Ultraviolet Productsi, Inc. UV Black-Ray meter, Model Jazl. 
There appeared to be little difference between the various pre-penetrant drying methods used on the gross cracks. Fresumably, these cracks were so larse that entrapment of small quantities of water or cleaning solution did not effectively reduce the penetration of the penetrant into the cracks.

\section{(2) Post-Emulsifiable Penetrant System}

The effect of pre-penetrant dryine was also investigated for a post-emulsifiable penetrant system. A MII-I-25135, Group V fluorescent penetrant system was chosen for tne investigation. Specifically, Magnuflux ZI,-2A penetrant was used with Magnaflux $\mathrm{ZPX}-457$ nonaqueous wet developer. The excess penetrant was removed using Magnaflux $2 R-10$ remover at a concentration of 0.5 volume percent. The ZR-10 was metered into the water stream with a FMT Lab Pump, Model RRP.

As for the water washable system, grosis cracks (approximately .001 inch wide $x .25$ inch lone) were used as discontinujties. The specimens were alkaline cleaned, acid etched, and water rinsed followed by the applicable pre-penetrant drying method. The following arying methods were investigated: oven dry at. $22.5^{\circ} \mathrm{F}$ for 1.0 minutes, $175^{\circ} \mathrm{F}$ for 25 minuties, and $150^{\circ} \mathrm{F}$ for 40 minutes and aix dry at room temperature for 60 minutes. The penetrant dwel.J. time was 20 minutes and the development time was 15 mirutes. All other inspection parameters were as for the water washable penetrant.

The three oven dry schedules appeared to be more effective than aid air drying at room temperature for 60 minutes. However, the crack indications were all visible for all the conditions. There was little difference in the effectiveness of the 3 oren dryings methods.

\section{d. Penetrant Blecd-Out I'ime}

An important variable in the penetrant inspection process is the length of time that the penetrant is allowed to bleed out of the discontinuity after the excess penetrant has been removed and prior to the actual inspectivii. If the penetrant is not tiven enough time to bleed out of the discontinuity, the subsequent, penetrant indication may not attain maximum brilliance. In order to investigate penetrant bleed-out times, an investigation was carried out for both a water washable fluorescent penetrant system and a post-emulsifiable fluorescent penetrant system. 


\section{(1) Post-Emulsjifiable Perietrant System}

A MIL-I-25135, Group V fluorescent penetrant system was chosen for the investigation. Specifically, Magnaflux ZL-2A penetrant was used with Magnaflux ZE-3 emulsifier. The penetrant was used with Magnaflux ZPX-437 nonaqueous wet developer, with Magnaflux ZP-4 dry developer, and with Magnaflux ZP-13 aqueous wet developer in order to determine the effect of various developer types on the results. In addition, the penetrant was used without a developer although this system was not a MIL-I-25135, Group V system.

As can be seen from the Figure 7 test plan, the penetrant bleed-out times were evaluated by photographing the penctrant indications after the penetrant was allowed to bleed cut of the discontinuities for $1,5,10,15,20$, and 30 minutes. I'hen the photographs were visually compared to determine the penetrant, bleed-out time required for the indications to achieve their maximum br:11.ance. After the completion of the test plan shown in Pigure 7 , the entire program was repeated for penetrant dwell times of 10,20 , and 30 minutes and for nonaqueous wet developer, aqueous developer, and no developer. The dwell times were chosen based on the MIL-I-6866B dwell time requirement of 20 to 30 minutes for post-emlisifiable penetrants.

As shown in Figure 8, it was decided to slean the residual penetrant from the specimens between tests by trichlcrethylene vapor degreasing for 16 hours. In order to demonstrate the effectiveness of vapor degreasing between penetrant inspections, a speciinen with tight cracks and a specimen with a gross crack were penetrant, inspected, vapor degreased for 16 hours, and developer was applied to the surface. As shown in Figure 8 , no penctrant indications were visible after 6 hours of development time. Trichlorethylene vapor degreasing is not normally recommended for cleaning titanium production parts because the presence of residual chlorine can cause cracking under the stresses and elevated temperatures a part enccuntexs during service. Since the cracked panels used in this investigation were not subjected to stress, no further cracking of the panels was expected.

Specimens containing gross cracks (approximately .001 inch wido $x .25$ inch long) and sma.1. cracks (approximately .000? inch wide $x$ .007 to .060 1nch long) were used in the evaluation as well as porosity specimens. The specimens were completely jmmersed in the penetrant during the applicable penetrant dwell. Excess penetrant was washed from the specimens using a Tri-Con 400501 water spray nozzle after emulsification for 1 minute; the wash watior temperature was approximately $90^{\circ} \mathrm{F}$ and the wash water pressure was approximatcly $40 \mathrm{psi}$. Each specimen was washed until the specimen surface wis visualiy clean under 200 microwatts/ $\mathrm{cm}^{2}$ of ultraviolet light (approximately 1.5 seconds). Next, the specimens were dried until visually Ary (10-15 minutes) in a circulating air oven at $170^{\circ} \mathrm{F}$. 'lhe concentration of the aqueous wet developer, when used, was $1 / 2$ pound por 



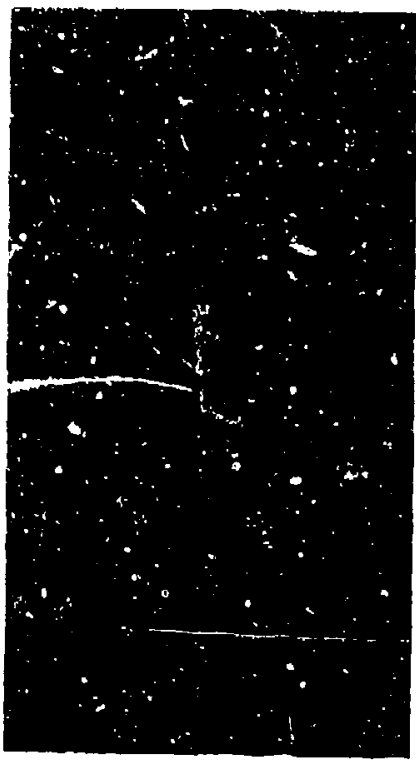

Gross Crack

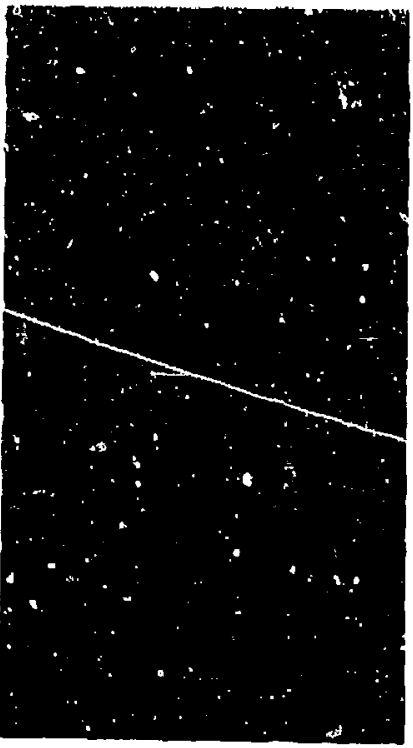

FIGURE 8

EFFECTIVENESS OF VAPOR DEGREASING BETWEEN PENETRANT INSPECTIONS
6 Hours Development Time)

Initial Penetrant Indications

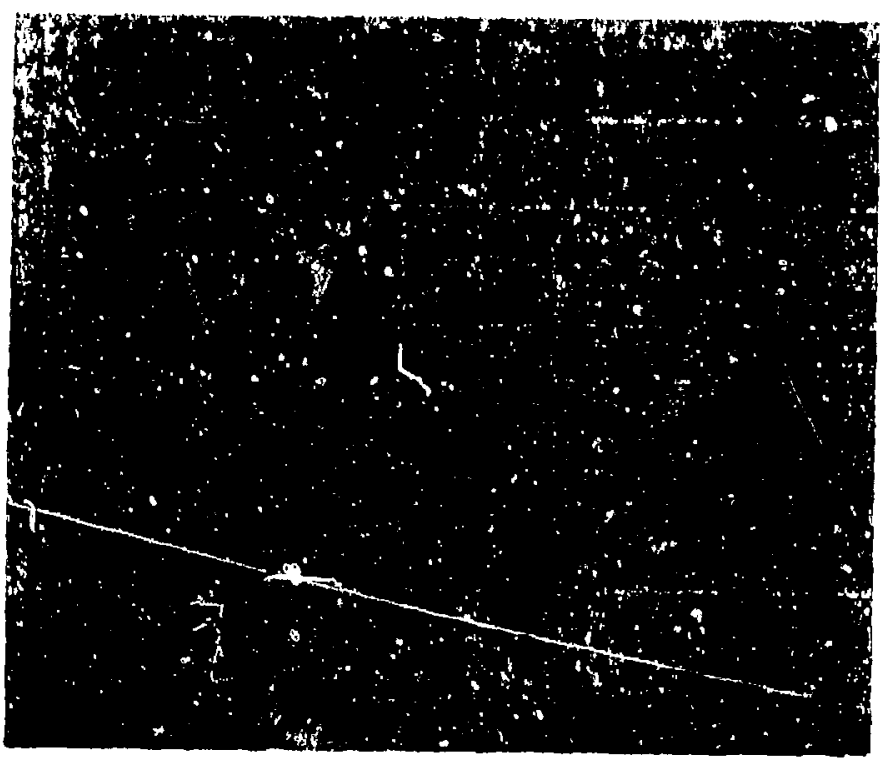

Gip/4011/142

\section{Tight Cracks}

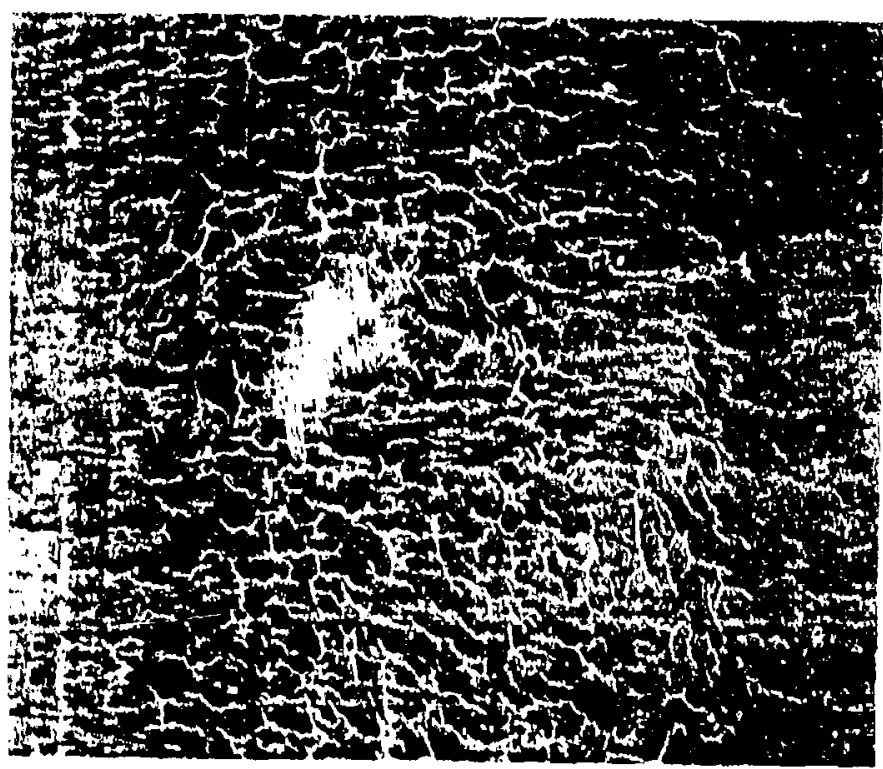


gallon. After the appropriate bleed-out times, the penetrant indications were photographed using the following parameters: approximately 1000 microwatts per $\mathrm{cm}^{2}$ of ultraviolet light, 25 second exposure at $f^{9} 9$, Royal Pan Film, Tiffen yellow No. 2 filter.

The results of the penetrant bleed-out time study as $A$ function of discontinuity type, developer trpe, and penetrant dwell time are summarized in Table $I$ and demonstrated in Figure 9. For the gross cracks and the porosity, no improvement in the penetrant indications was realized by increasing the penetrant bleed-out time abuve I minute. For several smaller, tighter cracks, the minimum penetrant bleed-out time varied from 1 to 15 minutes depending upon the developer used and the penetrant dwell time chosen.

Table 1 indicates that the penetrant bleed-out time should be at at least 1 minute for the most effective penetrant inspecition except for smalj, tight cracks where at least 1.5 minutes is necessary. Of course, the penetrant/developer combinations listed in Table 1 are not equivalent in effectiveness even when the penetrant bleed-out times are numericaldy equiveieni.

As previously mentioned, the study was performed on 2 penetrant systems and 3 discontinuity types. Consequently, this data on penetrant bleed-out time should be considered as only a guide to choosinf auequate bleed-out times in a production inspection environment. For example a longer blesd-out time mikht be necessary if the test parts to be inspected contain tighter, smaller cracks han those investigated in this program or if the test parts are not as clean as those investigated. in the jrogram.

\section{(2) Water Washable Penetrant System}

A high-sensitivity fluorescent waber washable penetrant was chosen for the investigation. Specifically, 'Tracer-Tech P-133 penetrant was used, which is eruivalent in sensitivity to a MIL-I25135, Group V penetrant when uied without develope... 'I'he perietrant was used without a develorer, with Tracei-l'ech $D 4990$ nonaqueous wet developer, with 'Iracer-l'ech $10493 \mathrm{~A}$ dry leveloper, and with Iracer-'T'ech 1)492C aqueous wet ceveloper (1/2 pound per galion) in order to determine the effest of various doveloper types on the resul.ts. The use of a developer increases tho smitivity of the aystien to that of a Groip VI system.

Gporimon: containing tight and pross crack: were unsw in the evinluatson us woll as porosity opecimens. The speciments were com-

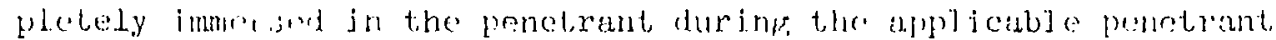

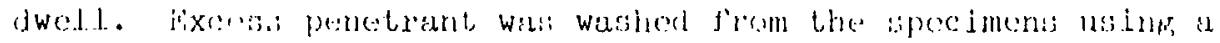

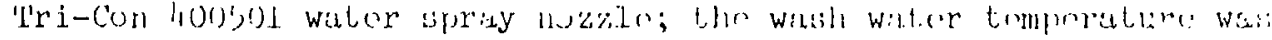

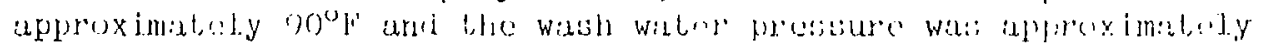


TABLE 1

MINIMUM BLEED-OUT TIME FOR POST-EMULSIFIABLE SYSTEM $\uparrow$

\section{Gross Cracks}

\begin{tabular}{|l|c|c|c|}
\hline \multirow{2}{*}{ Developer } & \multicolumn{3}{|c|}{ Minimum Bitgd-Out Time (Min) } \\
\cline { 2 - 4 } & \multicolumn{3}{|c|}{ Penetrant Dwell Time } \\
\cline { 2 - 4 } & 5 Min & 10 Min & 20 Min \\
\hline None & 1 & 1 & 1 \\
Nonaqueous Wet & 1 & 1 & 1 \\
Dry & 1 & 1 & 1 \\
Aqueous Wet & 1 & 1 & 1 \\
\hline
\end{tabular}

Porosity

\begin{tabular}{|l|c|c|c|}
\hline \multirow{2}{*}{ Developer } & \multicolumn{3}{|c|}{ Minimum Bleed-Out Time (Min) } \\
\cline { 2 - 4 } & \multicolumn{3}{|c|}{ Penetrant Dwell Time } \\
\cline { 2 - 4 } & 5 Min & 10 Min & 20 Min \\
\hline None & $i$ & 1 & 1 \\
Nonaquerus Wet & 1 & 1 & 1 \\
Dry & 1 & 1 & 1 \\
Aquoous Wet & 1 & 1 & 1 \\
\hline
\end{tabular}

Smaller, Tighter Cracks

\begin{tabular}{|l|c|c|c|}
\hline \multirow{2}{*}{ Developer } & \multicolumn{3}{|c|}{ Minimum Bloud-Out Time (Min) } \\
\cline { 2 - 4 } & \multicolumn{3}{|c|}{ Panetrant Dwell Time } \\
\cline { 2 - 4 } & $5 \mathrm{Min}$ & $10 \mathrm{Min}$ & $20 \mathrm{Min}$ \\
\hline None & 1 & 1 & 1 \\
Nonaqueous Wot & 1 & 1 & 1 \\
Dry & $1.15 \mathrm{2}$ & $1.15 \Omega 2$ & $1.5 \Omega$ \\
Aqueous Wet & 1 & 1 & 1 \\
\hline
\end{tabular}

A MIL.1.25135, Group $V$ posi.amulsthable ponotrant, 1 minute amulsiticotion timo

2. One minute bleod-out was surfictent for most cracks but a longer cime was roqutred for a fow small cracks 


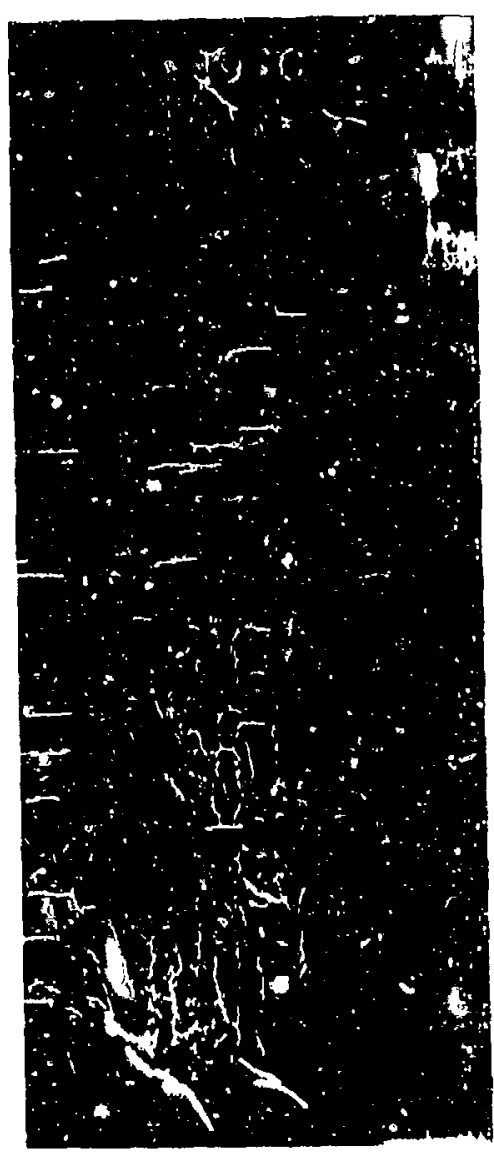

1 min Bleed-Out Time

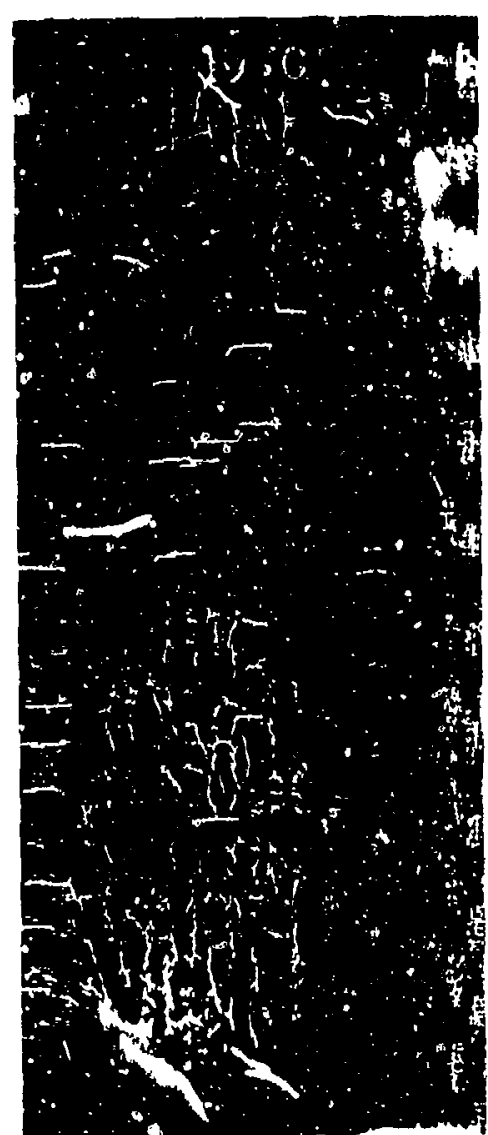

$15 \mathrm{~min}$ Bleed Out Time

FIGURE 9

EFFECT OF PENETRANT BLEED-OUT T!ME

Post-Emulsifiable Penetrant System with Dry Powder Developer 
40 psi. Each specimen was washed until the specimen surface was visually clean under $200 \mathrm{microwatts} / \mathrm{cm}^{2}$ of ultraviolet light (approximately 15 seconds). Next, the specimens were dried until visually dry (10-15 minutes) in a circulating air oven at $170^{\circ} \mathrm{F}$. After the appropriate bleed-out times, the penet? ant indications were photographed using the following parameters: approximately 1000 microwatts per $\mathrm{cm}^{2}$ of ultraviolet ligiat, 25 second exposure at f9, Royal Pan Film, Tiffer yellow No. 2 filter.

The test plan was similar to that used for the post-emulsifiable penetrant (Figure 7) except that the penetrant dwell times were 1, 5, and 20 minutes. Specjfic values for penetrant dwell time for highsensitivity water washable penetrants are not specified in MIL-I6866B. Consequently, the dwell times were based upon McDonnell Aircraft Company experience in production penetrant inspection. The penetrant bleed-out times were evaluated by photographing the penetrant indications after the penetrant was ailowed to bleed out of the discontinuities for $1,5,10,15,20$, and 30 minutes. Then the photographs were visually compared to determine the penetrant bleed-out time required for the indications to achieve their maximum brilliance.

The results of the penetrant bleed-out time study for the water washable penetrant are summarized in Table 2 as a function of developer type and discontinuity type. As in the case of the post-emullsifiable penetrant system, a penetrant bleed-out time of 1 minute was required for full development of the penetrant indications from the more open discontinuities such as the porosity and gross cracks. However, no improvement in the penetrant indications occurred by using a longer penetrant bleed-out time. For several smaller, tighter cracks, as much as 5 minutes was r'equired to f'ully develop the penetrant indicstions depending upon the developer type used.

It should be noted that Table 2 in no way indicates the re?ative effectiveness of various developer types or the effect of varying penetrant dwell times. For example, a shorter minimum bleedout time for aqueous wet developer versus di'y developer does not indicate that aqueous wet developer was more effective. These elfects are covered in later sections of this report.

As in the case of the post-emulsiriable penetrant system work, this investigation was performed with one penetrant system. Consequently, these minimum penctrant bleed-out times should be regarded only as guidelines for production penetrant inspection.

є. Penetrant Dwell Time

An important variable in the penetrant inspection process is the dwell time of the penetrant. I'h dwell time of the penetrant should be long enouph to allow the penetrant to enter any discontinuity; howevor, if the ponetriut dwell time is too long, the penetrant can dry or akings j.t difficult, to remove excess penetrant. N1:so, the minimum prortrant, dwoll time may vary as the size of the discontinulty varies. 
TABLE 2

MINIMUM PENETRANT BLEED. OUT TIME FOR WATER WASHABLE PENETRANT SYSTEM

\begin{tabular}{|l|c|c|c|}
\hline \multirow{2}{*}{ Developer } & \multicolumn{3}{c|}{ Minimum Bleed-Out Time (Min, } \\
\cline { 2 - 4 } & \multicolumn{3}{|c|}{ Penetrant Owell Time } \\
\cline { 2 - 4 } & 1 Min & 5 Min & 20 Min \\
\hline None & 1 & 1 & 1 \\
Nonaqueous Wet & 1 & 1 & 1 \\
Drv & 1 & 1 & 1 \\
Aqueous vivet & 1 & 1 & 1 \\
\hline
\end{tabular}

Porusity

\begin{tabular}{|l|c|c|c|}
\hline \multirow{2}{*}{ Developer } & \multicolumn{3}{|c|}{ Minimum Bleed-Out Time (Min) } \\
\cline { 2 - 4 } & \multicolumn{3}{|c|}{ Penetrant Dwell Time } \\
\cline { 2 - 4 } & 1 Min & 5 Min & 20 Min \\
\hline None & 1 & 1 & 1 \\
Nonaqueous Wet & 1 & 1 & 1 \\
Dry & 1 & 1 & 1 \\
Aqueous Wet & 1 & 1 & 1 \\
\hline
\end{tabular}

Smaller, Tighter Cracks

\begin{tabular}{|l|c|c|c|}
\hline \multirow{2}{*}{ Developer } & \multicolumn{3}{|c|}{ Minimuin Bleed-Out Time (:Nin) } \\
\cline { 2 - 4 } & \multicolumn{3}{|c|}{ Penetrant Dwell Time } \\
\cline { 2 - 4 } & 1 Min & 5 Min & 20 Min \\
\hline None & 1 & 1 & 1 \\
Nonaquenus Wet & 1 to 5 & 1 to 5 & 1 to 5 \\
Dry & 1 to 5 & 1 to 5 & 1 to 5 \\
Aqueous Wet & 1 & 1 & 1 \\
\hline
\end{tabular}

GP 740111192 
Consequently, this important aspect of peretrant testing was investigated for both a water washable fluorescent penetrant system and a post-emulsifiable fluorescent penetrant system.

\section{(1) Post-Enulsifiable Penetrant System}

The photographs of the penetrant indications taken during the bleed-out time sludy were useo to study the effect of penetrant dwell time.

The penetrant bleed-out time study indicated that under no circumstances was more than 15 minutes bleed-out time required to achieve maximum brilliance of the penetrant indications. Consequently, the penetrant dwell times were compared for a penetrant bleed-out time of 15 minutes.

The results of the penetrant dwell time study as a function of discontinuity type and developer type are summarized in Table 3 and demonstrated in Figure 10.

\section{MINIMUM PENETRANT DWELL TIME \\ (Post-Emulsifiable Penetrant System)}

\begin{tabular}{|c|c|c|c|}
\hline \multirow{2}{*}{ Developer } & \multicolumn{3}{|c|}{ Minimum Penetrant Dwell rime (Min) $\bigwedge$} \\
\hline & $\begin{array}{l}\text { Gross } \\
\text { Cracks }\end{array}$ & Porosity & $\begin{array}{c}\text { Smaller, Tighte } \\
\text { Cracks }\end{array}$ \\
\hline None & 20 & 20 & 20 \\
\hline Nonaqueous We! & 10 & 20 & 20 \\
\hline Dry & 5 & 20 & 5 and $20 / 2$ \\
\hline Aqueous Wet & 5 & 10 & 20 \\
\hline
\end{tabular}

(1) 1 inifo omulsilfication time was used

2. $5 \mathrm{~min}$ was sulficient for mest ctacks but 20 min was rocjuirod for several small crects

'I'h test results indicate that, the minimum penetrant dwell lime varies as a function of discontinuty type and developer type. The longest required penetrant dwell time was 20 minutes. If it is assumed that it is necessary to detect all three discontinuity types (Gross cracks, small cracks, and porcsity) in a penetrant inspection process, then, for all cases, at least a $2^{r}$ inute penetrant dwell time would be necessary. These data supp the present MIL-I-6866B dwell time requirement of .20 to 30 minutes. It should be noted that Table 3 in no way indicates the relative effectivaness of various developer types. For example, a shorter required dwell time, 
Gross Cracks Specimen 33C

Nonaqueous Wet Developer

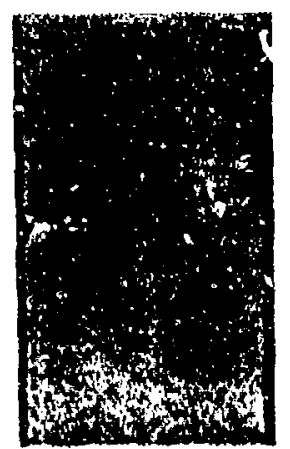

$5 \mathrm{~min}$

Dwell Time

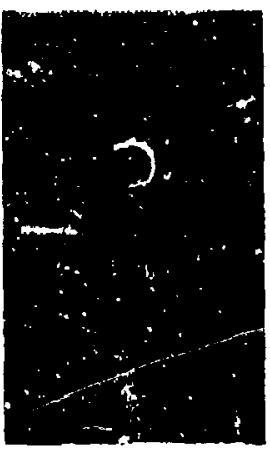

$10 \mathrm{~min}$

Dwell Time

Smaller, Tighter Cracks, Specimen 15SC No Developer

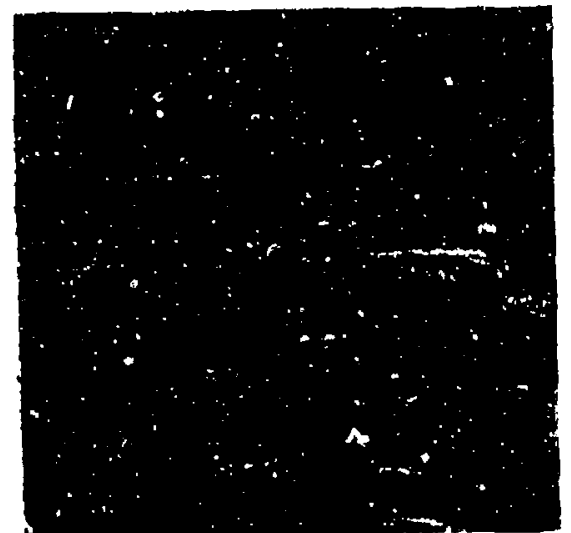

5 min

Dwell Time

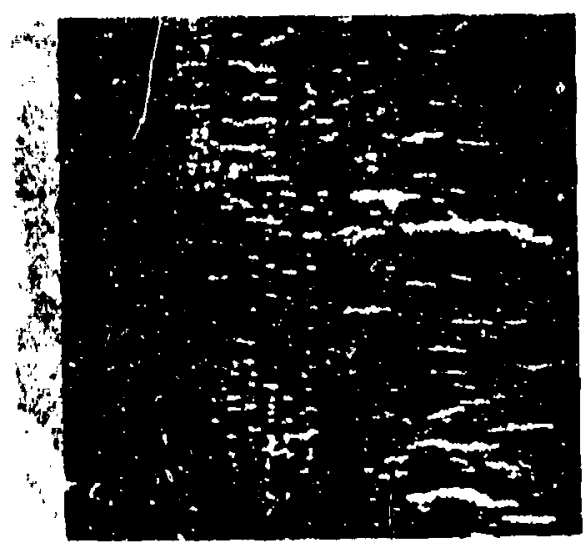

$20 \mathrm{~min}$ Dwell Time

FIGURE 10

EFFECT OF PENETRANT DWELL TIME

(Post-Emulsifiable Penetrant - 15 Min Bleed-Out Time) 


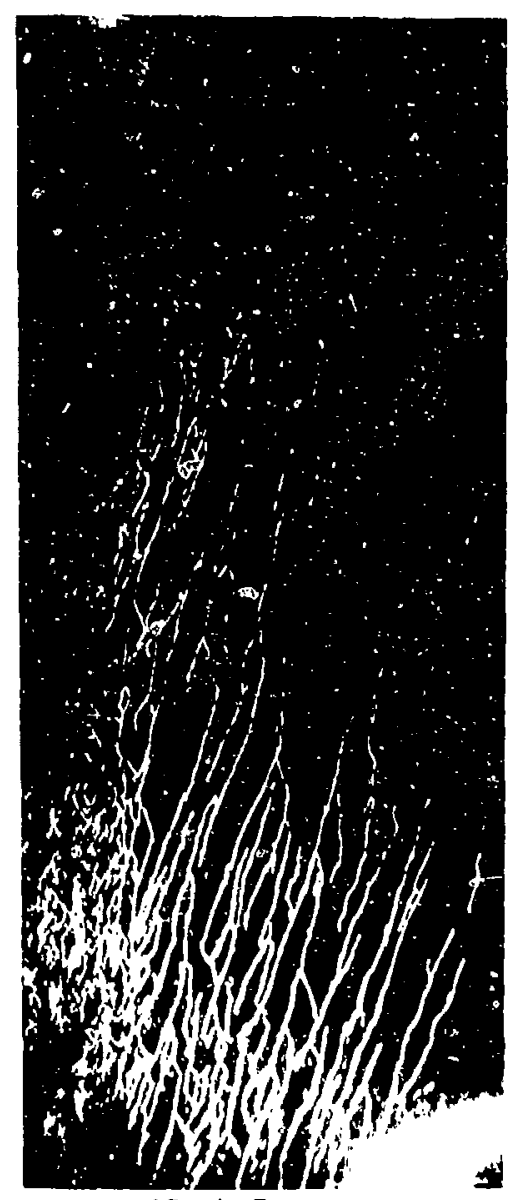

10 min Penetrant Dwell Time

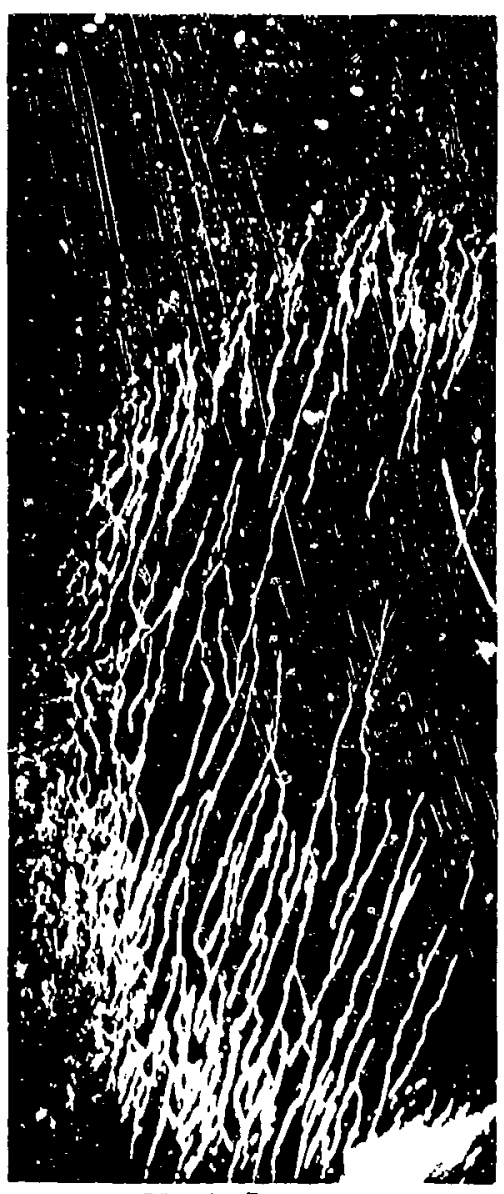

20 min Penetront Dwell Time

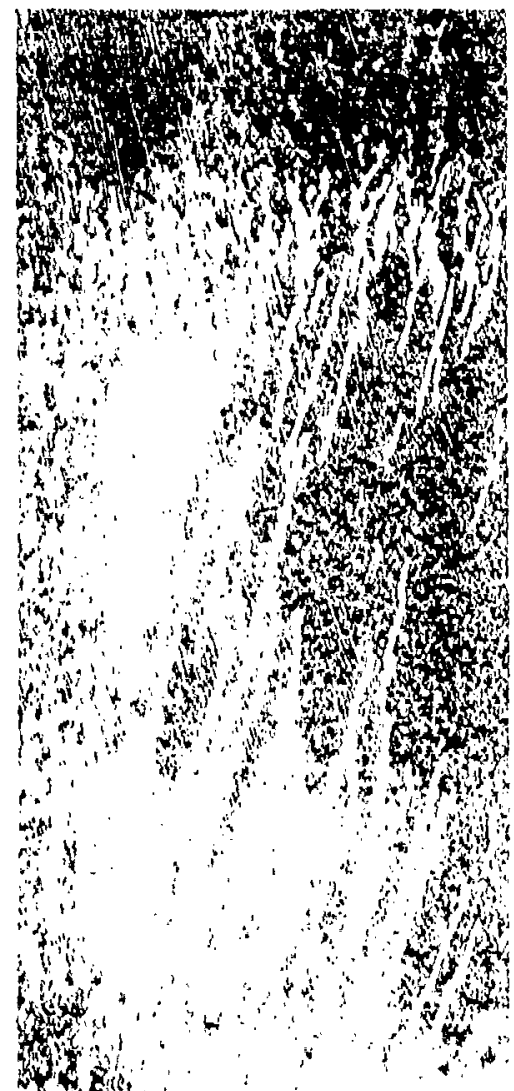

Nonds

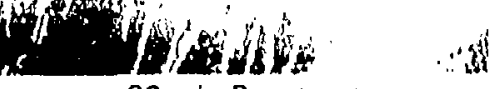

30 min Penetrant Dwell Time

FIGURE 10 (Continued)

EFFECT OF PENETRANT DWELL TIME

(Post-Emulsifiable Penetrant - 15 Min Bleed-Out Time) 
when using dry developer on gross cracks versus nonaquenous wet developer, did not necessarily indicate that the dry developer was more effective. These effects are covered in later sections of this report.

\section{(2) Water Washable Penetrant System}

As with the post-emulsifiable penetrant system, the photographs of the penetrant indications taken during the bleed-out time study were used to stridy the effect of pentrant dwell. time. The photographs of the penetrant indications wero visually compared to determine the penetrant dwell time necessary for maximum penetrant indication brilliance.

Since the penetrant bleed-out time study indicated that under no circumstances was more than 5 minuties bleed-out time required to achieve maximum brilliance of the penetrant indications, the penetrant dwell times were compared using a penet $x$ ant bleedout time of 's minutes.

The results of the penetrant dwell time study as a function of discontinuity type and developer type are surmarized in Table 4 and demonstrated in Figure 11.

As seen in Table 4, the required penetrant dwell time varied as a function of discontinuity type and developer type. The required. penetrant dwell time was 5 minutes for the gross cracks, irrespective of the developer type used. A variation in the required penetrant dwell time was noted for the smaller tigntex cracks depending upon the type of developer used. When no developer was used, the majorit: of the crack indications were present when the dwell time was 5 minutes. However, 20 minutes dwell time was required for several of the small, tight cracks. When nonaqueous wet developer or dry developer was used, a 5 minute penetrant dwell time was sufficient. For aqueous wet developer, a 1 minute dwell time is indicated, which indicates that the strengths of the indjeations were not improved by longer bleed-out times. However, this developer was totally ineffective as very few of the smaller, tighter crack indications were visible, no matter what penetrant dwe.1 1 time was used.

In summary, for the most eff'ective penetrant inspection, at least 20 minutes dwell tine should be used for a system without, developer or with rqueous developer, and at least 10 minutes dwell time should be used for systems employing a nonaqueous wet or dry developer. Of course, these penetrant/developer combinations are not equivalent in effectiveness even if the required penetrant dwed times are numberically equivalent. The relative nf fectiveness if the systems are discussed in section $1-\mathrm{k}$ of thit: repr.t.

It should be kept in mind that the pouetrant dwell tim atudy

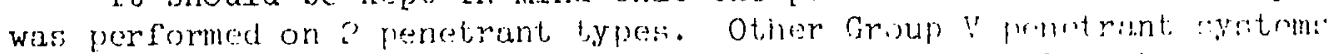

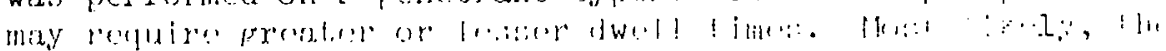

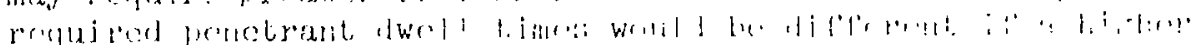

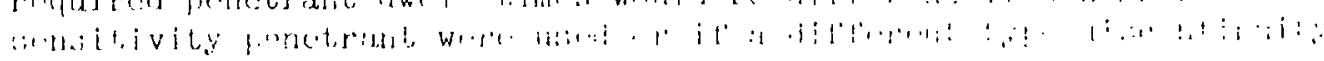



were to be detected. Also, the test specimens usad for thj s laboratory investigation were very carefully cleaned for the investigation. Prociuction parts cleaned prior to a production penetrant inspection may not attain this degrec of cleanliness and therefore, a longer penetrant dwell might be necessary. However, the penetrant dwell time data developed in this program can be used as a guideline for selecting adequate penetrant dwell times in a production penetrant inspection.

\section{f. Developer Effectiveness}

The purpose of a developer in penetrant inspection is to increase the visibility of the penetrant available at a discontinuity by spreading it and drawing more of it from the discontinuity and to provide a background from which to view the penetrant indications. Several types of developers are currently in use: nonaqueous wet, dry, and aqueous ret. Consequently, a program was undertaken to evaluate the relative effectiveness of these developer types in comparison with no developer.

\section{(1) Posi-Emulsifiable Penetrant System}

The photographs of the penetrant indications taken during the bleed-out time study were used to stidy the relative effectiveness of developer types. Previously mentioned studies indicated that no improvement in penetrant indications was noted for penetrant dwcl]. times greater than 20 minutes and for penetrant bleed-out times greater than 15 minutes. Consequently, the developer effectiveness was compared by evaluating the photographs of penetrant, indication. resulting from a penetrant dwelj. time of 20 minutes and a penetrant bleed-out of 15 minutes. A 1 minute emulsification time was used.

The results of the developer effectiveness study are summarized in l'able 5 and shown in f'igures 12. and 13.

\section{TABLE 5}

\section{RELATIVE EFFECTIVENESS OF DEVELOPER TYPES}

\begin{tabular}{|l|l|}
\hline Gross Cracks & $\begin{array}{l}\text { Post-Emulsifiable Penetrant } \\
\text { Equally Ef fective } \\
\text { (2) No Developer }\end{array}$ \\
\hline Porosity & $\begin{array}{l}\text { (1) Dry } \\
\text { (2) Nonaqueous Wet (Slightly Less) } \\
\text { (3) No Developer } \\
\text { (4) A.queous }\end{array}$ \\
\hline Smaller, & $\begin{array}{l}\text { (1) Nonaqueous Wet and Dry - Equally Eftective } \\
\text { Tighter Cracks }\end{array}$ \\
\hline
\end{tabular}

(OP140111168 

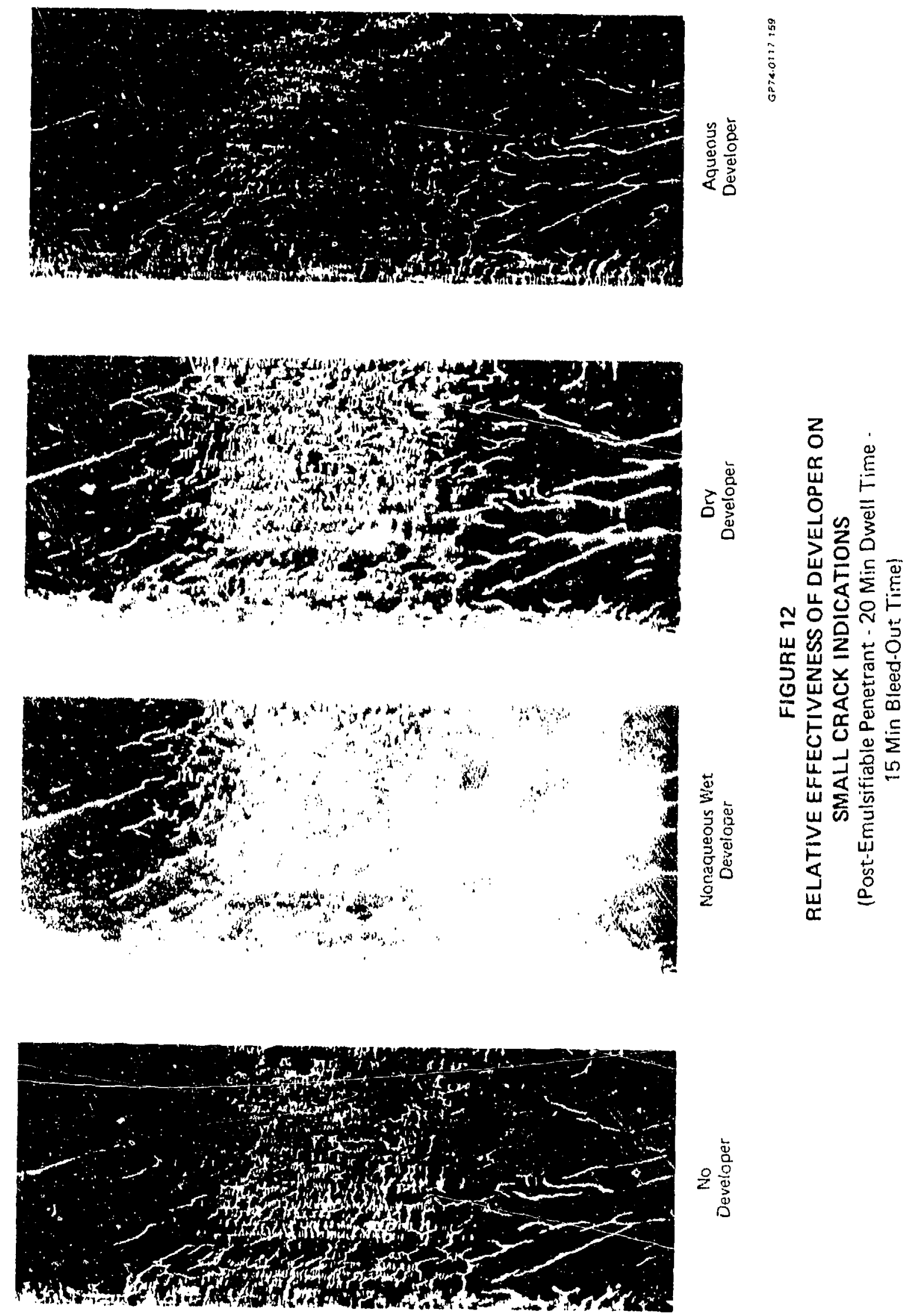
Specimen No. 34C

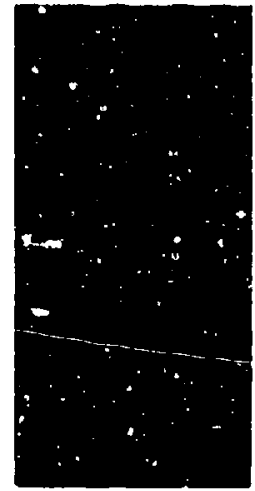

No Developer

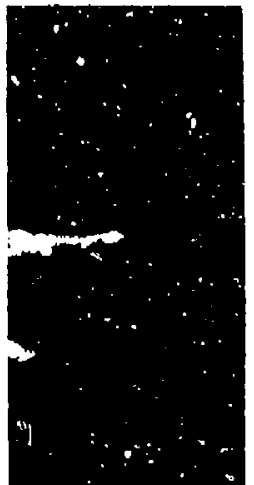

Nonaqueous Wiet Developer

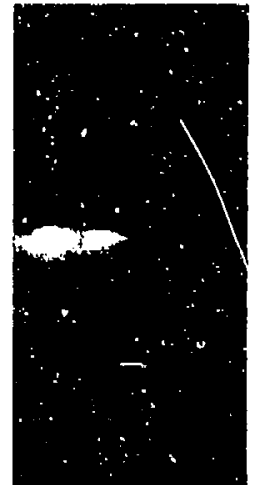

Dry

Developer

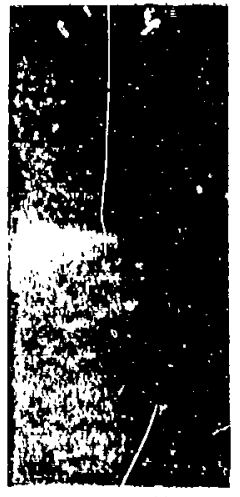

Aquersus Wet Developer

\title{
FIGURE 13 \\ RELATIVF EFFECTIVENESS OF DEVELOPER FOR DETECTION OF GROSS CRACKS \\ (Post - Fmulsifiable Penetrant - 20 Min Dwell Time - 15 Min Bleed.Out Time)
}

\begin{abstract}
The gross cracks (approximately .001 inch wide $x .25$ inch long) were ail visible for each of the four conditions (no developer, nonaqueous developer, ury developer, and aqueous wet developer); however, the indications were brighter when a developer was used. The three developer types were essentially equaliy effective on the gross cracks. As shown in Figure 12, aqueous wet developer was least effective for the tight cracks. For the detection of the smalier, tighter cracks (approximately .0002 inch wide $x .060$ inch long) nonaqueous and dry developers were most effective with no devoloper being slightly less effective. Aqueous developer was the least effective. For the detection of porosity, dry developer was the most effective with nonaqueous slightly less effective. No developer was next effective while aqueous developer was the least effective of all.
\end{abstract}

Based on these test results, then, there is a definite dirielence in the effectiveness of the various developer types depending on the discontinuity that is of interest and for a production penetrant inspection to be most effective these considerations should be kept in mind. 


\section{(2) Water Washable Penetrant System}

Specimens containing tight and gross cracks were used in the evaluation as well as po"csity specimens. T'ne spccimens were penetrant inspected using Tracer-Tech P-133 high sensitivity water. washable penetiant, equivalent in sersitivity to MIL-I-25135 Group $\mathrm{V}$ penetrant when used without a developer, Tracer-Tech D-499C nonarlueous wet leveloper, 'Iracer-Tech D493A dry developer, and Tracer-Tech, Dl,92C aqueous wet developer were used in the investigation as well. as no developer. The use of a developer increases the scrsitivity of tha system to that of a Group VI system. The ponetrant dwell times and developer bleed-out times used exceeded the minimum elfective times estabiished in the previously discussed dweli time study. The penetrant inspection parameters were the same ais used in the dwell time study.

The test results are summarized in Table 6 . The pentrant indications of the gross cracks (approximately .001 inch wide $x .25$ inch long) were essentialiy equivalent when any of the three developers were used, but the crack indications without developer were less effective. Because of the large crack area involved, a large reservoir is available for the penetrant. Consequently, the difference between developers is probably reduced due to the large volume of penetrant within the cracks.

The effectiveness of the developers on smaller. tighter sracks (approximately .0002 inch wide $x .060$ inch long) is demonstrated in irigure 14. Aqueous wet developer was nearly totally inef'ective when used with the water washable penetrant to detect the smaller, tighter cracks, as very f'ew of the crack indications were evident. Many crack indications were evident when no developer

TABLE 6 RELATIVE EFFECTIVENESS OF DEVELOPER TYPES

\begin{tabular}{|l|l|}
\hline \multicolumn{2}{|c|}{ Water Washable Penetrant } \\
\hline Gross Cracks & $\begin{array}{l}\text { (1) Nonaqueous We', Dry and Aqueous - } \\
\text { Equally Effective } \\
\text { (2) No Developer }\end{array}$ \\
\hline Porosity & All Types Equally Effective \\
\hline Smaller, & $\begin{array}{l}\text { (1) Nonaqueous Wet and Dry - Equally Effective } \\
\text { Tighter, Cracks }\end{array}$ \\
\hline
\end{tabular}

GP/4011/ in 
Specimen 4SC

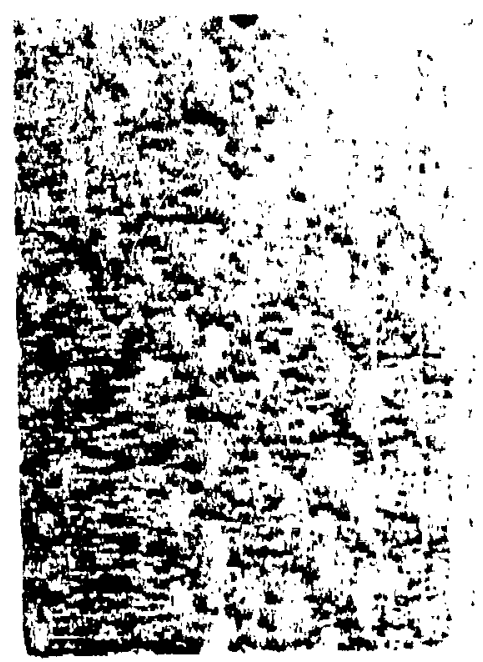

No Developer

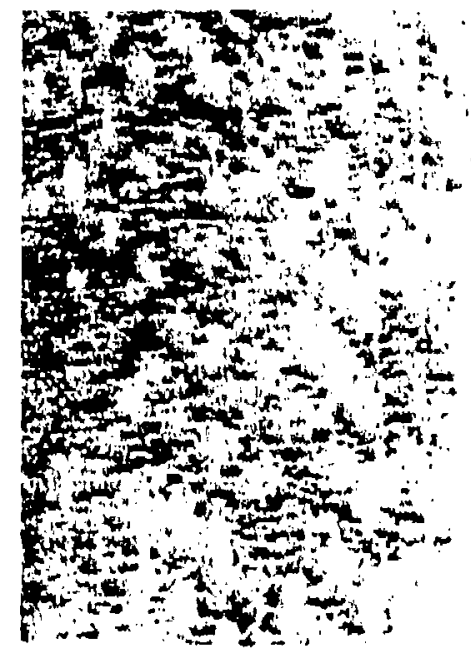

Nonaqueous Wet Developer
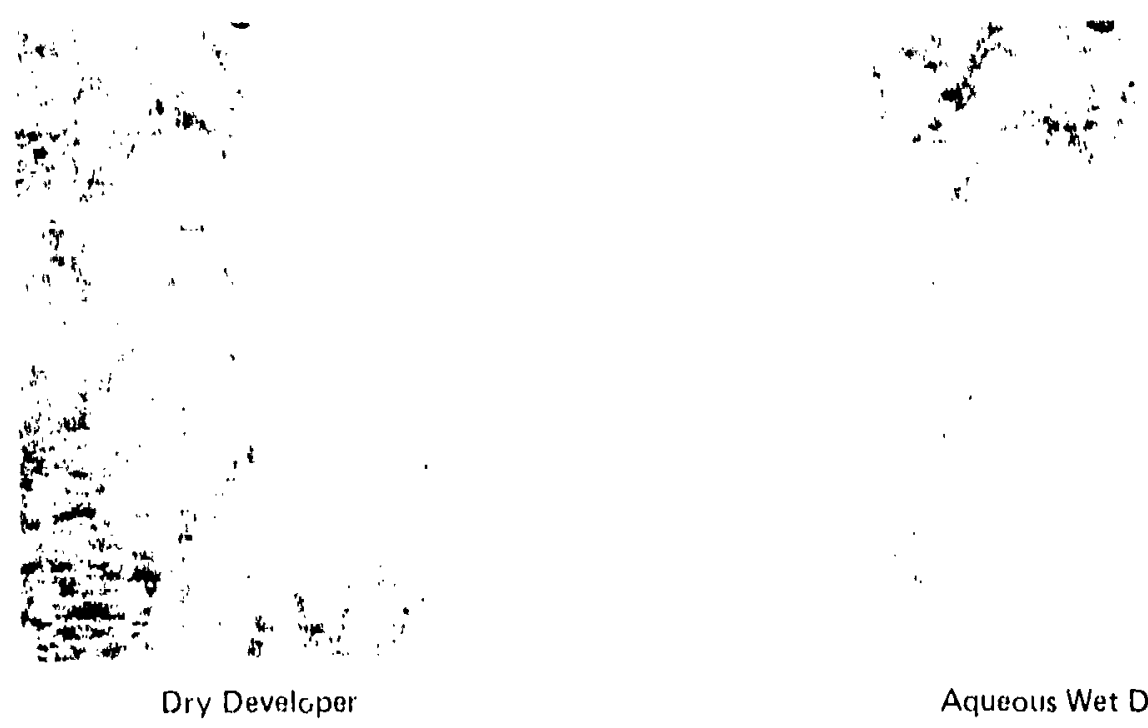

Aqueous Wet Developer

FIGURE 14

RELATIVE EFFECTIVENESS OF DEVELOPER FOR

DETECTION OF SMALLER, TIGHTER CRACKS

(Water Washable Penetrant) 
was used but these indications were emhanced when either ory or nonaqueous wet developer was applied. Noraqueous wet and dry developers were the most effective. ixcept for a few isolated cases, the nonaqueous wet and dry developers were equivalent in et'fectiveness.

All three developer types, as well as no developer, were equally effective on porosity indications. As in the case of the gross cracks, the porosity probably holds a relatively large volume of penetrant compared with the smaller, tighter cracks, lessening the difference between developers. It should be noted, however, that the aqueous wet reveloper terds to make the porosity indications indistinct.

\section{g. Tmulsification Itive}

In a post-emulsification penetrant system, the emulisifier is applied in a separate step prior to washing excess penetrant from the test part surface. The time that the emulaifjer remains in contact with the part must be long enough so that the excess penetrant can be offectively removed from the part surface but not so long as to cause penetrant to be removed f'rom discontinuities. 'lhis aspest of ponetrant testing was studied for the MIL-I-25135, Group V f'luorescent penctrunt (Magnaflux ZL-2A) used with Mangaflux ZPX-437 nonaqueous devejoper, Magnaflux ZP-4 dry developer Magnaflux ZP-1.3 aqueous wet developer, and without a developer. Magnaflux ZL-3 omulsifier was used and emulsificution times of 1,3 , and 10 minutes were evaluated. Ensed on the previous; results, a penetrant dwell time of 20 minutes whs used along with a penetrant bleed-out time of 15 minutes. As before, sjecimens containdng tight and Gross cracks were used us well as as porosity specimeng. A summary of the testing is shown in Figure 15. 


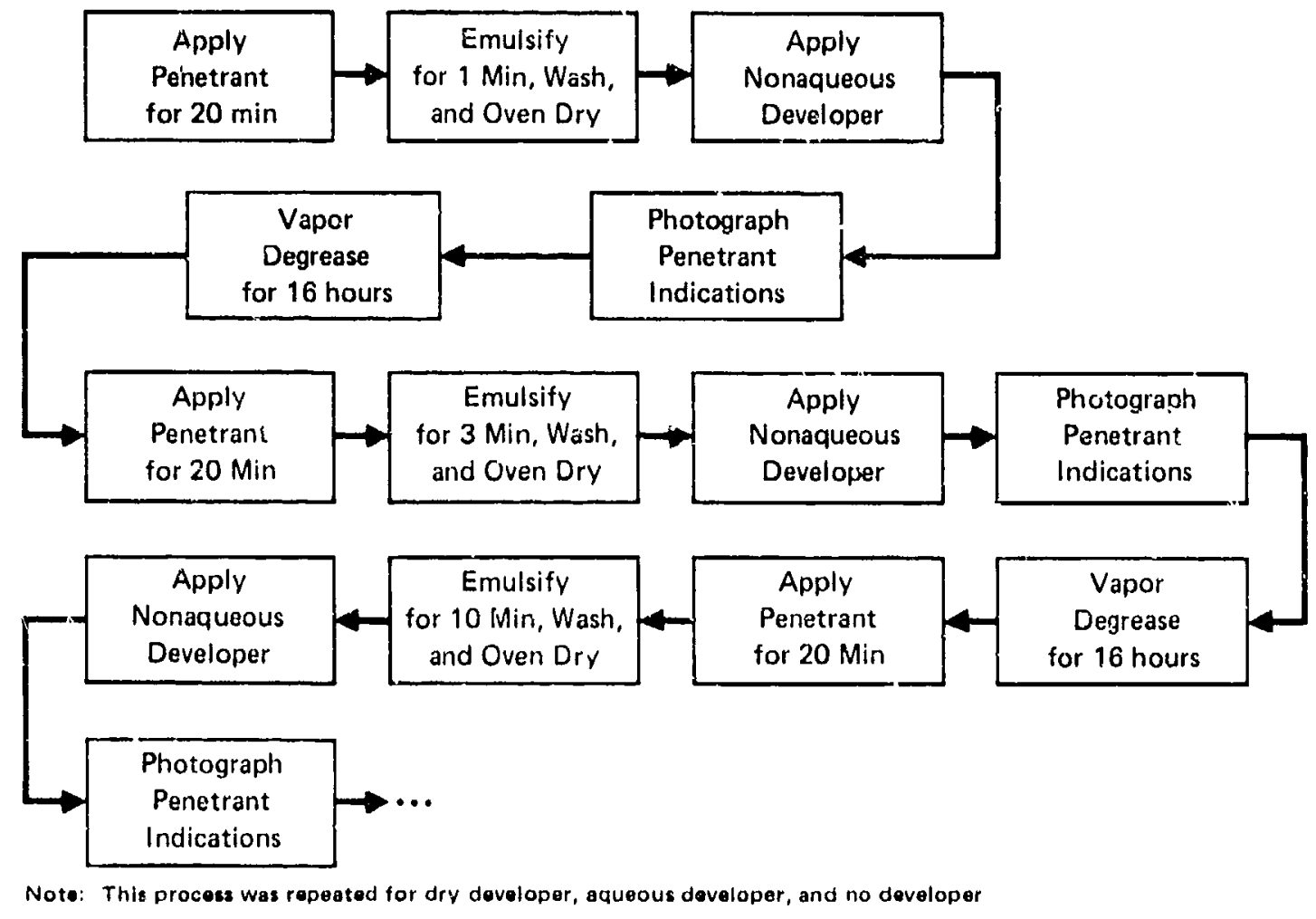

FIGURE 15

TEST PLAN FOR EMULSIFICATION TIME STUDY 
The specimens were completely imimersed in the penetrant during the applicable pentrant dwell time. Excess penetrant was washed frcm the specimens after the appropriate emulsification time using a Tri-Con 400501 water spray nozzle; the wash water temperature was approximately $90^{\circ} \mathrm{F}$ and the wash water pressure was approximately $40 \mathrm{psi}$. Each specimen was washed until the specimen surface was visually clean under $200 \mathrm{microwatts} / \mathrm{cm}^{2}$ of ultraviolet light (appro: imately 15 seconds). Next, the specimens were dried until visually dry (10-15 minutes) in a circulating air oven at $170^{\circ} \mathrm{F}$. The concentration of the aqueous wet developer, when used, was $1 / 2$ pound per gallon. After the 15 minute bleed-out time, the penetrant indications were photographed using the following parameters: approximately 1000 microwatts per $\mathrm{cm}^{2}$ of ultravioiet light, 25 second exposure at $f 9$, Royal Pan Film, Tiffen yellow No. 2 filter. The effect of emulsification time was evaluated by directly comparing the photographs of the penetrant indications resulting from 1,3 , and 10 minutes emulsjfication time.

The results of the emulsification time study ara sumnarized in Table 7. An emulsilication time of 1 minute was adequate f'or: effective removal of excess penetrant in all cases. For the gross cracks as much as 10 minutes emulsification time could be used without reducing the effectiveness of the penetrant test (Figure 16). However, for smaller, tighter discontinuities, the emulsification + ime had to be kept at 3 minutes or less to avoid a reduction in the brilliance of the penetrant indications. Based on these results, then, an emulsification time of less than 3 minutes should be used in order to effectively detect a wide variety of crack and porosity sizes using a MIT,I-25135, Group V post-tmulsifiable penetrant system.

By necessity, the emulsification study was limited in senpe. Only a few emulsification times and one surface condition (as-machined) was investigated. Consequently, these results should be used only as guidelines to the selection of emulsification times for alternate surface conditions such as as-cast or us-forged surfaces.

TABLE 7

EFFECTIVE EMULSIFICATION RANGE

\begin{tabular}{|c|c|c|c|}
\hline \multirow{2}{*}{ Developer } & \multicolumn{3}{|c|}{ Effective Emulsification Range (Min) 1} \\
\hline & $\begin{array}{l}\text { Gross } \\
\text { Cracks }\end{array}$ & Porosity & $\begin{array}{c}\text { Smaller, Tighter } \\
\text { Cracks }\end{array}$ \\
\hline None & 1 to 10 & 1 to Less Than 3 & 1 to Less Than 3 \\
\hline Nonaqueous Wet & 1 to 10 & 1 to Less Than 3 & 1 to $3 \Omega$ \\
\hline Dry & 1 to 10 & 1 to 3 & 1 to Less Than $3 \widehat{2}$ \\
\hline Aqueous Wet & 1 to 10 & 1 to 3 & 1 to Less Than 3 \\
\hline
\end{tabular}

1) Penetrant bleed-out time $(15 \mathrm{mini}$ and penetrant dwell time $(20 \mathrm{~min})$ exceeded the minimum reduired (2) $10 \mathrm{~min}$ emulsification time was acceptable or most cracks but was too long for several small cracks 
Gross Cracks - Specimen 30C

Dry Developer
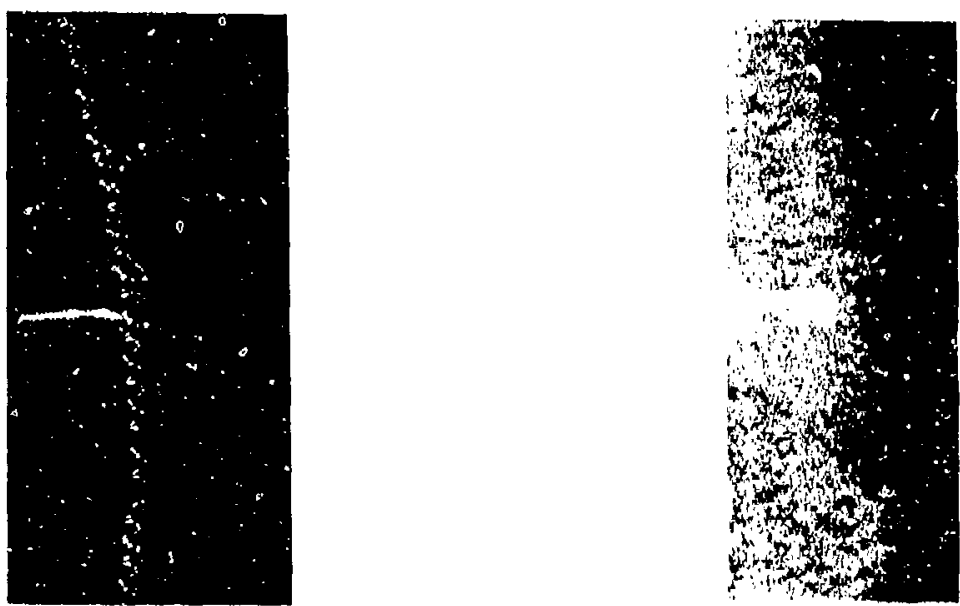

$10 \mathrm{~min}$

Emulsification

Em:alsification

Time

FIGURE 16

GP74.0117.165

\section{EFFECT OF EMULSIFICATION TIME}

(Post-Emulsifiable Penetrant System - 20 Min Penetrant Dwell Time and $15 \mathrm{Min}$ Penetrant Bleed-Out Time) 
Smaller, Tighter Cracks - Specimen 19SC

Nonaqueous Wet Developer

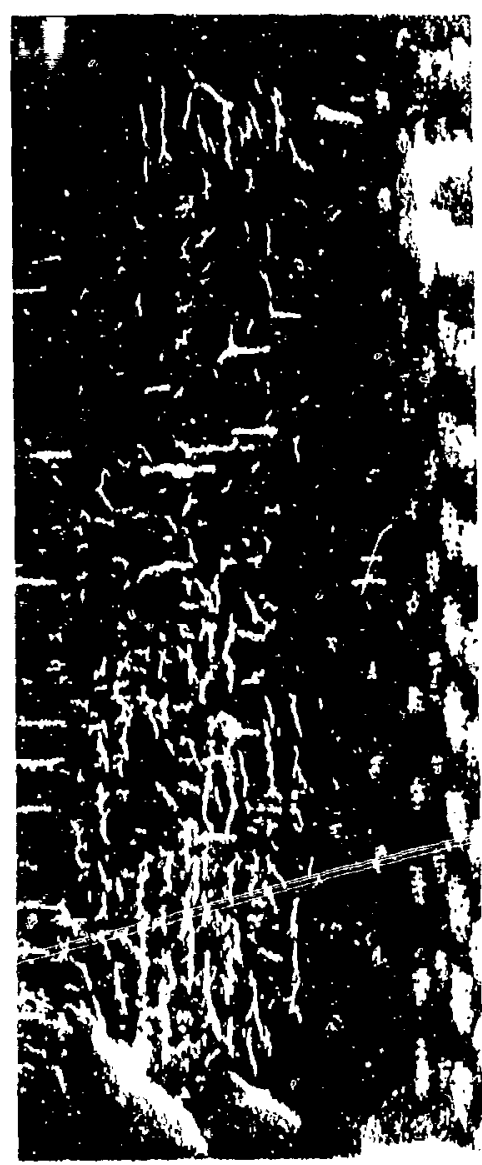

1 min

Emulsification

Time

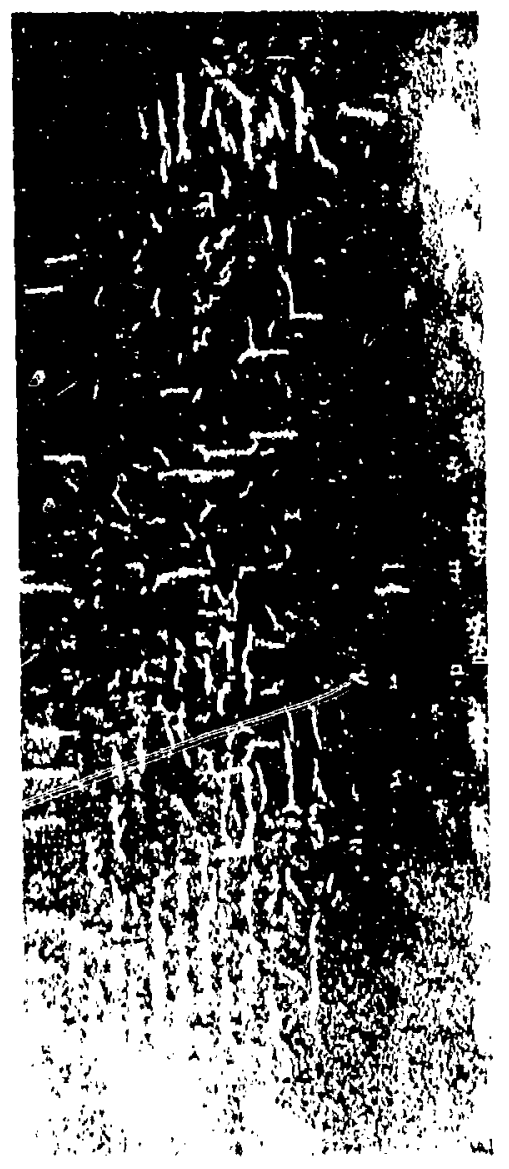

$3 \min$

Emulsification

Time

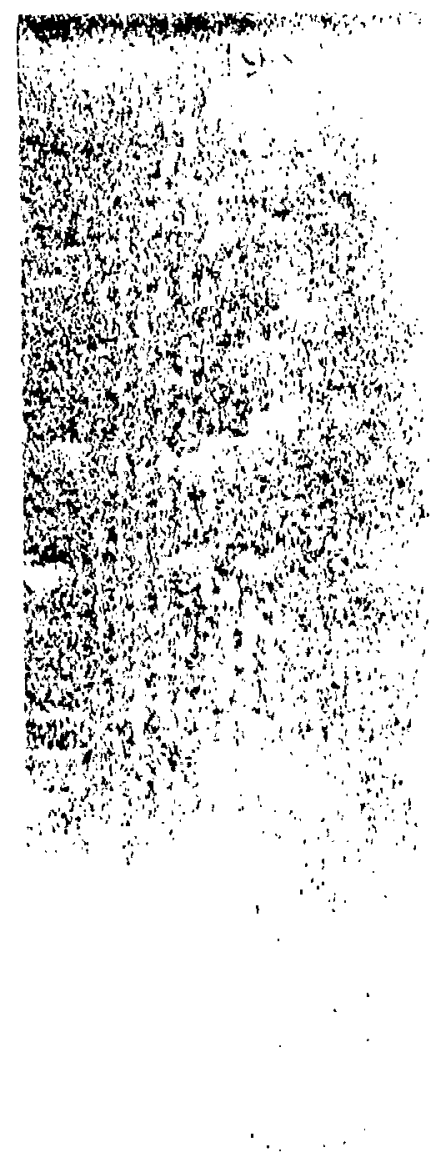

$10 \mathrm{~min}$

Emulsification

Time

FIGURE 16 (Continued)

EFFECT OF EMULSIF:CATION TIME

(Post-Emulsifiable Penetrant System . 20 Min Penetrant Dwell Time and 15 Min Penetrant Eleed-Out Time) 


\section{h. Water Washing Techniques}

The removal of the excess penet ant prior to examination is an important step in the penetrant inspection process. The purpose of removing the excess penetrart is to remove any confusing background or false indications which may interfere with the indications of discontinuities. At the same time, the cleaning operation must not remove penetrant from discontinuities themselves.

Several types of cleaning operations can be used to remove excess penetrant. Wiping the surface with cloths, either dry or moistened. with solvent, has been done but has the disadvantage of being too slow for quantity production inspection. When cleaning by spraying with solvent:3, it can be difficult to avoid removal of penetrant from discontinuities. Probably the most important and videly-used cleaning technique is washing with water; this can be accomplished either by using penetrant with an incorporated emulsifier or by application of the emulsifier as a separate step. Because of the emphasis upon water washing in production penetrant inspections, this portion of the program concentrated on the variables involved in water washing. Hand held sprayers were used for this portion of the program; therefore, the angle of water impingement raried throughout the entire washing operation.

\section{(1) Post-Emulsifiable Penetrant}

An investigation was performed to establish acceptable water washing parameters for removal of excess penetrant using a postemulsifiable penetrant system.

Magnaflux ZL-iA penetrant (NIL-I-25135, Group V fluorescent penetrant) was used along with Magnaflux ZE-3 emulsifier and Magnaflux ZPX-437 nonaqueous developer. I'he penetrant dwell time was 20 minutes, the emulsification time was 1 minute, and the penetrant b.leed-out time was 15 minutes; these choices were based upon the results of the previous testing

Specimens containing tight and gross cracks were used in the evaluation as well as porosity specimens. T'he specimens were completely inmersed in the penetrant during the applicable penetrant dwell. After emulsification, excess penetrant wis washed from the specimens using the applicable washing parameters shown in Table 8 . Each specimen was washed until the specimen surface was visually clean under $200 \mathrm{microwatts} / \mathrm{cm} 2$ of ultraviciet light. 
TABLE 8

WATER WASHING PARAMETERS

\begin{tabular}{|c|c|c|}
\hline $\begin{array}{l}\text { Water Removal } \\
\text { Method }\end{array}$ & $\begin{array}{c}\text { Water Temp } \\
\left({ }^{\circ} \mathrm{F}\right)\end{array}$ & $\begin{array}{c}\text { Water Pressure } \\
\text { (psi) }\end{array}$ \\
\hline \multirow{3}{*}{$\begin{array}{l}\text { Water Spray } \\
\text { (Nozzle) } 1\end{array}$} & 70 & $\begin{array}{l}40 \\
60 \\
90 \\
\end{array}$ \\
\hline & 100 & $\begin{array}{l}40 \\
60 \\
90 \\
\end{array}$ \\
\hline & 145 & $\begin{array}{l}40 \\
60 \\
90\end{array}$ \\
\hline Immersion & $\begin{array}{c}70 \\
100 \\
145\end{array}$ & $\begin{array}{l}- \\
-\end{array}$ \\
\hline
\end{tabular}

A Tri-Con 400501 heavy duty spray wash gun was used for the spray wash portion of the program. The spray gun was hel.d 8 inches from the specimen surface during the washing. Initial testing indicated that approximately 7 seconds washing time was required to remove all the excess penetrant from the specimens; consequently, a 7 second washing time was used throughout the program for consistency.

The immersion wash tests were carried out using a $10 \times 16$ inch container, 6 inches deep. The water in the container was air agitated using a stainless steel tube ( $3 / 8$ inch I.D. $x$ I2 inches long) which had 44 holes drilled in it for aj.r passage. The stainless steel tube was directly connected to a $90 \mathrm{psi}$ air line. It was found that a time of 2 minutes was required to wash excess penetrant from each specimen using this apparatus and, consequently, a two minute wash time was used throughout the program. The specimens were dried after washing until visually dry (10-15 min.) in a circulating air oven at $170^{\circ}$ and aiter the appropriate bleed-out times, the penetrant indications were photographed using the following parameiers: approximately 1000 microwatts per cme of ultraviolet light, 25 second exposure at f9, Royal Pan Film, Tiffen yellow No. 2 filter. Next, specimens were vapor degreased for 16 hours in order to remove residual penetrant and the testing was repeated using another set of washing parameters. 
The water washing parameters were evaluated by visually comparing the photographs of the penetrant indications resulting from each test condition. Since it was found initially that the excess penetrant could be adequately removed by washing for 7 seconds at $40 \mathrm{psi}$ and $70^{\circ} \mathrm{F}$, the photographs of the penetrant indications resulting from the other washing conditions were compared to the $40 \mathrm{psi} / 70^{\circ} \mathrm{F}$ indications to determine if any overwashing occurred at the higher pressures and temperatures. The results of the investigation indicated that the specimens containing gross cracks could be washed using water pressures up to $90 \mathrm{psi}$ and water temperatures up to $145^{\circ} \mathrm{F}$ without reducing the strength of the penetrant indications by overwashing (see Table 9).

The more open discontinuities, such as porosity, could be effectively vashed without overwashing as long is the spray water was either $40 \mathrm{psi} / 70^{\circ} \mathrm{F}$ or $40 \mathrm{psi} / 100^{\circ} \mathrm{F}$. Increasing the water pressure to $60 \mathrm{psi}$ or the water temperature to $145^{\circ} \mathrm{F}$ reduced the strength of the penetrant indications as demonstrated in Figure 17 .

TABLE 9

ACCEPTABLE WASHING CONDITIONS

Post-Emulsifiable Penetrant System

\begin{tabular}{|c|c|c|}
\hline $\begin{array}{l}\text { Removal } \\
\text { Method }\end{array}$ & $\begin{array}{c}\text { Discontinuity } \\
\text { Type }\end{array}$ & Acceptable Conditions \\
\hline \multirow{3}{*}{$\begin{array}{l}\text { Spray } \\
\text { Nozzle } \\
\text { (Tri-Con- } \\
400501 \text { ) } \\
\text { for } 7 \\
\text { Sec }\end{array}$} & Gross Cracks & $\begin{array}{l}40 \mathrm{psi} \cdot 70^{\circ} \mathrm{F} \text { to } 145^{\circ} \mathrm{F} \\
60 \mathrm{psi}-70^{\circ} \mathrm{F} \text { to } 145^{\circ} \mathrm{F} \\
9 \mathrm{psi} \cdot 70^{\circ} \mathrm{F} \text { to } 145^{\circ} \mathrm{F}\end{array}$ \\
\hline & Porosity & $<60$ psi $\cdot 70^{\circ} \mathrm{F}$ to $>100^{\circ} \mathrm{F}$ but $<145^{\circ} \mathrm{F}$ \\
\hline & $\begin{array}{c}\text { Smaller, } \\
\text { Tighter Cracks }\end{array}$ & $\begin{array}{c}40 \mathrm{psi}-70^{\circ} \mathrm{F} \text { to } 145^{\circ} \mathrm{F} \\
60 \mathrm{psi} \cdot 70^{\circ} \mathrm{F} \text { to } 145^{\circ} \mathrm{F} \\
<90 \text { psi } \cdot 70^{\circ} \mathrm{F} \text { to }>100^{\circ} \mathrm{F} \text { but }<145^{\circ} \mathrm{F}\end{array}$ \\
\hline \multirow{3}{*}{$\begin{array}{l}\text { Immersion } \\
\text { For } 2 \text { Min }\end{array}$} & Gross Cracks & $70^{\circ} \mathrm{F}$ to $145^{\circ} \mathrm{F}$ \\
\hline & Porosity & $70^{\circ} \mathrm{F}$ to $145^{\circ} \mathrm{F}$ \\
\hline & $\begin{array}{c}\text { Smaller, } \\
\text { Tighter Cracks }\end{array}$ & $<60 \mathrm{psi} \cdot 70^{\circ} \mathrm{F}$ to $>100^{\circ} \mathrm{F}$ but $<145^{\circ} \mathrm{F}$ \\
\hline
\end{tabular}




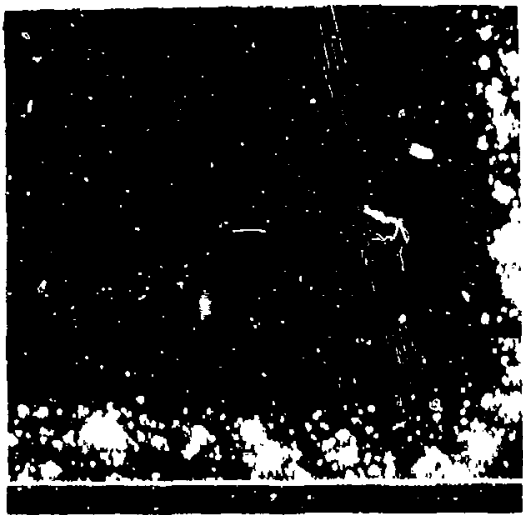

$40 \mathrm{psi} \cdot 70^{\circ} \mathrm{F}$

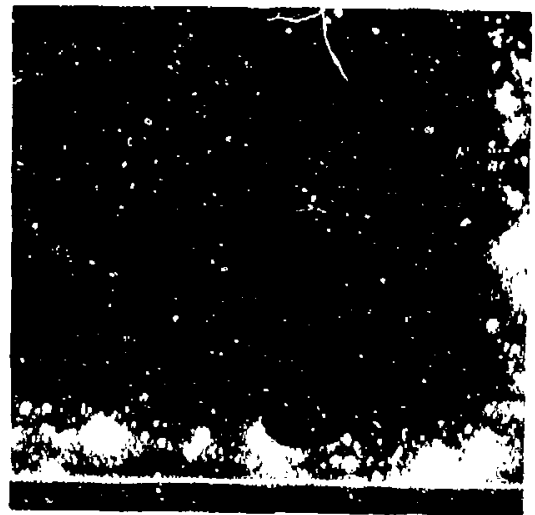

$90 \mathrm{psi} \cdot 145^{\mathrm{n}}$ :

\section{FIGURE 17 \\ DEGRADATION IN PFNETRANT INDICATIONS DUE TO \\ OVER WASHING}

(Post-Emulsifiable Penetrant System)

The specimens containing smalier, tighter cracks could be washed at a.1 water pressure/water temperature combinations except $90 \mathrm{psi} / 145^{\circ} \mathrm{F}$ without overwashing.

Overwashing of small discontinuities was less of a problom with the immersion method than with the water spray method. There was no reduction in the penetrant effectiveness for porosity at $145^{\circ} \mathrm{F}$ compared with $70^{\circ} \mathrm{F}$. In addition, the porosity penetrant, indications wers larger and more distinct after immersion washing as compared with spray washing. Presumably, the mechanical scrubbing action of the water spray removes some of the penetrant from the pores while the immersion method does not.

Ail of the specimens were washed for 2 minutes during the immersion tests in order to evaluate the water temperatures under equivalent washing times. However, it was found that the time required to wash excess penetrant f'rom the specimen surfaces was a function of water temperature. At $70^{\circ} \mathrm{F}$, ? minutes were required; ai $100^{\circ} \mathrm{F}$, 15 seconds were required; and at $145^{\circ} \mathrm{H}, 30$ seconds were required.

These test results bear out the importance of controllinfs the water washing parameters, even with a post-emulsitiable penetrant system. For example, if a production penetrant inspection were to be performed with the intent being to detect open, shallow discontinujties, such as porosity, the spray wash should be performed at a maximum water pressure which lies between 40 psi and fo psi and at a maximum water temperature which 1 ies between $100^{\circ} \mathrm{F}$ and $14^{1} 5^{\circ} \mathrm{F}^{\prime}$. 


\section{(2) Water Washable Penetrant}

An investigation was made of the effect of wash water pressure and temperature for the water washable penstrant system.

Tracer-Tech P-133 penetrant was used, which is equivalent in sensitivity to a MIL-I-25135, Group V penetrant. The penetrant was used with Tracer-Tech D49S: nonaqueous wet developer. Based on the previous results, a penetrant dwell time of 20 minutes was used alone with a penetrant bleed-out time of 15 minutes.

Specimens containing tight and gross cracks were used in the evaluation as well as porosity specimens. The penetrant testing was performed using the same equipment and $t \in c h n i q u e s$ described above for the post-emulsifiable penetrant system.

As in the case of the post-emulsifiable penetrant system, the excess penetrant was adequately removed by washing for 7 seconds at $40 \mathrm{psi}$ and $70^{\circ} \mathrm{F}$. Consequently the photographs of the penetrant indications resulting from the other washing conditions were compared to the $40 \mathrm{psi} / 70^{\circ} \mathrm{F}$ indicatiuns to determine if any overwashing occurred at higher pressures and temperatures,

The results indicated that the specimens containing gross cracks could be washed using water pressures up to $90 \mathrm{psi}$ and water temper'atures up to $145^{\circ} \mathrm{F}$ without reducing the strength of the penetrant indications by overwashing (see Table 10).

TABLE 10

\section{ACCEPTABLE WASHING CONDITIONS}

(Water Washable Penetrant System)

\begin{tabular}{|c|c|c|}
\hline $\begin{array}{l}\text { Removal } \\
\text { Method }\end{array}$ & $\begin{array}{c}\text { Discontinuity } \\
\text { Type }\end{array}$ & Acceptable Conditions \\
\hline \multirow{3}{*}{$\begin{array}{l}\text { Spray } \\
\text { Nozzle } \\
\text { (Tri-Con- } \\
400501 \text { ) } \\
\text { for } 7 \\
\text { Sec }\end{array}$} & Gross Cracks & $\begin{array}{l}40 \mathrm{psi} \cdot 70^{\circ} \mathrm{F} \text { to } 145^{\circ} \mathrm{F} \\
60 \mathrm{psi} \cdot 70^{\circ} \mathrm{F} \text { to } 145^{\circ} \mathrm{F} \\
90 \mathrm{psi} \cdot 70^{\circ} \mathrm{F} \text { to } 145^{\circ} \mathrm{F}\end{array}$ \\
\hline & Porosity & $<$ to psi $\cdot 70^{\circ} \mathrm{F}$ to $<100^{\circ} \mathrm{F}$ \\
\hline & $\begin{array}{c}\text { Smaller. } \\
\text { Tighter Cracks }\end{array}$ & $\begin{array}{l}40 \mathrm{psi}-70^{\circ} \mathrm{F} \text { to } 145^{\circ} \mathrm{F} \\
60 \mathrm{psi} \cdot 70^{\circ} \mathrm{F} \text { to } 145^{\circ} \mathrm{F} \\
90 \mathrm{psi} \cdot 70^{\circ} \mathrm{F} \text { to } 145^{\circ} \mathrm{F} .1\end{array}$ \\
\hline \multirow{3}{*}{$\begin{array}{l}\text { Immersion } \\
\text { For } 2 \text { Min }\end{array}$} & Porosity & $70^{\circ} \mathrm{F}$ to $<100^{\circ} \mathrm{F}$ \\
\hline & Gross Cracks & $70^{\circ} \mathrm{F}$ to $<100^{\circ} \mathrm{F}$ \\
\hline & $\begin{array}{c}\text { Smaller, } \\
\text { Tighter Cracks }\end{array}$ & $70^{\circ} \mathrm{F}$ to $<100^{\circ} \mathrm{F}$ \\
\hline
\end{tabular}


However, as might be expected, the porosity was much more susceptible to overwashing. Overwashing occurred when the water pressure was increased from $40 \mathrm{psi}$ to $60 \mathrm{psi}$ or when the water temperature was increased from $70^{\circ} \mathrm{F}$ to $100^{\circ} \mathrm{F}$. The smaller, tighter cracks could be washed at water pressures of up to 90 psi and water temperatures of up to $145^{\circ} \mathrm{F}$ (in most cases) without overwashing cccurring. Typical photographs of the results are shown in Figure 18.

The water washable penetrant system was quite sensitive to water temperature when the immersion technique was used. If the water temperature was increased from $70^{\circ} \mathrm{F}$ to $100^{\circ} \mathrm{F}$, the excess penetrant was very difficult to remove, even with extended washing tines. Several penetrant manufacturers were contacted concerning this situation and it was learned that most high sensitivity water washable penetrants are formulated such that washing at higher water temperatures is difficult. Apparontly, this is overcome by scrubbing action during water spray removal.

An investigation was made of the effect of washing time on subsequent penetrant indications. A few of the test panel.s contalning the smaller, tighter cracks were spray washed as shown below:

\begin{tabular}{|c|c|c|c|}
\hline Specimen No, & $\begin{array}{l}\text { Wash Water } \\
\text { Pressure (psi) }\end{array}$ & $\begin{array}{l}\text { Wash Water } \\
\text { Demp. (OF) }\end{array}$ & Washing Time \\
\hline A & $\begin{array}{l}40 \\
40\end{array}$ & $\begin{array}{l}70 \\
70\end{array}$ & $\begin{array}{l}7 \text { seconds } \\
60 \text { seconds }\end{array}$ \\
\hline $\mathrm{B}$ & $\begin{array}{l}40 \\
40\end{array}$ & $\begin{array}{l}70 \\
70\end{array}$ & $\begin{array}{l}7 \text { seccnds } \\
2 \text { minutes }\end{array}$ \\
\hline C & $\begin{array}{l}40 \\
4 n\end{array}$ & $\begin{array}{l}70 \\
70\end{array}$ & $\begin{array}{l}7 \text { seconds } \\
3 \text { minutes }\end{array}$ \\
\hline
\end{tabular}

The cursory examination of the effect of washing time revealed that the smaller, tighter cracks could be washed for as long as 3 minites at a water pressure of $40 \mathrm{psi}$ and a water temperature of $70^{\circ} \mathrm{l}$ without any degradation 'in the strength of the penetrant indications (see Figure 1.9). However, extrapolation of these results to other discontinuity types should be done with caution. More open discontinuities, such as porosity, most surely would be more sensitive to washing time. 


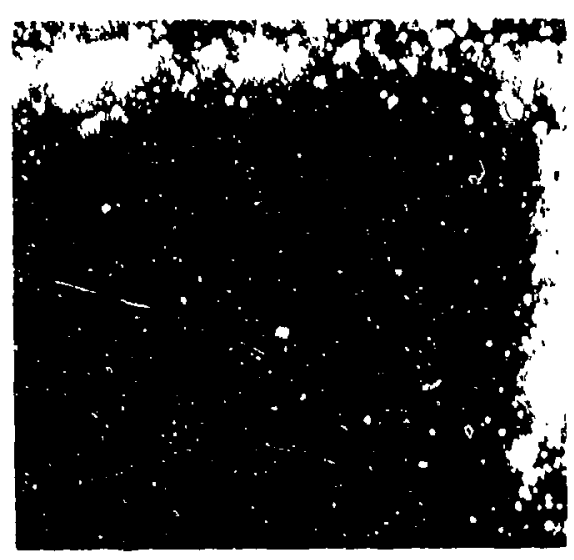

$40 \mathrm{psi} \cdot 70^{\circ} \mathrm{F}$

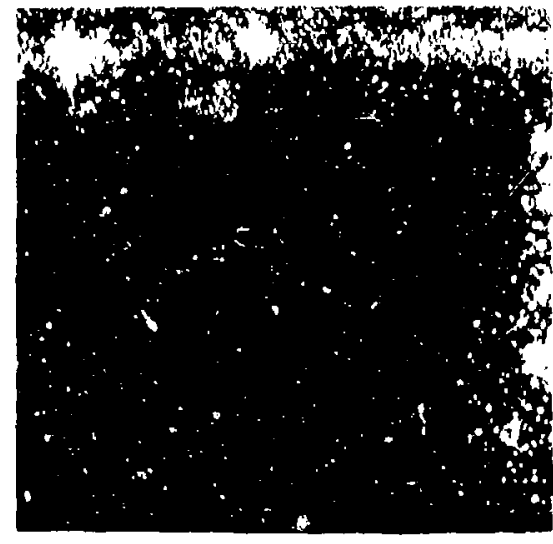

$60 \mathrm{psi} \cdot 70^{\circ} \mathrm{F}$

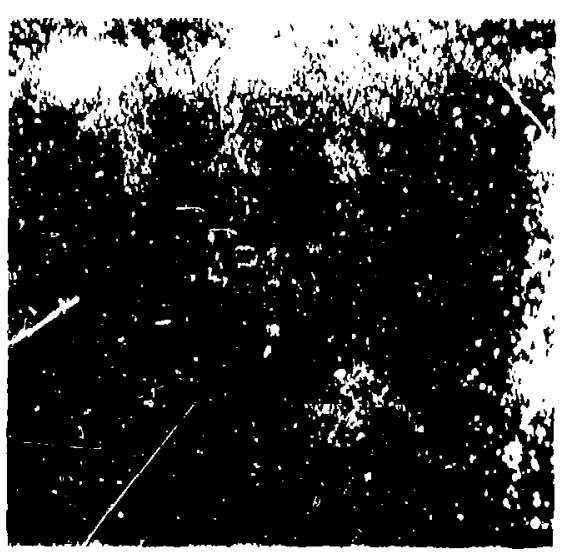

$40 \mathrm{psi} \cdot 145^{\circ} \mathrm{F}$

FIGURE 18

DEGRADATION IN PENETRANT INDICATIONS DUE TO OVE:R WASHING

(Water Washable Penetrant System) 
A separate test program was conducted in cooperation with and through the courtesy of the Magnaflux Corporation, Chicago, Illinois, in order to further study water washin. parameters. The specimen types used for this study were four specimens with gross cracks, four specimens with tight cracks, and two specimens containing porosity. A MIL-I-25135, Group V fluorescent penetrant system was chosen for the investigation. specifically, Magnaflux ZL-2A penetrant was used with Magnaflux ZP-9 nonaqueous wet developer. Isimited additional work was done using Magnaflux ZP-4 dry powder developer and Magnaflux ZP-13A aqueous wet developer. The excess penetrant was removed in all cases with Magnaflux $\mathrm{ZR}-10$ remover. A summary of the test parameters is shown in Table 11 .

Initially, all specimens were vapor degreased for 16 hours as a cleaning method. Next, the specimens were immersed in the penetrant bath and allowed to dwell immersed for 5 minutes. Excess penetrant was removed by spraying ZR-10 remove: solution onto the specimen surface at $70^{\circ} \mathrm{F}$. In practice, the specimens were hand-held by clamps and oscillated up and down and from side-to-side in a spraying area which directed two remover/water streams at the front and rear of the specimens. The ZR-10 remover concentration was controlled by metering the remover into the wash water stream with a calibrated piston pump. After washing for the specified time, the specimens were dipped into clean water and immediately blown with compressed air to remove residual $\mathrm{ZR}-10$ remover. Next, the specimens were force air dried for 3 minutes at $175^{\circ} \mathrm{F}$ before application of the developer. The ZP-9 nonaqueoils wet developer was applied by aerosol can. Three or four pusses were made over each surface. The development time was 10 minutes. The effect of varying the washing parameters was determined by measuring che brightness of selected penetrant indications with a Spectra Spot Meter, Model UB 1/4, manufactured by the Photo Research Division of Kollmorgen. I'he Spectra Spot Meter was used with the visual brightness filter supplied with the instruient in order to make the light meter closely follow the sensitivity of the eye. The brightness measurements were made while the specimens were illuminated with 3000 microwatts per $\mathrm{cm}^{2}$ of ultraviolet light at the specimen surface as measured with the Ultraviolet Light Products Model J-22l light meter. The Spectra Spot Meter measures the visible 


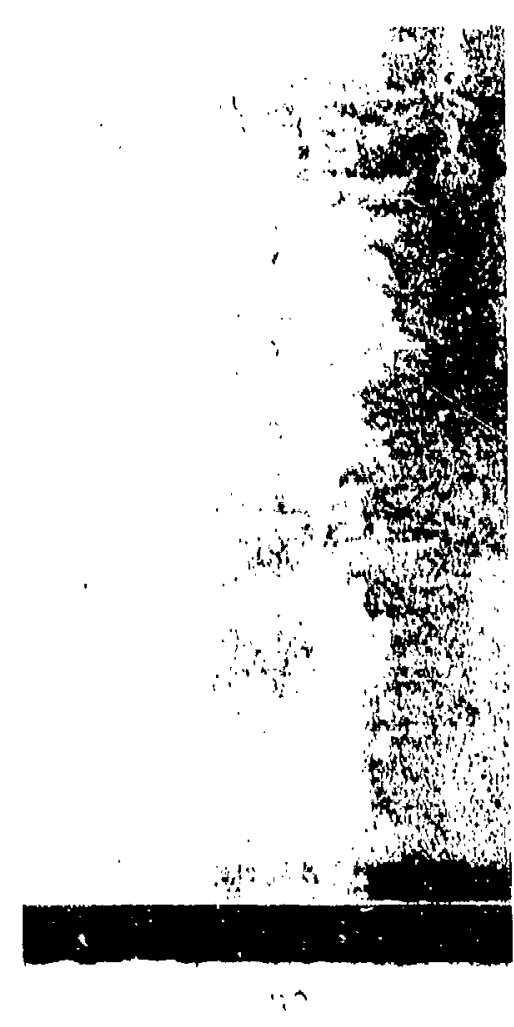

7 sec Wash Time

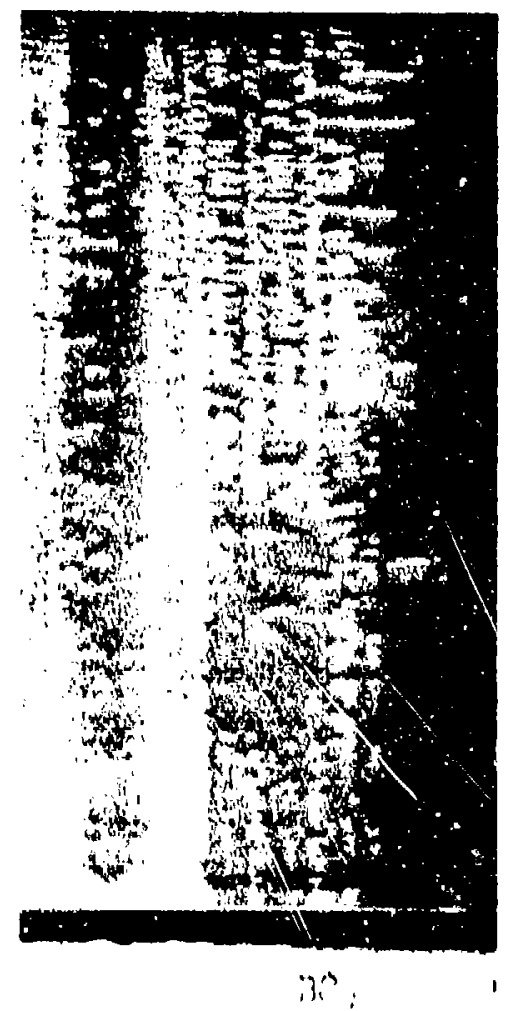

3 min Wash Time

FIGURE 19

(ip/401111/2

EFFECT OF WATER WASHING TIME

(Spray Washing - $40 \mathrm{PSI} / 70^{\circ} \mathrm{F}$ ) 
TABLE 11

W'ASHING PARAMETERS

\begin{tabular}{|c|c|c|}
\hline $\begin{array}{l}\text { Wash Time } \\
\text { (sec) }\end{array}$ & $\begin{array}{l}\text { Water } \\
\text { Prossure } \\
\text { (psi) }\end{array}$ & $\begin{array}{l}\text { ZR-10 Remover } \\
\text { Concentration } \\
\text { (Volume \%) }\end{array}$ \\
\hline \multirow{4}{*}{15} & 10 & $\begin{array}{l}0.29 \\
0.43\end{array}$ \\
\hline & 25 & $\begin{array}{l}0.00 \\
0.1 n \\
0.2^{\prime} 9\end{array}$ \\
\hline & 35 & $\begin{array}{l}0.35 \\
1.07\end{array}$ \\
\hline & 40 & 0.29 \\
\hline \multirow{4}{*}{60} & 10 & $\begin{array}{l}0.29 \\
0.43\end{array}$ \\
\hline & 25 & $\begin{array}{l}0.00 \\
0.10 \\
0.29\end{array}$ \\
\hline & 35 & $\begin{array}{l}0.35 \\
1.07\end{array}$ \\
\hline & 40 & 0.29 \\
\hline \multirow{4}{*}{120} & 10 & $\begin{array}{l}0.29 \\
0.43\end{array}$ \\
\hline & 25 & $\begin{array}{l}0.00 \\
0.10 \\
0.29\end{array}$ \\
\hline & 35 & $\begin{array}{l}0.36 \\
1.07\end{array}$ \\
\hline & 40 & 0.29 \\
\hline \multirow{4}{*}{300} & 10 & $\begin{array}{l}0.29 \\
0.43\end{array}$ \\
\hline & 25 & $\begin{array}{l}0.00 \\
0.10 \\
0.29 \\
\end{array}$ \\
\hline & 35 & $\begin{array}{l}0.35 \\
1.07\end{array}$ \\
\hline & 40 & 0.29 \\
\hline
\end{tabular}

aip $/ 40111216$ 
brishtness of an arei 1/60 inch in diameter. For the network of tight cracks, brightness measurements were made at the junction between racks where the developed indications occupied appmoximate.y 10 to 25 percent of the viewing area. Approximately 16 measurements were made for each specimen and the readings were averaged. T'ile gross crack indications occupied the entire viewing area and the porosity indications occupied from 50 to 1.00 percent of the viewing arca. Approximately 6 measurements were made lor each gross crack and the readings were averaged.

Alter the brightness measurements were made, the specimens were cleaned to remove all residual penetrant materials so that the specimens could be reprocessed using another set of washing parameters. The specimens were cleaned by perchlorethylene vapor degreasing for 30 minutes followed by ul.trasonic cleaning with porchlorethyl.ene lor 10 minutes.

An examination of the indication brightness as 7 function of water pressure indicated that there was no significant overwashing, for water pressures up to $40 \mathrm{psi}$. l'o: the purposes of these tests a significant change in indication brightress is considered at least on percent change since this is approximately the mallest. change which can be detected by the eye.

'Lhe ef'tect of ZR-10 remover concentration on the indication brightness is shown in Table 12 for a 60 second wash time and 25 psi. water pressure. The indicalion brightness decreased uignificantiy where the remover concentration was increased from 0.35 volume percent to 1.07 volume perce.. . It should a .50 be noted that the backeround lluorescence was easily removed with a cuncentration as low as 0.1 volume percent. These rrisults indicate that machined parlis can be properly processed with zli-10 remover without overwashing but that the concentration of the 2R-1.0 remover is a factor that should be contrulled.

'Lhe effect of spray time on indication brifhtness is demorstrated in Table 13. Tach indication brightness value was arrived at by using a total of 4 specinens containing small cracks and 4 specimens containing gross cracks. For each of the / specimens containing small. cracks, approximately 16 indication brightness measurements were made and an average for each specimen was computed. For each of the It specimens containing gross cracks, arproximately I $_{4}$ brightness moasurements were made and an average was computiod for each. l'inally, a single ralue of indication brightnes; for that particular spray wash time was arriver at by adding the 8 average brightness ralues. It is this summation value that appears in Table 13. It can be seen that for the parameters chosen, the wash time did not appear to reduce the slrength of the penetrant indications significantly. 


\section{i. Viewing Light Intensity}

During inspection using fluorescent penetrant, the piece to be inspected is illuminated with ultraviolet light. The fluo-escent dye in the discontinuities absorbs the black light and re-emits the energy in the visible light range. Consequently, the brilliance of the discontinuity indication varies with the intensity of the black light at the inspection area.

In order to study the effects of ultraviolet light versus background white light, tests were conducted in cooperation with and through the courtesy of the Magnaflux Corporation, Chicago, IIlinojs.

\section{(1) l'est Procedure}

A test specimen containing porosity was used. 'l'he penetrant indications were produced by penetrant testing with Magnaflux ZI- 2 A post-emulsifiable fluorescent penetrant which is a MIL-I-25135, Group V penetrant. 'The porosity specimen was dipped into the penetrant and allowed to drain in air for 5 minutes. Ixcess penetrant was renoved using Magnaf'Lux 2,R-10 remover infected into a water stream at a concentration of . 29 volume percent, a water temperature of $170^{\circ} \mathrm{F}$, and a wash water pressure of $25 \mathrm{psi}$. The ZR-10 remover was metered into the wash water stream by a calibrated piston pump. The wash time was 60 seconds and the water spray was approximately 90 degrees to the specimen surface. After spray washing, the specimen was dipped into clean water to remove excess $7 R-10$ and excess water was removed with compiessed air. Next, the specimen was force air dried for three minutes at $175^{\circ} \mathrm{F}$ and Magnaf'lux $2 \mathrm{P}-9$ nonaqueous wet developer was applied. After a development time of 10 minutes, brightness measurements were made.

The brightness measurements were made using a Spectra Spot Meter, Model UB 1/4, manufacturer by the Photo Research Division of Kol.Lnorgen. The Spectra Spot Meter was used with the visual brightness filter supplied wic: the instrument in order to make the meter light response closely follow the sensitivity of the eye (see ligure 20). Brightness measurements in the visiblo range were made on one of the penetrant imlications under the lollowing lighting conditions:

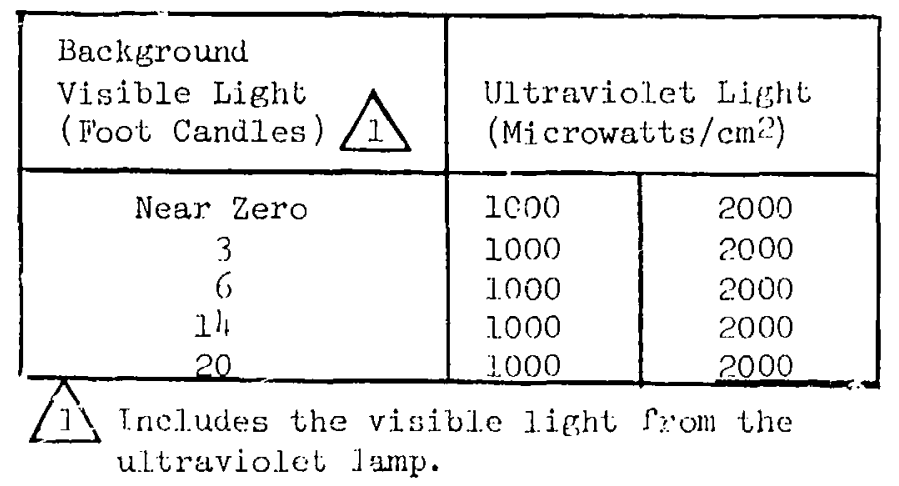




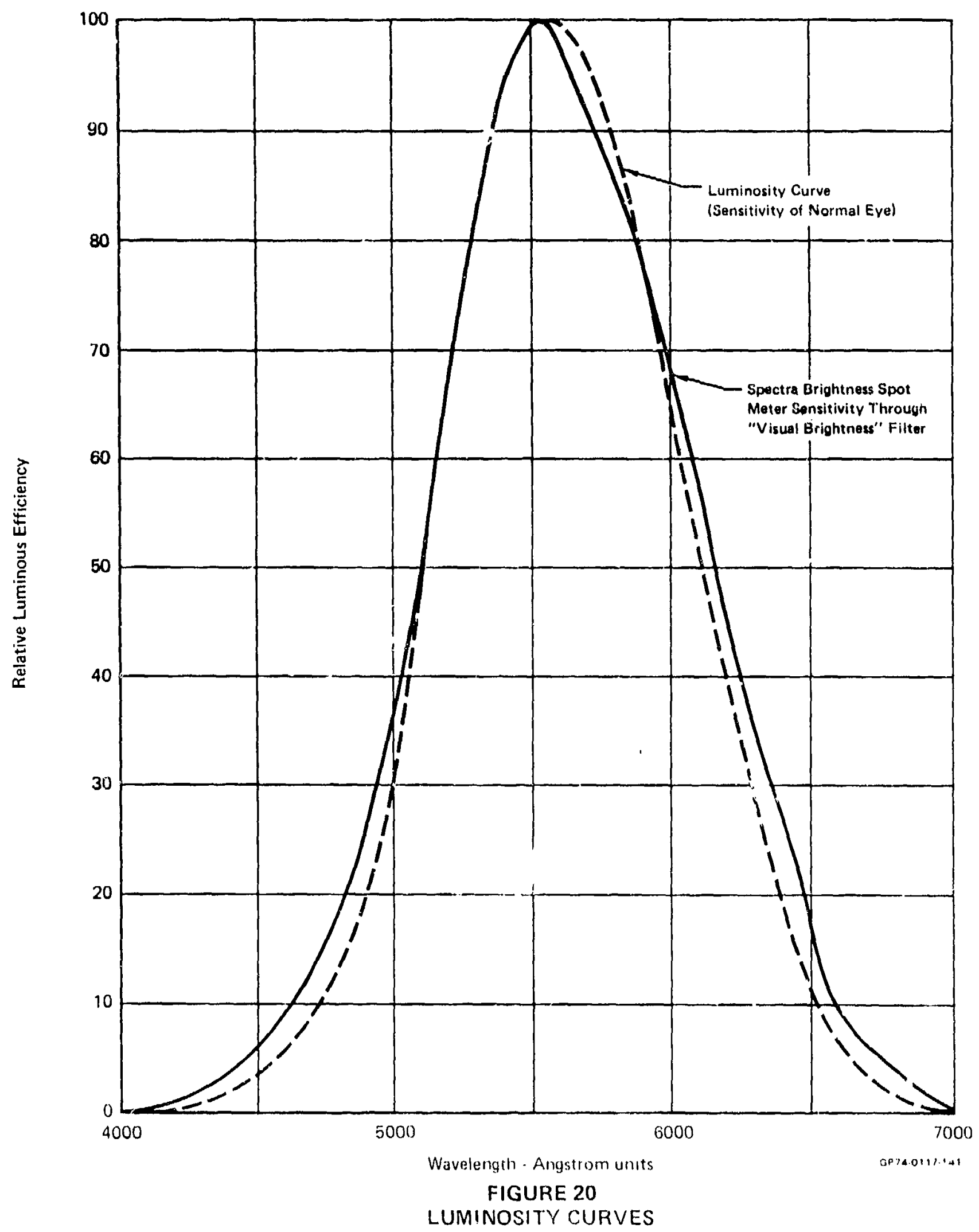

47 
The background visible light level was increased or decreas ad by adding or removing lamps. The background light level was measured with the Spectra Spot Meter in conjunction with a magnesium oxide reflector plate. The ultraviolet light intensity was varied by changing the distance vetween the test specimen and the 100 watt mercury arc lamp. The ultraviolet light intensity was measured with an Ultraviolet Light Products Model J22l light meter. The Model J22I measures both the ultraviolet and infrared components of the light emitted by the mercury arc lamp. The infrared component was measured independently and was found to comprise approximately 5 percent of the total J22l reading at 1.5 inches from a 100 watt mercury arc larpp.

The measurements of the indication brightness were made by focusing the Spectra Spot Meter on a single indication. The actual area measured was $1 / 60$ inch in diameter and the penetrant indication filled approximately $50 \%$ of the measured area. After measuring the indication brightness, the field of view was moved to an adjacent area away from any penetrant indication and the brightness of the developer background was measured. From this data, the ratio of indication brightiness to background brightness was calculated. Obviously, high brightness ratios are desired.

The test results are plotted in Figure 21 and photographically demonstrated in Figures 22 and 23. It sholid be noted that, in Figures 22 and 23, the lines are scratches on the negative and are not penetrant indications. The importance of inspecting parts in a relatively dark inspection booth (less than 3 foot candles) is demonstrated. For a coustant ultraviolet light intensity, the brightness ratio is reduced from approximately 65 to approximately 2.5 when the visible light level is increased from nearly zero to 3 foot candles. The visible licht level has a much greater effect on the brightness ratio than does the ultraviolet 7.ight level. For example, at a constant visible light level of near zero increasing the ultraviolet light level from 1,000 to 2,000 microwaits only increases the brightness ratio from 62.1. to 68.6. However, at a constant 2,000 microwatts/ $\mathrm{cm}^{2}$ of ultraviolet light, decreasing the visible light level from 3 foot candles to nearly zero causes the brightness ratio to go from 2.8 to 68.6 .

After the above testing was performed, similar experiments were conducted using a fatigue crack as a discontinuity. Magnafiux ZL-?. penetrant was again used and the specimen was dipped in the penet, 1 : t and allowed to drain in air for 10 mjnutes. Magnaf'lux ZJ-3 emulsifier was applied for 30 seconds and excess penetrant was washed from the specimen using a. Magnaflux $\mathrm{P} / \mathrm{N} 3070$ waier spray nozzle. The water temperature was approximately $50^{\circ} \mathrm{F}$ and the water pressure was 30-40 psi. The specimen was dried for? minutes at $175^{\circ} \mathrm{F}$ in a circulating in oven. linally, Magnaflux ZP-9 nonaqueous 


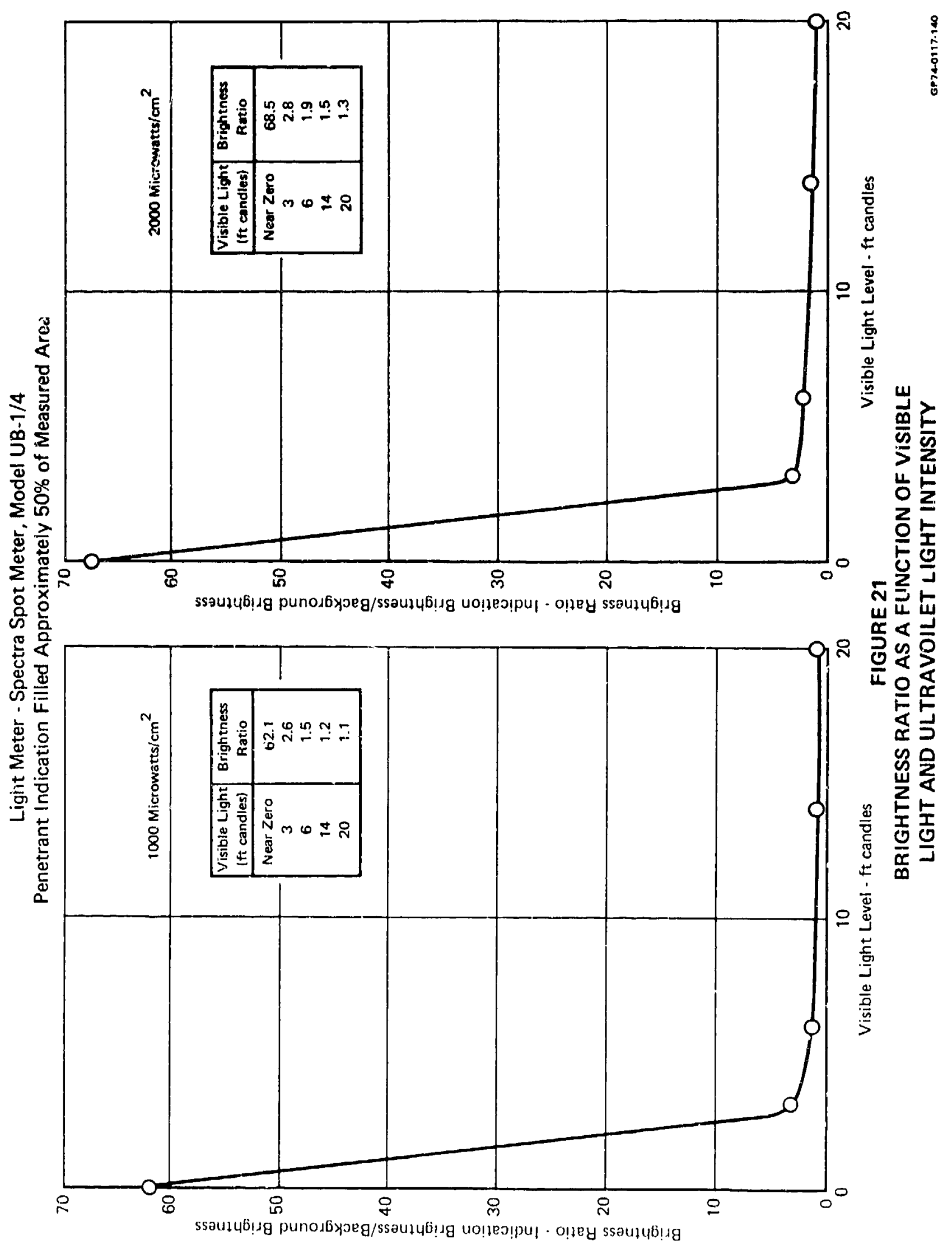




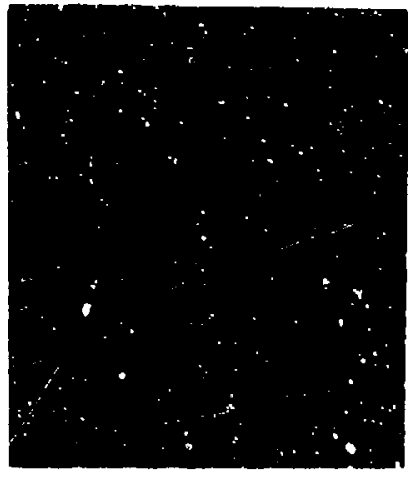

Near Zero ft Candies

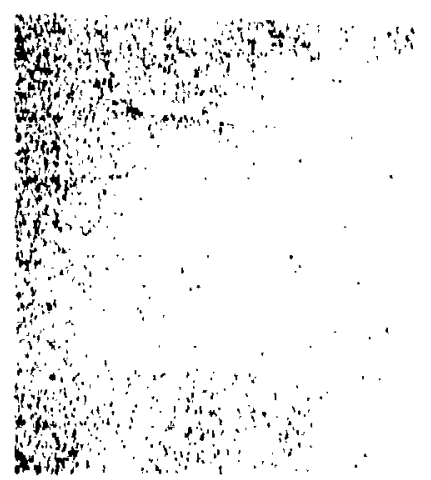

$6 \mathrm{ft}$ Candles

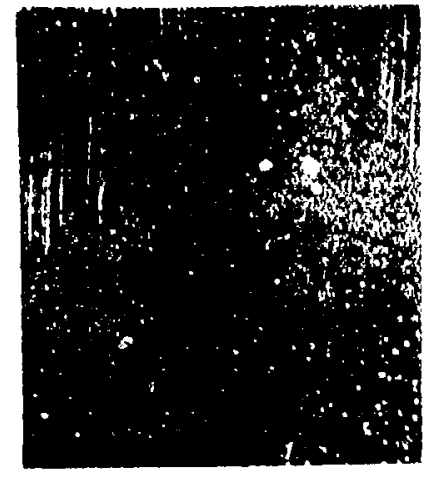

$3 \mathrm{ft}$ Candles

$20 \mathrm{ft}$ Candles

FIGURE 22

GP74.6 17.130

PENTRANT INDICATIONS UNDER VARIOUS LEVELS OF VISIBLE LIGHT

(Ultraviolet Light Level is 1000 Microwatts Per $\mathrm{cm}^{2}$ ) 


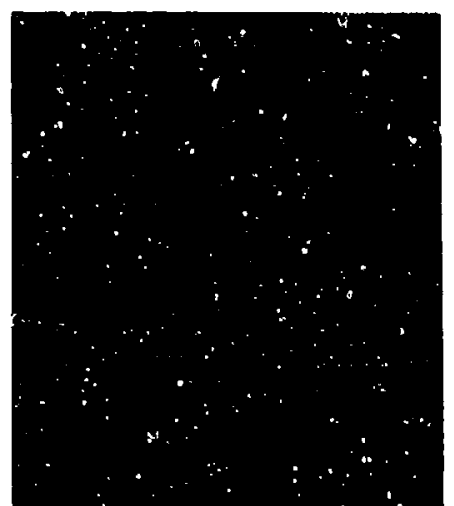

Near Zero ft Candles

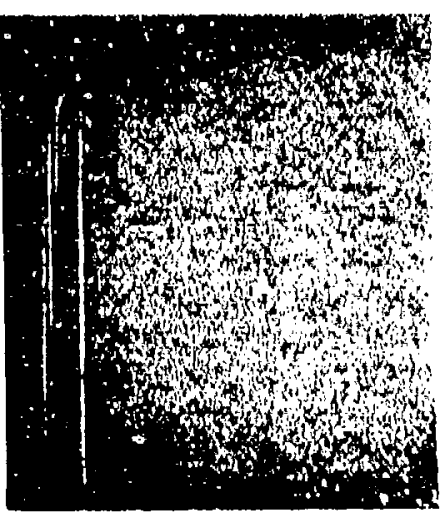

$3 \mathrm{ft}$ Candles

4

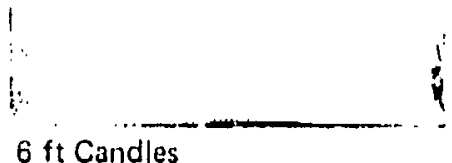

$20 \mathrm{ft}$ Candles

FIGURE 23

$0 \times 74.011 \% 134$ PENETRANT INDICATIONS UNDER YARIOUS LEVELS OF VISIBLE LIGHT (Ultraviolet Light Level is 1,000 Microwatts Per $\mathrm{cm}^{2}$ ) 
TABLE 12

EFFECT OF REMOVER CONCENTRATION ON INDICATION BRIGHTNESS

\begin{tabular}{|c|c|c|c|c|c|c|}
\hline \multirow{2}{*}{ Flaw Type } & \multirow{2}{*}{$\begin{array}{c}\text { Specimen } \\
\text { No. }\end{array}$} & \multicolumn{5}{|c|}{ Indication Brightness (foot-lamberts) } \\
\hline & & $0 \%$ & $0.10 \%$ & $0.29 \%$ & $0.35 \%$ & $1.07 \%$ \\
\hline \multirow{4}{*}{ Gross Cracks } & 39 & 15.5 & 19.4 & 13.8 & 23.2 & 11.2 \\
\hline & 40 & 36.8 & 36.6 & 44.2 & 33.0 & 16.1 \\
\hline & 41 & 20.0 & 21.4 & 17.2 & 19.4 & 11.8 \\
\hline & 42 & 38.0 & 34.8 & 36.7 & 27.1 & 15.7 \\
\hline \multirow{4}{*}{ Small Cracks } & SC 29 & 10.4 & 8.2 & 8.9 & 13.6 & 4.3 \\
\hline & SC 32 & 10.0 & 7.4 & 5.4 & 11.5 & 2.6 \\
\hline & SC 33 & 10.0 & 8.6 & 7.5 & 12.6 & 4.5 \\
\hline & SC 34 & 14.0 & 11.8 & 10.9 & 14.3 & 3.9 \\
\hline \multirow{2}{*}{ Porosity } & $17 \mathrm{P} 1$ & 5.8 & 4.2 & 5.1 & 2.5 & 4.6 \\
\hline & $17 \mathrm{P} 2$ & 39.0 & 37.4 & 37.2 & 32.0 & 5.6 \\
\hline
\end{tabular}

TABLE 13

EFFECT OF WASH TIME IN INDICATION BRIGHTNESS (FOOT-LAMBERTS)

\begin{tabular}{|c|c|c|c|c|c|c|c|}
\hline \multirow{2}{*}{ Penetrant } & \multirow{2}{*}{ Developer } & \multirow{2}{*}{$\begin{array}{c}\text { Water } \\
\text { Pressure } \\
\text { (psi) }\end{array}$} & \multirow{2}{*}{$\begin{array}{c}\text { Remover } \\
\text { Concentration } \\
(Y o l \%)\end{array}$} & \multicolumn{4}{|c|}{ Wash Time (sec) } \\
\hline & & & & 15 & 60 & 120 & 300 \\
\hline \multirow{7}{*}{ ZL.2A } & \multirow[t]{4}{*}{$Z P \cdot 9$} & 25 & 0.01 & 127 & 148 & 155 & 111 \\
\hline & & & 0.29 & 179 & 201 & 188 & 177 \\
\hline & & 10 & 0.43 & 156 & 202 & 124 & 146 \\
\hline & & 35 & 1.07 & 76 & 70 & 67 & 63 \\
\hline & ZP.4 & 25 & 0.29 & 78 & 90 & 63 & 55 \\
\hline & ZP-13 & 25 & 0.29 & 39 & 43 & 42 & 36 \\
\hline & ZP.13A & 25 & 0.29 & 24 & 20 & 23 & 22 \\
\hline$Z L \cdot 22 A$ & ZP.9 & 25 & 0.29 & 218 & 280 & 228 & 264 \\
\hline
\end{tabular}

cin/40112256 
TABLE 14

BRIGHTNESS MEASUREMENTS MADE ON FATIGUE CRACK

\begin{tabular}{|c|c|c|c|c|}
\hline \multirow{2}{*}{\multicolumn{2}{|c|}{$\begin{array}{l}\text { Ultraviolet Light } \\
\text { Intensity } \\
\text { (microwatts } \\
\text { per } \mathrm{cm}^{2} \text { ) }\end{array}$}} & \multicolumn{3}{|c|}{$\begin{array}{l}\text { Ambient Light Intensity } \\
\text { (foot candles) }\end{array}$} \\
\hline & & 0 & $21 / 2$ & 5 \\
\hline \multirow{3}{*}{500} & $A$ & 1.62 & 3.8 & 5.9 \\
\hline & $B$ & 0.115 & 1.7 & 5.3 \\
\hline & C & 14.1 & 2.2 & 1.1 \\
\hline \multirow{3}{*}{920} & $A$ & 3.0 & 4.9 & 6.9 \\
\hline & B & 0.21 & 2.0 & 5.5 \\
\hline & $C$ & 14.3 & 2.5 & 1.25 \\
\hline \multirow{3}{*}{1300} & f. & 4.2 & 6.1 & 8.1 \\
\hline & B & 0.30 & 2.1 & 5.6 \\
\hline & $\mathrm{C}$ & 14.4 & 1.9 & 1.4 \\
\hline \multirow{3}{*}{3500} & $A$ & 11.2 & 12.1 & 13.2 \\
\hline & $B$ & 0.8 & 2.3 & 6.1 \\
\hline & $\mathrm{C}$ & 14.0 & 5.3 & 2.2 \\
\hline \multirow{3}{*}{6450} & A & 19.0 & 19.7 & 20.5 \\
\hline & $B$ & 1.15 & 2.5 & 6.5 \\
\hline & C & 16.5 & 7.9 & 3.1 \\
\hline \multirow{3}{*}{7900} & $A$ & 20.0 & 21.8 & 23.5 \\
\hline & $B$ & 1.3 & 2.7 & 6.8 \\
\hline & $c$ & 15.5 & 8.0 & 3.5 \\
\hline
\end{tabular}

A - Brighthess or crack Indication in foot. Lamborts

$B$-.. Brtghtness of background in foot candios

C - Hatio of indication brighuess and background brightnoss 
wet developer was applied. After a 10 minute develounant; time, brightness measurements were made.

The Spectra Spot Meter was used to take the brightness measurements at several ultraviolet and background visible light values. The crack indicatica filled about $1 / 16$ of the measured area. For these tests, a si igle brightness measurement was made for each condition. The results are shown in l'rble 1.4 and plotted in Pigure 24. As before, the importance of low buckground light levels it deilonstrated. The data in T'able it also demonstrates that by increasing the amount of ultraviolet light a greater anount of ambiert white light intensity can be tolerated without any loss in brightness ratio.

\section{j. Eftect of Mechanical Processing Prior to Penetrart Inspection}

Penetrant inspection can be an el'ective inspection method only if. tho discontinuities are open to the surface so that peretrant can enter the disconlinuity. Ary process which oloses the disccrtinuity can destroy the reliability and resolution limits of the subsequent penetrant inspection; such "missked" discontinuities may bo completely undetented. Sone mechanical jrocessing operatione performed prior to penetrant inspection may mask discoritinuties by causing surface material to p.Lastically def'or'm, flow over and neal discontinuities. consequently, a program was sonducted to identify severa.l of the detrimental processes.

The mechanical processes investigated were glass bead peeninis, Exinding, face mijling, rotary liling, disc sanding, and shot peening. The Eilass bead peening was pertomed using MIL-G-9954, Bize 13 glass beadis. A nozzl.e pressure of 70 pis. was used and earh specimen was peened f'or 30 seconds.

The grinding was performed on a production surfaco grinder. The 1 Inch wide, 9 inch diameter silicon carbide grinding wheel was 60 grit with $J$ hardness. The work plece was flooded with Macco 472 coolant ( 1 to 30 mixture). The test specimens were ground using a whesl speed of approximately 4,200 surface feet per minute. Initially, three passes were made to remove 0.0005 inch per pass and, finally, several passes were made to remove 0.0002 inch per pass such that a total of 0.003 Inch was ground from the surface.

Face milling was performed with a 5 inch diometer carbide insert face mill. The cuts were made perpendicular to the cracks in the specimens. Macec 472 coolant was used at a mixture of 1 to 30.

Rotary filing was accomplished using a $3 / 4$ inch diameter $x 1$ inch lung high speed steel cutter at approximately $8000 \mathrm{rpm}$ to remove approximately 0.001 inch of material. 


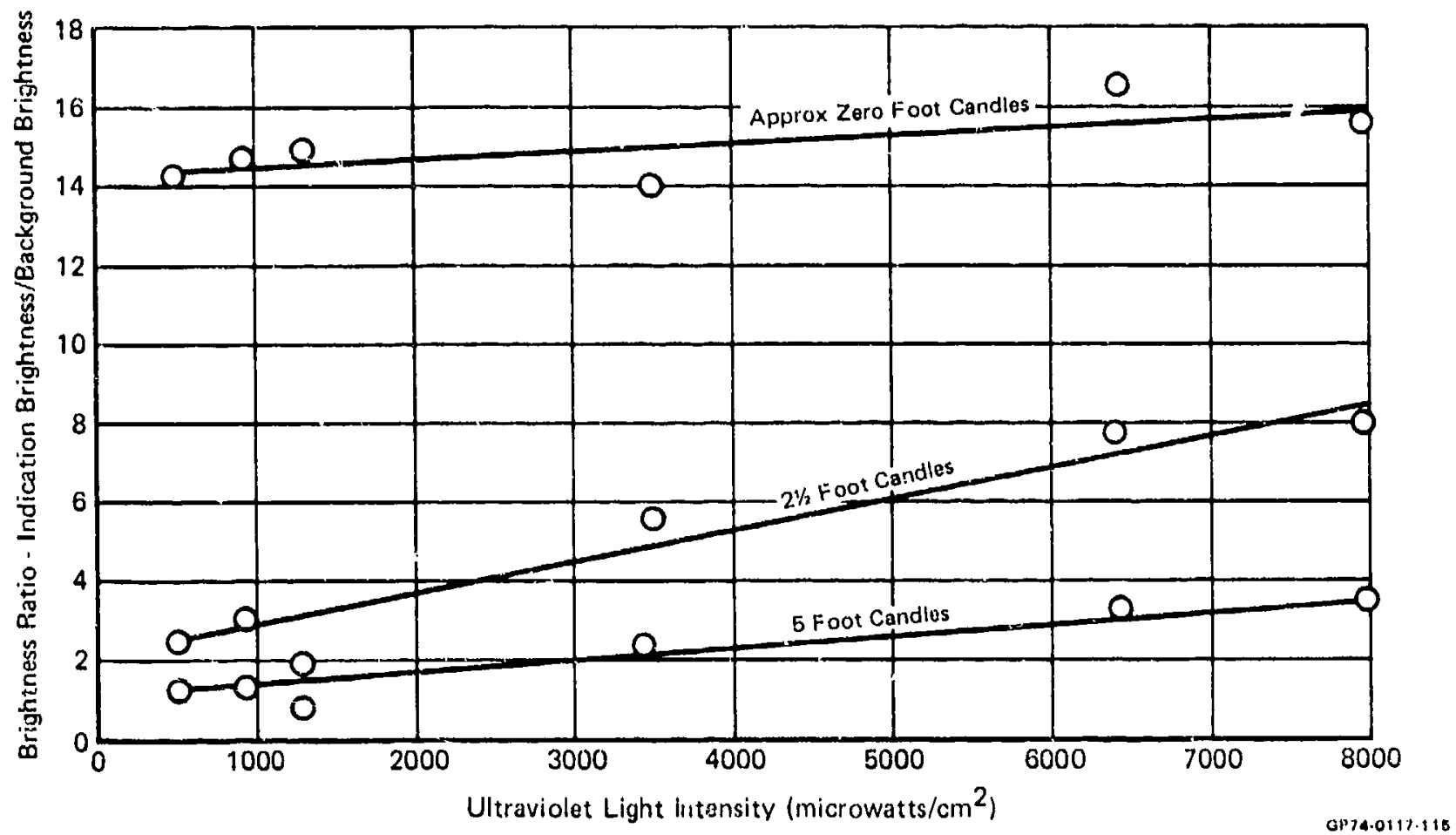

FIGURE 24

BRIGHTNESS RATIO AS A FUNCTION OF VISIBLE LIGHT AND ULTRAVIOLET LIGHT INTENSITY (FATIGUE CRACK) 
The disc sanding was performed with 80 grit. 2 inch diameter aluminum oxide sanding aiscs at 1200 to $1500 \mathrm{rpm}$.

Shot pesning was performed using No. 330 steel shot and a nozzle pressure of $20 \mathrm{psi}$. Each specimen was shot peened for approximately 30 seconds. below.

The specimen types used to study each process are indicated

Process

Face Milling

Glass Bead Peening

Grinding

Rotary Filing

Disc Sandins

Shot Peening
Specimen Type

Gross cracks

Gross cracks

Tight cracks

Gross cracks

Gross cracks

Gross cracks

Gross cracks

Tight eracks
Number of Specimens

7

7

7

7

7

7
7

'Whese crack types are the seme as those previously described in Section $1-6$.

The schematic shown in ligure 25 is representative of the teat procedure used to investigate the effect of each process. The photographs of the penetrant indications were compared both before and after the mechanical process. If the strength of the penetrant indications were reduced by the particular mechanical process, the specimens were pickled to remove surface metal and re-penetrant inspected. This was repeated until the penetrant indications returned to ful.I strength. 

Wach penetrant inspection was performed using Tracer-Tech P-133 fluorescent penetrant, equivalent in sensitivity to a MIL-I-25135, Group V penetrant. The developer used as 'Irecer-Tech D499C nonaqueous wet developer. Basied on the previous program resul.ts, a penetrant dwell time of 20 minutes was used and a developer dwell time of 15 minutes was used. The specimens wore completely immersed in the penetrant during the applicable penetrant dwell. Excess penetrant was washed from the specimens using a Iri-Con 400501 water spray nozzle; the wash water temperature was approximately 40 psi. Fach specimen was washed until the specimen surface was visually clean under $200 \mathrm{microwatts} / \mathrm{cm}^{2}$ of ultraviolet lisht (approximately 3200 to 3000 Angstrom units in wavelength) which took approximately 15 seconds. Next, the specimens were dried until visually dry (10-15 minutes) in a circulating air oven at $170^{\circ} \mathrm{F}$. Aftier the bleed-out time, the penetrant indications were photographed using the following parameters: approximately 1000 microwatts per cm? of ultraviolet light, 25 second exposure at $\mathrm{f}^{\prime} 9$, Royal Pan F'j.Im, 'Iliffen Yellow No. 2 filter.

The results of the investigatior are tabulated in Iable 15 and demonstrated in Figures 26 and 27 . As might be expected, the ef rect of rechanical processing varied as a function of the process and crack size. The most detrimental processes were glass bead and shot peening. Nearly all the penetrant indications were obliterated by these two processes. Face milling, grinding, and rotary filing were much less severe; but, even so, the streneth of the penetrant indications were reduced. It should be kept in mind that these processes were used only on gross cracks. Disc sanding had no effect on the gross cracks (tight cracks were not used to evaluate disc sanoing).

The test results also demonstrate that the detrimental eff'ects of' certain processes performed prior to penetrant inspection can be alleviatci by chemical etching. 'The amount of material that need be romoved by etching varied from 0.000 . inch to more than 0.0017 inch, dependine upon the process (see Table 15). Based upon these results, production purts which have undergone proccssing such as grit bilasting should be etched prior to penctrant inspection.

TABLE 15

EFFECT OF MECHANICAL PROCESSING PRIOR TO PENETRANT INSPECTION

\begin{tabular}{|c|c|c|}
\hline \multirow{2}{*}{ Mnchanical Process } & \multicolumn{2}{|c|}{ Erching Required to Restore Indications (In.) } \\
\hline & Gross Cracks & Small Cracks \\
\hline Disc, Sanding & No Effect & $\cdots$ \\
\hline $\begin{array}{l}\text { Face Milling } \\
\text { Grinding } \\
\text { Rotary Filing }\end{array}$ & 0.0002 & \\
\hline $\begin{array}{l}\text { Glass Bead } \\
\text { Peenmon }\end{array}$ & 0.0007 仓 & More than 0.0012 仓 \\
\hline Shot Peening & $00007 \AA$ & More than $0.0017 \mathrm{~A}$ \\
\hline
\end{tabular}




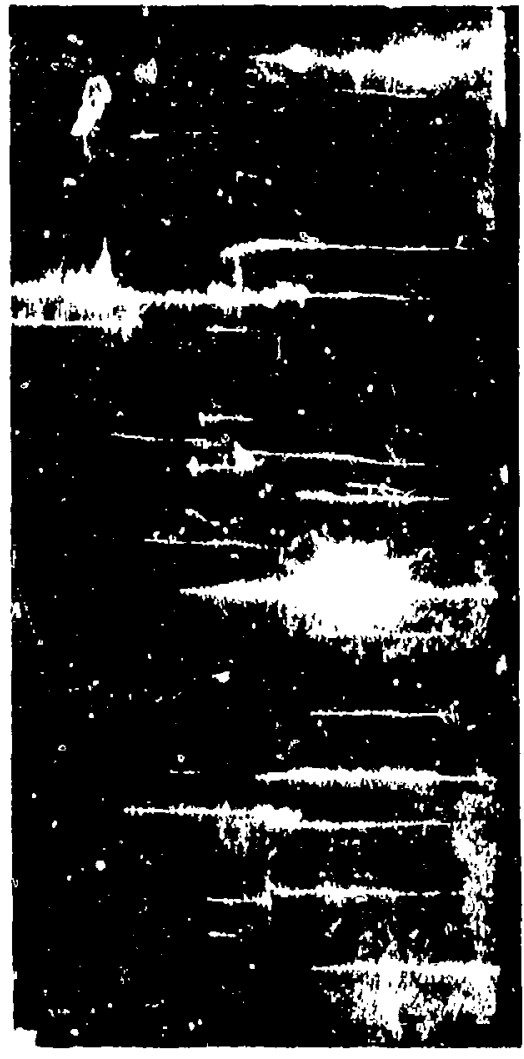

Initial Indications

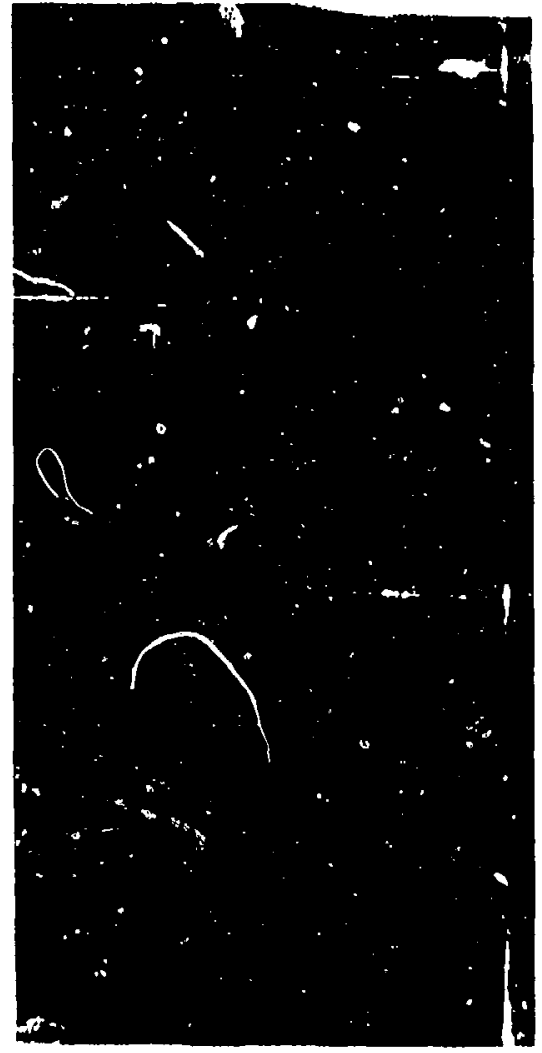

Aiter

Shot Peening

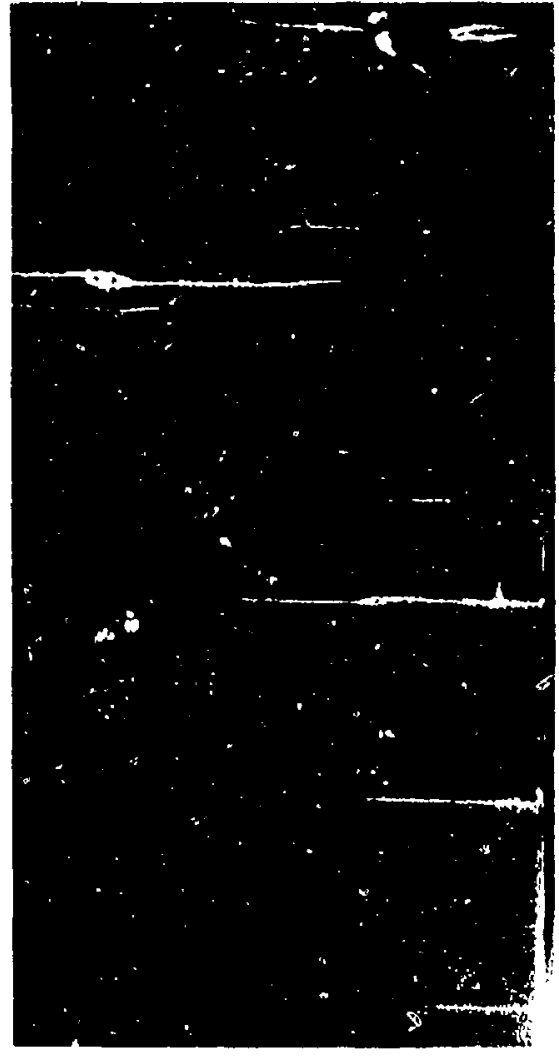

After

Etching 0.0017

FIGURE 26

EFFECT OF MECHANICAL PROCESSING UPON PENETRANT INDICATIONS OF TIGHT CRACKS 


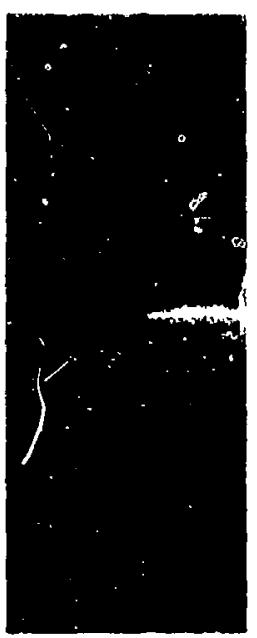

Initial

Indication

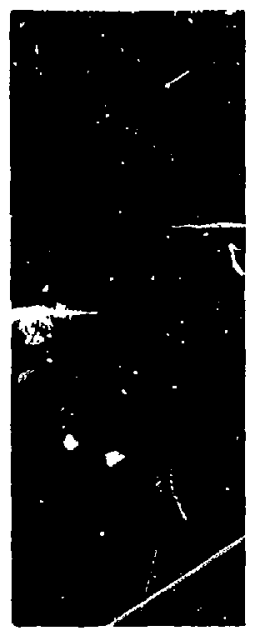

Initial Indication

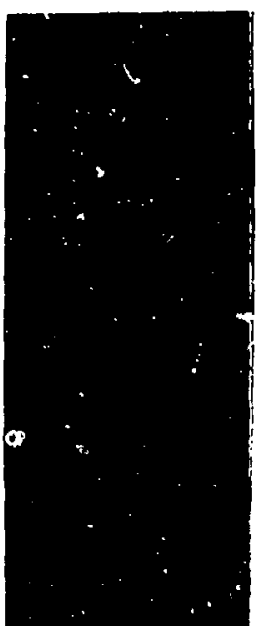

After

Peenirig

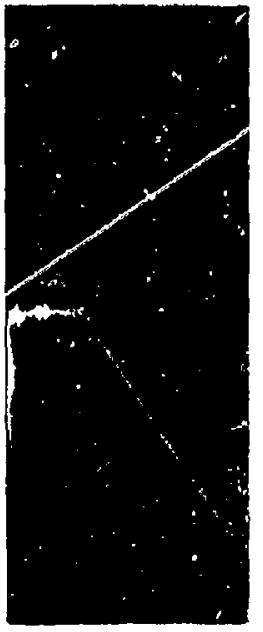

After

Grinding
After

Etching 0.0007

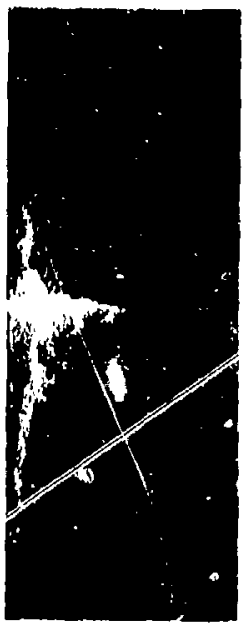

After

Etching 0.0002

FIGURE 2 ?

(..91/401:11:34

OF GROSS CRACKS 


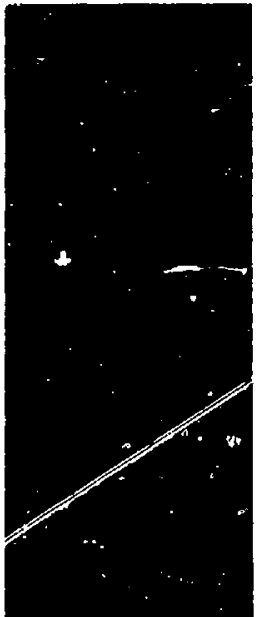

Initial

Indication

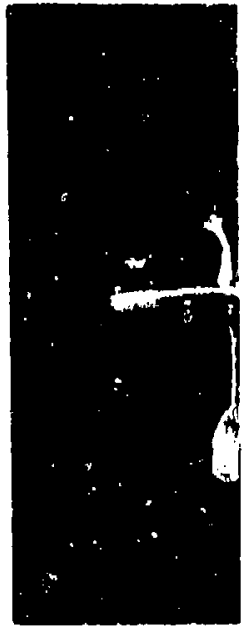

Initial Indication

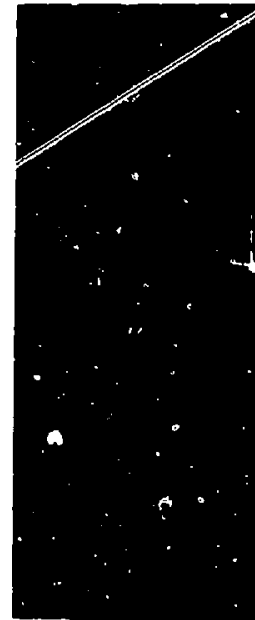

After

Milling

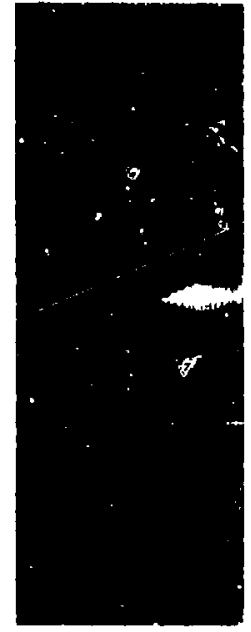

After

Rotary Filing

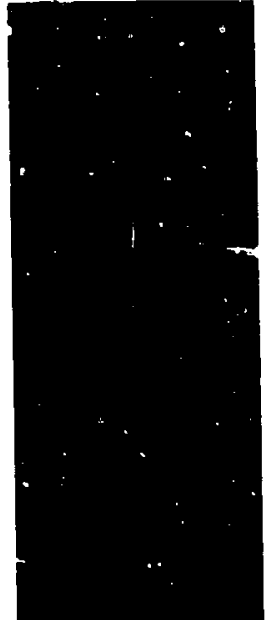

After

Etching 0.0002

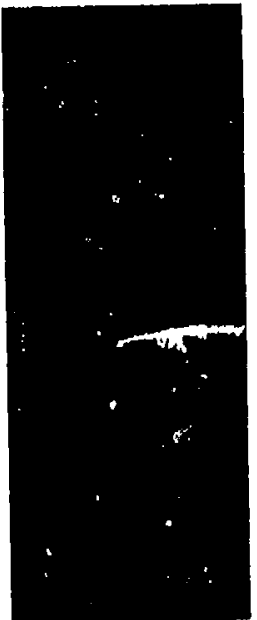

After

stching 0.0002

FIGURE 27 (Continued)

EFFECT OF MECHANICAL PROCESSING UPON PENETRANT INDICATIONS OF GROSS CRACKS 
k. Penetrant System Effectiveness

A summation of the overall relative effertiveness of the various penetrant systems is presented in Table 16. The ranking of systems is based upon the studies of penetrant bleed-out times, penetrant dwell times, emulsification times, developer effectiveness, and water washing techniques discussed previously. These summaries are predicted on the ascumption that it is desirable to be able to detect gross cracks, smaller cracks, and porosity in the same penetrant inspection. For example, if a MII-I-25135, Group $V$ sensitivity postemulsifiable penetrant was chosen for a / pieal production penetrant inspection in which a variety of discontinuities has to be detected, then, for the most effective inspection, either a nonaqueous wet or a dry fowder developer should be used, the penetrant dwell time should be at least 20 minutes, and the penetrant bleed-out time should be at least 5 minutes (see Table 16).

No effort was made during this investigative program to compare the effectiveness of a post-emulsifiable penetrant system with that of a water washable penetrant system and Table 16 should not be used to this end. It was felt that in order to make a comparison, a large number of systens would have to be compared and this was outslde the scope and intent of the progrum. 


\section{RADIOGRAPHIC METHOD}

Two of the most important parameters in the radiographic method are the choice of kilovoltage and beam spectrum. There is a wide range of kilovoltages that can be selected to yield the same apparent test sensitivity when the image quality is evaluated by the use of penetrameters such as the plaque type shown in MLL-STU-453. However, if the selected kilovoltage is too high, the subject contrast may be so jow as to render the test ineffective, even though the MIL-STD-453 penetrameter indicates that the quality of the radiograph is acceptable. Consequently, data are necassary to aid in the establishment of maximum acceptable kilovoltaces as a function of material thickness and subject contrast and definition quality.

A test program has been conducted to determine the k1lovoltages required to obtain varying levels of contrast sensitivity. The effect of beam spectrum was investigated by using three types of $\mathrm{X}$-ray machines (full wave rectified, self-rectifled, and constant potential) with varying inherent filtration.

\section{a. Fabrication of Stiep Wedges}

Nine step wedges were fabricated from $\mathrm{Ti}-6 \mathrm{Al}-4 \mathrm{~V}$ plate for use in the program. The step wedges were designei to represent a $1 / 2 \%, 1 \%$, and $2 \%$ thickness change for a total thickness of $.125, .50,1.00,2.00$, und 4.00 inches. The configuration of these specimens is show in Figure 28. As can be seen below, the effect of surface finish was also taken into eccount.

\begin{tabular}{|c|c|c|}
\hline Configuration & I'hickness & Surface rit \\
\hline A & 0.125 & $63 \mathrm{RMS}$ \\
\hline B & 0.25 & 125 lRMS \\
\hline B & 0.50 & $63 \mathrm{RMS}$ \\
\hline B & 0.50 & $125 \mathrm{RMS}$ \\
\hline B & 1.00 & $6.3 \mathrm{RMS}$ \\
\hline B & 1.00 & 125 RMS \\
\hline$B$ & 2.00 & $63 \mathrm{RMS}$ \\
\hline B & 2.00 & $125 \mathrm{RMS}$ \\
\hline C & $4.01 \% *$ & $63 \mathrm{RMS}$ \\
\hline
\end{tabular}

* 'iwo inch specimen used with a 2 inch thick shim.

The thickness changes of $1 / 2 \%, 1 \%$, and $2 \%$ were chosen because contrast sensitivities of $1 \%$ and $2 \%$ are commonly used in radiographis. inspection o ${ }^{\prime}$ airframe components. $\wedge 1 / 2 \%$ thickness change was included to determine if a greater than normal contrast serultivity could be achieved. 'The width of the step wedges was chosen to reduce the effect of undercutting at the edges during the exposures. A denstiy gradient across the steps could occur on the ritm if the step wedge whoth was too smull. 


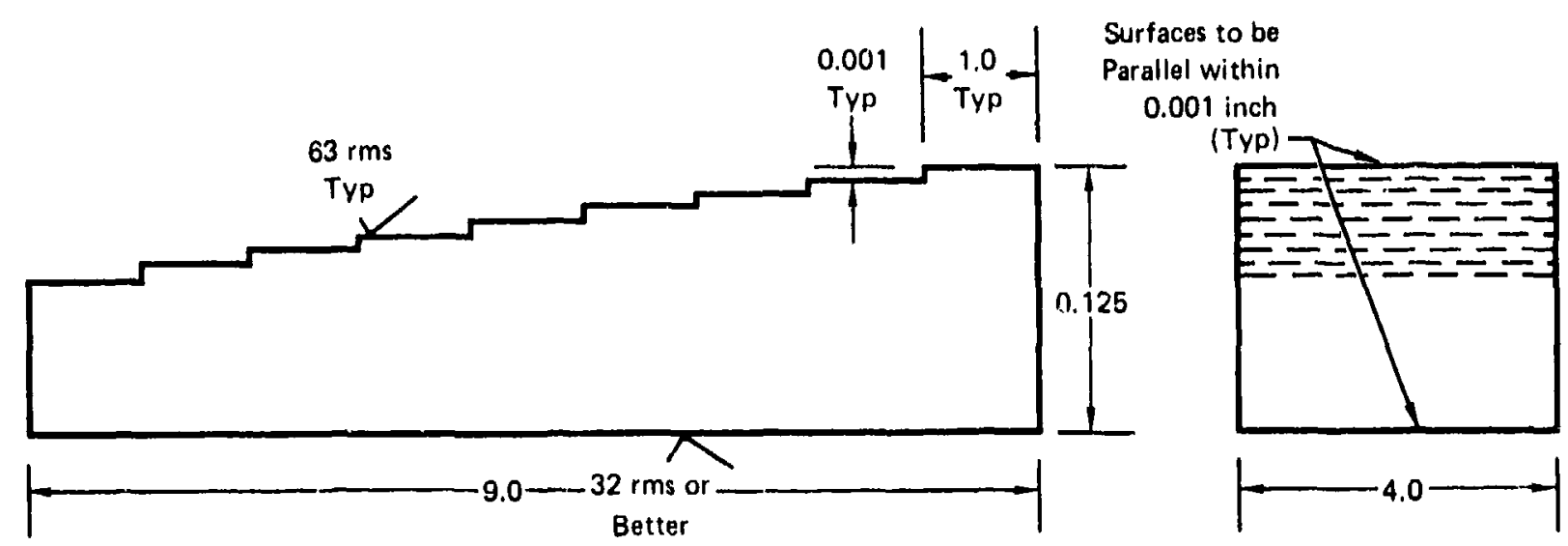

Configuration $\mathrm{A}$.
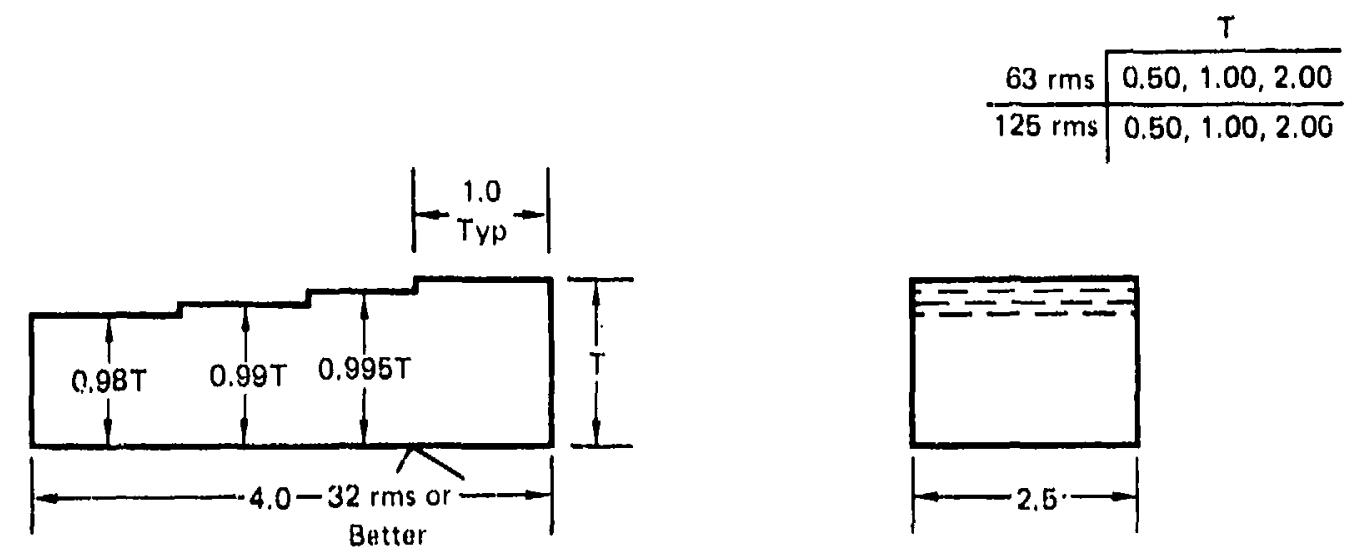

Configuration B
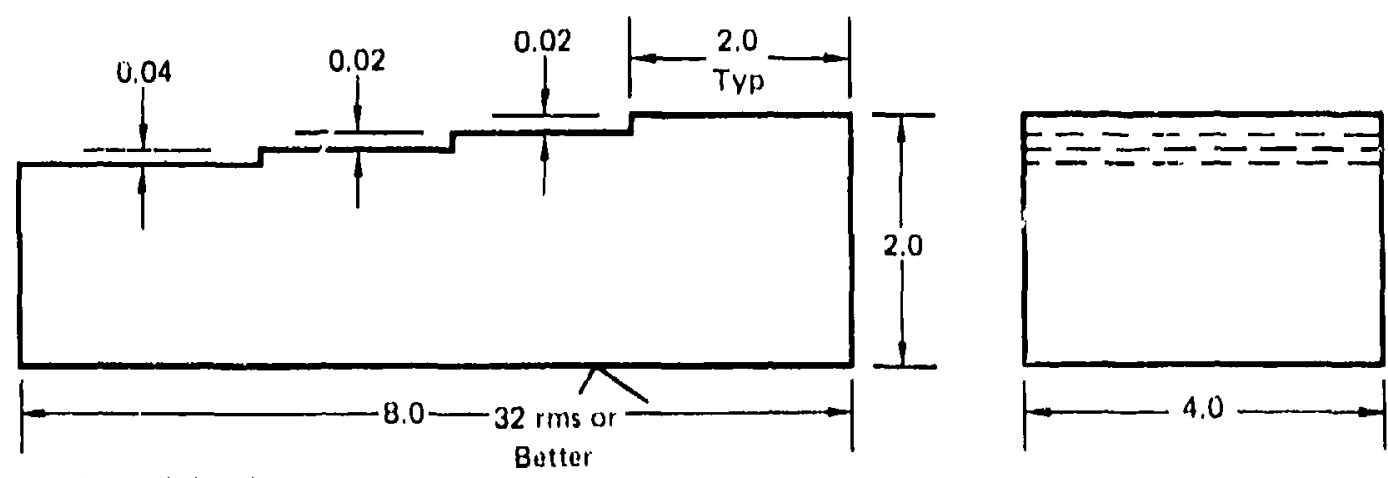

Note: Each etep must be poraliel ts the other stelse withwi 0.0006 inch.

Configuration $\mathrm{C}$

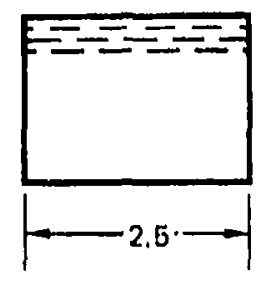

FIGURE 28

RADIOGRAPHIC TEST SPECIMENS 



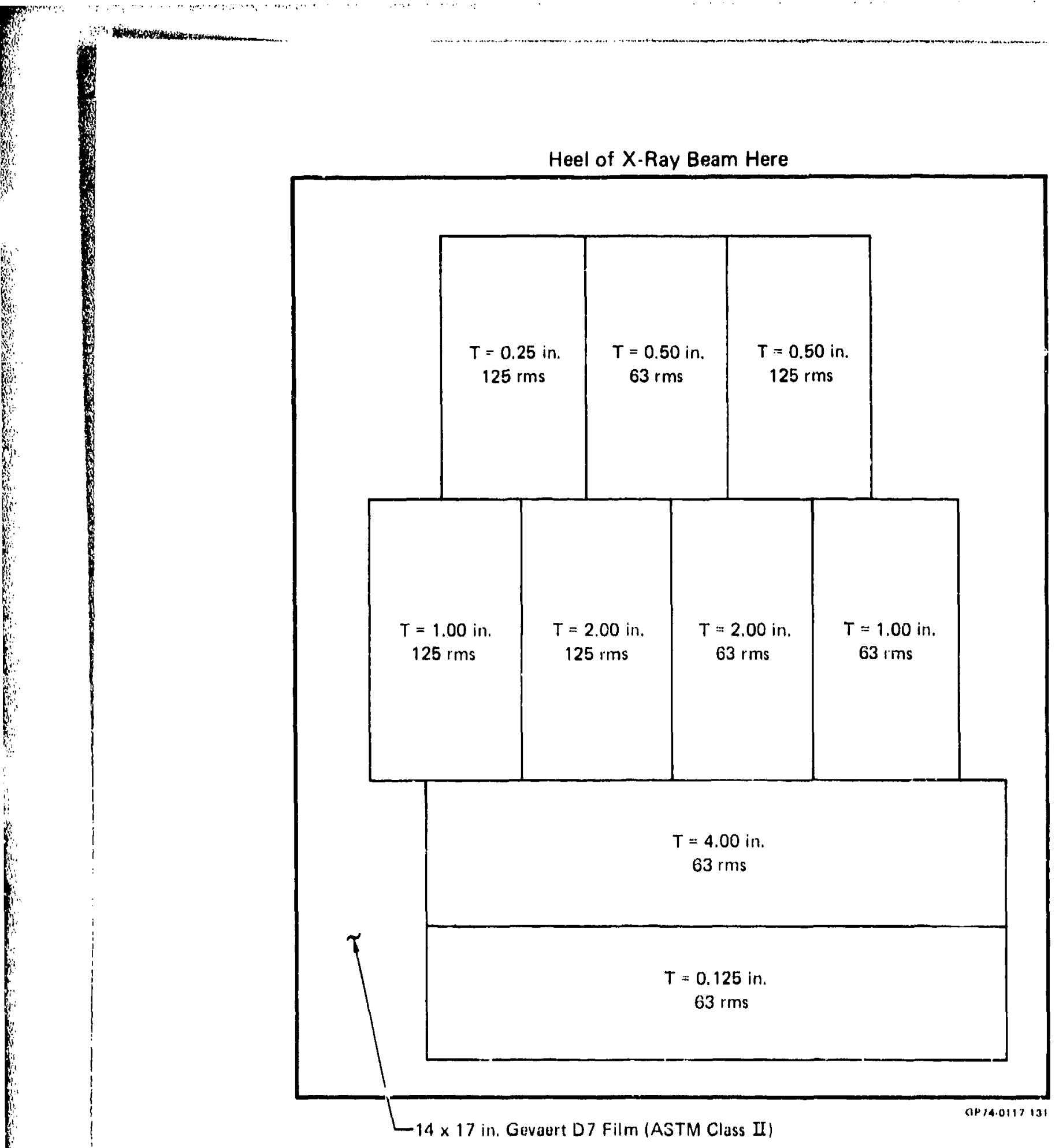

FIGURE 29

TEST SPECIMEN ARRANGEMENT 



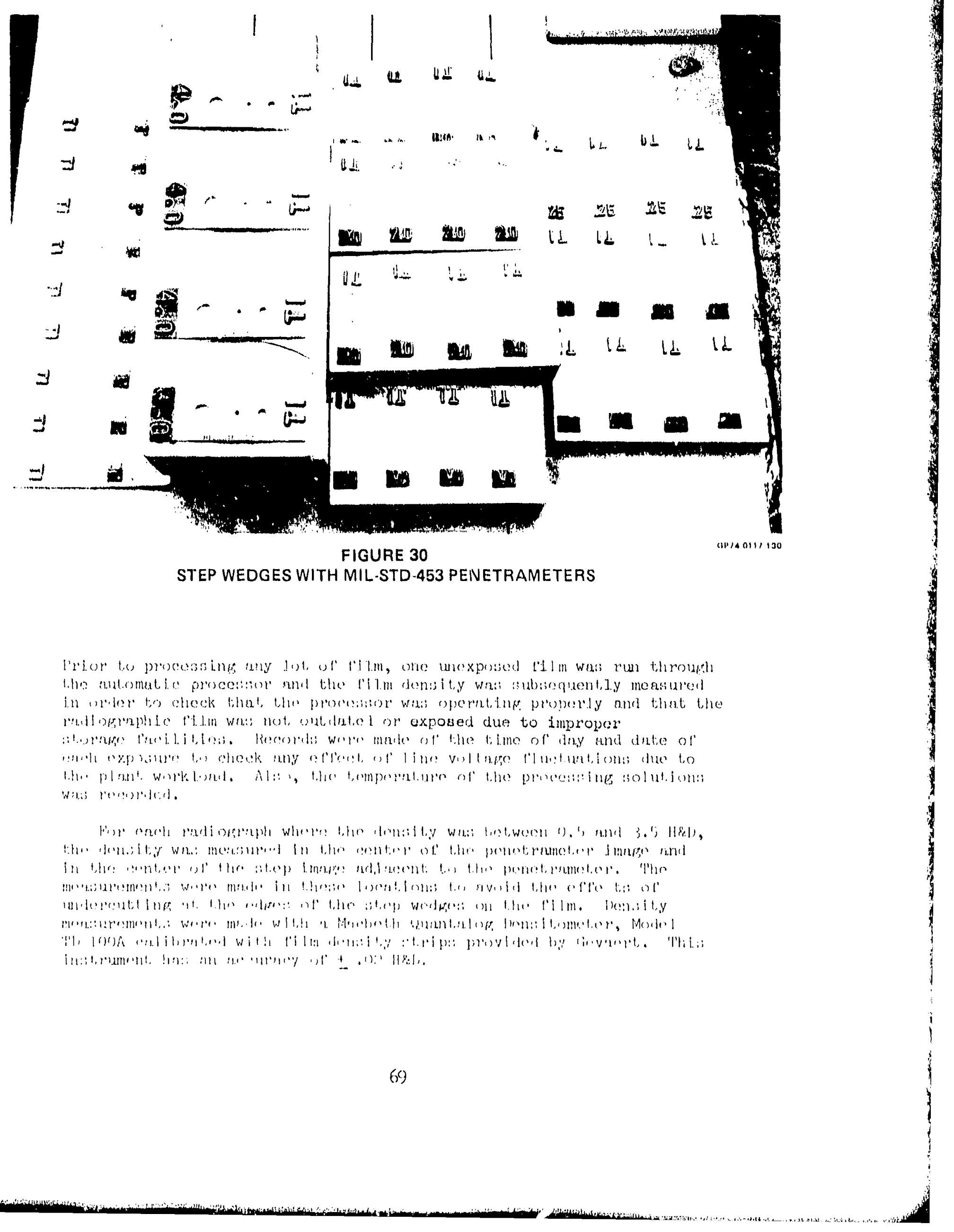


In order to determine the effect of kilovoltage on contrast sensitivity, the density data for a particular thickness change were normalized to an overall film density of 2.00 by using the characteristic curve to arrive at the $\log$ relative exposure (LRE). A film density of approximately $2.00 \mathrm{HED}$ is usually used in industrial radiography since the $\mathrm{X}$-ray film characteristic curves are linear in this density range and the film behavior is quite predictable. Also, X-ray film illuminators have sufficient intensity such that viewing of films with density of approximately 1.0 to $3.0 \mathrm{H} \& \mathrm{D}$ can be accomplished.

The LRE for each film density was determined from the characteristic film curve and the difference in LRE for various thickness changes were calculated. By applying this difference in LRE to the LRE for a 2.0 H\&D density, the LRE differences are normalized and the true exposure change and/or contrast can be determined. Thus it was not necessary for each film to have the same nominal density in order to make comparisons.

An example of the use of log relative exposure is shown in figure 31. For this hypothetical example, the difference in the log relative exposure was .021 for $160 \mathrm{KV}$ and .025 for $120 \mathrm{KV}$. Since the difference in $\log$ relative exposure is greater for the lower kilovoltage, it could be concluded from this data that, greater subject contrast was attained with the lower kilovoltage. The data, however, did seem to substantiate the use of lower kilovoltage/higher contrast techniques. l'able $L^{\prime c}$ is a list of penetrameter contrast and the minimum detect$\Rightarrow$ le hole size for that penetrametier for all data puints falling in a film density range of 1.5 t:0 $2.5 \mathrm{H} \& \mathrm{D}$. No difforentiation was made between instruments or specimen surface finish as in the collection of these data points. It can be seen that

(1) In general, as the kilovoltage becomes lower for a given thickness, the hole resolution increases and the contrast is increased.

(2) It is far easier to achieve a ?-1!'l' Imafe qualtty in large section thicknesses and therefore the penetrameter's role as an image quality indicator dimintshes.

(3) Data of this type could be used to plot I'l or 'xl' or 'A' resolution as a function of' kilovol.tege and seetion thickness.

(14) Apparent differences in penetrameter thicknesses or material. types exist. As an example, the hole resolution for .50 fuch thick sections was as expected for the 100,120 , and 140 kilovoltage exposures but was not as expected at the 160 k1.0voltage. 'this coild be explained by an inadvertent excharige of one penetrameter with unother - each having the same identif'teniton ass to type and material. 
TABLE 18

CONTRAST AND RESOLUTION AS A FUNCTION OF KILOVOLTAGE AND THICKNESS

\begin{tabular}{|c|c|c|c|c|c|c|}
\hline \multirow{2}{*}{ Kilowoltage } & \multicolumn{6}{|c|}{ Thicknoss (in.) } \\
\hline & 0.12 & 0.25 & 0.50 & 1.0 & 2.0 & A.0 \\
\hline 70 & $\begin{array}{l}1 / 0.08 \\
1 / 0.11 \\
1 / 0.10\end{array}$ & $1 / 0.10$ & & & & \\
\hline 90 & $2 / 0.06$ & $2 / 0.05$ & & & & \\
\hline 100 & $\begin{array}{l}2 / 0.06 \\
2 / 0.04 \\
2 / 0.05\end{array}$ & $\begin{array}{l}2 / 0.06 \\
2 / 0.04\end{array}$ & $\begin{array}{l}1 / 0.10 \\
1 / 0.10\end{array}$ & & & \\
\hline 120 & & $\begin{array}{l}2 / 0.04 \\
4 / 0.02\end{array}$ & $\begin{array}{l}2 / 0.10 \\
2 / 0.02 \\
2 / 0.02 \\
2 / 0.08\end{array}$ & & & \\
\hline 140 & & & $\begin{array}{l}4 / 0.03 \\
4 / 0.02\end{array}$ & $\begin{array}{l}2 / 0.07 \\
2 / 0.07 \\
2 / 0.04 \\
\end{array}$ & & \\
\hline 160 & & & $\begin{array}{l}2 / 0.04 \\
2 / 0.04 \\
\end{array}$ & $\begin{array}{l}1 / 0.08 \\
1 / 0.14 \\
\end{array}$ & & \\
\hline 180 & & & & $\begin{array}{l}2 / 0.09 \\
2 / 0.03 \\
2 / 0.04 \\
\end{array}$ & & \\
\hline 200 & & & & $\begin{array}{l}2 / 0.02 \\
2 / 0.01 \\
2 / 0.04 \\
\end{array}$ & & \\
\hline 250 & & & & & $1 / 0.10$ & \\
\hline 300 & & & & & $\begin{array}{l}1 / 0.08 \\
1 / 0.08\end{array}$ & $1 / 0.10$ \\
\hline 350 & & & & & & $1 / 0.12$ \\
\hline 380 & & & & & & $1 / 0.10$ \\
\hline
\end{tabular}




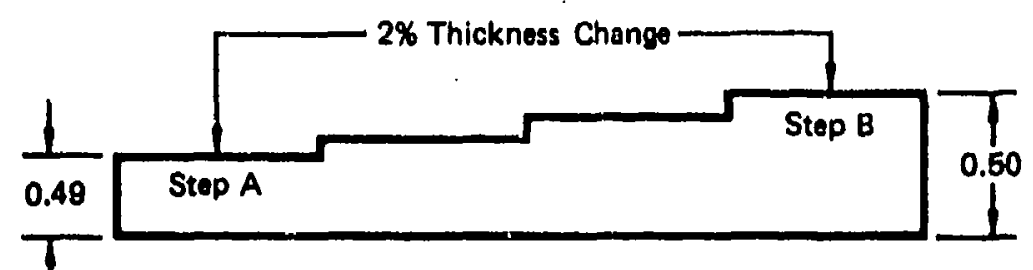

\begin{tabular}{|c|c|c|c|c|c|}
\hline \multicolumn{3}{|c|}{ Density (H8D) } & \multicolumn{2}{c|}{$\begin{array}{c}\text { Log Rolative } \\
\text { Exposure (LRE) }\end{array}$} & $\begin{array}{c}\text { Changs } \\
\text { in } \\
\text { LAE }\end{array}$ \\
\hline KV & Step A & Step B & Step A & Step B & \\
\hline 160 & 0.87 & 0.83 & 1.489 & 1.458 & 0.021 \\
120 & 2.66 & 2.51 & 2.052 & 2.027 & 0.025 \\
\hline
\end{tabular}

FIGURE 31

LOG RELATIVE EXPOSURE USED TO EVALUATE THE DATA 
Analysis of the actual data taken in the program indicated that the data were inconclustre in terms of arriving at the relationship between contrast and kilovoltage. The chosen thickness changes ( $1 / 2 \%, 1 \%$, and 2\%) were so small that the density differences were in the range of scatter of the densitometer instrument measurements.

Although it was not known at the time of these tests, variations in penetrameter thickness may have also contributed to the data scetter.

A small internal program has revealed a problem with using the plaque-type penetrameter as an image quality indicator. It has been found that there can be a significant effect of the difference in penetrameter thickness for MIL-STD-453 penetrameters. A titanium weli assembly was radiographed using a certain MIL-STD-453 penetrameter. It was subsequently necessary to radiograph the part again and a second MIL-STD-453 penetrameter was used. A difference was noted in the radiographic quality of the two radiographs even though the exposure conditions were the same.

In one radiograph the $1 T$ hole was easily resolvabje, however, in the second radiograph the IT hole was not detectable. In addition, the peretrameter contrast was much lower in the second radiograph. Consequently, the two penetrameters were exposed side-by-side simultaneously on the same film so that the exposure conditions were identical and the film densities were measured. These densities were as follows:

\begin{tabular}{|c|c|c|c|}
\hline & $\begin{array}{l}\text { Minimum } \\
\text { Resolvable } \\
\text { Hole }\end{array}$ & $\begin{array}{l}\text { Density At } \\
\text { Penetrameter } \\
\text { (H\&D) }\end{array}$ & $\begin{array}{l}\text { Density Adjacent } \\
\text { To Penetrameter } \\
\text { (H\&D) }\end{array}$ \\
\hline enetrameter A & $1 T$ & 2.78 & 3.05 \\
\hline Penetrameter $B$ & $2 \Gamma$ & 3.10 & 3.12 \\
\hline
\end{tabular}

Next, the thicknesses of the penetrameters were measured and found to be $.00^{\prime \prime}$ and .0085 inch. The MIL-STD- 453 thickness requirement for a .37 penetrameter is .0063 to .0077 inch. Tt can be seen that one of the penetremeters exceeds the MII-STD-453 toierances even though it was marked by the manufacturers as conformisg to MIL-SID-453. The penetrameter which exceeded the tolerance requirement was close enough to the maximum a.l lowable thickness to suggest that the MIL-STD-453 thickness range may resul.t in a density spread which is quite significant. It is possible the.t the MIL-STD- 453 tolerances are too large.

Based on these results, It would appear that MLL-STL-453 penetrameters do not provide for a consistent indscation of the quality of a particular radiograph with the present thickness toleiances. MIL-STD00453 presently requires tinat a minimum of $.02 \mathrm{H} \& \mathrm{D}$ density untes between the penetrameter image and the image adjacent to the penetrameter be obtained for a 2-1T radiographic qua ity. Based on the difficulties of measuring small density differ ances and on the variation in penetrameter thicknesses, it is questicuable if this is a workable requirement no matter how desirabl:. 
It is also positile that tighter tolerances on material types might have to be imposed since $X$-ray transmission/absorption varies directly with both thickness and density.

It should also be noted that there are no penetrameters manufactured for use with thicknesses less than $1 / 4$ inch. Since the cursent $1 / 4$ inch penetrameter is inadequate for defining contrast or detail for thin section thicknesses, special penetrameters would be of great use for thin section radiography.

The test program highlighted some information which is of practical use for industrial radiography. One such example concerns the output of constant potential $X-r a y$ machines when compared to self-rectified and full wave rectified $X-r$ ay machines. Based on the electrical circultry, the output from a constant potential circuit to that from a selfrectified circuit is sigrificantly higher.

Halmshaw indicates in "Physics of Industrial Radiology" that selfrectified circuiis emit $X$-rays with a maximum output at photon energies corresponding to about $60 \%$ of the peak voltage applied to the tube and constant potential circuits emit $x$-rays with a maximum output corresponding to about $76 \%$ of the peak applied voltage. Thus it would appear ihat the maximum emission from a self-rectified unit would be about $79 \%$ as high as that from a constant potential unit. However, it was found that, in practice, this relationship may be hidden because of factors such as the effect of different target materials and different inherent filtration due to tube windows, the conling medium sround the tube and different ports. An example of this is shown in Table 19 where: for several step wedges and kilovoltages, the resultant film density is greater for the self-rectified X-ray machine than for the constant potential $\mathrm{X}$-ray machine under the same exposure conditions.

TABLE 19

COMPARISON OF FILM DENSITIES FOR EXPOSURES UNDER THE SAME CONDITIONS WITH ISOVOLT 400 AND PG300 X-RAY MACHINES

\begin{tabular}{|c|c|c|c|c|}
\hline $\begin{array}{c}\text { Thickness } \\
\text { of Stjp } \\
\text { Wedge } \\
\text { (in.) }\end{array}$ & $\mathrm{kV}$ & $\begin{array}{c}\text { Exposure } \\
\text { (MAM) }\end{array}$ & $\begin{array}{c}|c| \\
\text { Isovolt 400 } \\
\text { (Constant Potential) }\end{array}$ & $\begin{array}{c}\text { PG300 } \\
\text { (Self-Rectified) }\end{array}$ \\
\hline & $1^{\prime}, 0$ & 16 & 0.58 & 0.84 \\
$1 / 2$ & 140 & 16 & 1.26 & 1.64 \\
& 160 & 16 & 2.20 & 2.51 \\
\hline $1 / 4$ & 120 & 16 & 1.50 & 2.03 \\
& 140 & 16 & 2.96 & 3.47 \\
\hline $1 / 8$ & 120 & 16 & 2.66 & 3.31 \\
\hline
\end{tabular}


The common practice today is to express the radiographic quality level in terms of the visibility of a penetrameter image on the film and in terms of the smallest visible penetrameter hole on the film. For example, a 2-IT quality level indicater that a penetrameter whose maximum thickness is $2 \%$ of the test part thickness is visible on the film and that the penetrameter hole with a diameter equal to the penetrameter thickness is also visible on irle film. It is left up to the radiographic interpreter to judge whether or not the penetrameter image and penetrameter hole is visible on the film and hence, the desirea quality level has been achieved.

Sixteen radiographs of the step wedges were selacted to measure the variation $i_{\text {.: }}$ judgment from one inspector to another as to the smallest discernible hole in a penetrameter image on a radiograph. One of the observeds used was a laboratory technician whereas the remaining two observers were production radiographic interpreters. All three people have been quilified technically to supplement A of SNT-IC-J.A, Level II. Each man was irstructed to record the smallest hole which ne could see in each penetrameter.

The radiographlc films were viewed with an illuminator equipped with a variable controlled light source capable of reading a film density up to 3.5. The illuminator had a minimum brightness capability of 30,000 candelas per square meter at the illuminator opal glass. For the actual viewing of the films, the background illuminator adjacent to the illuminator was approximately the same as the image on the film.

A total of 162 penetrameter images were examined by each man. Of these, all 3 men recorded the same hole in 127 of the penetrameters. The variation for the remaining 35 penetrameters is shown in Table 20

The data in Table 20 were examined to see if any individual consistently interpreted the hole image more conservatively than others. It was found that Inspector A, the laboratory technician, chose a hole diameter larger than that chosen by the other two people $43 \%$ of the time. Ihese percentages were $29 \%$ and $3 \%$ for the other two people.

Since acuity is a relative phenomenon, there can be no judgements as to who is right or who is wrong. However, the subject was presented to illustrate one of the possible differerces which can result in two evaluations of the same material even with optimum technique conditions.

The variation shown in lable 20 has a particular significance when i.t is considered that it is also a suggestion of the variation to be expected when actual radiographs of production parts are interpreted. One man could cunceivably reject a condition where another man would accept it purely on a difference in visua]. abuity and judgement.

The data were examined to determine if the smaller penetrameter holes were visible more often if the surface finiuh was $63 \mathrm{kMS}$ as compared to 125 RMS. The dat indicated that the surface finish was not a significant factor for the two inishes evaluated. 
In conclusion, there are many radiugraphic factors which need to ba controlled for reproducible radiographs. If penetrameter contrast measurements are to be used to properly control radiographic image contrast, tighter tolerances may be nesessary on the penetrameter thickness. Also, penetrameters for use with section thicknesses less than .?'; inch are needed for thin section radiography. Kilovoltage and beam spectrum must also be controlled in order to control radiographic image contrast.

A choice of kilovoltage as a function of thickness can produce different results from une $X-r a y$ machine to another. For example, the actua: potential across the electron emitter and target is not directiy mes;ured by the voltmeter on the machine. Voltmeter accuracy must be checied u a periodic basis to ensure reproducibility. Nlso, variations in inhwrent filtration between $X$-ray tubes should be taken into cor:sideration. Fluctuations in line voltage due to plant workload can also have an eifect.

TABLE 20 VARIATION IN DETERMINATION IN RADIOGRAPHIC QUALITY 1

\begin{tabular}{|c|c|c|c|c|c|}
\hline \multicolumn{3}{|c|}{ Smallest Detectable Hole } & \multicolumn{3}{|c|}{ Smallest Dotectable Hole } \\
\hline$\underset{\text { Inspecto }}{\text { I }}$ & $\begin{array}{c}\text { Inspector } \\
\text { B }\end{array}$ & $\begin{array}{c}\text { Inspector } \\
\mathrm{C}\end{array}$ & $\begin{array}{c}\text { Inspector } \\
\text { A }\end{array}$ & $\begin{array}{c}\text { Inspector } \\
\text { B }\end{array}$ & $\begin{array}{c}\text { Insuector } \\
\mathrm{C}\end{array}$ \\
\hline $1 \mathrm{~T}$ & $2 T$ & $1 T$ & $2 T$ & $1 T$ & $1 T$ \\
\hline $4 T$ & $2 T$ & $2 \mathrm{~T}$ & $2 T$ & $4 T$ & $2 \uparrow$ \\
\hline $4 \mathrm{~T}$ & $2 T$ & $2 T$ & $2 \mathrm{~T}$ & $4 T$ & $2 T$ \\
\hline 17 & $1 T$ & $2 T$ & $4 T$ & $2 T$ & $2 T$ \\
\hline $2 T$ & $1 \mathrm{~T}$ & $1 T$ & $4 T$ & $2 r$ & $2 T$ \\
\hline $2 T$ & $2 \mathrm{~T}$ & $1 \mathrm{~T}$ & $4 T$ & $2 T$ & $2 r$ \\
\hline 21 & $2 T$ & $1 T$ & $2 \mathrm{~T}$ & $4 T^{\circ}$ & ?T \\
\hline $2 T$ & $1 \mathrm{~T}$ & $1 T$ & $2 T$ & $4 T$ & $2 T$ \\
\hline $2 \mathrm{~T}$ & $1 \mathrm{~T}$ & $1 \mathrm{~T}$ & $2 T$ & $4 T$ & $2 T$ \\
\hline $2 T$ & $2 \mathrm{~T}$ & $1 \mathrm{~T}$ & $2 \Gamma$ & $4 T$ & $2 T$ \\
\hline $2 \mathrm{~T}$ & $2 \mathrm{~T}$ & $1 \mathrm{~T}$ & $2 T$ & $4 T$ & $\angle T$ \\
\hline $2 \mathrm{~T}$ & $1 T$ & $1 \mathrm{~T}$ & $2 \mathrm{~T}$ & $4 T$ & $2 T$ \\
\hline $2 T$ & $2 \mathrm{~T}$ & $1 \mathrm{~T}$ & $2 T$ & $4 T$ & $2 T$ \\
\hline $2 \mathrm{~T}$ & $1 T$ & $1 T$ & $2 T$ & $4 \mathrm{~T}$ & 41 \\
\hline $2 T$ & $1 \mathrm{~T}$ & $T$ & $2 T$ & $2 r$ & $1 \mathrm{~T}$ \\
\hline $2 T$ & $1 \mathrm{~T}$ & $1 \mathrm{~T}$ & $2 T$ & $1 T$ & $1 T$ \\
\hline $2 T$ & $1 T$ & $2 T$ & $2 \mathrm{~T}$ & $1 \mathrm{~T}$ & $1 \mathrm{~T}$ \\
\hline 27 & $1 \mathrm{~T}$ & $2 T$ & & & \\
\hline
\end{tabular}

1. The: 3 inspectors detectol the samo hole 11127 penetramoters. 


\section{ULTRASONIC METHOD}

Severai ultrasonic inspection parameters were investigated during the program. These include the effect of surface curvature, the detection of discontinuities located near the surface of the test article, and the effect of variations in sound transmission characteristics of the reference standard vs. those of the material to be tested. Also, an investigation was made to improve ultrasonic inspection of titanium plate and thin section machined parts.

\section{¿. Surface Curvatire Compensation}

Many iitanium die f'orgings which must be ultrasonically tested possess curved surfaces. Also, round bars and billets are frequent., ultrasonic tester. However, if the commonly used flat surface reference standards are used, compensation for the curved surface must be necessary ir erroneous results may be obtained. Without correction, a discontinuity in a production part may appear to be smaller or larger than it actually is and a rejectable part may be accepted or vice versa.

Consequently, a test program has been undertaken to study the effect of convex and concave sound entry surfaces.

T'wenty-seven convex and thirty concive ultrasoric test specimens have been fabricated to the figure 32 and 33 configuration. Several radii of curvature and metal travel distances were used. The convex specimens were sectioned from round stock of the appropriate dianeter prior to machining. The concave specimens were sectioned from 3 inch thick plate with the 3 inch specimen dimension parallel to the 3 inch plate thickress. After the convex and concave specimens were machined and drilled, the hole depth, hole diameter, and metal travel were measured to establish that they were within tolerance. The hole orientation and location were measured on several selected specimens to ensure that the drilling set-up had been correct. The flatness of the hole bottom was checked optically.

$\Lambda$ number of the larger diameter reference standards were fabricated from aluminum. Testing was performed with these in order to determine if aluminum contour blocks can be used for inspecting titanium. Obviously, fabricating a set of aluminum contoui surface reference standards would be less expensive than falricating titanium standards; due to lower material cost and machining costs. 21.

A photograph of several concave specimens is presented in fikfure

Flat surface reference standards, fabricated from 2-1/8 incl dianeter T'i-6Ai-4V bar, were used in conjunction with the curved specimens to compare responses from the flat bottom hole (Figure j5). This configuration was used to conform to the ASTM Eil27 configuration. prior to drilling the flat bottom holes to a depth of $0.5+.050$ inch, the har was cut into several $7 "$ long sections and the $2-1 / \overline{8}$ irich diameter faces were machined flat and to a 63 rms or better inish. 

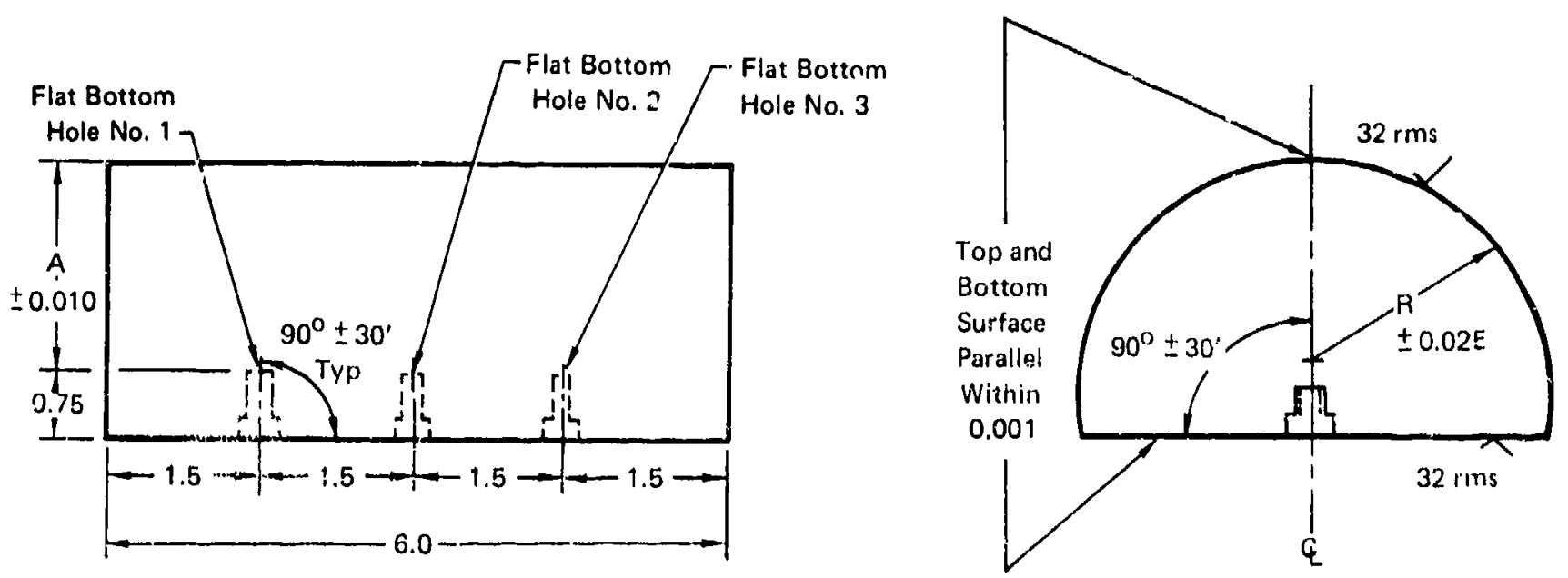

Hole Bottom Must be Flat Within $0.001 \mathrm{in.} / 1 / 8 \mathrm{In}$. and Located Within $0.015 \mathrm{ln}$. of Radial Axis

\begin{tabular}{|c|c|c|c|c|c|}
\hline Material & $\begin{array}{c}\text { Radius, R } \\
\text { (Inches) }\end{array}$ & $\begin{array}{c}\text { A } \\
\text { (Inches) }\end{array}$ & $\begin{array}{l}\text { Hole No. } 1 \\
( \pm 0.001)\end{array}$ & $\begin{array}{l}\text { Hole No. } 2 \\
( \pm 0.0005)\end{array}$ & $\begin{array}{l}\text { Hole No. } 3 \\
( \pm 0.001)\end{array}$ \\
\hline Ti-6Al.4V & $\begin{array}{l}0.5 \\
0.5 \\
1.0 \\
1.0 \\
1.5 \\
1.5 \\
1.5 \\
2.0 \\
2.0 \\
2.0\end{array}$ & $\begin{array}{l}0.5 \\
0.75 \\
0.5 \\
0.75 \\
0.5 \\
0.75 \\
1.25 \\
0.5 \\
0.75 \\
2.25\end{array}$ & $\begin{array}{l}5 / 64 \\
5 / 64 \\
E, 64 \\
5 / 64 \\
5 / 64 \\
5 / 64 \\
5 / 64 \\
5 / 64 \\
5 / 64 \\
5 / 64\end{array}$ & $\begin{array}{l}3 / 64 \\
3 / 64 \\
3 / 64 \\
3 / 64 \\
3 / 64 \\
3 / 64 \\
3 / 64 \\
3 / 64 \\
3 / 64 \\
3 / 64\end{array}$ & $\begin{array}{l}1 / 8 \\
1 / 8 \\
- \\
- \\
- \\
- \\
- \\
1 / 8 \\
1 / 8 \\
1 / 8\end{array}$ \\
\hline 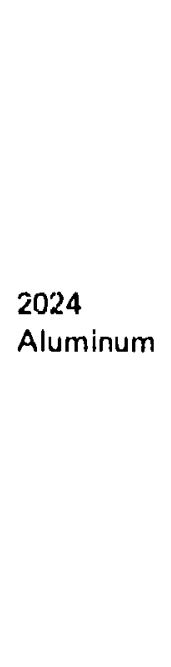 & $\begin{array}{l}2.0 \\
2.0 \\
2.5 \\
2.5 \\
2.5 \\
2.5 \\
2.5 \\
3.0 \\
3.0 \\
3.0 \\
3.0 \\
3.0 \\
4.0 \\
4.0 \\
4.0 \\
4.0 \\
4.0\end{array}$ & $\begin{array}{l}0.5 \\
2.5 \\
0.5 \\
1.00 \\
1.5 \\
2.5 \\
4.0 \\
0.5 \\
1.0 \\
1.5 \\
2.5 \\
4.0 \\
0.5 \\
1.0 \\
1.5 \\
2.5 \\
4.0\end{array}$ & $\begin{array}{l}5 / 64 \\
5 / 64 \\
5 / 64 \\
5 / 64 \\
5 / 64 \\
5 / 64 \\
5 / 64 \\
5 / 64 \\
5 / 64 \\
5 / 64 \\
5 / 64 \\
5 / 64 \\
5 / 64 \\
5 / 54 \\
5 / 64 \\
5 / 64 \\
5 / 64\end{array}$ & $\begin{array}{c}3 / 64 \\
3 / 64 \\
3 / 64 \\
3 / 64 \\
3 / 64 \\
3 / 64 \\
3 / 64 \\
3 / 64 \\
3 / 64 \\
3 / 63 \\
3 / 64 \\
3 / 64 \\
3 / 64 \\
3 / 64 \\
3 / 64 \\
3 / 64 \\
3 / 64\end{array}$ & $\begin{array}{l}- \\
- \\
- \\
- \\
- \\
- \\
- \\
- \\
- \\
- \\
- \\
- \\
- \\
- \\
- \\
- \\
-\end{array}$ \\
\hline
\end{tabular}



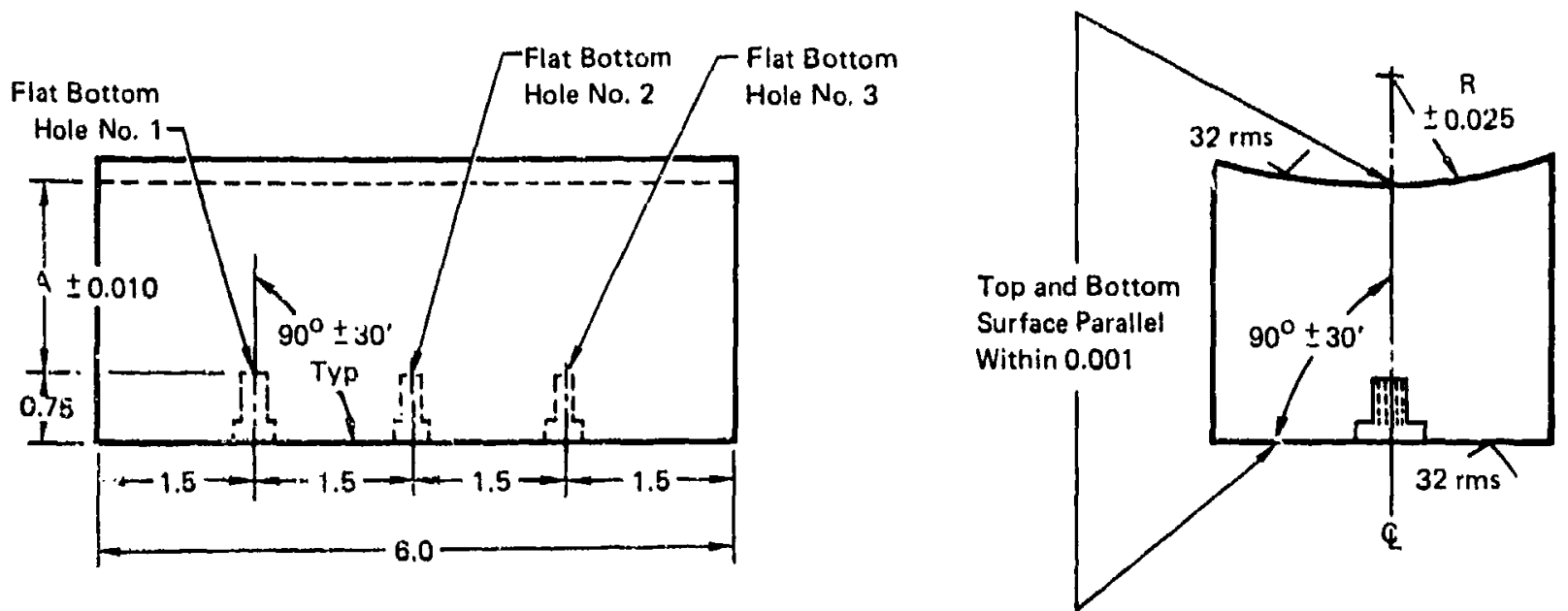

Hole Bottom Must be Flat With in $0.001 \ln . / 1 / 8 \ln$. and Located Within 0.015 In. of Radial Axis

\begin{tabular}{|c|c|c|c|c|c|}
\hline Material & $\begin{array}{c}\text { Radius, R } \\
\text { (Inches) }\end{array}$ & $\begin{array}{c}\text { A } \\
\text { (Inches) }\end{array}$ & $\begin{array}{l}\text { Hole No. } 1 \\
( \pm 0.001)\end{array}$ & $\begin{array}{l}\text { Hole No. } 2 \\
( \pm 0.0005)\end{array}$ & $\begin{array}{l}\text { Hole No. } 3 \\
( \pm 0.001)\end{array}$ \\
\hline$T i .6 \mathrm{~A} \mid .4 \mathrm{~V}$ & $\begin{array}{l}1 / 2 \\
1 \\
1 \\
1 \\
1 \\
1 \cdot 1 / 2 \\
1 \cdot 1 / 2 \\
1 \cdot 1 / 2 \\
1 \cdot 1 / 2 \\
2 \\
2 \\
2 \\
2\end{array}$ & $\begin{array}{l}0.50 \\
0.75 \\
0.50 \\
0.75 \\
1.25 \\
0.50 \\
0.15 \\
1.25 \\
2.25 \\
0.50 \\
0.75 \\
2.25 \\
3.25\end{array}$ & $\begin{array}{l}5 / 64 \\
5 / 64 \\
5 / 64 \\
5 / 64 \\
5 / 64 \\
5 / 64 \\
5 / 64 \\
5 / 64 \\
5 / 64 \\
5 / 64 \\
5 / 64 \\
5 / 64 \\
5 / 64\end{array}$ & $\begin{array}{l}3 / 64 \\
3 / 64 \\
3 / 64 \\
3 / 64 \\
3 / 64 \\
3 / 64 \\
3 / 64 \\
3 / 64 \\
3 / 64 \\
3 / 64 \\
3 / 64 \\
3 / 64 \\
3 / 64\end{array}$ & $\begin{array}{c}8 / 64 \\
8 / 64 \\
- \\
- \\
- \\
- \\
- \\
- \\
- \\
8 / 64 \\
8 / 64 \\
8 / 64 \\
8 / 64\end{array}$ \\
\hline $\begin{array}{l}2024 \\
\text { Aluminum }\end{array}$ & $\begin{array}{l}2 \\
2 \\
2 \cdot 1 / 2 \\
2 \cdot 1 / 2 \\
2 \cdot 1 / 2 \\
2 \cdot 1 / 2 \\
2 \cdot 1 / 2 \\
3 \\
3 \\
3 \\
3 \\
3 \\
4 \\
4 \\
4 \\
4 \\
4\end{array}$ & $\begin{array}{l}0.50 \\
2.50 \\
0.5 \\
1.00 \\
1.50 \\
2.50 \\
4.00 \\
0.50 \\
1.00 \\
1.50 \\
2.50 \\
4.00 \\
0.50 \\
1.00 \\
1.50 \\
2.50 \\
4.00\end{array}$ & $\begin{array}{l}5 / 64 \\
5 / 64 \\
5 / 64 \\
5 / 64 \\
5 / 64 \\
5 / 64 \\
5 / 64 \\
5 / 64 \\
5 / 64 \\
5 / 64 \\
5 / 64 \\
5 / 64 \\
5 / 64 \\
5 / 64 \\
5 / 64 \\
5 / 64 \\
5 / 64\end{array}$ & $\begin{array}{l}3 / 64 \\
3 / 64 \\
3 / 64 \\
3 / 64 \\
3 / 64 \\
3 / 64 \\
3 / 64 \\
3 / 64 \\
3 / 64 \\
3 / 64 \\
3 / 64 \\
3 / 64 \\
3 / 64 \\
3 / 64 \\
3 / 64 \\
3 / 64 \\
3 / 64 \\
3 / 64\end{array}$ & $\begin{array}{l}- \\
.- \\
-- \\
- \\
- \\
- \\
. . \\
. \\
\ldots \\
- \\
- \\
. \\
\ldots \\
. \\
. \\
. \\
. . \\
. .\end{array}$ \\
\hline
\end{tabular}

CONCAVE. CURVATURE REFERENCE STANDARDS 


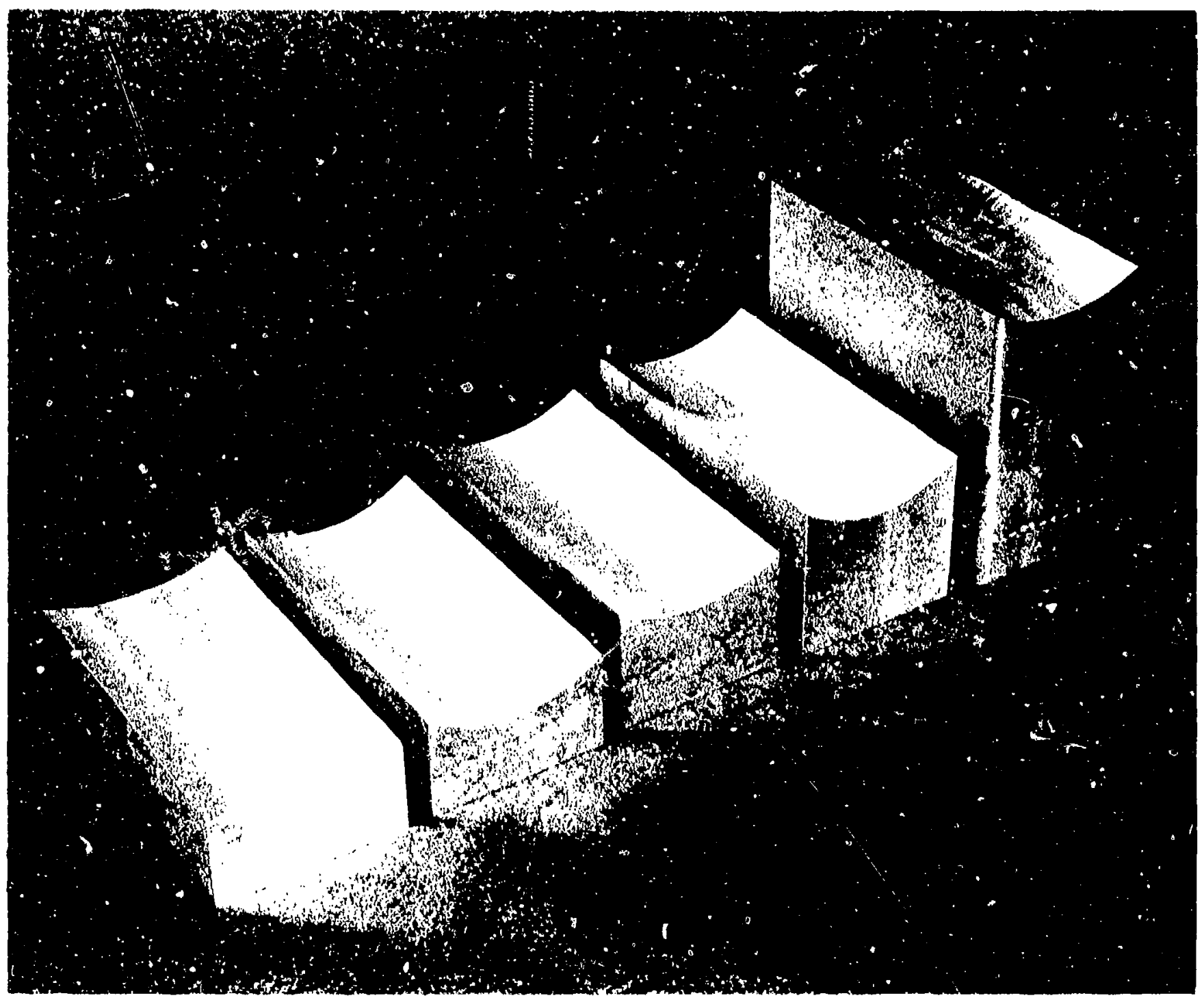

FIGUIRE 34

CONCAVE ULTRASONIC SPECIMENS 


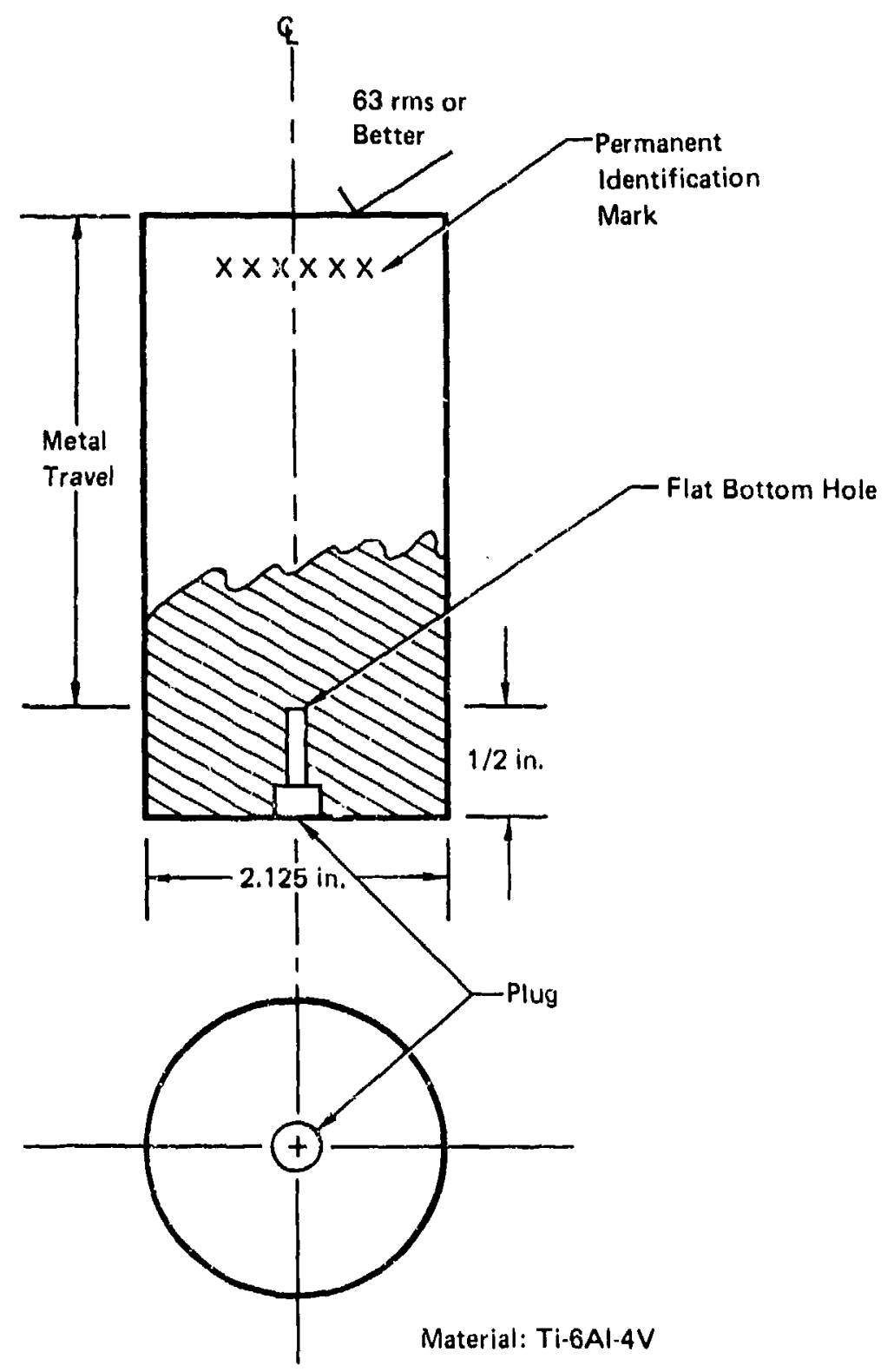

FIGURE 35

FLAT SURFACE REFERENCE STANDAKD 
In order to select pieces which were closely matched acousticaliy, immersion straight beam through-transmission tests were performed on each piece by sending the sound beam parallel to the 7 inch axis. A $3 / 4$ inch diameter, $5 \mathrm{MF}$ SIZ search unit was used as a receiver. During these iests, it was noticed that, in some pieces, the sound was attenuated more in one direction than in the other. For the majority of the specimens, the difference wes $n$ the order of $2 \mathrm{~dB}$ but, for a few, the difference was as much as 6ais. This difference in attenuation with direction may be due to such factors as a preferential grain pattern and the prior working history of the bar. This data serves to emphasize the sound transmission differences that can occur between, say, the reference standard and the part to be inspected during a normal production ultrasonic inspection, and also between different sets of reference standards. obviously, correction for these differences is desirable.

The curved surface testing was performed using straight beam immersion techniques. Initially, a flat surface reference standard was placed in the water and the immersion search unit was adjusted to a 3 inch water path. A 3 inch water path was selected because it represents a common industry water path used for production ultrasonic inspection. The choice of the 3 inch water pain caused all the testing to be performed in the near field. Testing was performed with the reject control and the damping control off. Next, the search unit was positioned and angulated to maximize the response from the $3 / 64$ diameter flat bottom hole in the flat surface standard and the instrument gain was adjusted to bring the response from the flat bottom hole to $80 \%$ of saturation. The $d B$ setting at this point was recorded. Then the search unit was positioned over a curved surface specimen containing a $3 / 64$ inch diameter flat bottom hole at the same metal travel distance and the gain was changed in order to bring the hole response to $80 \%$ of saturation. The $a B$ required to bring the response to $80 \%$ of saturation was recorded. From the data recorded, the decibel difference between the responses and the response ratio (flat surface/curved surface) were calculated.

The ultrasonic instrumencs and search units used for the investigation are listed in Table 21.

The data developed during the above testing was given an adjustment for any differences in sound transmission characteristics between the titanium flat surface reference standard and the titanium curved surface test specimens. These differences might result from differences in grain structure, prior working history, surface finish, and heat treatment. As shuwn in Figure 36 , a piece was removed from that concave specimen with a 2 -inch radius and 3.25-inch metal travel. The response from the flat bottom hole was maximized and aljusted to $80 \%$ of fuld saturation. Next, the search unit was moved to the flat surface reference standard with an identical metal travel and the $\mathrm{dB}$ required to bring the rosponse to $80 \%$ of f'ull saturation was measured. The dB difference between the two responses was measured 
TABLE 21

ULTRASONIC INSTRUMENTS AND TRANSDIUCERS USED FOR CURVED SURFACE STUDY

\begin{tabular}{|c|c|}
\hline $\begin{array}{l}\text { Ultrasonic } \\
\text { Instrument }\end{array}$ & Transducer \\
\hline Branson 600 & 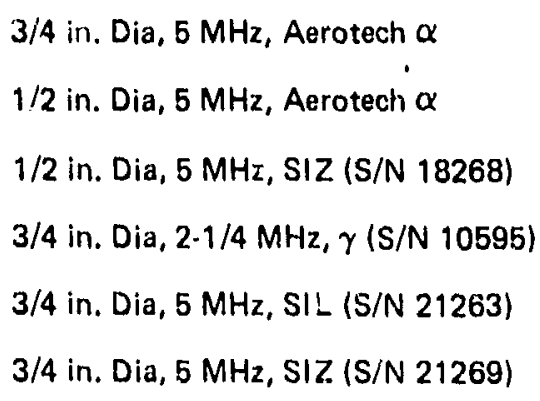 \\
\hline Sperry UM-715 & $\begin{array}{l}1 / 2 \text { in. Dia, } 5 \text { MHz, SIZ (S/N 18268) } \\
3 / 4 \text { in. Dia, } 5 \text { MHz, SIZ (S/N 21269) } \\
3 / 4 \text { in. Dia, } 5 \text { MHz, SIL (S/N 21263) }\end{array}$ \\
\hline
\end{tabular}



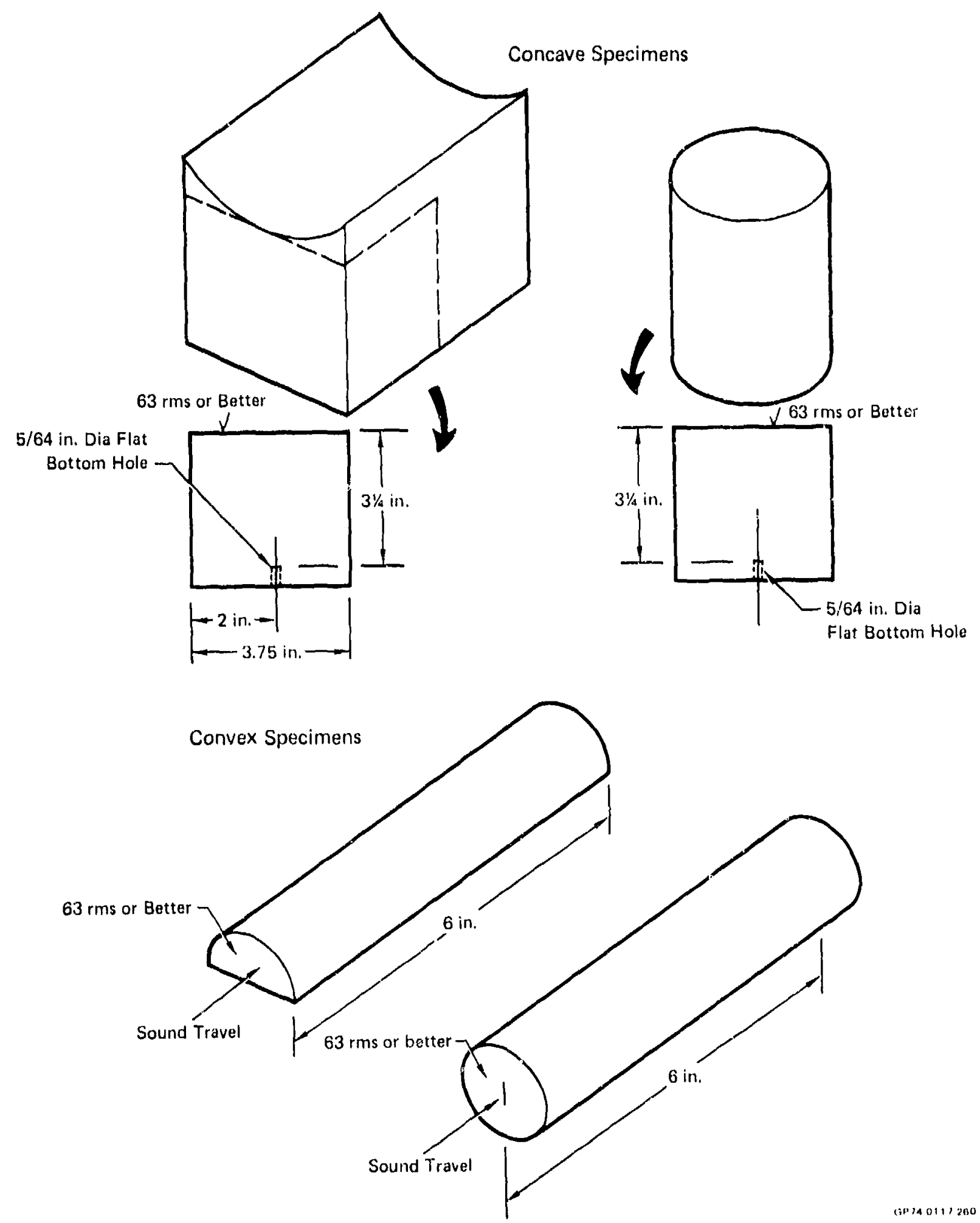

FIGURE 36

TESTS TO ESTABLISH DIFFERENCE IN SOUND TRANSMISSION

CHARACTERISTICS 
to be $7 \mathrm{~dB}$. Since all the concave specimens were fabricated from one piece of 2 inch thick plate, the data for the concave specimens were corrected by $2.15 \mathrm{~dB}$ per inch of metal travel.

Correction for convex specimens were made by adjusting the back reflection through a 6 inch long flat surface reference standard to $80 \%$ of full saturation and noting the $\mathrm{dB}$ required to bring the back surface response in the convex specimen to $80 \%$ of full saturation (see Figure 36). It was found that $\mathrm{dB}$ difference was so small that data correction was unnecessary for the convex specimens.

The results of the testing are shown in Tables 22 and 23. The general shapes of the piots of decibel difference as a function of radius of curvature for concave and convex surfaces are shown in Figure 37. It should be pointed out that decibel measurements were made because of the difficulty in accurately measuring small amplitude heights directly off a cathode ray tube screen.

As can be seen from the test data, the response from the $f^{\prime}$ at bottom hole was always less with a convex sourd entry surface than with a flat sound entry surface; that is, the decibel differecne was always positive. Consequently, during a normal production ultrasonic inspection, a discontinu.j.ty will appear smaller than it actually is due to the influences of a convex sound entry surface. The data presented indicates that the amplitude of the response due to the convex entry surface can be as small as $10 \%$ of the response with a flat sound entry surface over a metal travel range of $1 / 2$ to $3-1 / 4$ inches.

It is significant that the decibel difference varies as a function of radius and metal travel for this implies that a total correction for curvature can only be made after the discontinuity is located. vonsequently, an ultrasonic inspection of a production part in the areas with a curved surface of a particular radius should be conducted at a scanning gain high enough to ensure the detection of all discontinuities at that radius regardless of their depth location. Then, a second evaluation should be made using the appropriate scanning gain corrections as a function of the metal travel to determine the true size of the discontinuity.

The hole responses from specimens with concave sound entry surfaces were sometimes less and greater than those specimens with flat entry surfaces depending upon the concave radius and metal travel distance. The sound beam converges after passing through the concave water/ metal interface. The maximum response from a reference reflector within the metal would nccur a a metal travel equivalent to the focal distance.

Typical variations in decivel difference as a function of search unit are showl in Figure 38. Two ultrasonic instruments are also represented. The curves in Figure 38 were all for the responsc from a $3 / 54$ inch diameter hole at a $3 / 4$ inch metal travel. $\Lambda$ s can 
TABLE 22

RESPONSE RATIO OF FLAT SURFACE RESPONSE (If) TO CURVED SURFACE RESPONSE $\left(I_{C}\right)$ - TITANIUM SPECIMENS

Ultrasonic Instrument - Eranson 600

Reflector - 3/64 In. Dia Flat Sottum Hole $3 / 4$ In. Dia, $5 \mathrm{MHz}$, Aerotech $\alpha$

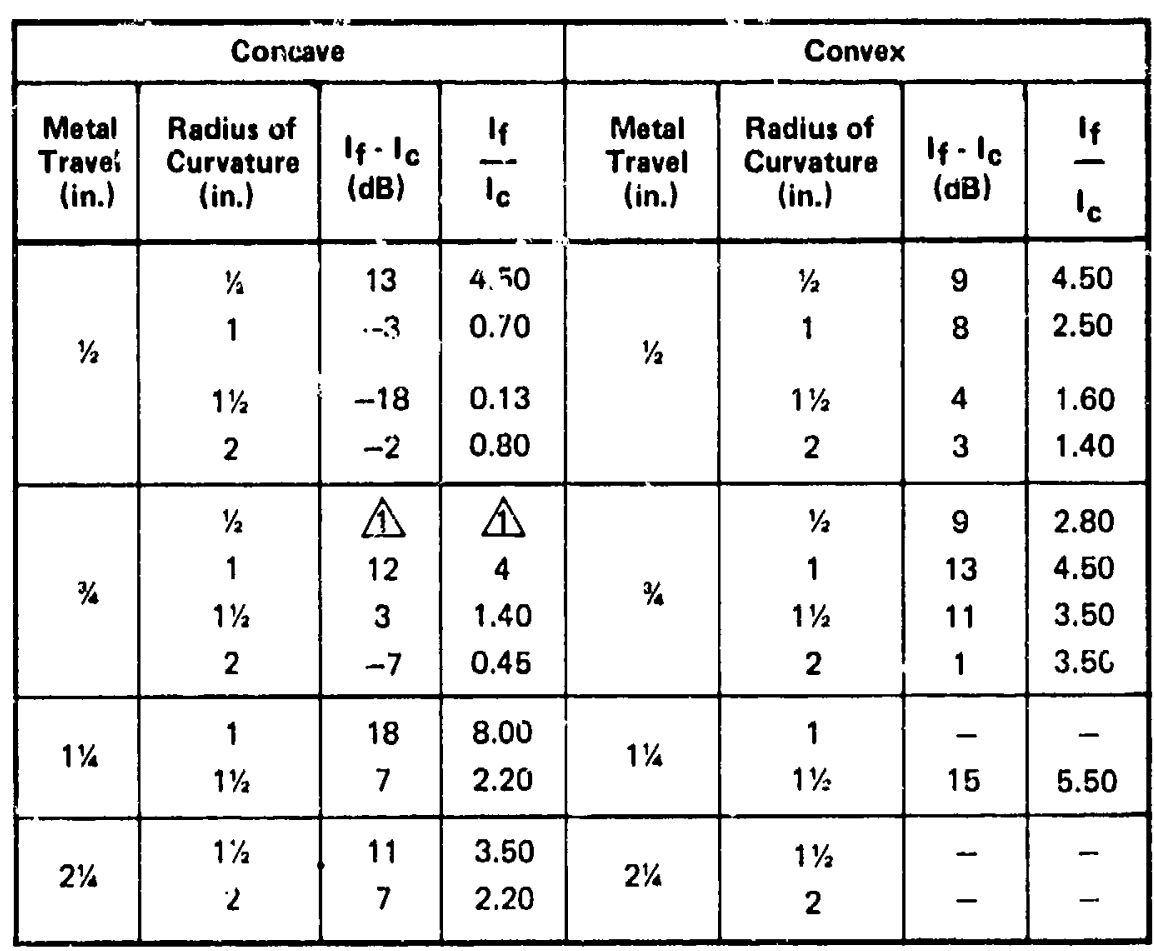

1. Response from flat bottom hole could not be soperated fiom spurlous indlcations. 
TABLE 22 (Continued)

RESPONSE RATIO OF FLAT SURFACE RESPONSE ( $f$ ) TO CURVED SURFACE RESPONSE $\left(I_{c}\right)$ - TITANIUM SPECIMENS

1,2 In. Dia, $5 \mathrm{MHz}$, Aerotech $\alpha$

\begin{tabular}{|c|c|c|c|c|c|c|c|}
\hline \multicolumn{4}{|c|}{ Concave } & \multicolumn{4}{|c|}{ Convex } \\
\hline $\begin{array}{c}\text { Metal } \\
\text { Travel } \\
\text { (in.) }\end{array}$ & $\begin{array}{c}\text { Radius of } \\
\text { Currature } \\
\text { (in.) }\end{array}$ & $\begin{array}{r}I_{f} \cdot I_{c} \\
(d B)\end{array}$ & $\frac{I_{f}}{I_{c}}$ & $\begin{array}{c}\text { Metal } \\
\text { Travel } \\
\text { (in.) }\end{array}$ & $\begin{array}{l}\text { Radius of } \\
\text { Survature } \\
\text { (in.) }\end{array}$ & $\begin{array}{l}I_{f}-I_{c} \\
(d B)\end{array}$ & $\frac{I_{f}}{I_{c}}$ \\
\hline \multirow{4}{*}{$1 / 2$} & $1 / 2$ & 15 & 5.50 & \multirow{4}{*}{$1 / 2$} & $1 / 2$ & 17 & 7.00 \\
\hline & 1 & 3 & 1.40 & & 1 & 10 & 3.20 \\
\hline & $11 / 2$ & -6 & 0.50 & & $11 / 2$ & 7 & 2.20 \\
\hline & 2 & -2 & 0.80 & & 2 & 5 & 1.80 \\
\hline \multirow{4}{*}{$3 / 4$} & $1 / 2$ & $\widehat{\Delta}$ & $\Delta$ & \multirow{4}{*}{$3 / 4$} & $1 / 2$ & 21 & 11.00 \\
\hline & 1 & 13 & 4.50 & & 1 & 15 & 5.50 \\
\hline & $11 / 2$ & 8 & 2.50 & & $1 \frac{1}{2}$ & 12 & 4.00 \\
\hline & 2 & 2 & 1.25 & & 2 & 10 & 3.20 \\
\hline \multirow{2}{*}{$1 \%$} & 1 & 15 & 5.50 & \multirow{2}{*}{$11 / 4$} & 1 & - & - \\
\hline & $1 \frac{1}{2}$ & 11 & 3.50 & & $11 \frac{1}{2}$ & 16 & 6.30 \\
\hline \multirow{2}{*}{$21 / 4$} & $1 \frac{1}{2}$ & 17 & 7.00 & \multirow{2}{*}{$21 / 4$} & $1 \frac{1 / 2}{2}$ & & \\
\hline & 2 & 13 & 4.50 & & 2 & & \\
\hline
\end{tabular}

1 Response from flat bottom hole could not be separated from spurious signals.

Gr74 0111.2914 
TABLE 22 (Continued)

RESPONSE RATIO OF FLAT SURFACE RESPONSE (If) TO CURVED SURFACE RESPONSE $\left(I_{C}\right)$ - TITANIUM SPECIMENS

$1 / 2$ In. Dia $5 \mathrm{MHz}$ Lead Zirconate Titanate Search Unit ( $S / N$ 18268)

\begin{tabular}{|c|c|c|c|c|c|c|c|}
\hline \multicolumn{4}{|c|}{ Concave } & \multicolumn{4}{|c|}{ Convex } \\
\hline $\begin{array}{l}\text { Metal } \\
\text { Travel } \\
\text { (in.) }\end{array}$ & $\begin{array}{l}\text { Radius } \\
\text { of } \\
\text { Curvature } \\
\text { (in.) }\end{array}$ & $\begin{array}{l}I_{F-1} C^{-} \\
(\mathrm{dB})\end{array}$ & ${ }^{I} F / I_{C}$ & $\begin{array}{c}\text { Metal } \\
\text { Travel } \\
\text { (in.) }\end{array}$ & $\begin{array}{l}\text { Radius } \\
\text { of } \\
\text { Curvature } \\
\text { (in.) }\end{array}$ & $\begin{array}{l}I_{F} \cdot I_{C} C \\
(\mathrm{~dB})\end{array}$ & $I_{f:} / I_{C}$ \\
\hline $1 / 2$ & $\begin{array}{c}1 / 2 \\
1 \\
1-1 / 2 \\
2\end{array}$ & $\begin{array}{c}10 \\
2 \\
-10 \\
-4\end{array}$ & $\begin{array}{l}3.2 \\
1.25 \\
0.32 \\
0.63\end{array}$ & $1 / 2$ & $\begin{array}{c}1 / 2 \\
1 \\
1 \cdot 1 / 2 \\
2\end{array}$ & $\begin{array}{l}13 \\
9 \\
6 \\
4\end{array}$ & $\begin{array}{l}4.5 \\
2.8 \\
2.0 \\
1.6\end{array}$ \\
\hline $3 / 4$ & $\begin{array}{c}1 / 2 \\
1 \\
1-1 / 2 \\
2\end{array}$ & $\begin{array}{c}\Delta \\
10 \\
1 \\
-6\end{array}$ & $\begin{array}{l}\Delta \hat{1} \\
3.2 \\
1.1 \\
0.5\end{array}$ & $1 / 2$ & $\begin{array}{c}1 / 2 \\
1 \\
1 \cdot 1 / 2 \\
2\end{array}$ & $\begin{array}{l}15 \\
13 \\
9 \\
7\end{array}$ & $\begin{array}{l}5.5 \\
4.5 \\
2.8 \\
2.2\end{array}$ \\
\hline $1 \cdot 1 / 4$ & $\begin{array}{c}1 \\
1 \cdot 1 / 2\end{array}$ & $\begin{array}{c}16 \\
8\end{array}$ & $\begin{array}{l}6.3 \\
2.5\end{array}$ & $1.1 / 4$ & $1 \cdot 1 / 2$ & 14 & 5.0 \\
\hline $2 \cdot 1 / 4$ & $\begin{array}{c}1.1 / 2 \\
2\end{array}$ & $\begin{array}{c}12 \\
8\end{array}$ & $\begin{array}{l}4.0 \\
2.5\end{array}$ & & & & \\
\hline
\end{tabular}

A Response from flat bottom hole could not be suparated from spurlous indications

3/4 In. Dia 2.1/4 MHz Ceramic Sea:cí Unit (S/N 10595)

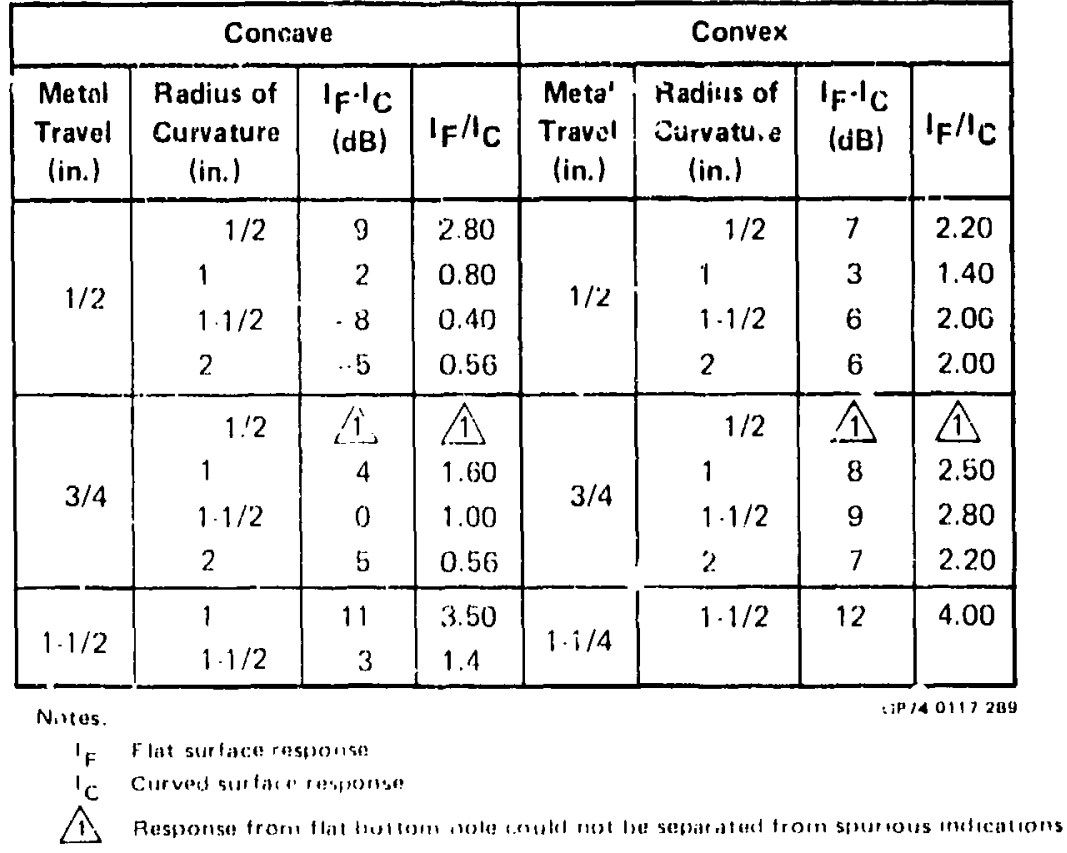


TABLE 22 (Continuer)

RESPONSE RATIO OF FLAT SURFACE RESPONSE $\left(I_{f}\right)$ TO CURVED SURFACE

RESPONSE $\left(I_{C}\right)$ - TITANIUM SPECIMENS

$3 / 4$ In. Dia 5MHz. LiSO 4 Suarch Unit (S/N 21263)

\begin{tabular}{|c|c|c|c|c|c|c|c|}
\hline \multicolumn{4}{|c|}{ Concave } & \multicolumn{4}{|c|}{ Convex } \\
\hline $\begin{array}{l}\text { Motal } \\
\text { Travel } \\
\text { (in.) }\end{array}$ & $\begin{array}{c}\text { Radius of } \\
\text { Curvature } \\
\text { (in.) }\end{array}$ & $\begin{array}{l}I_{F-1} \cdot C \\
(d B)\end{array}$ & $I_{F} / I_{C}$ & $\begin{array}{c}\text { Metal } \\
\text { Travel } \\
\text { (in.) }\end{array}$ & $\begin{array}{l}\text { Radius of } \\
\text { Curvature } \\
\text { (in.) }\end{array}$ & $\begin{array}{r}I_{F} \cdot \mathbf{C} C \\
(\mathrm{~dB})\end{array}$ & $I_{F} / I_{C}$ \\
\hline \multirow{4}{*}{$i / 2$} & $1 / 2$ & 5 & 1.80 & \multirow{4}{*}{$1 / 2$} & $1 / 2$ & 7 & 2.2 \\
\hline & 1 & -5 & 0.56 & & 1 & 7 & 2.2 \\
\hline & $1.1 / 2$ & -16 & 0.16 & & $1 \cdot 1 / 2$ & 5 & 1.8 \\
\hline & 2 & -10 & 0.32 & & 2 & 4 & 1.6 \\
\hline \multirow{4}{*}{$3 / 4$} & $1 / 2$ & $\hat{1}$ & 1 & \multirow{4}{*}{$3 / 4$} & $1 / 2$ & 1 & 1 \\
\hline & 1 & 7 & 2.20 & & 1 & 8 & 2.5 \\
\hline & $1 \cdot 1 / 2$ & 2 & 1.25 & & $1.1 / 2$ & 9 & 2.8 \\
\hline & 2 & -6 & 0.50 & & 2 & 5 & 1.8 \\
\hline
\end{tabular}

3/4 In. Dia 5MHz Lead Zirconate Titanate Search Unit (S/N 21269)

\begin{tabular}{|c|c|c|c|c|c|c|c|}
\hline \multicolumn{4}{|c|}{ Concoys } & \multicolumn{4}{|c|}{ Convex } \\
\hline $\begin{array}{c}\text { Metal } \\
\text { Travel } \\
\text { (in.) }\end{array}$ & $\begin{array}{c}\text { Radius of } \\
\text { Curvature } \\
\text { (in.) }\end{array}$ & $\begin{array}{l}I_{F} \cdot{ }^{\prime} C \\
|d B|\end{array}$ & $I_{F} / I_{C}$ & $\begin{array}{l}\text { Metal } \\
\text { Travel } \\
\text { (in.) }\end{array}$ & $\begin{array}{l}\text { Radius of } \\
\text { Curvature } \\
\text { (in.) }\end{array}$ & $\begin{array}{l}I_{F}{ }^{-1} C \\
(d B)\end{array}$ & $I_{F} / I_{C}$ \\
\hline \multirow{4}{*}{$1 / 2$} & $1 / 2$ & 8 & 2.50 & \multirow{4}{*}{$1 / 2$} & $1 / 2$ & 9 & 2.80 \\
\hline & 1 & -1.5 & 0.85 & & 1 & 8 & 2.50 \\
\hline & $1.1 / 2$ & -16 & 0.14 & & $1.1 / 2$ & 4.5 & 1.70 \\
\hline & 2 & -15 & 0.18 & & 2 & 4 & 1.60 \\
\hline \multirow{4}{*}{$3 / 4$} & $1 / 2$ & $\hat{1}$ & 1 & \multirow{4}{*}{$3 / 4$} & $1 / 2$ & 18 & 8.00 \\
\hline & 1 & 15 & 5.60 & & 1 & 10 & 3.20 \\
\hline & $1.1 / 2$ & 2 & 1.30 & & $1.1 / 2$ & 11 & 3.50 \\
\hline & 2 & .5 & 0.56 & & 2 & 8 & 2.50 \\
\hline \multirow{2}{*}{$1 \cdot 1 / 4$} & 1 & 20 & 10.00 & \multirow{2}{*}{$1 \cdot 1 / 4$} & \multirow{2}{*}{$1.1 / 2$} & \multirow[t]{2}{*}{19.5} & \multirow[t]{2}{*}{9.50} \\
\hline & $1.1 / 2$ & 11 & 3.50 & & & & \\
\hline \multirow{2}{*}{$2 \cdot 1 / 4$} & $1.1 / 2$ & 12 & 4.00 & & & & \\
\hline & 2 & 0 & 1.00 & & & & \\
\hline $3.1 / 4$ & 2 & 7.5 & 2.40 & & & & \\
\hline & & & & & & \multicolumn{2}{|r|}{ A } \\
\hline 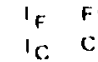 & 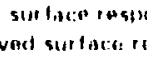 & se & & & & & \\
\hline
\end{tabular}


TABLE 22 (Continued)

RESPONSE RATIO UF FLAT SURFACE RESPONSE (If) TO CURVED SURFACE RESPONSE $\left(i_{c}\right)$ - TITANIUM SPECIMENS

Ultrasonic Instrument - Sperry UM-715

Reflector - $3 / 64$ In. Dia Flat Bottum Hole $1 / 2$ In. Dia, $5 M H z, S I Z$ (S/N 18268)

\begin{tabular}{|c|c|c|c|c|c|c|c|}
\hline \multicolumn{4}{|c|}{ Concuve } & \multicolumn{4}{|c|}{ Convex } \\
\hline $\begin{array}{l}\text { Motal } \\
\text { Trevel } \\
\text { fin.l }\end{array}$ & $\begin{array}{c}\text { Redius } \\
\text { of } \\
\text { Curvature } \\
\text { (in.) }\end{array}$ & $\begin{array}{l}I_{f}-I_{c} \\
(d B)\end{array}$ & $\frac{I_{f}}{I_{c}}$ & $\begin{array}{c}\text { Motal } \\
\text { Travel } \\
\text { (in.) }\end{array}$ & $\begin{array}{l}\text { Radius } \\
\text { of } \\
\text { Cuivature } \\
\text { (in.) }\end{array}$ & $\begin{array}{l}I_{f}-I_{c} \\
(d B)\end{array}$ & $\frac{I_{f}}{I_{c}}$ \\
\hline $1 / 2$ & $\begin{array}{c}1 / 2 \\
1 \\
11 / 2 \\
2\end{array}$ & $\begin{array}{r}7 \\
-1 \\
-9 \\
-1\end{array}$ & $\begin{array}{l}2.20 \\
0.90 \\
0.35 \\
0.90\end{array}$ & $1 / 2$ & $\begin{array}{c}1 / 2 \\
1 \\
11 / 2 \\
2\end{array}$ & $\begin{array}{l}11 \\
8 \\
5 \\
5\end{array}$ & $\begin{array}{l}3.50 \\
2.60 \\
1.80 \\
1.80\end{array}$ \\
\hline$\%$ & $\begin{array}{c}1 / 2 \\
1 \\
11 / 2 \\
2\end{array}$ & $\begin{array}{c}23 \\
9 \\
1 \\
-5\end{array}$ & $\begin{array}{c}10.40 \\
2.80 \\
1.10 \\
0.56\end{array}$ & $3 / 4$ & $\begin{array}{c}1 / 2 \\
1 \\
1 \% \\
2\end{array}$ & $\begin{array}{c}14 \\
10 \\
9 \\
6\end{array}$ & $\begin{array}{l}5.00 \\
3.20 \\
2.80 \\
2.00\end{array}$ \\
\hline $11 / 4$ & $\begin{array}{c}1 \\
11 / 2\end{array}$ & $\begin{array}{c}15 \\
9\end{array}$ & $\begin{array}{l}5.60 \\
2.80\end{array}$ & $1 \%$ & $\begin{array}{c}1 \\
11 / 2\end{array}$ & $\frac{-}{13}$ & $\frac{-}{4.50}$ \\
\hline $21 / 4$ & $\begin{array}{c}11 / 2 \\
2\end{array}$ & $\begin{array}{c}10 \\
7\end{array}$ & $\begin{array}{l}3.20 \\
2.20\end{array}$ & & & & \\
\hline $31 / 4$ & 2 & 6 & 2.00 & & & & \\
\hline
\end{tabular}

(i1) $1401123+1$ 
TABLE 22 (Continued)

RESPONSE RATIO DF FLAT SURFACE RESPONSE (If) TO CURVED SURFACE RESPONSE $\left(I_{G}\right)$ - TITANIUM SPECIMENS

$3 / 4$ In. Dia, $5 \mathrm{MHz}$, SIZ (S/N 21269)

\begin{tabular}{|c|c|c|c|c|c|c|c|}
\hline \multicolumn{4}{|c|}{ Concave } & \multicolumn{4}{|c|}{ Convex } \\
\hline $\begin{array}{c}\text { Matal } \\
\text { Travel } \\
\text { (ir.) }\end{array}$ & $\begin{array}{c}\text { Radius } \\
\text { of } \\
\text { Curvature } \\
\text { (in.l }\end{array}$ & ${ }^{I_{f}-I_{c}}(\mathrm{~dB})$ & $\frac{I_{f}}{I_{c}}$ & $\begin{array}{l}\text { Metal } \\
\text { Travel } \\
\text { (in.) }\end{array}$ & $\begin{array}{c}\text { Radius } \\
\text { of } \\
\text { Curvature } \\
\text { (in.) }\end{array}$ & $\begin{array}{l}l_{f} \cdot I_{c} \\
(d B)\end{array}$ & $\frac{I_{f}}{I_{c}}$ \\
\hline \multirow{4}{*}{$1 / 2$} & $1 / 2$ & 10 & 3.3 & \multirow{4}{*}{$1 / 2$} & $1 / 2$ & 10 & 3.2 \\
\hline & 1 & -3 & 0.7 & & 1 & 6 & 2.0 \\
\hline & $11 / 2$ & -12 & 0.25 & & $11 / 2$ & 5 & 1.8 \\
\hline & 2 & -7 & 0.45 & & 2 & 3 & 1.4 \\
\hline \multirow{4}{*}{$3 / 2$} & $1 / 2$ & 4 & $\Delta$ & \multirow{4}{*}{$\%$} & $1 / 2$ & 16 & 6.3 \\
\hline & 1 & 9 & 2.8 & & 1 & 12 & 4.0 \\
\hline & $11 / 2$ & 2 & 1.25 & & $11 / 2$ & 12 & 4.0 \\
\hline & 2 & -1 & 0.9 & & 2 & 10 & 3.2 \\
\hline \multirow{2}{*}{$1 \%$} & 1 & 16 & 6.3 & \multirow{2}{*}{$1 \% / 4$} & 1 & - & - \\
\hline & $1 \frac{1}{2}$ & 9 & 2.8 & & $11 / 2$ & 16 & 6.3 \\
\hline \multirow{2}{*}{$2 \%$} & $1 \frac{1}{2}$ & 18 & 8.0 & \multirow{2}{*}{$2 \%$} & $11 / 2$ & - & - \\
\hline & 2 & 19 & 9.0 & & 2 & - & - \\
\hline $31 / 4$ & 2 & 9 & 2.8 & - & - & - & - \\
\hline
\end{tabular}

OP74011730u 
TABLE 22 (Continued)

RESPONSE RATIO OF FLAT SURFACE RESPONSE $\left(l_{f}\right)$ TO CURVEC SURFACE RESPONSE $\left(I_{C}\right)$ - TITANIUM SPECIMENS

$3 / 4$ In. Dia, $5 \mathrm{MHz}$, SIL (S/N 21263)

\begin{tabular}{|c|c|c|c|c|c|c|c|}
\hline \multicolumn{4}{|c|}{ Concivy } & \multicolumn{4}{|c|}{ Convex } \\
\hline $\begin{array}{l}\text { Mota! } \\
\text { Travel } \\
\text { (in.) }\end{array}$ & $\begin{array}{c}\text { Radius } \\
\text { of } \\
\text { Curvature } \\
\text { (in.) }\end{array}$ & $\begin{array}{l}I_{4} \cdot I_{c} \\
(d B)\end{array}$ & $\frac{I_{f}}{I_{c}}$ & $\begin{array}{c}\text { Metal } \\
\text { Travel } \\
\text { (in.) }\end{array}$ & $\begin{array}{c}\text { Radius } \\
\text { of } \\
\text { Curvature } \\
\text { (in.) }\end{array}$ & $\begin{array}{l}I_{f} \cdot I_{c} \\
(\mathrm{~d} B)^{2}\end{array}$ & $\frac{I_{f}}{I_{c}}$ \\
\hline \multirow{4}{*}{$1 / 2$} & $1 / 2$ & 9 & 2.80 & \multirow{4}{*}{$1 /:$} & $1 / 2$ & 7 & 2.2 \\
\hline & 1 & -2 & 0.80 & & 1 & 7 & 2.2 \\
\hline & $11 / 2$ & -13 & 0.22 & & $11 / 2$ & 5 & 1.8 \\
\hline & 2 & -1 & 0.90 & & 2 & 4 & 1.6 \\
\hline \multirow{4}{*}{$3 / 4$} & $1 / 2$ & $\Delta$ & $\Delta$ & \multirow{4}{*}{$1 / 4$} & $1 / 2$ & 8 & 2.5 \\
\hline & 1 & $T$ & 2.20 & & 1 & 9 & 2.8 \\
\hline & $11 / 3$ & 3 & 1.41 & & $1 \frac{1 / 2}{2}$ & 8 & 2.5 \\
\hline & 2 & -7 & 0.46 & & 2 & 7 & 2.2 \\
\hline \multirow{2}{*}{$11 / 4$} & 1 & 15 & 5.60 & \multirow{2}{*}{$11 / 4$} & 1 & - & - \\
\hline & $1 \frac{1}{2}$ & 13 & 4.50 & & $1 \frac{1}{2}$ & 19 & 9.0 \\
\hline
\end{tabular}

1) Rewonse from flat bottom hole could not he separated from spurlous signals 
TABLE 23

RESPONSE RATIO OF FLAT SUFFACE RESFONSE (If $)$ TO CUFVED SURFACE RESPONSE $\left(I_{C}\right)$ - ALUMINUM SPECIMENS

Ultrasonic Instrument - Branson 600

Reflector - 3/64 In. Dia Flat Bottom Hole

$3 / 4$ In. Dia, 5MHz, SIL (S/N 21263i

\begin{tabular}{|c|c|c|c|c|c|c|c|}
\hline \multicolumn{4}{|c|}{ Concave } & \multicolumn{4}{|c|}{ Convex } \\
\hline $\begin{array}{l}\text { Metal } \\
\text { Travel } \\
\text { (in.) }\end{array}$ & $\begin{array}{c}\text { Radius } \\
\text { of } \\
\text { Curvature } \\
\text { (in.) }\end{array}$ & $\begin{array}{l}I_{f}-I_{c} \\
(d B)\end{array}$ & $\frac{I_{f}}{I_{c}}$ & $\begin{array}{c}\text { Motal } \\
\text { Travel } \\
\text { (in.) }\end{array}$ & $\begin{array}{c}\text { Radius } \\
\text { of } \\
\text { Curvature } \\
\text { (in.) }\end{array}$ & $\begin{array}{l}1_{f}-I_{c} \\
(d B)\end{array}$ & $\frac{I_{f}}{I_{c}}$ \\
\hline \multirow{4}{*}{$1 / 2$} & 2 & -11 & 0.28 & \multirow{4}{*}{$1 / 2$} & 2 & 7 & 2.2 \\
\hline & $2 \frac{1}{2}$ & -8 & 0.40 & & $21 / 2$ & 5 & 1.8 \\
\hline & 3 & -7 & 0.45 & & 3 & 6 & 2.0 \\
\hline & 4 & -3 & 0.70 & & 4 & 3 & 1.4 \\
\hline \multirow{3}{*}{1} & $21 / 2$ & 1 & 1.10 & \multirow{3}{*}{1} & $21 / 2$ & 11 & 3.5 \\
\hline & 3 & -4 & 0.61 & & 3 & 10 & 3.2 \\
\hline & 4 & -5 & 0.55 & & 4 & 8 & 2.5 \\
\hline \multirow{3}{*}{$11 / 2$} & $2 \frac{1}{2}$ & 6.5 & 2.10 & \multirow{3}{*}{$1 \frac{1}{2}$} & $21 / 2$ & 11.5 & 3.7 \\
\hline & 3 & 5.5 & 1.90 & & 3 & 11.5 & 3.7 \\
\hline & 4 & -0.5 & 0.95 & & 4 & 8.5 & 2.7 \\
\hline \multirow{4}{*}{$2 \%$} & 2 & 13 & & \multirow{4}{*}{$21 / 2$} & 2 & 15 & 5.5 \\
\hline & $2 \frac{1}{2}$ & 10 & 3.20 & & $21 / 2$ & 11 & 3.5 \\
\hline & 3 & 10 & 3.20 & & 3 & 11 & 3.5 \\
\hline & 4 & 7 & 2.20 & & 4 & 10 & 3.3 \\
\hline \multirow{3}{*}{4} & $21 / 2$ & 12 & 4.00 & \multirow{3}{*}{4} & $2 \frac{1}{2}$ & 12. & 4.0 \\
\hline & 3 & 10 & 3.20 & & 3 & 12 & 4.0 \\
\hline & 4 & 10 & 3.20 & & 4 & 11 & 3.5 \\
\hline
\end{tabular}


TABLE 23 (Continued)

RESPONSE RATIO OF FLAT SURFACE RESPONSE ( $\left.l_{f}\right)$ TO CURVED SURFACE RESPONSE $\left(I_{c}\right)$ - ALUMINUM SPECIMENS

Ultrasunic Instrument - Branson 600

Reflector - 3/64 In. Dia Flat Bottom Hole

$3 / 4$ In. Dia, $5 \mathrm{MHz}, \mathrm{SIZ}$ (S/N 21269)

\begin{tabular}{|c|c|c|c|c|c|c|c|}
\hline \multicolumn{4}{|c|}{ Concave } & \multicolumn{4}{|c|}{ Convex } \\
\hline $\begin{array}{l}\text { Motal } \\
\text { Travel } \\
\text { (in.) }\end{array}$ & $\begin{array}{c}\text { Radius } \\
\text { of } \\
\text { Curvature } \\
\text { (in.) }\end{array}$ & $\begin{array}{l}I_{f} \cdot I_{c} \\
(d B)\end{array}$ & $\frac{i_{f}}{i_{E}}$ & $\begin{array}{c}\text { Metal } \\
\text { Travel } \\
\text { (in.) }\end{array}$ & $\begin{array}{c}\text { Radius } \\
\text { of } \\
\text { Curvature } \\
\text { (in.) }\end{array}$ & $\begin{array}{l}I_{f}-I_{c} \\
(d B)\end{array}$ & $\frac{t_{f}}{t_{c}}$ \\
\hline \multirow{4}{*}{$1 / 2$} & 2 & -10 & 0.32 & \multirow{4}{*}{$1 / 2$} & 2 & 5.5 & 1.90 \\
\hline & $21 / 2$ & -8 & 0.40 & & $21 / 2$ & 4.5 & 1.70 \\
\hline & 3 & -6 & 0.50 & & 3 & 3.5 & $: .50$ \\
\hline & 4 & -3 & 0.70 & & 4 & 3 & 1.40 \\
\hline \multirow{3}{*}{1} & $21 / 2$ & -2.5 & 0.76 & \multirow{3}{*}{1} & $2 \frac{1}{2}$ & 7.5 & 2.30 \\
\hline & 3 & -6 & 0.50 & & 3 & 6.5 & 2.10 \\
\hline & 4 & -7 & 0.45 & & 4 & 5 & 1.80 \\
\hline \multirow{3}{*}{$11 / 3$} & $21 / 2$ & 6 & 2.00 & \multirow{3}{*}{$11 / 2$} & $2 \frac{1}{2}$ & 12 & 4.00 \\
\hline & 3 & 4 & 1.80 & & 3 & 11 & 3.60 \\
\hline & 4 & -2.5 & 0.75 & & 4 & 8 & 2.50 \\
\hline \multirow{4}{*}{$21 / 2$} & 2 & 12.5 & 4.20 & \multirow{4}{*}{$2 \frac{1}{2}$} & 2 & 13.5 & 4.70 \\
\hline & $21 / 2$ & 11.5 & 3.70 & & $21 / 2$ & 11.5 & 3.70 \\
\hline & 3 & 10 & 3.20 & & 3 & 11 & 3.50 \\
\hline & 4 & 7.5 & 2.40 & & 4 & 10.5 & 3.30 \\
\hline \multirow{3}{*}{4} & $21 / 2$ & 12 & 4.00 & \multirow{3}{*}{4} & $2 \frac{1}{2}$ & 13.5 & 4.70 \\
\hline & 3 & 11 & 3.50 & & 3 & 11.5 & 3.70 \\
\hline & 4 & 10 & 3.20 & & 4 & 11 & 3.50 \\
\hline
\end{tabular}

GP/40111296 
TABL.E 23 (Continued)

RESPONSE RATIO OF FLAT SURFACE RESPONSE (If) TO CURVED SURFACE RESPONSE $\left(I_{c}\right)$ - ALUMINUM SPECIMENS

'Jltrascnic Instrument - Branson 600

Reflector - 3/64 In. Dia Flat Bottom Hole

$1 / 2$ In. Dia, $5 \mathrm{MHz}$ Aerotech $\alpha$

\begin{tabular}{|c|c|c|c|c|c|c|c|}
\hline \multicolumn{4}{|c|}{ Concave } & \multicolumn{4}{|c|}{ Convex } \\
\hline $\begin{array}{c}\text { Metal } \\
\text { Traval } \\
\text { (in.) }\end{array}$ & $\begin{array}{c}\text { Radius } \\
\text { of } \\
\text { Curvature } \\
\text { (in.) }\end{array}$ & $\begin{array}{l}I_{f} \cdot I_{c} \\
(d B)\end{array}$ & $\frac{I_{f}}{I_{c}}$ & $\begin{array}{c}\text { Metal } \\
\text { Travel } \\
\text { (in.) }\end{array}$ & $\begin{array}{c}\text { Redius of } \\
\text { Curvature } \\
\quad \text { (in.) }\end{array}$ & $\begin{array}{c}I_{f}-I_{C} \\
(\mathrm{~dB})\end{array}$ & $\frac{I_{f}}{I_{c}}$ \\
\hline \multirow{4}{*}{$1 / 2$} & 2 & -7 & 0.45 & \multirow{4}{*}{$1 / 2$} & 2 & 7 & 2.20 \\
\hline & $21 / 2$ & -5 & 0.56 & & $21 / 2$ & 5 & 1.80 \\
\hline & 3 & -4.5 & 0.60 & & 3 & 4.5 & 1.70 \\
\hline & 4 & -4 & 0.64 & & 4 & 4 & 1.60 \\
\hline \multirow{3}{*}{1} & $21 / 2$ & -2 & 0.80 & \multirow{3}{*}{1} & $21 / 2$ & 11 & 3.50 \\
\hline & 3 & -3 & 0.70 & & 3 & 9 & 2.80 \\
\hline & 4 & -3 & 0.70 & & 4 & 7.5 & 2.30 \\
\hline \multirow{3}{*}{$1 \frac{1}{2}$} & $21 / 2$ & 6 & 2.00 & \multirow{3}{*}{$1 \frac{1}{2}$} & $21 / 2$ & 9 & 2.80 \\
\hline & 3 & 6 & 2.00 & & 3 & 9.5 & 3.00 \\
\hline & 4 & -1 & 0.90 & & 4 & 7 & 2.20 \\
\hline \multirow{4}{*}{$21 / 2$} & 2 & 13.5 & 4.70 & \multirow{4}{*}{$21 / 2$} & 2 & 12 & 4.00 \\
\hline & $21 / 2$ & 9 & 2.80 & & $21 / 2$ & 11 & 3.50 \\
\hline & 3 & 9 & 2.80 & & 3 & 10 & 3.20 \\
\hline & 4 & 6 & 2.00 & & 4 & 9 & 2.80 \\
\hline \multirow{3}{*}{4} & $21 / 2$ & 10 & 3.20 & \multirow{3}{*}{4} & $21 / 2$ & 11 & 3.50 \\
\hline & 3 & 9 & 2.80 & & 3 & 9 & 2.80 \\
\hline & 4 & 10 & 3.20 & & 4 & 9 & 2.8? \\
\hline
\end{tabular}

$0+14011 / 20: 3$ 

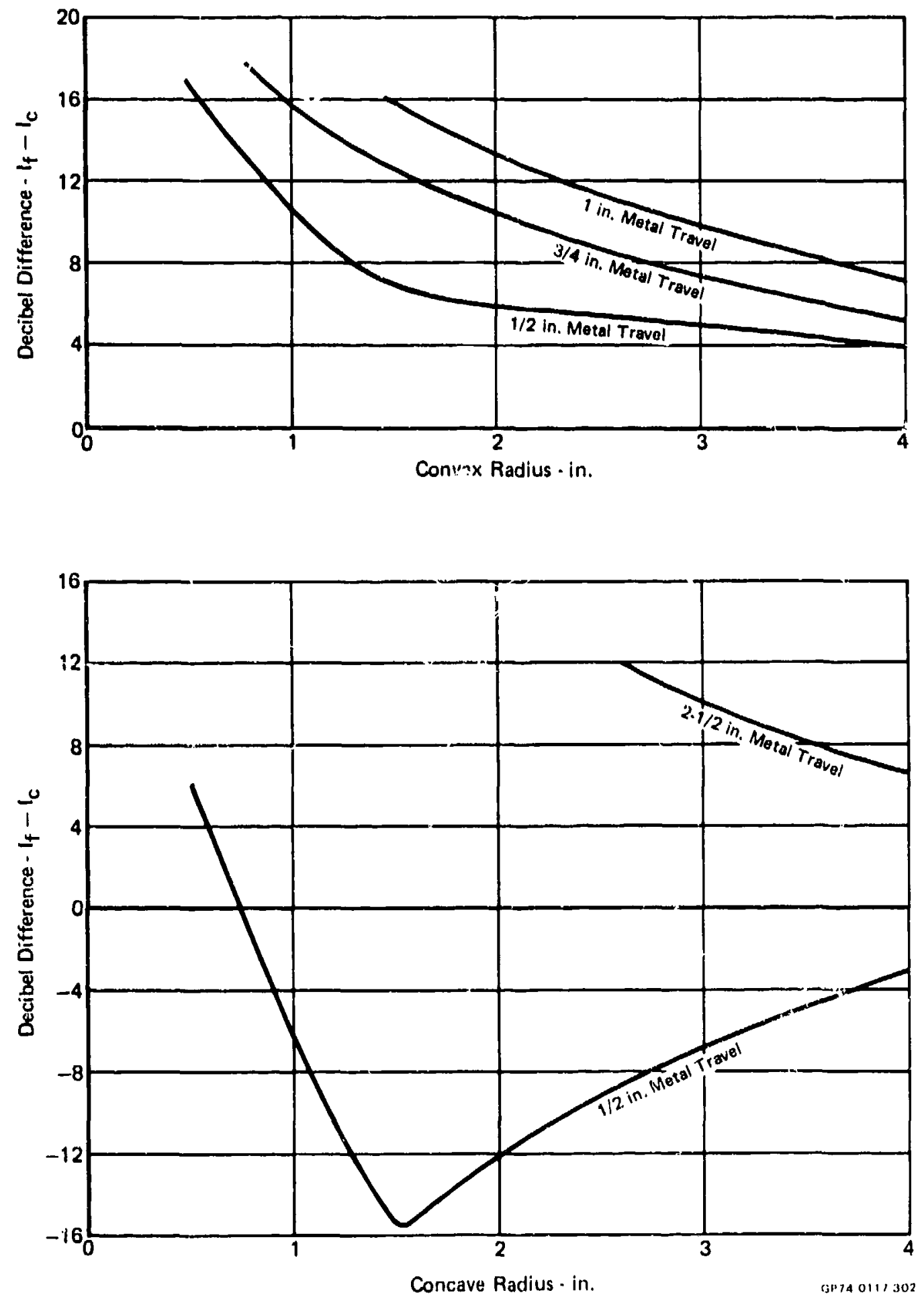

FIGURE 37

TYPICAL CURVES FOR CONTOUR SURFACE EFFECT 


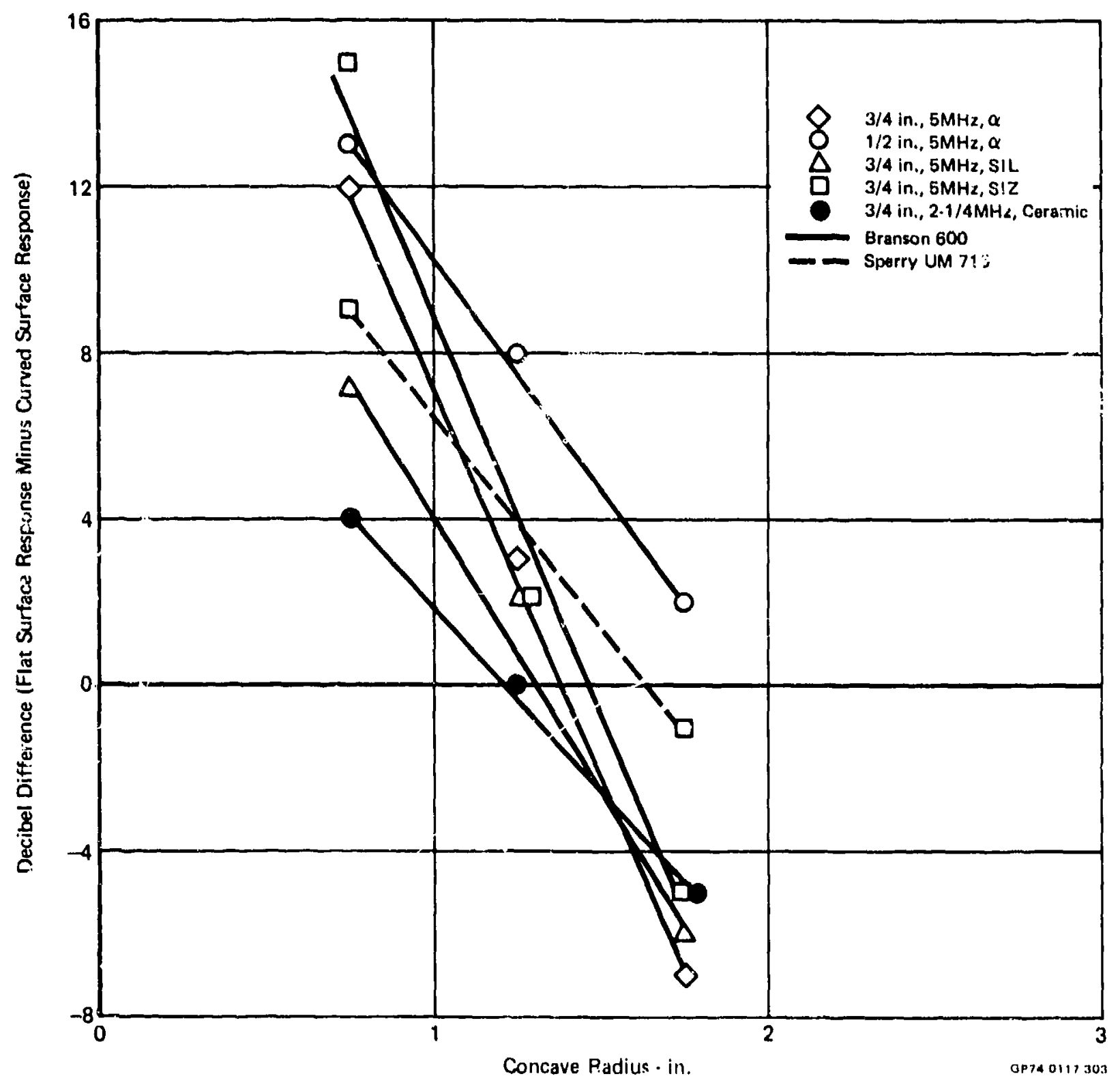

FIGURE 38

VARIATION IN dB DIFFERENCE AS A FUNCTION OF SEARCH UNIT AND ULTRASONIC INSTRUMENT (TITANIUM SPECIMENS - 3/64 IN. DIAMETER FLAT BOTTONI HOLE - 3/4 IN. METAL TRAVEL) 


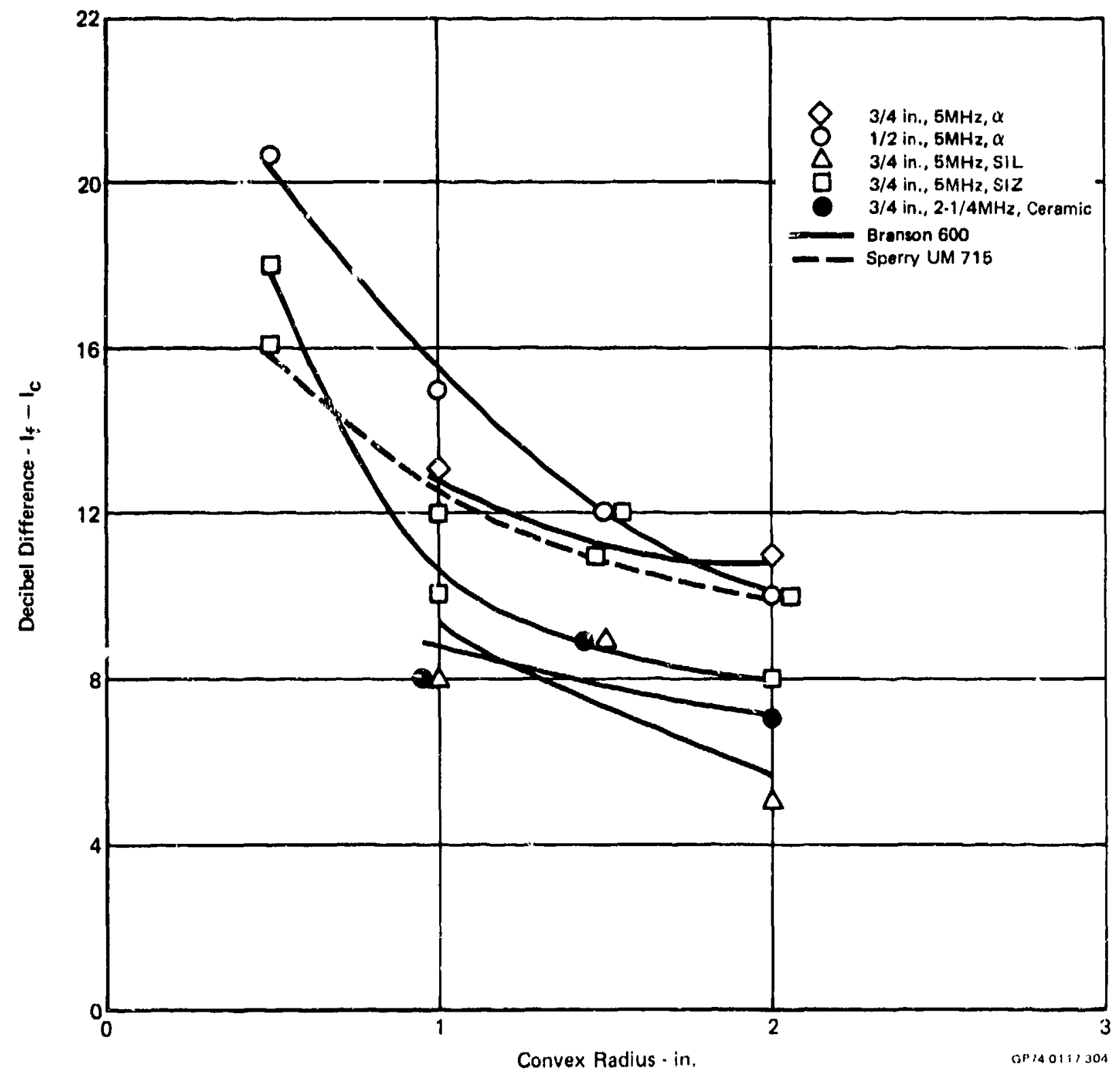

FIGURE 38 (Continued)

VARIATION IN dB DIFFERENCE AS A FUNCTION OF SEARCH UNIT AND ULTRASONIC INSTRUMENT (TITANIUM SPECIMENS - 3/64 IN. DIAMETEK FLAT BOTTOM HOLE - 3/4 IN. METAL TRAVEL) 
be seen, the variution is quite large au several of the radius values. For example, there is an $8 \mathrm{~dB}$ difference in correction between the $1 / 2$ inch diameter, $5 \mathrm{MHz}$, Alpha search unit and the $3 / 4$ inch diameter, $5 \mathrm{MHz}$, SIL search unit for a convex radius of 1 inch. The variation in slope as a function of search unit is probably due to beam spread variations. The large variation in correction values for contour surfaces as a function of search unit and ultrascnic instruments suggests that development of correction curves may be difficult. It appears that a new set of correction curves would be required for each selection of equipment. A more ressonable approach might be the direct use of curved surface reference standards during the actual ultrasonic inspection of production parts.

fis mentioned previo:isly, both aluminum and titanium convex and concave blocks were fa'uricated with a 2 inch radius of curvature and a $1 / 2$ inch metal travel. In order to study the feasibility of using aluminum contour blocks in the ultrasonic inspection of titanium, the following tests were performed. The titanium and aluminum contour blocks, along with titanium and aluminum flat surface ASTM-type reference standards, were placed in the immersion tank. All six pieces contained a $3 / 64$ inch diameter flat bottom hole at $a \perp / 2$ inch metal travel. In each of the six blocks, the hole response was adjusted to 80 percent of saturation and the $\mathrm{dB}$ setting was recorded. Ihese tests were repeated for 4 search units. In all cases, the decibel difference between the aluminum flat surface response and the aluminum curved surface response was within $2 \mathrm{~dB}$ of the decibel difference for titanium. These results indicate that the material difference (aiuminum versus titaniun) does not affect the sound beam refraction sufficiently to invalidate the use of aluminum standards when inspecting titanium providing adjustment is made for surface finish differences. Further, evidence to support this conclusion can be derived from a theoretical plot of the focal distance as a function of radius of curvature for concave surfaces in aluminum and titanium (see Figure 39). There is little difference between the focal distance for aluminum and titanium which indicates that the sound beam is affected in essentially the same way by the concave surface in both aluminum and titanium.

Typical curves fur one search unit and radii from $1 / 2$ to 4 inches are shown in Figure 40. As can be seen, the ef fect of the concave and convex surfaces are still quite evident at a radius of 4 inches. obviously, the radius of curvature at which correction is no longer necessary is greater than 4 inches.

An examination of the data can be of use in cesigning a set of contour surface reference standards for use in a production ultrasonic inspection. It aipears that it is not necessary to f'abricate a set which contains all the radji and metal travels which are to be encount. ered. For example, with a $1 / 2$, $5 \mathrm{MIz}$, Alpha search unit, there is very little variation in $\mathrm{dB}$ difference for convex radi. of $2-1 . / 2,3$, and 4 inches at a metel travel of $1 / 2$ inch. Consequently, a conve. 


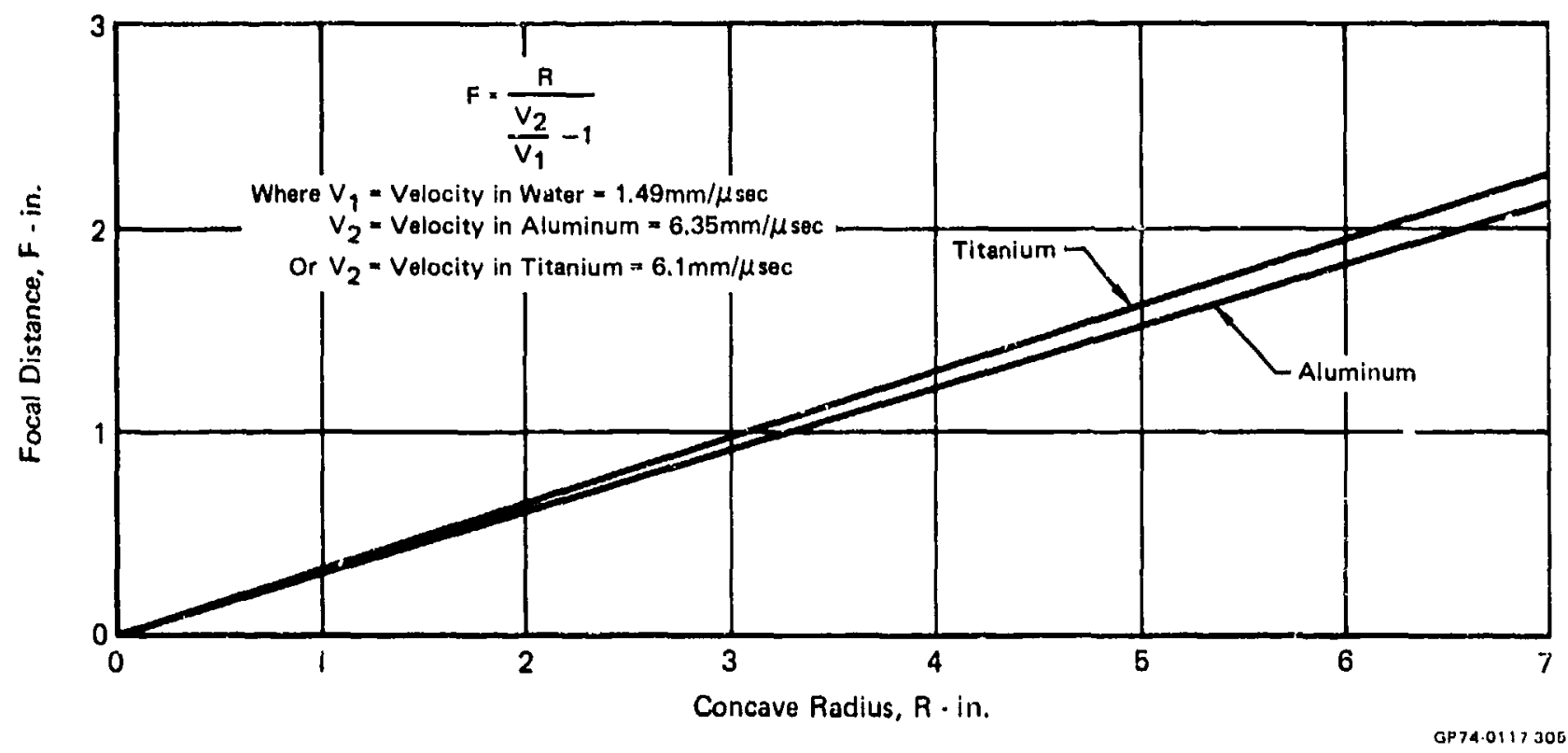

FIGURE 39

FOCAL DISTANCE VS CONCAVE RADIUS OF CURVATURE 


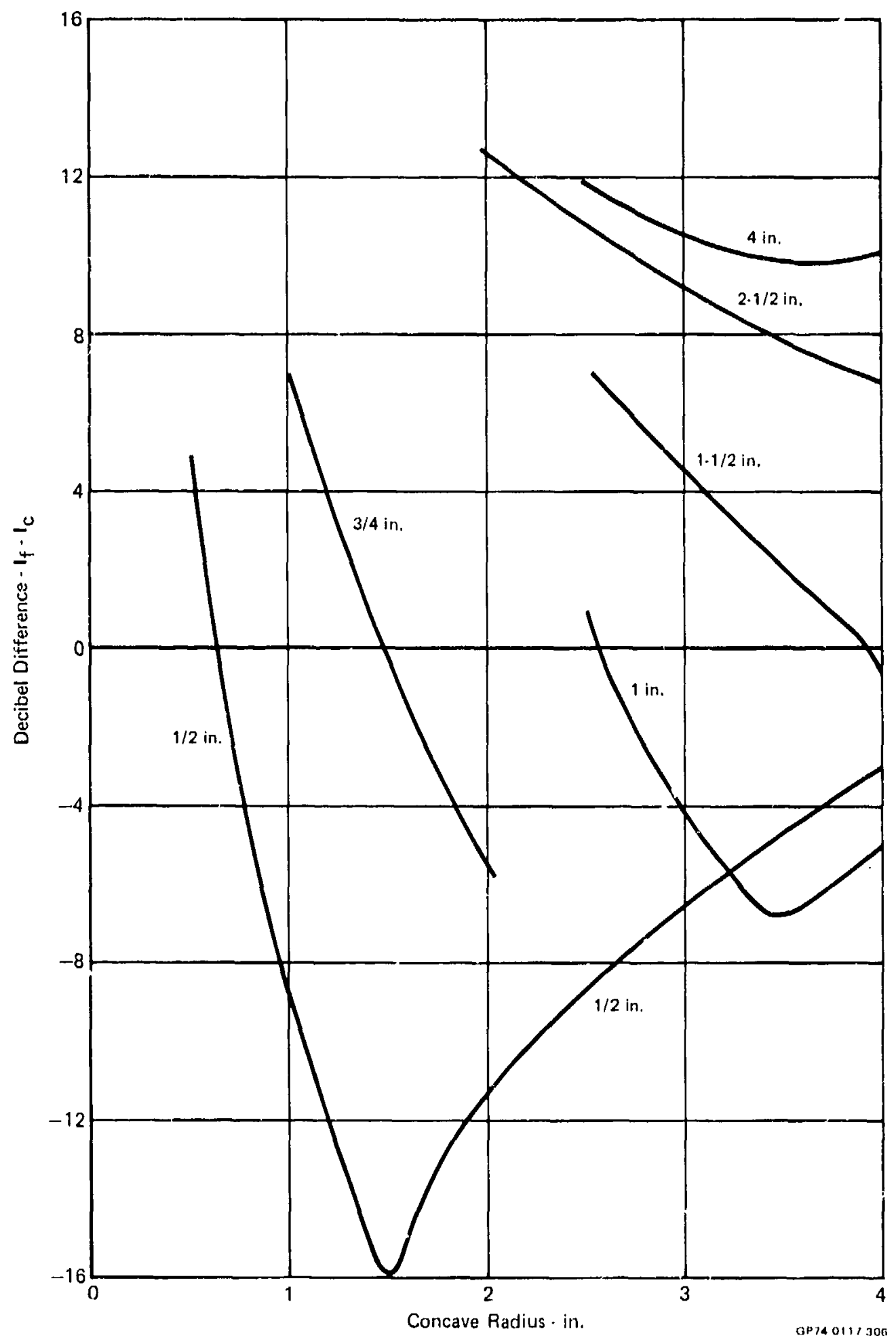

FIGURE 40

DECIBEL DIFFERENCE BETWEEN FLAT SURFACE RESPONSE AND CURVED SURFA.CE RESPONSE AS A FUNCTION OF RADIUS AND METAL TRAVEL (3/4 IN. DIAMETER, $5 \mathrm{MHz}$, SIL SEARCH UNIT) 


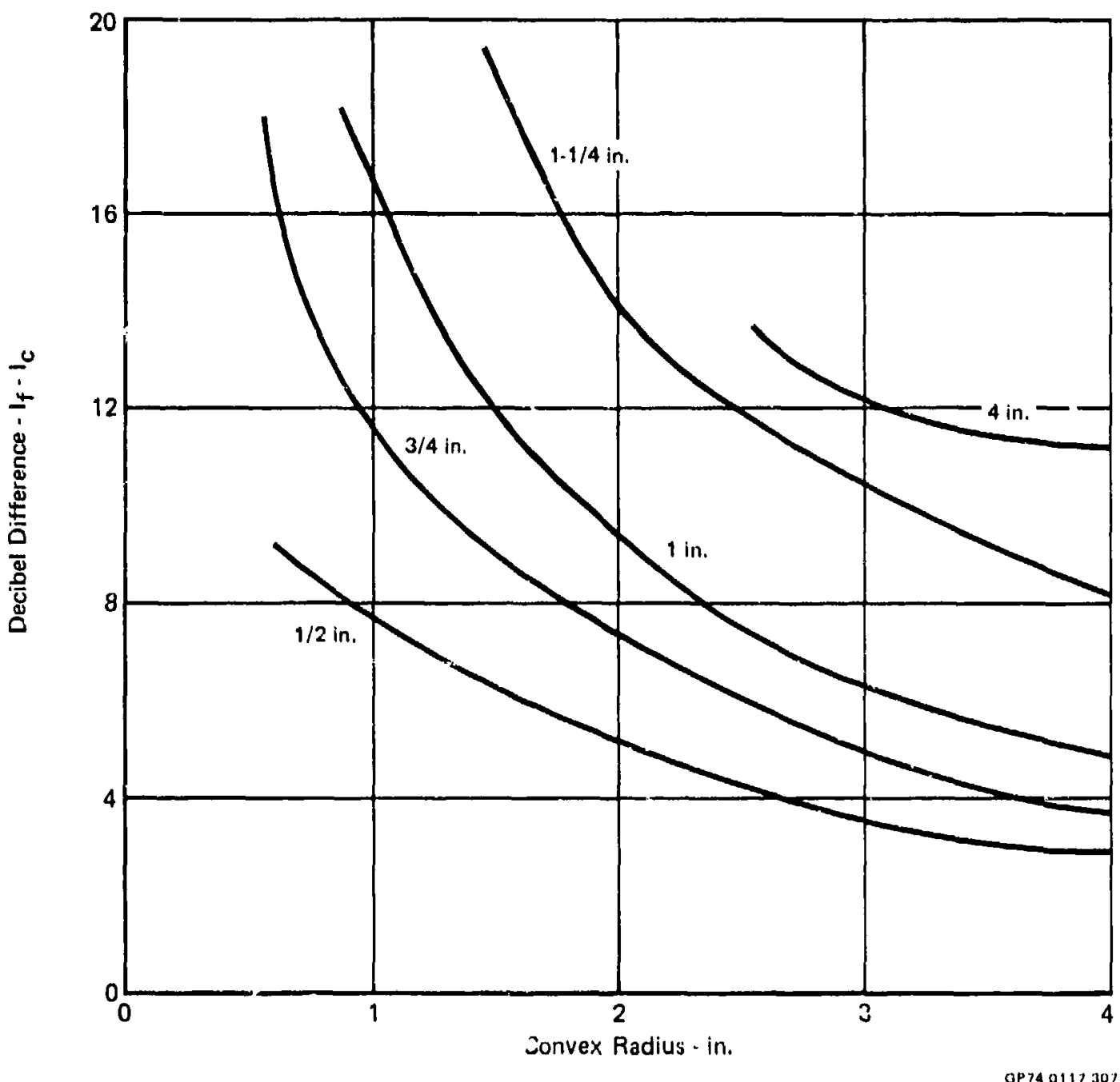

FigURE 40 (Continued)

DECIBEL DIFFERENCE BETWEEN FLAT SURFACE RESPONSE A.ND CURVED SURFACE RESPONSE AS A FUNCTION OF RADIUS AND METAL TRAVEL (3/4 IN. DIAMETER, $5 \mathrm{MHz}$, SIL SEARCH UNIT) 
entry surface reference standar 1 with a 3 inch radius and $1 / 2$ inch metal iravel could be used to inspect all radii from $2-1 / 2$ to 4 inches if a $1 / 2$ inch metal travel. Of particular interest, and concern, are those combinations of concave radii and metal travels which result in negative decibel differences. Here the differences can change very rapidly with small ariations in either radius or metal travel. Differences between search units, even of similar type, are likely to be large as well.

b. Near Suri'ace Resolution

The resolution of discontinulties near the soind entry surface is a factor that shou'd be considered during straight beam immersion ultrasonic inspertion. Resolution is sometimes difficult or impossible due to the mess ritile of the response from the water/metial interface. Variation of test parameters, such as test frequency, can result in improved near surface resolution. (A highwr frequency results in a nerrower water/metal. Interface spike on the cathode ray tube (CRT)). Other considerations, howevel, must be taken into account. For example, it may lot be possible to test through the entire thickness of the part du to increased attenuation. Also, surface finilih and mill product furm may have a significant effect on the problem

In order to gain = better understanding of the near surface resolution capabilicies of the straight beam immersion test, a program was conducted to determine the effects of product form, surface finish, and test frequency on near surface defect resolution.

\section{(1) Specimen Fabricatiun}

Ultrasonic test specimens wore fabricated from 2 und 4 inch thick as-rolled Ti-6Al-4V plate, 5 inch thick Ti-6Al-4V die forging. The forged pieces were sawcut from a production die forging (see Figure 41.). Several sections were sawcut from each as shown for the plate in Figure 42. The as-received surfaces vere kept intact and ultrasonic specimen; were fabricated according to the Figure 43 configuration. The sourd metal travel distances were as shown in Table 24. Photographs of the specimens are shown in Figure 44. After the testing was performed upon the as-received specimens, the as-received surfaces vere machined to a $125 \mathrm{rms}$ or better finish on several of the specimens. Further testing was performed to study the near surface resolution capability in final machined parts. 


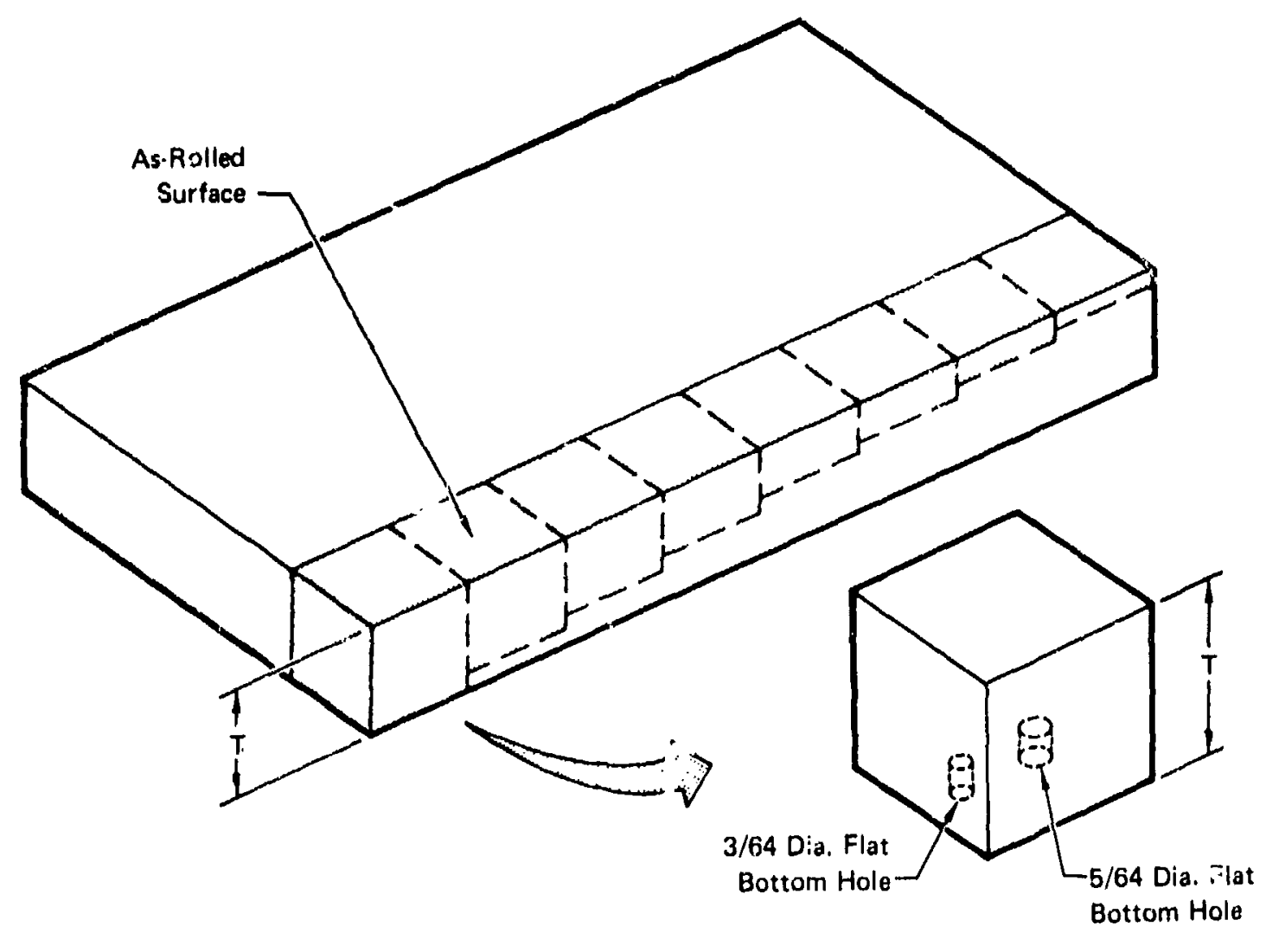

FIGURE 42

NEAR SUR FACE RESOLUTION SPECIMENS - AS-ROLLED PLATE 


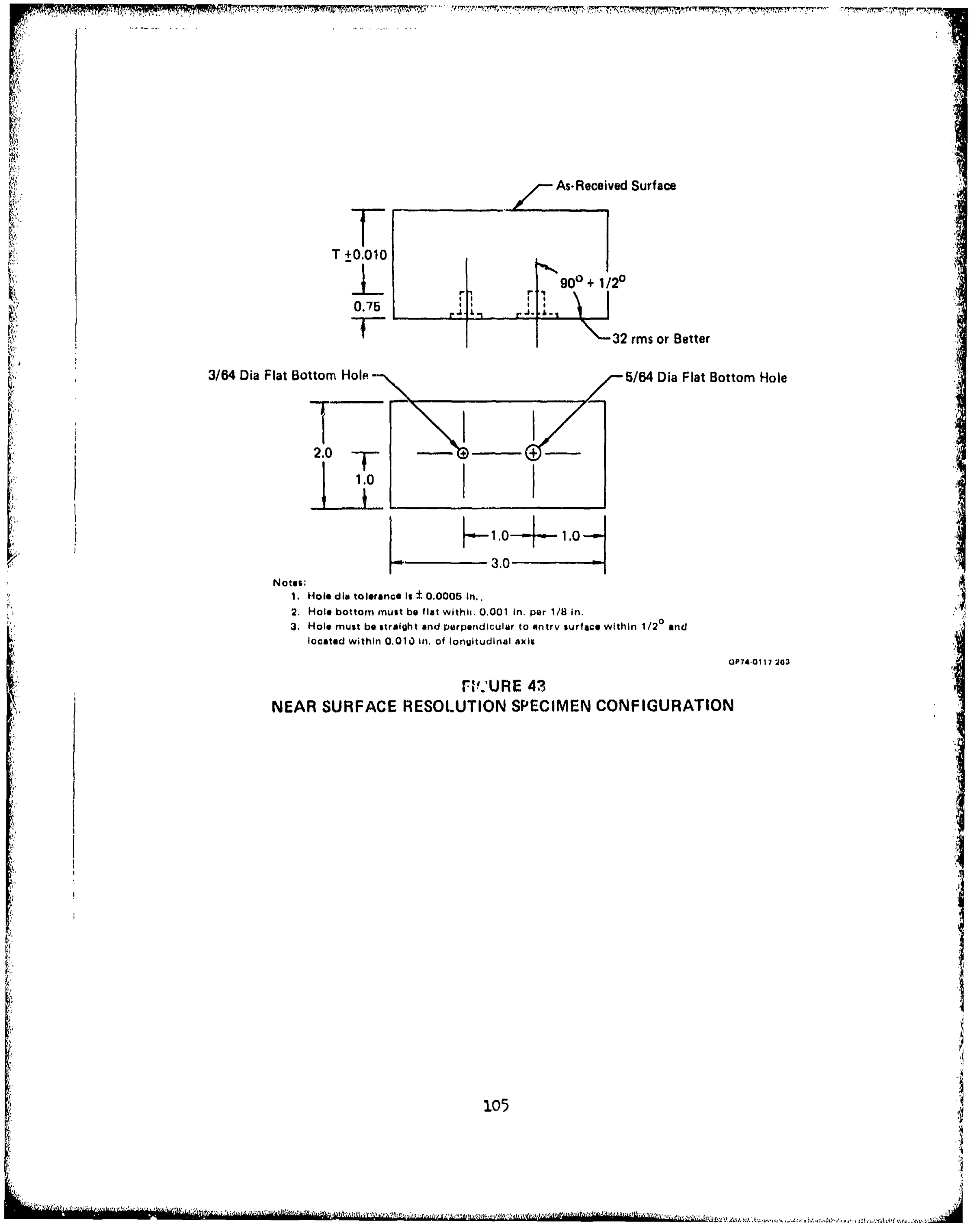


TABLE 24

METAL TRAVELS USED FOR NEAR SURFACE RESOLUTION STUDY

\begin{tabular}{|c|c|c|c|}
\hline \multirow{2}{*}{$\begin{array}{l}\text { Product } \\
\text { Form }\end{array}$} & \multirow{2}{*}{$\begin{array}{l}\text { Specimen } \\
\text { No. }\end{array}$} & \multicolumn{2}{|c|}{ Motal Travel (in.) } \\
\hline & & $\begin{array}{c}\text { As-Received } \\
\text { Surface } 11\end{array}$ & $\begin{array}{l}\text { Machineg } \\
\text { Surface } 3\end{array}$ \\
\hline \multirow{7}{*}{$\begin{array}{l}\text { As-Rolled } \\
4 \text { in. Plate }\end{array}$} & 14 & 3.3522 & 3.31 \\
\hline & $2-4$ & 2.00 & - \\
\hline & 3.4 & 1.00 & - \\
\hline & $4-4$ & 0.60 & - \\
\hline & $5-4$ & 0.40 & 0.37 \\
\hline & $6 \cdot 4$ & 0.25 & 0.17 \\
\hline & 7.4 & 0.125 & 0.08 \\
\hline \multirow{6}{*}{$\begin{array}{l}\text { As. Rolled } \\
2 \text { in. Plate }\end{array}$} & 1.2 & $1.25 \Omega$ & 1.19 \\
\hline & $2 \cdot 2$ & 1.00 & - \\
\hline & 3.2 & 0.50 & 0.49 \\
\hline & $4 \cdot 2$ & 0.40 & 0.38 \\
\hline & $5 \cdot 2$ & 0.25 & 0.20 \\
\hline & $6-2$ & 0.125 & 0.11 \\
\hline \multirow{7}{*}{$\begin{array}{l}\text { As.Forged } \\
\text { Die } \\
\text { Forged }\end{array}$} & $F .3 .5$ & $4.35 \Omega$ & 4.27 \\
\hline & $21 / 2 \cdot F \cdot 3 \cdot 5$ & 2.50 & - \\
\hline & $08 \cdot F \cdot 3 \cdot 5$ & 0.80 & 0.41 \\
\hline & $06 \cdot F \cdot 3 \cdot 5$ & 0.60 & 0.21 \\
\hline & $04 \cdot F \cdot 3 \cdot 5$ & 0.40 & 0.15 \\
\hline & $02 \cdot F \cdot 3 \cdot 5$ & 0.20 & - \\
\hline & $0125 \cdot F \cdot 3 \cdot 5$ & 0.125 & 0.10 \\
\hline
\end{tabular}

A Dimensions are approximate.

2 Both the sound entry surface and the surface opposten are in the at-reculvad condlton.

$(3 P)+(1) 111113$ (3) Both surfacias were machilneds. 


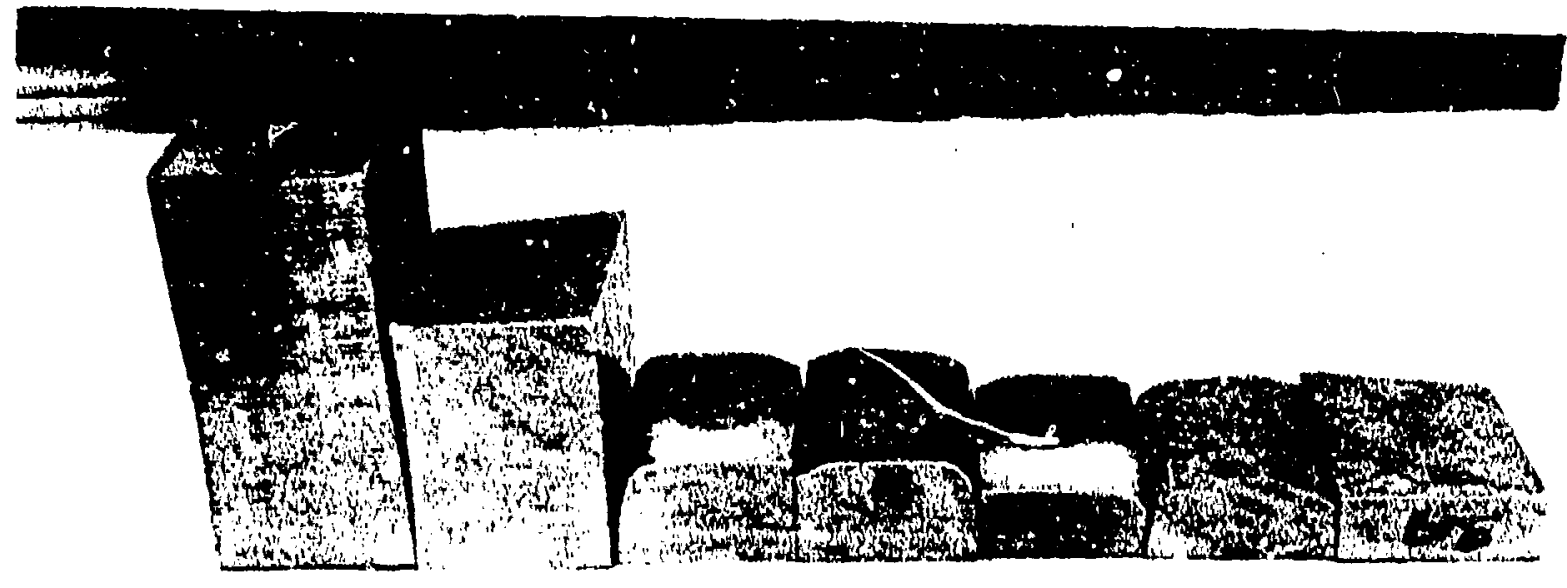

Die Forging
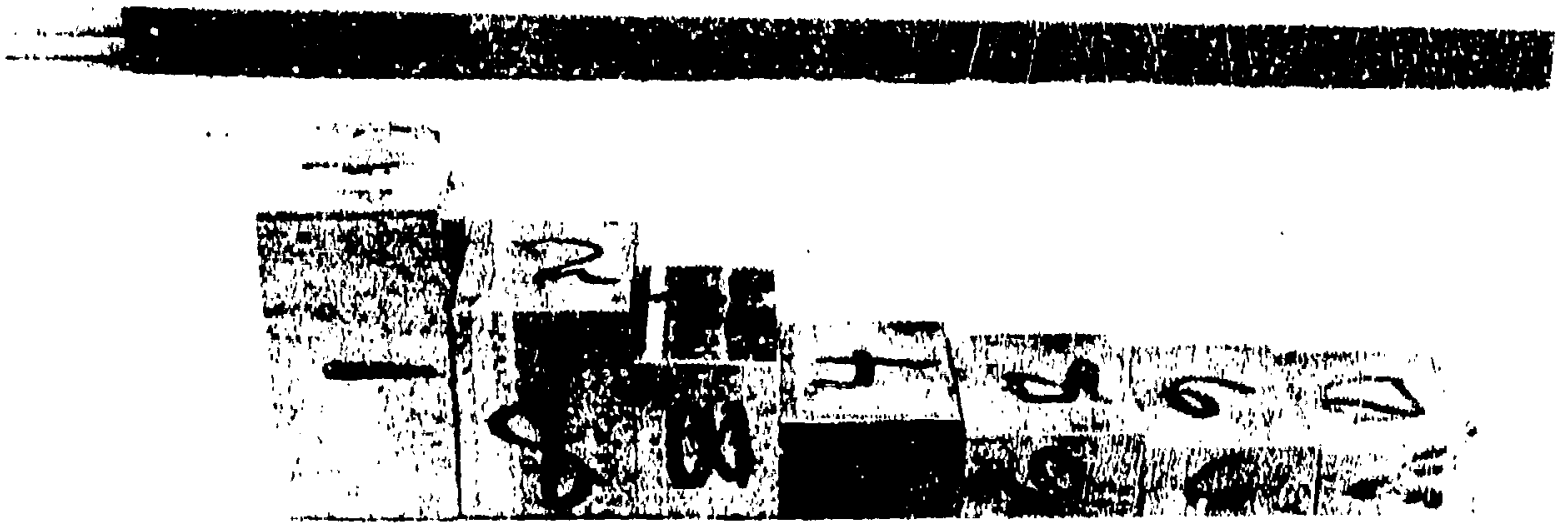

4 Inch Plato

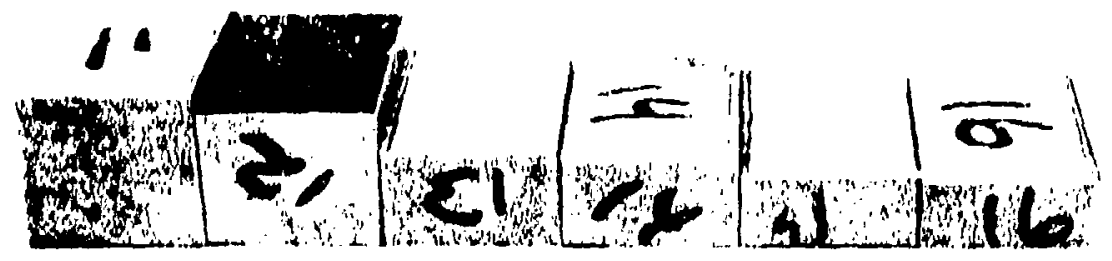

2 Inch Plate

FIGURE 44

NEAR SURFACE RESOLUTION SPECIMENS 


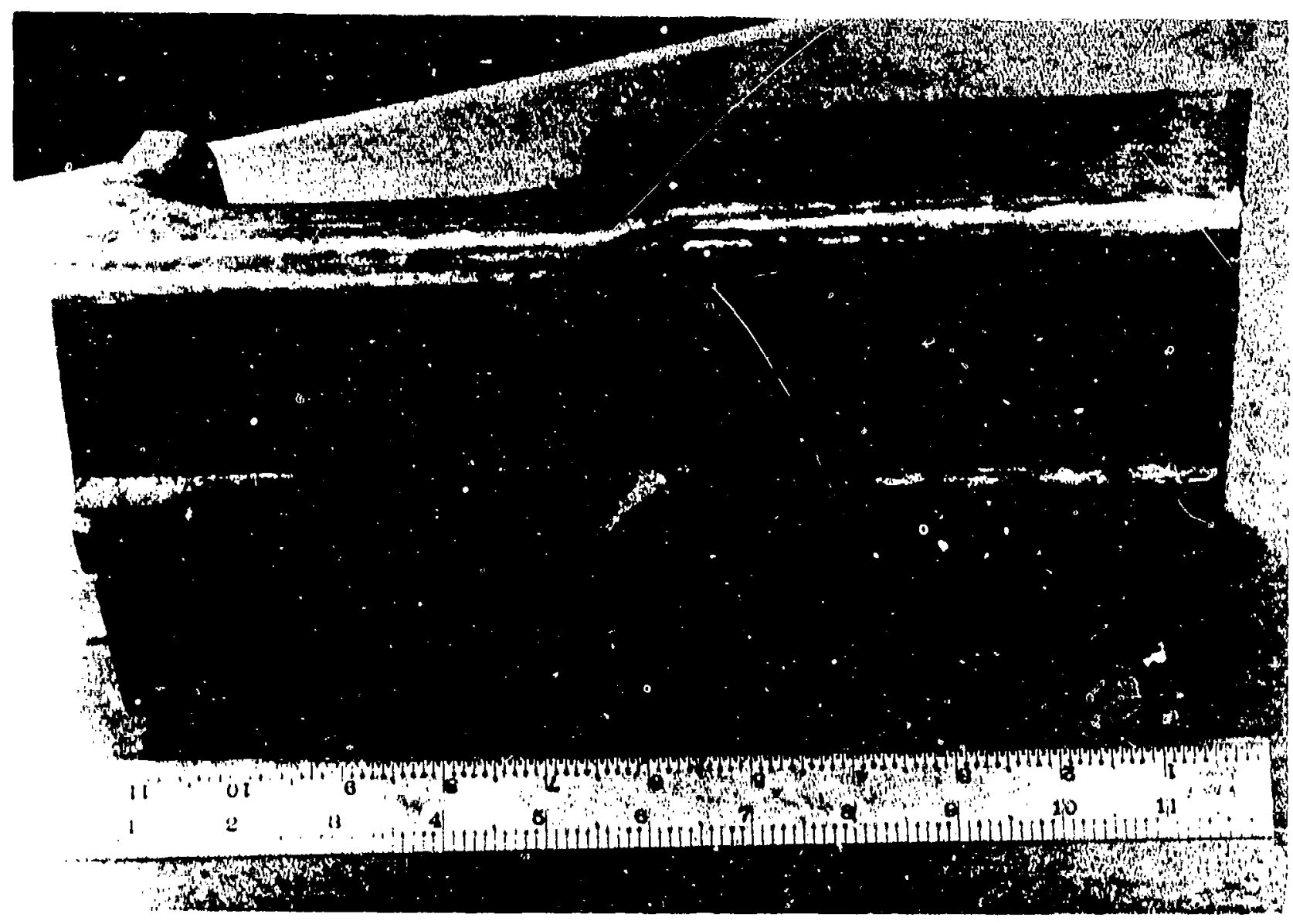

FIGURE 41

DIE FORGING USED FOR NEAR SURFACE RESOI.UTION STUDY

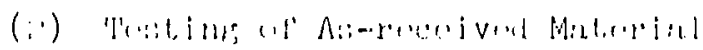

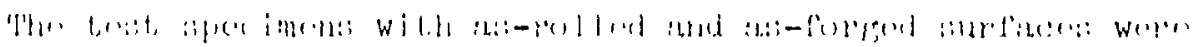

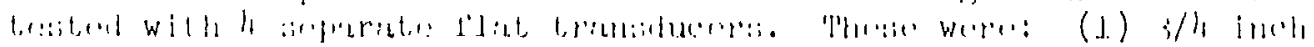

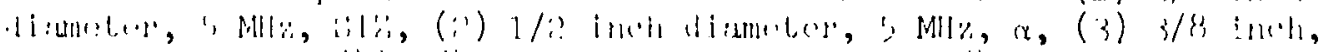

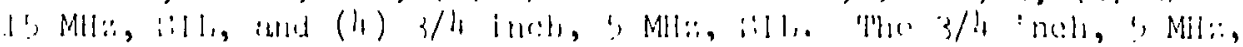

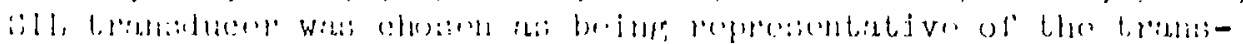

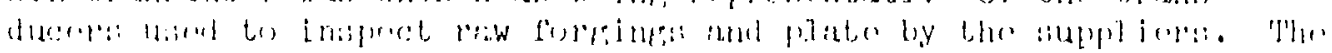

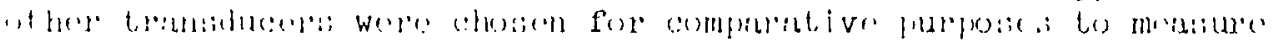

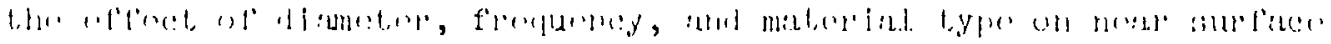

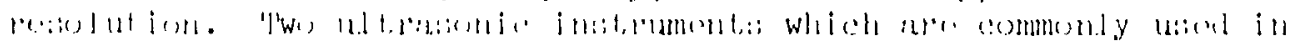

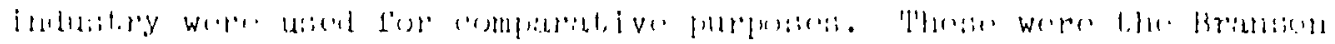

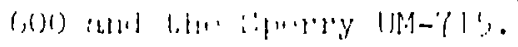


Prior to any testing, the vertical and horizontal linearity of the systems were determined according to ASTM E31.7-68. The upper linearity limit was greater than 95 percent of the vertical limit, the lower linearity limit was less than 10 percent of the vertical limit, and the horizontal linearity ranie wos: greater than 85 percent of the horizontal limit as bes's in measuldi with the ASTM E317-68 method. The search unit is "ile data, obtained upon purchase of the search unite, were examined to confirm that the peak radiated frequency was withir \pm 1.0 percent of the specifird frequency.

The testinf performed on tho specimens from the 4 inch thick plate was typical of the testing pertormed on the other pieces. Initially, all seven of the 4 inch plate test specimens wero placed into the liumersion tank. The search unit was adjusted to the chocen water path and angulated to maximize the response from the $3 / 64$ inch diameter flat bottom hole. A 3 inch water path was used for the majority of the tevting since this is commonly used in industry. A 9 inch water puth was also investigated in order to see if the near surface resolution could be improved by testing the holes outside the near field of the sound beam. Ihe testing was performed using the distance - amplitude correction (DAC) curve method which is often used in the ultrasonte inspection of airframe components. 'The test specimein in the set of seven which exhibited the maximun response wa:3 solected. 'jhe response from that hole was adjusted to $80 \%$ of saturation. "inen, without changing the gain, the search unit was moved to ench of the other specimens and the noav surface rosolution was determined by noting the minimun distance betweon tho sound ontry surface and the flat bottom hole that produend a first-echo indication whose leading edge mot the horizontal swoop lino. 'lho amplitude of the response at each metal travel. was also recorded. It Is recognized that, in actual pratice, that firto ocho findications can sometimes be resolved oven if thoy do not meet the horimontul. sweep Iine. However, in order to perform a reproducible test, the designated convention was chosen.

The testing was then repeated using a $5 / 64$ inch diameter flat bottom hole in each specimen.

The rear surfuce resolution capability us a function of product form, instrument, and s'areh unit, is summrimed in l'ables 25 and 26. For these test purposos, the nour surface restolution must be exprossed as a range sinco tho motal travols invostigated were varied in only a few increments. For exumple, i near surfaco

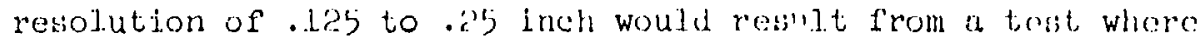
the flat bottom hole was rosolvable at ..? inch but not at . 1.is inch.

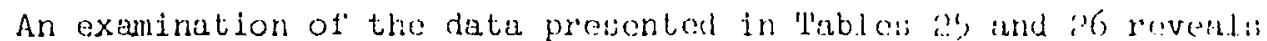
soveral important points. In several oases, the noar surficen rosolution was improved by lengthenling the water peth from 3 inches to

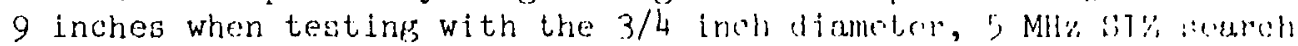
unit. 'the hole was located in the lat fleded of the sound berm with a 9 inch whter path, and, presumably, this improved the near aur-

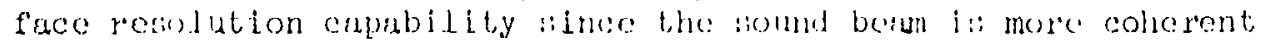
and interference-frees in the far lowd. 
TABLE 25

NEAR SURFACE RESOLUTION OF AS-RECEIVED SPECIMENS (3/64 INCH DIA FLAT BOTTOM HOLE RESPONSE)

\begin{tabular}{|c|c|c|c|c|c|}
\hline \multirow[b]{2}{*}{ Product Form } & \multicolumn{4}{|c|}{ Branson 600} & SperTy UM-715 \\
\hline & $\begin{array}{l}3 / 4 \text { in., } 5 \text { MHz, } \\
\text { sI z, (3 in. } \\
\text { Woter Path) }\end{array}$ & $\begin{array}{l}3 / 4 \ln ., 5 \mathrm{MHz} \\
\text { SIZ, }(9 \mathrm{in.} \\
\text { Water Path })\end{array}$ & $\begin{array}{c}1 / 2 \text { in., } 10 \mathrm{MHz}, \\
\text { siz, ( }(9 \mathrm{in.} \\
\text { Wotor Path) }\end{array}$ & $\begin{array}{l}3 / 8 \text { in., } 15 \text { MHz } \\
\text { Sil, (3 in. } \\
\text { Water Path) }\end{array}$ & $\begin{array}{l}3 / 4 \text { in., } 5 \mathrm{MHz} \\
\text { SIL, ( } 3 \text { in. } \\
\text { Water Path) }\end{array}$ \\
\hline 4 in. Plate & 0.25 to 0.40 & 0.125 to 0.25 & $\begin{array}{c}0.125 \text { to } 0.25 \\
\text { 仓 }\end{array}$ & 0.125 tu 0.25 & 0.25 to 0.40 \\
\hline 2 in. Plate & 0.25 to 0.40 & 0.25 to 0.40 & 0.125 to 0.25 & 0.125 to 0.25 & 0.25 to 0.40 \\
\hline Die Forging & $\begin{array}{c}0.20 \text { to } 0.40 \\
1\end{array}$ & $\begin{array}{c}0.2 .0 \text { to } 0.40 \\
\text { A }\end{array}$ & $\begin{array}{c}0.125 \text { to } 0.20 \\
\text { CS }\end{array}$ & $\begin{array}{l}\text { Less than } \\
0.125 \triangle\end{array}$ & $\begin{array}{c}0.20 \text { to } 0.40 \\
\text { (1) }\end{array}$ \\
\hline
\end{tabular}

A Rusponse iromi laruest metal travel was lese than $10 \%$ of eaturution

TABLE 26

NEAR SURFACE RESOLUTION OF AS-RECEIVED SPECIMENS (5/64 INCH DIA FLAT BOTTOM HOLE RESPONSE)

\begin{tabular}{|c|c|c|c|c|c|}
\hline \multirow[b]{2}{*}{ Product Form } & \multicolumn{4}{|c|}{ Branson 600} & \multirow{2}{*}{$\begin{array}{c}\text { Sperry UM.715 } \\
3 / 4 \text { in, } 5 \text { MHz } \\
\text { SIL, ( } 3 \text { in. } \\
\text { Water Poth) }\end{array}$} \\
\hline & $\begin{array}{l}3 / 4 \text { in., } 5 \text { MHz, } \\
\text { S1Z, (3 in. } \\
\text { Whter Path) }\end{array}$ & $\begin{array}{l}3 / 4 \text { in., } 5 \mathrm{MHz}, \\
\text { SIZ, (9 in. } \\
\text { Whtor Path) }\end{array}$ & $\begin{array}{l}1 / 2 \text { in., } 10 \mathrm{MHz}, \\
\text { SIZ, (9 in. } \\
\text { Woter Path) }\end{array}$ & $\begin{array}{l}3 / 8 \text { in. } 16 \mathrm{MHz} \\
\text { SIL (3 in. } \\
\text { Water Path) }\end{array}$ & \\
\hline 4 in. Plate & 0.25 to 0.40 & $\begin{array}{c}0.125 \text { to } 0.25 \\
\text { 1 }\end{array}$ & $\begin{array}{c}0.125 \text { to } 0.25 \\
\text { (1) }\end{array}$ & $\begin{array}{l}\text { Less than } \\
0.125 \text { 1 }\end{array}$ & 0.125 to 0.25 \\
\hline 2 in. Plate & 0.2 .5 to $2 . \wedge 0$ & 0.125 to 0.25 & 0.125 to 0.25 & $\begin{array}{c}\text { Less than } \\
0.125\end{array}$ & 0.125 to 0.25 \\
\hline Die Forging & 0.20 to 0.40 & 0.20 to 0.40 & $\begin{array}{c}0.125 \text { to } 0.20 \\
\Delta S\end{array}$ & $\begin{array}{l}\text { Less than } \\
0.125 \not 1\end{array}$ & 0.20 to 0.40 \\
\hline
\end{tabular}

Pexponse from largast metal travel was lass thun $10 \%$ nit sisturation 



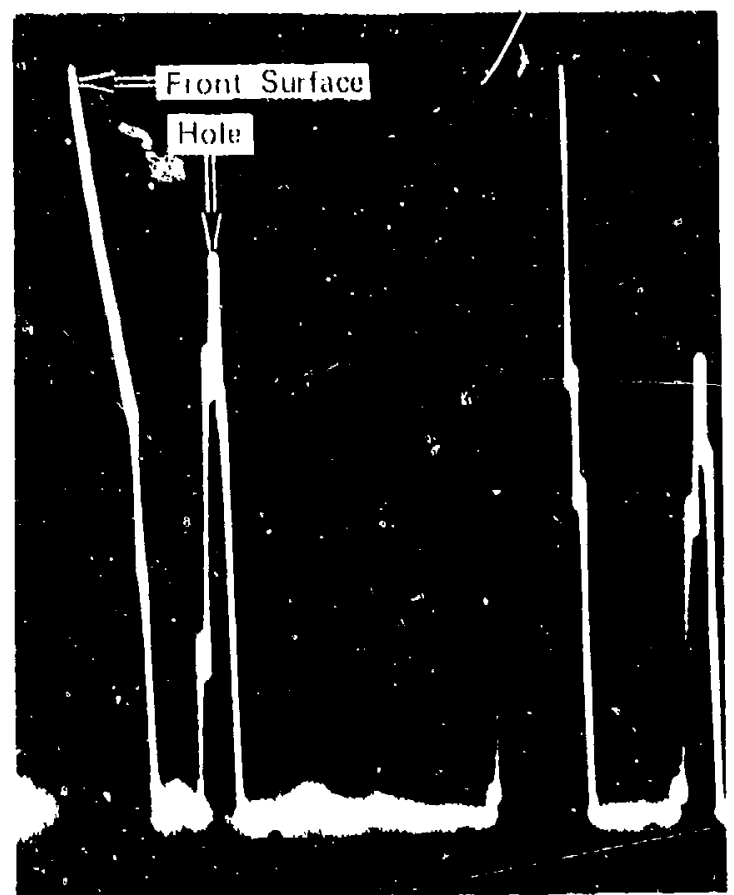

Metal Travel $=0.40 \mathrm{in}$. Hole is Resolved

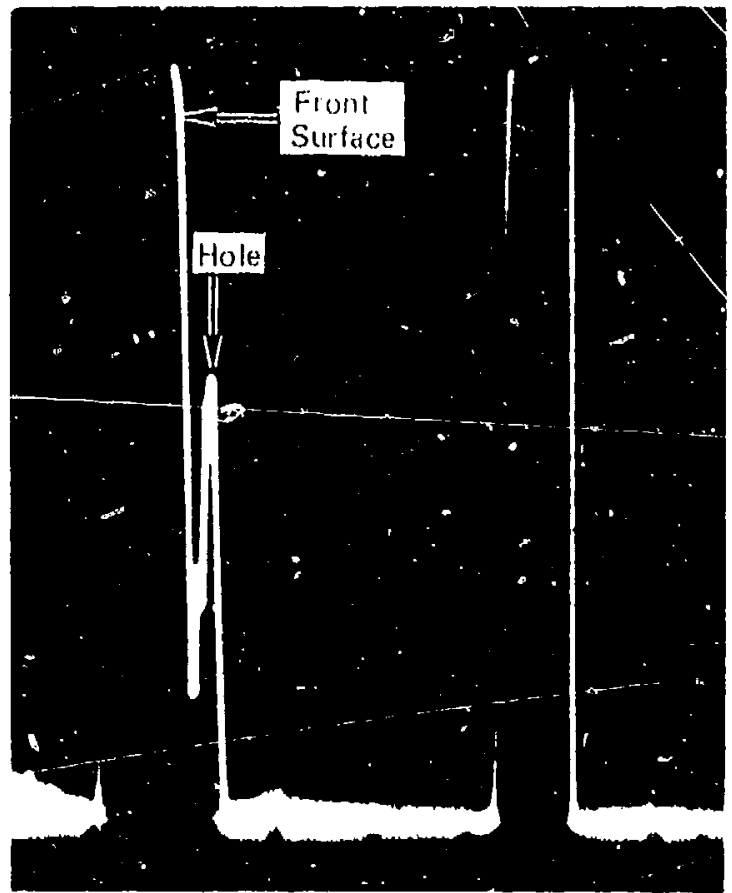

Metal Travel $=0.25 \mathrm{in}$. Hole is not Resolved

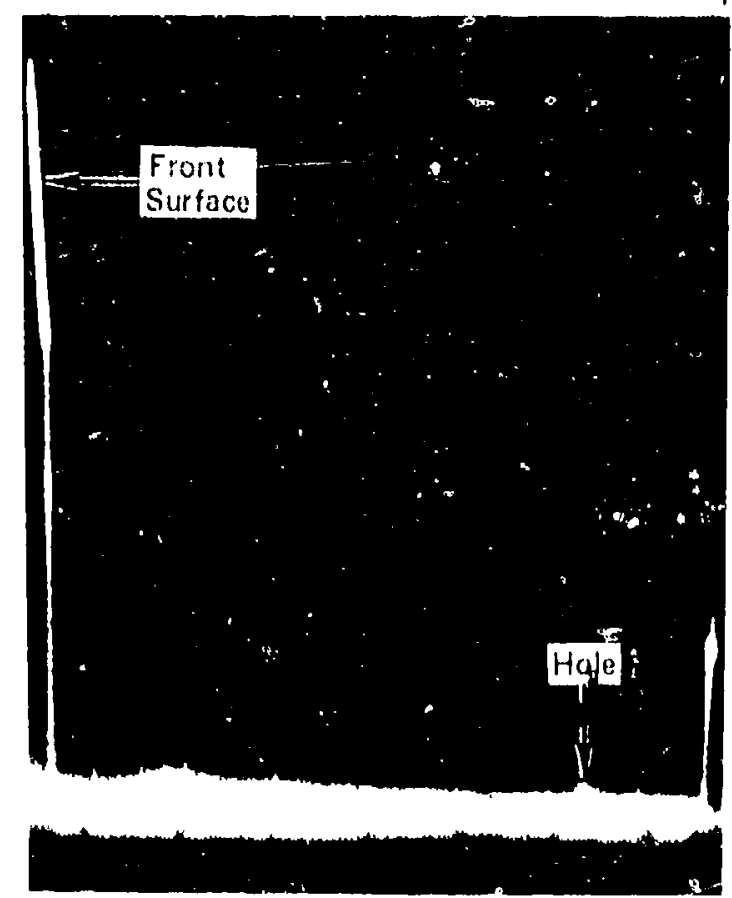

Metal Travel $=3.35 \mathrm{in}$.

Hole Response is Less than $10 \%$ : saturation

FIGURE 45

RESPONSES FROM 3/64 INCH DIA FLAT BOTTOM HOLE IN 4 INCH PLATE AS.ROLLED (3/4 INCH DIA, 5MHz, 512 TRANSUDCER WITH 9 INCH WATER PATH) 
The near surface resclution capability as a function of product form, instrument, and search uni is summarized in Tables 27 and 28.

An examination of the data, indjcates that the near surface resolution was again improved by inareasing the test frequency. For example, with Test $A$, the near surface rescilution in 4 inch plate was .17 to .37 inches with the $3 / 4$ inch, $5 \mathrm{MHz}$, SIZ search unit but was .08 to .17 inches with the $3 / 8$ inch, $15 \mathrm{MHz}$, SIL.

As in the case of the as-received material tests, there were several instances where, during Tests 3 , the hole response at the largest, metal travel was less than 10 percent of saturation. Hence, it would not be possible to inspect through the total thickness of the 4 inch plate and 5 inch die forging unde. those conditions. It should be ncted that by choosing the lower frequency $(3 / 4$ inch, $5 \mathrm{MHz}$, SIZ) it was possible to test through the tutal thickness of the materiat at the experise of reducing the near surface resolution capability.

It is interssting to compare the results from the two test methods. Obviously, using Test Method $A$, where the minimum reponse is adjusted to 80 percent of saturation, there is no difficulty in testing through the total thickness as was the case several times when testing with 'Test Method B. It might be thought that the near surface resolution would be less with Test Method A since the higher scan gain required, compared with Test Method B, would tend to broaden the water/metal interface response. It was found that in most cases, however, that the near surface resolution capability of Test Method A was not less than that of Test Method B. Only in one case, in fact, was it less; that being for the $3 / 8$ inch, $15 \mathrm{MHz}$, SIL search unit. It would seem from these results, that, if it were imperative to inspect material from one side only, it could bo done so using Test Method A without any effect upon the near surface resolution capability. However, the increased ultrasonic noise level may at least partially offset the gains obtained by inspecting at higher sensitivity.

A. comparison of the near surl'ace resolution data for the asreceived material and the michined material was made. In a few cases, the near surface resclution was improved after machining. For exanple, for a 3/4 inch: $5 \mathrm{MHz}$, SIZ search unit the $3 / 64$ inch digmeter hole in the die forging was resolved at a metal travel of .20 inch after machining, whereas it was not resolved when the sound entry surface was in the as-forged condition. Improvement was made due to machining in the rollowing cases:

(a) die forging - $3 / 4$ inch, $5 \mathrm{MHz}$, SIZ with Branson 600

(b) die forging - 3/4 inch, $5 \mathrm{MHz}$, SIL with Sperry IMM -115 
TABLE 27

NEAR SURFACE RESOLUTION OF MACHINED SPECIMENS

(3/64 In. Dia meter Flat Bottom Hole Response)

\begin{tabular}{|c|c|c|c|c|}
\hline \multirow{3}{*}{ Product Form } & \multicolumn{4}{|c|}{$\widehat{\Lambda} T \operatorname{sest} A$} \\
\hline & \multicolumn{3}{|c|}{ Branson 600} & \multirow{2}{*}{$\frac{\text { Sperry UM.715 }}{\begin{array}{c}3 / 4 \text { in., } \\
\text { Sil }\end{array}}$} \\
\hline & $\begin{array}{c}3 / 4 \text { in., } 5 \mathrm{MHz} \\
\text { siz }\end{array}$ & $\begin{array}{c}1 / 2 \text { in., } 5 \mathrm{MHz} \\
\alpha\end{array}$ & $\begin{array}{c}3 / 8 \text { in., } 15 \mathrm{MHz} \\
\text { Sli }\end{array}$ & \\
\hline 4 in. Plate & 0.17100 .37 & 0.08 to 0.17 & 0.08 to 0.17 & 0.17 io 0.37 \\
\hline 2 in. Plate & 0.10100 .20 & 0.10 to 0.20 & 0.10 to 0.20 & 0.20 to 0.38 \\
\hline Die Forging & 0.15 to 0.21 & 0.15 to 0.21 & 0.10 to 0.15 & 0.15 to 0.21 \\
\hline
\end{tabular}

\begin{tabular}{|c|c|c|c|c|}
\hline \multirow{3}{*}{ Product Form } & \multicolumn{4}{|c|}{ 2. Test B } \\
\hline & \multicolumn{3}{|c|}{ Branson 600} & \multirow{2}{*}{$\frac{\text { Sperry UM.715 }}{\begin{array}{c}3 / 4 \text { inn. }_{\text {SiL. }} \\
\text { MHz }\end{array}}$} \\
\hline & $\begin{array}{c}3 / 4 \text { in., } 5 \mathrm{MHz} \\
\text { siz }\end{array}$ & $\underset{\alpha}{1 / 2 \text { in., } 5 \mathrm{MHz}}$ & $\begin{array}{c}3 / 8 \text { in, }_{\text {SIL }} 15 \mathrm{MHz} \\
\text { SiL }\end{array}$ & \\
\hline 4 in, Plate & 0.17 to 0.37 & $\begin{array}{c}0.08 \text { to } 0.17 \\
\angle 3\end{array}$ & $\begin{array}{c}0.08 \text { to } 0.17 \\
\text { 3 }\end{array}$ & 0.17 to 0.37 \\
\hline 2 in. Plate & 0.10 to 0.20 & 0.10 to 0.20 & 0.10 to 0.20 & 0.20 to $0.3 \mathrm{C}$ \\
\hline Die Forging & 0.15 io 0.21 & $\begin{array}{c}0.15 \text { co } 0.21 \\
3\end{array}$ & $\begin{array}{c}0.15 \text { to } 0.21 \\
3\end{array}$ & 0.15 to 0.21 \\
\hline
\end{tabular}

1. Test A was performed by setting the inlnimum response to $80 \%$ of saturation.

2 Test 8 was performed by adjusting the maximum response to $80 \%$ of saturation.

Resporse from largest metal travel was less than $10 \%$ of saturation. 

In each case the near surface resolution went from .20-.40 inch to $.15-.21$ inch.

Upon completion of the near surface resolution study, the machined specimens were used to investigate scan index. Durirg an ultrasonic inspection of production parts, one of the parameters which must be selected i:s the scan index. It is important that the scan index be small erough to ensure 100 percent inspection of the parts. During a typical ultrasonic inspection all discontinuities whose amplitude exceeded 50 percent of the distance-amplitide curve would be marked for further evaluation since the response may not be maximlzed on the discontinuity. The final evaluation would be made by positioning the search unit, for maximum response from the discontinuity and, if the response exceeded the distance - amplitude curve, the discontinuity wuild be considered rejectable. On this basis of testing, then, it is important to choose a scan index thr ugh which no less than $50 \%$ of the reference standard response is obtained.

Several tests wele performed to determine the maximum scan index for the test specimens on hand. Initially, the search unit was positioned to maximize the response from the flat bottom hole with a 3 inch water path and then moved of $f$ centerline until response dropped to 50 percent of its initial anplitude. This, then, was considered ore-half the maximum scan index. The results of tho testing are shown in Table 29. In general, the maximum scan index increases with search unit diameter and with the reference reflector size.

c. Sound Transmission Characteristins

In many ultrasonic inspection situations, there exists a significant difference in sound transinission chtracteristics betwe the reference standard and the part to be inspected. In addition to attentuation differences, such things as surfare finish variations, grain flow direction, and metallureical variations can contribute to the difference. If corrections are not made for the differences, it is possible that rejectable defects car be accepted because thej can appear smallor than they actually are based on their ultrasonic response.

A test program was conducted to quantitatively deternine the magnitude of sound transmission differences for rolled plate and die forging material. The test specimens were those f'abricated for the near surface resolution study described previously (see ligure 43 and Table 24 ). In addition to these specimens, a set of ASTM-type Ti-6A1-l,V reference standards containing $3 / 64$ inch diameter f'lat bottom holes were used to rcpresent typical straight beam immersion reference standards (see Fiprure 35 ).

Initially, a distance-amplitude correction ,DAC) curve was constructed using the ASIM-type reference standards with $3 / 64$ inch diameter filat bottom hole: and with netal. travels varying from $1 / 2$ to $5-1 / 2$ inches. The AsI'M-type standards were placed in the water, the scarch unit was 
TABLE 29

MAXIMUM SCAN INDEX FOR MACHINED SOUND ENTRY SURFACE

(Metal Travels are Indicated in Parenthesis';

\begin{tabular}{|c|c|c|c|c|c|c|}
\hline \multirow{2}{*}{ Search Unit } & \multicolumn{2}{|c|}{ A in. Plato } & \multicolumn{2}{|c|}{2 in. Plate } & \multicolumn{2}{|c|}{ Die Forging } \\
\hline & $\begin{array}{c}3 / 64 \text { in. } \\
\text { Hole }\end{array}$ & $\begin{array}{c}5 / 64 \text { in. } \\
\text { Hole }\end{array}$ & $\begin{array}{c}3 / 64 \text { in. } \\
\text { Hole }\end{array}$ & $\begin{array}{c}5 / 64 \text { in. } \\
\text { Hole }\end{array}$ & $\begin{array}{c}3 / 64 \text { in. } \\
\text { Hole }\end{array}$ & $\begin{array}{c}5 / 64 \text { in. } \\
\text { Hole }\end{array}$ \\
\hline $\begin{array}{l}3 / 8 \mathrm{in} . \mathrm{Dia} \\
15 \mathrm{MHz}, \mathrm{SIL} \\
\text { (S/N 17205) }\end{array}$ & $\begin{array}{l}0.060 \\
(0.17)\end{array}$ & $\begin{array}{c}0.20 \\
(0.08)\end{array}$ & $\begin{array}{l}0.060 \\
(0.20)\end{array}$ & - & $\begin{array}{r}0.050 \\
(0.15)\end{array}$ & - \\
\hline $\begin{array}{l}3 / 4 \text { in. Dia } \\
5 \mathrm{MHz}, \mathrm{SIZ} \\
\text { (S/N 21269) }\end{array}$ & $\begin{array}{c}0.18 \\
(0.37)\end{array}$ & - & - & - & $\begin{array}{c}0.20 \\
(0.21)\end{array}$ & - \\
\hline $\begin{array}{l}1 / 2 \text { in. Dia } \\
5 \mathrm{MHz} \text {, } \\
\text { Aerotech } \alpha\end{array}$ & $\begin{array}{c}0.10 \\
(0.37)\end{array}$ & $\begin{array}{c}0.14 \\
(0.08)\end{array}$ & $\begin{array}{c}0.08 \\
(0.20)\end{array}$ & - & $\begin{array}{c}0.06 \\
(0.21)\end{array}$ & - \\
\hline $\begin{array}{l}3 / 4 \mathrm{in}, \mathrm{Dia} \\
5 \mathrm{NiHz}, \mathrm{SIL} \\
\text { (S/N 21263) }\end{array}$ & $\begin{array}{c}0.18 \\
(0.37)\end{array}$ & - & $\begin{array}{c}0.18 \\
(0.38)\end{array}$ & - & $\begin{array}{c}0.12 \\
(0.21)\end{array}$ & - \\
\hline
\end{tabular}

047.0118 .100 
adjusted to the selected water path, and the refercnce standard which exhibited the marimum response was located. Then, the amplitude of that response was adjusted to 80 percent of suturation. Without changing the gain, the amplitude responses from the other ASTM-type standards was recorded and distance-s wlitidie curves (DAC) were constructed.

These tests were performed using the following search unit and ultrasonic instrument combinations:

(a) $3 / 4$ inch diameter, $5 \mathrm{MHz}$, SIZ (3/N 21269) with the Brunson 600

(b) $1 / 2$ inzh diameter, $10 \mathrm{MHz}$, SIZ (Si ..544) with Brunson 600

(c) 3/8 inch alameter, $15 \mathrm{MHz}$, SIL (S/N 1720 $)$ ) with Branson 600

(d) $3 / 4$ inch diameter, : MHz, SIL (S/N 2l263) with Sperry UM-715

The testing was repeated 7 times using the same technician, the $\mathrm{S} / \mathrm{N} 2 \mathrm{2} 269$ search unit and a 3 inch water path. Also, the testing was repeated 4 times with the same technician, the $S / \mathbb{N} 21269$ search unit and a 9 inch water path. These tests were repeated in order to measure the variation in response from one test to another. Each repeated test was initiated from the beginning with the placing of the reference standards made for the program in the water. The data was normalized prior to plotting the DAC curves by adjusting the maximun response in each test to an mplitude of 1 inch with the remaining amplitudes in the DA rrve adjusted uccordingly. 'lypical plots of the relative amplitudes us a function of metal travel are: shown in Figures 46 and 47 . Also, shown are the positions of the near field in the metal as calculated from the search unit diameter, sound velocity, and test frequency. A decibel (dB) scale is included in each p.lot for reference.

When plotted lofarithmically, the amplitude responise versus metal travel for a constant f'lat bottom hole alze, should follow a stralght line. However, deviations from this straight line may occur in repeated lests since the holes may not be exactly of the stune diameter and orientation. Also, there may be some variation in repeatability due to variations in search unit orientation with respect to the reference standard, etc.

The data was anslyzed and it was found that one standard deviation for the response variation from the ideal atratght line due to variation in hole preparation was approximately $1.7 \mathrm{~dB}$. One standard deviation due to test repatability was approximately $1.3 \mathrm{~dB}$. For a 95 percent confitunce level, then, a speciflc $3 / 64$ inch diameter holo respons was within $\pm 3.5 \mathrm{~dB}$ of the theoretical response. The testretest repeatability of the operator, equirment, and setup combination wass \pm 2.5 dB. It should be noted that these speclfic valuni; could be expected to vary with such factor:: as search unit sta, test frequency, and hole preveration. 
After the distance-amplitude curves were produced, tustirir, wus performed upon the as-rolled plate and as-forged die forging material. contuining flat bottom holes. Ihese tests were performed using the same operator, and equipment as describad above. Fhe search unit: was positioned over the particular piece and, with the gain setting the same as for the previously tested standard, thr responso from the flat bottom hole was recorded. Ty!ical nomalized responson are plotted in Figures 46 and 47.

Next, the plate and forging joces were machined to a 195 rms or better surface finish and the testing was repeated. 'Ir)ichl. normalized responses are plottra in pigures 46 and 47.

A comparison of the relative responses from the plate, foret ing and ASTM-type reference stardards was made for those data joint:; in the far field. This comparison is documented in Tablo :0. TH. should be recalled that the resporse variution was \pm 6 dis due to the sum of the variations in hole geometry and test-retost ropeatublilty. As shown in lable 30, the only case whore the resfonse. difference exceeded \pm 6 ab was for the 4 inch machined lidute. "l'n. greater attenuation of the machinea plato was axpeoted du lo lih: hiphor nolse levelo normalily experienced in produrtion muchined part ultrasonic inspestion whenever the ultranonic boin l: litroctad normal to the Brate fl'low of the part.

A comparison of the distance-nmplitude plots in the athinght Iline region for the ASTM-type reference standards revealed that hre silop of the stralght line vurled an a function of the acarch unil disul.

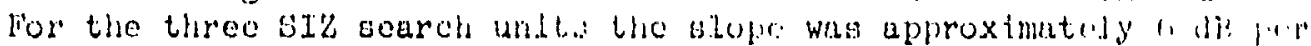

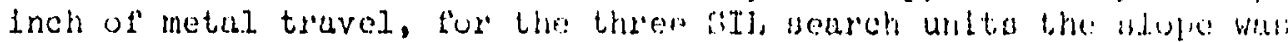

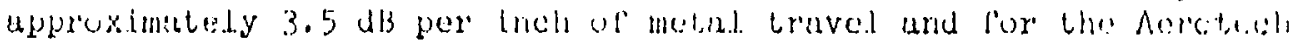

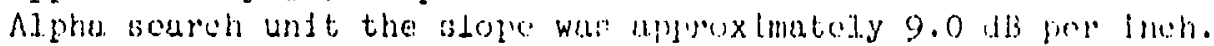

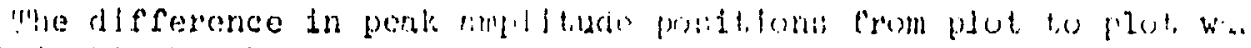

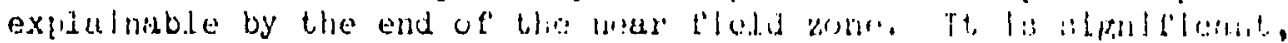

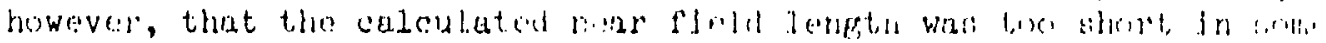

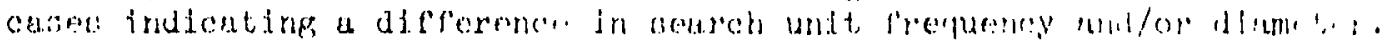

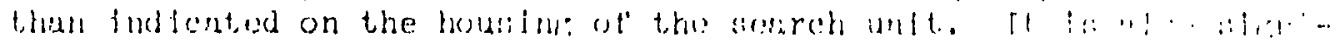

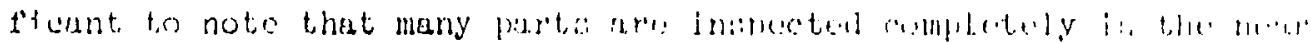
llablenon.

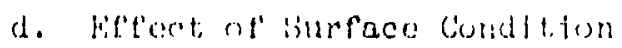

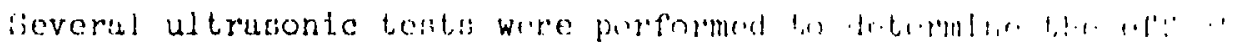

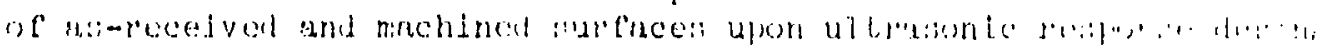

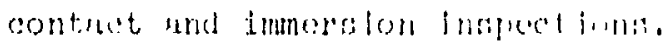

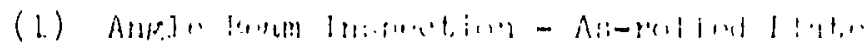

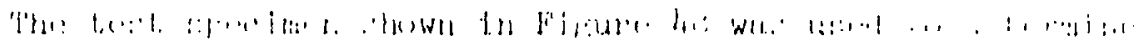

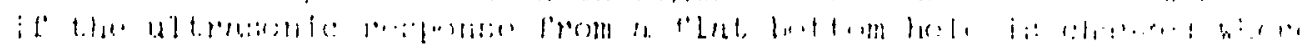

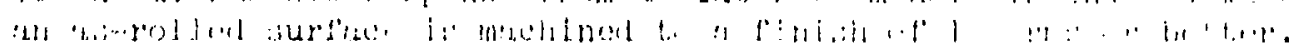




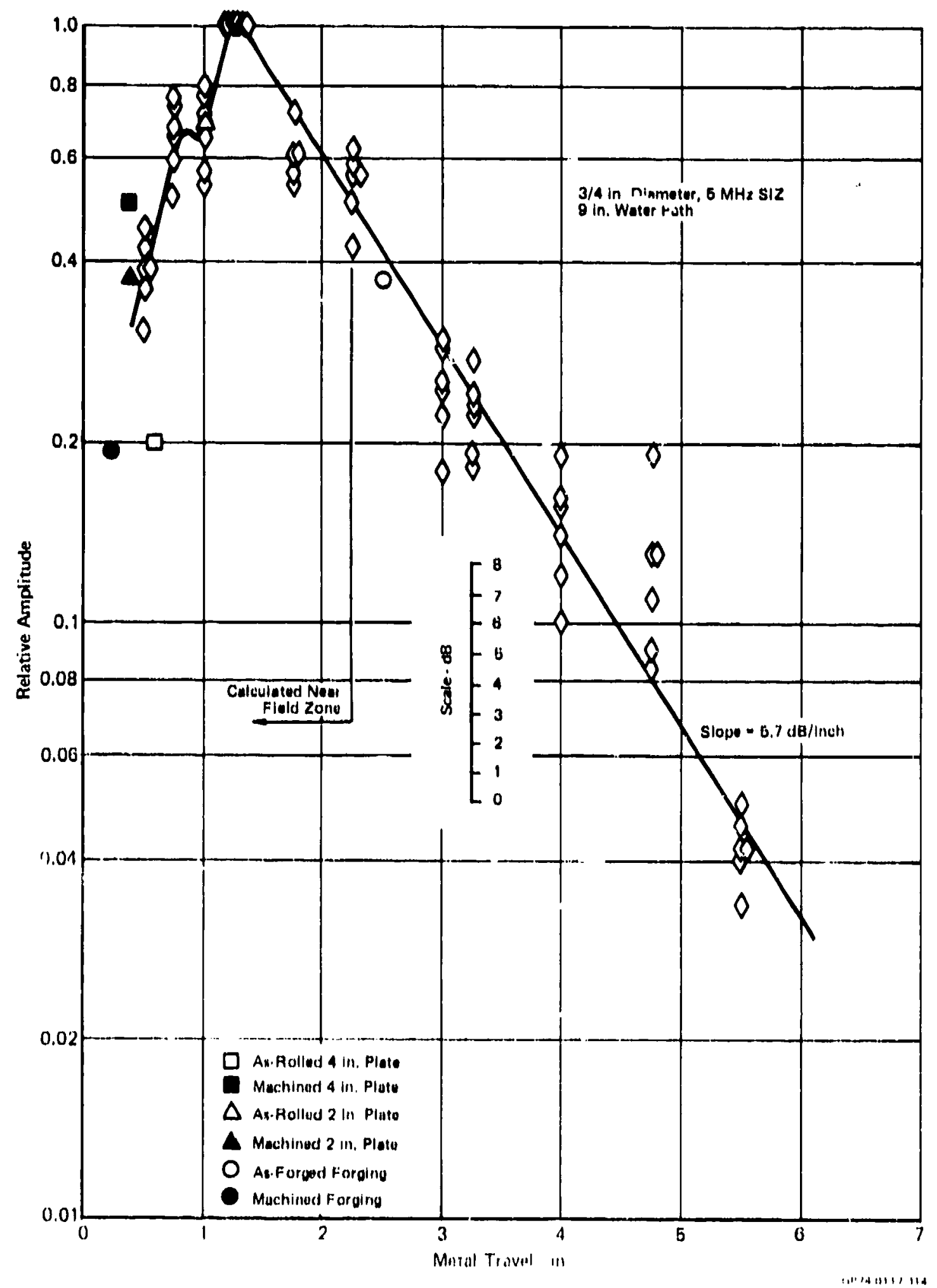

FIGURE 46

NELATIVE RESPONSE VS METAL TRAVEL 


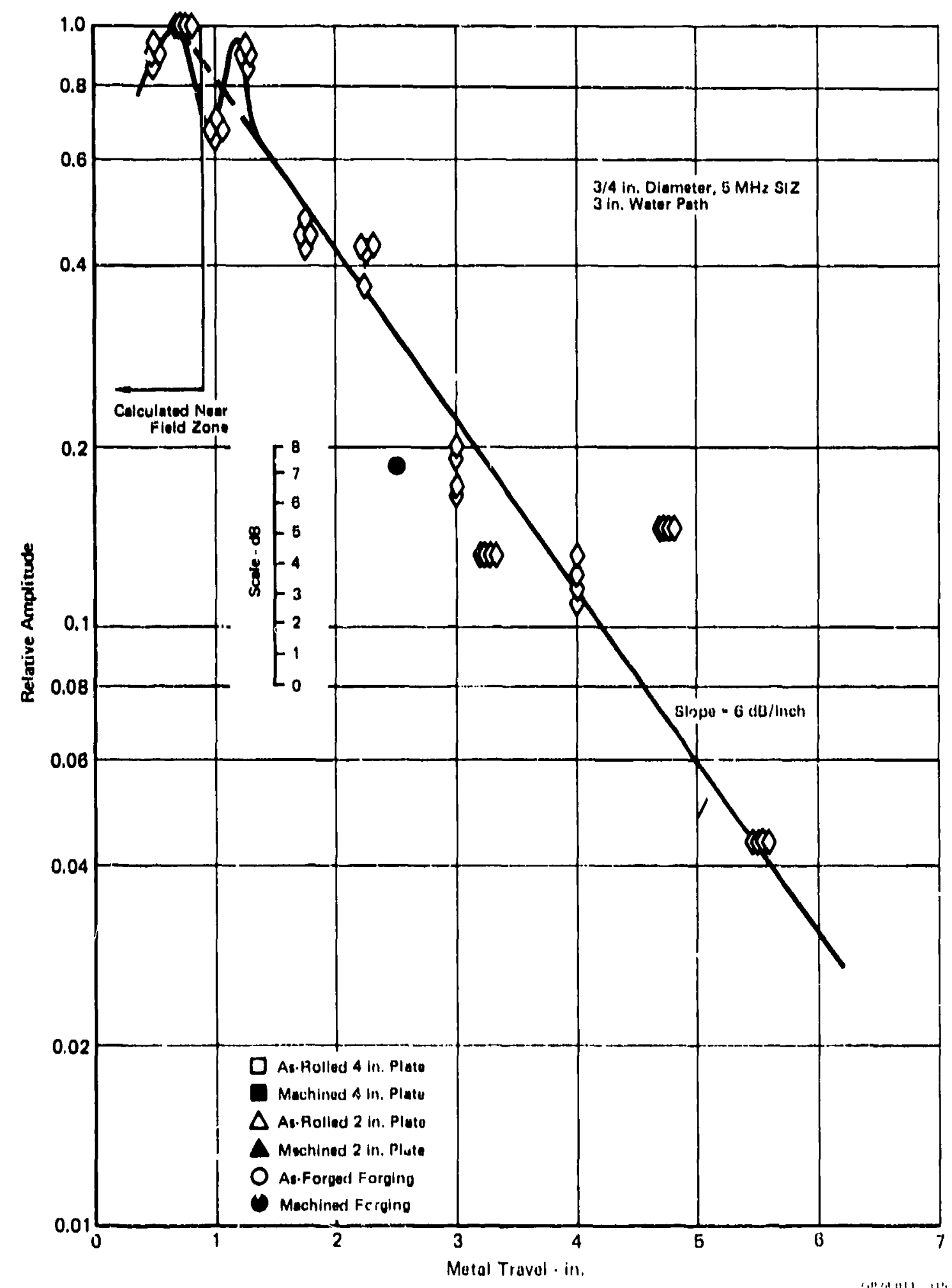

FIGURE 47

RELATIVE RESPONSE VS METAL TRAVEL 


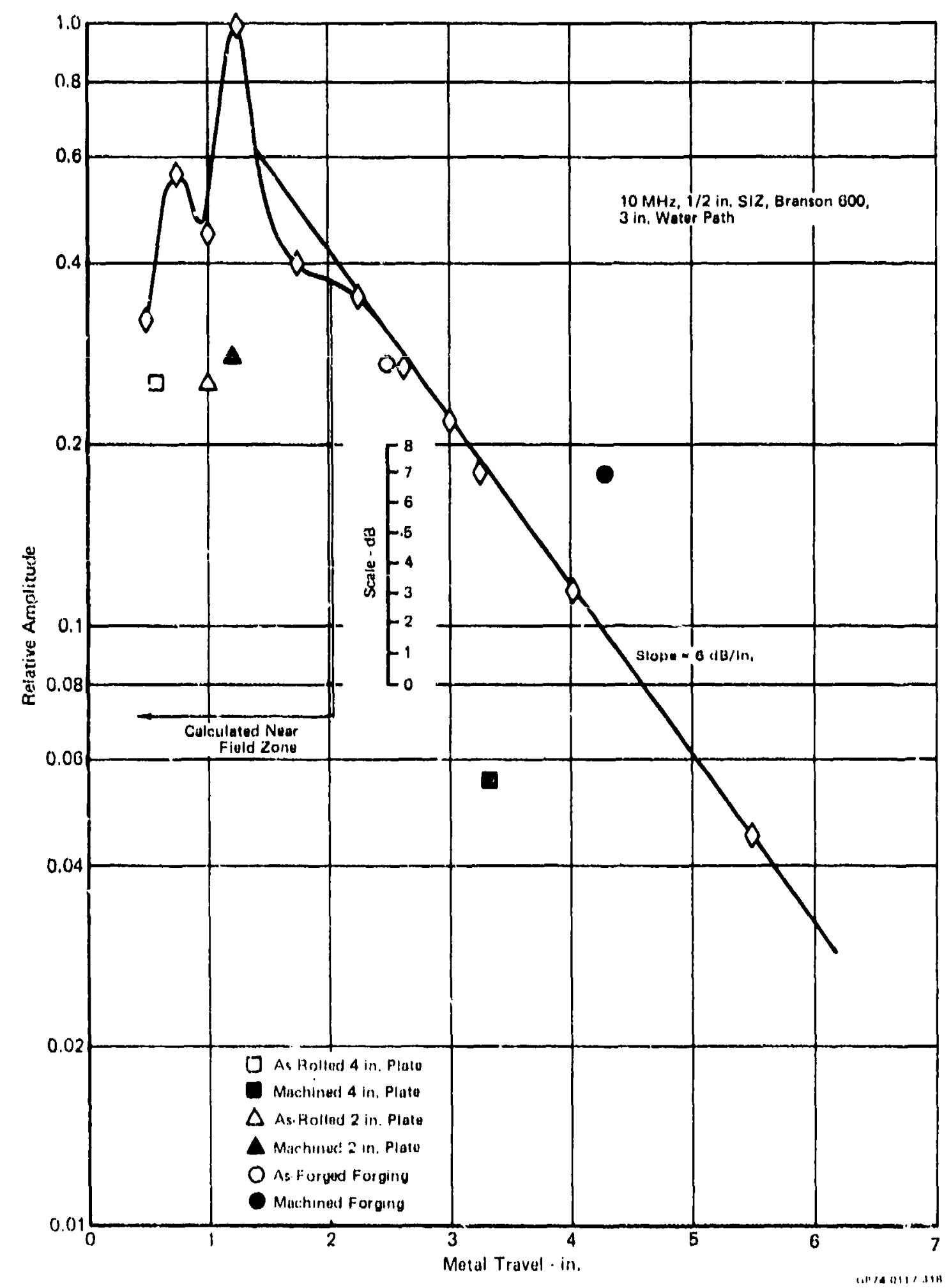

FIGURE 47 (Continued)

RELATIVE RESPONSE vS METAL TRAVEL 


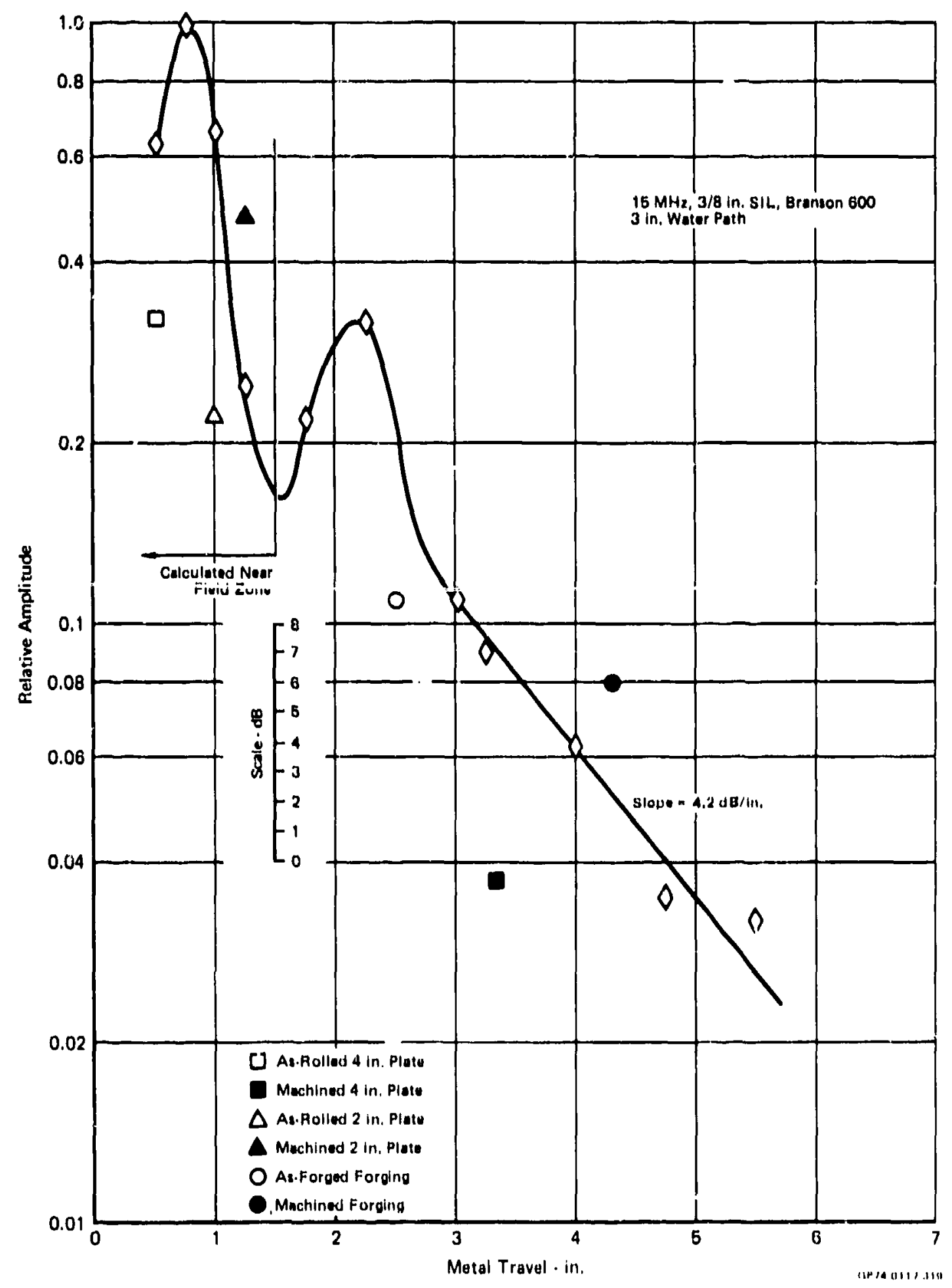

FIGURE 47 (Continued)

RELATIVE RESPONSE V\& METAL TRAVEL 


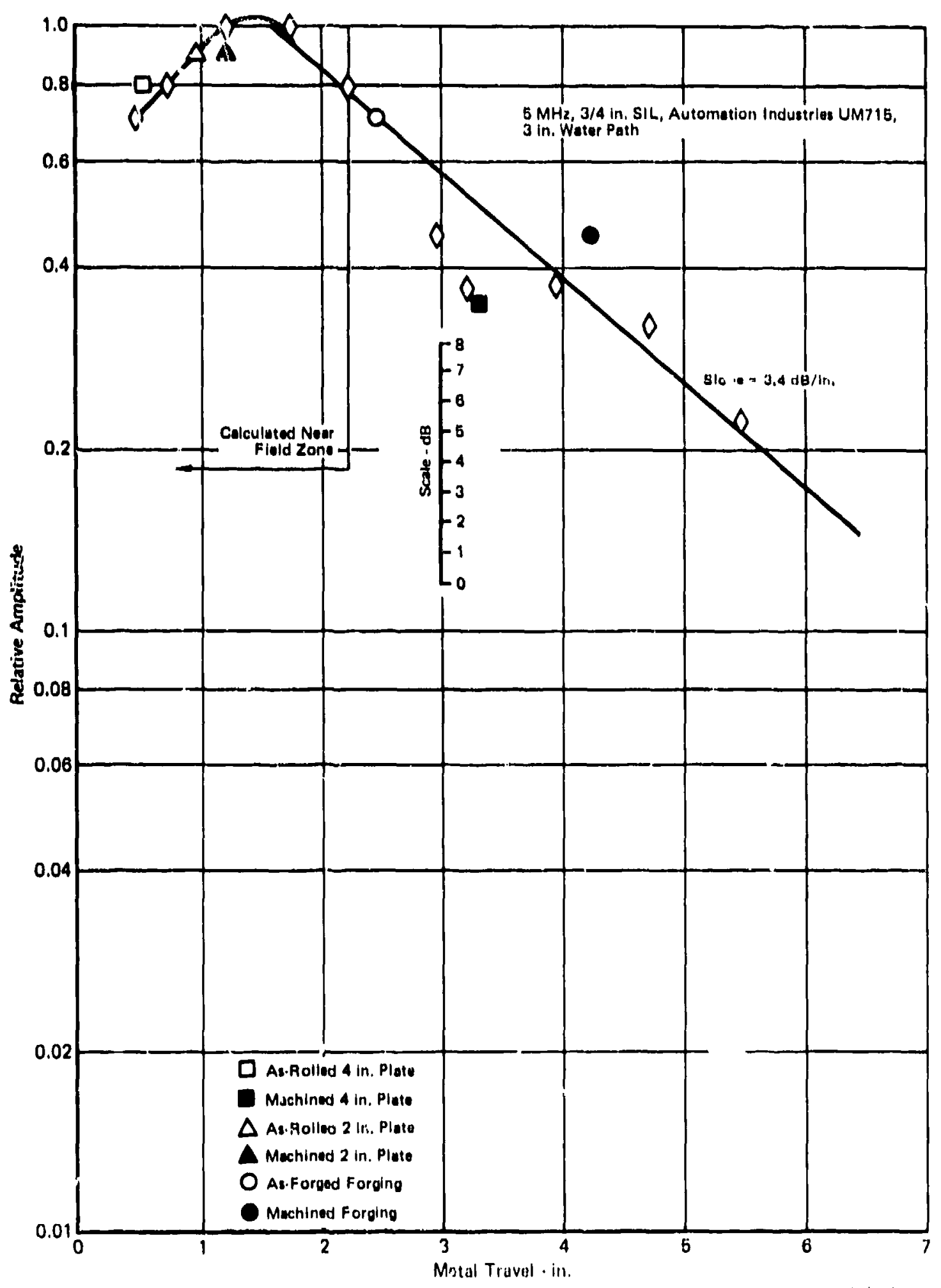

FIGURE 47 (Continued)

RELATIVE RESDONSE VS METAL TRAVEL 


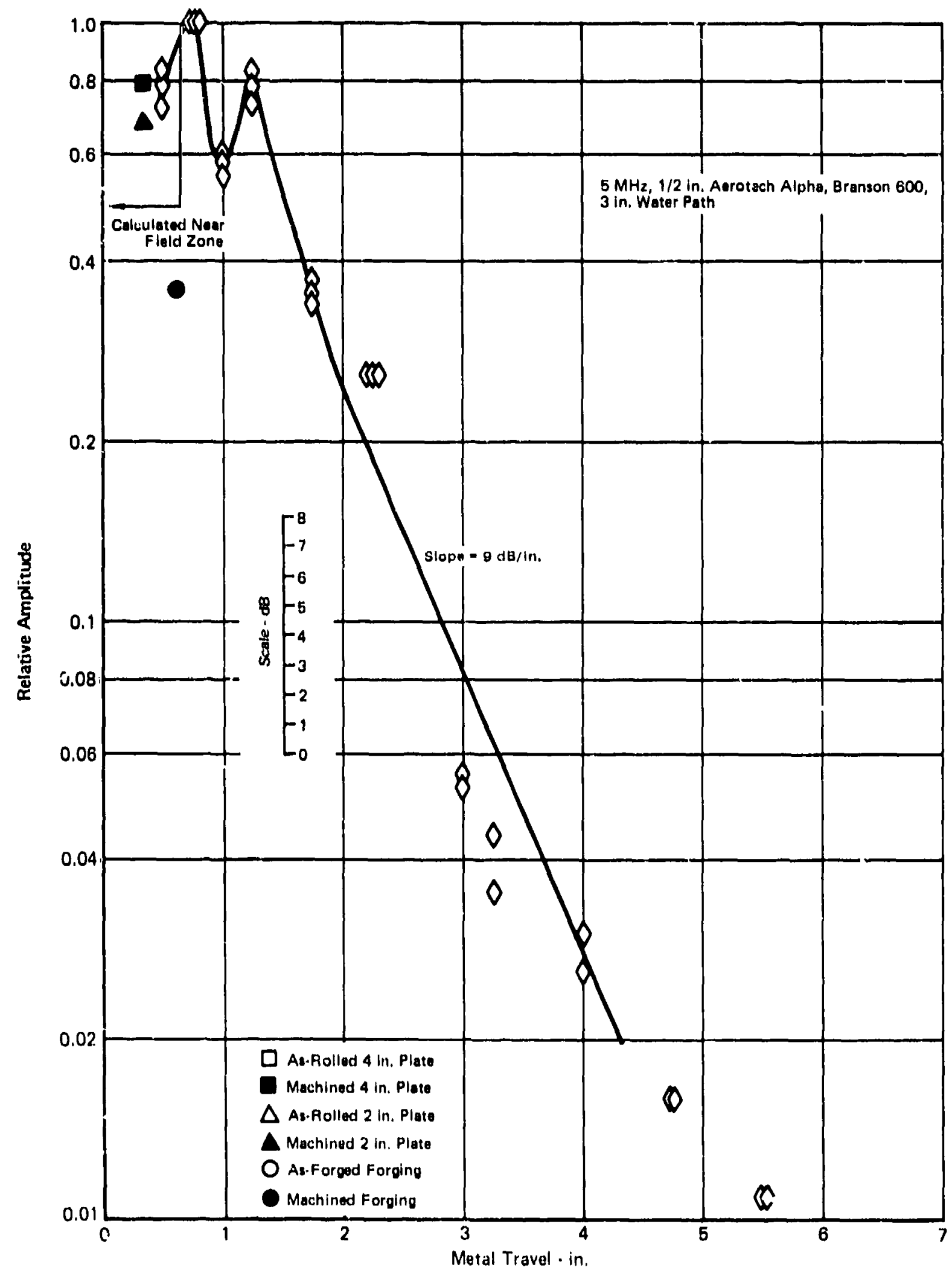

FIGURE 47 (Continued)

QP740111.321

FELATIVE RESPONSE vs METAL TRAVEL 


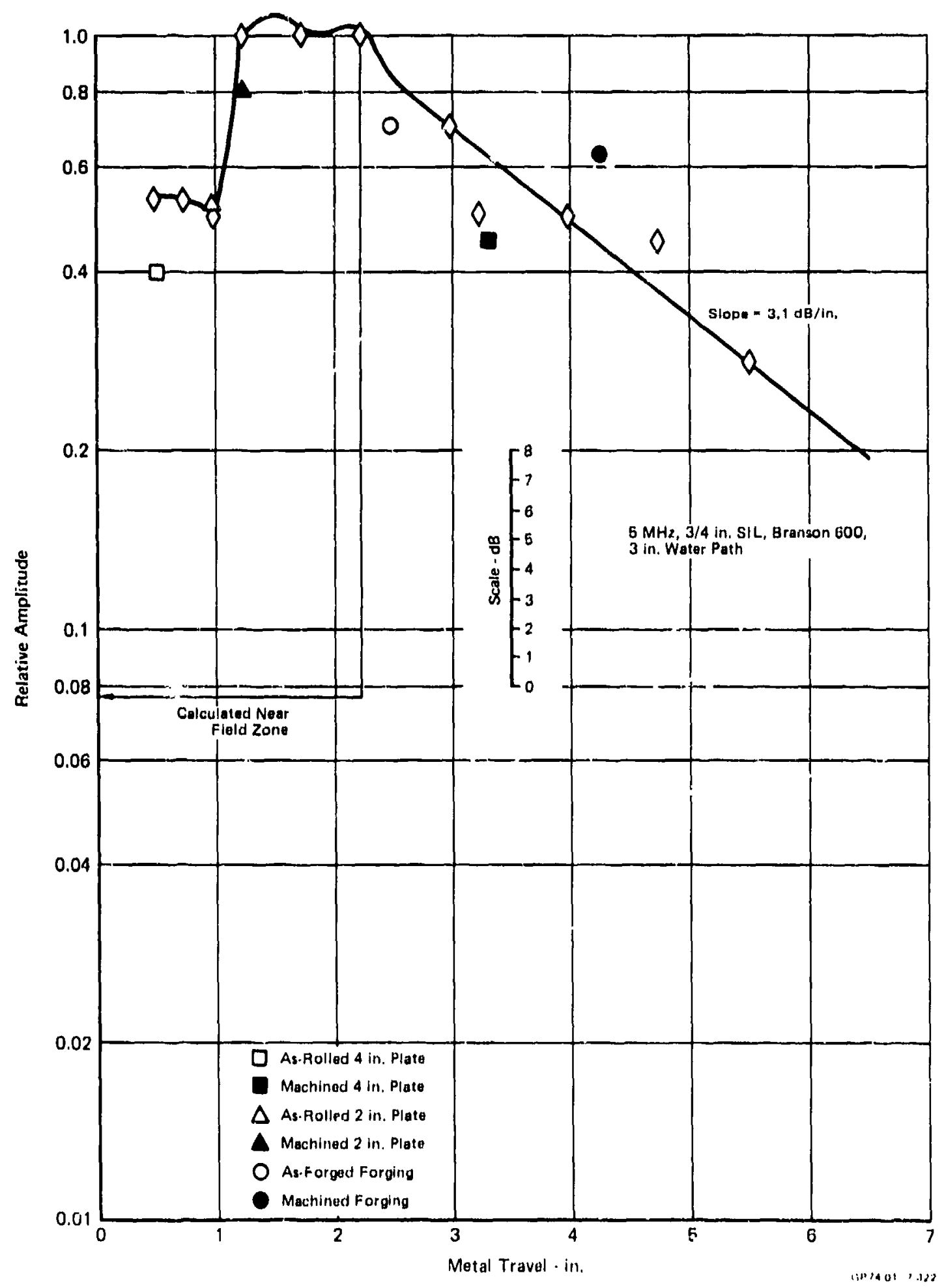

FIGURE 47 (Continued)

REL,ATIVE RESPONSE VS METAL TRAVEL 


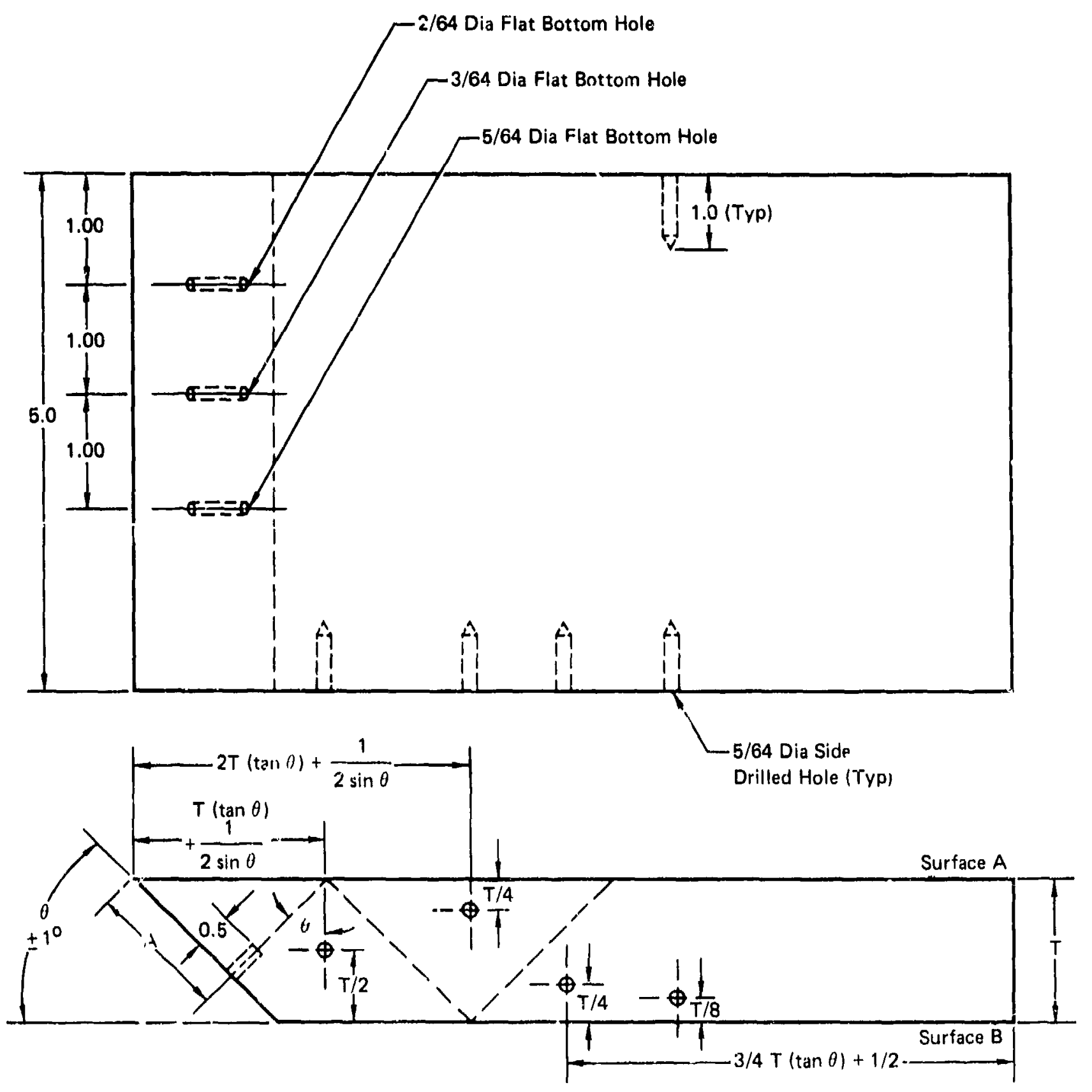

Notel:

1. Surfece $A$ and Surface $B$ must be flat and parallal within 0.001 inch.

2. Ali dimensions are $\pm 0.03 \mathrm{in}$. except for hole diameters which are $\pm 3 \%$ of the dlameter specitied.

3. Hole jottom must be flat within $0.001 \mathrm{ln}$. per $1 / 8 \mathrm{ln}$, diarracer.

FIGURE 48

ANGLE BEAM TEST SPECIMEN 
TABLE 30

DIFFERENCE IN RESPONSE BETWEEN PLATE AND FORGING AND ASTM - TYPE AEFERENCE STANDARDS

\begin{tabular}{|c|c|c|c|c|}
\hline \multirow{2}{*}{ Search Unit } & \multicolumn{4}{|c|}{ Response Variation (dB) } \\
\cline { 2 - 5 } & $\begin{array}{c}2 \text { in. } \\
\text { As-Fiolled } \\
\text { Plate }\end{array}$ & $\begin{array}{c}4 \text { in. } \\
\text { Mashined } \\
\text { Plate }\end{array}$ & $\begin{array}{c}\text { As-Forged } \\
\text { Forging }\end{array}$ & $\begin{array}{c}\text { Machinad } \\
\text { Forging }\end{array}$ \\
\hline $3 / 4$ in. Diameter, $5 \mathrm{MHz}, \mathrm{SIZ}$ & -2 & -2.75 & -1 & +2.5 \\
$1 / 2$ in. Diameter, $10 \mathrm{MHz}, \mathrm{SIZ}$ & -4 & -8 & -1 & +3.5 \\
$3 / 8$ in. Diameter, $15 \mathrm{MHz}$, SIL & -4 & -8.5 & -1 & +3.5 \\
\hline
\end{tabular}


Initially, the $1-1 / 2$ inch thick as-rolled plate specimen was positioned in the water tank and a $3 / 4$ inch diameter, $5 \mathrm{MHz}$, SIZ search unit (S/N 21269) was adjusted to a 3 inch wuter path and a refracted sound beam angle in the metal of 45 degrees \pm 5 degrees. A Branson 600 ultrasonic instrument was used for the testing. The response from the flat bottom hole was adjusted to 80 percent of saturation and the gain control setting and $\mathrm{dB}$ setting were recorded.

Next, the testing with an as-rolled sound entry surface was repeated for the contact angle beam method. A $5 \mathrm{MHz}, 45$ degree contact angle beam search unit was used along with "Iubriplate" grease as a couplant. Again, the responses from the flat bottom holes were adjusted to 80 percent of saturation and the gain and $d B$ setting were recorded.

After testing was completed with an as-rolled sound entry surface, the surfaces were machined to a rinish of $125 \mathrm{rms}$ or better. The previous testing was repeated by returning to the original gain setting, adjusting the hole response to 80 percent of saturation, and recording the $d B$ setting. The results are shown below.

\begin{tabular}{|c|c|c|c|}
\hline \multicolumn{3}{|c|}{$\mathrm{dB}$ Difference In Response From } \\
As-Rolled and Machined Specimens \\
\hline \multicolumn{3}{|c|}{ Immersion } & \multicolumn{3}{c|}{ Contact } \\
\hline $3 / 64$ Hole & $5 / 64$ Ilole & 0 & 0 \\
\hline $1-1 / 2$ & $1-1 / 2$ & Hole & $5 / 64$ Hole \\
\hline
\end{tabular}

As can be seen, the response difference between as-rolled and machined was insignificant for both the immersion and contact testing for the size reference holes used. This would appear to indicate that an as-rolled sound entry surface on a piece of plate would not reduce the inspectability of that plate as compared to a machined sound entry surface.

\section{(2) Straight Beam Inspection - Extrusion}

In oider to investigate the effect of an extruded sound entry surface, a $3 / 64$ inch diameter flat bottom hole was drilled in a $1 / 2$ inch thick piece of titanium extrusion. The hole was drilled to a depth of approxinately $1 / 8$ inch. With the as-extruded surface intact, a straight beam immersion test was performed at a water path of 3 inch using a $1 / 2$ inch diameter, $10 \mathrm{MHz}$ Aerotech Alpha search unit and again with $8.1 / 2$ inch, $5 \mathrm{MHz}$ Aerotech Alpha search unit along with a Branson 600 instrument. The hole response was adjusted to 80 percent of saturation and the gain and $d B$ setting were recorded. 
After testing the as-extrudad piece, the sound entry surface and back surface were machined to a finish of $125 \mathrm{rms}$ or better. The testing was repeated at the original gain setting. The results are shown below.

$\begin{gathered}\mathrm{dB} \text { Difference In Response From } \\ \text { As-Extruded and Machined Specimens }\end{gathered}$
$\frac{10 \mathrm{MHz}}{2}$

As can be seen, the response difference sas insignificant for the inmersion tests.

\section{e. Inspection of Thin, Machined Parts}

Some airframe manufacturer's employ ultrasonic inspection techniques on final machines parts particularly in thin sections including such arcas as the webs of machined bulkheads. Testing performed during this program has demonstrated the value of such inspections. There are defects that can be detected in final machined parts that cannot be detected in thicker product forms such as raw forgings. As shown in section 3 of the NDT capability portion of this report, the detectability of internal cracks with angle beam techniques can be quite low in thick section parts because of the part thickness and crack orientation. However, a large number of these cracks can be detected after final machining: to a thinner section (see Table 69).

A program was conducted to investigate several ultrasonic techniques for application to ultrasonic inspection of thin areas.

\section{(1) Pulse - Echo}

Initially, pulse-echo immersion testing was examined with tho intent being to establish the resolution capabilities of the method: for flaws lying parallel to the machined surface as a function of test frequency. Two search units wore evaluated. These were a $1 / 2$ inch diameter $10 \mathrm{MHz}$ SIL lone focus search unit ( 3.7 inch focal. length in water) and a $5 / 16$ inch diameter $25 \mathrm{MHz}$ SIL focuserl search unit. Both search units were used in conjunction with a Branson 600 ultrasonic instrument and a $623 \mathrm{Ts}$ pulser/receiver. Test specimens ranging in thickness from .050 to .437 inch were drilled with $2 ; 64,3 / 64$, and 5/6! inch diameter flat botiom holes as shown in Figure 49. These flat bottom holes were designed to represent discontinuities in parts of various thickness.

The test. specimens were placed in the water and the searoh unit was adjusted to bring the focal point to the front surface of the particular specimen being tested. Next, the search unit wis moved to the $5 / 64$ diameter hole and positioned to peak the response from the hole. The gain was adjusted to position the response to $80 \%$ of saturation on tire cathode ray tube in order to simulate the scanning gain for an actual inspection where the minimum reiponsic is adjuster to $80 \%$ of saturition. 

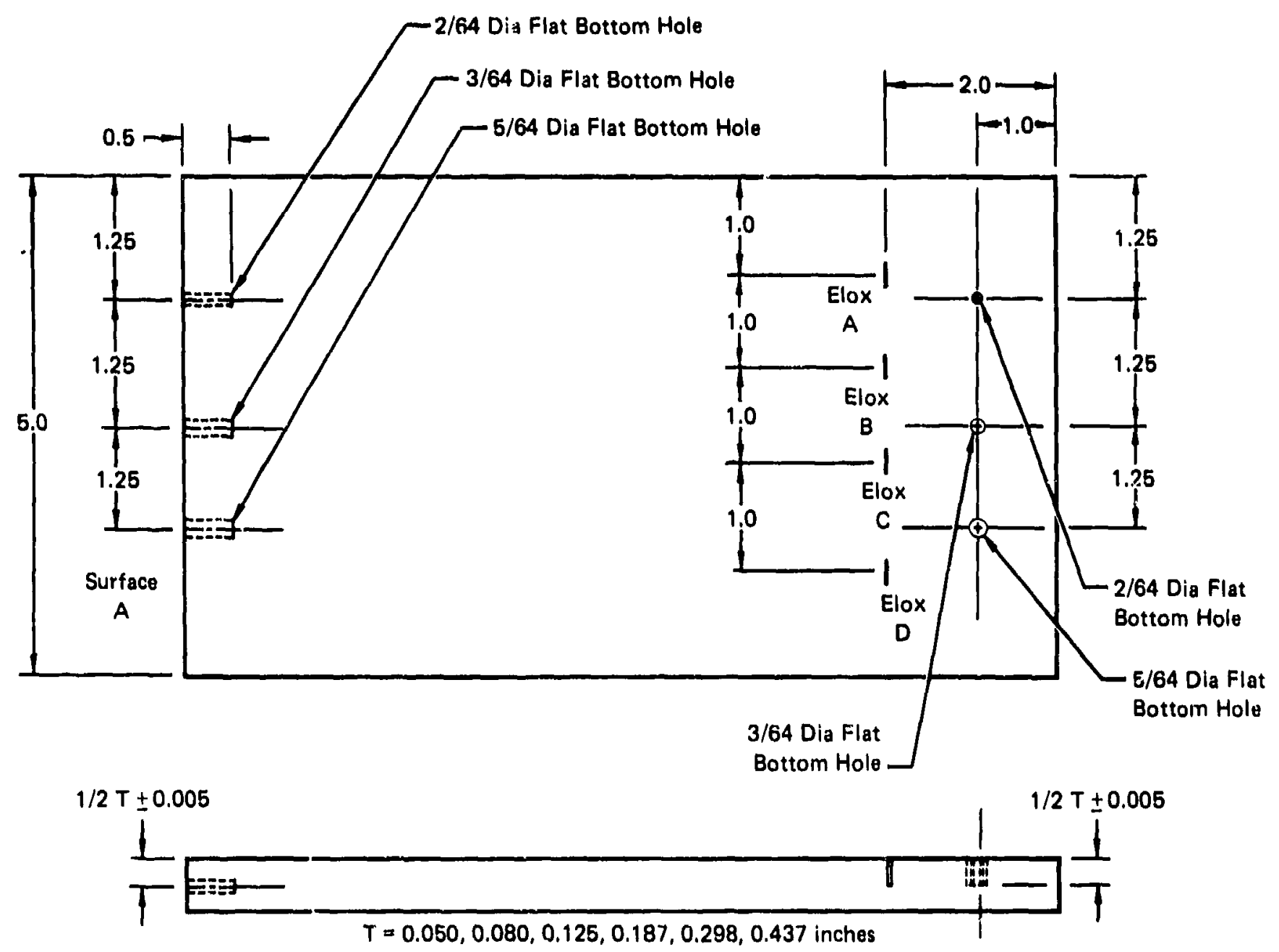

Notes:

1. Hole bottom must be flat within $0.001 \mathrm{In}$. por $1 / 8$ die.

2. All dimensions are $+0.03 \mathrm{in}$. except for hole dlemeters which are $+3 \%$ of the epecified die.

3. Plene of flat bottom holes and elox slote must be perpendiculer to sound entry surface and perallel to 5 In. dimension within +2 degreas.

4. Side drilled flat bottom holes must be perpendicular to Surface $A \pm 1$ degrea In two directions 90 u qurees opposed. 
It was noted whether or not the hole response was resolvable from the water/metal interface and if the back surface was resolvable from the water/metal interface. Also, the noise level was measured on the CRT screen. For the purposes of this test, the hole and back surface response was considered resolvable if they came completely down to the baseline on the CRT (see Figure 50).

Next, the search unit was moved to the $5 / 64$ inch diameter hole in the 0.298 inch thick piece and the hole response was adjusted to $80 \%$ of saturation. The dB required to adjust the hole response to $80 \%$ of saturation was measured. Again it was noted whether or not the hole response and the back surface were resolvable.

This test procedure was repeated for all the test specimens and all the flat bottom holes in an attempt to ascertain the best cholce of search unit for inspection of flat thin parts using the pulise-echo technique.

A summary of the results is presented in Table 31. A series of photographs demonstrating typical CRT displays 15 shown in Figures 51 thru 53. It can be seen from Table 31 that an improvement in resolution was obtained by increasing the test frequency from $10 \mathrm{MHz}$ to $25 \mathrm{MHz}$. For example, the $3 / 64$ inch dianeter hole was resolvable at a .063 inch metal travel with $25 \mathrm{MHz}$ but not with $10 \mathrm{MHz}$ (see Figure 52 ;.

The ultrasonic noise from the test apecimens was quite low; never exceeding $10 \%$ of saturation at the gain level required for a hole response of $80 \%$ of saturation.

Separation of the back surface response from the water/metal interface response was also improved by ircreasing the test frequency to $25 \mathrm{MHz}$ from $10 \mathrm{MHz}$. An example of a CRT display is shown in Figure 53 .

Based on these results, it appears tiat it is possible to resol.ve discontinuities equivalent to a $2 / 64$ inch diameter flat bot.tom hole at metal travels as small as 0.094 inch.

\section{(2) Reflector Plate Method}

Another potential technique for ultrasonic inspection of thin partis is the reflector plate technique demonstrated in Figure 54. 


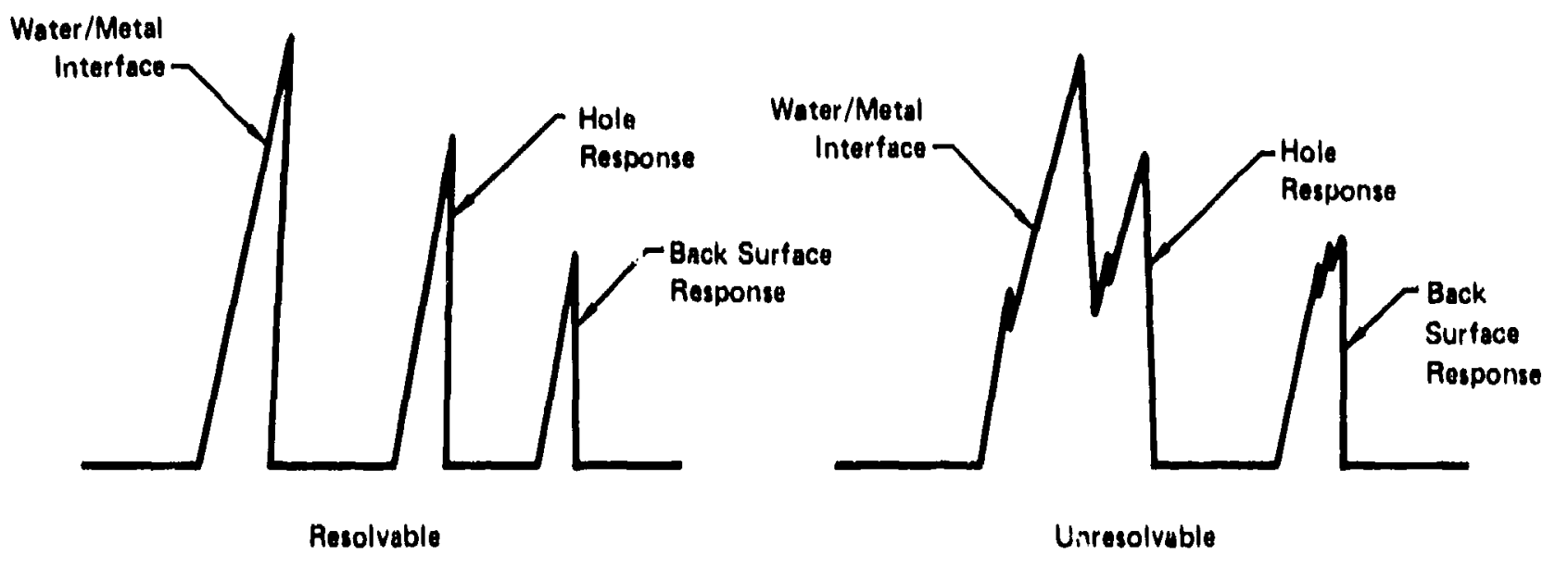

FIGUKE 50

DEFINITION OF NEAR SURFACE RESOLUTION AND BACK SURFACE RESOLUTION 
TABLE 31

IMMERSION PULSE ECHO TESTING

$5 / 64$ in. Dia Flat Bottom Holes

\begin{tabular}{|c|c|c|c|c|}
\hline \multirow{2}{*}{$\begin{array}{l}\text { Motal Travel } \\
\text { (In.) }\end{array}$} & \multicolumn{2}{|c|}{ dB for $80 \%$ Rosponse } & \multicolumn{2}{|c|}{ Bnok Surfece Resolvable } \\
\hline & $10 \mathrm{MHz}$ & $26 \mathrm{MHz}$ & $10 \mathrm{MHz}$ & $26 \mathrm{MHz}_{2}$ \\
\hline 0.218 & 21 & $\theta$ & Yer & Yos \\
\hline 0.149 & 21 & 10 & Yes & Yos \\
\hline 0.084 & 16 & 14 & Yes & Yos \\
\hline 0.083 & & & Yas & Yos \\
\hline 0.040 & & & No & Yos \\
\hline 0.026 & $\angle$ & $\triangle$ & No & No \\
\hline
\end{tabular}

$3 / 64$ in. Dia Flat Bottom Holes

\begin{tabular}{|c|c|c|c|c|}
\hline \multirow{2}{*}{$\begin{array}{c}\text { Metel Travel } \\
\text { (In.) }\end{array}$} & \multicolumn{2}{|c|}{ dB for $80 \%$ Response } & \multicolumn{2}{|c|}{ Buok Surfoce Resolvable } \\
\hline & $10 \mathrm{MHz}$ & $26 \mathrm{MHz}$ & $10 \mathrm{MHz}$ & $26 \mathrm{MHz}$ \\
\hline 0.218 & 15.5 & 7 & Yor & Yas \\
\hline $0.14 \theta$ & 14 & 10 & You & You \\
\hline 0.094 & & 12 & No & Yos \\
\hline 0.083 & & 12 & Nu & Yes \\
\hline 0.040 & & & No & Yos \\
\hline 0.025 & $\Delta$ & $\Delta$ & No & No \\
\hline
\end{tabular}

2/64 in. Dia Flat Bottom Holes

\begin{tabular}{|c|c|c|c|c|}
\hline \multirow{2}{*}{$\begin{array}{c}\text { Meral Truvel } \\
(\ln .)\end{array}$} & \multicolumn{2}{|c|}{ dB for $80 \%$ Responso } & \multicolumn{2}{|c|}{ Baok surface Resolvable } \\
\hline & $10 \mathrm{MHz}$ & $26 \mathrm{MHz}$ & $10 \mathrm{MHz}$ & $25 \mathrm{M} \cdot \mathrm{Hz}$ \\
\hline 0.218 & 10 & 2 & Yos & Yos \\
\hline 0.149 & 16 & 5 & Yes & Yos \\
\hline 0.094 & & 10 & No & Yos \\
\hline 0.063 & & & No & Yos \\
\hline 0.040 & & $\angle$ & No & Yas \\
\hline 0.025 & $\Delta$ & $\Delta$ & No & Yos \\
\hline
\end{tabular}

Hole not Resolved

ap14011111 


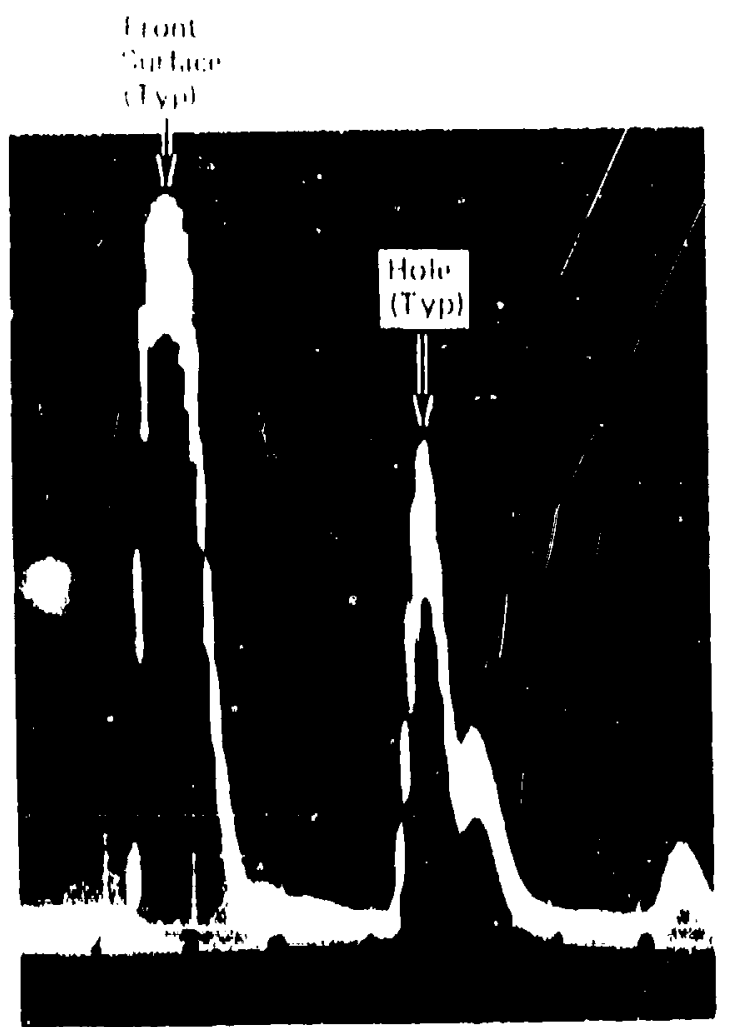

0.149 in. Motal Truvol

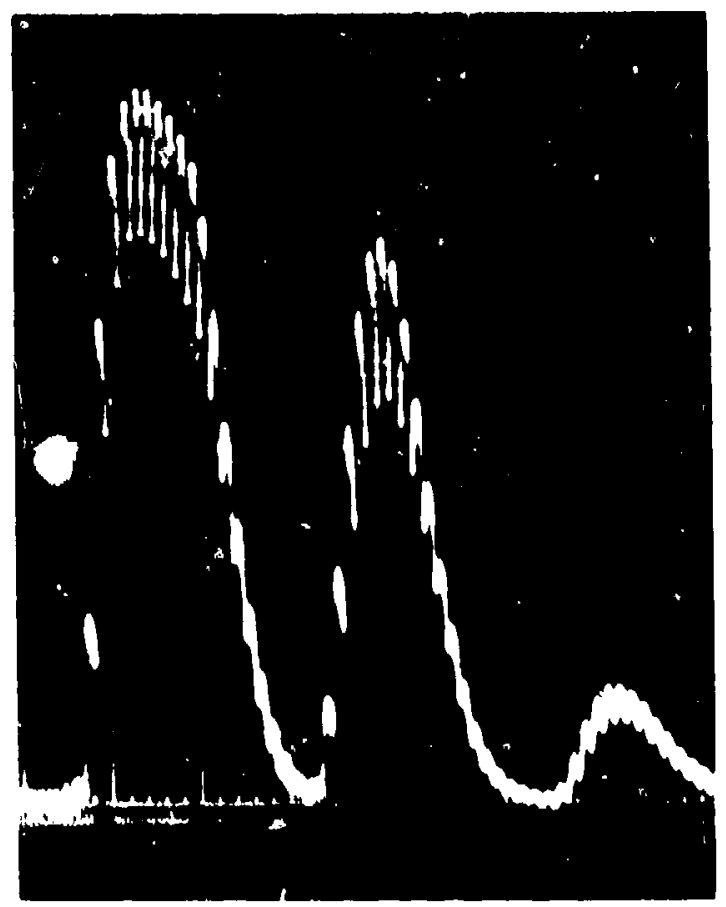

0.094 in Motal Travel

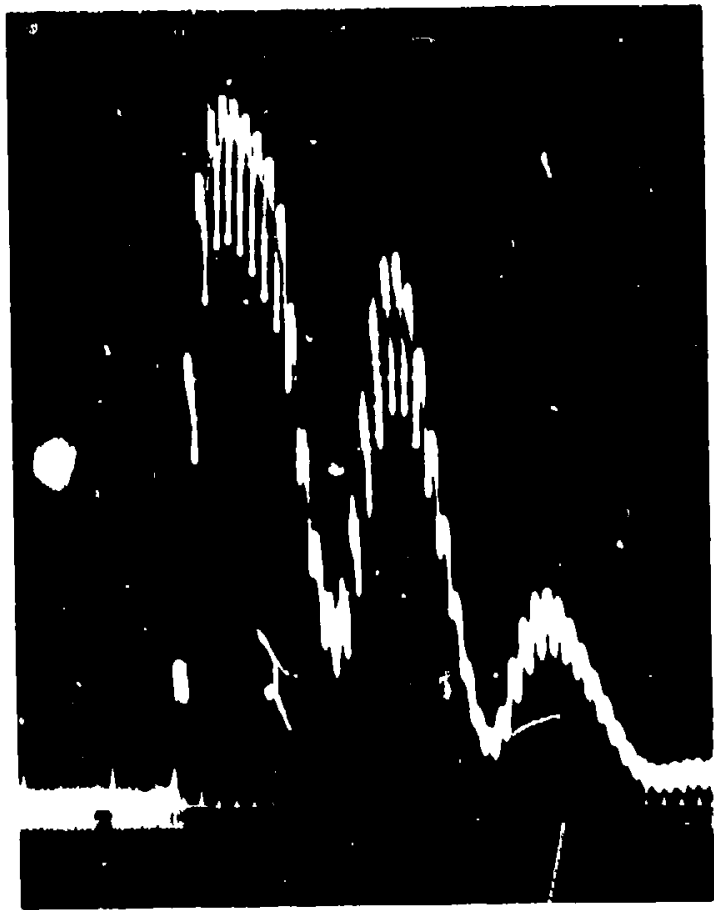

0.063 in. Metal Travel (Unresolved)

FIGURE 51

TYPICAL CRT DISPLAYS FOR PULSE ECHO TESTS

$2 / 64$ In. Dia Flat Bottom Holes

5/16 In. Dia, 25, mH. SIL Search Unit 


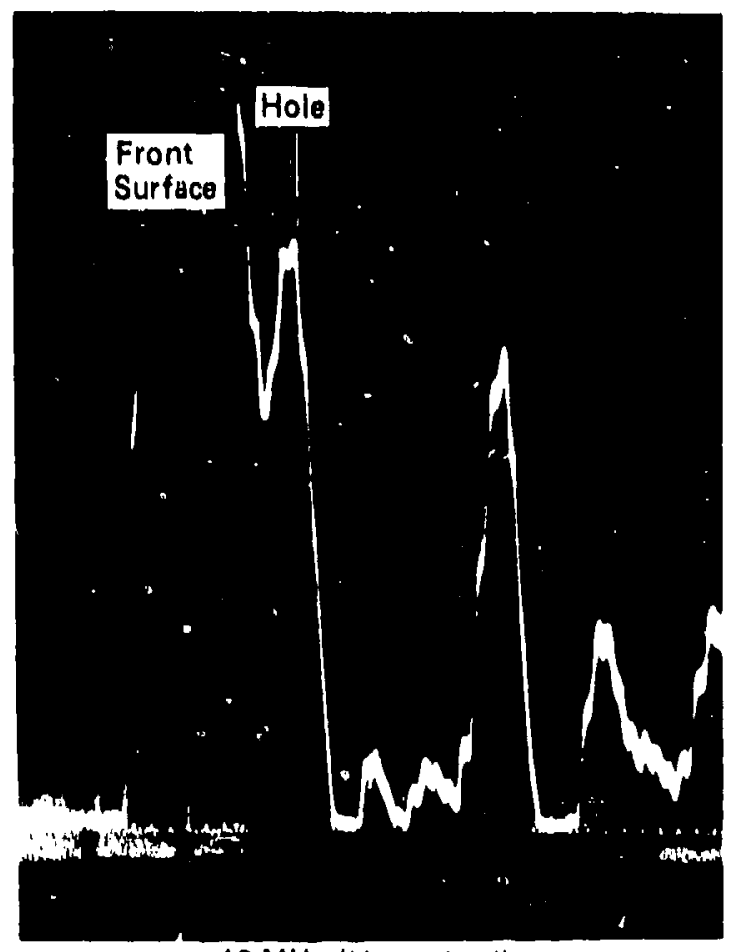

$10 \mathrm{MHz}$ (Unresolved)

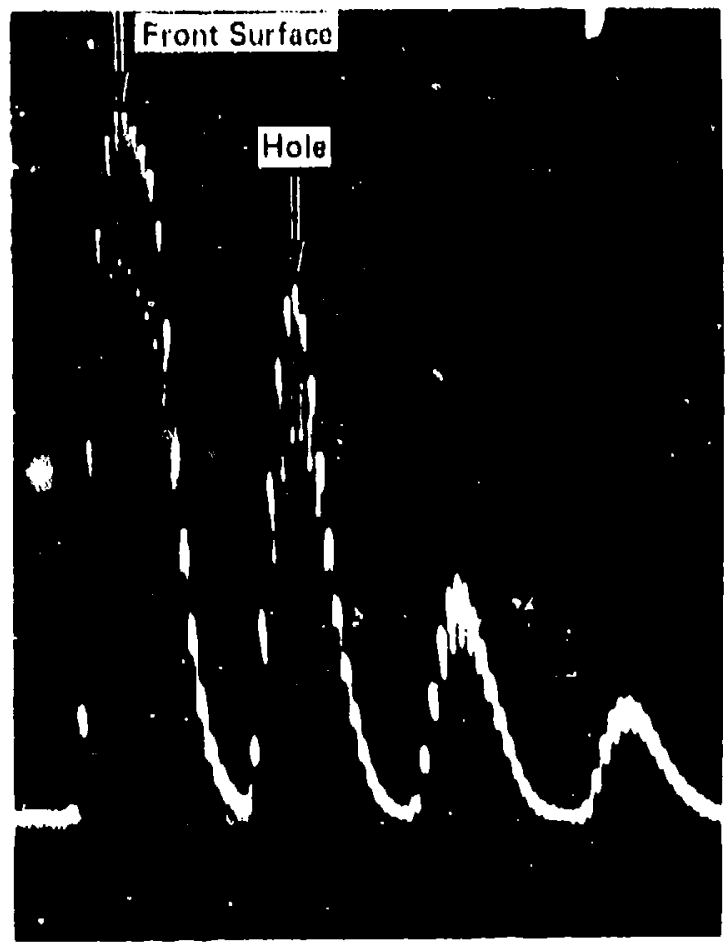

$25 \mathrm{MHz}$ (Resolved)

FIGURE 52

014.0111.48

INCREASE IN RESOLUTION WITH 25 MHZ TEST FREQUENCY (3/64 IN. DIA HOLE, 0.094 INJ. METALL TRAVEL) 


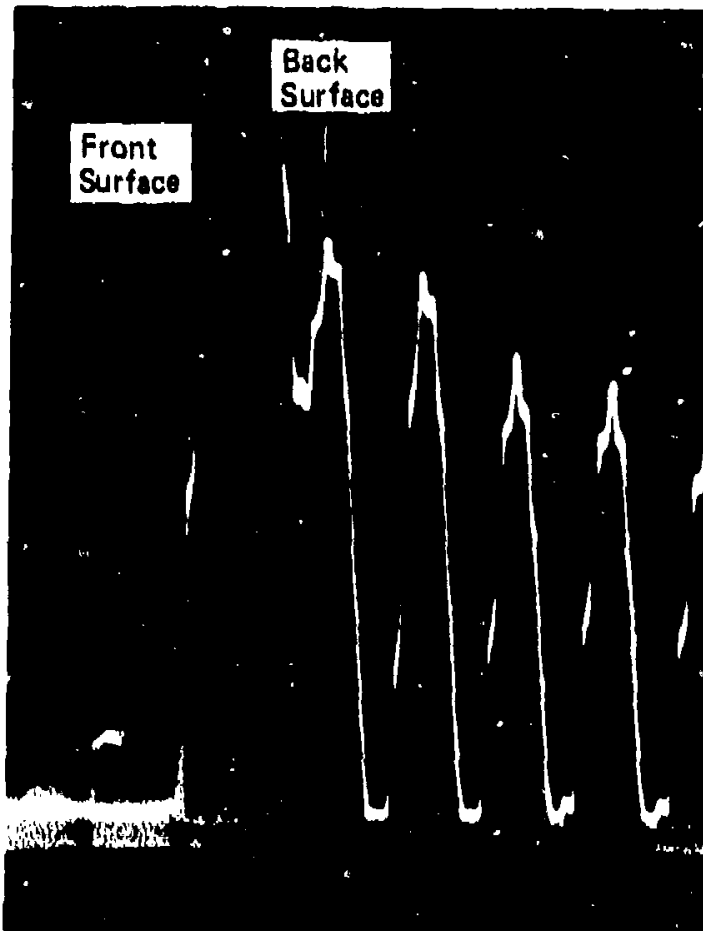

0.040 in. Metol Travel $10 \mathrm{MHz}$ (Unresolved)

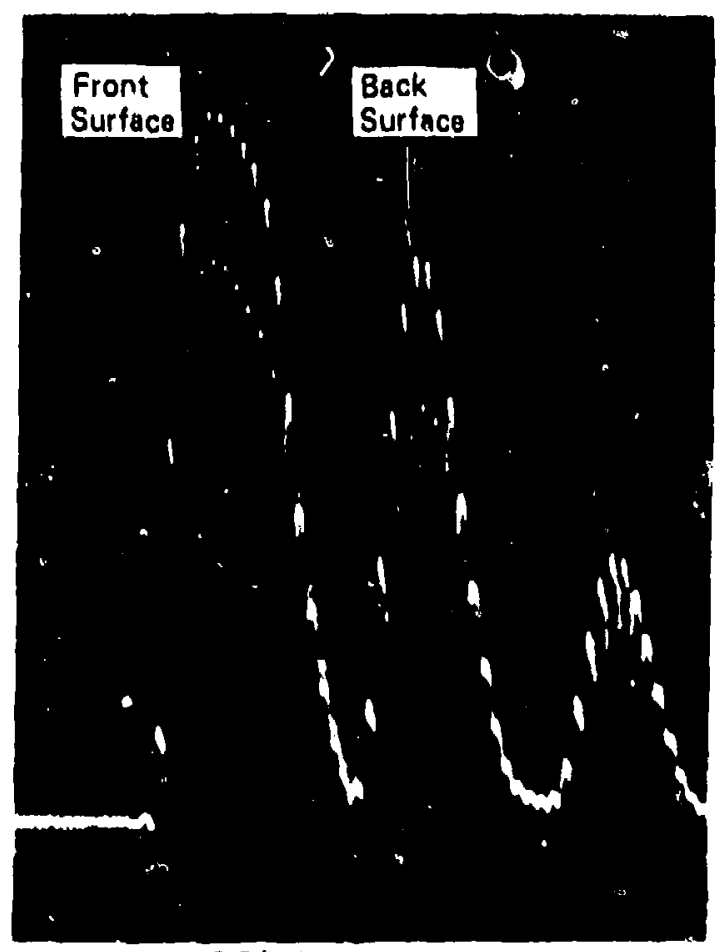

0.040 in. Metal Travol $25 \mathrm{MHz}$ (Resolved)

FIGURE 53

INCREASED RESOLUTION OF BACK SURFACE WITH INCREASED

QP74.0111.07 TEST FREQUENCY 


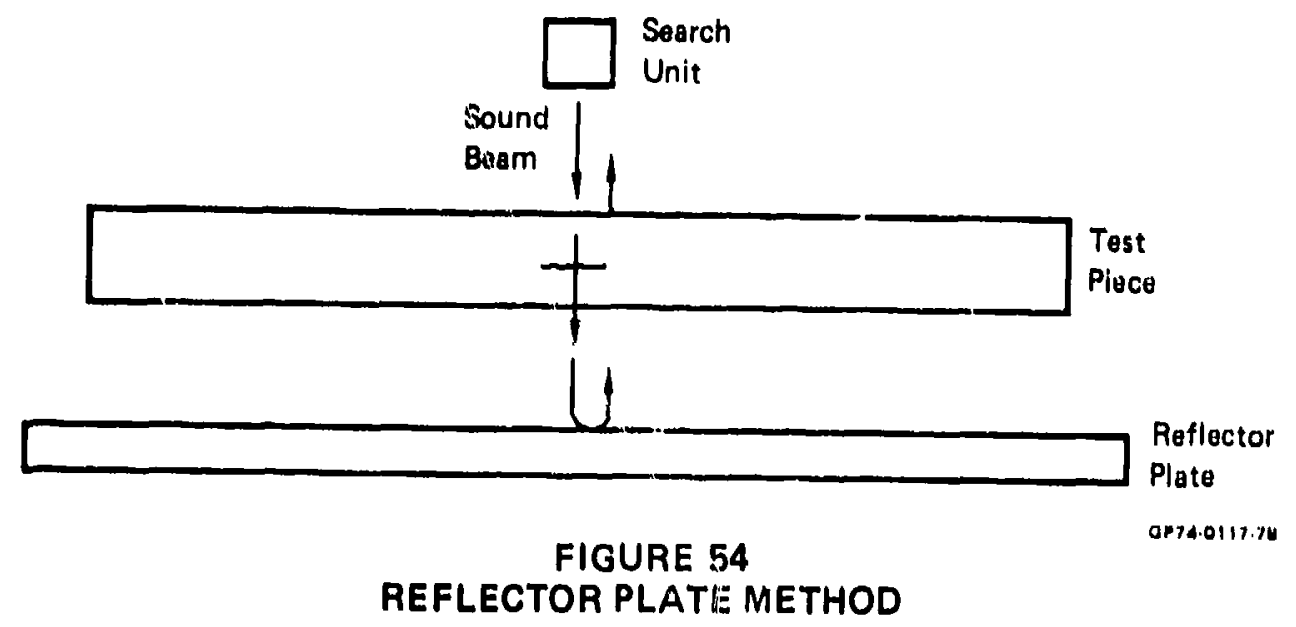

As can be seen, the sound beam it transmitted through the test piece, reflected from the reflector plate, transmitted back through the teat plece and, finaliy, recelved by the search unit. Interruption of the sound beam by a discontinuity in the test plece reduces the amplitude of the rof'lector plate response. Resolution of discontinuitios near the surface may be easier with the reflector plate method than pulse-echo because the response oocurs further out in time and, hence, is less affected by the large water/metul interface response.

I'he test specimens, seurch units, and pulse recelver were the sume as previously ussed in the pulse-echo tests. The flberpherolic reflector plate wes 1 inch thick. Inftially, the test specimens were immersed in the witor and the search unit and reflector plate were positioned as shown in Figure 55.

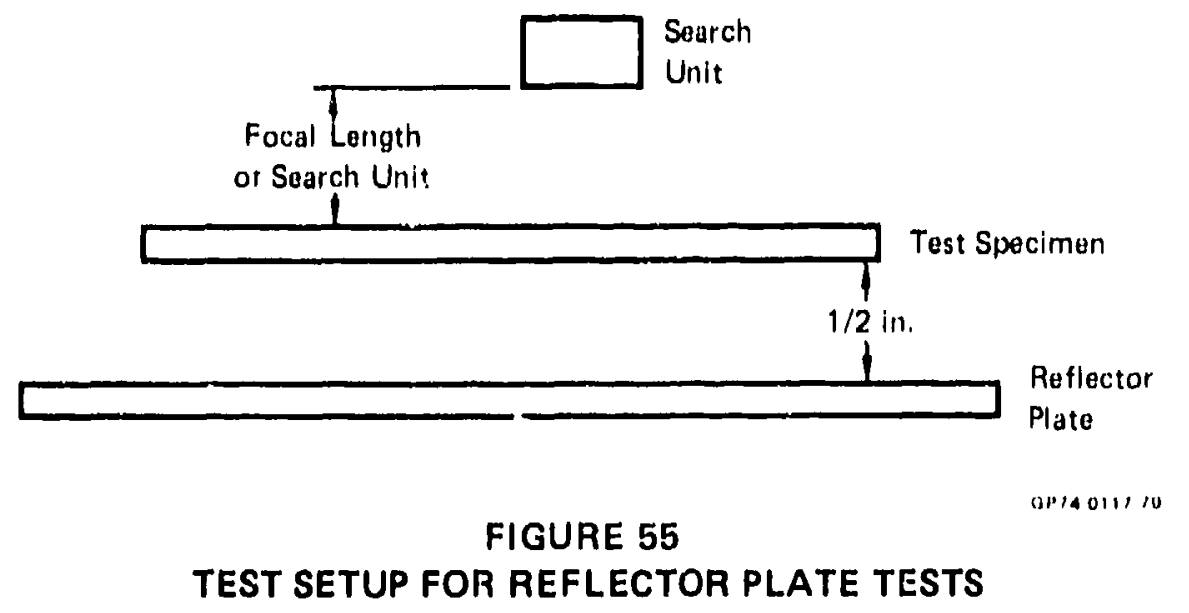


The reflection from the reflector plate, through the test specimen, was adjusted to $80 \%$ of saturation in a non-hole area of the test specimen. Then, the search unit was moved over the 5/64 inch diameter hole in the specimen and the reduction in amplitude from the reflector plate was measured by recording the $\mathrm{dB}$ required to return the signal to $80 \%$ of saturation. This was repeated for all the holes in each of the specimens. In this way, the smallest detectable hole was identified as a function of the test piece thickness and test frequency. In order to measure the scanning nolse level, the search unit was moved to a non-hole area, and with the reflector plate signal adjusted to $80 \%$ of saturation, the search unit was transversed back and forth over the reflector plate. Multiple exposure photographs were taken of the CRT display and the variation in amplitude of the reflector plate signal was noted to be $3 \mathrm{~dB}$.

The resuj.ts of the testing are shown in Table 32 .

TABLE 32

TEST RESULTS FOR REFLECTOR PLATE TESTING

$10 \mathrm{MHz}, 1 / 2 \mathrm{In}$. Dia SIL Search Unit

\begin{tabular}{|c|c|c|c|c|}
\hline $\begin{array}{c}\text { Plate } \\
\text { Thicknsss } \\
\text { (in.) }\end{array}$ & $\begin{array}{c}\text { Metal } \\
\text { Travel } \\
\text { (in.) }\end{array}$ & \multicolumn{3}{|c|}{$\begin{array}{c}\text { Signal Reduction Dus to Flat } \\
\text { Bottom Hole (dB) }\end{array}$} \\
\hline 0.487 & 0.218 & 10 & 14 & 20 \\
0.298 & 0.149 & 11 & 14 & 18 \\
0.187 & 0.094 & 8 & 17 & 20 \\
0.125 & 0.063 & 8 & 14 & 20 \\
0.080 & 0.040 & 6 & 12 & 17 \\
0.050 & 0.025 & 5 & 0 & 13 \\
\hline
\end{tabular}

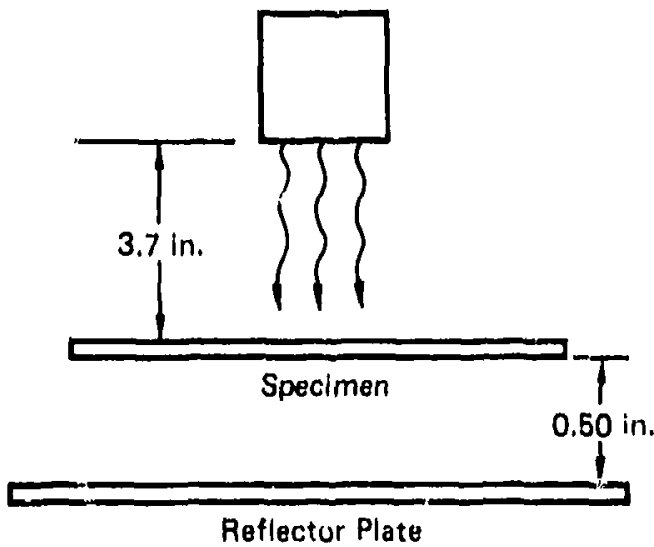

QP14.011180

It was found that at a test frequency of $25 \mathrm{MHz}$, there was not enough power to get a signal back from the reflector plate. This was true for all thicknesses except for 0.050 inch where a very low amplitude signa.l was received. As can be seen in Table 32 , all the holes were detectabje in all the specimens using $10 \mathrm{MHz}$. The scanning noise was found to be approximately $3 \mathrm{~dB}$. Based upon these result5, it appears that the reflector plate method is better than the pulse-echo method for locating flaws and evaluating their size in flat, thin machined parts. 


\section{(3) Ringing Method}

An ultrasonic ringing methoc was investigated for application to inspection of thin rarts. This method is based upon the presence of sound reverberations within the part and the change in the reverberations. Then tru metal travel distance is changed the $10 \mathrm{MHz}$ and $25 \mathrm{MHz}$ focused search units and Branson 600 instrument used in the pulse-echo tests were use in the immersion ringing tests. The gate was adjusted to monitor changes in the wiath and amplitude of the water/metal interface erho. Initially, the water/metal interface response was adjusted tc saturation in a non-hole area of the test specimen (see Figure 49 for specimen configuration) and the gato was adjusted to trigger at 30 percent of saturation on the right hand side of the response. The etate was adjusted to monitor the last 3 spikes without changing the gain; the search unit was positioned over each flat bottom hole In order to measure detectability of the holes.

The results of these tests indicated that the ringing method was ineffective. It was not possibie to detect any of the flat bottom holes in any of the specimens.

\section{(4) Pitch-Catch}

Contact pitch-catch tests were performed upon the test specinens: using a $5 \mathrm{MHz}$ Bransen $1 / 4$ inch fingertip probe with a Branson 600 ultrasonic instrument. 'The $2 / 64,3 / 64$, and $5 / 64$ inch diameter flat bottom holes in the specimens shown in Figure 49 were used as artificial reflectors. The couplant was "Lubriplate" grease. The search unit was oriented to provide for maximum response from the chosen flat bottom hole and the hole response was adjusted to 80 percent of saturation. The $d B$ setting at 80 percent of saturation was recorded and it was noted whether or not the hole response was resolvable f'rom the back surface response. For the purposes of this testing, the tralling edge of the hole response had to mert the horizontal sweep line to be considered resolved from the' ${ }^{\prime} k$ surface response.

Tinally, the testing was repeated using a $10 \mathrm{MH}$ \% Branson $1 / 4$ inch probe.

The test results are shown in l'able 33. As can be seen, in every case, except for the $3 / 64$ inch hole at $5 \mathrm{MHz}$, the hole was resolvable down to a test part thickness of .187 inch (.094 inch metal travel). Based on these results, it appears that thinner parts can be ultrasonically inspected with the $5 \mathrm{MHz}$ or $10 \mathrm{MHz}$ pitch-catch technique than with the $10 \mathrm{MHz}$ pulse-echo technique. With the $10 \mathrm{MHz}$ pulse-echo technique, it was not possible to resolve the hole response (2/64 and $3 / 64$ inch diameter holes) for metal travels less than .149 inch. However, in comparing the pitch-catch and pulse-echo methods with the reflection plate method, it could be conclude 1 that, the reflector plate method i:; superior in that metal traves.; as small as . Oes inch can be inspected. 
TABLE 33

RESULTS OF PITCH-CATCH TESTS

$5 \mathrm{MHz}$

\begin{tabular}{|c|c|c|c|c|}
\hline \multirow{2}{*}{$\begin{array}{c}\text { Plate } \\
\text { Thickness }\end{array}$} & \multirow{2}{*}{$\begin{array}{l}\text { Metal } \\
\text { Travel } \\
\text { (in.) }\end{array}$} & \multicolumn{3}{|c|}{$\mathrm{dB}$ for $\mathbf{8 0} \%$ of Saturation } \\
\hline & & 2/64 & $3 / 64$ & $5 / 64$ \\
\hline 0.437 & 0.218 & 26 & 32 & 39 \\
\hline 0.298 & 0.149 & 24 & 34 & 41 \\
\hline 0.187 & 0.094 & 24 & $33 \widehat{\wedge}$ & 40 \\
\hline 0.125 & 0.063 & 1 & $\uparrow$ & $\hat{\Lambda}$ \\
\hline 0.080 & 0.040 & 1 & $\widehat{1}$ & 1 \\
\hline 0.650 & 0.025 & 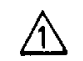 & 1 & 11 \\
\hline
\end{tabular}

$10 \mathrm{MHz}$

\begin{tabular}{|c|c|c|c|c|}
\hline \multirow{2}{*}{$\begin{array}{c}\text { Plate } \\
\text { Thickness }\end{array}$} & \multirow{2}{*}{$\begin{array}{l}\text { Metal } \\
\text { Travel } \\
\text { (in.) }\end{array}$} & \multicolumn{3}{|c|}{ dt or $80 \%$ of Saturation } \\
\hline & & $2 / 64$ & $3 / 64$ & $5 / 64$ \\
\hline 0.437 & 0.218 & 19 & 25 & 31 \\
\hline 0.298 & 0.149 & 20 & 27 & 36 \\
\hline $0 .{ }^{1} 87$ & 0.094 & 17 & 23 & 28 \\
\hline 0.125 & 0.063 & $\Delta$ & $\Delta$ & 1 \\
\hline 0.080 & 0.040 & is & $\Delta$ & $\widehat{\Delta}$ \\
\hline 0.050 & 0.025 & $\hat{1}$ & $\hat{1}$ & 今 \\
\hline
\end{tabular}

1) Hole response was not resolved from back surface response.

GP74.0117.81 


\section{f. Angle Beam Immersion Testing of Plate}

A program was conducted to evaluate the effectiveness of various search units during angle beam immersion testing of specimens fabricated from plate. A total of 9 test specimens (Ti-6AI-4V) were fabricated to the Figure 48 configuration with the following dimensjons :

\begin{tabular}{ccccc}
$\begin{array}{c}\text { Thickness, T } \\
\text { (Inches) }\end{array}$ & $\begin{array}{c}\text { Surface Finish } \\
\text { (RMS) }\end{array}$ & $\begin{array}{c}\theta \\
\text { (Degrees) }\end{array}$ & $\begin{array}{c}\text { A } \\
\text { (Inches) }\end{array}$ \\
\cline { 1 - 2 } 1.00 & 63 & 30 & 1.44 \\
1.00 & 125 & 30 & 1.44 \\
1.00 & as-rolled & 30 & 1.44 \\
1.50 & 63 & 45 & 1.55 \\
1.50 & 125 & 45 & 1.55 \\
1.50 & as-rolled & 45 & 1.55 \\
2.00 & 63 & 45 & 1.91 \\
2.00 & 125 & 45 & 1.91 \\
2.00 & as-roiled & 45 & 1.91
\end{tabular}

As shown in Figure 48, flat bottom holes, having diameters of $2 / 64$, 3.64 , and $5 / 64$ inch, were incorporated as artificlal reflectors.

Five flat search units were compared. These were:

(a) $3 / 4$ inch diameter, 2-1/4 MHz, Aerotech Gamma

(b) $3 / 4$ inch diameter, $5 \mathrm{MHz}$, Aerotech Gamma

(c) $3 / 4$ inch, $2-1 / 4 \mathrm{Milz}$, SIZ

(d) $3 / 4$ inch, $5 \mathrm{MHz}$, SIZ

(e) $3 / 4$ inch, $5 \mathrm{MHz}$, SIL

A Branson 600 ultrasonic instrument was used along with a 622' pulser/ receiver for each test. Each search unit was adjusted for a 3 inch water path and a refracted sound beam angle in the specimen of 145 degrees \pm 5 degrees for the 1-1/2. and 2 inch thick specimens and 60 degrees $\mp 5$ degrees for tha 1 inch thick specimen. The sound entry point was adjusted to Position 1 (see Figure 56) and the flat bottom hole response was adfisted to 80 percent of saturation. The responseto-noise ratio was measured off the cathode ray tube. Next, the search unit was moved to Position 2 and the testing was repeated. A few selectsd tests were performed from Position 3. 


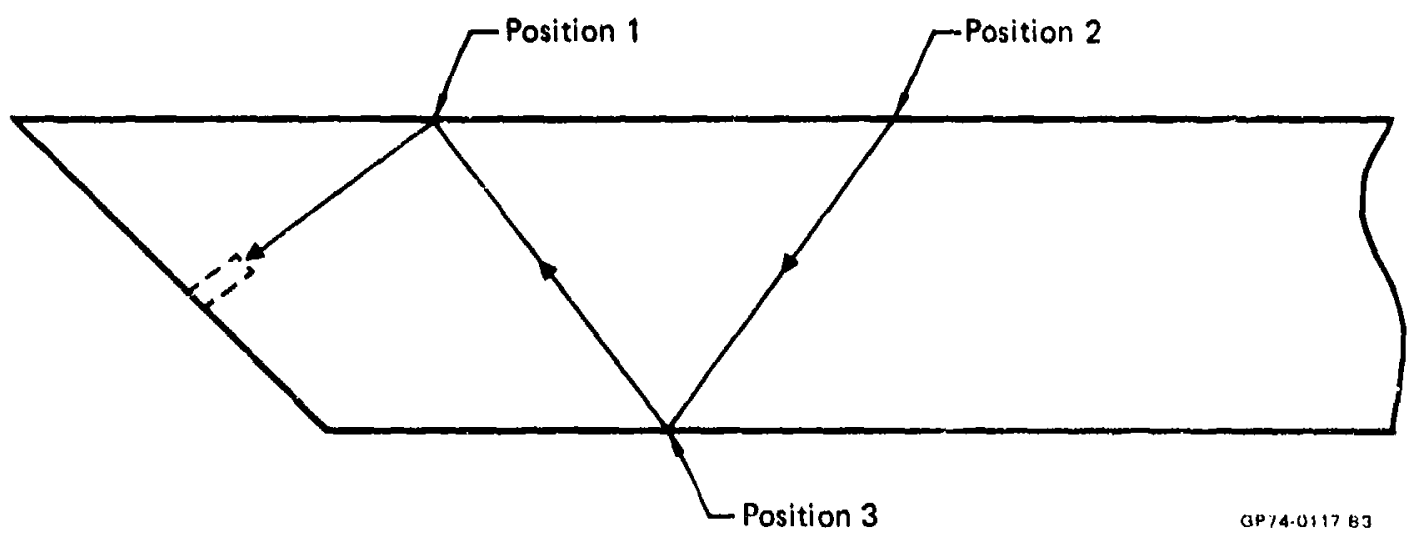

FIGURE 56

SOUND ENTRY POSITIONS

The results of the tests are shown in Tables 34 through 42 . With the sound entry point at Position 1 ( $1 / 4$ skip), the 3 flat bottom holes were detectable in all cases. The ultrasonic noise anplitude varied from 0.05 to 1.6 inches with the hole response adjusted to 2.4 inches. In several cases, there was little difference between the signal-tonoise ratio for the 5 search units. In those cases where there was a difference, it was found that the SIZ search units produced the greatest signal-to-noise ratio.

It was not possible to detect any of the flat bottom. holes at $1-1 / 4$ skips (Position 2). At $3 / 4$ skips (Position 3 ) it was pousible to detect the holes in a few crses. The:je results indicate that angle beam immersion inspection of a plat. ' inch thick or greater should be confined to less than $3 / 4$ skips.

It should be noted that it is not possible to determine the elfect of machining upon ultrasonic response from this data since the pieces were removed from different plates. These effects were studied in a separate program which is described in section $3-d$. 
TABLE 34

ULTFIASONIC NOISE DURING ANGLE BEAM IMMERSION TESTING

OF 2 INCH AS-ROLLED PLATE

$2 / 64$ in. Dia Flat Bottom Holes

\begin{tabular}{|c|c|c|c|}
\hline \multirow{2}{*}{ Search Unit } & \multicolumn{3}{|c|}{ Ultrasonic Signal-to-Noise Ratio $\hat{\imath}$} \\
\hline & Position 1 & Position 2 & Position 3 \\
\hline $2.1 / 4 \mathrm{MHz}$, Gamma & $2.4 / 0.3$ & 2 & 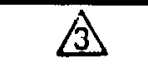 \\
\hline $5 \mathrm{MHz}$, Gamma & $2.4 / 0.25$ & & \\
\hline $2 \cdot 1 / 4 \mathrm{MHz}, \mathrm{SIZ}$ & $2.4 / 0.5$ & & \\
\hline $5 \mathrm{MHz}, \mathrm{SIZ}$ & $2.4 / 0.2$ & & 2 \\
\hline $5 \mathrm{MHz}, \mathrm{SIL}$ & $2.4 / 0.7$ & 1 & 3 \\
\hline
\end{tabular}

$3 / 64$ in. Dia Flat Bottom Holes

\begin{tabular}{|c|c|c|c|}
\hline \multirow{2}{*}{ Search Unit } & \multicolumn{3}{|c|}{ Ultrasunic Noise Level $\widehat{1}$} \\
\hline & Position 1 & Position 2 & Position 3 \\
\hline 2-1/4 MHz, Gamma & $2.4 / 0.1$ & 2 & \\
\hline $5 \mathrm{MHz}$, Gamma & $2.4 / 0.1$ & & $0.2 / 0.1$ \\
\hline $2 \cdot 1 / 4 \mathrm{MHz}, \mathrm{SIZ}$ & $2.4 / 0.3$ & & \\
\hline $5 \mathrm{MHz}, \mathrm{SIZ}$ & $2.4 / 0.05$ & & 2 \\
\hline $5 \mathrm{MHz}, \mathrm{SIL}$ & $2.4 / 0.15$ & & 3 \\
\hline
\end{tabular}

$5 / 64$ in. Dia Flat Bottom Holes

\begin{tabular}{|c|c|c|c|}
\hline \multirow{2}{*}{ Search Unit } & \multicolumn{3}{|c|}{ Ultrasnnic Noise Leval \ } \\
\hline & Position 1 & Position 2 & Position 3 \\
\hline 2-1/4 MHz, Gamma & $2.4 / 0.1$ & (2) & \\
\hline $5 \mathrm{MHz}$, Gamna & $2.4 / 0.05$ & & $0.6 / 0.05$ \\
\hline $2 \cdot 1 / 4 \mathrm{MHz}, \mathrm{SIZ}$ & $2.4 / 0.1$ & & (3) \\
\hline $5 \mathrm{MHz}, \mathrm{SIZ}$ & $2.4 / 0.01$ & & 2 \\
\hline $5 \mathrm{MHz}, \mathrm{SIL}$ & $2.4 / 0.1$ & f & $\widehat{3}$ \\
\hline
\end{tabular}

1) Amplitude of the noise in inches when the hole response is adjusted to $80 \%$ of saturation. 2 No hole iesponse

(3) Testing not performed from Position 3

QP\$4.0117.84 
TABLE 35

ULTRASONIC NOISE DURING ANGLE BEAM IMMERSION TESTIING

OF 2 INCH PLATE - 125 RMS

2/64 in. Dia Flat Bottom Holes

\begin{tabular}{|c|c|c|c|}
\hline \multirow{2}{*}{ Search Unit } & \multicolumn{3}{|c|}{ Ultrasonic Signal-to-Noise Ratio 1} \\
\hline & Position 1 & Position 2 & Position 3 \\
\hline 2-1/4 MHz, Gamma & $2.4 / 1.0$ & $\Delta$ & $B$ \\
\hline $5 \mathrm{MHz}$, Gamma & $2.4 / 0.3$ & & \\
\hline $2 \cdot 1 / 4 \mathrm{MHz}, \mathrm{SIZ}$ & $2.4 / 0.7$ & & 3 \\
\hline $5 \mathrm{MHz}, \mathrm{SIZ}$ & $2.4 / 0.5$ & & 2 \\
\hline $5 \mathrm{MHz}, \mathrm{SIL}$ & $2.4 / 0.1$ & 1 & 3 \\
\hline
\end{tabular}

$3 / 34$ in. Dia Flat Bottom Holes

\begin{tabular}{|c|c|c|c|}
\hline \multirow{2}{*}{ Search Unit } & \multicolumn{3}{|c|}{ Ultrasonic Noise Level 19} \\
\hline & Position 1 & Position 2 & Position \\
\hline 2.1/A MHz, Gamma & $2.4 / 0.25$ & 2 & 3 \\
\hline $5 \mathrm{MHz}$, Gamma & $2.4 / 0.1$ & & 2 \\
\hline $2 \cdot 1 / 4 \mathrm{MHz}, \mathrm{SIZ}$ & $2.4 / 0.5$ & & $\measuredangle$ \\
\hline $5 \mathrm{MHz}, \mathrm{SIZ}$ & $2.4 / 0.2$ & & 2 \\
\hline $5 \mathrm{MHz}, \mathrm{SIL}$ & $2.4 / 0.4$ & & (3) \\
\hline
\end{tabular}

$5 / 64$ in. Dia Flat Bottom Holes

\begin{tabular}{|c|c|c|c|}
\hline \multirow{2}{*}{ Search Unit } & \multicolumn{3}{|c|}{ 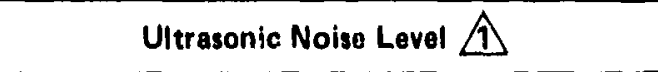 } \\
\hline & Position 1 & Position 2 & Position 3 \\
\hline 2-1/4 MHz, Gamma & $2.4 / 0.12$ & 2 & $\widehat{3}$ \\
\hline $5 \mathrm{MHz}$, Gamma & $2.4 / 0.05$ & & $\hat{2}$ \\
\hline $2-1 / 4 M H z, S I Z$ & $2.4 / 0.1$ & & 3 \\
\hline $5 \mathrm{MHZ}, \mathrm{SIZ}$ & $2.4 / 0.01$ & & 2 \\
\hline $5 \mathrm{MHz}, \mathrm{SIL}$ & $2.4 / 0.15$ & 1 & 3 \\
\hline
\end{tabular}

1. Amplitude of the noise in inches when the hole response is adjusted to $80 \%$ of soturation. 2 No hole rusponse

3. Tustine not performed from Position 3. 
TABLE 36

ULTIAASONIC NOISE DURING ANGLE BEAM IMMERSION TESTING

OF 2 INCH PLATE - 63 RMS

$2 / 64$ in. Dia Flat Bottom Holes

\begin{tabular}{|c|c|c|c|}
\hline \multirow{2}{*}{ Search Unit } & \multicolumn{3}{|c|}{ Ultrasonic Noise Levol 1} \\
\hline & Position : & Position 2 & Position 3 \\
\hline 2-1/4 MHz, Gamma & $2.4 / 1.1$ & 2 & 3 \\
\hline $5 \mathrm{MHz}$, Gamma & $2.4 / 0.9$ & & \\
\hline $2 \cdot 1 / 4 \mathrm{MH} \geq, \mathrm{SIZ}$ & $2.4 / 0.9$ & & \\
\hline $5 \mathrm{MHz}, \mathrm{SIZ}$ & $2.4 / 1.0$ & & \\
\hline $5 \mathrm{MHz}, \mathrm{SIL}$ & $2.4 / 1.2$ & f & f \\
\hline
\end{tabular}

$3 / 64$ in. Dia Flat Bottom Holes

\begin{tabular}{|c|c|c|c|}
\hline \multirow{2}{*}{ Search Unit } & \multicolumn{3}{|c|}{ Ultrasonic Nolse Level 1} \\
\hline & Position 1 & Position 2 & Position 3 \\
\hline 2.1/4 MHz, Gamma & $2.4 / 0.3$ & 2 & $\hat{3}$ \\
\hline $5 \mathrm{MHz}$, Gamma & $2.4 / 0.15$ & & \\
\hline $2 \cdot 1 / 4 \mathrm{MHz}, \mathrm{SIZ}$ & $2.4 / 0.3$ & & \\
\hline $5 \mathrm{MHz}, \mathrm{SIZ}$ & $2.4 / 0.2$ & & \\
\hline $5 \mathrm{MHz}, \mathrm{SIL}$ & $2.4 / 0.3$ & 1 & \\
\hline
\end{tabular}

$5 / 64$ in. Dia Flat Bottom Holes

\begin{tabular}{|c|c|c|c|}
\hline \multirow{2}{*}{ Search Unit } & \multicolumn{3}{|c|}{ Ultrasonic Noise Level $\hat{\mathrm{i}}$} \\
\hline & Position 1 & Position 2 & Position 3 \\
\hline 2.1/4 MHz, Gamma & $2.4 / 0.08$ & 2 & 3 \\
\hline $5 \mathrm{MHz}$, Gamma & $2.4 / 0.02$ & & \\
\hline $2.1 / 4 \mathrm{MHz}, \mathrm{SIZ}$ & $2.4 / 0.1$ & & \\
\hline $5 \mathrm{MHz}, \mathrm{SIZ}$ & $2.4 / 0.02$ & & \\
\hline $5 \mathrm{MHz}, \mathrm{SIL}$ & $2.4 / 0.1$ & $d$ & 1 \\
\hline
\end{tabular}

1. Amplitude of the nolse in inches when the hole response is adjusted to $80 \%$ of satiration. 2. No hole response

3 Testing not performed from Position 3. 
TABLE 37

ULTRASONIC NOISE DURING ANGLE BEAM IMMERSION TESTING OF $1 \frac{1}{2}$ INCH AS-ROLLED PLATE $2 / 64$ In. Dia Flat Bottom Holes

\begin{tabular}{|c|c|c|c|}
\hline \multirow{2}{*}{ Search Unit } & \multicolumn{3}{|c|}{ Ultrasonic Noise Level $\widehat{1}$} \\
\hline & Position 1 & Position 2 & Position 3 \\
\hline 2.1/4 MHz, Gamma & $2.4 / 0.6$ & 2) & (3) \\
\hline $5 \mathrm{MHz}$, Gamma & $2.4 / 0.3$ & 2 & $0.6 / 0.35$ \\
\hline $2 \cdot 1 / 4 \mathrm{MHz}, \mathrm{SIZ}$ & $2.4 / 1.0$ & 2 & (3) \\
\hline $5 \mathrm{MHz}, \mathrm{SIZ}$ & $2.4 / 0.5$ & 2 & 3 \\
\hline $5 \mathrm{MHz}$, SIL & $2.4 / 1.6$ & 2 & 3 \\
\hline
\end{tabular}

$3 / 64$ In. Dia Flat Bottom Holes

\begin{tabular}{|c|c|c|c|}
\hline \multirow{2}{*}{ Search Unit } & \multicolumn{3}{|c|}{ UItrasonic Noise Level @ } \\
\hline & Position 1 & Position 2 & Position 3 \\
\hline $2.1 / 4 \mathrm{MHz}$, Gamma & $2.4 / 0.3$ & $\hat{2}$ & $\widehat{3}$ \\
\hline $5 \mathrm{MHz}$, Gamma & $2.4 / 0.1$ & 20 & $0.55 / 0.2$ \\
\hline $2 \cdot 1 / 4 \mathrm{MHz}, \mathrm{SIZ}$ & $2.4 / 0.15$ & 2 & $\hat{3}$ \\
\hline $5 \mathrm{MHz}, \mathrm{SIZ}$ & $2.4 / 0.05$ & 2 & (3) \\
\hline $5 \mathrm{MHz}, \mathrm{SIL}$ & $2.4 / 0.4$ & 2 & $\hat{3}$ \\
\hline
\end{tabular}

$5 / 64$ In. Dia Flat Bottom Holes

\begin{tabular}{|c|c|c|c|}
\hline \multirow{2}{*}{ Search Unit } & \multicolumn{3}{|c|}{ Ultrasonic Noise Level $\$} \\
\hline & Position 1 & Position 2 & Position 3 \\
\hline $2.1 / 4 \mathrm{MHz}$, Gamma & $2.4 / 0.15$ & 2 & $\hat{3}$ \\
\hline $5 \mathrm{MHz}$, Gamma & $2.4 / 0.05$ & 2 & $0.8 / 0.1$ \\
\hline $2 \cdot 1 / 4 \mathrm{MHz}, \mathrm{SIZ}$ & $2.4 / 0.1$ & (2) & $\hat{3}$ \\
\hline $5 \mathrm{MHz}, \mathrm{SIZ}$ & $2.4 / 0.01$ & 2 & $0.25 / 0.01$ \\
\hline $5 \mathrm{MHz}, \mathrm{SIL}$ & $2.4 / 0.2$ & 2 & 3 \\
\hline
\end{tabular}

1. Amplitude of the nolse in inches when the hole response is adlusted to $80 \%$ of saturation. (2) No hole response

(3) Testing not performed from Position 3. 
TABLE 38

ULTRASONIC NOISE DURING ANGLE BEAM IMMERSION TESTING OF 1 $1 \frac{1}{2}$ INCH PLATE - 125 RMS $2 / 64$ In. Dia Flat Bottom Holes

\begin{tabular}{|c|c|c|c|}
\hline \multirow{2}{*}{ Search Unit } & \multicolumn{3}{|c|}{ Ultrasonic Noise Level $\triangle 1$} \\
\hline & Position 1 & Position 2 & Position 3 \\
\hline 2.1/4 MHz, Gumma & $2.4 / 4.2$ & 2 & $\hat{3}$ \\
\hline $5 \mathrm{MHz}$, Gamma & $2.4 / 1.2$ & 2 & $\hat{3}$ \\
\hline $2 \cdot 1 / 4 \mathrm{MHz}, \mathrm{SIZ}$ & $2.4 / 0.8$ & 2 & $\widehat{3}$ \\
\hline $6 \mathrm{MHz}, \mathrm{SIZ}$ & $2.4 / 0.63$ & 2 & 3) \\
\hline $5 \mathrm{MHz}, \mathrm{SIL}$ & $2.4 / 1.6$ & 2 & 3 \\
\hline
\end{tabular}

$3 / 64$ In. Dia Flat Bottom Holes

\begin{tabular}{|c|c|c|c|}
\hline \multirow{2}{*}{ Search Unit } & \multicolumn{3}{|c|}{ Uitrasonic Noise Lovel 1} \\
\hline & Position 1 & Position 2 & Position 3 \\
\hline $2.1 / 4 \mathrm{MHz}$, Gaınma & $2.4 / 0.4$ & 2 & $\widehat{3}$ \\
\hline $5 \mathrm{MHz}$, Gamma & $2.4 / 0.36$ & 2 & (3) \\
\hline $2 \cdot 1 / 4 \mathrm{MHZ}_{2}, \mathrm{SIZ}$ & $2.4 / 0.4$ & (2) & 3 \\
\hline $5 \mathrm{MHz}, \mathrm{SIZ}$ & $2.4 / 0.2$ & 2) & 3 \\
\hline $5 \mathrm{MHz}, \mathrm{SIL}$ & $2.4 / 0.6$ & 2 & $\widehat{3}$ \\
\hline
\end{tabular}

$5 / 64$ In. Dia Flat Bottom Holes

\begin{tabular}{|l|c|c|c|}
\hline \multirow{2}{*}{ Search Unit } & \multicolumn{3}{|c|}{ Ultrasonic Noise Level $\widehat{\text { 1 }}$} \\
\cline { 2 - 4 } & Position 1 & Position 2 & Prsition 3 \\
\hline $2.1 / 4 \mathrm{MHz}$, Gamma & $2.4 / 0.2$ & $\hat{2}$ & $\hat{3}$ \\
$5 \mathrm{MHz}$, Gamma & $2.4 / 0.2$ & $\hat{2}$ & $\hat{3}$ \\
$2.1 / 4 \mathrm{MHz}, \mathrm{SIZ}$ & $2.4 / 0.1$ & $\hat{2}$ & $\hat{3}$ \\
$5 \mathrm{MHz}, \mathrm{SIZ}$ & $2.4 / 0.1$ & $\hat{2}$ & $\hat{3}$ \\
$5 \mathrm{MHz}, \mathrm{SIL}$ & $2.4 / 0.2$ & $\hat{2}$ & $\hat{3}$ \\
\hline
\end{tabular}

(1) Amplitude of the noise in inches when the hole response is adjusted to $80 \%$ of saturation. (2) No hole response 
TABLE 39

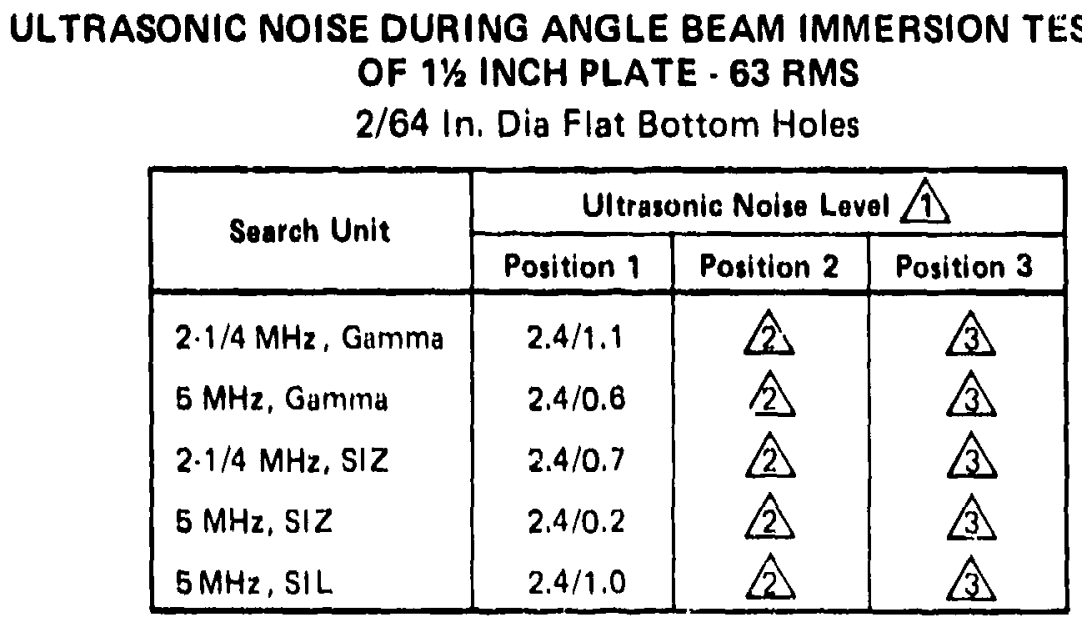

3/64 In. Dia Flat Bottom Holes

\begin{tabular}{|l|l|c|c|}
\hline \multirow{2}{*}{ Search Unit } & \multicolumn{3}{|c|}{ Ultrisonic Noise Laval $\hat{1}$} \\
\cline { 2 - 4 } & Position 1 & Position 2 & Pusition 3 \\
\hline $2.1 / 4 \mathrm{MHz}$, Gamma & $2.4 / 0.4$ & $\hat{2}$ & $\widehat{3}$ \\
$5 \mathrm{MHz}$, Gamma & $2.4 / 0.25$ & $\hat{2}$ & $\hat{3}$ \\
$2.1 / 4 \mathrm{MHz}, \mathrm{SIZ}$ & $2.4 / 0.3$ & $\hat{2}$ & $\hat{3}$ \\
$5 \mathrm{MHz}, \mathrm{SIZ}$ & $2.4 / 0.2$ & $\hat{2}$ & $\hat{3}$ \\
$5 \mathrm{MHz}, \mathrm{SIL}$ & $2.4 / 0.4$ & $\hat{2}$ & $\hat{3}$ \\
\hline
\end{tabular}

$5 / 64$ In. Dia Flat Bottom Holes

\begin{tabular}{|c|c|c|c|}
\hline \multirow{2}{*}{ Search Unit } & \multicolumn{3}{|c|}{ Ultrasonic Noise Level $/ 1$} \\
\hline & Position 1 & Position 2 & Position 3 \\
\hline 2.1/4 MHz, Gamma & $2.4 / 0.2$ & & \\
\hline $5 \mathrm{MHz}$, Gamma & $2.4 / 0.25$ & & \\
\hline $2 \cdot 1 / 4 \mathrm{MHz}, \mathrm{SIZ}$ & $2.4 / 0.1$ & & \\
\hline $5 \mathrm{MHz}, \mathrm{SIZ}$ & $2.4 / 0.1$ & & \\
\hline $6 \mathrm{MHz}, \mathrm{SIL}$ & $2.4 / 0.2$ & & \\
\hline
\end{tabular}

(1) Amplltude of the nolse in inches when the hole respones is adjusted to $80 \%$ of safuration. 2. No hole response

3. Testing not performed from Position 3.

QP/4.011783 
TABLE 40

ULTRASONIC NOISE DURING ANGLE BEAM IMMERSION TESTING OF 1 INCH PLATE AS-ROLLED

$2 / 64$ In. D , Flat Bottom Holes

\begin{tabular}{|c|c|c|c|}
\hline \multirow{2}{*}{ Search Unit } & \multicolumn{3}{|c|}{ Ultrasonic Noise Level $\triangle$} \\
\hline & Position 1 & Position 2 & Position 3 \\
\hline 2.1/4 MHz, Gamma & $2.4 / 0.3$ & 7 & \\
\hline $5 \mathrm{MHz}$, Gamma & $2.4 / 0.1$ & $\Leftrightarrow$ & \\
\hline $2 \cdot 1 / 4 \mathrm{MHz}_{3} \mathrm{SIZ}$ & $2.4 / 0.1$ & 2 & 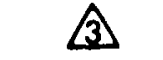 \\
\hline j $M H z, S I Z$ & $2.4 / 0.6$ & 2 & $(\Delta)$ \\
\hline $5 \mathrm{MHz}, \mathrm{SIL}$ & $2.4 / 0.15$ & 2 & 3 \\
\hline
\end{tabular}

$3 / 64$ in. Dis Flat Bottom Holes

\begin{tabular}{|c|c|c|c|}
\hline \multirow{2}{*}{ Search Unit } & \multicolumn{3}{|c|}{ Ultrasonic Noise Level 10} \\
\hline & Pissition 1 & Position 2 & Position 3 \\
\hline $2 \cdot 1 / 4 \mathrm{MHz}$, Gamma & $2.4 / 0.3$ & 2 & is \\
\hline $5 \mathrm{MHz}$, Gamma & $2.4 / 0.1$ & (2) & 3 \\
\hline $2 \cdot 1 / 4 \mathrm{MHz}, \mathrm{SIZ}$ & 2.4 .0 .1 & (2) & (3) \\
\hline $5 \mathrm{MHz}, \mathrm{SIZ}$ & 2.4 .12 .7 & 2 & $\angle$ \\
\hline $5 \mathrm{MHz}, \mathrm{SIL}$ & $2.4 / 0.1$ & 2 & (3) \\
\hline
\end{tabular}

$5 / 64$ In. Dia Flat Bottom Holes

\begin{tabular}{|c|c|c|c|}
\hline \multirow{2}{*}{ Seorch Unit } & \multicolumn{3}{|c|}{ Ultrasonic Noise Level \ } \\
\hline & Position 1 & Position 2 & Position 3 \\
\hline $2 \cdot 1 / 4 \mathrm{MHz}$, Gamma & $2.4 / 0.12$ & 2 & $\hat{3}$ \\
\hline $5 \mathrm{MHz}$, Gumma & $2.4 / 0.05$ & 2 & (3) \\
\hline $2 \cdot 1 / 4 \mathrm{MHz}_{2} \mathrm{SIZ}$ & $2.4 / 0.1$ & 2. & $\hat{3}$ \\
\hline $5 \mathrm{MHz}, \mathrm{SIZ}$ & $2.4 / 0.8$ & 2 & 3 \\
\hline $5 \mathrm{MHz}, \mathrm{SIL}$ & $2.4 / 0.15$ & 2 & $\hat{3}$ \\
\hline
\end{tabular}

(1) Amplitude of the noiso in inches when the hole response is adjusted to $80 \%$ nt saturation. (2) No hole response

3) Testing not partormad from Position 3 
TABLE 41

ULTRASONIC NOISE DURING ANGLE BEAM IMMERSION TESTING OF $1 \frac{1}{2}$ INCH PLATE - 125 RMS

$2 / 64$ In. Dia Flat Bottom Holes

\begin{tabular}{|c|c|c|c|}
\hline \multirow{2}{*}{ Search Unit } & \multicolumn{3}{|c|}{ Ultrasonic Noise Level $\widehat{\imath}$} \\
\hline & Position 7 & Position 2 & Position 3 \\
\hline $2 \cdot 1 / 4 \mathrm{MHz}$, Gamma & $2.4 / 0.4$ & (2) & 3 \\
\hline o $\mathrm{MHz}_{\text {, Gamma }}$ & $2.4 / 0.2$ & & \\
\hline $2 \cdot 1 / 4 \mathrm{Mitz}, \mathrm{SIZ}$ & $2.4 / 0.2$ & & \\
\hline $5 \mathrm{MHz}, \mathrm{SIZ}$ & $2.4 / 0.3$ & & \\
\hline $5 \mathrm{MH}+\mathrm{z}, \mathrm{SIL}$ & $2.4 / 0.2$ & f & 1 \\
\hline
\end{tabular}

$3 / 64$ In. Dia Flat Bottom Holes

\begin{tabular}{|c|c|c|c|}
\hline \multirow{2}{*}{ Search Unit } & \multicolumn{3}{|c|}{ Uitrasonic Noise Level 1} \\
\hline & Position 1 & Position 2 & Position 3 \\
\hline 2.1/4 MHz, Gamma & $2.4 / 0.4$ & 2 & 3 \\
\hline $5 \mathrm{MHz}$, Gamma & $2.4 / 0.3$ & & \\
\hline $2 \cdot 1 / 4 \mathrm{MHz}, \mathrm{SIZ}$ & $2.4 / 0.2$ & & \\
\hline $5 \mathrm{MHz}, \mathrm{SIZ}$ & $2.4 / 0.3$ & & \\
\hline $5 \mathrm{MHz}, \mathrm{SIL}$ & $2.4 / 0.2$ & 1 & 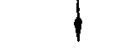 \\
\hline
\end{tabular}

$5 / 64$ In. Dia Flat Bottom Holes

\begin{tabular}{|c|c|c|c|}
\hline \multirow{2}{*}{ Search Unit } & \multicolumn{3}{|c|}{ Ultrasonic: Noise Level $\widehat{1}$} \\
\hline & Position 1 & Position 2 & Position 3 \\
\hline 2.1/4 MHz, Gamina & $2.4 ! 0.4$ & 2 & (3) \\
\hline $5 \mathrm{MHz}$, Gamma & $2.4 / 0.2$ & & \\
\hline $2.1 / 4 \mathrm{MHz}, S \mid Z$ & $2.4 / 0.3$ & & \\
\hline $5 \mathrm{MHz}, \mathrm{SIZ}$ & $2.4 / 0.2$ & & \\
\hline $5 \mathrm{MHz}, \mathrm{SIL}$ & $2.4 / 0.5$ & $f$ & 1 \\
\hline
\end{tabular}

(1) Amplitude of the noiso in inches whon tho hole responso is adjusted $t 280 \%$ ui saturation. 2. No hole renponso

(3) Testing not performod fiom Positlun 3. 
TABLE 42

ULTRASONIC NOISE DURING ANGLE BEAM IMMERSION TESTING OF $1 \frac{1}{2}$ INCH PLATE - 63 RMS

$2 / 64$ In. Dia Flat Bottom Holes

\begin{tabular}{|c|c|c|c|}
\hline \multirow{2}{*}{ Search Unit } & \multicolumn{3}{|c|}{ Ultrasonic Noise Leval $\widehat{\Lambda}$} \\
\hline & Position 1 & Position 2 & Position 3 \\
\hline 2.1/4 MHz, Gamma & $2.4 / 0.15$ & 2 & $A$ \\
\hline $5 \mathrm{MH}$, Gamma & $2.4 / 0.3$ & 2 & 20 \\
\hline $2 \cdot 1 / 4 \mathrm{MHz}, \mathrm{SIZ}$ & $2.4 / 0.1$ & 2 & 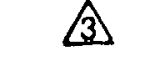 \\
\hline $5 \mathrm{MHz}, \mathrm{SIZ}$ & $2.4 / 0.4$ & 2 & 3 \\
\hline $5 \mathrm{MHz}$, SIL & $2.4 / 0.1$ & (2) & 3 \\
\hline
\end{tabular}

$3 / 64$ In. Dia Flat Bottom Holes

\begin{tabular}{|c|c|c|c|}
\hline \multirow{2}{*}{ Stsarch Unit } & \multicolumn{3}{|c|}{ 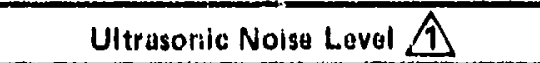 } \\
\hline & Position 1 & Position 2 & Position 3 \\
\hline 2.1/4 MHz, Gamma & $2.4 / 0.2$ & 2 & $\widehat{3}$ \\
\hline $5 \mathrm{MHz}_{2}$, Gamma & $2.4 / 0.1$ & $\cos$ & \\
\hline $2 \cdot 1 / 4 \mathrm{MHz}, 512$ & $2.4 / 0.7$ & 2 & 今 \\
\hline $5 \mathrm{MH} \rightarrow \mathrm{SIZ}$ & $2.4 / 0.3$ & 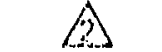 & 3 \\
\hline $5 \mathrm{MHH}_{2}$, Sll. & $2.4 / 0.1$ & $A$ & $\hat{3}$ \\
\hline
\end{tabular}

5/64 In. Dia Flat Bottorn Holes

\begin{tabular}{|c|c|c|c|}
\hline \multirow{2}{*}{ Search Unit } & \multicolumn{3}{|c|}{ Ultrasonic Noise Level 1} \\
\hline & Position 1 & Position 2 & Position 3 \\
\hline $2 \cdot 1 / 4 \mathrm{MHz}$, Gamma & $2.4 / 0.2$ & A & 3 \\
\hline $6 \mathrm{MH} \therefore$ Gamma & $2.4 / 0.2$ & 2 & (3) \\
\hline $2 \cdot 1 / 4 \mathrm{MH}_{2}, 51 Z$ & $2.4 / 0.1$ & 2 & 3 \\
\hline $5 \mathrm{MHZ}, \mathrm{SIZ}$ & $2.4 / 0.6$ & 2 & $\widehat{3}$ \\
\hline $5 \mathrm{MHL}_{2}, \mathrm{SH}$ & $2.4 / 0.15$ & 2 & $\hat{3}$ \\
\hline
\end{tabular}

(1) Amplitudo of the rlotse in inchas when tha hole rasponse is adjusted to gon of saturation. 2. Ne holu respunso

Testing not partomed from Position a. 
SECTION IV

\section{PROCESSING OF INGOT}

This program was concerned with the detection of typical aiscontinuities in titanium alloy components lising nondestructive methocks.

The sources of defects in components manufactured from titanium alloys include many of those which also are common to other metals. However, sponge reduction, consumable elactrode fabrication, and arc melting processes present a number of problem sources which are unique to titanlum alloys. These problems have been of particular concern since NDI methods were not always originally selected with the alm of finding these unusual types of defects. In addition, some of these defects were found to be of a size and character winch necessitated the development of more sensitive and sophisticated NDT techniques.

A considerable effort has been expended over the past several years in an attempt to identily, and insofar as possible prevent, the sources of defects in titaniun compoients. These sources may be divided into those associated with raw materials (sponge, alloying elements, etc.) and ingot melting conditions an! thos: asscciated with thermo-mechanical processing of Ingots to billet, bar, show!, ete., and of mill products to firished components (forging, machining, fomint, he treating, etc.).

The defects assonital with raw matorials and anciting are more or less peculiar to titanium metillurgy, while those associated with thermumechenical processing iriclude defects which are also comon to other materials. Discontinuities which might occur in titanium ingot include pipe in the top of the ingot, Type I. and Thy II alpha. etabilized defects and genera? porosity. Type I alpha stabilized defects are characterized by high lurd.ness, high thermal stability and in inclewsed oxygen and nitrogen content compared with the matrix. T'ype Il alpha stabilized defects are characterized by a lower hardness than lype I, a lower themal stabilit;, ani an increased aluminum content compared with the matrix. (Reference 3 ).

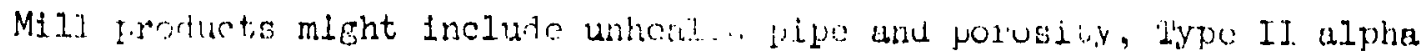

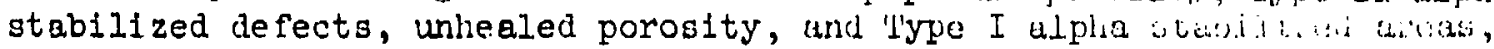
with or without assoniated voids. Forgings might contain unhedich pije and porosity, Type II alpha stabilized defects, unhealed porosity, and Iype I alpha stabilized areas, with or without associated voids.

Consequently, a full size production ingot was melted using techniques to intentionally induce Type I and II a.pha stabilized areas.

The ingot was converted to bar, plate, airframe forginge, and engine disk forgings, containing the discontinuities. The capability of appropriate NDT methods for the detertion of the serrecates was established. 


\section{INGO' MELTING}

A full size double vacuum melted production Ti-6Al-4V ingoc (24 inch dlameter, 7,500 pounds) vas produced for the program by Uregon Metallurgical Company (Oremet) in A.lbany, Oregon. The ingot raw material components were sponge, alloy, and revert chip. A photograph of the first melt ingot is shown in Flgure 57.

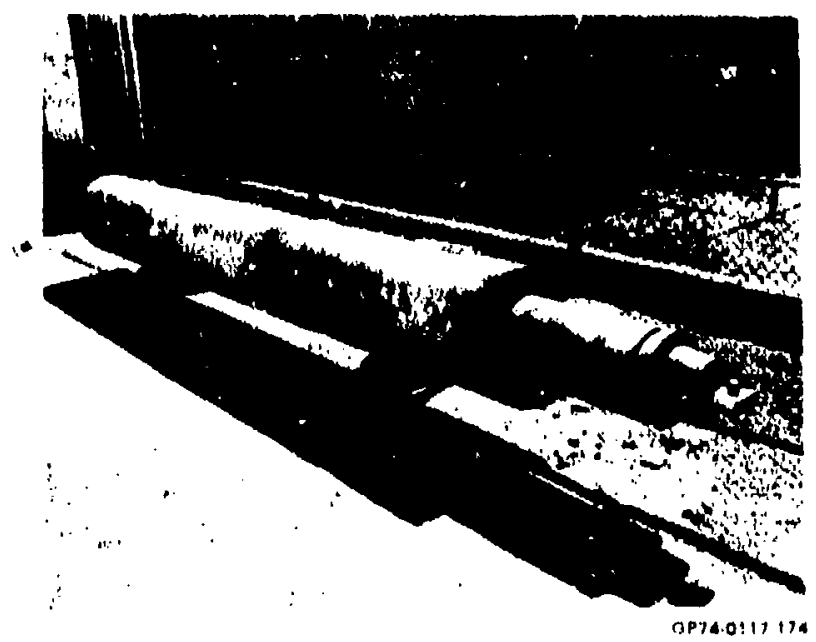

FIGURE 57

FIRST MELT INGOT

Ln urdes to intontionally produce lype 1. alpha stabilized defectis in tho ingot, the flrst melt alectrole was secded with titunium nitride. This seeding technique las bern successfilly used in the past by the U. S. Bureau of mines, Albany orepon station, under Air Force sponsorship and has been found to produce defects which closely resemble those which have occasionally cocurred in numit. we l.tinf, proctice (Reference $l_{t}$ ).

LWo types of lifol nitrogen seeds, nitrided sponge and mejted buttons,

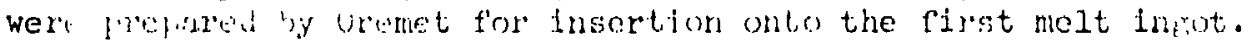

Initiajly, nitridud aponge wai produced by placing approximately 10 poumb

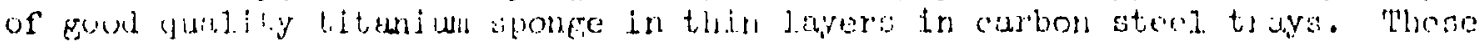

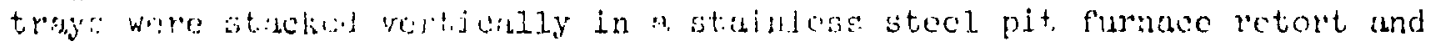

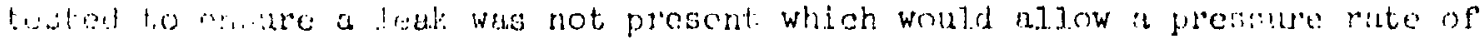

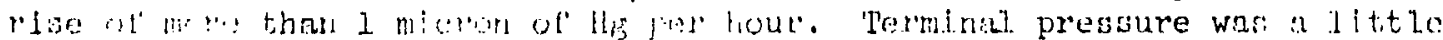

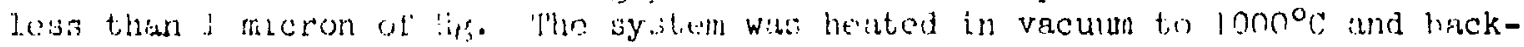

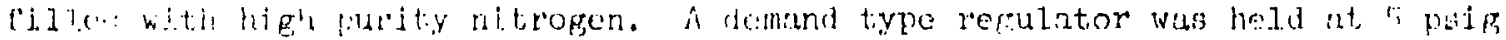

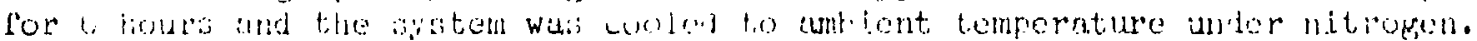


In order to increase the chances of inducing typical defects, two types of seeds were used for the ingot. The first type was the nitrided sponge itself. The second type was 15 to $25 \mathrm{gram}$ (approximate) nonconsumable arc melted buttons made from randomly selected nitrided sponge. The buttons were broken with a hamer and seeds were selected from the piecss. Each of the seed types used were 1 to 4 grams as Oremet experience indicated this range of seed sizes would yield a range of segregate sizes. A total of 79 seeds were selected for use in the ingot.

Figure 58 is a photograph of typical seeds along with the chemical analysis data.

Holes, $1 / 2$ inch diameter $x 1$ inch deep were drilled in 79 locations in the first melt ingot so that the seeds could be inserted. Hole locations for the first melt ingot were profiled in the form of a right hand spiral shown in Figure 59. Each hole was coded with proper identity to be certain correct seeds were inserted. The seeds were inserted and normal sponge particles inside. Care was taken not to break brittle seeds in this proness.

The second melt wa.s made using the seeded first melt ingot as an electrode. Melting was accomplished according to standasd practice. The melting was stopped 3 inches from the top. Power cutback on termination of remelt was purposely extremely rapid in comparison to normal practice in order to induce a large pipe and shrinkage zone in the ingot top with possir.le Type II alpha stabilized defects.

The second melt inget, Figure 60, was chanfered on the top and bottom to break the sharp corners to minimize cracking during subsequent forging and was shifped to the Ladish Company for conversion to billet stock.

The cilemical analysis of samples removed from the top and bottom of the ingot is as follows:

\begin{tabular}{|l|c|c|c|}
\hline \multicolumn{3}{|c|}{ Ingot Chemical Composition (Hoat No. RD 2234) } \\
\hline \multirow{2}{*}{ Element } & \multicolumn{2}{|c|}{ \% by Weight } & Ingot \\
\cline { 2 - 4 } & Top & Bottom & Aim \\
\hline Aluminum & 6.20 & 6.40 & 6.2 \\
Vanadium & 4.03 & 4.10 & 4.0 \\
Iron & 0.166 & 0.164 & 0.16 \\
Oxygen & 0.15 & 0.14 & 0.16 \\
Carbon & 0.062 & 0.062 & Low \\
Nitrogen & 0.010 & 0.008 & Low \\
Hydrogen & 0.0019 & 0.0016 & Low \\
\hline
\end{tabular}

QP74.0111111 


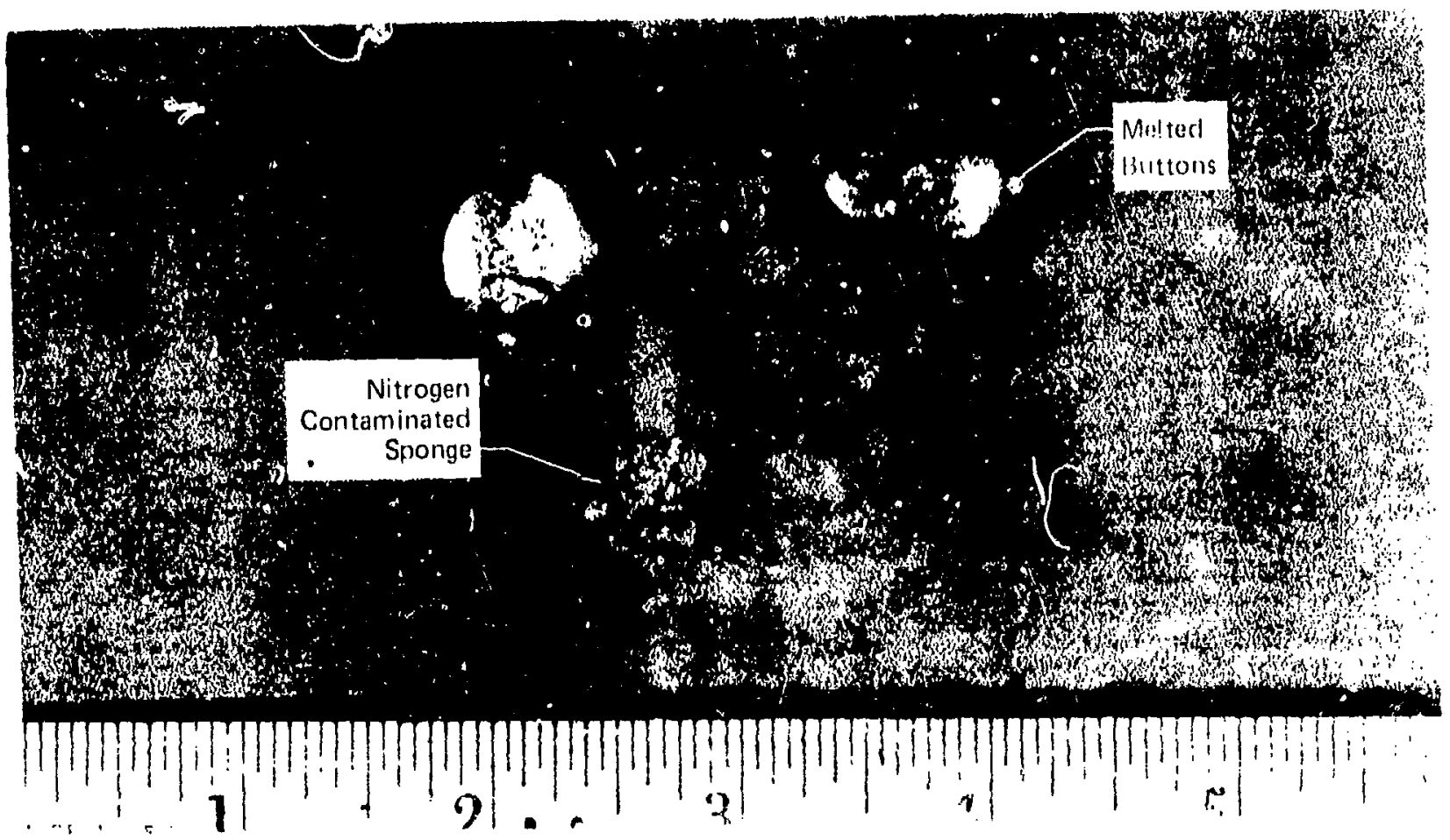

Chemical Analysis of Seed Material

\begin{tabular}{|l|c|}
\hline \multicolumn{1}{|c|}{ Seed Type } & $\begin{array}{c}\text { Nitrogen Content } \\
\text { (Weight Percent) }\end{array}$ \\
\hline Sponge No.1 & 8.4 \\
Sponge No. 2 & 4.4 \\
Sponge No. 3 & 8.0 \\
Melted Button No.1 & 8.8 \\
Melten Button No. 2 & 8.7 \\
\hline
\end{tabular}

FIGURE 58

SEEDS USED TO INTENTIONALLY PRODUCE ALPHA SEGREGATION 


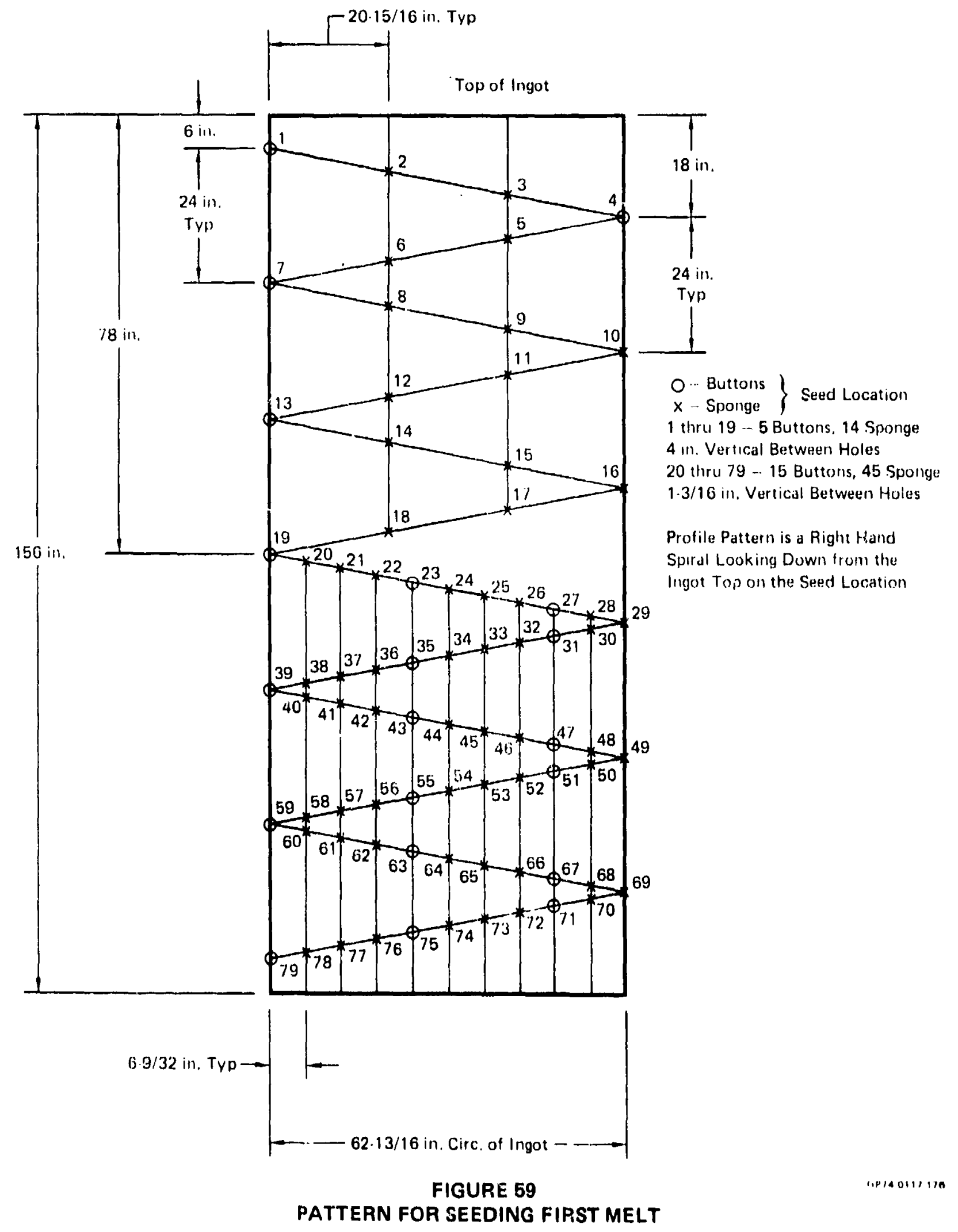




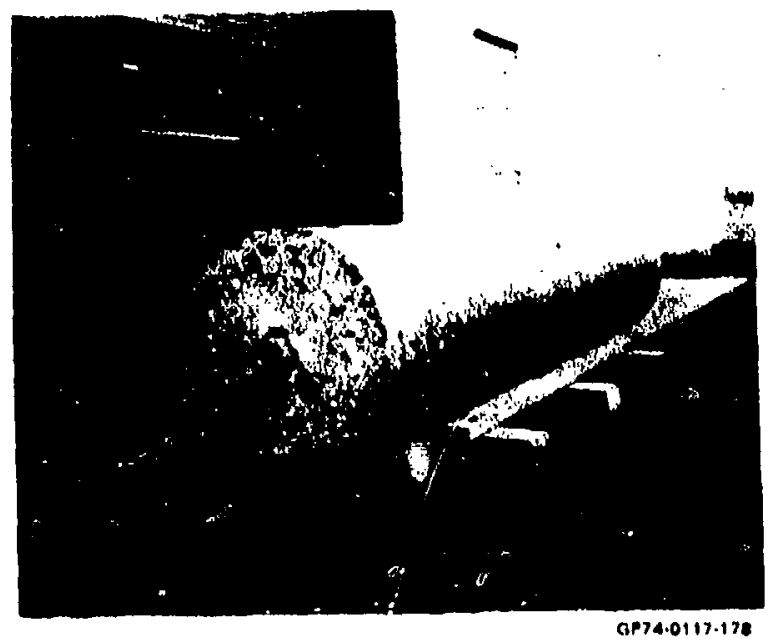

FIGURE 60

FINAL MELT INGOT'

The defects expected to be present in the 24 inch diameter ingot included a vold region with Type II alpha atabilized defects in the top 12-18 inches of the ingot (900-1300 pounds in weight). It was expected that the void area would be healed by diffusion bonding during the forging operations. However, it has been observed that these voids can be lined with ar aluminum rich zone, and an attempt was made to preserve this segregation by usirs relatively low working temperatures and short heating times during the ingot conversion process. The initial ingot conversion took place at the Ladish Company. Ladisi usualiy forges at $2050-2100^{\circ} \mathrm{F}$ for initial ingot breakdown but they used $1950^{\circ} \mathrm{F}$ for the subject ingot in order to retain the segregation. It is also possible that the relatively rapid f'reezing rate without hot-topping produced one or more zones of segregation in the top section of the ingot.

The buttom portion of the ingot was expected to contain the Type I segregation zones. Figure 61 shows the expected general locations of the various defects.

\section{INGOT CONVERGION TO BILLET, BAR PIATE, AND FORGINGS}

A schematic showing the steps taken to convert the ingot is shown in Figzires $62,63,64$, and 65. After having been lathe turned to a 125 rms surface finish and inspected, ihe irgot was heated to $1950^{\circ} \mathrm{i}^{\prime}$ and press forged by the Ladish Company to 18 inch round corner square (RCS) in one heat. Nuxt, the 18 inch RCS was reheated to $1800^{\circ} \mathrm{F}$ and press forged to 14 inch lRCS. The RCS was hot sheared to 3 lengths (101., 67 and 62 inches) with the section locations being based upon the discontinuity locations determined by the ultrasonic and radiographic inspections.

'i'he three billets were heat treated according to a proprietury ladish process. fifter reheating to $1750^{\circ} \mathrm{F}$ the three billets were press forged to 10 inch RCS. The 10 inch IRC; from the mldd]e and bottom portions if the ingot were hot shoured us shown in lifure 62. The 10 inch RCS from the top portion 'f' the ingot was not, hot, sherred at this starge to avoid any possibility of cutisinfe thrulph the inpot pjpe. If the inpot pipe was opened to the atmosphere at this itape, the surficces of the pipe would oxidize preventing the pipe form hesline, upon gubsequent forging. 
$\sim 900 \mathrm{lb}$

$\sim 4100 \mathrm{lb}$

$\sim 2500 \mathrm{lb}$

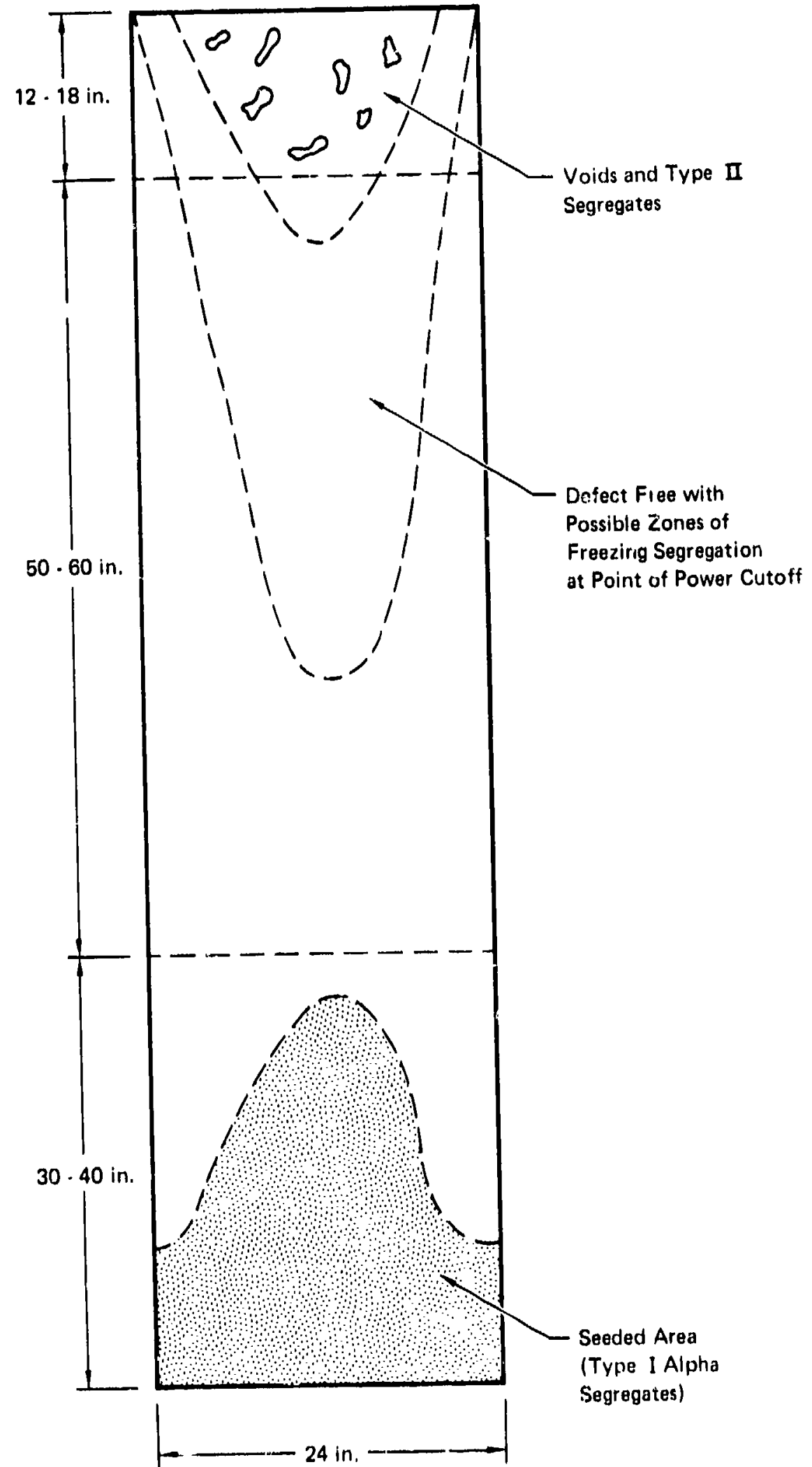

FIGURE 61

EXPECTED INGOT DEFECTS AFTER SECOND MELT 


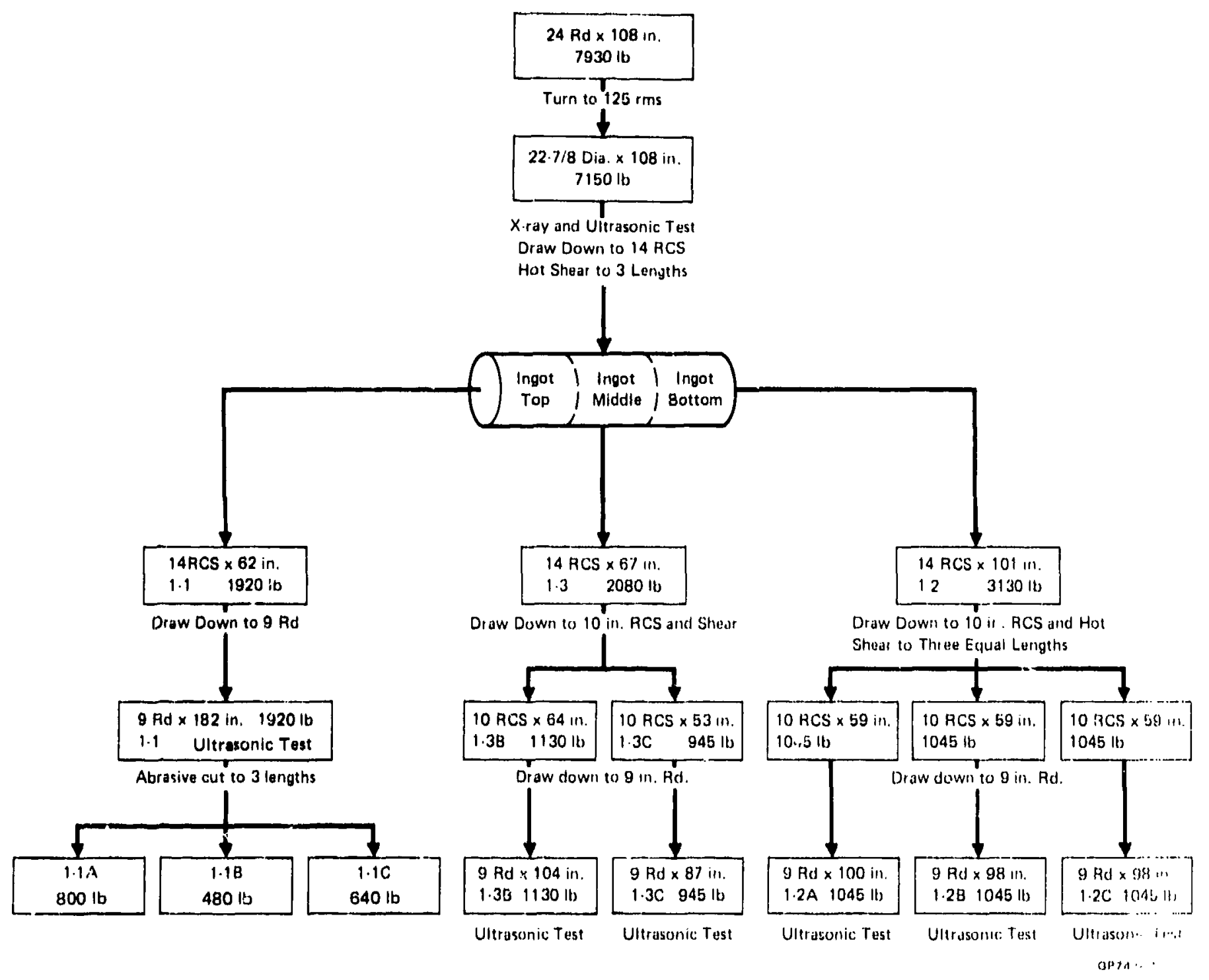

FIGURE 62

CONVERSION OF INGOT TO 9 INCH ROUND BILLET 


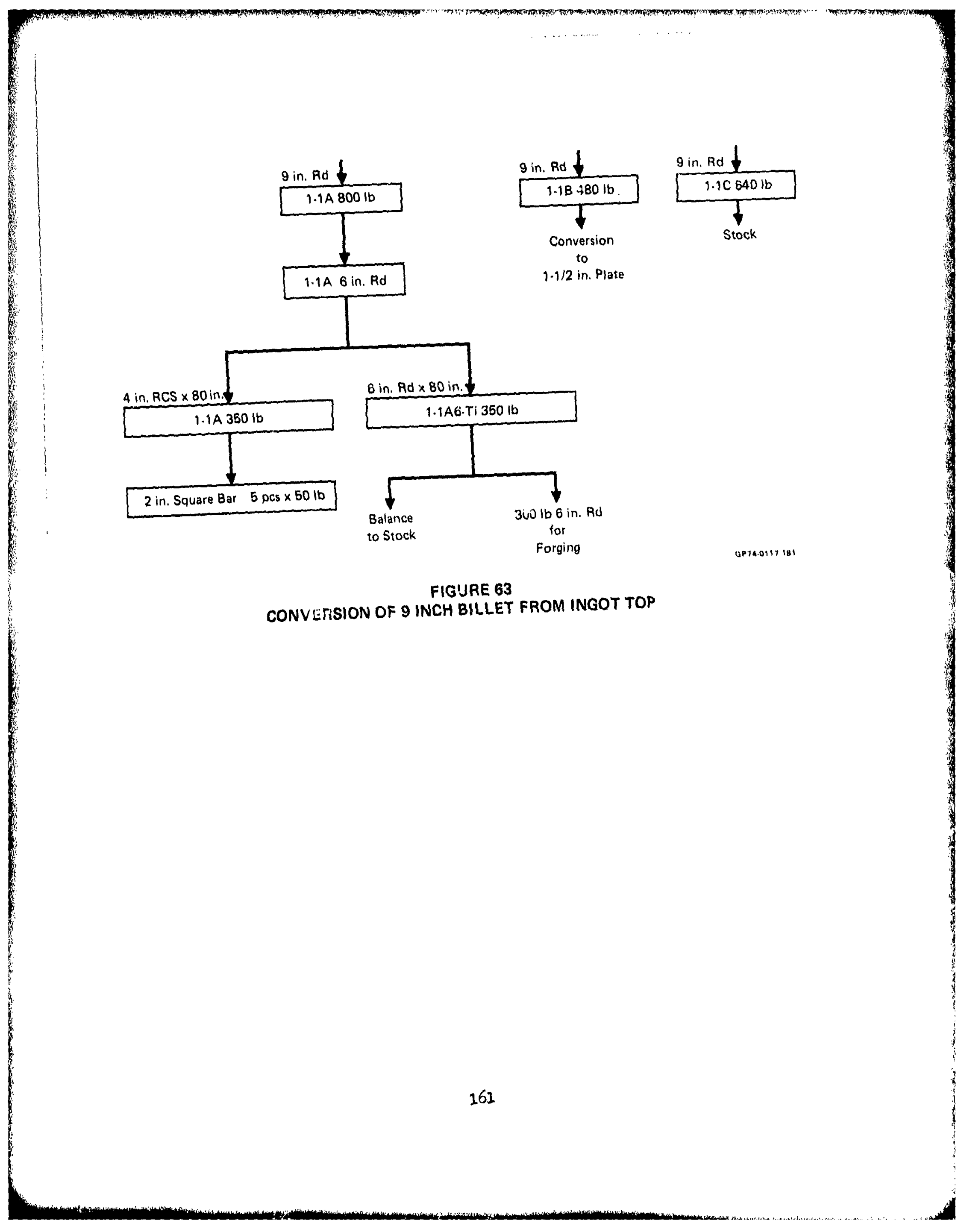




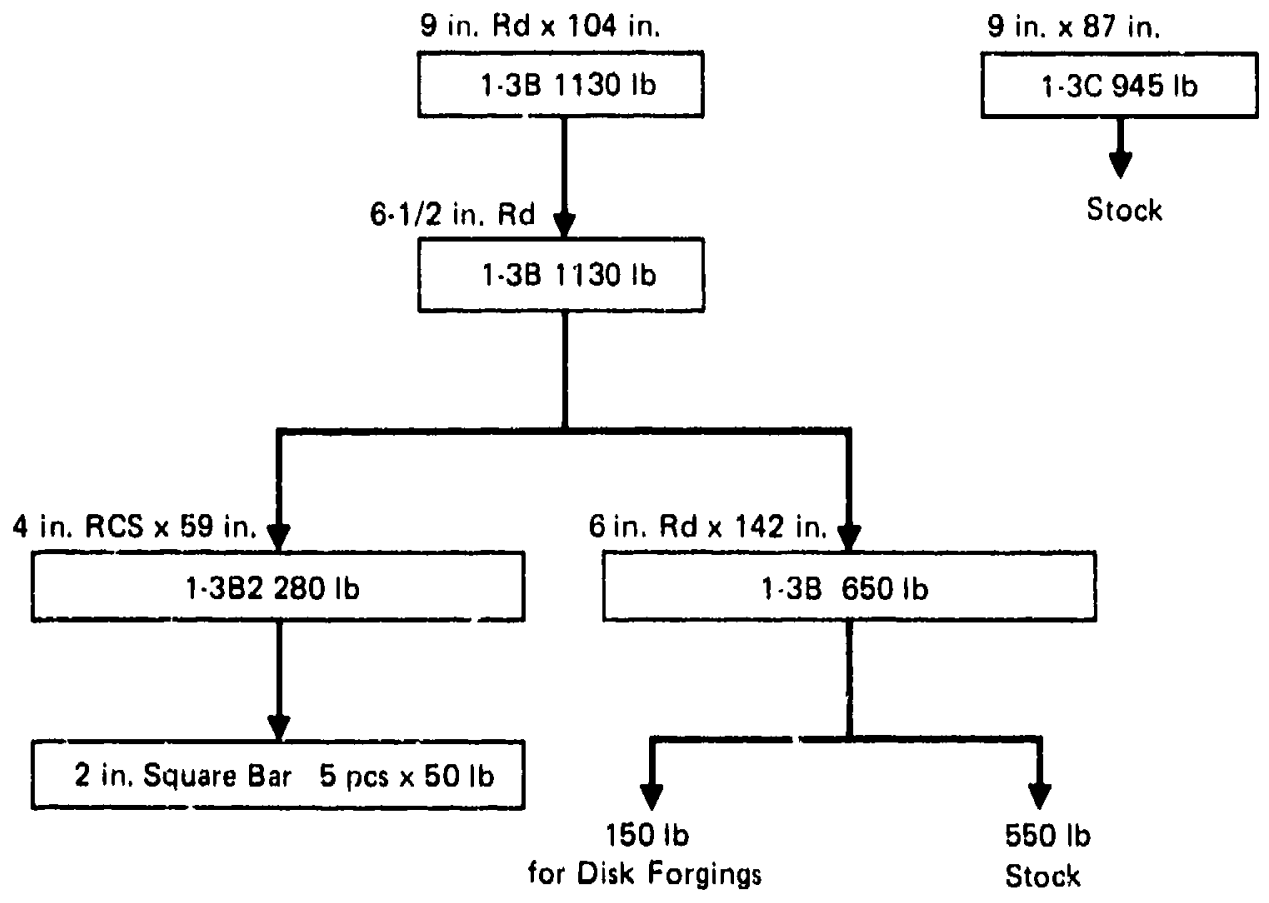

0.71 .0111 .182

FIGURE 64 CONVERSION OF 9 INCH BILLET FROM INGOT MIDDLE

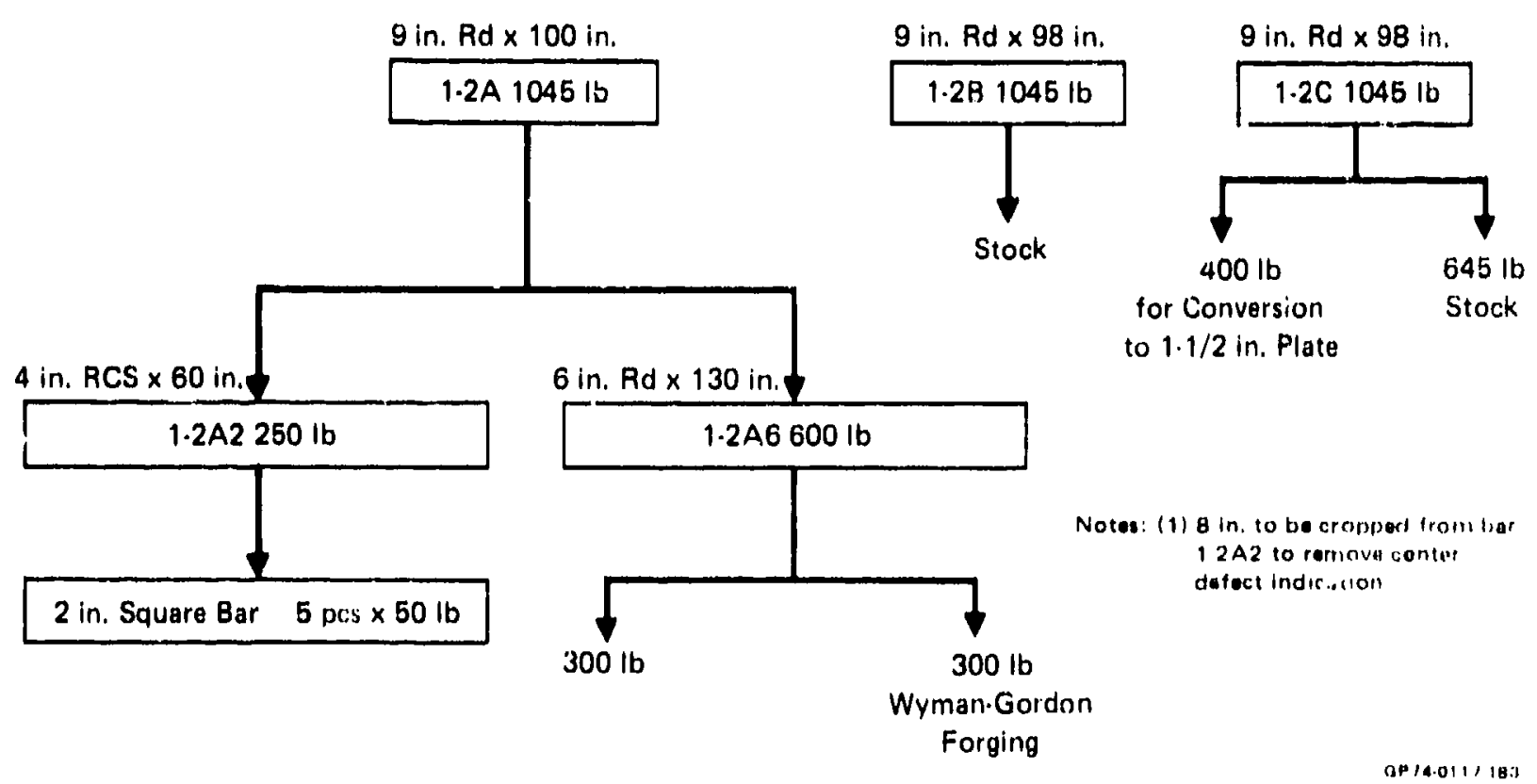

FIGURE 65

CONVERSIINN OF 9 INCH BILLET FROM INGOT BOTTOM 
Next, each 10 inch RCS was heated to $1750^{\circ} \mathrm{F}$ and press forged to $9-1 / 4$ inch rough round. The surfaces were Tysaman ground to 9 inch round with a 125 rms surface finish.

As shown in Figures 63, 64, and 65, one piece of 9 inch round from each of the three ingot sections was hented to $1750^{\circ} \mathrm{F}$ and press forged to 6 inch round by the Ladish Company. These pieces were then converted by the Ladish Company to 2 inch square bar and forging blanks. The 2 inch square bar was produced by open die hammer forging at $1750^{\circ} \mathrm{F} \cdot 1800^{\circ} \mathrm{F}$.

Plate, 1-1/2 inches thick, was produced from 9 inch round billets from tho top and bottom of the ingot. The 9 inch diameter billets were initially fluttened to $4-1 / 2$ inches thick by cross die forging at $1950^{\circ} \mathrm{F}$ by RMI Company. Finally, the two pieces were roliled on a foum-high rolling mill to $1-1 / 2$ inches thick from a furnace temperature of $1875^{\circ} \mathrm{F}$. The plate was rolled without reheating. A photograph of the two pieces of plate is shown in Figure 66.

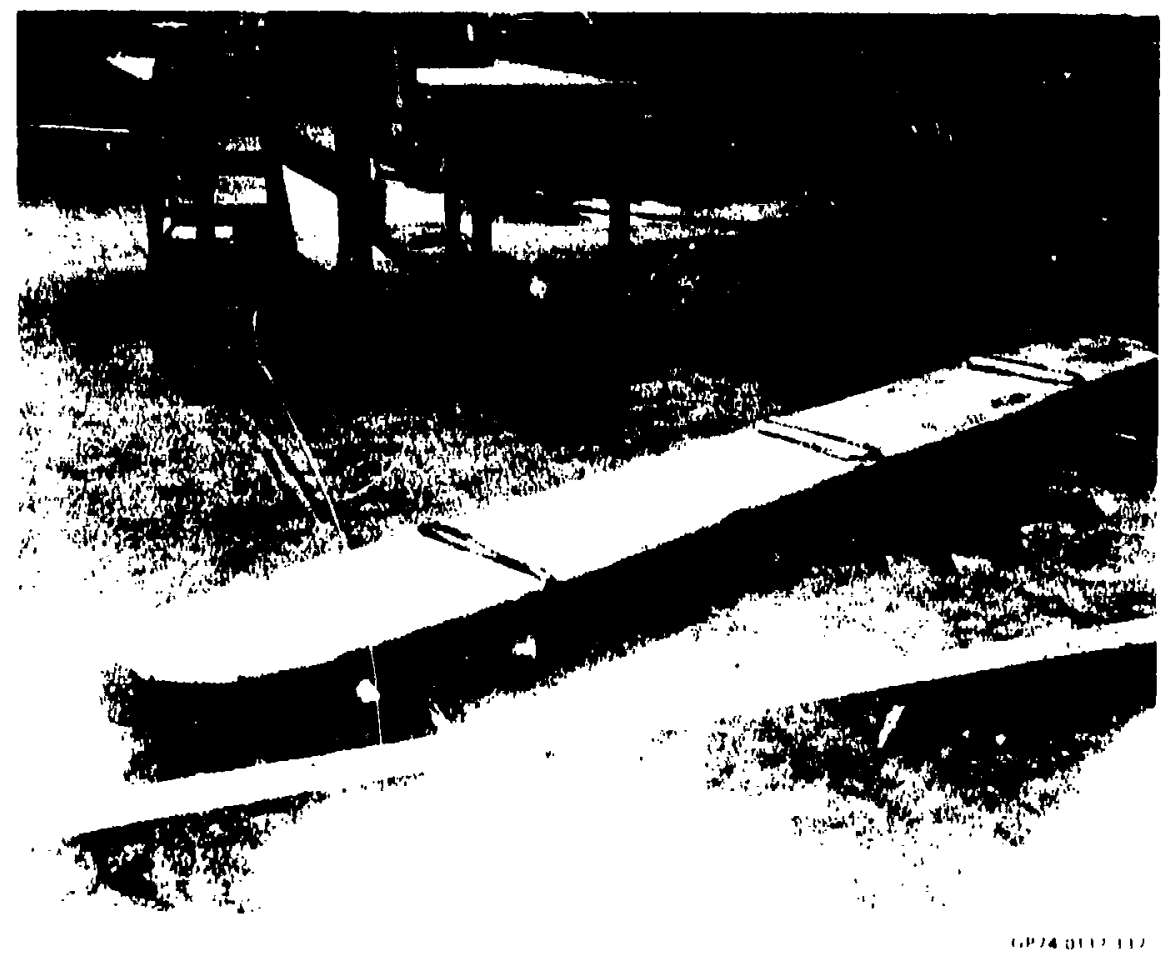

FIGURE 68

TWO PIELES OF DNE AND ONE-HALF INCH THICK PLATE 


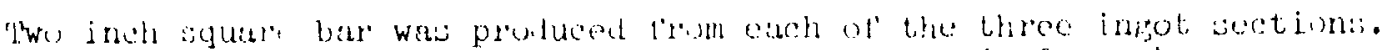

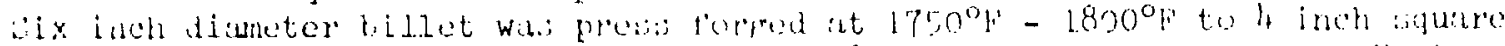

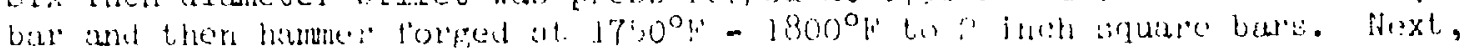

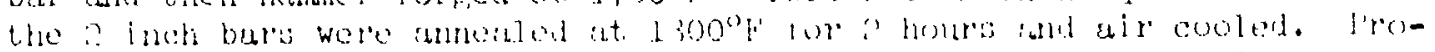

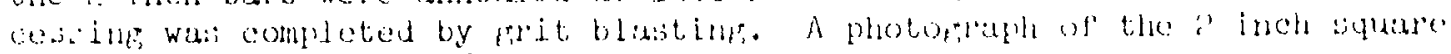
bitr is siown in likure $6 \%$.

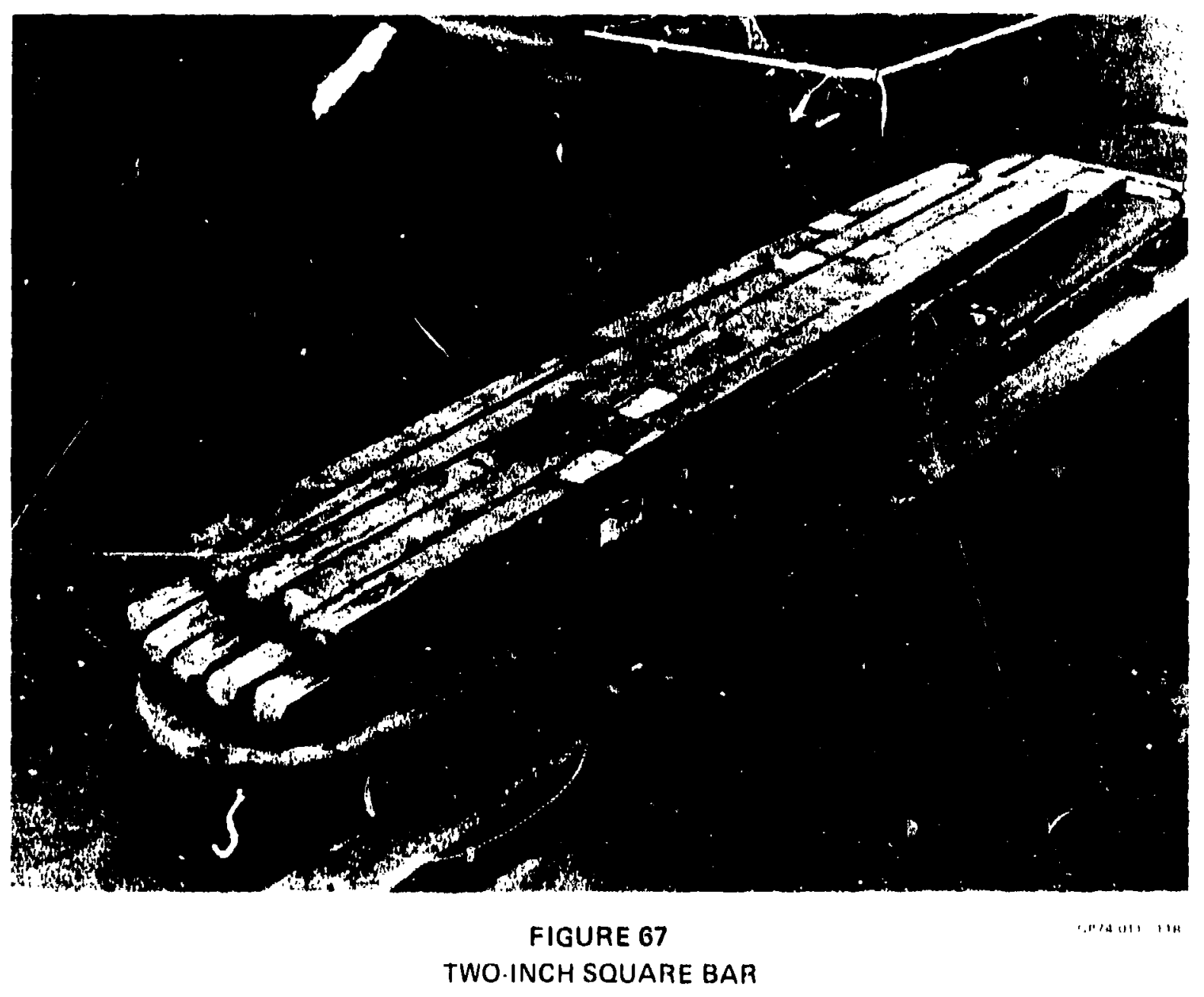

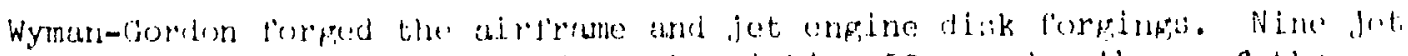

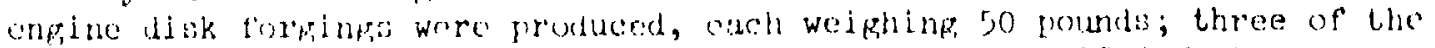

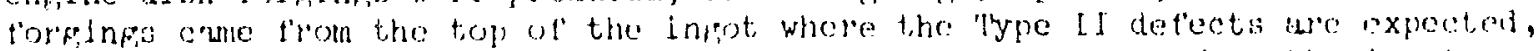
three eame from the defest-free infot contes, and three came from the infot.

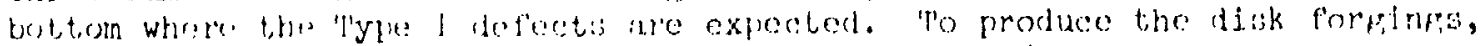

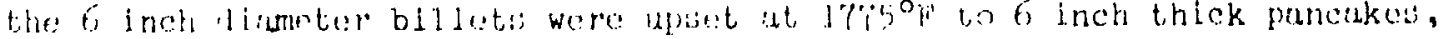

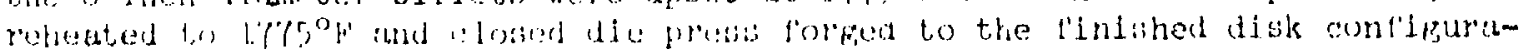

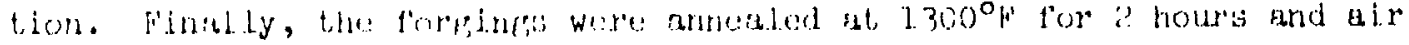
aoded. 
Light airframe f'orgings were produced, each weighing 25 pounds. Four of the forgings came f'rom the iugot top and four came from the infot bottom. The initial 6 inch aiameter billets were shaped on open dies at $1775^{\circ} \mathrm{F}$. After being reheated to $1775^{\circ} \mathrm{F}$, the pieces were blocker to intermediate shape on a press and each blocked shape was cut in half to make two forgings. The pieces were reheated to $1775^{\circ} \mathrm{F}$ and closed die press forged to the finished part shape. Finally, the finishod forgings were annealed at $1300^{\circ} \mathrm{F}$ for 2 hour s and uir cooled.

Prior to shipping, all the forgings were grit blusted and pickled to remove any alpha case. Photographs of the foreings are presented in Figures 68 and 69 . Drawings of the forging configurations are shown in Figures 70 and 71.
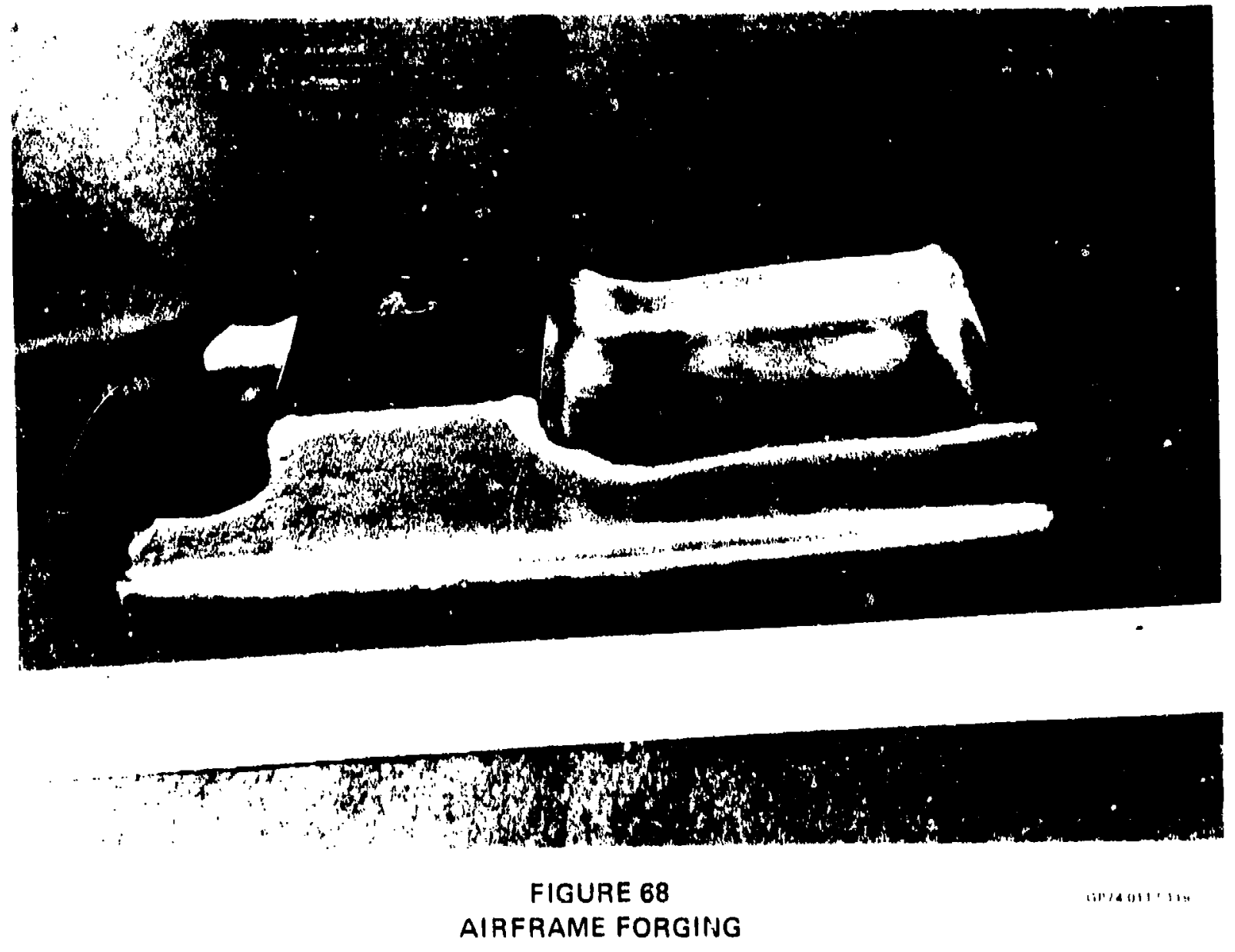

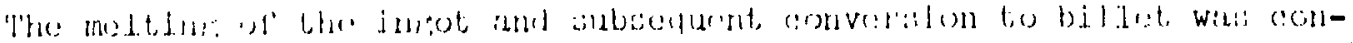

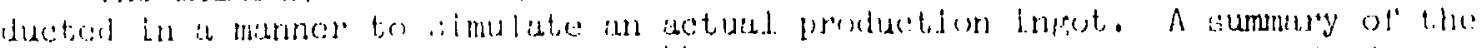

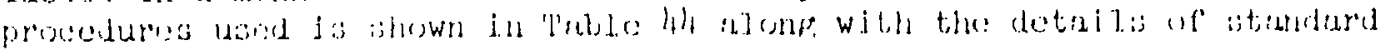
proselian.

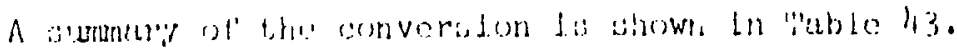





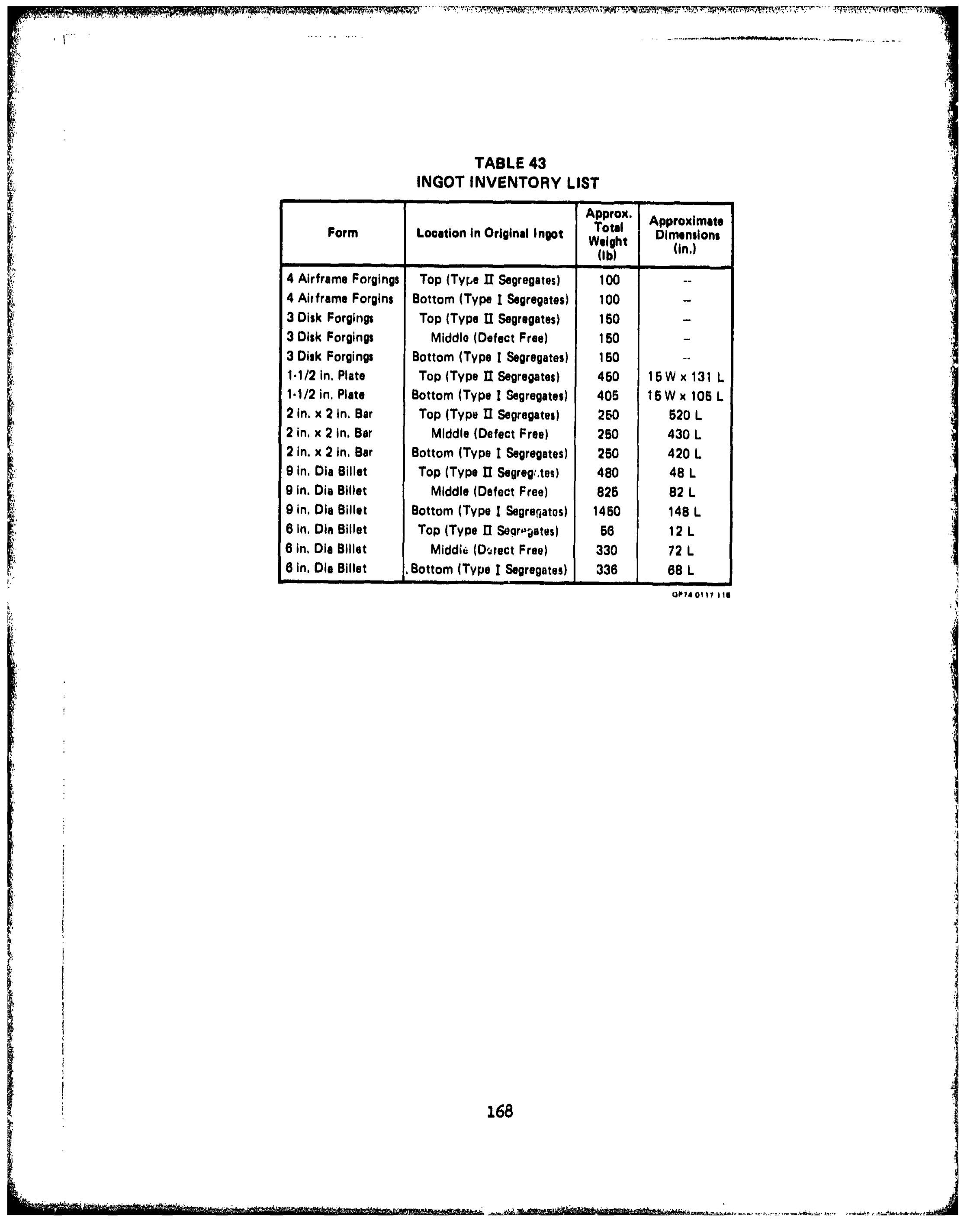




\section{INCPECTION OF INGO ${ }^{3}$}

The ingot was inspected both radiographically and ultrasonically. Since a previous Air Force program had been conducted to improve nondestructive testing for inspection of titanium alloy ingots, tha inspection of the subject ingot was not developmental fn nature (Reference 2). Many of the Allis Chalmers and Ladish Company established production inspection techniques were utilized since the primary objective of the ingot inspection was to select the locations for shearing the ingot after the first draw down. In addition, certain General Electric inspection techniques were used to increase the effectiveness of the inspections. However, the inspections were not intended to establish the minimum detectable defect size nor to precisely detail the location of each discontinulty in the ingot.

\section{a. Radlography}

The radiographic inspection of the ingot (125 rms surface finish) was carried out by Allis Chalmers in Milwaukee, Wisconsin. The inspection was performed using a $24 \mathrm{MeV}$ Allis Chalmers betatron and an exposure of 1900 Roentgens. An ASTM E-142 No. 100 penetrameter was used as an image quality indicator. Front and back lead screens, 0.060 inch thick, were used and the back-up material. was one inch thick lead. The Kodak AA filn was processed manually. Figure 72 shows the plan for the exposures taken ( 6 circumferential positions for each of 10 axial positions). Twelve inch wide axial areas were exposed using $14 \times 17$ inch film proviäing for film overlap. A schematic of the ingot being radiographed is in Figure 73. During the exposures the film was flat as opposed to being curved around the ingot. The image of the $1 T$ hole and the outer edge of the penetrameter panel were visible on all the radiographs resulting in an equivalent penetrameter sensitivity of 0.29 percent. The density range of the radiographs was 1.5 to $3.0 \mathrm{H}$ and $\mathrm{D}$ units.

The results of the radiographic inspection are shown in Table 45. The schematic in Figure 74 indicates the location of the axial and appareat circumferential dimensions lister in Table 45. As shown at the bottom of Figure 74 , there are two possible circumferential locations for each indication since it is not possible to determine if the indication lies on the far side or near side of the ingot using the chosen techniques. The ingot pipe was found to start within 2 inches of the top of the ingot and to extend to a depth of 16 inches from the ingot top. Low density indications were evident throughout the length of the ingot. A tota? of 22 indications were located (not including the ingot pipe) varying in approximate size from $.005 \times .050$ inch to $.010 \times .150$ inch. The large accumulation of Type I segregates expected in the bottom of the ingot apparently was unresolvable by the radiographic inspection.

\section{b. Ultrasonic Inspection}

The ultrasonic inspection of the ingot was carried out at the I, ajish cumpary in Milwakee, Wisconsin. Prior to the inspection, the surface of the ingot was lathe turned to a $125 \mathrm{ims}$ finish. For both 


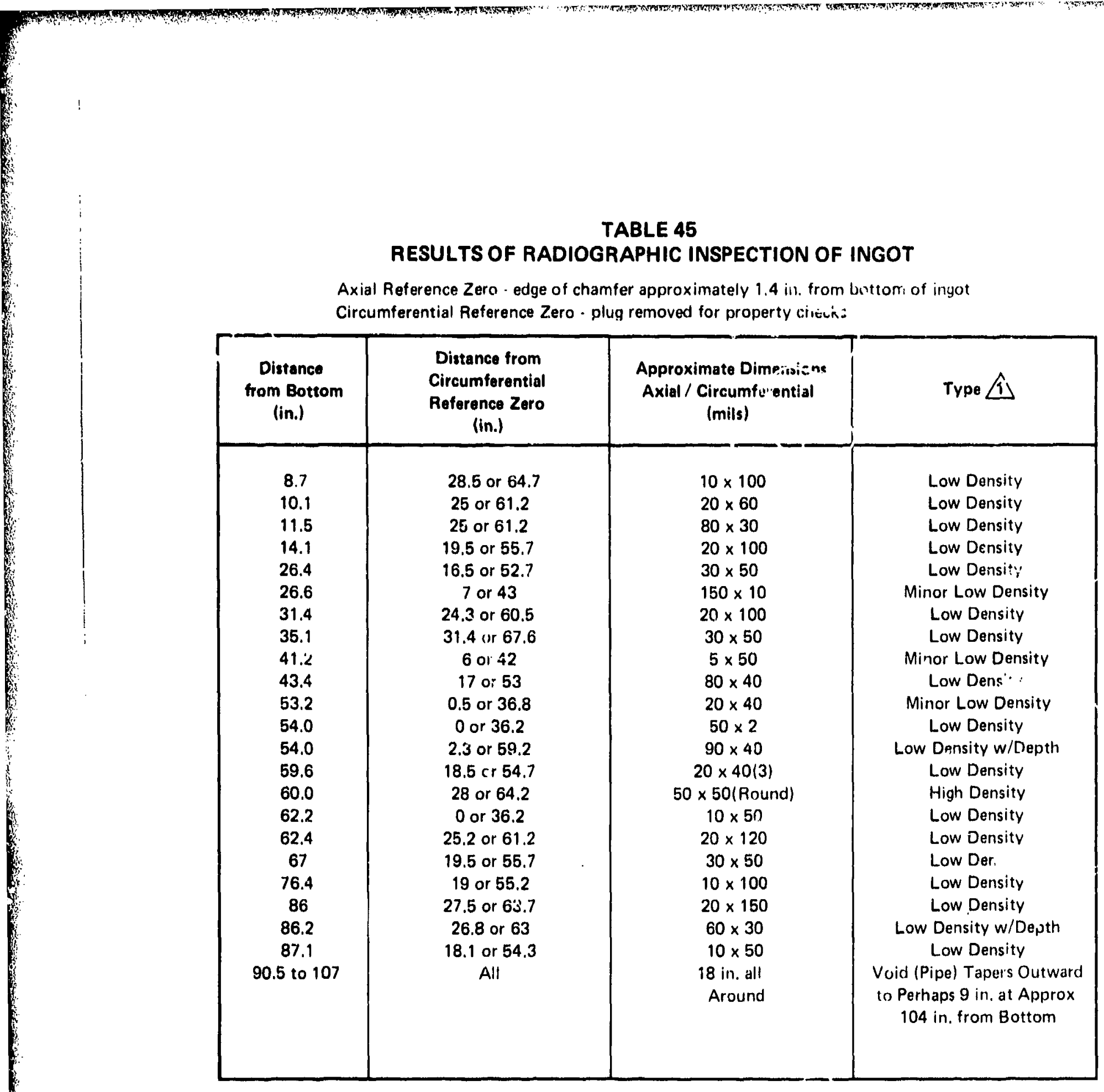

A Indiratisns wore visually iudgod to be lov. Ansity or high density.

GP740111.187

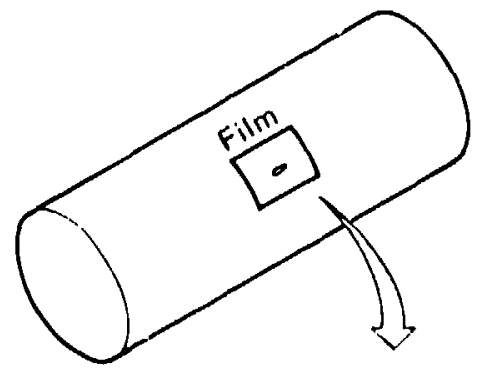

$A=A x i a t$ Dimension

$\mathrm{C}=$ Circumferential Dimerision

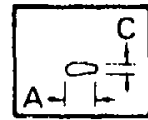


the longitudinal and shear inspection, two separate pulser/recelvers (Sperry 10N and Sperry 5N) were used in confunction with two Automation Industries unfocused transducers and two Sperry 721 oscilloscopes a.s shown in Figure 75. The vertical linearity of the electronic system had been checked by Ladish within 30 cays of the ingot inspection. Each pulser/receiver was checked for noise and calibration response on the same reference standard; there was little difference in the response of each. As shown in Figure 76, the two transducers were positioned 4 inches apart and the scan direction was parallel to the longitudinal axis of the ingot.

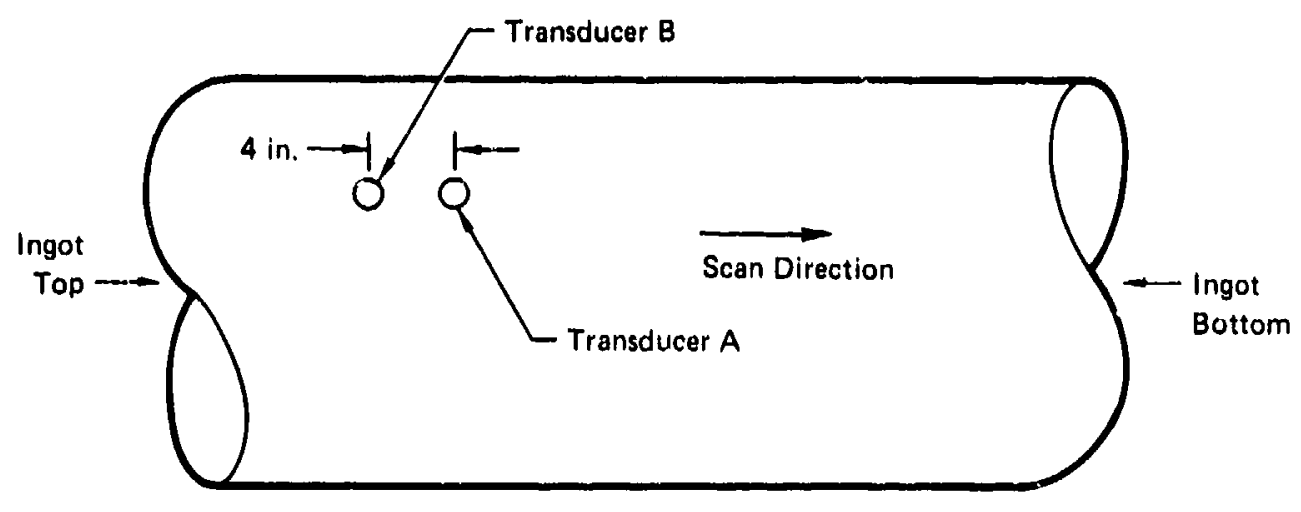

FIGURE 76
SCAN PLAN FOR INGOT

The scan rate was approximately 3 inches per second; prior to the actual ingot inspection, the scan rate was checked on the reference standard to ensure that the holes in the reference standard were detectable at that scan rate. After the transducers had scanned the full length of the ingot, the ingot was rotated less than $1 / 2$ inch and the scanning was continued.

During the inspection, the automatic alarm was set to trigger at $50 \%$ of the response from a $3 / 64$ inch diameter flat bottom hole, since the search unit may not be positioned for maximum response when it passed over each discontinuity. Therefore, prior to the inspection, the reference standard was checked to verify that with a $1 / 2$ inch scan index the response was greater than $50 \%$ of the max mum response from the 3/64 inch diametel flat bottom hole in the reference standard. When an indication is found, in order to determine i.ts actual size as compared to the reference standard, the search unit must be manipulated to maximize the signal response before making a value judgment. 

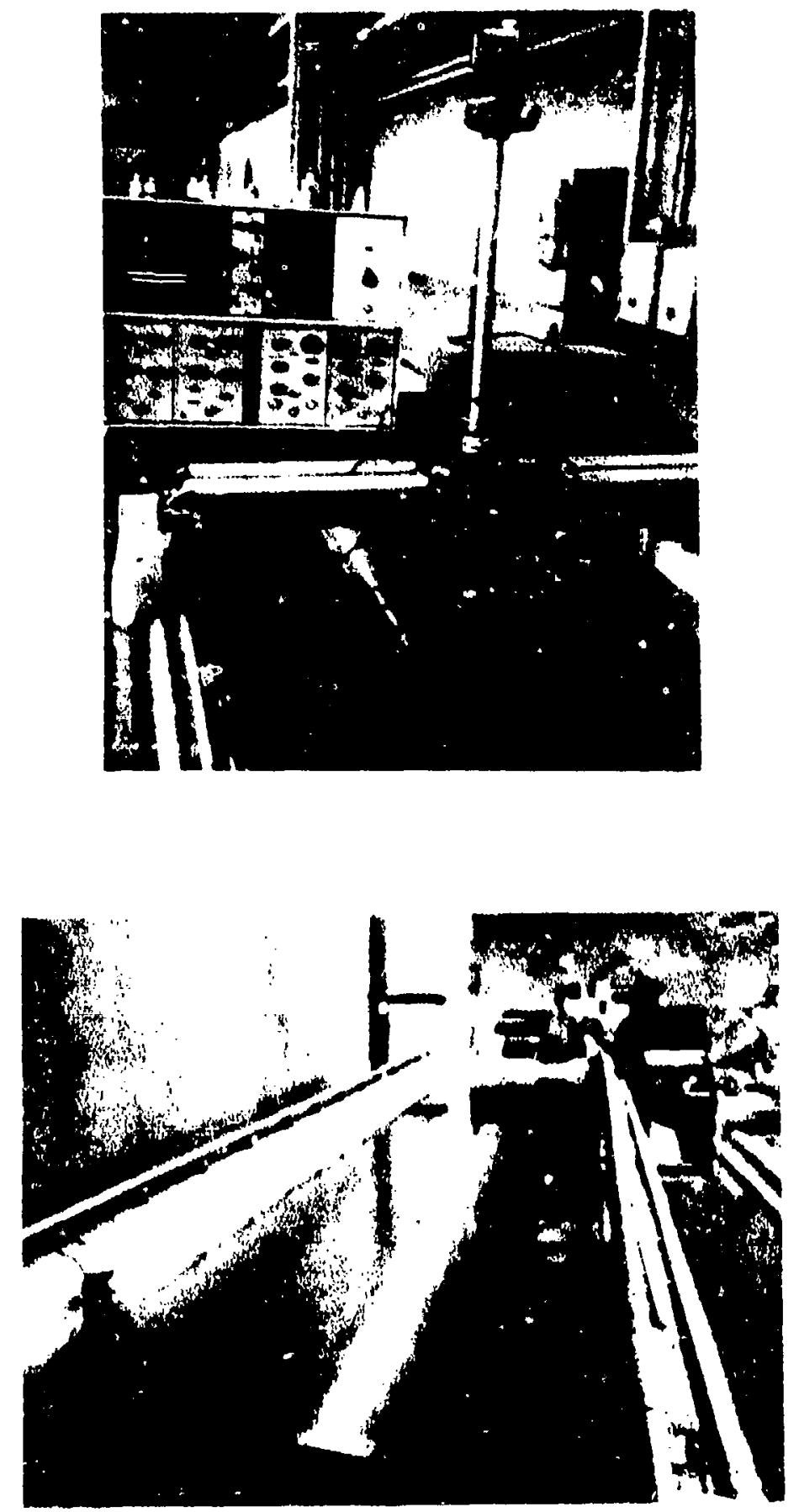

FIGURE 75

ULTRASONIC INSPECTION OF INGOT 
SIJ series ceramic transducers were obtained from Automation Industries for the ingot inspection. A group of transducers were tuned for use with the pulser/receiver to be used in the ingot inspection. From this group, several optimum transducers were selected by using the transducers on severa?. Ti-6Al-4V test blocks containing both natural and artificial defects. The characteristics of a typical transducer used in the ingot inspection are shown in Figure 77.

Figure 77 shows the spectrum analysis when the transducer was driven by a wide range pulser (Automation HRL) and also by the equipment used in the inspections. As can be seen, the peak radiated frequency using the $10 \mathrm{~N}$ pulser was within $+10 \%$ of the specified frequency.

Previous experience in inspecting jet engine disk forgings indicated that some discontinuities undecectable using longitudinal inspecticr wre aetectable using shewr. Consequently, both longitudinal and shear wave immersion inspections were carrled out on the ingot. The loneitudinal inspection was performed using 1 inch diameter unfocusfd transducers and a frequency of $2.25 \mathrm{MHz}$ and a 5 -inch water path. A frequency of $2.25 \mathrm{MHz}$ was necessary to inspect to the center of the 24 -inch diameter ingot. The sound beam path was as shown in Figure 78. The reference standard used for the longitudinal inspection was a 14-inch diameter iorged Ii-6AI-4V standard provided by the Ladish Company with $3 / 64$ inch dianeter flat bottom holes at metal travel distances of 6 and 7.5 inches (Figure 79). It would have been preferred to use a reference standard with the same diameter as the ingot ( 24 inches) but only a 14-inch diameter was avalable at Ludish. During the inspection, the automatic alarm system was set to trigger at $50 \%$ of the response from a $3 / 64$ diameter flat bottiom hole. As mentioned previousiv, two pulser/receivertransducer arrangements were used. One channel was gated to inspect the first 6 inches in depth of ingot and the second channel was gated to inspect from a depth of 5 to 12 irches. The $5 \mathrm{~N}$ pulser/recelver, which was affected least by noise, was used for the 5-12 inch inspection. A summary of the equipment used is presented in Table 46.

Both an axial and circumferentlal stear wave inspection were also performed. The same transducer and pulser/receiver arrangement was used as was with the longiturinal inspection. Again, a scan rate of approximately 3 inches per second was used and the scan index was less than $1 / 2$ inch. The sound bean directions within the ingot are depicted in Figure 78. With circumferential shear wave, approximately the first 5 inches of the ingot was inspected, whareas, with axial shear, the ingot material. from the surface to the center (12 inches) was inspected. 'I'wo $3 / 4$ inch diameter unfocused transducers were used at a test frequency of $5 \mathrm{kHz}$. The sound beam angle in water was chosen such that the sound beam angle in the metal. was 45 degrees. The water path was It inches. The reference standard used for circumferential shear was $n$ $11.5-i n c h$ diameter torged $P 1-6, \mathrm{~A} 1-4 \mathrm{~V}$ standard provided by the Ladish 

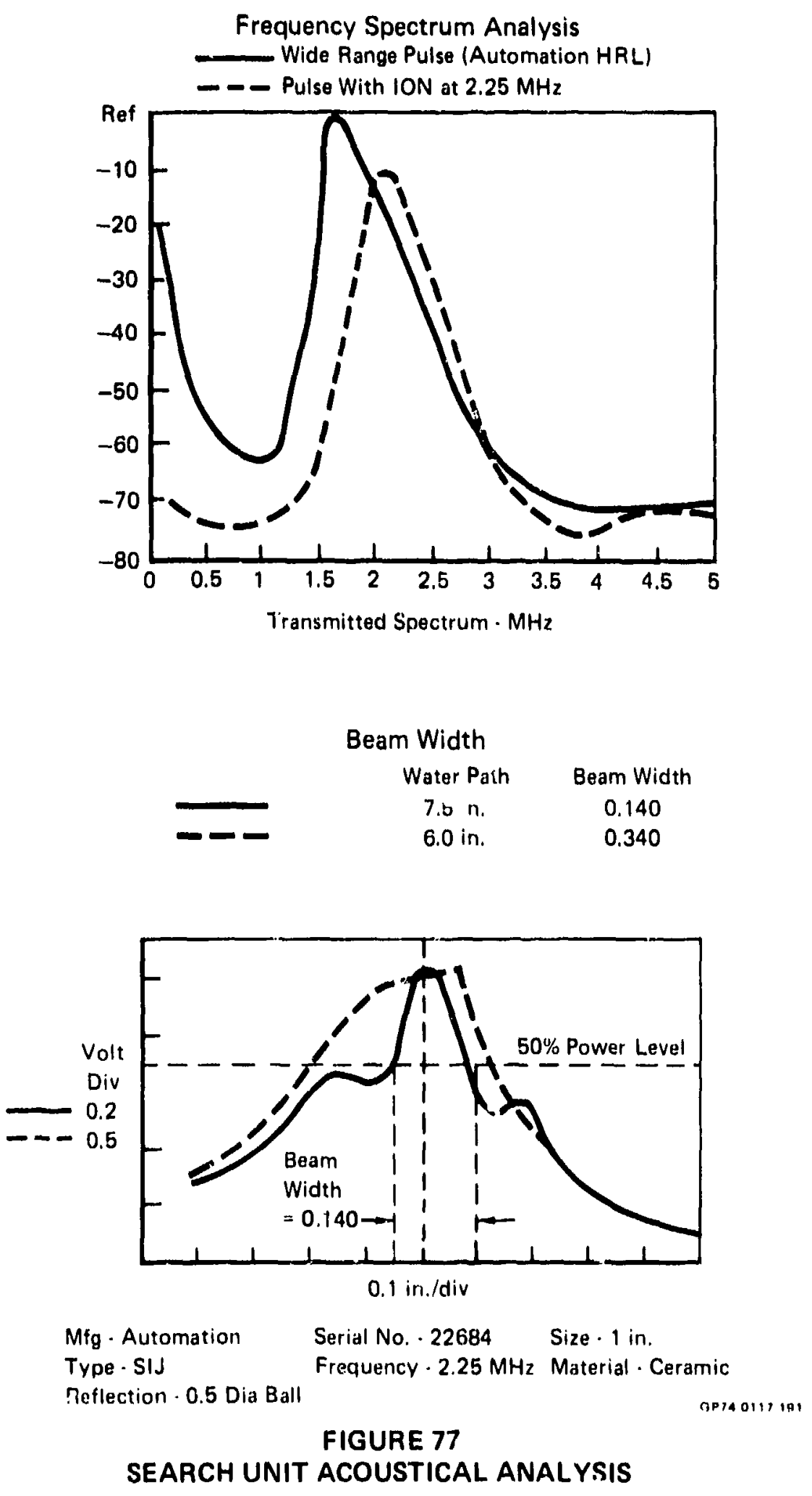


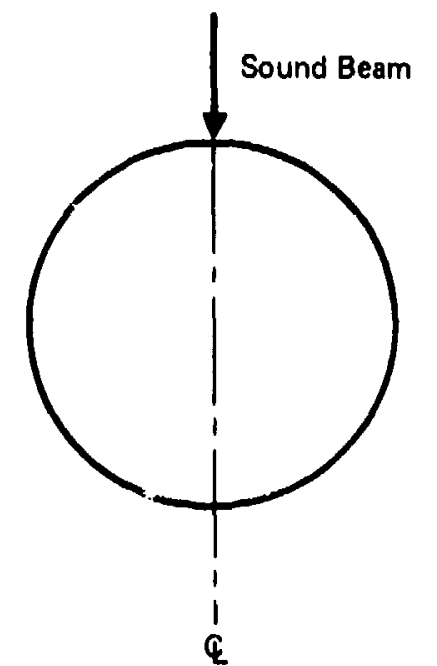

Longitudinal

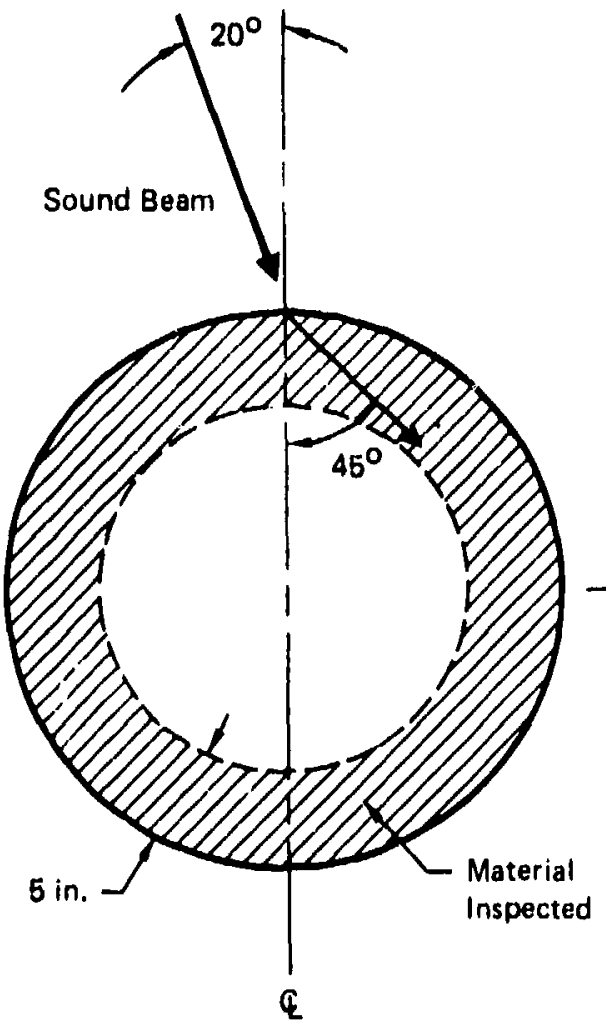

Circumferential Shear
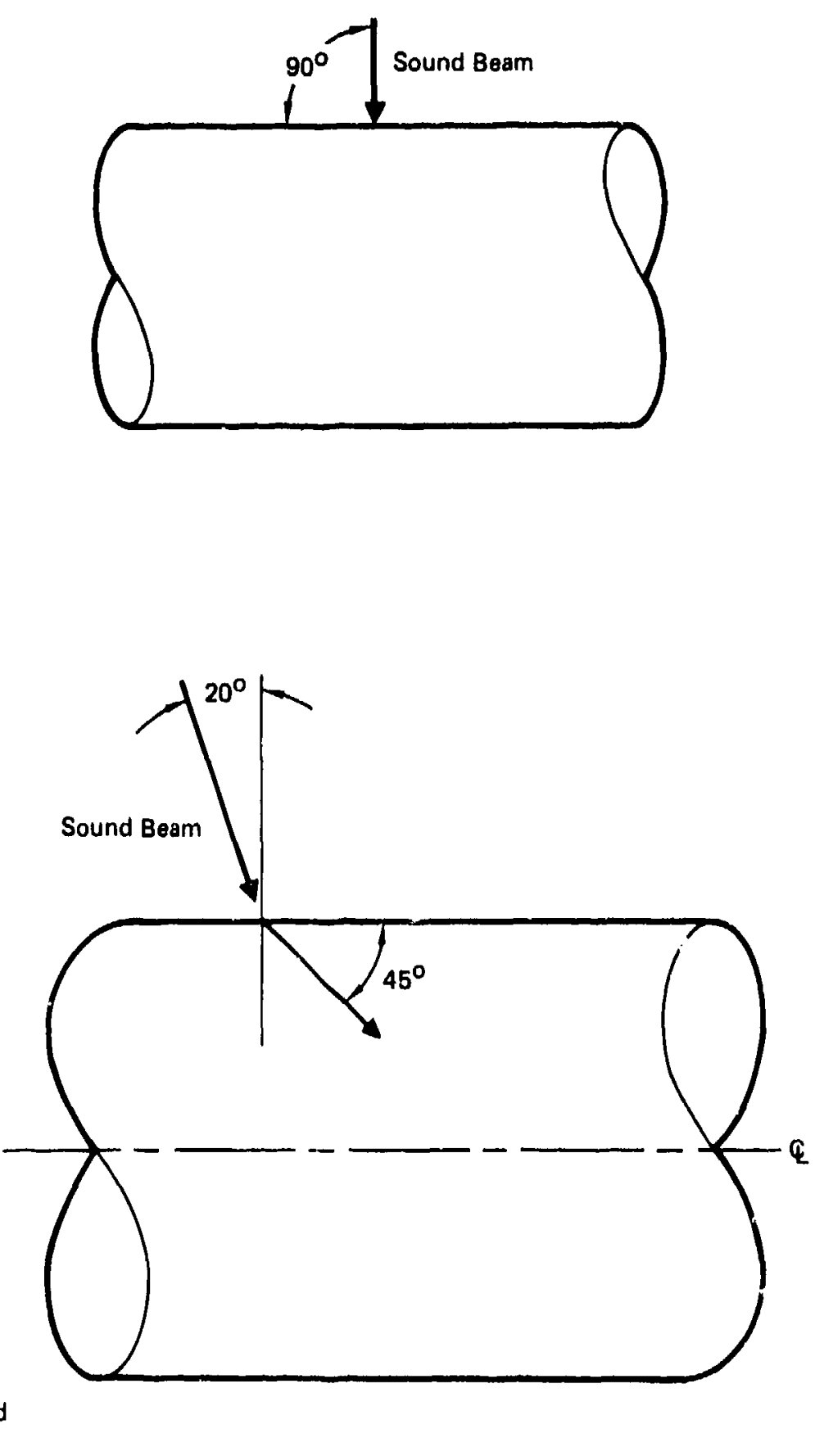

Axial Shear

FIGURE 78

0P74.0117192

SOUND BEAM PATH 

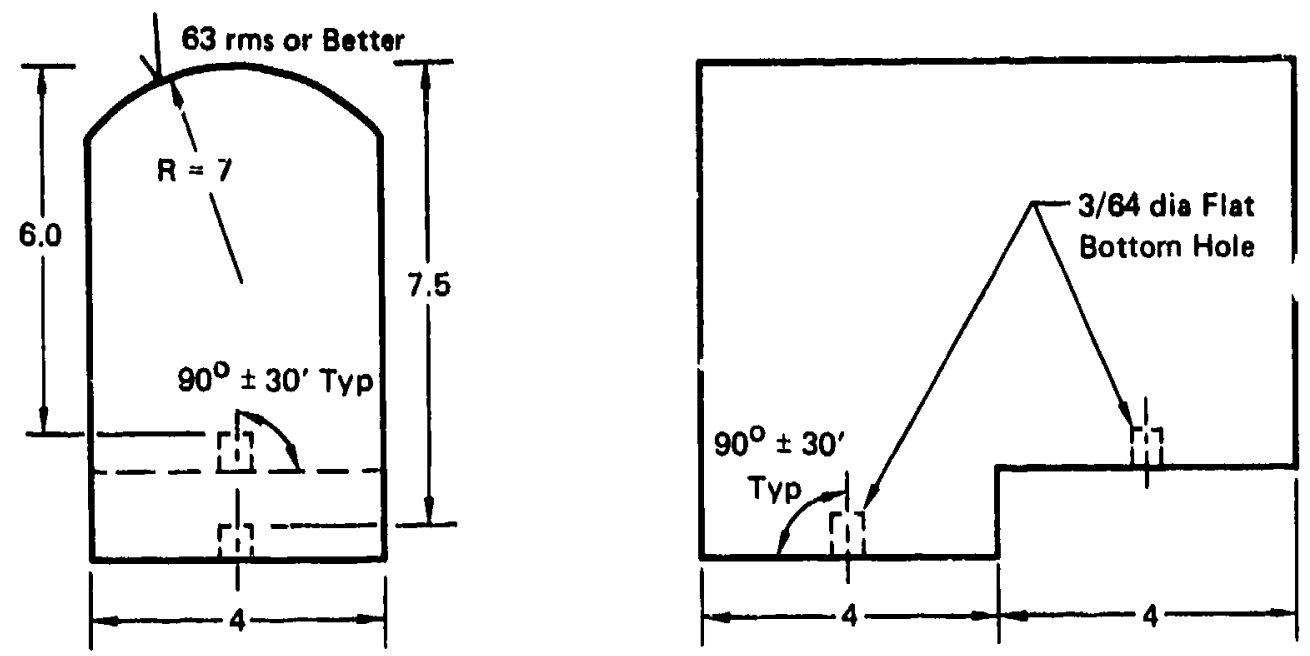

Longitudinal
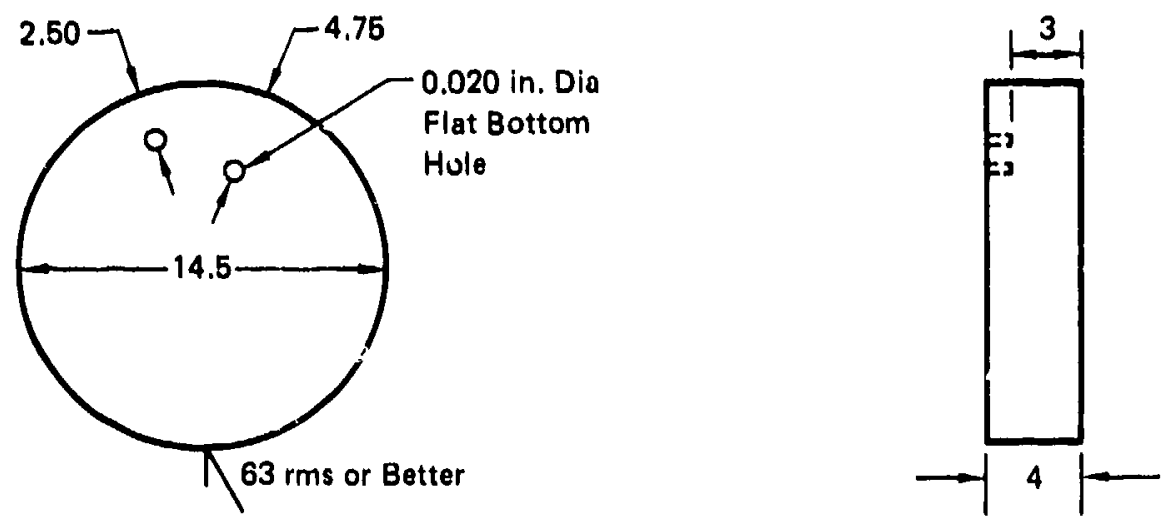

Circumferential Shear
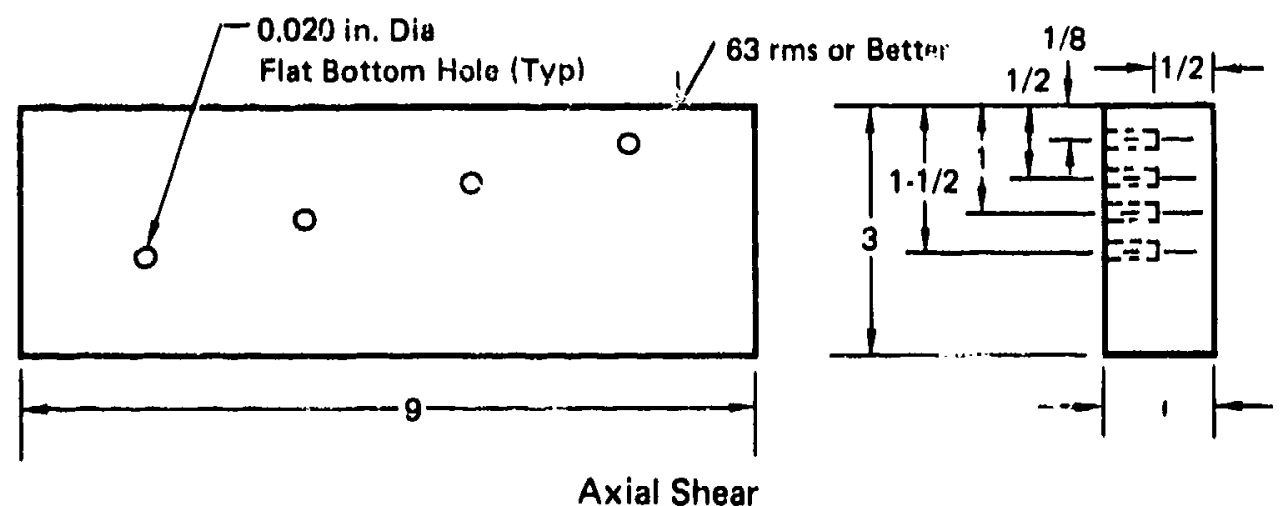

FIGURE 79

ULTRASONIC REFERENCE STANDARDS FOR INGOT INSPECTION 
TABLE 46

EQUIPMENT USED FOR INGOT INSPECTION

Display Units - Sperry 721

Pulser Receivers - Sperry $10 \mathrm{~N}$ (2 Units)

Sperry 5N (2 Units)

\begin{tabular}{|c|c|c|c|c|c|c|c|c|}
\hline \multicolumn{9}{|c|}{ Transducers } \\
\hline Serial & Make & $\begin{array}{l}\text { Size } \\
\text { (in.) }\end{array}$ & Material & $\begin{array}{c}\text { Focal } \\
\text { Distance } \\
\text { in Water } \\
\text { (in.) }\end{array}$ & & $\begin{array}{l}\text { Spec } \\
\text { Freq } \\
\text { (MHz) }\end{array}$ & $\begin{array}{l}\text { Water } \\
\text { Path } \\
\text { (in.) }\end{array}$ & Use \\
\hline 22684 & Automation & 1 Dia & $\begin{array}{c}\text { SIJ } \\
\text { Ceramic }\end{array}$ & $>7.5$ & 2.25 & 2.25 & 5 & Longitudinal \\
\hline $\begin{array}{l}26226 \\
26227\end{array}$ & Automation & 3/4 Dia & $\begin{array}{c}\text { SIJ } \\
\text { Ceramic }\end{array}$ & 6.5 & 5 & 5 & 4 & $\begin{array}{l}\text { Axial and Circumferential } \\
\text { Shear }\end{array}$ \\
\hline
\end{tabular}

GP74.0117.103 
Company with 0.020 inch diameter side drilled holes drilled st metal travel distances of 2.50 and 4.75 inches (Figure 79). Aggin, a. 24inch diameter reference standard would have been preferred to uatch the ingot diameter; however, the 14-inch diameter was the largest available at Ladish. The reference standard for axial shear was as shown in Figure 79.

I'he results of the ultrasonic inspection are shown in Table 47. During the actual streight beam scanning of the ingot material, the background nolse amplitude never exceeded 20 percent of full saturation. This was true for the inspection of the first 6 inches of ingot and, also, for the 5 to 12-inch depth scan. Each indication location was recorded with reference to the axial sestion, depth from the surface, and longitudinal section. The indications in the top 16 inches of the ingut (49 indications total) are probably due to the ingot pipe. It should also be noted that a large number of indications ( $75^{\circ}$ total) are located in the bottoin 48 inches of the ingot, where the Type I alpha segregates are expected. It is possible that several of the shear indications are from the same discontinuity as a longitudinal wave indication. In Sections $1-E A$ and $1-2 B$, it is apparent that several discontinuities that were detected using shear wave were not detected by longitudinal wave. In Section 1-2A, 11 axial shear wave indications were present with only 9 longitudinal wave indications. In Section $1-2 B$, there were $1 . \perp$ additicnal axial shear wave indications. These results are further proof that discontinuties can often be detected using the shear mode when they are undetectable uring the longitudinal mode. This may be due to the orientation of the discontinuities. Also, since the wavelengih rf shear waves is less than that uf longitudinal waves (for a constani frequency), the resolution capability with shear waves is probably greater than with longitudinal waves.

An analysis of the sound transmission charneteristics indicates that there was a difference of at least $12 \mathrm{~dB}$ between the reference standards and the ingot material. Also, a variation of as much as 18 al existed within small sections 0 : the ingot itse $f$.

oased upon these results of the ultrasonic inspection, the ingot was cut into ise 8 longituainal sections shown in Table 47 in preparation for further conversion to billet. 


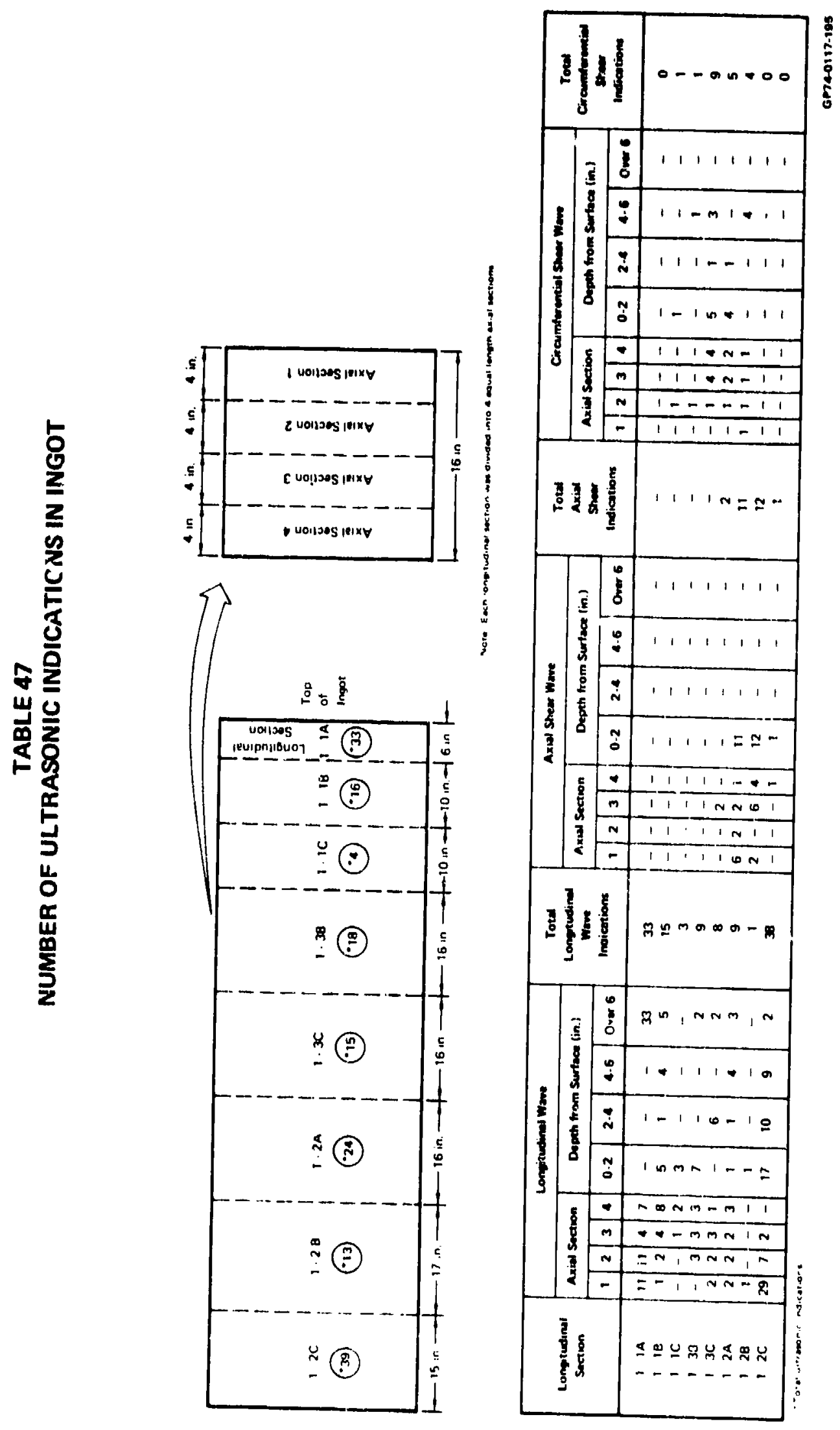


4. INSPECTION OF 9 INCH DIAMETER BILLET

\section{a. Radiography}

The radiographic inspection of the billet Sections $1-1 \mathrm{~A}, 1-2 \mathrm{C}$, and 1-3B (see Table 47) was carrled out by Allis Chalmers in Milwaukee, Wisconsin. The inspection was performed using a P. MeV Alis Chalmers betatron and an exposure of 200 Roentgens. An ASTM No. 40 penetrameter was used as an image quality indicator and was placed on the iource side of the billet. Front and back lead screens, 0.060 inch thick, were used and the back-up materitl was one inch thick lead. The source-to-film distance was 9 feet and the film (Kodak $M$ ) was placed directly against the billet materlal. The film was processed manually. Flgure 80 show: the plan for the exposures taken. During eack exposure the fillin as flat as opposed to being curved around the bil.let. Twelve inch wide axlal areas were exposed using $14 \times 17$ inch film to provide for overlapping of exposures. The image of the IT hole and the outer edge of the penetrameter panel were visible on all the radiographs resulting in an equivalent penetrameter sensitivity of 0.31 percent. the film density ranged from 1.5 to $3.0 \mathrm{H} \& \mathrm{D}$ units.

The results of the radiographic inspection are shown in Iable 4$\}$. As with the ingot inspection, there are two possible circumferential. losations for each inalcation since it is not possible to deternine if the Indication lies on the far side or the near aide of the billet using the chosen techniques. In comparing these results with the results of the Ingot inspection, it is clear that the ingot pipe healed during conversion to 9 inch billet. The pipe originally started within : inches of the ingot and extended to a depth of 16 inches.

\section{b. Ultrasonic Inspection}

The ul.trasonic inspection of the 9 inch billct was cerried ont at the Ladish Company in Milwaukee, Wisconsin. Two separate pulser/recedriris were used in confunction with i.wn long, focused timnsducers and two Sperry 721 oscllloscopes. The vertical linearity of the electroni.: ayste?: had been checked by Jadish wilhin 30 days of the inspection. Fach pulsfy/ recelver was checked for noise al: calibration response on the "ame rel'erence standard; there was 1 ittle difference in the respnise 1 ich. sur.mary of the equipment used 1 ; shown in Table 49 . As shown in Fighing 81 , the two transducers were positioned 4 inches apart and the bill let. was rotatel such that the scan was in a spiral. Whe sesu rate vals inche: per second; prior to the actual. billet inspection, the scan rute. war ah ked on the reference standard to susure that the roference hule: wore de l, w: in at a scan rate of 2 inches per second. The scan inlex wis $1 / 4$ f.lloh r...

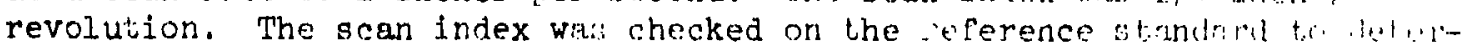
mine that with the chosen scan index, the response was frorte.t. "inan 50 ;... cunt of the maximum response from $3 / 64$ dianeter flat bottom hile in the reference standard. 


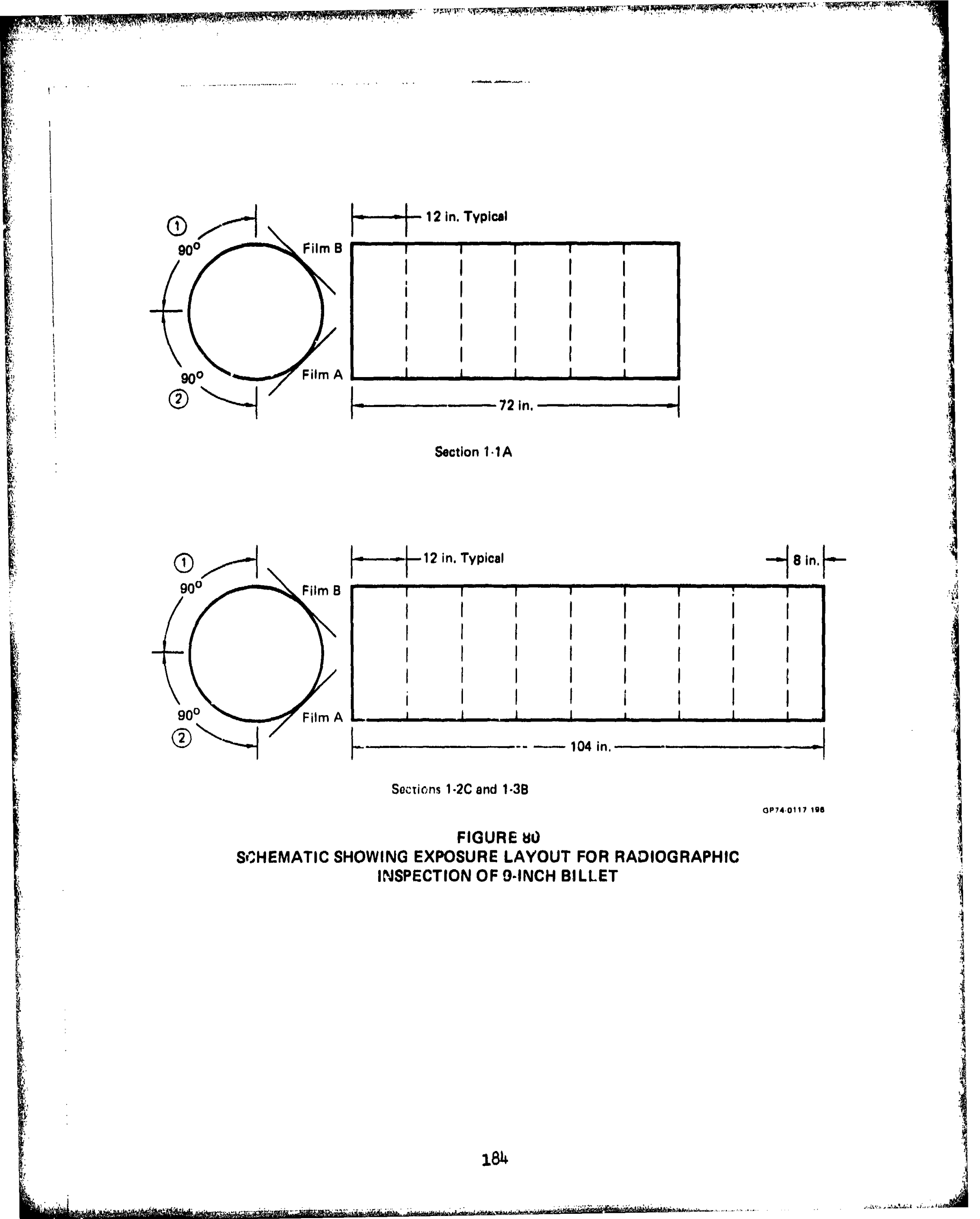



Several transducers were obtalned for the billet inspection. These transducers were focused, some with a focal length of approximately 9 inches in water and others with a fucal length of approximateiy 6.5 inches in water. The transducers were optimlzed for the billet inspection using the methods desiribed under the ingot inspection. The transducers were selected specifisally for use with a apecific pulser/recelver (either Sperry 5N or Sperry 1ON, as appl1cable). Previous experience has indicated that some discontinulties that are not detectable using the longltudinal mode are detectable using a shear mode inspection. Consequently, both longitudinal and shear wave immersion inspections were carried out on the 9 inch diameter billet.

The longltudinal inspection was performed using a $3 / 4$ inch diameter focused search unit pulsed at $5 \mathrm{MHz}$. Two Sperry $5 \mathrm{~N}$ pulser/receivers were 118es. The sound beam angle 18 shown in Figure 78. A 6 inch water path was uised. The reference standard used for the longitudinal inspection was a 9.25 inch round of forged T1-6Al-4V supplied by Ladish Company with $3 / 64$ inch dianeter flat bottom holes at metal travel distances of 2,3 , and 5 inches (Figure 82).

As previously mentioned, the scan index was $1 / 4$ inch per revolution of the billet and the scan rate was 2 inches per second. Both the scan rate and the index were checked on the reference standard prior to testing.

The afference in sound transmisaion characteristics between the reference standard and the 9 inch billet was checked using the 9 inch round circumferential shear reference standard and a representative plece of blllet. The pleces were set-up for straight beum immersion testing and back-surface reaponse through the refrence standard was adjusted to 80 percent of saturation. Next, without changing the gain the backsurface response through the 9 inch billet was monitored. Ii was found that there was no more than $2 \mathrm{~dB}$ difference between the two. Since the circumferential shear reference standard and the longltudinal reference standard were machined out of the same piece of materiul, it was assumed that the circumferential shear standard could be substituted for the longltudinal standard to make these measurements.

The scanning gain was established by adjusting the response to the hole at 5 inches metal travel to 80 percent of saturation. All discontinulties whose amplitude exceeded 50 percent of saturation were evaluated further. The search unit was posirioned over the discontinulty and the response was compared to that from the hole in the reference standard with a metal travel closest to that of the discontinutity.

Both an axial and clrcumferential shear wave inspection were performed. The same test equipment arrangement was used as with the :ongitudinal inspection. Again, a scan rate of 2 inches per sacond was used with a scan Index of $1 / 4$ inch per revolution. Each were checked with the reference standard prior to testing. 


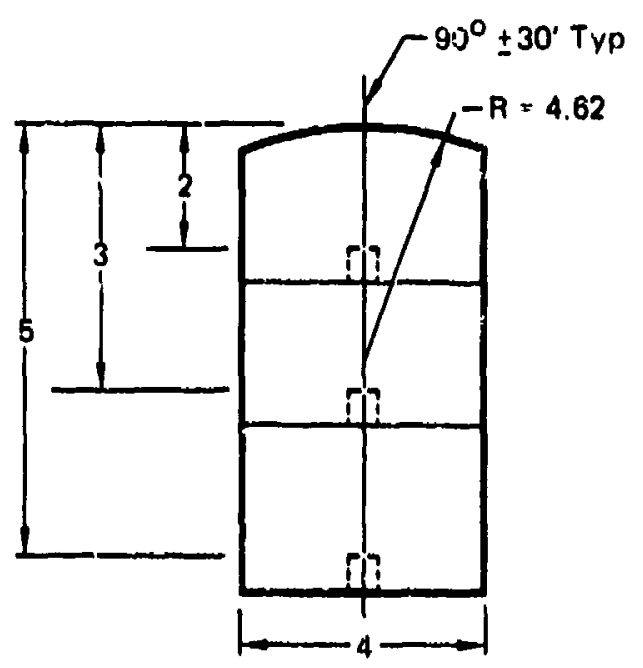

3/64 Dia Flat Bottom Hole (Typ)

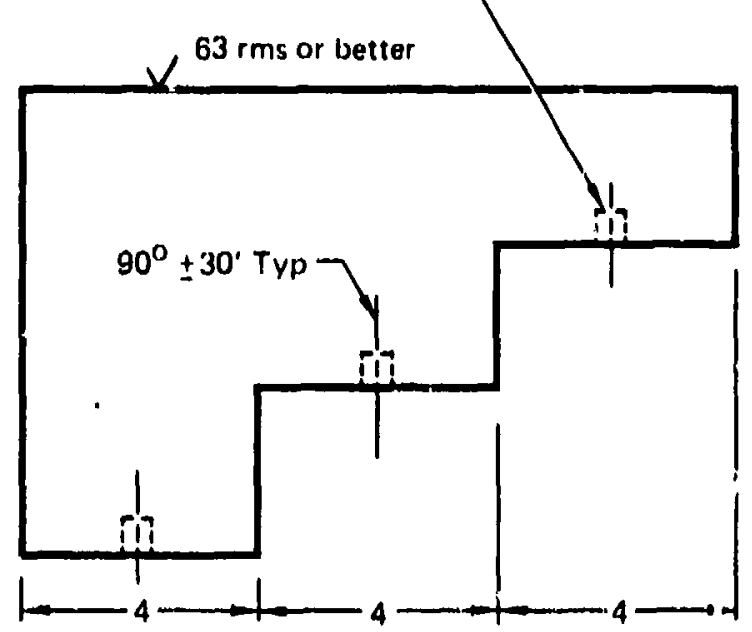

Lonyitudinal
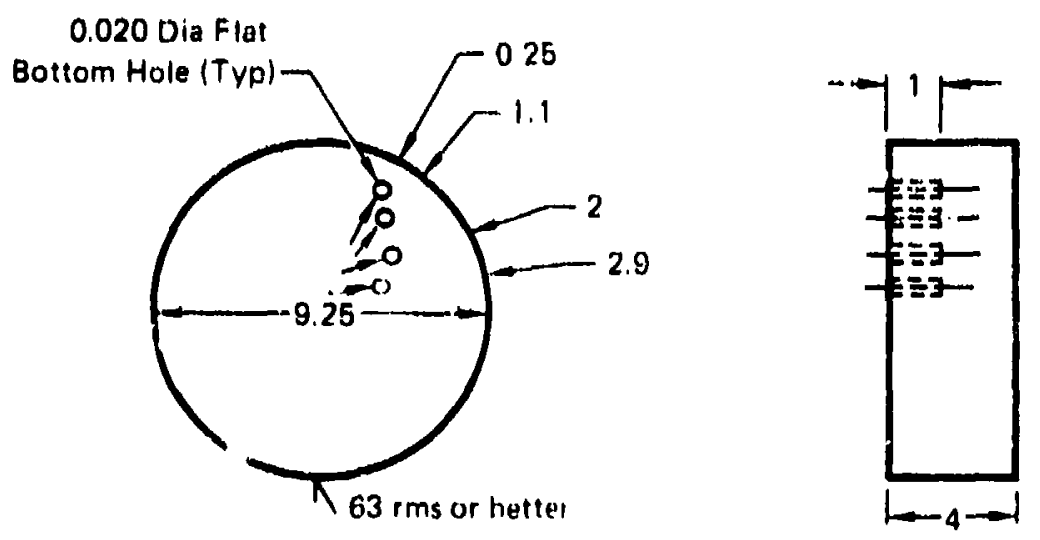

Circumferential Shear
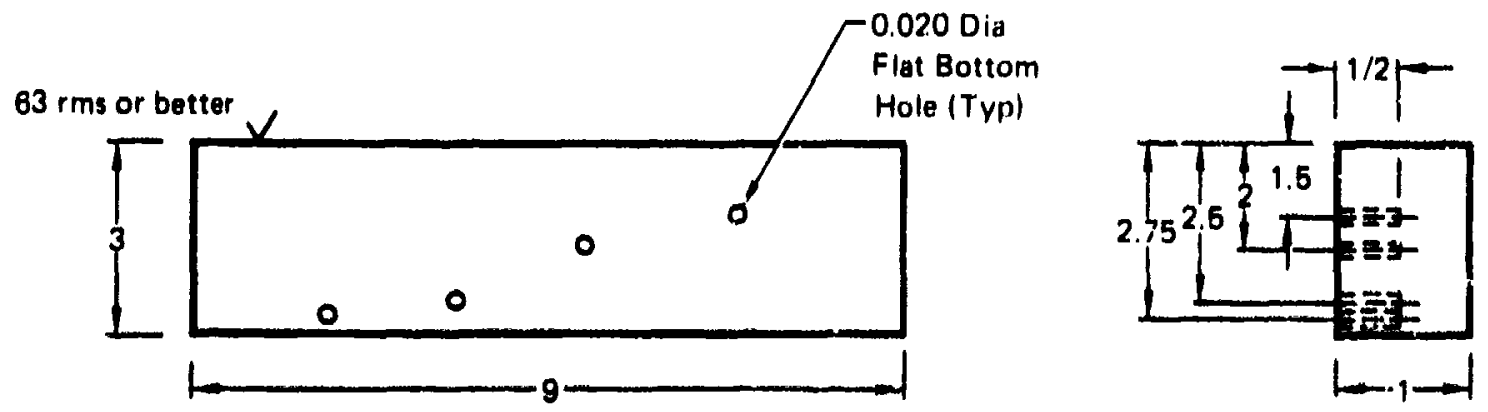

Axial Shear

FIGURE 82

0974.0117200

ULTRASONIC REFERENCE STANDARDS FOR 9 INCH BILLET INSPECTION 
With circumferential shear wave, approximately the firgt 3 inches of the billet was inspected, whereas with axial shear, the billet material from surface to center ( $4-1 / 2$ inches) was inspected. Billet Sections 1-1 and $1-2 B$ were inspected using two Sperry $5 \mathrm{~N}$ pulser/recelvers, two long focused Branson transducers, $3 / 4$ inch diameter, pulsed at $5 \mathrm{MHz}$. The sound beam angle 1s shown in Figure 78. The water path was 6 inches. Billet Sections $1-2 A$ and 1-2C were inspected using two Sperry ION pulser/receivers, two long focused Automation transducers, $3 / 4$ inch in diameter, pulsed at $51 \mathrm{~Hz}$. The sound beam angle is shown in Figure $7 \mathcal{E}$ and a water path of 5 inches was used. This arrangeinent was necrasitatad by the avallability of equipment. Tha reference standard used for circumferential shear was a 9.25 inch diameter round of forged T1-6AI-4V supplied by the Ladish Company with 0.020 inch diameter alde drilled holes (FIgure 82). The 9.25 Inch diameter forged reference atandard had been fabrlcated in a manner similar to the 9 inch diameter billet to be inspected rnsulting in littia difference (less than $2 \mathrm{~dB}$ ) in sound transmission characterlstics between the two.

A reference 8 tandard w1th 0.020 Inch diameter slde drilled holes at metal travels of $1.5,2,2.5$, and 2.75 inches was used for the axial shear Inspection (F1gure 82).

The results of the ultrasonic inspections are shown in Table 50. The Indication found by longitudinal wave in Axial Section I In Longitudinal Section 1-1A was 1.3 Inches long; it is suspected that this is a section of ingot pipe still remaining as is the 3 inch long indication found by longitudinal wave in Axial section 4 in Longltudinal Section 1-ic.

In Section No. 1-2A, it is apparent that several discontinuities detected using circumferential shear wave were not detected using longltudinal wave. Specifically, there were 21 clrcumferential shear indications and only 8 longitudinal indications in the same volume of material. Obviously, the effectiveness of billet inspection can often be increased by iupplementing the usual longltudinal wave inspection with a shear wave inspection due to defect orfentation and the difference in resolution capability between longitudinal and shear waves.

c. Mucioesuhing and Anodic Etch

A cross section was cut from each of the elght 9 inch diameter billets for etching evaluation. Prior to etching, the disks were machined flat, Macroetching was performer by the Ladish Company using a $15 \% \mathrm{HNO}_{3}-5 \%$ $\mathrm{HF}$ - Balance $\mathrm{H}_{2} \mathrm{O}$ solution. The general appearance of the macroetched surfaces were aimflar to that of a typtcal commercial 9 inch round T1-64.1-4V blllet as shown in F1gures 83 and 84 . Examination of all the macroesched surfaces revealed only on discontinuity. That discontinulty was located in the disk cut $f^{\prime}$ om the bottom of the ingot; It was this area that had been irtentionally seeded to produce Type I stabilized alpha. A photograph of the macro-tehed surface at the discontinuity is shown in Figure 85. 


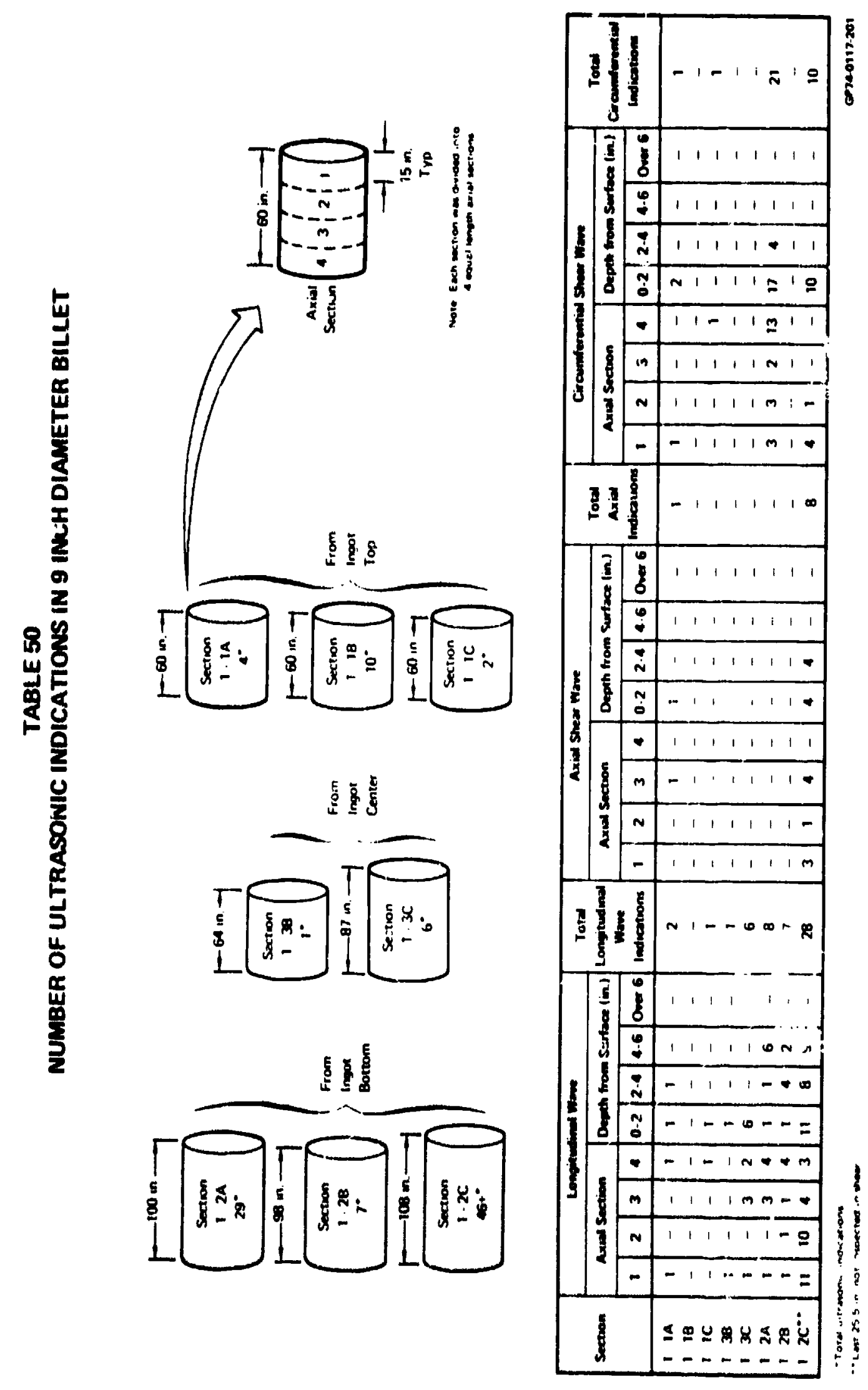




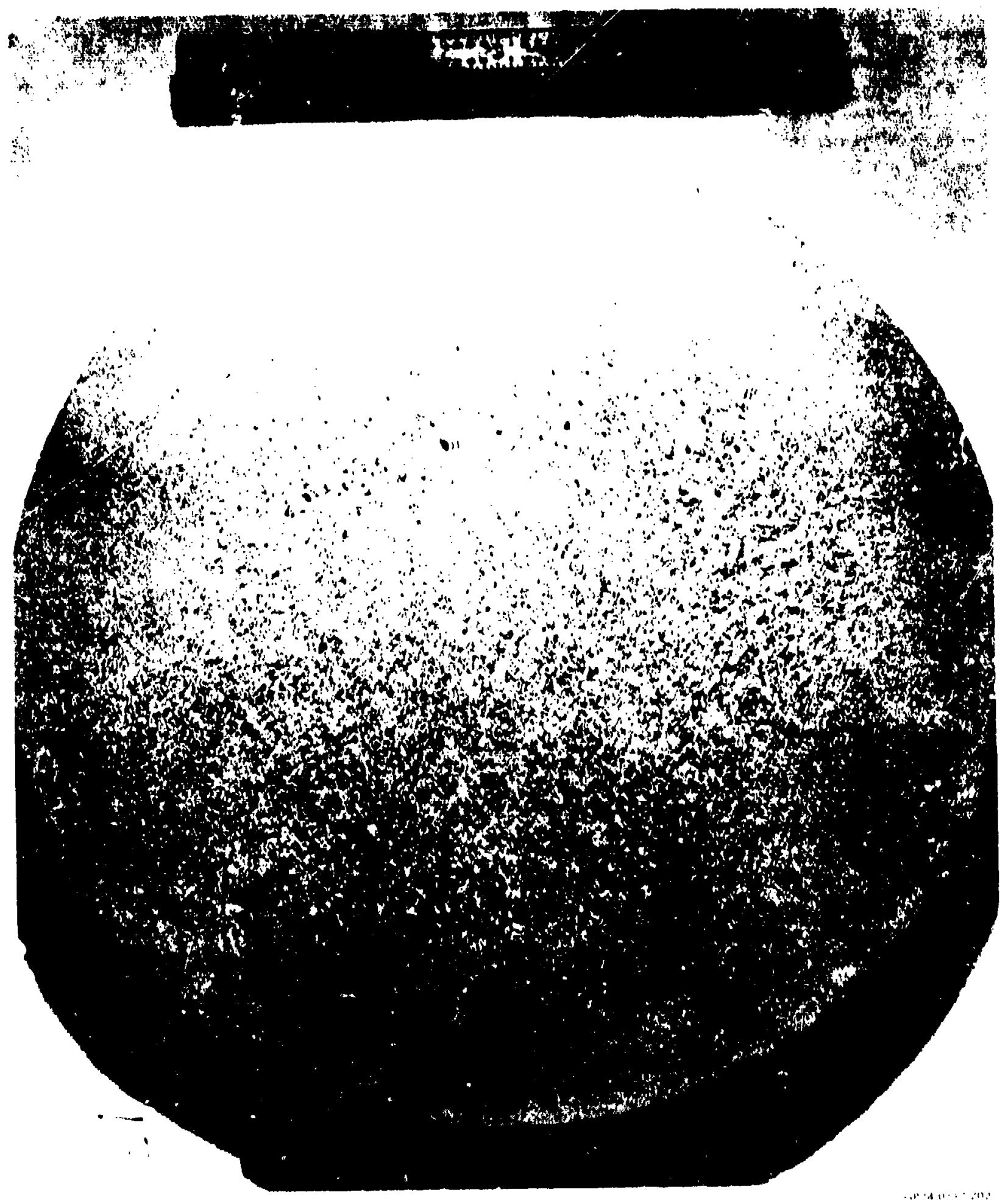

FIGURE 83

TYPICAL MACROETCHED BILLET SURFACE FROM SEEDED INGOT 


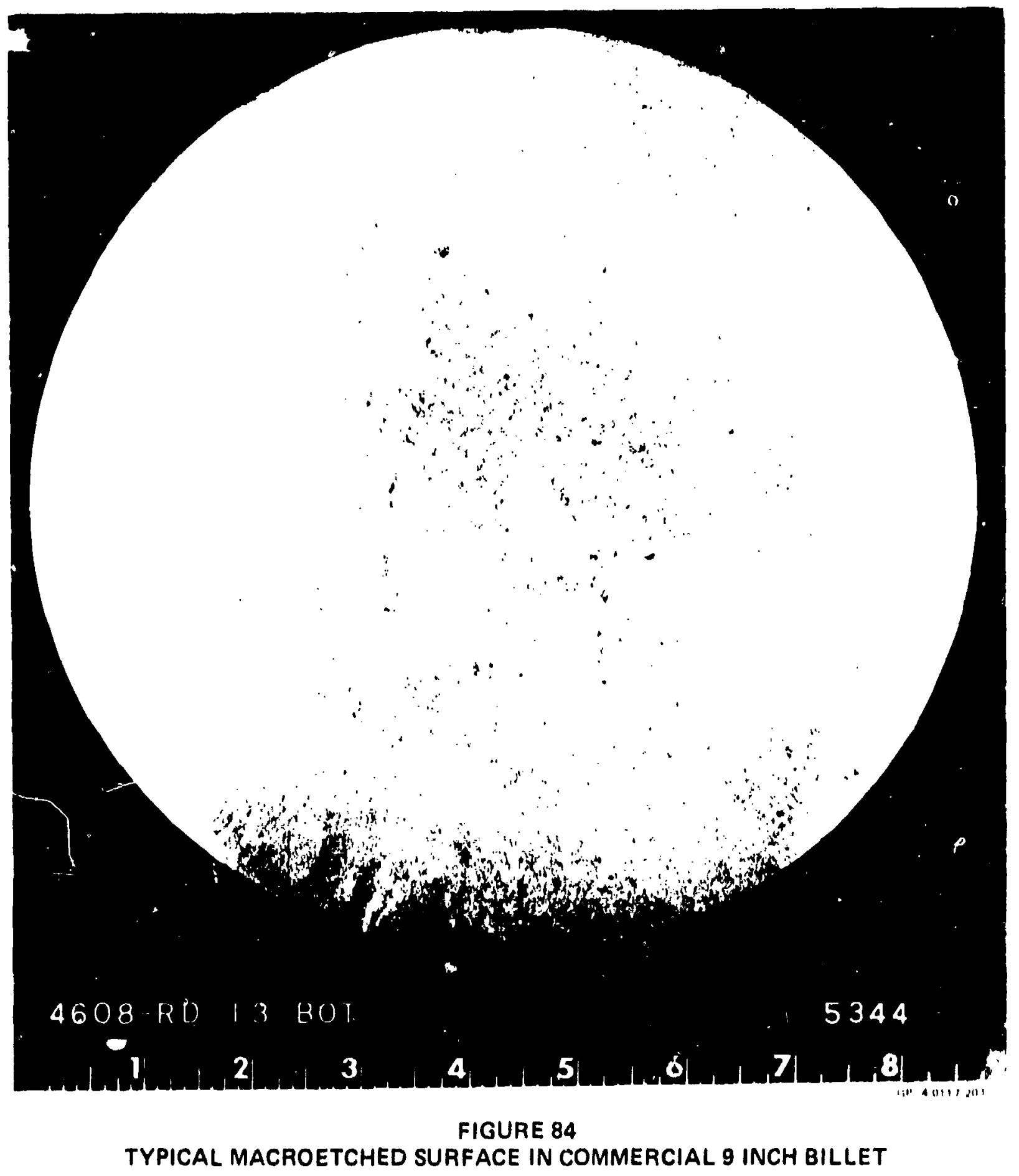



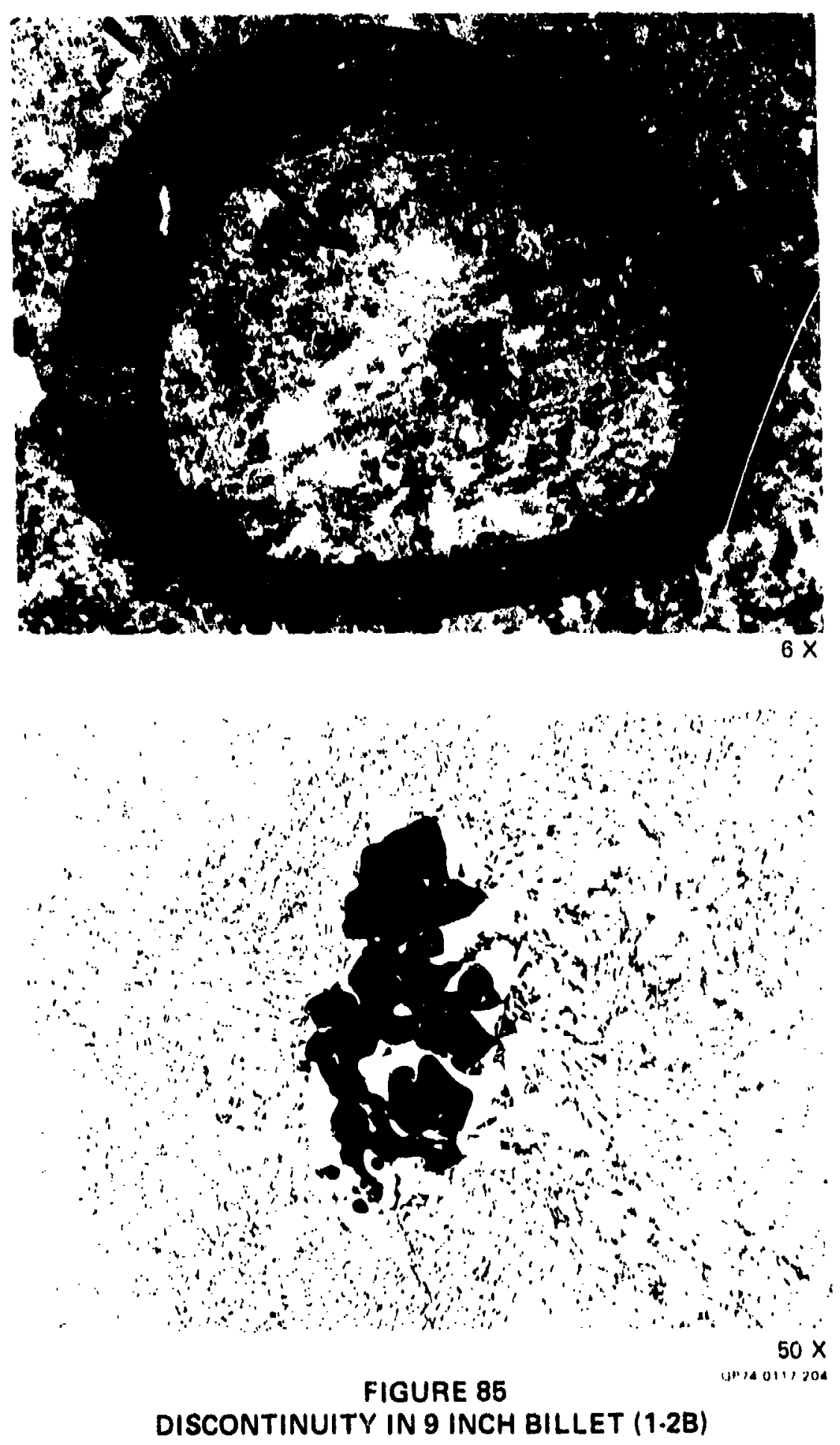
Arter macroetching, the disks were sent to Metals Testing Company in South Windsor, Connecticnt to be anodically etched. The discontinuity detected during macroetching etched dark blue in this process. No other obvious defects vere revealed. However, some of the disks from the top section of the ingot, Bar 1-IB in particular, showed patches of blue etching alpha of a deeper shade than surrounding areas. These fireas did not have the typical "lightening streak," zig-zag, pattern of aluminum segregation found in $\mathrm{T} 1-6 \mathrm{~A} I-4 \mathrm{~V}$ forgings in the past.

Following the anodic etching, metallographlc cross sectlons were taken through several of the lisks. One cross section was taken through the discontinuity revealed by macroetching and anodic etching. In addition, a total of 12 metallographic cross sections were taken at random from several of the disks. The discontinuity previously detected by macroetching was found to $\gamma_{3}$ a typical Type I alpha stabilized vold with crackIng around the vold (see Figure 85). No additional alscontinulties were found in the random cross sections.

Since only one Type I alpha stablized area was detected, it appears that macroetching and anodic etching of random billet sections are ineffective techniques for establishing the existence of Type I alpha stabilized areas. This conclusion is based upon the assumption that a large number of Type I discontinuities are present in the $P$ inch billets as indicated by the ultrasonic indications.

The lack of macroetching indications in the billet sections from the top of the ingot suggests that the ingot pipe was completely healed during ingot conversion. 


\section{INSPECTION OF 6 INCH DIAMETER BILLET}

\section{a. UItrasonic Inspection}

The 6 inch diameter billet sections to be converted to bar and forgings were ultrasonically inspected. Prior to ultrasonic inspection, the billet surfaces were Tysaman ground to a $125 \mathrm{rms}$ or better surface finish.

A summary of the equipment used during the inspection is show in Table 51. The inspections were carried out by a varfety of inspection personnel at several locations within the plant; hence, the large variety of equipment. Again, as with the ingot and 9 inch diameter billet inspections, two separate pulser/recelvers were used in conjunction with two transducers and two Sperry 721 oscilloscopes. One pulser/receiver-transducer combination was used to inspest to a depth of 1.5 inches while the other was used from 1 to 3 inches. The vertical linearity of the electronic systems used had been checked by Ladish within 30 days of the inspection. Each pulser/recelver was checked for nolse and calibration response on the same reference standard; there was little difference in the response of each.

The position of the transducers during inspection is shown in Figure 86 . The 6 inch billet sections were rotated such that the scan was in a spiral. The scan rate was 3.9 inches per second; prior to the actual billet inspection, the scan rate was checked on the reference standard to ensure that the reference holes were detectable at a scan rate of 3.9 inches per second. The scan index was 0.1 inch per revolution. The scan index was checked on the reference standard to determine that with the shosen scan index the response was greater than 50 percent of the maximum response from the applicable flat bottom hole in the reference standard. Each billet section wis examined through the halfsection thickness.

The reference standards used for the inspections are shown in Figure 87. Prior to the inspections the difference in sound transmission

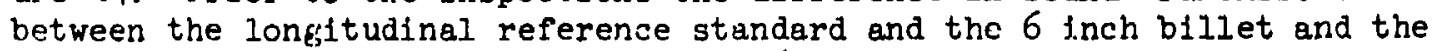
axial shear reference standard and the 6 inch billet kere measured. First, the 6 inch diameter circumferential shear and 6 inch diameter billet were placed in the water. The back surface reflection of a straight beam through the reference standard was adjusted to 69 percent of saturation. Next, without changing the gain, the back reflection through the 6 inch billet was noted to be 57 percent of saturation.

The axial shear reference standard and the 6 inch billet were checked next. In this case, the sound beam in the shear mode was reflected off a corner of the axial shear reference standard through 6 inches of metal. The response was adjusted to 60 percent of saturation. Then, witnout changing the gain, the sound beam in the shear mode was reflected off the far surface of the billet, and, this response was 75 percent of saturation.

It was decided, from these tests, that it was not necessary to compensate for sound transmission differences. 


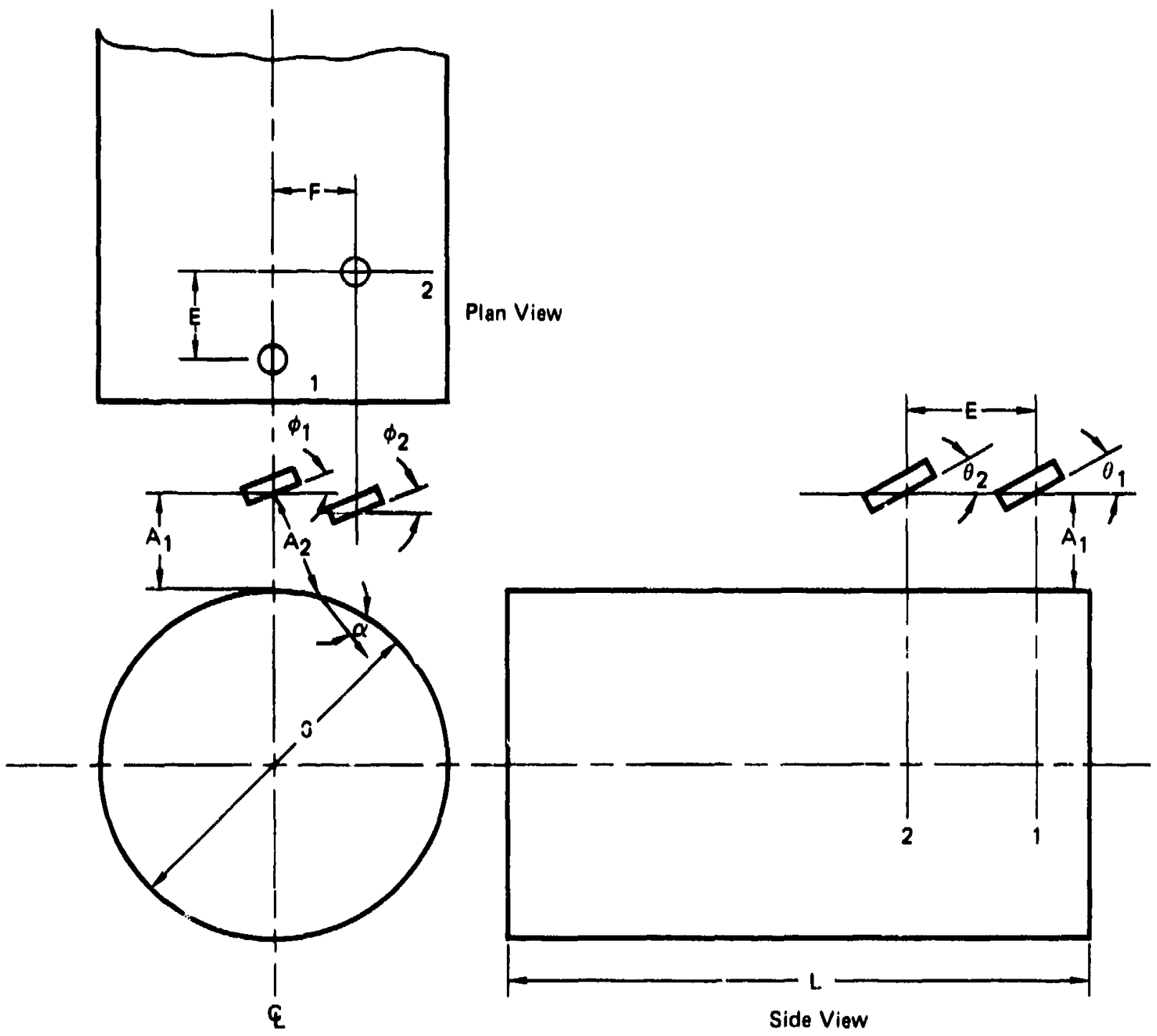

Front View

-f Otfsot Both Chunnels

\begin{tabular}{|c|c|c|c|c|c|c|}
\hline $\begin{array}{c}\text { Type } \\
\text { Inspection }\end{array}$ & $\begin{array}{l}A_{1} \\
\text { or } A_{2} \\
\text { (in.) }\end{array}$ & $\begin{array}{c}E \\
(|\mathrm{n} .|\end{array}$ & $\begin{array}{c}\alpha \\
0^{0}\end{array}$ & $\begin{array}{l}\phi_{1} \\
\phi_{2}\end{array}$ & $\begin{array}{l}\theta_{1} \\
\theta_{2}\end{array}$ & $\begin{array}{c}\text { F* } \\
\text { (in.) }\end{array}$ \\
\hline $\begin{array}{l}\text { Longitudinal } \\
\text { Axial Shear } \\
\text { Clrcum Shear }\end{array}$ & $\begin{array}{l}\text { Water Path } \\
\text { Water Path } \\
\text { Water Path }\end{array}$ & $\begin{array}{l}7.5 \\
7.5 \\
7.5\end{array}$ & $\begin{array}{l}90^{\circ} \\
45^{\circ} \\
45^{\circ}\end{array}$ & $\begin{array}{r}0^{\circ} \\
0^{\circ} \\
19^{\circ}\end{array}$ & $\begin{array}{c}0^{\circ} \\
19^{\circ} \\
0^{\circ}\end{array}$ & $\begin{array}{c}0 \\
0 \\
0.4\end{array}$ \\
\hline
\end{tabular}

FIGURE 86

ULTRASONIC INSPECTION SETUP 


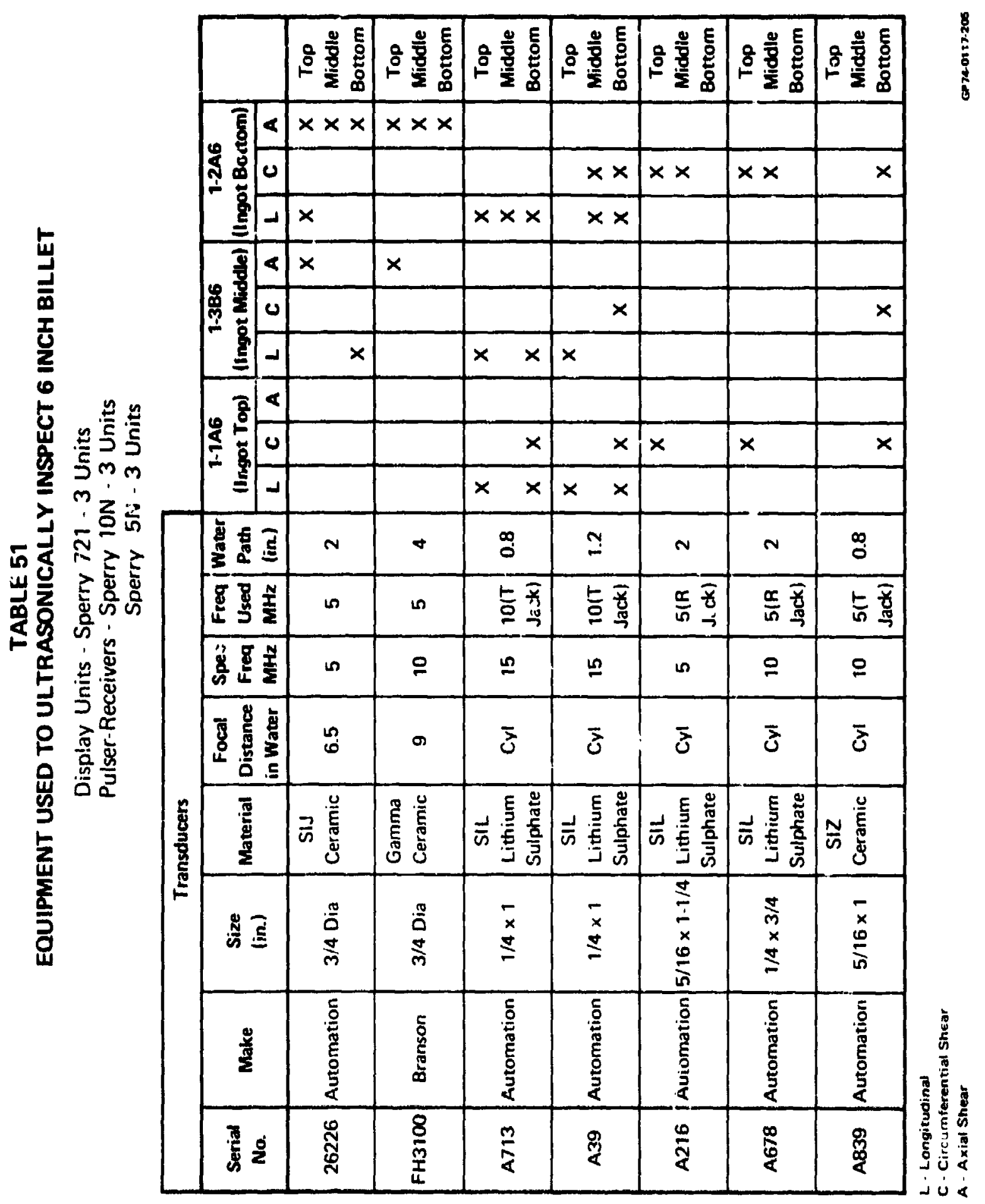


a. Ultrasonic Inspection (Continued)

The results of the ultrasonic inspections are shown in Table 52. As can be seen, there are a large number of indications in those pleces which were converted to 2 Inch square ber and forgings.

\section{b. Radlograph1c Inspection}

The radiographlic Inspection of those 6 inch diameter blilet portions to be converted into forgings was carried out at the General Electric Company in Evendale, Oh10. The inspection was performed using a $2 \mathrm{MeV}$ Vandergraf accelerator and an exposure of 650 Roentgens. A 0.015 inch thick MIL-STD-453 penetrameter was used as an 1mage quality indicitor and was placed on the source slde of the blllet. Front and back laad screens, 0.060 inch thick, were used and the back-up material was one inch thick lead. The source-to-film distance was 4 feet and the f1lm (DuPont NDT 75) was placed directly against the blllet materlal. The f1lm was processed manually. Flgure 88 shows the plan for the exposures taken. During each exposure, the flim was held flat as opposid to being curved around the billet. Twelve inch wide axial areas were exposed using $14 \times 17$ inch film to provide the overlapping of exposures. The overall $\mathrm{f} 1 \mathrm{~lm}$ density ranged from 1.5 to $3.0 \mathrm{H}$ and $D$ units. The IT penetrameter hole and the outer edge of the penetrameter panel were discernible in every radiograph reaulting in an equivalent sensitivity of 0.18 percent.

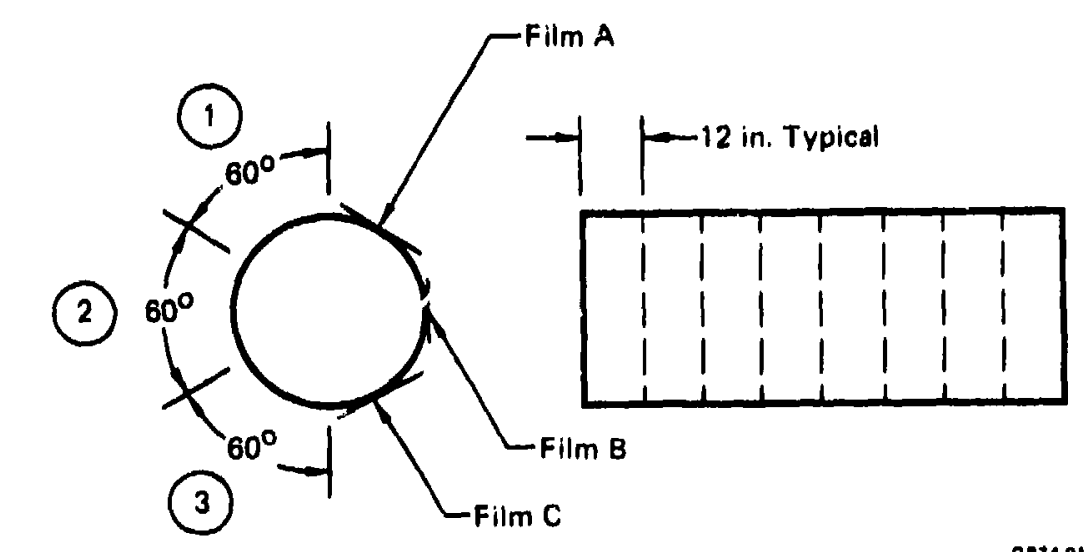

\section{FIGURE 88 \\ SCHEMATIC SHOWING EXPOSURE LAYOUT FOR RADIOGRAPHIC INSPECTION OF 6 liN. BILLET}

The results of the radiographic inspection are shown in Table 53 and a comparison of the radiographic indications with the results of the previous ultrasonic 1nspection is presented in l'able 54. As can be seen from Table 54, many more indications were discovered witi the ultrasonic method as opposed to the radiographic method. 

TABLE 63

RESULTS OF RADIOGRA.PHIC INSPECTION OF 6 INCH BILL.TT 1.2A6

\begin{tabular}{|c|c|c|c|c|c|c|c|c|}
\hline \multirow[t]{2}{*}{$\begin{array}{l}\text { Forging } \\
\text { Blank }\end{array}$} & \multirow[t]{2}{*}{$\begin{array}{l}\text { Forging } \\
\text { No. }\end{array}$} & \multirow{2}{*}{$\begin{array}{l}\text { Distence } \\
\text { from } \\
\text { Blank } \\
\text { End } \$\end{array}$} & \multicolumn{3}{|c|}{ Dintance from Circumferential Zero (C) 2} & \multicolumn{3}{|c|}{$\begin{array}{l}\text { Approximate Dimensions } \\
\text { (Axiai/Circumferential) (in.) }\end{array}$} \\
\hline & & & Film A 3 & Film B $\hat{3}$ & Film $c B$ & Film A $\hat{3}$ & Film $B$ & Film c 3 \\
\hline 3 & GE5 & $\begin{array}{c}7 \\
7 \\
4.7 / 8 \\
1 / 2 \\
1 / 2\end{array}$ & $\begin{array}{l}- \\
- \\
6.7 \\
6.7 \\
7.6\end{array}$ & $\begin{array}{l}7.0 \\
2.3 \\
- \\
- \\
-\end{array}$ & $\begin{array}{l}- \\
- \\
- \\
-\end{array}$ & $\begin{array}{c}\overline{-} \\
\overline{1 / 32 \times 11 / 2} \\
0.025 \mathrm{Dia} \\
0.025 \mathrm{Dig}\end{array}$ & $\begin{array}{c}1 / 16 \times 1 / 8 \\
1 / 16 \mathrm{Dia} \\
- \\
- \\
-\end{array}$ & $\begin{array}{l}\bar{z} \\
\bar{z} \\
\overline{-}\end{array}$ \\
\hline 5 & $\overline{G E 6}$ & $\begin{array}{c}2 \cdot 1 / 4 \\
1.5\end{array}$ & $\begin{array}{l}12.1 \\
-\end{array}$ & 2.35 & $\overline{16.3}$ & $\begin{array}{c}0.070 \mathrm{Dig} \\
-\end{array}$ & $\begin{array}{c}0.050 \\
0.040 \mathrm{Dia}\end{array}$ & - \\
\hline 1 & G::4 & $\begin{array}{l}0.2 \\
2.9\end{array}$ & $\begin{array}{r}16.6 \\
1.9 \\
\end{array}$ & $\begin{array}{l}13.4 \\
10.1 \\
\end{array}$ & $\begin{array}{l}7.2 \\
6.7 \\
\end{array}$ & $\begin{array}{l}0.154 \\
0.34\end{array}$ & $\begin{array}{l}0.15 \& \\
0.15 \&\end{array}$ & $\begin{array}{l}0.4 \$ 4 \\
0.34\end{array}$ \\
\hline 2 & $M \cdot 1,2$ & $\begin{array}{l}2.8 \\
8.0 \\
8.5 \\
9.7\end{array}$ & $\begin{array}{r}17.0 \\
0.2 \\
0.5 \\
1.3\end{array}$ & $\begin{array}{l}13.4 \\
11.6 \\
11.9 \\
11.7\end{array}$ & $\begin{array}{l}6.6 \\
7.0 \\
6.4 \\
6.2\end{array}$ & $\begin{array}{cc}0.5 & \triangle 4 \\
\cdots & \\
0.5 & \Delta\end{array}$ & $\begin{array}{l}0.4 \\
0.2 \\
0.3\end{array}$ & $\begin{array}{ll}0.3 & 4 \\
0.3 & 4 \\
0.3 & 4 \\
0.3 & 4\end{array}$ \\
\hline 4 & $M \cdot 3,4$ & $\begin{array}{l}4.0 \\
6.1 \\
9.8\end{array}$ & $\begin{array}{r}0.5 \\
17.2 \\
1.1\end{array}$ & $\begin{array}{l}13.1 \\
12.4 \\
13.2\end{array}$ & $\begin{array}{l}5.0 \\
7.4 \\
4.4\end{array}$ & $\begin{array}{l}0.15 \text { 幽 } \\
0.5 \\
0.4\end{array}$ & - & $\begin{array}{c}0.3 \mathrm{Dia} \\
0.2 \mathrm{Dia} \\
0.15 \mathrm{Dia}\end{array}$ \\
\hline
\end{tabular}

(1) Forging Blarik End Nearket Ingot Ton

2

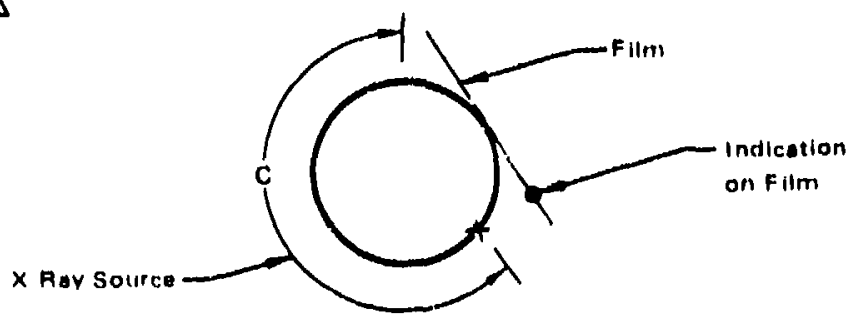

(3) See Figure 43 tar Flim Location (4) Ellipre Length

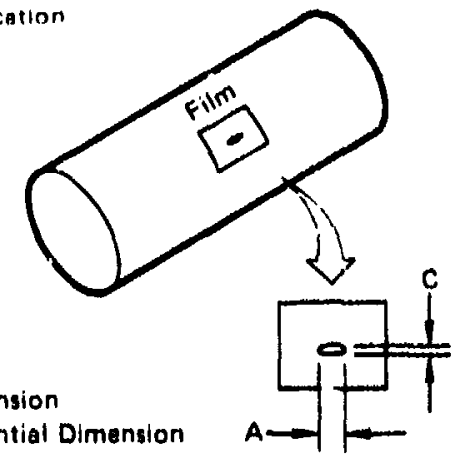


TABLE 54

COMPARISON OF RADIOGRAPHIC AND ULTRASONIC INDICATIONS

IN 6 INCH BILLET 1.2A6

\begin{tabular}{|c|c|c|c|c|c|}
\hline \multirow{2}{*}{$\begin{array}{c}\text { Forging } \\
\text { No. }\end{array}$} & \multirow[b]{2}{*}{$\begin{array}{c}\text { Billet Part } \\
\text { No. }\end{array}$} & \multirow[b]{2}{*}{$\begin{array}{l}\text { Forging } \\
\text { Blank }\end{array}$} & \multicolumn{3}{|c|}{ Number of Indications } \\
\hline & & & $\begin{array}{l}\text { Ultrasonle } \\
\text { Longltudina }\end{array}$ & $\begin{array}{l}\text { Ultrasonle } \\
\text { Shear }\end{array}$ & Radiography \\
\hline GF.1 & $1.38 \cdot 6$ & 7 & 2 & 0 & - \\
\hline GE2 & $1.38 \cdot 6$ & 8 & 3 & 0 & - \\
\hline GE3 & $1.38 \cdot 6$ & 9 & 4 & 0 & - \\
\hline GE4 & $1.2 A .6$ & 1 & 11 & 4 & 2 \\
\hline GE6 & $1.2 A .6$ & 3 & 9 & 0 & 5 \\
\hline GE6 & $1.2 A \cdot 6$ & 5 & 9 & 8 & 2 \\
\hline GE7 & $1 \cdot 1 A \cdot 6$ & 10 & $\mathbf{a}$ & 2 & - \\
\hline GE8 & $1 \cdot 1 \mathrm{~A} \cdot 6$ & 12 & 6 & 2 & - \\
\hline GE9 & $1.1 A \cdot 6$ & 14 & 7 & 5 & - \\
\hline $\begin{array}{l}\mathrm{MC1} \\
\mathrm{MC2}\end{array}$ & $\begin{array}{l}1.2 A \cdot 6 \\
1.2 A .6\end{array}$ & 2 & 19 & 0 & 4 \\
\hline $\begin{array}{l}\text { MC3 } \\
\text { MC4 }\end{array}$ & $\begin{array}{l}1.2 A \cdot G \\
1.2 A \cdot 6\end{array}$ & 4 & 9 & 5 & 3 \\
\hline $\begin{array}{l}\text { MC5 } \\
\text { MC6 }\end{array}$ & $1.1 \mathrm{~A} \cdot 6$ & 11 & 6 & 2 & - \\
\hline $\begin{array}{l}\text { MC7 } \\
\text { MC8 }\end{array}$ & $1.1 A \cdot 6$ & 13 & 9 & 1 & - \\
\hline
\end{tabular}




\section{CORRELATION OF INSPECTION RESULTS}

The ultrasonic inspection results for the ingot, 9 inch dianeter billet and 6 inch dlameter billet were analyzed to determine how many of the long1tudinal and shear wave indications result from the same discontinuity. A total of 172 ultrasonic indlcations have been evaluated as to thelr location. of these 172 indications, only a few were slose enough together to coneider the shear wave and longltudinal wave indlcations vere from the same disaontinulty. For example, there were a tota 1 of 138 indications detected by longltudinal wave and a total of 15 indications detected by clrcumfarential shear wave in section 1-2A of the 6 inch billet. Since none of these indlcations were in close proximity, it can be concluded that 15 discontinuities were detected by shear wave that were not detected by longltudinal wave. Th1s may be due to the orientation of the discontiulities. Also, since the wavelength of shear waves $1 \mathrm{~g}$ less than that of longltudinal waves (for a constant frequency), the resolution capability with shear waves is probsbly greater than with longltudinal waves.

\section{SUMMARY OF NDT RESULTS}

A sumary of the ultrasonic and radiographic test results lor the ingot, 9 inch billet, and 6 inch billet inspections $1 \mathrm{~s}$ show in Figure 89. From these results, it can be seen that the ingot pipe, which was intentionaliy exaggerated during melting, was healed during the conversion to 9 inch billet. The total number of longitudinal indleations decreased from 57 to 3 when the total number of shear indications decreased from 11 to 2. Also, the plpe was not detected during the radiographic inspection of the 9 inch biliet. As can be seen from the 6 inch billet results, a large number of Indications are present in the material to be converted to bar and forginge indicatine that a large number of segregates survived the conversion procnss.

As was previously mentloned, the ultrasonic and radiographlc testin/s conducted on the ingot and billet materia]. was r.st developinental in nature as a previous Alr Force prouram had been conducted to improve nondestruct1ve testing of ingct and billet material (Reference 2). The purpose of the inspections was to select the locations for shearing the material for subsequent conversion. It became clear during the program that severul ultrasonic techniques still need to be implemented into ultrasonic inspection of ingot and billet as presentiy practiced by the industry. For example, reference standards should be used which have metal travels extending over the depth range to which the test part is to be inspected. Such reference standarda were not avallable for the ultragonic inspection of the ingot. The billet surfaces were prepured for ultrasonlc inspection by Tysaman grinding and the reference standarda had a machined surface of $63 \mathrm{rms}$ or better. It was learned that no compensation is normally made for this difference in surface finish from reference standard to test part. Several other aspects of ultrasonic inspection do not seem to be adequately controlled through specifications. For example, inaccuracies were found in the decade switches on some of the pulsei/receivers and these are not normally checked perjodically. It was found that the search unit characteristics are not always jequired to be checked and compensation requirements for differences in sound transmission characteristics between the reference standard and the test part are not 


\section{SUMMARY OF NDT RESULTS (Continued)}

well defined in some cases. Also, it was found that many of the techniques developed in the previous Air Force developmental program on Ingot and billet inspection have not been implemented on a day-to-day basis.

Based on these observations, then, it appears that many improvements still need to be made in areas of ingot and billet ultrasonic inspection.

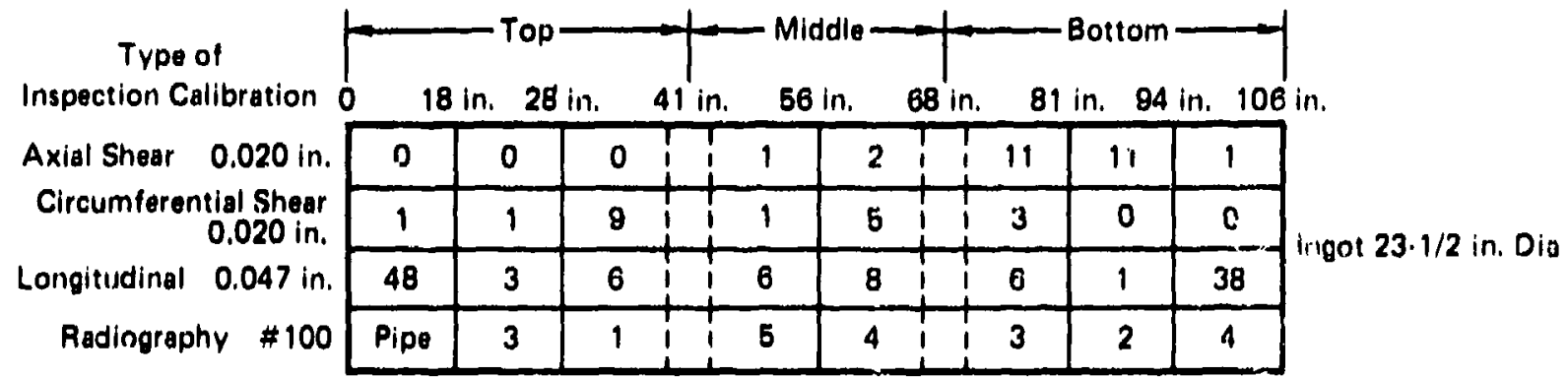

075 in. 120 in. 182 in. $0 \quad 103$ in. 189 in. $0 \quad 99$ in. 192 in. 291 in.

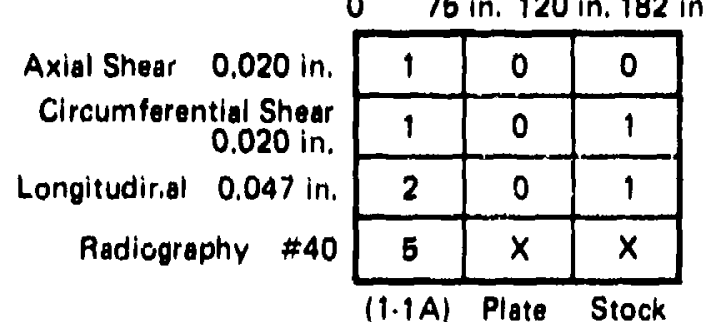

(1.1A) Plate Stock

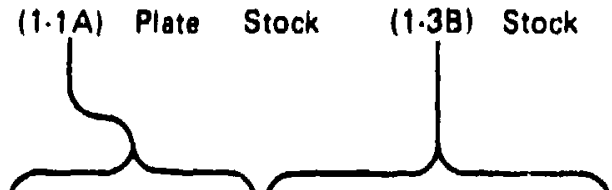

$080 \mathrm{in.} 158 \mathrm{in.} 0 \quad 59 \mathrm{in.} 139 \mathrm{in.} 201 \mathrm{in.}$

\begin{tabular}{|c|c|}
\hline$x$ & $x$ \\
\hline$x$ & $x$ \\
\hline 1 & 6 \\
\hline 1 & $x$ \\
\hline
\end{tabular}

(1.38) Stock

\begin{tabular}{|c|c|}
\hline 0 & 0 \\
\hline 3 & 21 \\
\hline $68(3)$ & $47(0)$ \\
\hline$x$ & 0 \\
\hline
\end{tabular}

Bar 6

Stock Forgings

(1.1AG) (1.1AG.TI)

\begin{tabular}{|c|c|c|}
\hline 1 & 0 & 0 \\
\hline 4 & 0 & 3 \\
\hline 61 (1) & $35(2)$ & $2(0)$ \\
\hline$x$ & $x$ & 0 \\
\hline
\end{tabular}

$(1.38)$

\begin{tabular}{|c|c|c|}
\hline 0 & 0 & 0 \\
\hline 21 & 0 & 10 \\
\hline 8 & 7 & 28 \\
\hline$X$ & $X$ & 10 \\
\hline
\end{tabular}

(1.2A) Stock Plate

(1.2B) Stock

$(1.2 \mathrm{C})$ Billet 9 in. Dia

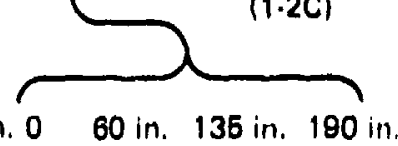

\begin{tabular}{|c|c|c|}
\hline 1 & 1 & 0 \\
\hline 0 & 12 & 3 \\
\hline $42(10)$ & $66(7)$ & $30(2)$ \\
\hline$x$ & 16 & $x$ \\
\hline Bar & 6 & Srock \\
\hline
\end{tabular} Billet 6 in. Dia

(1.2A2) Forgings

$(1.2 \mathrm{AB})$

Number In parenthesls lis the number of the indloatlone whlsh ined enturated pesponse.

$x$ Not Done

FIGURE 89

OP74 0111200 SUMMARY OF NDT RESULTS 
The capability of the improved penetrant, ultrasonic, eddy current, and radiographic methods for the detection of diacontinuities was measured. Discontinuity types used were surface cracks, internal cracks, porosity, fatigue cracks in fastener holes, and Iype I and l'ype II segregation in bar, plate, airframe forgings, and engine diuk forgings. Many of the test specimens were inspected under laboratory, production, and overhaul inspection conditions by jet engine inspection personnel and airframe inspection personnel. The nondestrustive testing techniques were intender to represent the present state-of-the-art; however, where possible, technique improvements developed earlier in the program were incorporated. Finally the actual size of several of the varlous discontinuities were measured.

\section{SURFACE CONNLC'IED CRACKS}

A program was carried out in order to measure the capability of penetraint, ultrasonlc, radjographic, and eddy current testing for detection of surtace cracks in titanium. A summary of the test program is presented in rable 55.

TABLE 66

SUMMARY OF INSPECTION METHODS USED FOR DETECTION OF SURFACE CRACKS

\begin{tabular}{|l|c|c|}
\hline Environment & Testing Group & Test Method \\
\hline Laboratory & Airframe & $\begin{array}{r}\text { Fluorescent Penetrant } \\
\text { Eddy Current }\end{array}$ \\
\hline Production & Airframe & $\begin{array}{c}\text { Fluorescent Penetrant } \\
\text { Surface Wave Ultrasonics } \\
\text { Contact Angle Beam Uitrasonics } \\
\text { Radiography }\end{array}$ \\
\hline Overhaul & Airframe & Fluorescent Ponetrant \\
\hline Laboratory & Engine & Fluorescent Penctrant \\
\hline Production & Engine & Fluorescent Penetrant \\
\hline Laboratory & AFML. & Fluorescent Penetrant \\
\hline
\end{tabular}

a. Tension - Tension Fatigue Specimen Fubrication

Specimens containing surface connected cracks were produced by subjecting futigue specimene (see Figure 90) to tension-tension fatigue using a 50,000 pourd Sonntag fat1gue machine. Electrical discharge machined (EDM) slots were Incorporated at varlous locations to serve as 

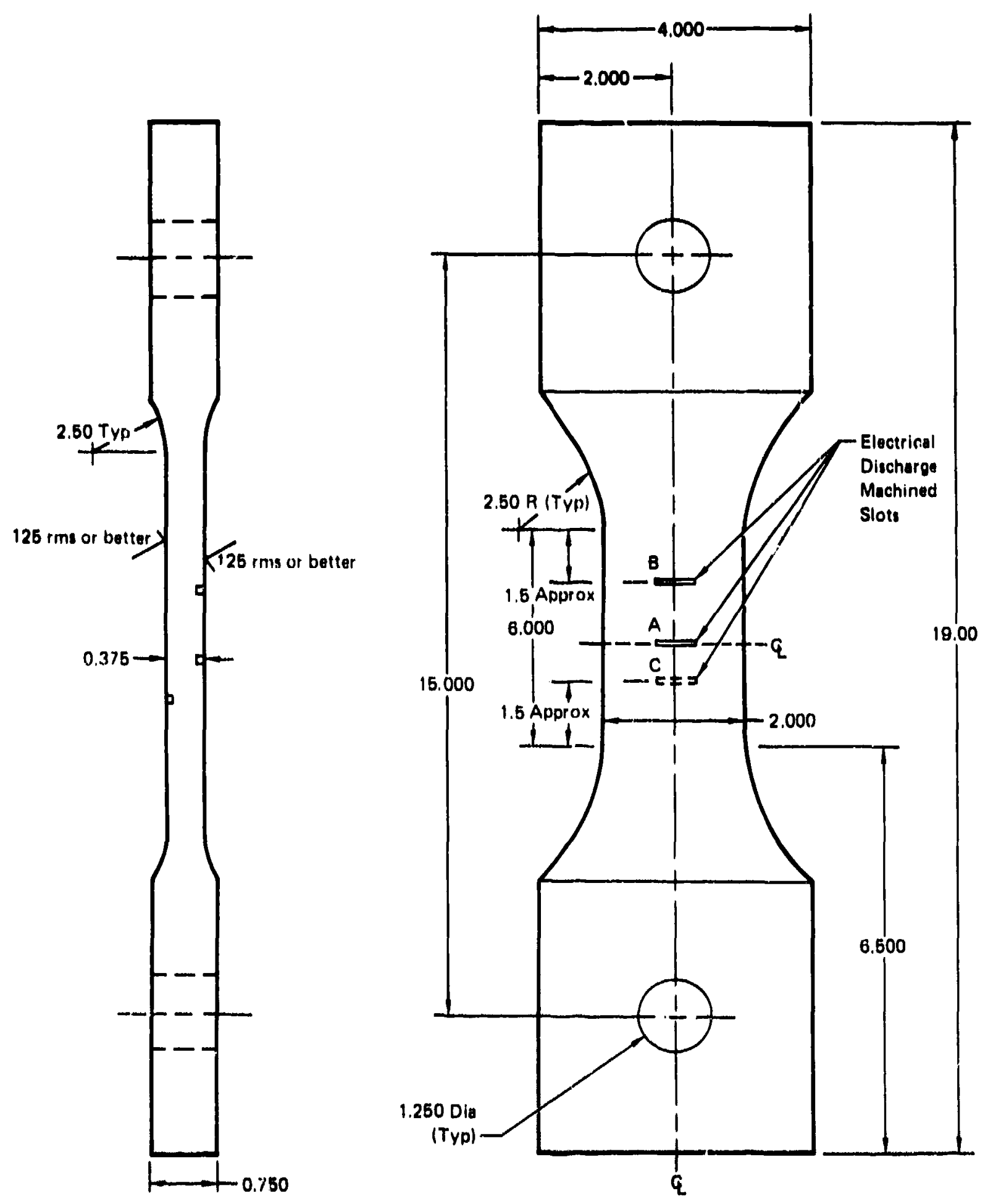

FIGURE 90

FATIQUE SPECIMEN

ar140117210 
fatigue crack Inftiators (see Flgure 90). During ratiguing a cyclic rate of 30 cycles per second was used. A summary of the fatigue parameters 1 s shown in Table 56. As shown, more than one crack was produced in several apecimens. Therefore, the same specimen number may appear in more than one location in Table 56. The fatigue cracks were grown to predeternined lengths by optically monitoring the crack growth. For those specimens which had more than one EDM alot, the crack in Position A was monitored. After the fatigue cracks were grow, the grip ends were cut off tise specimens and the EDM slots were machined off. The surface finish after machining was better than $6 \mathrm{I} \mathrm{rms}$. A set of specimens were selected from the group such that ten cracks were avallable in each of the following crack length ranges:

$$
\begin{aligned}
& \text { less than } .025 \text { inch } \\
& .025 \text { to } .050 \text { inch } \\
& .050 \text { to } .10 \text { Inch } \\
& .10 \text { to } .25 \text { inch } \\
& .25 \text { to } .50 \text { inch }
\end{aligned}
$$

\section{b. Liquid Penetrant Testing of Tension-Tension Fatigue Specimens}

\section{(1) Laboratory Inspection}

The test specimens described in Table 56 were all penetrant inspected under laboratiory conditions using a high sengltivity rluorescent penetrant system. Tracer-Tech F-133 penetrant was used, aloug with Tracer-Tech D499C nonaqueous wet develnper. This system is equivalent In sensitivity to a MLL-I-25135, Group VI system. A laboratory ND'I specialist, with several years experlencr: with penetrant inspection, performed the inspections using laboratory equipment. The technician did not know the location of the cracks in the specimens. The specimens were flrat alkaline cleaned, pickled to remove 0.0004 inch f'rom euch s.rerace, and water rinsed. Next, the specimens were vapor detreased for 16 hours. Penetrant was applied by dipping. A penetrant dwell time of 10 minutes was used and the specimens were allowed to drain in air during that perlod of time. Excess penetrant was removed using a Tri-Con 400501 water spray nozzle; the wash water temperature was approximately $70^{\circ} \mathrm{F}$ and the wash water pressure was approximately $40 \mathrm{pgi}$. 'The specimens were washed until clean under 200 microwatts per $\mathrm{cm}^{2}$ of ultraviolet light. Next, the specimens were dried for 20 minutes in a circulating alr oven at $170^{\circ} \mathrm{F}$. After a bleed-out time of 5 minutes, the specimens were visually examined for crack indications. Prior to examining the specimenis, the laboratory inspector allowed 5 minutes for his eyes to adapt to the darkness of the inspection booth. During the inspection, the uj.traviolct light intensity at the specimen surface was greater than 6,000 mlcrowatti per $\mathrm{cm}^{2}$ as measured with the UIiraviolet Products BLAK RAY UV meter, Model J-221, and the visible light level in the infpection booth was less than 1/2 foot candle as measured with the Photo Research White-Spectra Illuminator Meter, Model FC-200A. The lavoratory NDI specialist was instructed to mark linear indicatisis. Rounded indications were nut consldered. The inspections were periormed on 3 separate occasions. The flrst round consisted of inspecting approximately 60 pleces which included 
TABLE 66

PARAMETERS FOR SURFACE CONNECTED CRACKS MADE BY TENSION - TENSION FATIGUE (STRESS RATIO $=0.1$ )

\begin{tabular}{|c|c|c|c|c|}
\hline $\begin{array}{l}\text { Target } \\
\text { Crack Longth } \\
\text { (In.) }\end{array}$ & $\begin{array}{l}\text { Elox } \\
\text { Size } \\
\text { (in.) }\end{array}$ & $\begin{array}{l}\text { Specimen } \\
\text { Number }\end{array}$ & $\begin{array}{l}\text { Lond } \\
\text { (Ib) }\end{array}$ & $\begin{array}{c}\text { Number of } \\
\text { Cycles }\end{array}$ \\
\hline $\begin{array}{l}\text { Less } \\
\text { Than } \\
0.025\end{array}$ & $0.015 \times 0.05 \times 0.003$ & $\begin{array}{l}39 \\
46 \\
47 \\
59 \\
54 \\
56 \\
65 \\
70 \\
76 \\
77 \\
81\end{array}$ & $\begin{array}{c}33,750 \\
33,750 \\
33,750 / 45,000 \\
45,000\end{array}$ & 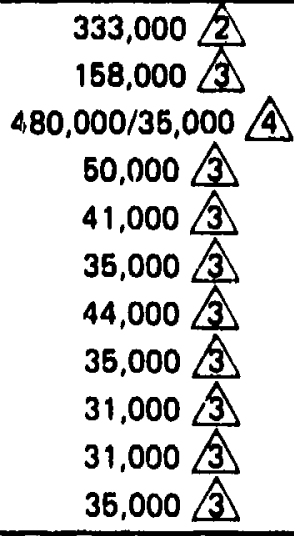 \\
\hline $\begin{array}{l}0.025 \\
\text { to } \\
0.050 \widehat{\Lambda}\end{array}$ & $0.030 \times 0.010 \times 0.003$ & $\begin{array}{l}34 \\
13 \\
14 \\
67 \\
67 \\
64 \\
66 \\
72 \\
73 \\
75\end{array}$ & 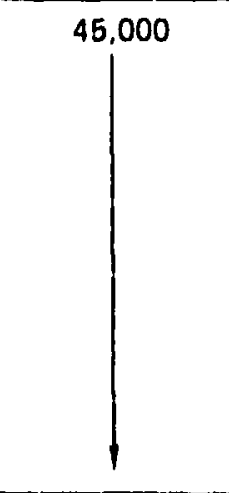 & 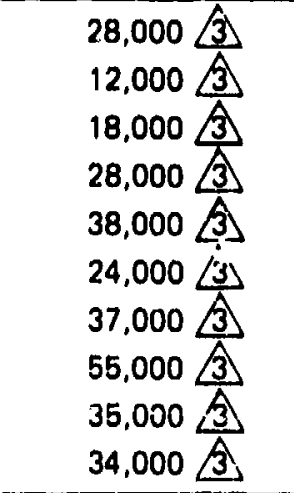 \\
\hline $\begin{array}{l}0.050 \\
\text { to } \\
0.100\end{array}$ & $0.060 \times 0.020 \times 0.005$ & $\begin{array}{l}33 \\
35 \\
24 \\
38 \\
10 \\
49 \\
56 \\
14 \\
63 \\
18\end{array}$ & $\left.\right|^{33,750}$ & $\begin{array}{l}35,000 \\
44,000 \\
95,000 \\
84,000 \\
71,000 \\
55,000 \\
65,000 \\
32,000 \\
45,000 \\
86,000\end{array}$ \\
\hline
\end{tabular}

0014.0117210 
TABLE 66 (Continued)

PARAMETERS FOR SURFACE CONNECTED CRACKS MADE BY TENSION - TENSION FATIGUE (STRESS RATIO $=0.1$ )

\begin{tabular}{|c|c|c|c|c|}
\hline $\begin{array}{c}\text { Target } \\
\text { Crack Length } \\
\text { (in.) }\end{array}$ & $\begin{array}{l}\text { Elox } \\
\text { Size } \\
\text { (in.) }\end{array}$ & $\begin{array}{c}\text { Specimen } \\
\text { Number }\end{array}$ & $\begin{array}{l}\text { Load } \\
\text { (Ib) }\end{array}$ & $\begin{array}{c}\text { Number of } \\
\text { Cycles }\end{array}$ \\
\hline $\begin{array}{l}0.100 \\
\text { to } \\
0.25\end{array}$ & $0.060 \times 0.020 \times 0.005$ & $\begin{array}{c}3 \\
4 \\
9 \\
11 \\
13 \\
15 \\
19 \\
20 \\
25 \\
27\end{array}$ & $\left.\right|^{33.750}$ & $\begin{array}{c}104,000 \\
152,000 \\
138,000 \\
114,000 \\
81,000 \\
168,000 \\
148,000 \\
129,000 \\
146,000 \\
141,000\end{array}$ \\
\hline $\begin{array}{l}0.25 \\
\text { to } \\
0.50\end{array}$ & $0.060 \times 0.020 \times 0.005$ & $\begin{array}{c}2 \\
8 \\
12 \\
21 \\
22 \\
23 \\
28 \\
29 \\
30 \\
31\end{array}$ & 13 & $\begin{array}{c}201,000 \\
132,000 \\
199,000 \\
135,000 \\
110,000 \\
122,000 \\
113,000 \\
115,000 \\
81,000 \\
123,000\end{array}$ \\
\hline
\end{tabular}

1) Terget lengeth was 0.00 o in. Specimen surface wes machined to reduce crack length to 0.025 to $0.080 \mathrm{in}$. ronge 2. Salt was applied to the Elox after 320,000 cyeles

3 Salt was applicd initially

4 Fatlgued for $480,000 \mathrm{cycles}$ at $33,750 \mathrm{lb}$; then another 35,000 crcles at $45,000 \mathrm{lb}$

ap 74.0117 .220

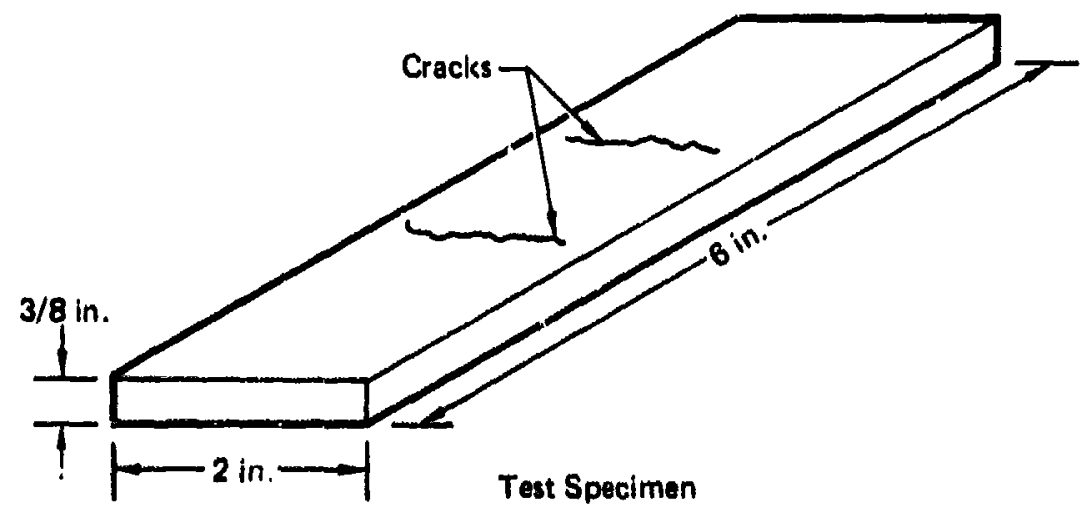


25 uncrucked "dunny" specimens. The second and third rounds were performed on approximately 12 pieces of which 4 were uncracked dummies. Each specimen was steel stamped with an identification number which was random and bore no relationship to the crack size in the specimen.

The results of the inspectiol, are presented in Table 57.

The test data is binomial in that each flaw is either detected or not detected. Consequently, the data can be presented in terms of the probabili.ty of detection. The confidence of the test was established at 95 percent and it was desired to find the crack size range at which the probability of detecion is greater than 90 percent. As can be seen from Table 57, for cracks .025 to .050 inch long, 30 out of 30 were detected. These resiults indicate that, 95 percent of the time, the probahility of detecting cracks .025 to .050 inch long is at least 90 percert. If one considers the data for all cracks greater than .025 inch long, it can be said that, 9: percent of the time, a.t least 95 percent of the cracks will be detecred.

During the entire laboratory testing, a total of two false indications were marked. A false indication, for the purposes of these tests, was considered an indication located where cracks were not intentionally grown. No measures were taken to determine the origin of the false indications (surface pits, scratches, etc.).

\section{(2) Production Inspection}

The test specimens described above were penetrant inspected using production facilities and 1:1spection personnel. The test specimens were initiali.y vapor degreased for 16 hours after the lahoratory inpsection effort previously described had been completed. Penetrant inspection was performed using Tracer-Tech P-133A fluorescent penetrant and $1499 \mathrm{C}$ nonaqueous wet developer. This system is equivalent in sensitivity to a MIL-I-25i35, Group VI system. The specimens were immersed for 10 minutes in the penetrant and then excess penetrant was removed by water spray washing using a Tri-Con 400501 nozzle, a wash water pressure of $40 \mathrm{psi}$ and a water tamperature of $780 \mathrm{~F}$. The specimens were washed until they appeared clean under 200 microwatts per $\mathrm{cm}^{2}$ of ultraviolet light. After having been dried with forced alr heated to $159^{\circ} \mathrm{F}$, the specimens were sprayed with Tracer-Tech D499C nonaqueous wet developer. A Devilbiss Co. type MBC 715893 spray gun was used with a 1 quart type $K K$ suction feed cup. After a 15 minute bleed-out time, the specimens were examined by a production penetrant inspector, designated Inspector A. All the production penetrant inspectors used for the program have been qualified to Level II of ASNT Recommended Practice No. SNT-TC-1A, Supplement D. The ultraviolet light intensity at the inspection surface was greater than 6,000 microwatts per $\mathrm{cm}^{2}$ as measured with an UItraviolet Products, Inc. BLAK-RAY UV meter, Model J-22l, and the background white light level was less than 1 foot candle as measured with a Weston 703 meter. Fricr to inspecting the specimens, the inspector allowed 5 minutes for dark adaptation. The specimens were inspected in batches of appruximately 30 pieces of which approximately 10 pieces were uncracked "dummies". The inspectors and supervisors were not eware of the location of any of the 

cracks from onc inspection to another. During each inspection, the crack locations were marked with a china marker pencil and returned to an angineer for evaluaion. After the data was recorded by the engineer, the specimene were vapor degreased for 16 hours to remove residual penetrant. A total of 6 production penetrant inspectors were used in the study. The results of the inspections of each specimen is shown in mable 58. The test results indicate that, 95 percent of the time $(95$ percent confidence level), the probability of detecting cracks .050 to .10 inch long is at least 88 percent. Obviously by choosing an NDT plan, the overall crack detection capability for a particular part can be increased. For example, the penetrant might: be followed by surface wave and contact angle beam ultrasonic inspections. It also should be noted that these results are statistically relevant to the actual test including the penetrant materials, processing equi.pment, and inspectors actually used in these tests.

The number of false crack indications detected by Inspectors $D$, $E$, and $F$ are shown in Table 59 as a function of the number of pieces examined, including uncracked dummies. For the purposes of these tests, : false indication was considered an indication in a location where a crack was not intentionally grown. No efforts were take: to determine the source of false indications (surface pits, scratches, etc.). As can be seen, quite a large number of false indication was recorded. There appears to be a difference between inspectors in this respect because Inspector $D$ recorded approximately 1 false indication for every 2 pleces examined, Inspector $E$ recorded approximatcly 1 false ind sation for every one piece examined, and Inspentor $F$ recorded approximately 1 false indication for every 3 pieces examined.

It was not possible to measure the number of false indications recorded by Inspectors $A, B$, and $C$ since these 3 inspectors recorded all penetrant indications, be they rounded or linear indications.

A compurison of the detection capability of each inspector is shown in I'abie 6o. For the larger crack sizes, there is little difference among the variuus inspectors. However, for the smaller cracks there appesirs to be a significant difference. For the cracks with lengths ip to .050 inch, Inspector $k$ letected only 2 of 34 cracks whereas Inspector $D$ detected $4 \%$ of 31 and Inspector F detected 22 of 28.

Geveril of the cracks went undetected more often than others. The data f'or actual crack size (see Section $1-k$ ) was examined to determine if the size of those cracks varied from the more "detectable" cracks within a crack size range but no correlation was found. For example, crack No. $65 \mathrm{~B}$ was detected 7 of 12 times whereas crack No. $38 \mathrm{~A}$ was detected 12 of 12 times. The actual size of each, however, was nearly the sume $(.080 \times .020$ inch versus $.070 \times .025$ inch

\section{(3) Overhaul Inspection}

The test specinens described in Table 56 were penetrant inspected at a facility representatlve of a penetrant inspection at an overhaul facility. This laclifty is a converted overhaul inspection facility where 
TABLE 58

RESULTS OF PRODUCTION PENETRANT INSPECTION

\begin{tabular}{|c|c|c|c|c|c|c|c|c|c|c|}
\hline \multirow{2}{*}{$\begin{array}{l}\text { Crack L ength } \\
\text { Pange } \\
\text { (in.) }\end{array}$} & \multirow{2}{*}{$\begin{array}{c}\text { Grack } \\
\text { Locution }\end{array}$} & \multirow{2}{*}{$\begin{array}{c}\text { Srrocimon } \\
\text { No. }\end{array}$} & \multicolumn{6}{|c|}{ Production Ponotrant Inspactor } & \multirow{2}{*}{ Total } & \multirow{2}{*}{$\begin{array}{l}\text { Probability } \\
\text { of } \\
\text { Ootection }\end{array}$} \\
\hline & & & A & B & $\mathbf{C}$ & D & $\mathbf{E}$ & $\mathbf{f}$ & & \\
\hline $\begin{array}{l}\text { Loss } \\
\text { Than } \\
0.025\end{array}$ & $\begin{array}{l}C \\
A \\
A \\
A \\
A \\
C \\
B \\
A \\
A \\
A\end{array}$ & $\begin{array}{l}35 \\
53 \\
54 \\
55 \\
63 \\
63 \\
65 \\
70 \\
76 \\
77\end{array}$ & $\begin{array}{l}0.1 \\
1 / 1 \\
1 / 1 \\
0 / 1 \\
0 / 1 \\
1 / 1 \\
0 / 1 \\
0 / 1 \\
0 / 1 \\
0 / 1\end{array}$ & $\begin{array}{l}- \\
- \\
- \\
- \\
- \\
- \\
- \\
- \\
-\end{array}$ & $\begin{array}{l}- \\
- \\
- \\
- \\
- \\
- \\
- \\
- \\
- \\
-\end{array}$ & $\begin{array}{l}4 / 7 \\
2 / 3 \\
6 / 7 \\
2 / 7 \\
5 / 7 \\
2 / 7 \\
1 / 3 \\
2 / 3 \\
4 / 7 \\
1 / 7\end{array}$ & $\begin{array}{l}0 / 1 \\
0 / 1 \\
0 / 2 \\
0 / 2 \\
0 / 2 \\
0 / 2 \\
0 / 1 \\
0 / 2 \\
0 / 2 \\
0 / 2\end{array}$ & $\begin{array}{c}2 / 3 \\
- \\
- \\
- \\
- \\
- \\
1 / 3 \\
2 / 3 \\
- \\
-\end{array}$ & $37 / 05$ & $\begin{array}{c}\text { At least } \\
34 \%\end{array}$ \\
\hline $\begin{array}{l}0.025 \\
0.050\end{array}$ & $\begin{array}{l}A \\
B \\
A \\
A \\
A \\
B \\
A \\
B \\
A \\
A\end{array}$ & $\begin{array}{l}33 \\
33 \\
35 \\
39 \\
45 \\
57 \\
65 \\
70 \\
75 \\
81\end{array}$ & $\begin{array}{l}0 / 1 \\
0 / 1 \\
1 / 1 \\
1 / 1 \\
1 / 1 \\
1 / 1 \\
1 / 1 \\
1 / 1 \\
1 / 1 \\
1 / 1\end{array}$ & $\begin{array}{l}- \\
- \\
- \\
- \\
- \\
- \\
- \\
- \\
-\end{array}$ & $\begin{array}{l}- \\
- \\
- \\
- \\
- \\
- \\
- \\
- \\
- \\
-\end{array}$ & $\begin{array}{c}3 / 3 \\
1 / 3 \\
6 / 7 \\
- \\
- \\
- \\
2 / 3 \\
2 / 3 \\
1 / 1 \\
3 / 3\end{array}$ & $\begin{array}{c}1 / 2 \\
0 / 2 \\
0 / 2 \\
- \\
0 / 2 \\
- \\
0 / 2 \\
0 / 2 \\
1 / 2 \\
0 / 2\end{array}$ & $\begin{array}{c}3 / 3 \\
2 / 3 \\
2 / 3 \\
1 / 1 \\
- \\
-. \\
3 / 3 \\
3 / 3 \\
\cdots \\
3 / 3\end{array}$ & $45 / 68$ & $\begin{array}{c}\text { At leust } \\
59 \%\end{array}$ \\
\hline $\begin{array}{l}0.050 \\
0.10\end{array}$ & $\begin{array}{l}A \\
A \\
A \\
B \\
A \\
A \\
B \\
B \\
A \\
A\end{array}$ & $\begin{array}{l}28 \\
34 \\
38 \\
39 \\
47 \\
49 \\
56 \\
57 \\
59 \\
73\end{array}$ & $\begin{array}{l}5 / 5 \\
5 / 5 \\
5 / 5 \\
4 / 5 \\
5 / 5 \\
5 / 5 \\
3 / 5 \\
4 / 5 \\
4 / 4 \\
5 / 5\end{array}$ & $\begin{array}{l}2 / 3 \\
3 / 3 \\
3 / 3 \\
3 / 3 \\
3 / 3 \\
3 / 3 \\
1 / 3 \\
3 / 3 \\
3 / 3 \\
3 / 3\end{array}$ & $\begin{array}{l}1 / 1 \\
1 / 1 \\
1 / 1 \\
1 / 1 \\
1 / 1 \\
1 / 1 \\
1 / 1 \\
1 / 1 \\
1 / 1 \\
1 / 1\end{array}$ & $\begin{array}{l}2 / 3 \\
3 / 3 \\
3 / 3 \\
3 / 3 \\
3 / 3 \\
3 / 3 \\
2 / 3 \\
3 / 3 \\
3 / 3 \\
3 / 3\end{array}$ & $\begin{array}{l}\cdots \\
- \\
- \\
- \\
- \\
- \\
- \\
- \\
- \\
-\end{array}$ & $\begin{array}{l}\overline{-} \\
- \\
\overline{1 / 1} \\
- \\
- \\
- \\
- \\
- \\
-\end{array}$ & $110 / 119$ & $\begin{array}{c}\text { At least } \\
88 \%\end{array}$ \\
\hline $\begin{array}{l}0.10 \\
0.25\end{array}$ & $\begin{array}{l}A \\
A \\
B \\
A \\
A \\
A \\
A \\
A \\
A \\
A\end{array}$ & $\begin{array}{r}3 \\
9 \\
9 \\
11 \\
15 \\
25 \\
56 \\
64 \\
66 \\
72\end{array}$ & $\begin{array}{l}3 / 3 \\
3 / 3 \\
3 / 3 \\
3 / 3 \\
3 / 2 \\
3 / 3 \\
2 / 2 \\
3 / 3 \\
3 / 3 \\
3 / 3\end{array}$ & $\begin{array}{l}3 / 3 \\
3 / 3 \\
3 / 3 \\
3 / 3 \\
3 / 3 \\
3 / 3 \\
3 / 3 \\
3 / 3 \\
3 / 3 \\
2 / 3\end{array}$ & $\begin{array}{l}1 / 1 \\
1 / 1 \\
1 / 1 \\
1 / 1 \\
1 / 1 \\
1 / 1 \\
1 / 1 \\
1 / 1 \\
1 / 1 \\
1 / 1\end{array}$ & $\begin{array}{l}5 / 5 \\
3 / 3 \\
3 / 3 \\
3 / 3 \\
3 / 3 \\
3 / 3 \\
3 / 3 \\
3 / 3 \\
5 / 5 \\
2 / 3\end{array}$ & $\begin{array}{l}- \\
- \\
- \\
- \\
- \\
- \\
- \\
- \\
- \\
-\end{array}$ & $\begin{array}{l}- \\
- \\
- \\
- \\
- \\
- \\
- \\
- \\
- \\
-\end{array}$ & $101 / 11, i$ & $\begin{array}{c}\text { At least } \\
94 \%\end{array}$ \\
\hline $\begin{array}{l}0.25 \\
0.50\end{array}$ & $\begin{array}{l}A \\
A \\
A \\
A \\
A \\
A \\
C \\
A \\
B \\
A\end{array}$ & $\begin{array}{r}8 \\
12 \\
21 \\
22 \\
23 \\
28 \\
29 \\
30 \\
30 \\
31\end{array}$ & $\begin{array}{l}1 / 1 \\
1 / 1 \\
1 / 1 \\
1 / 1 \\
1 / 1 \\
1 / 1 \\
1 / 1 \\
1 / 1 \\
1 / 1 \\
1 / 1\end{array}$ & $\begin{array}{l}- \\
- \\
- \\
- \\
- \\
- \\
- \\
- \\
- \\
-\end{array}$ & $\begin{array}{l}- \\
- \\
- \\
- \\
- \\
- \\
- \\
- \\
- \\
-\end{array}$ & $\begin{array}{c}6 / 6 \\
6 / 6 \\
7 / 7 \\
7 / 7 \\
7 / 7 \\
7 / 7 \\
- \\
7 / 7 \\
5 / 7 \\
7 / 7\end{array}$ & $\begin{array}{c}2 / 2 \\
2 / 2 \\
2 / 2 \\
2 / 2 \\
2 / 2 \\
2 / 2 \\
- \\
2 / 2 \\
2 / 2 \\
2 / 2\end{array}$ & $\begin{array}{l}- \\
- \\
- \\
- \\
- \\
- \\
- \\
- \\
- \\
-\end{array}$ & $87 / 89$ & $\begin{array}{c}\text { At least } \\
93 \%\end{array}$ \\
\hline
\end{tabular}

A 98 percent confidanca loval 
TABLE 69

NUMBER OF FALSE INDICATIONS - PRODUCTION PENETRANT IRISPECTION

\begin{tabular}{|c|c|c|}
\hline Inspector & Total Number of Plecas Inspected & Total Number of False Indications \\
\hline D & 249 & 138 \\
E & 66 & 69 \\
F & 22 & 7 \\
\hline
\end{tabular}

TABLE 80

COMPARISON OF PRODUCT V PENETRANT INSPECTORS

\begin{tabular}{|c|c|c|c|c|c|c|}
\hline $\begin{array}{c}\text { Crack Length } \\
\text { Range } \\
\text { (in.) }\end{array}$ & \multicolumn{5}{|c|}{ Total Number of Cracks Detected } \\
\cline { 2 - 7 } & A & B & C & D & E & F \\
\hline Less than 0.025 & 3 of 10 & - & - & 29 of 68 & 0 of 18 & 5 of 9 \\
$0.025-0.050$ & 8 of 10 & - & - & 18 of 23 & 2 of 16 & 17 of 19 \\
$0.050-0.100$ & 45 of 49 & 27 of 30 & 10 of 10 & 28 of 30 & - & - \\
$0.100-0.250$ & 29 of 29 & 29 of 30 & 10 of 10 & 33 of 34 & - & - \\
$0.250-0.500$ & 10 of 10 & - & - & 59 of 61 & 18 of 18 & - \\
\hline
\end{tabular}


production parts are now inspected. For this inspection, Sherwin HM-3 penetrant, a water washable fluorescent penetrant, was used along with Sherw1: D-100 nonaqueous wet developer. This system is equivalent in sensitivity to a MLL-I-25135, Group VI system. Prior to penetraut inspection, the specimens were cleaned by trichlorethylene vapor degreasing for 16 hours. The specimens were immersed in the penetrant and allowed to drain in air for 10 minutes after whicl excess penetrant was spray washed off' with a Magnaflux 30\%0 nozzle. The water pressure was $40 \mathrm{psi}$ and the water temperature was $90^{\circ} \mathrm{F}$. Next, the sfecimens were dried in an oven for 10 minutes at $140^{\circ} \mathrm{F}$. The developer was ipplied and after a 5 minute development time the parts were inspected in a dark inspection booti. The two inspectors allowed for a dark adaptation time of 5 minutes and the ultraviolet light intensity at the test part surface was 4,300 microwatts $/ \mathrm{cm}^{2}$. The white light intensity in the booth was less than 2 foot cardles. During the inspection, the inspector marked all linear indications; rounded indications were not considered for this study.

The results of the overhaul inspection are presented in Tarle 61. These test results indicate that, 95 percent of the time, the probability of detesting cracks .025 to .050 inch long is at least 80 percent. For cracks .050 to .10 inch long, the probability increases to 94 percent.

The total number of false indications recorded by each inspector as a function of the number of pleces inspected, which includes uncracked dummies, is shown in Teble 62. As in the case of the production penetrant inspections, there is a large variation in the number of false indications from one inspector to another.

From these results, it would seem that an overhaul penetrant inspection is more effective than a production penetrant inspection. Such generalizations can be misleading, however. For example, two different penetrant systems were used. Even though the two penetrant systems are both equivalent in sensitivity to a MIL-T-25135, Group VI penetrant there probably is a difference in sensitivity between the two since the MIL-I-25l35 sensitivity test is qualitative in nature. Also, the work load in the inspection area at the time of testing can influence the results as this will affect the amount of time an inspector can spend examining a particular plece.

\section{c. Ultrasonic Surface Wave Ultrasonic Inspection}

\section{(1) Production Inspection}

The test specimens described in Table 56 were all ultrasonically inspected using contact surfice wave techniques. The inspections were performed in a production ultrasonic inspection fucility using production

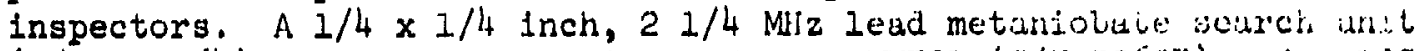
(S/N CF276li) was used along with a Sperry UM721 (S/N 59697) and a LOS dB pulser/recelver $(S / N$ 3719-0). The couplent was $20 \mathrm{~W}$ oil.

Several couplants were evaluated prior to selectins $20 \mathrm{~W}$ oil. Penetrant emulsifler, 20W oil, $90 \mathrm{~W}$ oil, and 40-20 011 were all 
TABLE 61

RESULTS OF OVERHAUL PENETRANT INSPECTION

\begin{tabular}{|c|c|c|c|c|c|c|c|c|c|}
\hline \multirow{2}{*}{$\begin{array}{c}\text { Crock Length } \\
\text { Rempe } \\
\text { (in.) }\end{array}$} & \multirow{2}{*}{$\begin{array}{c}\text { Conek } \\
\text { Location }\end{array}$} & \multirow{2}{*}{$\begin{array}{l}\text { Senetimen } \\
\text { Mo. }\end{array}$} & \multicolumn{5}{|c|}{ Overhaul Penotrant Inspector } & \multirow{2}{*}{ Total } & \multirow{2}{*}{$\begin{array}{c}\text { Probability } \\
\text { of } \\
\text { Dotection }\end{array}$} \\
\hline & & & $A$ & 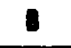 & C & 0 & E & & \\
\hline $\begin{array}{l}\text { Less } \\
\text { Than } \\
0.025\end{array}$ & $\begin{array}{l}C \\
A \\
A \\
A \\
A \\
C \\
B \\
A \\
A \\
A\end{array}$ & $\begin{array}{l}35 \\
53 \\
54 \\
65 \\
63 \\
63 \\
65 \\
70 \\
76 \\
77 \\
\end{array}$ & $\begin{array}{l}1 / 2 \\
1 / 1 \\
1 / 1 \\
0 / 1 \\
0 / 1 \\
1 / 1 \\
2 / 3 \\
2 / 3 \\
0 / 1 \\
0 / 1\end{array}$ & $\begin{array}{l}- \\
- \\
- \\
- \\
- \\
- \\
- \\
- \\
- \\
-\end{array}$ & & & & $8 / 16$ & - \\
\hline $\begin{array}{l}0.025 \\
0.050\end{array}$ & $\begin{array}{l}A \\
B \\
A \\
A \\
A \\
B \\
A \\
B \\
A \\
A \\
\end{array}$ & $\begin{array}{l}33 \\
33 \\
35 \\
39 \\
46 \\
57 \\
65 \\
70 \\
75 \\
81 \\
\end{array}$ & $\begin{array}{l}3 / 3 \\
1 / 3 \\
2 / 3 \\
3 / 3 \\
3 / 3 \\
3 / 3 \\
3 / 3 \\
3 / 3 \\
3 / 3 \\
3 / 3 \\
\end{array}$ & $\begin{array}{c}- \\
- \\
- \\
2 / 2 \\
- \\
2 / 2 \\
- \\
- \\
- \\
- \\
\end{array}$ & & & & $31 / 34$ & $\begin{array}{c}\text { At least } \\
80 \%\end{array}$ \\
\hline $\begin{array}{l}n .050 \\
0.10\end{array}$ & $\begin{array}{l}A \\
A \\
A \\
B \\
A \\
A \\
B \\
B \\
A \\
A\end{array}$ & $\begin{array}{l}29 \\
34 \\
38 \\
39 \\
47 \\
49 \\
56 \\
57 \\
59 \\
73 \\
\end{array}$ & $\begin{array}{l}3 / 3 \\
3 / 3 \\
3 / 3 \\
3 / 3 \\
3 / 3 \\
3 / 3 \\
3 / 3 \\
3 / 3 \\
3 / 3 \\
3 / 3 \\
\end{array}$ & $\begin{array}{l}2 / 2 \\
2 / 2 \\
2 / 2 \\
2 / 2 \\
2 / 2 \\
2 / 2 \\
2 / 2 \\
2 / 2 \\
2 / 2 \\
2 / 2 \\
\end{array}$ & & & & $60 / 50$ & $\begin{array}{c}\text { At least } \\
94 \%\end{array}$ \\
\hline $\begin{array}{l}0.10 \\
0.25\end{array}$ & $\begin{array}{l}A \\
A \\
B \\
A \\
A \\
A \\
A \\
A \\
A \\
A\end{array}$ & $\begin{array}{c}3 \\
9 \\
! 1 \\
11 \\
15 \\
25 \\
56 \\
64 \\
06 \\
\because \because\end{array}$ & $\begin{array}{l}1 / 1 \\
1 / 1 \\
1 / 1 \\
1 / 1 \\
1 / 1 \\
1 / 1 \\
3 / 3 \\
1 / 1 \\
1 / 1 \\
1 / 1\end{array}$ & $\begin{array}{l}- \\
- \\
- \\
- \\
- \\
- \\
2 / 2 \\
- \\
- \\
-\end{array}$ & & & & $14 / 14$ & - \\
\hline $\begin{array}{l}0.25 \\
0.50\end{array}$ & $\begin{array}{l}A \\
A \\
A \\
A \\
A \\
A \\
C \\
A \\
B \\
A\end{array}$ & $\begin{array}{r}8 \\
12 \\
21 \\
21 \\
23 \\
28 \\
29 \\
30 \\
30 \\
31\end{array}$ & $\begin{array}{l}1 / 1 \\
1 / 1 \\
1 / 1 \\
1 / 1 \\
1 / 1 \\
1 / 1 \\
3 / 3 \\
1 / 1 \\
1 / 9 \\
1 / 1\end{array}$ & $\begin{array}{c}. \\
\ldots \\
- \\
- \\
- \\
- \\
2 / 2 \\
- \\
- \\
.\end{array}$ & & & & $14 / 14$ & - \\
\hline
\end{tabular}


TABLE 62

NUMBER OF FALSE INDICATIONS - OVERHAUL PENETRANT INSPECTION

\begin{tabular}{|c|c|c|}
\hline Inspector & $\begin{array}{c}\text { Number } \\
\text { of Pieces } \\
\text { Examined }\end{array}$ & $\begin{array}{c}\text { Number } \\
\text { of False } \\
\text { Indications }\end{array}$ \\
\hline A & 122 & 44 \\
B & 30 & 2 \\
\hline
\end{tabular}

investigated. A 0.125 fnch thick reference standard containing an EDM notch which is .010 inch wide, .029 inch deep and .057 inch long (equivalent in reflecting area to a $3 / 64$ inch diameter flat bottom hole) was used in conjunction with the search unit. The couplant was applied to the surface and the signal from the EDM notch at a 4 inch metal travel was adjusted to 80 percent of saturation. The search unit was held steady and the variation in signal amplitude was observed. It was found that the 90 weight oil und the $20 \mathrm{~W}$ oil provided a constant signal amplitude whereas the signal dropped $0.6 \mathrm{nnch}$ in a lis second period with the 40-20W o1l and 0.8 inch with the emulsifier.

The scanning gain was established with an lilox ylot (.057 long $x$ .029 deep $x .010$ wide) in a .1 .25 inch thick plece of T1-6Al-4V machined to $63 \mathrm{rms}$ or better. The scanning gain was established by peaking the gignal from the slot at the meial travel distance which ylelded the maximum response and adjusting the signal to $80 \%$ of saturation. At that gain, a distance-amplitude correction (DAC) curve was constructed at metal travels of $1-1 / 2,2,2-1 / 2,3,3-1 / 2$, and 4 inches by marking the amplitudes on the CRT and drawing a smooth curve throlugh the points. Finaliy, the gain was increased by subtracting 19 dB of attenuation. Ihis, then, is approximately equivalent to setting the responise from an lilox slot .019 inch long $x .0095$ inch deep $x .010$ inch wide (equivalent in area to a $1 / 64$ inch diameter flat bottom hole) to $80 \%$ of isaturation on the CRT.

At that gain level, each $2 \times 6$ inch test specinen was hand scanned as shown in Figure 91. The search unit wus swiveled from right. to left, through an included angle is approximately 60 degrees during each scan. All indications with amplitudes equal to or greater than the DAC curve were narked on the surface of the specimen using a china mirker pencil. No attempt was made to evaluate the size of the cracks. Although many of the cracks were detected, their amplitude did not exceed the DAC curve and were, therefore, not recorded as being, detected.

Constderable difficulty was encountered in establishing $u$ reproducible diatance-anplitude curve during the surfuce wave testing. The amplitude of the response was very sensitive to variations in hund pressure on the search unit. In order to demonstrate this eftect, it DAC 


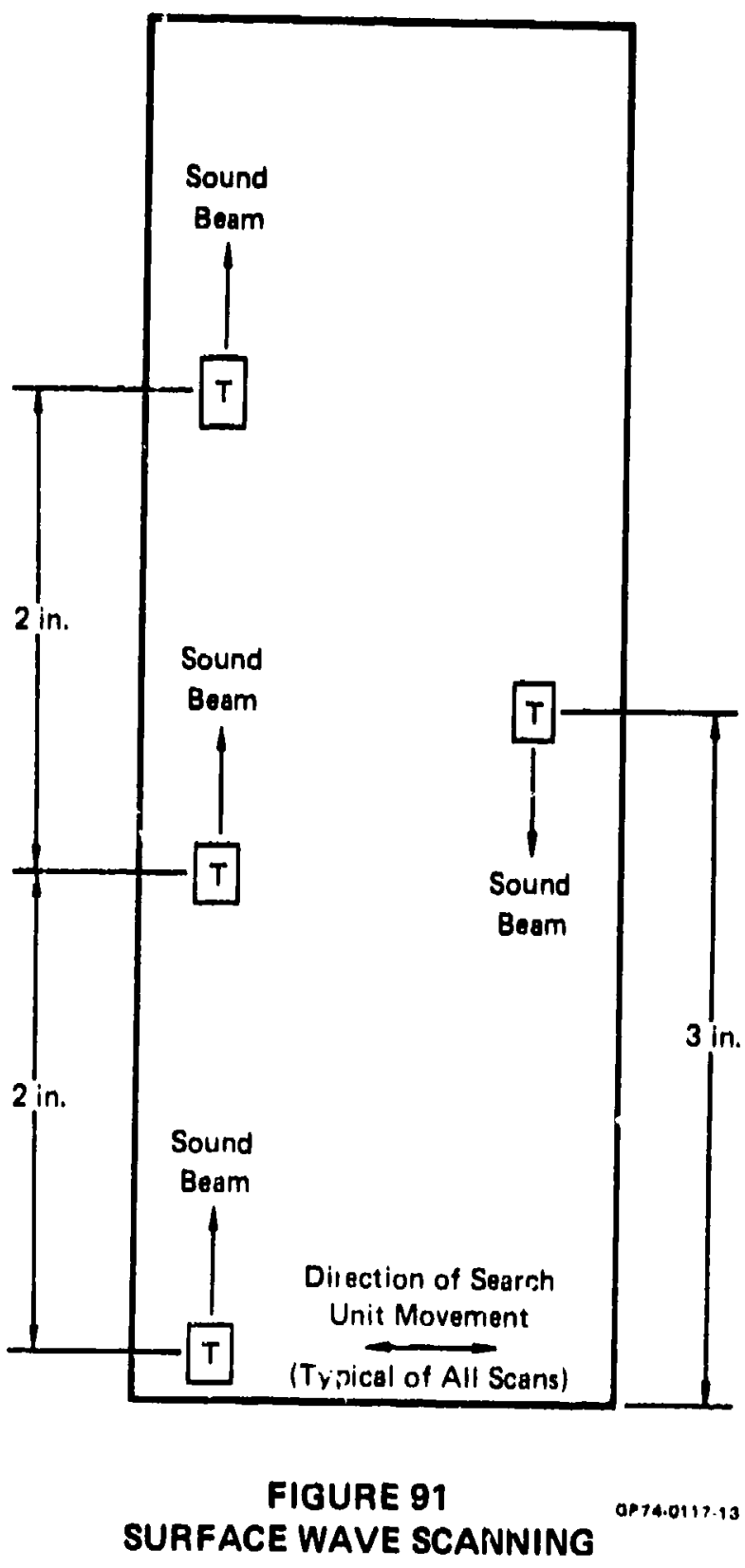


curves were constructed (Bee Figure 92). Two of the curves are for the same technleian (desigmated B). As can be seen, the varlation between technlcians (designeted A, B, and C) can become signiflcant at the larger metal travels. In addition, there is a significant variation between the two curves for the same technician (designated B).

Obviously, with such variations it would be difficult to accurately determine the size of a discontinuity in a test part. This was of no consequence for the surface wave testing performed on the cracked specimens alnce the objective was only to detect the cracks and not to evaluate their size.

The results of the production surface wave testing are show in Table 63. A notation such as $3 / 3$ indicates that 3 cracks were detected

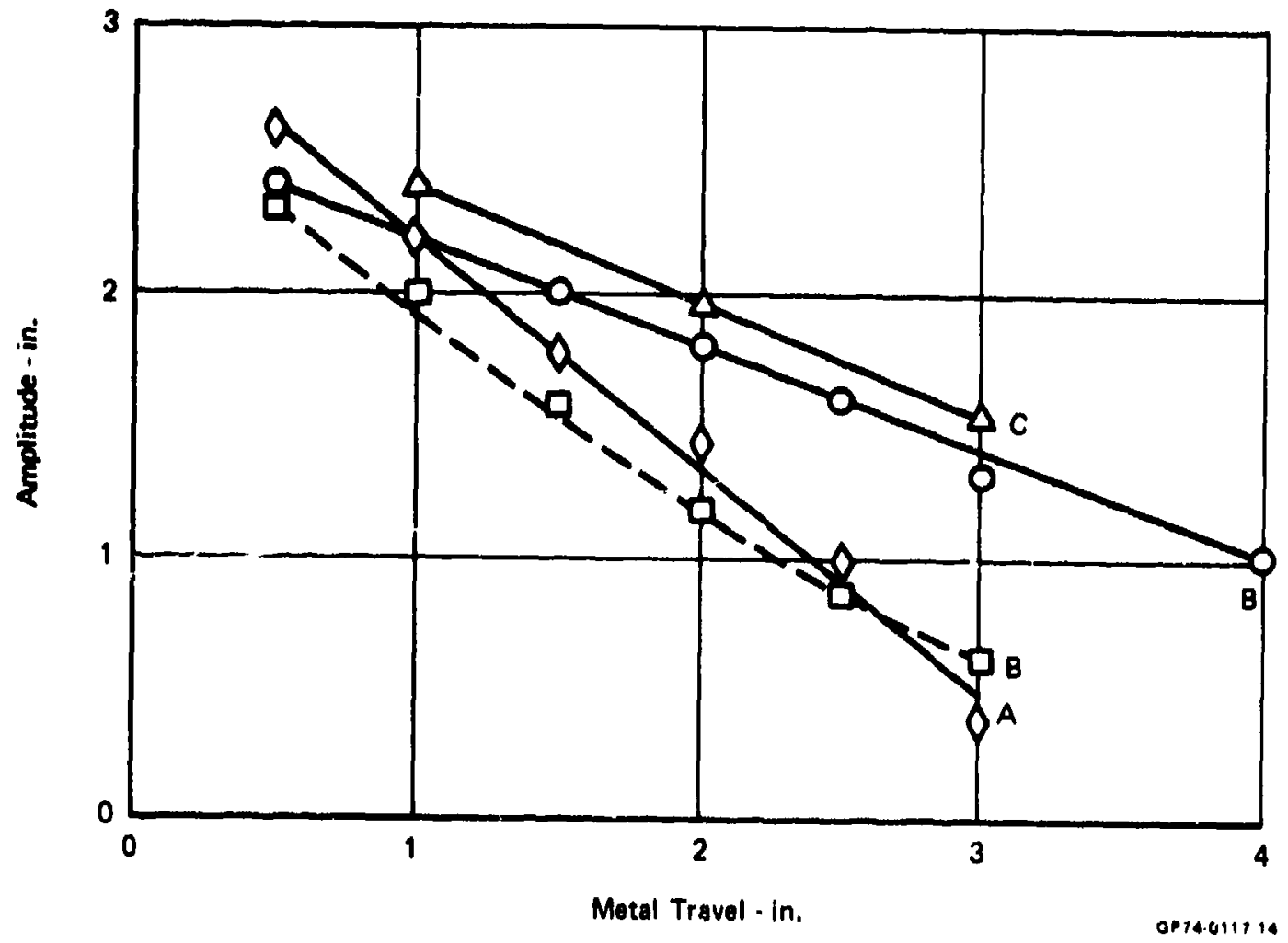

FIGURE 92

DISTANCE AMPLITUDE CORRECTION (DAC) CURVES FOR THREE REPRESENTATIVE TECHNICIANS 
TABLE 63

RESULTS OF PRODUCTION SURFACE WAVE ULTRASONIC INSPECTIONS

\begin{tabular}{|c|c|c|c|c|c|c|c|c|c|}
\hline \multirow{2}{*}{$\underset{\substack{\text { Conet Lexplith } \\
\text { (im) }}}{ }$} & \multirow{2}{*}{$\begin{array}{l}\text { Croch } \\
\text { Lecotion }\end{array}$} & \multirow{2}{*}{ Esmiman } & \multicolumn{5}{|c|}{ Production Surfece Wove Ultrasonies Inspector } & \multirow{2}{*}{ Toul } & \multirow{2}{*}{ Protability/ } \\
\hline & & & A & - & C & 0 & E & & \\
\hline $\begin{array}{l}\text { Less } \\
\text { Than } \\
0.026\end{array}$ & $\begin{array}{l}C \\
A \\
A \\
A \\
A \\
C \\
B \\
A \\
A \\
A\end{array}$ & $\begin{array}{l}36 \\
53 \\
54 \\
65 \\
63 \\
63 \\
65 \\
70 \\
76 \\
77\end{array}$ & $\begin{array}{l}0 / 1 \\
- \\
- \\
- \\
- \\
- \\
1 / 1(3) \\
1 / 1 \\
- \\
-\end{array}$ & $\begin{array}{l}0 / 1 \\
- \\
- \\
- \\
- \\
- \\
0 / 1 \\
- \\
- \\
-\end{array}$ & $\begin{array}{l}- \\
- \\
- \\
- \\
- \\
- \\
- \\
- \\
-\end{array}$ & $\begin{array}{l}0 / 1 \\
0 / 1 \text { (2) } \\
0 / 1 \\
0 / 1 \\
0 / 1 \\
0 / 1 \\
0 / 1 \\
0 / 1 \\
0 / 1 \text { (2) } \\
0 / 1\end{array}$ & $\begin{array}{l}0 / 7 \\
0 / 2 \text { (3) } \\
0 / 2 \\
1 / 6 \text { (2) } \\
0 / 5 \\
0 / 5 \\
0 / 7 \text { (1) } \\
0 / 7 \\
0 / 5 \text { (3) } \\
0 / 5 \text { (1) }\end{array}$ & 3 of 66 & $\begin{array}{c}\text { At loast } \\
1 \%\end{array}$ \\
\hline $\begin{array}{l}0.025 \\
0.050\end{array}$ & $\begin{array}{l}A \\
B \\
A \\
A \\
A \\
B \\
A \\
B \\
A \\
A\end{array}$ & $\begin{array}{l}33 \\
33 \\
35 \\
39 \\
45 \\
67 \\
65 \\
70 \\
75 \\
81 \\
\end{array}$ & $\begin{array}{l}- \\
- \\
1 / 1 \\
1 / 1 \\
- \\
3 / 3(7) \\
0 / 1 \\
1 / 1 \\
- \\
- \\
\end{array}$ & $\begin{array}{c}- \\
- \\
0 / 1 \\
2 / 2 \\
- \\
2 / 3 \\
0 / 1 \\
0 / 1 \\
- \\
- \\
\end{array}$ & $\begin{array}{l}- \\
- \\
- \\
1 / 1 \\
- \\
- \\
- \\
- \\
- \\
-\end{array}$ & $\begin{array}{l}1 / 1 \\
0 / 1 \text { (2) } \\
0 / 1 \\
\cdots \\
- \\
0 / 1 \\
0 / 1 \text { (3) } \\
\cdots \\
0 / 1\end{array}$ & $\begin{array}{l}1 / 2(2) \\
0 / 2 \\
0 / 5 \\
2 / 2 \\
0 / 5(2) \\
0 / 5 \\
0 / 7 \\
0 / 5 \\
0 / 5 \\
0 / 2(4) \\
\end{array}$ & 16 of 62 & $\begin{array}{c}\text { At least } \\
18 \%\end{array}$ \\
\hline $\begin{array}{l}0.60 \\
0.10\end{array}$ & $\begin{array}{l}A \\
A \\
A \\
B \\
A \\
A \\
B \\
B \\
A \\
A\end{array}$ & $\begin{array}{l}29 \\
34 \\
38 \\
39 \\
47 \\
49 \\
58 \\
57 \\
59 \\
73\end{array}$ & $\begin{array}{l}3 / 3 \text { (4) } \\
2 / 2 \text { (7) } \\
3 / 3 \text { (10) } \\
0 / 1 \\
0 / 2 \\
3 / 3 \text { (4) } \\
3 / 3 \text { (5) } \\
1 / 3 \text { (1) } \\
3 / 3 \\
2 / 2 \text { (3) }\end{array}$ & $\begin{array}{l}2 / 3 \text { (4) } \\
3 / 3 \\
2 / 3 \text { (4) } \\
2 / 2 \\
0 / 3 \\
0 / 3 \\
0 / 3 \text { (3) } \\
0 / 3(1) \\
2 / 3 \\
0 / 3\end{array}$ & $\begin{array}{l}- \\
- \\
0 / 1 \\
1 / 1 \\
0 / 1 \\
- \\
- \\
- \\
- \\
0 / 1\end{array}$ & $\begin{array}{l}- \\
- \\
- \\
. \\
- \\
- \\
- \\
- \\
- \\
-\end{array}$ & $\begin{array}{l}1 / 2 \\
1 / 3 \\
- \\
0 / 2 \\
- \\
0 / 2 \\
0 / 1 \\
2 / 5 \\
4 / 4(1) \\
-\end{array}$ & 40 of 77 & $\begin{array}{c}\text { At least } \\
47 \%\end{array}$ \\
\hline $\begin{array}{l}0.10 \\
0.25\end{array}$ & $\begin{array}{l}A \\
A \\
B \\
A \\
A \\
A \\
A \\
A \\
A \\
A\end{array}$ & $\begin{array}{r}3 \\
9 \\
9 \\
11 \\
15 \\
25 \\
50 \\
64 \\
66 \\
72\end{array}$ & $\begin{array}{l}1 / 2 \text { (6) } \\
2 / 2(5) \\
1 / 2 \\
3 / 3 \\
2 / 2 \\
1 / 2 \\
3 / 3 \\
3 / 3 \\
1 / 1 \\
1 / 1 \\
12\end{array}$ & $\begin{array}{l}1 / 3 \\
2 / 2 \\
2 / 2 \\
2 / 2 \\
2 / 2 \\
2 / 2 \\
3 / 3 \\
2 / 2 \\
2 / 2 \\
2 / 2\end{array}$ & $\begin{array}{l}-. \\
- \\
-. \\
\cdots \\
1 / 1 \\
0 / 1 \\
- \\
1 / 12 \\
1 / 12 \\
1 / 1\end{array}$ & $\begin{array}{l}- \\
. . \\
-. \\
\ldots \\
. \\
- \\
- \\
- \\
- \\
-\end{array}$ & $\begin{array}{l}0 / 2 \\
1 / 1 \\
1 / 1 \\
1 / 1 \\
\ldots \\
0 / 4 \\
1 / 1 \\
4 / 4 \bigcirc \\
4 / 5 \\
0 / 1\end{array}$ & 55 of 68 & $\begin{array}{c}\text { At least } \\
74 \%\end{array}$ \\
\hline $\begin{array}{l}0.25 \\
0.50\end{array}$ & $\begin{array}{l}A \\
A \\
A \\
A \\
A \\
A \\
C \\
A \\
B \\
A\end{array}$ & $\begin{array}{r}8 \\
12 \\
21 \\
22 \\
23 \\
28 \\
29 \\
30 \\
30 \\
31\end{array}$ & $\begin{array}{l}- \\
- \\
- \\
1 / 1 \\
- \\
1 / 1 \text { (4) } \\
3 / 3 \\
1 / 1 \\
1 / 1 \text { (2) } \\
1 / 1 \text { (3) }\end{array}$ & $\begin{array}{l}\cdots \\
- \\
- \\
1 / 10 \\
- \\
1 / 1 \\
3 / 3 \\
1 / 1 \\
1 / 1 \\
1 / 1(2)\end{array}$ & $\begin{array}{l}- \\
. \\
. \\
. \\
. \\
- \\
- \\
- \\
-\end{array}$ & $\begin{array}{l}- \\
\cdots \\
0 / 1 \\
1 / 1(1) \\
0 / 1 \\
1 / 1 \\
- \\
1 / 1 \\
1 / 1 \\
0 / 1(2)\end{array}$ & $\begin{array}{l}-7 / 4 \text { (5) } \\
3 / 5 \text { (1) } \\
5 / 5(2) \\
6 / 6 \text { (3) } \\
5 / 5 \\
3 / 3 \\
1 / 1 \\
111 \\
6 / 6 \text { (4) }\end{array}$ & 64 of 59 & $\begin{array}{c}\text { At loast } \\
84 \%\end{array}$ \\
\hline
\end{tabular}

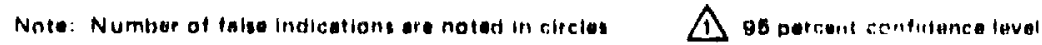


out of 3 crack present. A comparisor of these results with the production penetrant results would seem to indicate that the penetrant method is more reliable for detecting surface cracks (see Table 64).

From these results; it would appear that the surface wave methud is not very effective. It should be pointed out, however, that as discussad below, the surface wave has an effective depth of penetration wh1ch allows subsurface cracks to be detected. Consequently, an effective NDT plan for machined parts might include a penetrant inspection to detect surfece cracks and a surface wave inspection to detect both surface and subsurface cracks.

A comparison of the capability of the various inspectors is shown in Table 65.

\section{TABLE 64}

COMPARISON OF PENETRANT AND SURFACE WAVE TEST RESULTS

\begin{tabular}{|c|c|c|c|c|}
\hline \multirow{2}{*}{$\begin{array}{l}\text { Crack Length } \\
\text { (in.) }\end{array}$} & \multicolumn{2}{|c|}{ Numbor Cracks Dotected } & \multicolumn{2}{|c|}{ Probubility of Detection } \\
\hline & Penotiant & $\begin{array}{c}\text { Surface } \\
\text { Wave }\end{array}$ & Penotrant & $\begin{array}{c}\text { Surfuce } \\
\text { Wave } 1\end{array}$ \\
\hline Less Than 0.025 & 37 of 95 & 3 of 66 & At least $34 \%$ & At least 1\% \\
\hline $0.025 \cdot 0.050$ & 45 of 88 & 15 of 62 & At least 59\% & At least $18 \%$ \\
\hline $0.050-0.10$ & 110 of 119 & 40 of 77 & At least $88 \%$ & At least $47 \%$ \\
\hline $0.10 \cdot 0.26$ & 101 of 103 & 55 of 58 & At levist $94 \%$ & At least $74 \%$ \\
\hline $0.25 \cdot c \cdot 50$ & 87 of 89 & 54 of 59 & At least $93 \%$ & At least $84 \%$ \\
\hline
\end{tabular}

As in the case of the production penetrant tests, there appears to be a signiflcant variation in inspectur capability. For the surface wave tests, however, this variution extends to the larger crack sizes. For example, for cracks .10 to .25 inch long, Operator A detected 19 of 21 cracks whereas Operator $E$ detected only 12 of 20 . If the results from Operator $\mathbb{E}$ were not considered, the overall detection capability for cracks .10 to .25 1nch long would increase to 43 of 48 from 55 of 68 .

A number of the larger cracks were detected from both sides of the specimens during the surface wave inspection as shown in Table 66 . An estimate of the depth of penetration of the surface wave can be determined by considering the actual depth of the cracks. Several of these cracks were intentionally fractured to measure the actual depth of the crack. An eatimate of the depth of penetration of the aurface wave in the $3 / 8$ inch thick specimens appears below. 


\begin{tabular}{llll}
$\begin{array}{l}\text { Specimen } \\
\text { No. }\end{array}$ & $\begin{array}{l}\text { Crack } \\
\text { Length } \\
\text { (Inches) }\end{array}$ & $\begin{array}{l}\text { Crack } \\
\text { Depth } \\
\text { (Inches) }\end{array}$ & $\begin{array}{l}\text { Estimated Lepth of Penetration } \\
\text { of Surface Wave (Inches) }\end{array}$ \\
\hline 38 & .070 & .025 & .350 \\
$56(\mathrm{~B})$ & .080 & .020 & .355 \\
59 & .090 & .030 & .345 \\
11 & .070 & .070 & .305 \\
15 & .250 & .070 & .305 \\
25 & .15 & .020 & .355 \\
$56(\mathrm{~A})$ & .125 & .035 & .340 \\
$30(\mathrm{~A})$ & .48 & .18 & .195
\end{tabular}

TABLE 65

SUMMARY OF CRACK DETECTION CAPABILITY OF SURFACE WAVE ULTRASONICS BY OPERATOR

\begin{tabular}{|c|c|c|c|c|c|}
\hline $\begin{array}{c}\text { Crack Length } \\
\text { (lin.) }\end{array}$ & \multicolumn{5}{|c|}{ Oparntor } \\
\cline { 2 - 6 } & A & B & C & D & E \\
\hline Less than 0.025 & $2 / 3$ & $0 / 2$ & - & $0 / 10$ & $1 / 61$ \\
$0.025-0.060$ & $6 / 7$ & $4 / 8$ & $1 / 1$ & $1 / 6$ & $3 / 40$ \\
$0.050-0.100$ & $20 / 25$ & $11 / 29$ & $1 / 4$ & - & $8 / 19$ \\
$0.100-0.250$ & $19 / 21$ & $20 / 22$ & $4 / 5$ & - & $12 / 20$ \\
$0.250-0.500$ & $8 / 8$ & $8 / 8$ & - & $4 / 7$ & $34 / 36$ \\
\hline
\end{tabular}




\section{TABLE 68}

CRACKS DETECIED FROM BO TH SIDES OF SPECIMEN BY SURFACE WAVE ULTRASONICS (SUMMATION OF 5 OPERATORS)

\begin{tabular}{|c|c|c|}
\hline $\begin{array}{l}\text { Crack Length } \\
\text { (in.) }\end{array}$ & $\begin{array}{l}\text { Spocimen } \\
\text { No. }\end{array}$ & $\begin{array}{l}\text { Nimbar of Times Crack } \\
\text { Dotected from Both sides }\end{array}$ \\
\hline $0.050-0.10$ & $\begin{array}{l}29 \\
38 \\
49 \\
56 \\
59\end{array}$ & $\begin{array}{l}1 \text { of } 3 \\
1 \text { of } 3 \\
1 \text { of } 3 \\
1 \text { of } 3 \\
1 \text { of } 3\end{array}$ \\
\hline $0.100-0.25$ & $\begin{array}{l}9(A) \\
9(B) \\
11 \\
15 \\
25 \\
56\end{array}$ & $\begin{array}{l}1 \text { of } 2 \\
1 \text { of } 2 \\
2 \text { of } 3 \\
1 \text { of } 2 \\
1 \text { of } 2 \\
1 \text { of } 3\end{array}$ \\
\hline $0.250-0.50$ & $\begin{array}{c}12 \\
22 \\
23 \\
29 \\
29 \\
30(\mathrm{~A}) \\
30(\mathrm{~B}) \\
31\end{array}$ & $\begin{array}{l}1 \text { of } 1 \\
2 \text { of } 2 \\
3 \text { of } 6 \\
4 \text { of } 7 \\
8 \text { of } 10 \\
4 \text { of } 5 \\
2 \text { of } 2 \\
2 \text { of } 7\end{array}$ \\
\hline
\end{tabular}


From these results, it can be concluded that the ultrasonic surface wave from a $1 / 4 \times 1 / 4 \mathrm{inch}, 21 / 4 \mathrm{MHz}$ lead metaniobate search unit penetrates to a depth of at least .355 inch in Ti-6Al-4V. This information may prove useful in deciding if it is necessary to finspect a part from 2 sides or one side.

A tabulation of the false indications recorded by each inspector during the surface wave inspections as a function of the number of pieces examined, including uncracked dummies, is shown in Tuule 67.

\section{TABLE 67 \\ SUMMARY OF FALSE INDICATIONS - ULTRASONIC SURFACE WAVE}

\begin{tabular}{|c|c|c|}
\hline Inspector & Number of Specimens Examined & Number of False Indications \\
\hline A & 62 & 116 \\
B & 70 & 22 \\
C & 16 & 4 \\
D & 27 & 13 \\
E & 190 & 41 \\
\hline
\end{tabular}

Again, a false indication vas defined as an indication in a location where a crack was not intentionally grown. As in the case of the penetrant inspections, the number of false indications per pieces inspected varied considerably from one inspector to another. The overall ratio of false indications per piece inspected was 0.54 for surface wave and 0.65 for penetrant. It should be mentioned that several of the false indications that were recorded during the surface wave inspections were surface anomalies such as scratches or nicks.

\section{(2) Laboratory Inspection}

For comparison purposes, a laboratory test program was conducted on the specimens. The search unit, equipment, and procedure used were the same as for the production surface wave inspection. However, for the laboratory tests, the amplitude of all responses was noted, even if they were less then the corresponding distance-amplitude response. The results are shown in Table 68. As might be expected, the laborctory results are somewhat better than the production results, even though neithe: the production nor the laboratory inspectors knew the locations of the cracks and the inspection time was approximately the same for both. Several of the cracks detected in the Laboratory, however, exhibited responses of approximately 50 percent of the DAC curve. These responses would not have been recorded in the produtioin inspection since only 
TABLE 68

RESULTS OF LABORATORY SURFACE WAVE INSPECTION

\begin{tabular}{|c|c|c|c|}
\hline $\begin{array}{l}\text { Crack Length } \\
\text { (in.) }\end{array}$ & $\begin{array}{l}\text { Spaciman } \\
\text { Numbar }\end{array}$ & $\begin{array}{c}\text { Number of Crecks } \\
\text { Detweted }\end{array}$ & Total \\
\hline $0.025-0.050$ & 67 & $2 / 2$ & $2 / 2$ \\
\hline $0.050-0.10$ & $\begin{array}{l}29 \\
34 \\
38 \\
47 \\
49 \\
56 \\
67 \\
59 \\
73\end{array}$ & $\begin{array}{l}0 / 1 \\
1 / 2 \\
2 / 2 介 \\
1 / 2 介 \\
2 / 2 \\
0 / 2 \\
1 / 2 \\
2 / 2 介 \\
1 / 2 介\end{array}$ & $10 / 17$ \\
\hline $0.10-0.25$ & $\begin{array}{c}3 \\
9 \\
9 \\
11 \\
15 \\
25 \\
56 \\
64 \\
66 \\
72\end{array}$ & $\begin{array}{l}1 / 1 \\
1 / 1 \\
1 / 1 \\
1 / 1 \\
1 / 1 \\
1 / 1 \\
2 / 2 \\
1 / 1 \\
1 / 1 \\
1 / 1\end{array}$ & $11 / 11$ \\
\hline $0.25-0.50$ & 29 & $2 / 2$ & $2 / 2$ \\
\hline
\end{tabular}

One of the cracke detected had a responme amplitude of 50 percent of the DAC curve amplitude.

OP 14.0117 .21 



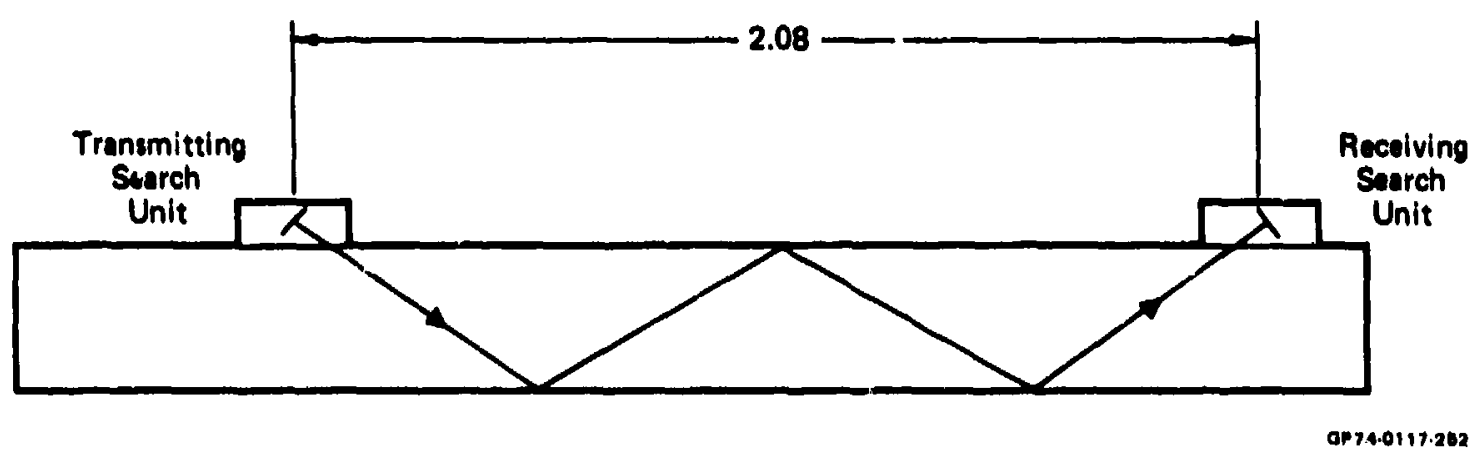

FIGURE 93

TEST SETUP USED TO MEASURE SOUND TRANSMISSION DIFFERENCE 


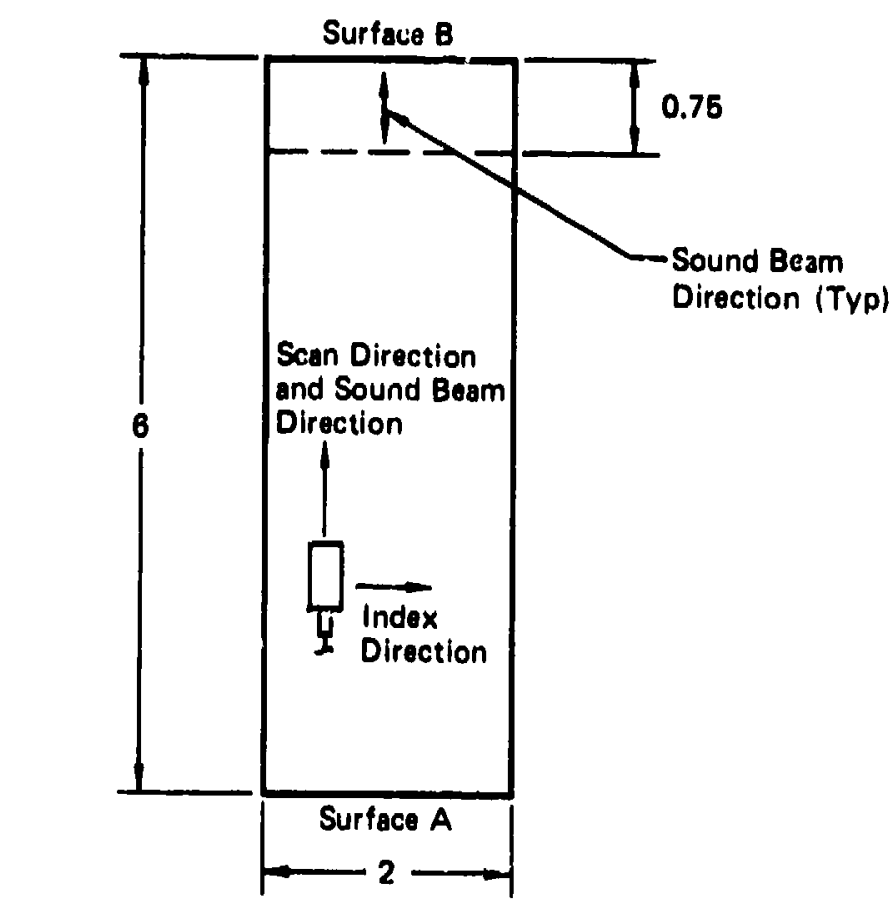

0814.0117 .104

FIGURE 96

SCAN PLAN FOR CONTACT ANGLE BEAM TFSTING

TABLE 69

RESULTS OF PRODUCTION CONTACT ANGLE BEAM INSPECTION

\begin{tabular}{|c|c|c|c|c|c|}
\hline \multirow{2}{*}{$\begin{array}{l}\text { Cruch } \\
\text { Length } \\
\text { Pange } \\
\text { (in.) }\end{array}$} & \multirow{2}{*}{$\begin{array}{c}\text { Spocimon } \\
\text { No. }\end{array}$} & \multicolumn{2}{|c|}{$\begin{array}{l}\text { Contect Angle Beem } \\
\text { Ultrasonic Inspector }\end{array}$} & \multirow{2}{*}{ Total } & \multirow{2}{*}{$\begin{array}{c}\text { Probubility } \\
\text { of } \\
\text { Detection } \\
\text { A }\end{array}$} \\
\hline & & A & $\mathbf{B}$ & & \\
\hline $0.025 \cdot 0.050$ & 57 & $9 / 9$ & $1 / 4$ & $10 / 13$ & - \\
\hline $0.050-0.100$ & $\begin{array}{l}57 \\
29 \\
34 \\
49\end{array}$ & $\begin{array}{l}8 / 8 \\
6 / 7 \\
7 / 7 \\
6 / 3\end{array}$ & $\begin{array}{l}2 / 4 \\
3 / 4 \\
2 / 5 \\
2 / 5\end{array}$ & $36 / 46$ & $\begin{array}{c}\text { At least } \\
69 \%\end{array}$ \\
\hline $0.10-0.25$ & $\begin{array}{r}72 \\
9 \\
9 \\
64\end{array}$ & $\begin{array}{l}4 / 6 \\
5 / 5 \\
5 / 5 \\
5 / 5\end{array}$ & $\begin{array}{l}4 / 5 \\
3 / 5 \\
5 / 5 \\
5 / 5\end{array}$ & $38 / 40$ & $\begin{array}{c}\text { At least } \\
80 \%\end{array}$ \\
\hline $0.25 \cdot 0.50$ & 29 & $7 / 7$ & $4 / 4$ & $11 / 11$ & - \\
\hline
\end{tabular}

96 percent confldence level 


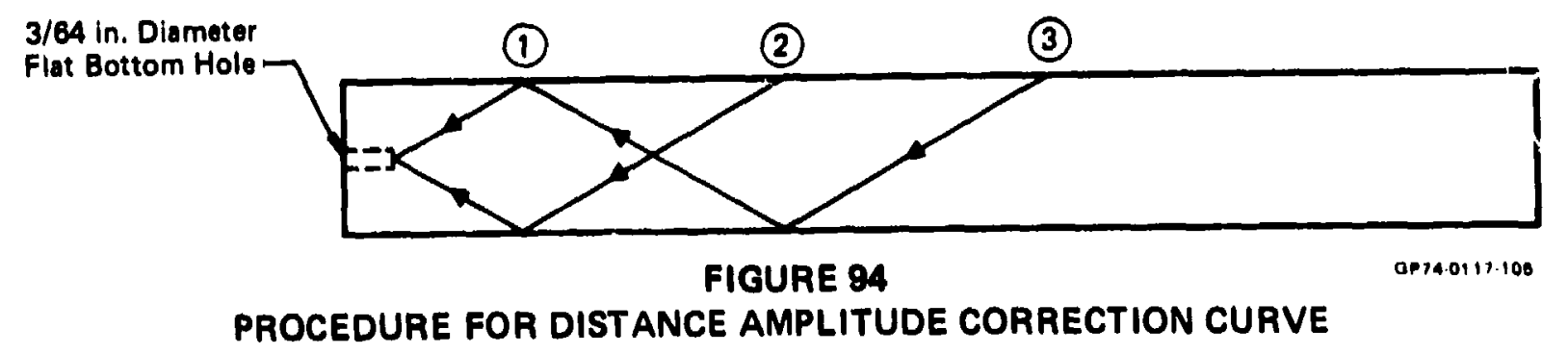

At this point $2 \mathrm{~dB}$ was removed to adjust for differences in sound transmission betweer the test pleces and the reference standards and another $6 \mathrm{~dB}$ was removed to increase the scanning gain.

Each test piece was hand scanned as shown in Figure 95. During each scan the search urit was swiveled within an included angle of 60 degrees to ensure 100 percent inspection coverage. Within 0.75 inch of surfaces $A$ and $B$, the pleces were scanned in 2 directions at 180 degrees to each other.

l'ach discontinuity whose amplitude equalled or exceeded the DAC curve, after the $6 \mathrm{~dB}$ had been added back in, was marked on the specimen surface. The results are shown in Table 69. In Table 69, an entry such as $3 / 5$ indicates that 3 cracks out of 5 were detected. It appears from the data that the detection capability of Inspector A was greater than Inspector $B$ even though both people have qualified to the same procedure (SNT-I'C-IA, Supplement C, Level II).

As shown in Table 70, on several occasions a crack was detected from both sides of the specimen. Hlowever, it is important to note that often $a$ crack was not detected from both which indicates that actual parts to be inspected should be inspected from both sides to increase the detection probability. 
TABLE 70

CRACKS DETECTED FROM BOTH SIDES OF SPECIMEN BY CONTACT ANGLE BEAM ULTRASONICS

Summation of 2 Inspestors

\begin{tabular}{|c|c|c|}
\hline $\begin{array}{l}\text { Crook } \\
\text { Leneth } \\
\text { (In.) }\end{array}$ & $\begin{array}{l}\text { Specimon } \\
\text { No. }\end{array}$ & $\begin{array}{l}\text { Number of } \\
\text { Times Dotected } \\
\text { from Both Sides }\end{array}$ \\
\hline $0.025-0.060$ & $67(A)$ & 6 of 13 \\
\hline $0.050 \cdot 0.10$ & $\begin{array}{l}57(B) \\
29(A) \\
34(A) \\
49(A)\end{array}$ & $\begin{array}{l}6 \text { of } 12 \\
6 \text { of } 11 \\
8 \text { of } 13 \\
5 \text { of } 12\end{array}$ \\
\hline $0.10 \cdot 0.26$ & $\begin{array}{r}72(A) \\
\theta(A) \\
\theta(B) \\
B 1(A)\end{array}$ & $\begin{array}{c}5 \text { of } 11 \\
8 \text { of } 11 \\
10 \text { of } 11 \\
9 \text { of } 12\end{array}$ \\
\hline $0.25 \cdot 0.50$ & $29(C)$ & 11 of 11 \\
\hline
\end{tabular}




\section{e. Overall Production NDT Capability}

The surface crack detection capability of individual NDT methods (penetrant, surface wave ultrasonics, and contact angle bearn ultrasonics) has been discussed in the previous paragraphs. In a production NDT operation, an individual production part might be inspected several times with various NDT methods to ensure the detection of harmful discontinuities. In these cases, the detection capability for the part is related to the combined detection capabilities of the individual NDT methods. An example of such an NDT plan would be to penetrant inspect the entire surface of a finished part to detect surface cracks. Next, the detecterl cracks would be removed by rework operations. Following the penetrant inspection and rework operations, selected areas on the part which will experience high stress levels and where a fllaw of critical size has a reasonable probabllity of occurring might be further inspected using surface wave ultrasonics to detect remaining surface cracks and cracks lying slightly below the surface. Finally, these high stress thicker areas $\mathrm{might}$ be inspected with contact angle beam ultrasonics to again detect surface cracks and cracks lying to a greater depth below the surface.

If such an NDT plan wore used, the overall NDT capab1lity for the detection of aurface cracks could be determined from the capabilities of the individual methods (penetrant, surface wave ultrasonios, and contact angle beam ultrasonics). The capablitty data discuesed previously was analyzed to arrive at an overall capabllity f1gure for an NDT plan which consists of a penetrant inspection followed by a surface wave and, In some cases, contact angle beam ultrasonde inspection. For example, the detection probability of a production inepection was found to be 88 percent at a 95 percent confidence level for cracks with lengtho of 0.050 to 0.10 inch. Then, in a given sample, 12 percent of the existing orscks may go undetected. If, then, the penetrant inspecticn was followed by an ultrasonic surface wave inspection, at least 47 percent of the cracks missed by the penetrant inspection (or 6 percent of the total cracks present orlginally) would be detected by the ultrasonic surface wave inspection. Based on these calculations, the detection probability for the combined inspections would be 88 percent plus 6 percent or 94 percent at a 95 percent confidence level. The overall NDT capability for surface cracks 18 shown below es a function of crack length.

\begin{tabular}{|c|c|c|}
\hline & \multicolumn{2}{|c|}{ Probability of Detection $\widehat{1}$} \\
\hline $\begin{array}{l}\text { Crack } \\
\text { Length } \\
\text { (in.) }\end{array}$ & $\begin{array}{l}\text { Penatrant } \\
\text { Followed by } \\
\text { Surface Wave }\end{array}$ & $\begin{array}{l}\text { Penetront Followed } \\
\text { by Surfece Wave } \\
\text { Followed by Angle Beam }\end{array}$ \\
\hline $\begin{array}{l}\text { Less Than } 0.025 \\
0.025 \cdot 0.050 \\
0.050 \cdot 0.10 \\
0.10 \cdot 0.25 \\
0.25 \cdot 0.50\end{array}$ & $\begin{array}{l}\text { At Least } 35 \% \\
\text { At Least } 66 \% \\
\text { At Least } 94 \% \\
\text { At Least } 98 \% \\
\text { At Least } 99 \%\end{array}$ & $\begin{array}{l}\text { At Least } 98 \% \\
\text { At Least } 99 \% \\
\text { 2. }\end{array}$ \\
\hline
\end{tabular}

A $95 \%$ Confladence Level.

A Data was Not Developed for Contact Angle Beem Inspection ot This Crack sizs. 
This data indicates that at least 98 percent of all surface cracks with lengths of .050 to .10 inches would be detected with the specified NDT plan.

All the NDT capability dara discussed to this point has been on the basis of a 95 percent confldence level. Obviously, the specified detection probability changes as the confidence level changes.

The NDT capability data presented in this report should be used as guldelines as to what can be reasonably expected in production inspections. The actual capability values are somewhat unique to the specific inspection parameters used. 'The capability values might change significantly when other inspection personnel, penetrant systems, calibration techniques, callbration standards, etc. are used.

\section{f. Laboratory Eddy Current Teating}

A selected number of the surface cracked specimens were chosen for several eddy current tests. In all, four separate laboratory eddy current tests were performed. The first test, designated Test A, was performed using a Nortec NDT-3 eddy current instrument with an absolute probe at $500 \mathrm{KHz}$. The absol 2 te probe was an Ideal specialty $\mathrm{P} / \mathrm{N} 6100-1 / 4 \mathrm{SP}$ probe with a .050 inch diameter ferrite core and 150 turns of No. 40 wire. Liftoff compensation was .003 inch and was accomplished by adjustIng lihe " $X$ " and " $R$ " controls to obtain the same meter indication with ard without a .003 inch paper shim between the probe and the test surface. The operating point was chosen using the sensitivity standard shown in Figure 96. The conductivity of the Ti-6Al-6V-2Sn is $1.10 \%$ IACS 


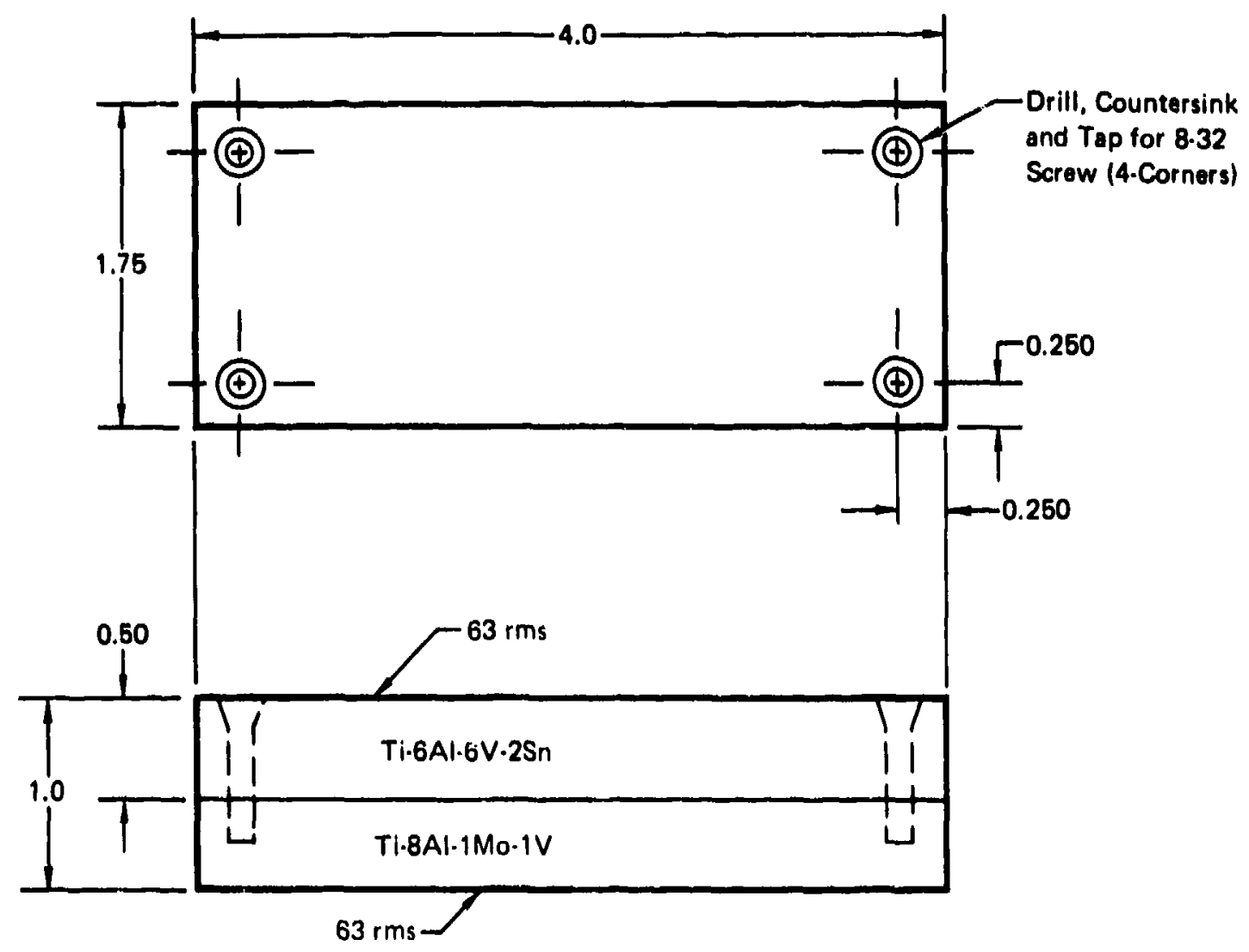

Notes:

1. All dimensions are in inches.

2. Tolarences are $\pm 0.010 \mathrm{in}$.

3. Surface finlsh is $126 \mathrm{rms}$ unless otherwiaw noted.

4. Material la in the annealed condition.

6. Inatell 8-32 ccrews in four coiners when complete. 
and the conductivity of the Ti-8Al-1Mo-1V is $0.87 \%$ IACS. A previous program Indicated that, for titanium, the operating point along the ift-off compensation locus should be chosen relatively far away from the material point in the complex impedance plane to give the maximum response ( 478 microamps per $1 \%$ IACS) to the conductivity difference between the two halves of the sensitivity standard. Crack Indications were read as meter deflections and the chosen scan index of $1 / 16$ inch was maintained without a fixture.

A second test, Test $B$, was performed in the same manner except that crack indications were recorded on a Mosely 680 strip chart recorder and a flxture was used to maintain the $1 / 16$ inch scan index.

Test $C$ was performed using a Magnaflux ED 520 eddy current instrument with an absolute probe. This particular instrument uses continuously varlable frequencies (from 55 to $200 \mathrm{KHz}$ ) which are fixed by the probe coil and the liftoff compensation chosen. No liftoff compensation was used. The absolute probe was the same as before. Again a strip cha't recorder was used as an ald for crack detection and a scan index fixturc was used for the $1 / 16$ inch scan index. The sensitivities of the instruments were set to yield a 110 microamp difference between the $\mathrm{Ti}-6 \mathrm{Al}-6 \mathrm{~V}-2 \mathrm{Sn}$ and T1-8Al-1Mo-IV halves of the sensitivity standard in tests $A, B$, and $C$.

Testing was performed in cooperation with and through the courtesy of NDT Instruments, Inc. These results are designated Test $D$.

An NDT Instruments Vector III was usid along with a $3 \mathrm{MHz}$ probe having a $1 / 16$ inch diameter f'errite sensor. This probe possessed an estimated .015 inch deep $x .062$ Inch wide sensing zone in the titanium. The instrument was adjlsted for approximately .002 inch liftoff compensation. The receiver sensitivity control was adjusted to $25 \%$ of the maximum. Crack indications were measured as meter deflections. No calibration, such as previously described, was performed. Prior to actual inspection a preliminary test was performed with the Vector III to compare the responses at $500 \mathrm{KHz}$ and $3 \mathrm{MHz}$. A Ti-6Al-4y reference standard with narrow 3 inch long $V$-notches having depths of .005 inah, .010 inch, and .015 inch was used. The results indicated that testin $\tilde{0}$ at $3 \mathrm{MHz}$ produced about 5 times the meter deflection obtained at $500 \mathrm{KHz}$ (see below). The data indicates that the sensitivity is increased at higher frequencies. The crack vector has a greater separation angle from the $11 \mathrm{ft}$-off vector at $3 \mathrm{MHz}$.

\begin{tabular}{|l|c|c|}
\hline $\begin{array}{c}\text { Notch Depth } \\
\text { (Inches) }\end{array}$ & Units of Meter Deflection \\
\cline { 2 - 3 } & $500 \mathrm{KHz}$ & $3 \mathrm{MHz}$ \\
\hline .015 & 40 & $100+$ \\
.010 & 12 & 70 \\
.005 & 7 & 35 \\
\hline
\end{tabular}

The results of the four tests are shown in Table 71. A summary appearis in Table 72 . As can be seen, the detection capability was enhanced by using a scan index and a strip chart recorder. The testing performed at $3 \mathrm{MHz}$ seemed to be more effective than the lower frequency tests, although the small data base does not allow a definite conclusion. Examples are shown below. 
TABLE 71

EDDY CURRENT TEST RESULTS

\begin{tabular}{|c|c|c|c|c|c|c|c|}
\hline \multirow{2}{*}{$\begin{array}{l}\text { Terryot } \\
\text { Cruak } \\
\text { Length } \\
\text { lin.l }\end{array}$} & \multirow{2}{*}{$\begin{array}{c}\text { Spectimon } \\
\text { No. }\end{array}$} & \multirow{2}{*}{$\begin{array}{l}\text { Actual } \\
\text { Crnek } \\
\text { Longeh } \\
\times \text { Dopth } \\
\text { (in.) } \\
\widehat{2}\end{array}$} & \multirow{2}{*}{$\begin{array}{c}\text { Tout } \\
\text { A }\end{array}$} & \multirow{2}{*}{$\begin{array}{c}\text { Test } \\
\text { C }\end{array}$} & \multirow{2}{*}{$\begin{array}{c}\text { Tont } \\
\text { B }\end{array}$} & \multicolumn{2}{|c|}{ Tent 0} \\
\hline & & & & & & $\begin{array}{l}\text { No. Cracks } \\
\text { Dotectod }\end{array}$ & Motilection \\
\hline \multirow{6}{*}{$\begin{array}{l}\text { Less } \\
\text { Than } \\
0.025\end{array}$} & 53 & - & $0 / 1$ & $0 / 1$ & $0 / 1$ & - & - \\
\hline & 54 & - & $0 / 1$ & $0 / 1$ & $0 / 1$ & - & - \\
\hline & 65 & - & $0 / 1$ & $0 / 1$ & $0 / 1$ & - & - \\
\hline & $70(A)$ & - & $0 / 1$ & $0 / 1$ & $0 / 1$ & - & - \\
\hline & 76 & - & $0 / 1$ & $0 / 1$ & $0 / 1$ & - & -. \\
\hline & 77 & - & $0 / 1$ & $0 / 1$ & $0 / 1$ & - & - \\
\hline \multirow{6}{*}{$\begin{array}{l}0.025 . \\
0.050\end{array}$} & 39 & $0.040 \times 0.015$ & $1 / 1$ & $1 / 1$ & $0 / 1$ & $1 / 1$ & 25 \\
\hline & 45 & $0.010 \times 0.005$ & $0 / 1$ & $1 / 1$ & $1 / 1$ & $1 / 1 \triangle$ & 41 \\
\hline & 65 & - & $0 / 1$ & $0 / 1$ & $0 / 1$ & - & - \\
\hline & $70(B)$ & - & $0 / 1$ & $0 / 1$ & $0 / 1$ & - & - \\
\hline & 75 & $0.060 \times 0.015$ & $0 / 1$ & $0 / 1$ & $0 / 1$ & $0 / 1 \hat{1}$ & 0 \\
\hline & 81 & - & $0 / 1$ & $0 / 1$ & $0 / 1$ & $0 / 1$ & 0 \\
\hline \multirow{6}{*}{$\begin{array}{l}0.050 \\
0.10\end{array}$} & 38 & $0.070 \times 0.025$ & $0 / 1$ & $1 / 1$ & $0 / 1$ & $1 / 1 \hat{\mathrm{i}}$ & 74 \\
\hline & 39 & $0.060 \times 0.040$ & $0 /:$ & $0 / 1$ & $0 / 1$ & $1 / 1$ & $>80$ \\
\hline & 47 & - & $0 / 1$ & $1 / 1$ & $1 / 1$ & $1 / 1$ & $>80$ \\
\hline & 49 & - & $0 / 1$ & $0 / 1$ & $0 / 1$ & - & - \\
\hline & 59 & $0.090 \times 0.030$ & $0 / 1$ & $1 / 1$ & $1 / 1$ & $1 / 1 \unlhd$ & 45 \\
\hline & 73 & - & $0 / 1$ & $0 / 1$ & $0 / 1$ & - & - \\
\hline \multirow{6}{*}{$\begin{array}{l}0.10 \\
0.25\end{array}$} & 3 & $0.119 \times 0.019$ & $0 / 1$ & $0 / 1$ & $0 / 1$ & $1 / 1$ & 15 \\
\hline & 11 & $0.20 \times 0.70$ & $1 / 1$ & $1 / 1$ & $1 / 1$ & $1 / 1 \triangle$ & $>80$ \\
\hline & 15 & $0.20 \times 0.70$ & $1 / 1$ & $1 / 1$ & $1 / 1$ & $1 / 1 \triangle$ & $>80$ \\
\hline & 64 & - & $1 / 1$ & $1 / 1$ & $1 / 1$ & - & - \\
\hline & 66 & $0.105 \cdot 0.030$ & $1 / 1$ & $1 / 1$ & $1 / 1$ & $1 / 1$ & 36 \\
\hline & 72 & - & $0 / 1$ & $1 / 1$ & $1 / 1$ & - & - \\
\hline \multirow{6}{*}{$\begin{array}{l}0.25 \\
0.50\end{array}$} & 8 & $0.43 \times 0.16$ & $1 / 1$ & $1 / 1$ & $1 / 1$ & - & .- \\
\hline & 12 & - & $1 / 1$ & $1 / 1$ & $1 / 1$ & - & - \\
\hline & 21 & $0.41 \times 0.17$ & $1 / 1$ & $1 / 1$ & $1 / 1$ & - & - \\
\hline & 22 & - & $1 / 1$ & $1 / 1$ & $1 / 1$ & - & - \\
\hline & 23 & - & $1 / 1$ & $1 / 1$ & $1 / 1$ & - & - \\
\hline & 31 & - & $1 / 1$ & $1 / 1$ & $1 / 1$ & - & - \\
\hline
\end{tabular}

A The locetion of the crack wasknown in order to setup the teit.

Qp 14.0117 .96

2. Actual erack dimentions were detarminad by fracturing the epecimen and examining the fracture surtace. 
TABLE 72

SUMMARY OF CRACK DETECTION CAPABILITY. LABORATORY EDDY CURRENT

\begin{tabular}{|l|c|c|c|c|}
\hline $\begin{array}{c}\text { Crack Length } \\
\text { (in.) }\end{array}$ & $\begin{array}{c}\text { Test } \\
\text { A }\end{array}$ & $\begin{array}{c}\text { Tsst } \\
\text { B }\end{array}$ & $\begin{array}{c}\text { Tost } \\
\text { C }\end{array}$ & $\begin{array}{c}\text { Test } \\
\text { D }\end{array}$ \\
\hline Less Than 0.025 & 0 of 6 & 0 of 6 & 0 of 6 & - \\
$0.025-0.050$ & 1 of 6 & 1 of 6 & 2 of 6 & 2 of 4 \\
$0.050-0.10$ & 0 of 6 & 2 of 6 & 3 of 6 & 4 of 4 \\
$0.10 \cdot 0.25$ & 4 of 6 & 5 of 6 & 5 of 6 & 4 of 4 \\
$0.25-0.50$ & 6 of 6 & 6 of 6 & 6 of 6 & - \\
\hline
\end{tabular}

aprs.011191 


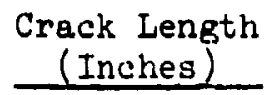

$.025-.050$

$.050-.10$

$.050-.10$

$.10-.25$
Specimen

No.

Test A Test 13 Test C Test D

39

38

39

3

$\begin{array}{ll}1 / 1 & 0 / 1 \\ 0 / 1 & 0 / 1 \\ 0 / 1 & 0 / 1 \\ 0 / 1 & 0 / 1\end{array}$

$1 / 1$

$1 / 1$

$1 / 1 \quad 2 / 1$

$0 / 1 \quad 1 / 1$

$0 / 1 \quad 1 / 1$

Following the eddy current testing, several of the cracks were intentionally fractured and the site of the crack was measured from the fracture surface. The actual size of those cracks are shown in Table 7l. An examination of crack depth or crack area did nct reveal any correlation with meter deflection. The smallest crack detected during the eddy current inspection had an actual length of .010 inch and at depth of .ons inch.

\section{g. Radiographic Inspection of Surface Crucks}

Threlve specimens, $3 / 8$ inch thick, ontuining fetigue cracks were radigraphicaliy inspected. 'These specimen had been fabricated in the manner previously described in Paragraph 1-a of the IDl ciapalility section of this report. The inspection was pertormed in a priduction radiofraphic inspection faciltey using production radiorraphic insoction personnel who had been qualified to SNT-TC-1A, jupplemeit $A$, Levol IT. The crucks examined had lengths which raried from 0.10 to 1.50 inches. The iwo 1.50 inch 1.ing cracks hed extended through the thickness of the panel. 'the radiographic parameters ised were as followe.

\begin{tabular}{|c|c|}
\hline Kilovoltage & $\begin{array}{l}75 \mathrm{kVP} \text { (with at } 3 \text { rum. focil spot) } \\
\text { Fuxitron }\end{array}$ \\
\hline $\begin{array}{l}\text { Focial Spot - 'Io - } \\
\text { film Distance }\end{array}$ & $a_{1}$ Inches \\
\hline 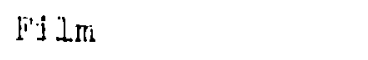 & Gaveart Dh (NoTM Clabs L) \\
\hline Screens & $\begin{array}{l}\text { No front icroen } \\
0.010 \text { inch thicl lewl back screen }\end{array}$ \\
\hline Causette & Cardbons!l \\
\hline
\end{tabular}

The cxposure was adjuster to cotain an overall film density of $1.7 t 0$

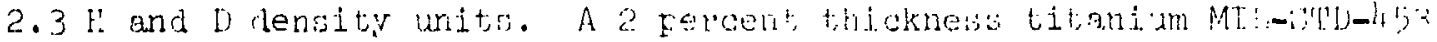
penetrameter was used ass un image quali! in indicator and the lit iole wers visible on all. the radfographs resulting in ar equivalent srnsitivity of 1.4 percent.

Three independent production radiographic interpreters were lased to interpret the films. Only two of the cracks were ietected; these were the 1.50 long cracks and all 3 interpreters detected them. No other cracks were detected even though there were some which had extended througl the full section thickness. Subsequently, the films, were examined again, 
only this time, the crack locations were known by the inteipreter. Again, only the two 1.50 inch long cracks were detected. These results inphasize the difficulty in detection cracks with radiographic techniques.

\section{h. Bending Fatigue Specimen Fabrication}

A second set of surfaise connected crack specimens were fabricated for use in airframe, engine, Eind AFML inspections. The specimens were made using $1 \times 2 \times 5$ inch pieces of T1-6Al-4V with an EDM slot in each as a crack initiator (see Figure 97). The specimens were fatigued in 3 point bending usixg the parameter's shown in table 73. The crack lengths were

\section{TABLE 73}

\section{PARAMETERS FCIR SURFACE CONNECTED CRACKS MADE BV BENDING FATIGUE $\uparrow$}

\begin{tabular}{|c|c|c|c|}
\hline $\begin{array}{c}\text { Specimen } \\
\text { No. }\end{array}$ & $\begin{array}{c}\text { E:DM } \\
\text { Longth } \times \text { Depth } \\
\text { (in.) }\end{array}$ & No. Cycles & $\begin{array}{c}\text { Final Crack } \\
\text { Length } \\
\text { (in.) }\end{array}$ \\
\hline P5 & $0.020 \times 0.008$ & 23,090 & 0.035 \\
\hline B2 & $0.030 \times 0.010$ & 30.700 & 0.055 \\
\hline $\mathrm{B} 13$ & $0.080 \times 0.1725$ & 10.000 & 0.129 \\
\hline $\mathrm{B} 8$ & $0.10 \times 0.030$ & 12,790 & 0.238 \\
\hline B10 & $0.10 \times 0.030$ & 17,500 & 0.363 \\
\hline$B 15$ & $0.10 \times 0.030$ & 54,990 & 0.496 \\
\hline
\end{tabular}

optically monitored during the fatiguing process. After the cracks were grown, the EDM siot was removed by a grinding operation. The grinding operation was intentionally light in order to uvold metal flow at the surface.

\section{i. Liquid Penetrant Testing of Bending Fatigue Specimens}

The set of 6 cracked specimens and three uncracked "dummy" specimens were penetrant inspected in an airframe and jet engine inspection environment as well as at the AFML for comparative purposes. Initially, the surface fatigue specimens were penetrant inspected in the laboratory at the jet engine manufacturer's installation. Three post-emulsifiable Magnaflux penetrants were used for comparative purposes ( $Z L-2 A, Z L-22 A$. and $Z L-30 A$ ). In addition, both Magnaflux ZP-4 dry powder developer and Tracer-Tech $0499 \mathrm{C}$ nonaqueous wet developer were used. All the penetrant systems used were MLL-I-25135, Group VI sensitivity systems. The 9 test specimens ( 6 cracked 


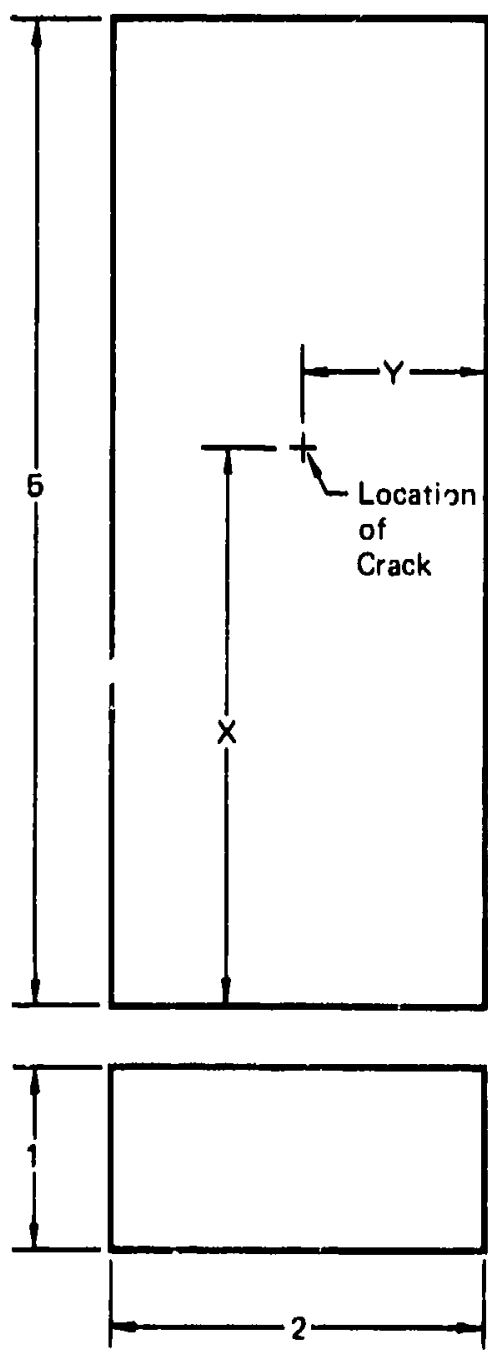

\begin{tabular}{|c|c|c|c|}
\hline $\begin{array}{c}\text { Specimen } \\
\text { No. }\end{array}$ & $\begin{array}{c}\text { Crack } \\
\text { Length } \\
\text { (in.) }\end{array}$ & $\mathrm{X}$ & $\mathrm{Y}$ \\
\hline $\mathrm{B} 5$ & 0.035 & 3 & $3 / 4$ \\
$\mathrm{~B} 2$ & 0.055 & $2 \cdot 1 / 4$ & $1 \cdot 1 / 2$ \\
B13 & 0.129 & $2 \cdot 3 / 4$ & $1 \cdot 1 / 8$ \\
B8 & 0.238 & 2 & 1 \\
B10 & 0.363 & $2 \cdot 1 / 2$ & $3 / 4$ \\
B15 & $0.49 E$ & $2 \cdot 1 / 2$ & $1-1 / 4$ \\
\hline
\end{tabular}

01 14011/103

FIGURE 97

CONFIGURATION OF BENDING FATIGUE SURFACE

CRACKED SPECIMENS 
and 3 uncracked) were inftially trichlorethylene vapor degreased and etched very lightly for 3 seconds with a $2 \%$ hydrofluoric acid solution prior to application of the penetrant. The penetrant dwell time was 30 minutes in each case. Ixcess penetrant was removed using Magnaf'lux $2 \mathrm{E}-4 \mathrm{~A}$ for 30 seconds followed by a water spray at $40 \mathrm{psi}$ with $70^{\circ} \mathrm{F}$ water. Next, the specimens were dried at $150^{\circ} \mathrm{F}$ in a recirculating hot air oven and developer was applied. A bleed-out time of 5 minutes was used. Finally, the specimens were examined in a darkened booth with 7,400 microwatts per $\mathrm{cm}^{2}$ of ultraviolet light at the specimen surface as measured with a Weston 703-60 light meter. The white light intensity in the bouth was not measured. The laboratory tests were performed by two inspectors. The length of each penetrant indication was measured and recorded.

The results of the laboratory inspection: are shown in Table 74 . There were no false indications recorded.

As can be seen from the Table 74 , each inspector detected all the cracks when nonaqueous wet developer was used. However, several of the smaller cracks went undetected when a dry powder developer was used, even with the higher sensitivity penetrant. It appeared that the dry powder did not adhere well to the ground surfaces.

Next, the specinens, including the uncracked dummies, were penetrant inspected at the engine manufacturer's pioduction penetrant inspection facilities. For comparison purposes, three separate penetrant systems were used. These were (a) Magnaflux ZL-22t. fluorescent post-emulsifiable penetrant, $\mathrm{ZE}-4 \mathrm{~A}$ emulsifler, and ZP-4A dry powder developer, (b) ZL-22A penetrant, $2 \mathbb{E}-4 \mathrm{~A}$ emulsifier, and Tracer-Tech $\mathrm{D} 499 \mathrm{C}$ nonaqueous wet developer, and (c) Turco P-4OB fluorescent post-emulsiflable, E-4 emulsifier, and DD-2 üry powder developer. All the systems vere MIL-I-25135, Group VI sensitivity systems.

The production inspection parameters were a 30 minute penetrant dwell time, a 30 second emulsification time, a 5 minute development time, a 140 to $160 \%$ drying temperature, and a viewing light intenoity of 7,400 microwatts per $\mathrm{cm}^{2}$. The viewing light intensity was measured with a Weston 703-60 11ght meter. Each plece was trichlorethylene vapor degreased between inspections. For each penetrant system, Independent production penetrant inspectors were used. The length of each crack indication detected was recorded. 
TABLE 74

RESULTS OF ENGINE LABORATORY PENETRANT TESTING OF SURFACE CRACKED SPECIMENS

(Results for Inspector B Shown in Parenthesis)

\begin{tabular}{|c|c|c|c|c|c|c|}
\hline \multirow{3}{*}{$\begin{array}{l}\text { Actual } \\
\text { Crack } \\
\text { Length } \\
\text { (in.) }\end{array}$} & \multicolumn{6}{|c|}{ Measured Indication Length } \\
\hline & \multicolumn{2}{|c|}{$\begin{array}{c}\text { ZL-2A } \\
\text { (MIL-1-25135, Group } \nabla)\end{array}$} & \multicolumn{2}{|c|}{$\begin{array}{c}\text { 2L-22A } \\
\text { (MIL-1-25135, Group } \text { II) }\end{array}$} & \multicolumn{2}{|c|}{$\begin{array}{c}\text { 2L-30A } \\
\text { (MIL-I-25135, Group } \overline{I I++)}\end{array}$} \\
\hline & $\begin{array}{c}\text { Dry } \\
\text { Doveloper }\end{array}$ & $\begin{array}{c}\text { Noinaqueous } \\
\text { Wet } \\
\text { Developer }\end{array}$ & $\begin{array}{c}\text { Dry } \\
\text { Developer }\end{array}$ & $\begin{array}{c}\text { Nonaqueous } \\
\text { Wot } \\
\text { Developer }\end{array}$ & $\begin{array}{c}\text { Dry } \\
\text { Developer }\end{array}$ & $\begin{array}{c}\text { Nonaqueous } \\
\text { Wot } \\
\text { Devoloper }\end{array}$ \\
\hline No Crack & NCF (NCF) & NCF (NCF) & NCF (NCF) & NCF (NCF) & NCF (NCF) & NCF (NCF) \\
\hline No Crack & NCF (NCF) & NCF (NCF) & NCF (NCF) & NCF (NCF) & NCF (NCF) & NCF (NCF) \\
\hline No Crack & NCF (NCF) & NCF (NCF) & NCF (NCF) & NCF (NCF) & NCF (NCF) & NCF (NCF) \\
\hline 0.035 & NCF (NCF) & $0.040(0.040)$ & NCF (NCF) & $0.040(0.040)$ & $0.040(0.040)$ & $0.040(0.040)$ \\
\hline 0.255 & NCF (NCF) & $0.010(0.010)$ & NCF (NCF) & $0.040(0.040)$ & NCF (NCF) & $0.045(0.045)$ \\
\hline 0.129 & NCF (NCF) & $0.120(0.120)$ & NCF (NCF) & $0.120(0.120)$ & NCF (NCF) & $0.120(0.120)$ \\
\hline 0.238 & $0.060(0.090)$ & $0.060(0.090)$ & $0.060(0.090)$ & $0.060(0.060)$ & $0.060(0.160)$ & $0.090(0.160)$ \\
\hline 0.363 & $0.150(0.090)$ & $0.150(0.090)$ & $0.120(0.120)$ & $0.120(0.120)$ & $0.090(0.150)$ & $0.090(0.150)$ \\
\hline 0.496 & $0.500(0.500)$ & $0.500(0.500)$ & $0.500(0.500)$ & $0.500(0.500)$ & $0.500(0.500)$ & $0.500(0.500)$ \\
\hline
\end{tabular}

TABLE 76

RESULTS OF ENGINE PRODUCTION PENETRANT INSPECTION OF SURFACE CRACKED SPECIMENS

\begin{tabular}{|c|c|c|c|c|c|c|c|c|}
\hline \multirow{4}{*}{$\begin{array}{c}\text { Actual } \\
\text { Crack } \\
\text { Length } \\
\text { (in.) }\end{array}$} & \multicolumn{8}{|c|}{ Measured Indication Length } \\
\hline & \multicolumn{3}{|c|}{$\begin{array}{l}\text { ZL.22A with } \\
\text { Dry Developer } \\
(Z P .4 A)\end{array}$} & \multicolumn{3}{|c|}{$\begin{array}{l}\text { P40.B } \\
\text { with Dry } \\
\text { Developer } \\
\text { (DD.2) }\end{array}$} & \multicolumn{2}{|c|}{$\begin{array}{l}\text { ZL-22A with } \\
\text { Nonaqueous } \\
\text { Wet Developer } \\
\text { (D498C) }\end{array}$} \\
\hline & \multicolumn{8}{|c|}{ Inspector } \\
\hline & $\mathbf{A}$ & B & C & A & B & $\mathbf{C}$ & A & B \\
\hline No Crack & 0 & 0 & 0 & 0 & 0 & 0 & 0 & 0 \\
\hline No Crack & 0 & 0 & 0 & 0 & 0 & 0 & 0 & 0 \\
\hline No Crack & 0 & 0 & 0 & 0 & 0 & 0 & 0 & 0 \\
\hline 0.035 & 0 & 0 & 0 & 0 & 0 & 0 & 0.030 & 0.030 \\
\hline 0.055 & 0 & 0 & 0 & 0 & 0 & 0 & 0.100 & 0.100 \\
\hline 0.129 & 0 & 0 & 0 & 0 & 0 & 0 & 0.100 & 0.100 \\
\hline 0.238 & 0 & 0.250 & 0.250 & 0 & 0 & 0 & 0.150 & 0.150 \\
\hline 0.363 & 0 & 0 & 0 & 0 & 0 & 0 & 0.125 & 0.125 \\
\hline 0.496 & 0 & 0 & 0.350 & 0 & 0 & 0 & 0.200 & 0.200 \\
\hline
\end{tabular}


The results are shown in Table 75. No fulse indications were recordej. As can be seen, the most effective system was the $\mathrm{ZL}-22 \mathrm{~A}$ penetrant/D499C nonaqueoui wet developer system. The dry powder developer did not work effectively as l.t did not adhere well to the smoothly ground surface of the specimens.

Next, the test specimens, including the uncracked dummies, were penetrant inspected at the airframe manufacturer's production penetrant facility usine Tracer-Tech P-133A fluorescent water washable penetrant, and $D 499 \mathrm{C}$ nonaqueous wet developer. The inspection parameters were the same as for the previous inspection of the surface cracks described in Section IV, Para. 1-l. The inupector was instructed to mark all linewr indicutions. The Length of the cracks were not measured during these tests.

Each piece wass inspected 3 times by the same man. The test results are shown in Table 76 . There were no false indications recorded.

Finally, the specimens, including the uncracked dumies, were penetrant Inspected at the AFWL. For these tests, the penetrant system wes $2 \mathrm{~L}-22 \mathrm{~A}$ peretrant, $2 E-3$ emuisifler, and Sherwin $D-100$ nonaqueous wot developor. The penetrant dwell time was 30 minutes, the emuleification time was 30 seconds, and the dryling conditions were 5 minutes at $180 \%$ in a recirculating hot air oven. The spocimens containing the .035 and .055 inch long cracks were inspected independently 10 times. The remaining specimens were Inspected independently "7 timos. Two inspectors participated in the testing. Prior to each inspection, the specimens were cleaned in a trichlorethylene degreaser for 1 hour.

The results of the inspections aro shown in Table 77. As can be seen, all the cracks were detected during each inspection. There were no false indications recorded.

\section{j. Radioactive Penotrant Testing}

The surface cracked test specimens were subjected to a laboratory Inspection by Industrial Nucleonics Corporation, using their proprietary radioactive penetrant method. The test specimens were placed in a vacuum chamber which then was evacuated. Next, a mixture of Krypton 84 and radloactive Kryption 85 was back-f1lled into the chamber. Finally, the Krypton mlxture was transferred to a storage contalner, the vacuum chamber was restored to rocm atmosphere, and the test specimens were removed. In order to record the crack indications, film was placed on the specimen surface and exposed by the residual radiation. A typical exposure tim was 2 hours. After the above technique was used, a second techntque was employed to detect the cracks. Th1s technique was 1dentical to the f1rst technique except that a .001 inch thick coating of plastic was placed on the surface of the specimen prior to placing the film on the part. 
TABLE 76

RESULTS OF AIRFRAME PRODUCTION PENETRANT INSPECTION OF GENERAL ELECTRIC SURFACF. CRACKED SPECIMENS

\begin{tabular}{|c|c|c|}
\hline $\begin{array}{c}\text { Spaciman } \\
\text { No. }\end{array}$ & $\begin{array}{c}\text { Crack Longth } \\
\text { (in.) }\end{array}$ & No. of Cracks Detectod \\
\hline B5 & 0.035 & 2 of 3 \\
B2 & 0.055 & 3 of 3 \\
B13 & 0.129 & 3 of 3 \\
B8 & 0.238 & 3 of 3 \\
B10 & 0.363 & 3 of 3 \\
\hline
\end{tabular}

TABLE 77

RESULTS OF AFML LABORATORY PENETRANT INSPECTION OF BENDING FATIGUE SURFACE CRACKED SPECIMENS

\begin{tabular}{|c|c|c|c|c|c|c|c|c|c|c|}
\hline \multirow{3}{*}{$\begin{array}{c}\text { Actual } \\
\text { Crock } \\
\text { Longth } \\
\text { (in.) }\end{array}$} & \multicolumn{10}{|c|}{ Messurad Indication Length (in.) } \\
\hline & \multicolumn{10}{|c|}{ Inspector } \\
\hline & A & B & C & D & E & $\mathbf{F}$ & G & H & 1 & J \\
\hline 0.035 & 0.046 & 0.046 & 0.046 & 0.046 & 0.046 & 0.046 & 0.046 & 0.046 & 0.046 & 0.046 \\
\hline 0.055 & 0.062 & 0.062 & 0.062 & 0.062 & 0.062 & 0.062 & 0.062 & 0.062 & 0.062 & 0.062 \\
\hline 0.129 & 0.125 & 0.125 & 0.125 & 0.125 & 0.125 & 0.125 & 0.125 & - & - & - \\
\hline 0.238 & 0.250 & 0.250 & 0.250 & 0.250 & 0.250 & 0.250 & 0.250 & - & - & - \\
\hline 0.363 & 0.375 & 0.375 & 0.375 & 0.375 & 0.375 & 0.376 & 0.375 & - & - & - \\
\hline 0.496 & 0.500 & 0.500 & 0.500 & 0.500 & 0.500 & 0.500 & 0.500 & - & - & - \\
\hline
\end{tabular}


A comparison of the actual crask length with the indication length is shown below.

TABLE 78

RESULTS OF RADIOACTIVE PENETRANT TESTI,JG

\begin{tabular}{|c|c|c|}
\hline \multirow{2}{*}{$\begin{array}{c}\text { Actual } \\
\text { Length } \\
\text { (in.) }\end{array}$} & \multicolumn{2}{|c|}{ Indication Length } \\
\cline { 2 - 3 } & Process No. 1 & Process No. 2 \\
\hline 0.035 & 0.023 & 0.021 \\
0.055 & 0.043 & 0.046 \\
0.129 & 0 & 0.106 \\
0.238 & 0.279 & 0.236 \\
0.363 & 0.369 & 0.366 \\
0.496 & 0.516 & 0.508 \\
\hline
\end{tabular}

k. Eday Current Inspection of Fastener Holes

Eddy current inspection techniques have been used primarily to detect surface connected cracks in components and assemblies where the penetrant method would be impossible or impractical to use effectively. of purticulin importince are the fastener hole surfaces. A test program was condueted to determine the detection capability for fatigue cracks in

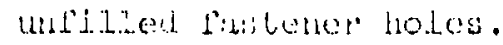

The test opecimens used for the eddy current study were dogbone fatigue specimenis which huid underene fatigue testing under unother program. Schematice of the three specimen types are shown in Figures 98, 99, and 1.00 Irior ti iny oldy arrent toating, the fatigue specimens were tested at room tempreratude to faliure. The specimens containing 0.250 and 0.375 inch diameter holes wore tested in axial loading on a 10,000 pound sonntag, Sil-10 patigue michine hiving a $5: 1$ load intensifying fixture mounted on is tiable ton. "in: ionntai, machine provided a cyclic rate of 30 cyctes

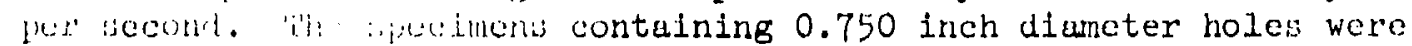
tristed on at wi:l, hyllitulic futigue machine which provided a cyelic rate

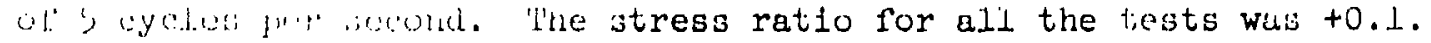
biseh spesimen w'i: lested until fracture occurred through one of the two holes.

$\Lambda$ tobil of : 30 f'ractured specimens were initiully eddy current tested to select holes containine secondary cracks (see figure 101). The intact hole in each specimen was scunned with a Nortec NDT-3 eddy current instrument capable of several discrete frequencles between $10 \mathrm{kHz}$ and $2 \mathrm{MHz}$. The instrument feutures an adjustable operating point within the complex impedance plane tor euch of the 7 avallable frequencles. Ideal specialty Co. absolute type hole probes of the appropriate size were used. These probes were a single coil and used a ferrite core of .050 inch nominal diameter from .130 to .160 inch long wound with 150 turns of $\$ 40$ wire. 


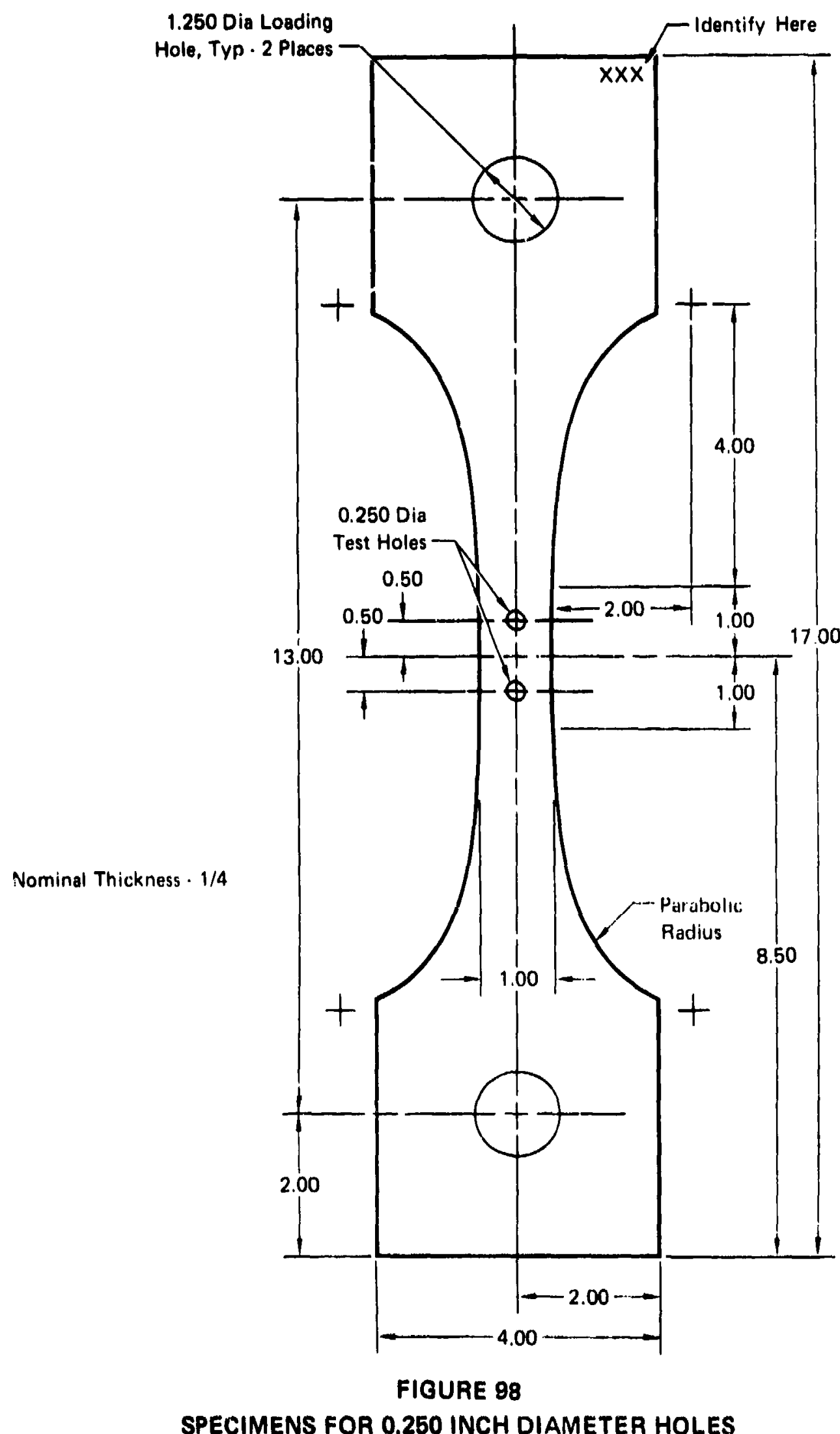

SPECIMENS FOR 0.250 INCH DIAMETER HOLES

(3P) $/ 40117225$ 


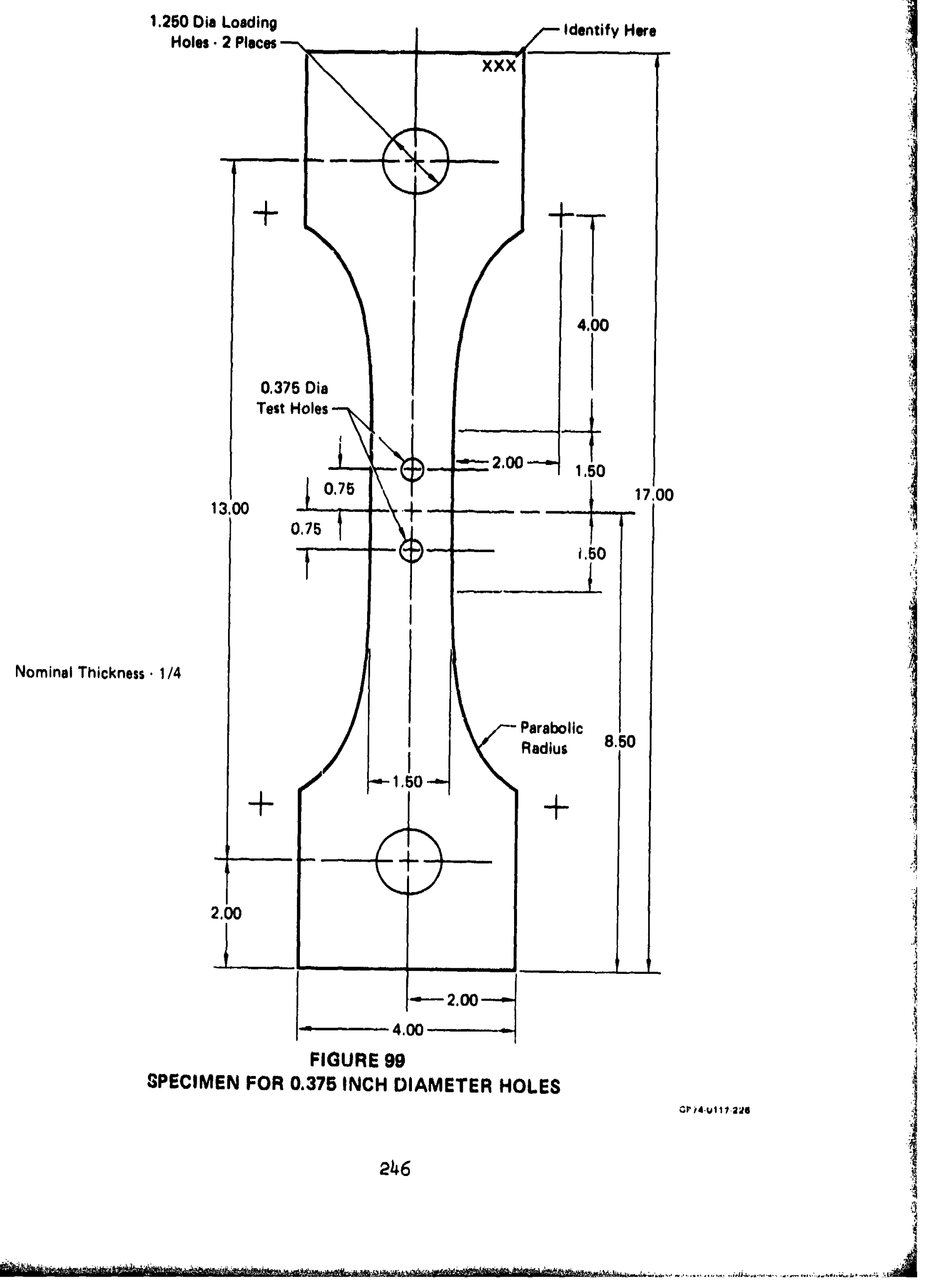




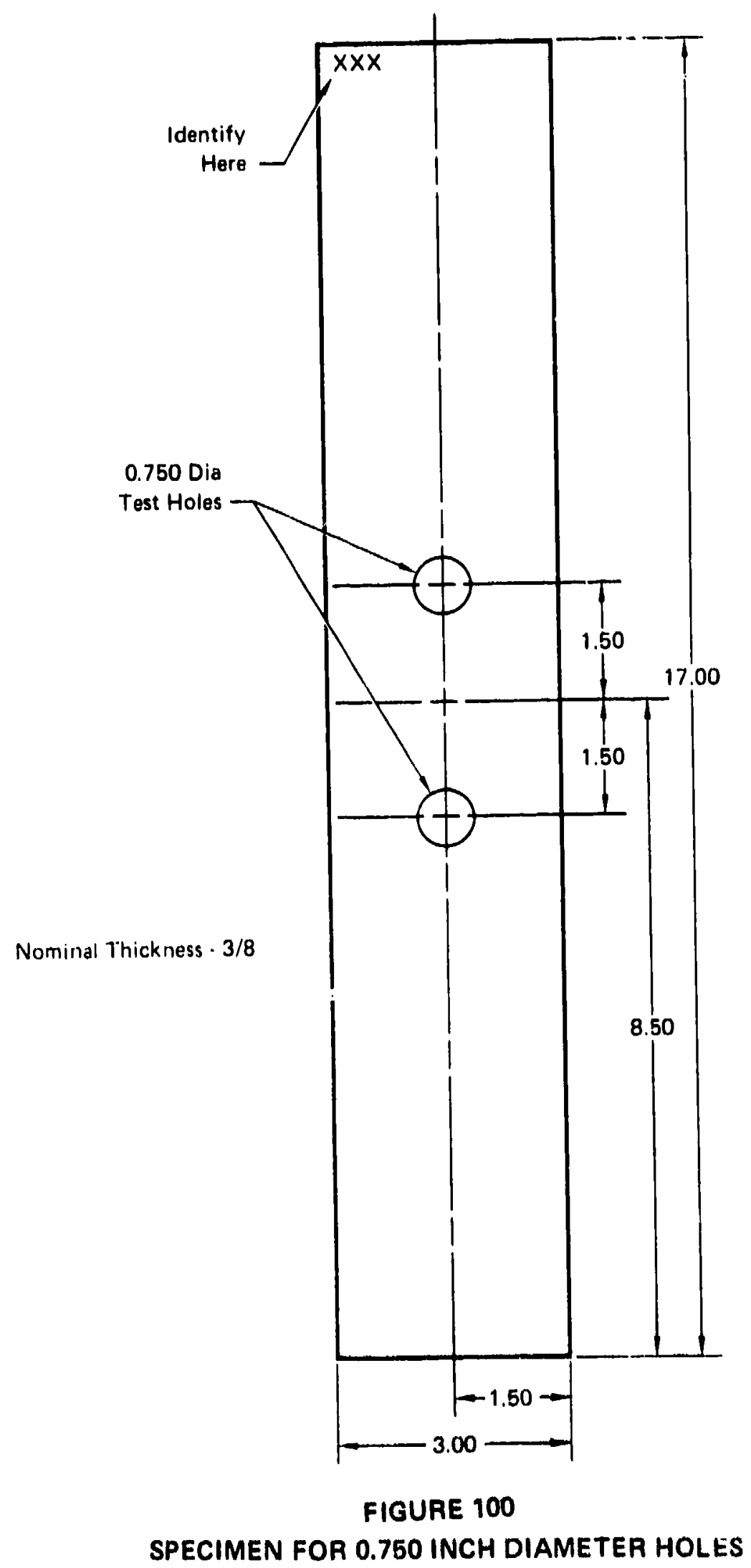

(4)140111227 


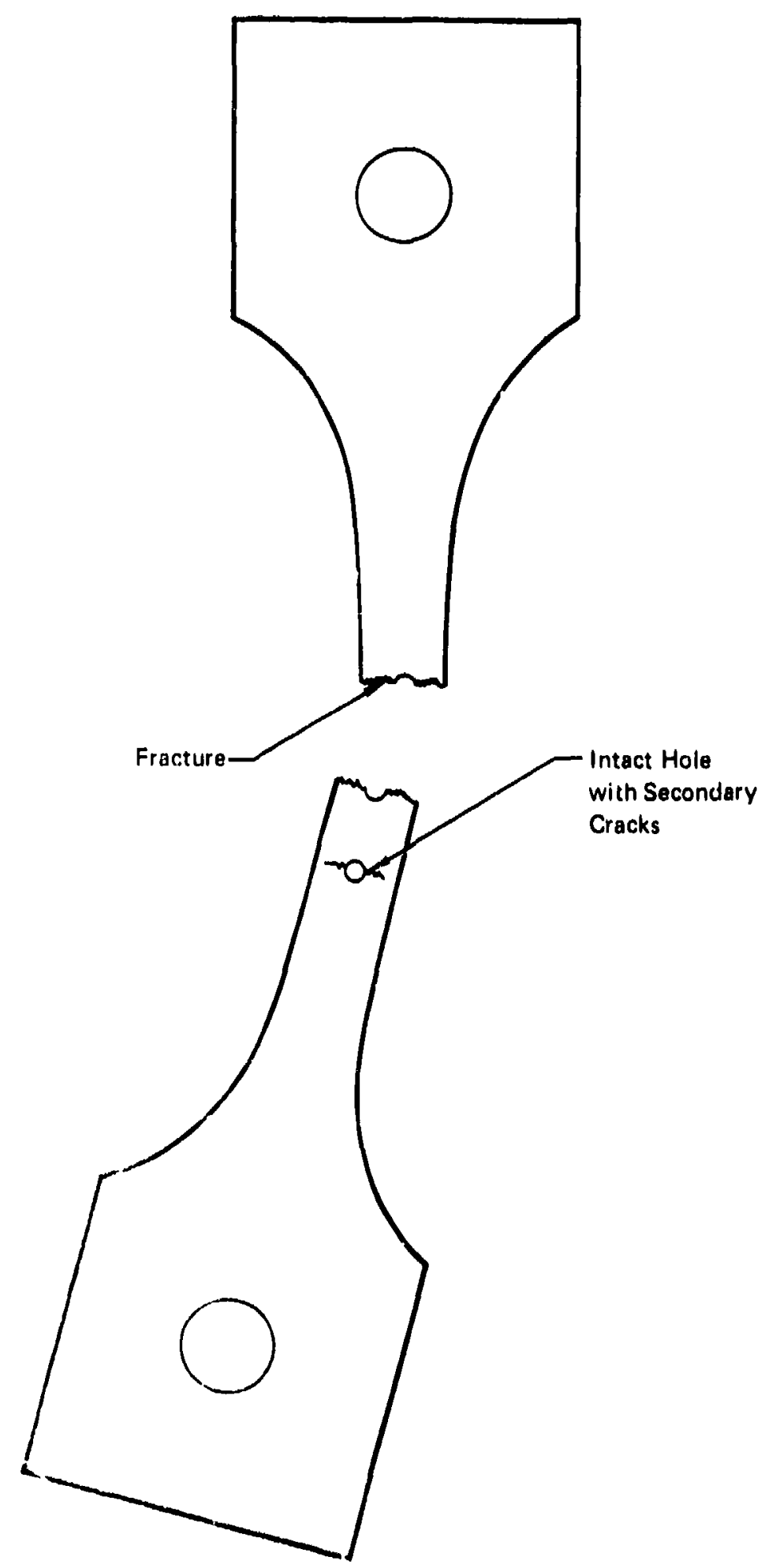

FIgure $10 \%$

ap 740117.222

SECONDARY CRACKS IN FASTENER HOLE

248 
Lift-off compensation was 0.003 inch and the test frequency was a r. $\operatorname{minal} 500 \mathrm{KHz}$ (464 $\mathrm{kHz}$ actual). The actual frequency was determined by monitoring the oscilloscope wave form of the signal. supplied to the eddy current probe during actual operation. Lift-off compensation was accomplished by adjusting the " $X$ " and " $R$ " controls to obtain the same metar indication with and without a .003 inch paper shim between the probe and hole surface.

The operating point was chosen using the sensitivity standard shown in Figure 102. The conductivity of the Ti-6Al-6V-2Sn is $1.10 \%$ IACS and the conductivity of the Ti-8Al-1Mo-1V is $0.87 \%$ IACS. A previous program indicated that, for t1tanium, the operating point alone the 11ftmoff compensation locus should be chosen relatively far away from the material point in the complex impedance plane to give the maximum response ( 478 microamps per $1 \%$ IACS) to the conductivity difference between the two halves of the sensitivity standard. 'The eddy current instrunent had been modified internalily to permiti recording of the signals on a Moseley 680 strip chart recorder which has a response o1 $100 \mathrm{HI}$. Previous experience has shown the strip chart recorder to be a great aid in detecting cracks because a meter deflection doesn't have to be constantly monitored. Also, the strip chart recorder responds to a crack much more quickly than does a meter def'lection. The scan index used was as show in Figure 103. The scan index was rinsen to provide for overlap of the inspection areas. The response frum each crack wis meinilred in microump. of the 230 holes inspected, a tota? of 39 holes containod indicatiuns.
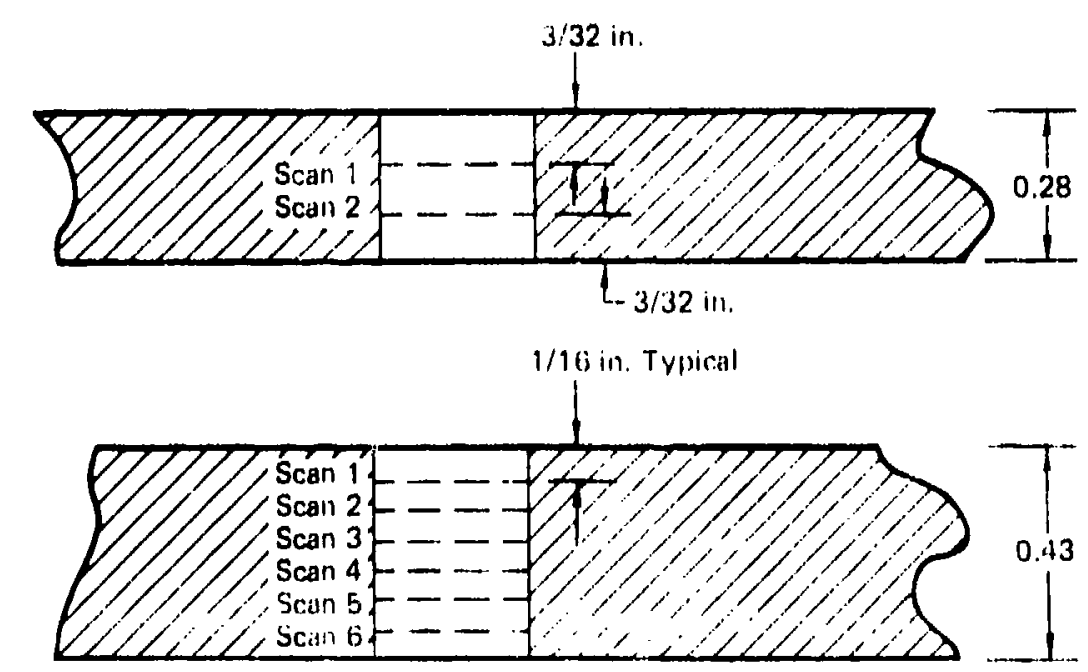

\section{FIGURE 103 \\ S@AN INDEX USED DURING EDDY CURRENT INSPECTICN}

Next, the 39 holes with indistions were endy current insucted usints the NDT-3 and the same inspection parimuters except that a nominal frequency of $100 \mathrm{KHz}$ (10/ Kalz actuil) was used. fior this lest, nophtive lift-ofr compensation wes used and the oporaline polnt wils sclecied for maximum response to the conductivily dilference fin lhe acnsi. irity stindard. 


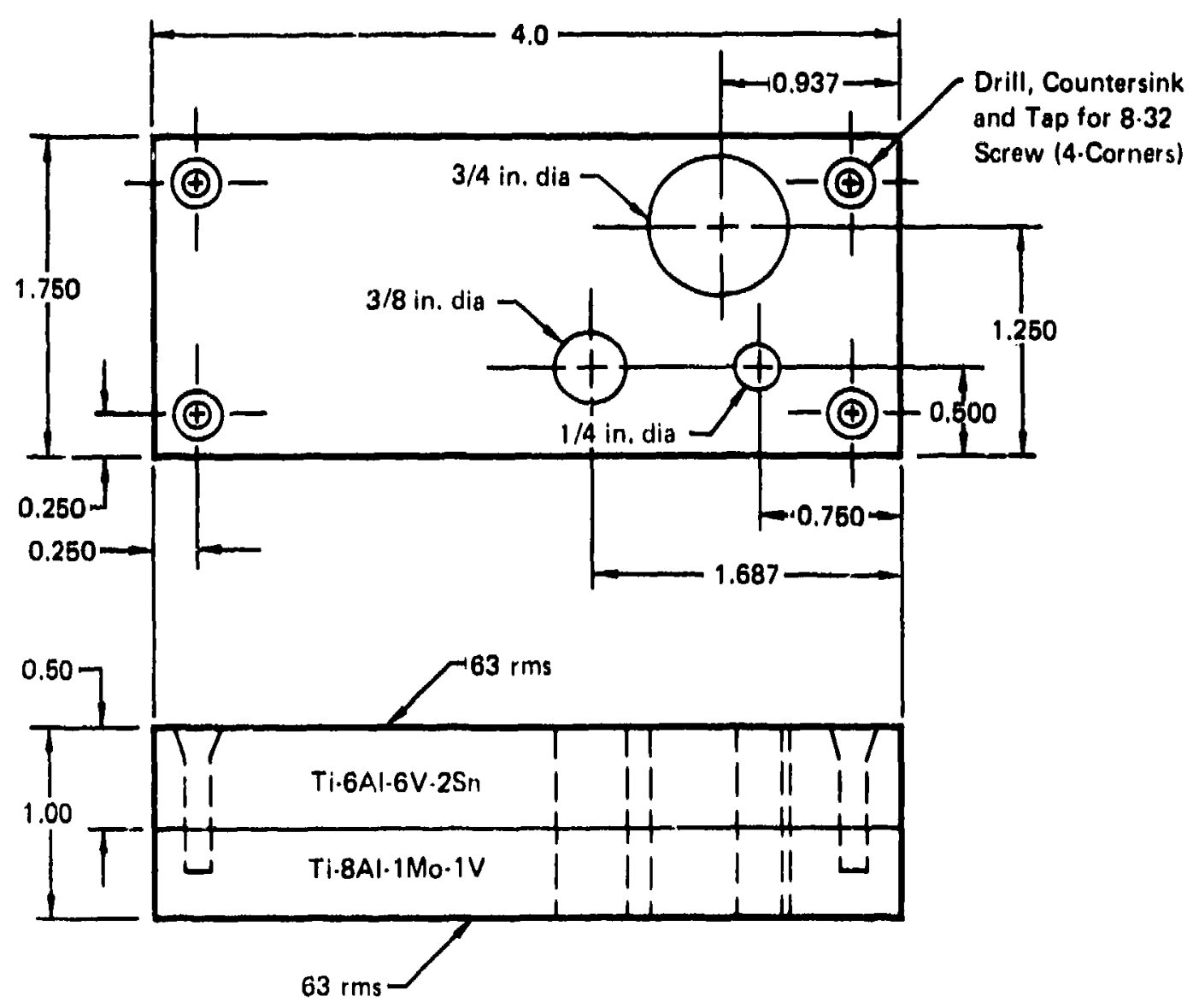

Notes:

1. All dimanutions are in uriches.

2. Tolerancus aro $: 0.010 \mathrm{in}$.

4. Materiol is in the snnealed condition.

3. Surlacu fin'sh is $125 \mathrm{rms}$ unless uthinewise noted.

B. Insesll 8.32 s.rowe in four corners wher complete.

FIGURE 102

TITANIUM EDDY CURRENT SENSITIVITY STANDARD 
A third test was performed upon the 39 holes using another eddy current instrument, the Magnaflux ED-520. This particular instrument used continuously variabl. Irequen. ies (from 55 to $200 \mathrm{KHz}$ ) which are fixed by the probe coil and lift-off compensation chosen. Again, approprlately sized Ideal Specialty absolute hole probes were used. Lift-off compensation was negative and the test frequency was $135 \mathrm{KHz}$. The operating point was selected to $R^{1}$ \%. ence in conductivity in the sensitivity standard. A fourth test was performed using the second eddy current instrument with negative lift-off compensation and a test frequency of $129 \mathrm{kHz}$. The operating point was changed alightly from that used in the third test because preliminary testing had suggested a superior slgnal-to-noise ratio might be realized.

Finally, a fifth test was performed using the first eddy current instrument and Nortec differential hole probes. The nominal test frequency was $500 \mathrm{KHz}$ (464 $\mathrm{kHz}$ measured). The instrument operating point was chosen to give the maximum signal-to-noise ratio by locating the null balance point in the impedance plane and measuring tha signal-to-noise ratio for several operating points near the null balance point.

After all the eddy current tests were complete, 14 of the cracks were intentionally fractured and the actual size of the crack was measured. A photograph of two of the fracture surfaces is shown in Figure 204. The results of the eddy current tests are shown in Tables 79 and 80 . It should be mentioned that, during the testing, each instrument sensitivity was adjusted to yield 22 percent of full scale for the conductivity difference in the reference standard. The ED-520 has a 500 microamp full scale and the NDT-3 has a 100 microamp full scale. Consequently, in order to normalize the data, the NDT-3 responses were multiplied by a factor of 5 . The normalized data is shown in Table 79. As can be seen from Table 79, the eday current response from the smaller cracks was greatest with the low frequency methods using negative lift-of $f$ compensation.

Based upon thess tests with the equipment used, it appears that the best eddy current method for inspection of unfilled holes in titanium is to use an absolute hole probe, negative lift-off compensation, and a low frequency of approximately 100 to $150 \mathrm{KHz}$. The smaj.lest crack detected by eddy current duriag these tests had a maximum depth of .024 1nch. It is not known if smaller cracks exist in the fastener holes since the crack growth was not controlled. Consequently, it is not possible to retermine the size of a minimum detectable crack from these result.s. It can be stated, however, that the eddy current method can detect cracks with depths of at least .024 inch.

The results of the previous progrum prompted further testing. Additional specimens were selected froin the same sollection as were the Figures 98 through 100 specimens. Several eddy current inspections, described below, were conducted on th $a$.

The test, designated as "NDT-3 $500 \mathrm{KHz}$ Comp" in Tabie 81, was performed using a Nortec NDT-3 eddy current instrument with an absoluve probe at $500 \mathrm{kHz}$. The absolute probe was an Ideal Specialty $\mathrm{P} / \mathrm{N} 64101-1 / 4$ SP probe 


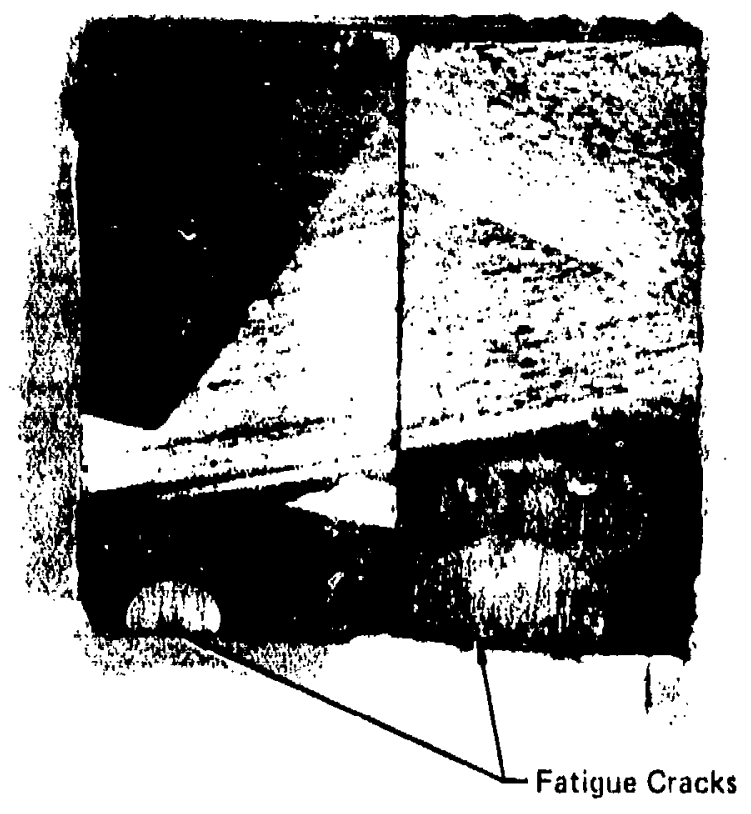

FIGURE 104

PHOTOGRAPH OF TYPICAL FRACTURE SURFACES 
TABLE 79

RESULTS OF EDDY CURRENT INSPECTION OF FASTENER HOLES

\begin{tabular}{|c|c|c|c|c|c|c|c|c|c|c|c|}
\hline \multirow{3}{*}{$\begin{array}{c}\text { Specimen } \\
\text { No. }\end{array}$} & \multirow{3}{*}{ Alloy } & \multirow{3}{*}{$\begin{array}{l}\text { Hole } \\
\text { Dis } \\
\text { lin.) }\end{array}$} & \multirow{3}{*}{$\begin{array}{c}\text { Material } \\
\text { Thicknass } \\
\text { (in.) }\end{array}$} & \multirow{3}{*}{$\begin{array}{c}\text { Maximum } \\
\text { Stresi } \\
\text { (ksi) }\end{array}$} & \multirow{3}{*}{$\begin{array}{l}\text { Fatigue } \\
\text { Cyeles }\end{array}$} & \multicolumn{4}{|c|}{ Absolute Probe Responses (microamps) } & \multirow{3}{*}{$\begin{array}{l}\text { Differential } \\
\text { Probe } \\
464 \mathrm{KHz}\end{array}$} & \multirow{3}{*}{$\begin{array}{c}\text { Maximum Crack } \\
\text { Depth } \\
\text { (in.) }\end{array}$} \\
\hline & & & & & & \multirow{2}{*}{$\frac{\text { Lift Off Compenmated }}{464 \mathrm{KHz}}$} & \multicolumn{3}{|c|}{ Nogatively Compensutod } & & \\
\hline & & & & & & & $134 \mathrm{KHz}$ & $129 \mathrm{KHz}$ & $104 \mathrm{KHz}$ & & \\
\hline $\begin{array}{l}152 \\
145 \\
148 \triangle \\
139 \\
112 \\
162 \\
160 \\
181 \\
148 \triangle \\
355 \\
34.3 \\
360 \\
361 \\
347 \\
356 \\
354 \\
358 \\
332\end{array}$ & $\begin{array}{l}\text { TI GAI 4V } \\
\text { (AIIIrealed) } \\
\text { Ti.6AI.4V } \\
\text { (STOA) }\end{array}$ & $\begin{array}{l}0.25 \\
0.25\end{array}$ & $\begin{array}{l}0.28 \\
0.28\end{array}$ & $\begin{array}{l}55 \\
55 \\
55 \\
55 \\
80 \\
60 \\
55 \\
65 \\
55 \\
55 \\
55 \\
55 \\
55 \\
60 \\
55 \\
55 \\
55 \\
55\end{array}$ & $\begin{array}{r}78,000 \\
138,000 \\
74,000 \\
490,000 \\
21,000 \\
69,000 \\
67,000 \\
56,000 \\
74,000 \\
100,000 \\
208,000 \\
99,000 \\
110,000 \\
89,000 \\
76,000 \\
139,000 \\
117,000 \\
85,000\end{array}$ & $\begin{array}{r}20 \\
20 \\
240 \\
200 \\
275 \\
320 \\
550 \\
310 \\
510 \\
240 \\
85 \\
225 \\
475 \\
525 \\
870 \\
950 \\
1610 \\
855\end{array}$ & $\begin{array}{r}40 \\
50 \\
280 \\
325 \\
310 \\
435 \\
455 \\
460 \\
500 \\
185 \\
185 \\
350 \\
420 \\
545 \\
960 \\
1040 \\
1600 \\
1040\end{array}$ & $\begin{array}{l}88 \\
40 \\
260 \\
275 \\
285 \\
365 \\
590 \\
320 \\
570 \\
225 \\
95 \\
260 \\
450 \\
510 \\
1110 \\
1070 \\
1870 \\
930\end{array}$ & $\begin{array}{c}8 \\
A \\
270 \\
290 \\
290 \\
425 \\
475 \\
410 \\
495 \\
170 \\
90 \\
300 \\
420 \\
500 \\
960 \\
930 \\
1600 \\
890\end{array}$ & $\frac{B}{B}$ & $\begin{array}{l}\text { None Found } \\
0.63 \\
0.37 \\
4 \\
0.62 \\
4 \\
0.43 \\
0.030 \\
0.037 \\
0.104 \\
4 \\
4 \\
0.179 \\
4 \\
4\end{array}$ \\
\hline $\begin{array}{l}219 \\
197 \\
198 \\
\end{array}$ & $\begin{array}{l}\text { TI.6Al.4V } \\
\text { (Annealed) }\end{array}$ & 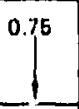 & 0.43 & $\begin{array}{l}55 \\
55 \\
55 \\
\end{array}$ & $\begin{array}{r}104,800 \\
63,900 \\
66,000 \\
\end{array}$ & $\begin{array}{r}60 \\
310 \\
500 \\
\end{array}$ & $\begin{array}{r}70 \\
280 \\
325 \\
\end{array}$ & $\begin{array}{c}25 \\
190 \\
260 \\
\end{array}$ & 8 & 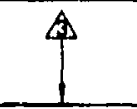 & 4 \\
\hline $\begin{array}{l}182 \\
193 \\
187 \\
180 \\
186 \\
194 \\
\end{array}$ & $\begin{array}{l}\text { TI-6Al.4V } \\
\text { (Anninaled) }\end{array}$ & 0.376 & 0.28 & $\begin{array}{l}55 \\
55 \\
55 \\
55 \\
55 \\
\end{array}$ & $\begin{array}{r}218,000 \\
67,000 \\
64,000 \\
72,000 \\
78,000 \\
\end{array}$ & $\begin{array}{r}40 \\
75 \\
95 \\
210 \\
520 \\
7: 0 \\
\end{array}$ & $\begin{array}{r}90 \\
125 \\
190 \\
380 \\
660 \\
830 \\
\end{array}$ & $\begin{array}{c}A \\
90 \\
90 \\
165 \\
335 \\
585 \\
750 \\
\end{array}$ & $\begin{array}{l}110 \\
85 \\
170 \\
366 \\
680 \\
910 \\
\end{array}$ & $\begin{array}{c}70 \\
105 \\
190 \\
310 \\
655 \\
810 \\
\end{array}$ & $\begin{array}{c}4 \\
0.030 \\
4 \\
4 \\
4\end{array}$ \\
\hline $\begin{array}{l}292 \\
287 \\
294 \\
205 \\
291 \\
\end{array}$ & $\begin{array}{l}\text { T1.OAl. } \\
\text { GV.2Sn } \\
\text { (Annpaled) }\end{array}$ & 0.375 & 0.28 & $\begin{array}{l}55 \\
55 \\
55 \\
55 \\
55\end{array}$ & $\begin{array}{r}36,000 \\
106,000 \\
65,000 \\
38,000 \\
38,000 \\
\end{array}$ & $\begin{array}{r}40 \\
80 \\
300 \\
350 \\
40 \\
\end{array}$ & $\begin{array}{r}50 \\
270 \\
440 \\
690 \\
30 \\
\end{array}$ & $\begin{array}{l}40 \\
210 \\
430 \\
610 \\
60 \\
\end{array}$ & $\begin{array}{c}65 \\
220 \\
460 \\
730 \\
B 0 \\
\end{array}$ & $\begin{array}{l}A \\
220 \\
460 \\
580 \\
B \\
\end{array}$ & $\begin{array}{c}.9 \\
0.056 \\
0.087 \\
0.087 \\
\text { None Found } \\
\end{array}$ \\
\hline $\begin{array}{l}380 \\
379 \\
\end{array}$ & $\begin{array}{l}\text { TI. } 6 A \mid . \\
2 S n \mid S T O A)\end{array}$ & 0.25 & 0.28 & $\begin{array}{l}56 \\
55\end{array}$ & $\begin{array}{l}1,308,000 \\
3,447,000\end{array}$ & $\begin{array}{l}30 \\
20\end{array}$ & $\begin{array}{l}30 \\
45\end{array}$ & $A$ & 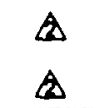 & 4 & $\begin{array}{l}\text { None Found } \\
\text { No }\end{array}$ \\
\hline $\begin{array}{l}275 \\
258 \\
270 \\
280 \\
\end{array}$ & $\begin{array}{l}T_{1.6 A l .6 V} \\
25 n \\
\text { (Annguled) }\end{array}$ & 0.25 & 19.28 & $\begin{array}{l}8 i \\
56 \\
55 \\
55 \\
\end{array}$ & $\begin{array}{l}77,000 \\
25,000 \\
53,000 \\
82,000 \\
\end{array}$ & $\begin{array}{l}25 \\
20 \\
25 \\
95 \\
\end{array}$ & $\begin{array}{r}40 \\
60 \\
40 \\
240 \\
\end{array}$ & $\begin{array}{c}Q 8 \\
50 \\
35 \\
225\end{array}$ & $\begin{array}{c}A \\
60 \\
15 \\
235 \\
\end{array}$ & & $\begin{array}{l}\text { None Found } \\
0.024 \\
98\end{array}$ \\
\hline $\begin{array}{l}391 \\
303\end{array}$ & $\begin{array}{l}T \cdot . \text { GAI.6V } \\
2 \mathrm{~S} \text { (STA) }\end{array}$ & 0.25 & 0.28 & $\begin{array}{l}55 \\
55 \\
\end{array}$ & $\begin{array}{l}32,000 \\
23,000\end{array}$ & $\begin{array}{r}45 \\
145\end{array}$ & $\begin{array}{r}80 \\
176\end{array}$ & $\begin{array}{l}16 \\
170\end{array}$ & $\begin{array}{l}66 \\
100 \\
\end{array}$ & & $\begin{array}{l}0.034 \\
4\end{array}$ \\
\hline
\end{tabular}




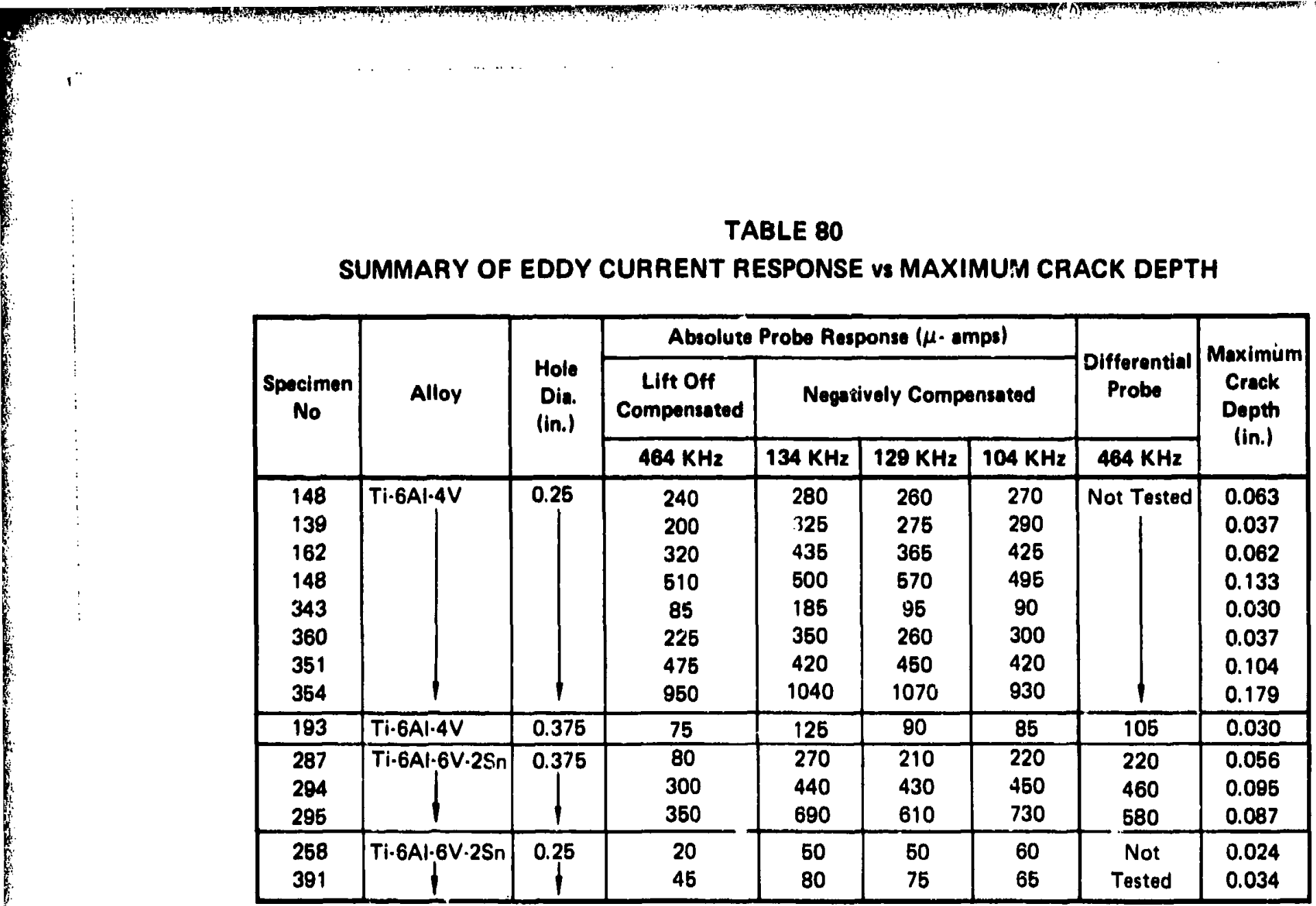

Typical Complex Impedance Plane

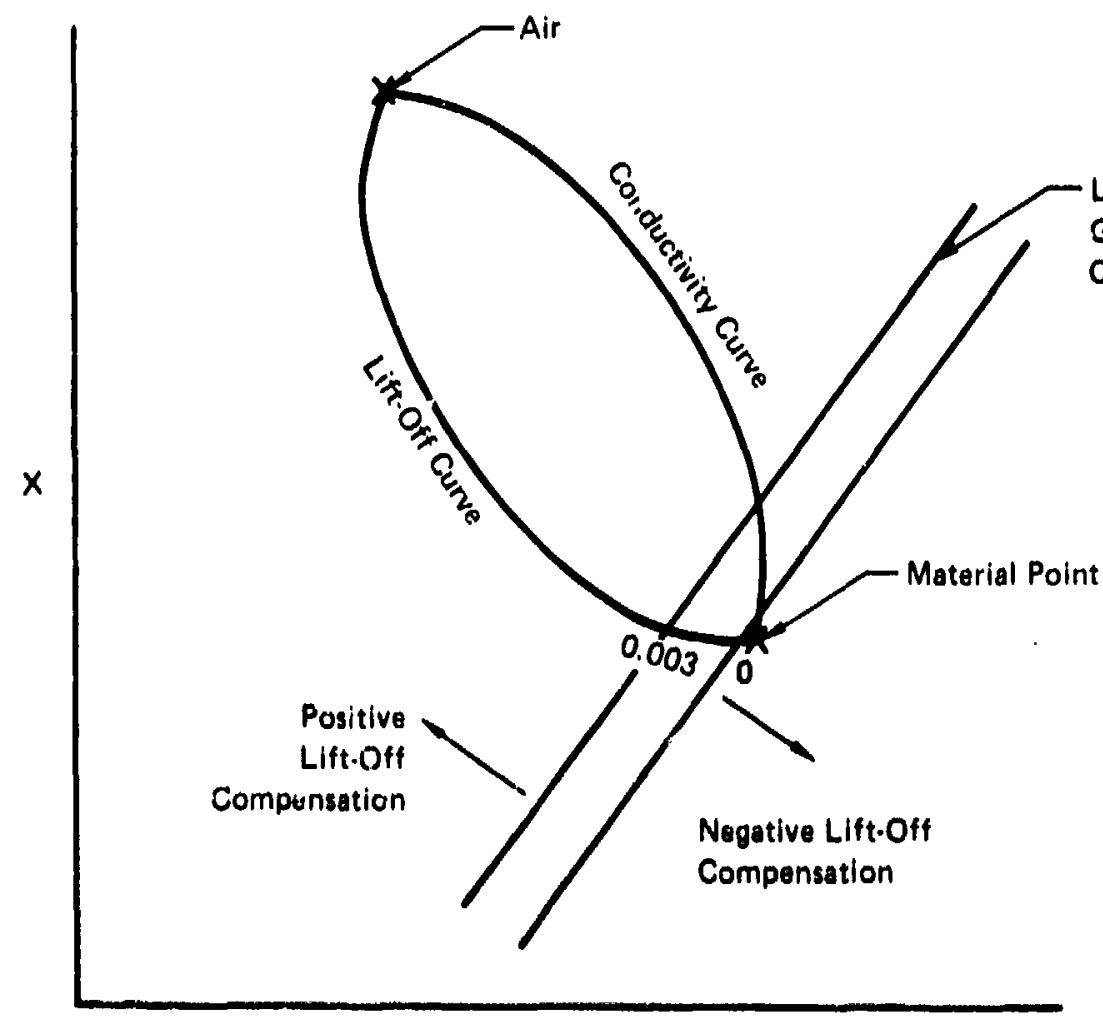

ค

OP 10.0117 .220 
with a .050 inch diameter ferrite core and 150 turns of No. 40 wire. Lift-off compensation was .003 inch and was accomplished by adjusting the " $X$ " and " $R$ " controls to obtain the same meter indication with and without a .003 inch naper shim between the probe and the test surface. The operating point was chosen using the sensitivity standard shown in Figlure 102. The conductivity of the Ti-6Al-6V-2Sn is $1.10 \%$ IACS and the conductivity of the Ti-8AI-1Mo-IV is $0.87 \%$ IACS. A previous program indicated that, for titanium, the operating point along the lift-off compensation lncus should be chosen relatively far away from the material point in the colplex impedance plane to give the mavimum response to the conductivity difference between the two halves of the sensitivity standard ( 478 microamps per 1\% IACS). Crack indications were recorded on a Moseloy 680 strip chart resorder and fixture was used to malntain the $1 / 16$ inch scan index.

The test identified as NDT-6 $1.0 \mathrm{OMH}$ Comp. was performed identically to that described above except that the frequency was $1.0 \mathrm{MHz}$. Although a $2.0 \mathrm{MHz}$ module was available for use in the NDT-3, insufficient gain was obtained with this module to warrant any further testing. Discussions with Nortec on this subject led to the use of the prototype NDT-11 instrument.

The Nortec NDT-11, deslgnated as "NDT-11 $1.5 \mathrm{MHz}$ Comp" in Table 81 has more gain at the higher operating frequencles than the NDT-3 or NDT-6. A $2 \mathrm{MHz}$ differential probe supplied by Nortec and an experimental absolute probe supplied by the Ideal Speciulty Co. were used to measure the capability of the NDI-11 prototype instrument. Both probes were hund rotated and indexed $1 / 16$ inch between scans. A flyture was used to naintain constant probe depth during each scan. The calibration methods were the same as was performed using the NDT-6. Medium afze fatigue cracks, selected from the previous results, were used in the calibration of the differential probe so that the comparisons found in Table 81 could be made. The Nortec differential probe was found to be no improvement over the previously evaluated NDT-3 and NDT-6 with an absolute probe. The results reported in Table 81 were obtained using the experimental Ideal Specialty absolute probe operating at $1.5 \mathrm{MHz}$. It consisted of a radial axis .050 inch diameter ferrite core wound with 50 turns of $\# 40$ wire. The test deslgnated as "Circograph" in Table 81 was performed with a Forster Circograph 6.230 using a $400 \mathrm{KHz}$ stainless steel differential probe rotating at 3,000 RPM. The instrument read-out is a cathode ray tube (CRT) whose display is synchironized with the rotation of the probe colls such that a flaw's location is readily determined. The method of callbration prevfously used with the NDT-3 and an absolute probe was not applicable to this method since both colls of the probe see the same bulk material conductivity simultaneously. For this reason, a medium size crack detected by the prevlously described methods (Specimen 393), was used for calibrating. The instrument was calibrated by adjusting the phase and the gain controls uritil the signal-to-noive ratio was minimized (about 10 to 1) for this particular crack. Once lnitially adjusted, the gain wad changed only silglitly to mulntaln the nolse at a level of less than $20 \%$ of the CRT helght in the individual holes; the phase position was not altered. The rotating probe was moved slowly in and 
TABLE 81

EDDY CURRENT CRACK RESPONSE

\begin{tabular}{|c|c|c|c|c|c|c|c|c|}
\hline \multirow[b]{2}{*}{$\begin{array}{c}\text { Specimen } \\
\text { No. }\end{array}$} & \multirow[b]{2}{*}{ Matorial } & \multirow[b]{2}{*}{$\begin{array}{c}\text { Maximum } \\
\text { Stross } \\
\text { (ksi) }\end{array}$} & \multirow[b]{2}{*}{$\begin{array}{l}\text { Fatigue } \\
\text { Cycles }\end{array}$} & $\begin{array}{l}\% \text { Full } \\
\text { Sereen } \\
\text { Helght }\end{array}$ & \multicolumn{4}{|c|}{ Microamp Response } \\
\hline & & & & $\frac{5}{8}$ & 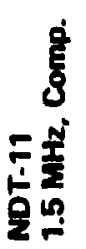 & 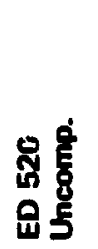 & 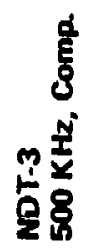 & 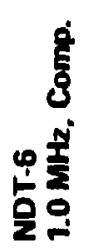 \\
\hline 276 & Ti.6Al.6V & 55 & 53,000 & - & - & 50 & - & - \\
\hline 280 & $2 S n$, Annealed & 56 & 82,000 & 75 & 210 & 160 & 160 & 170 \\
\hline 393 & $\begin{array}{l}\text { Ti.6Al.6V. } \\
2 \mathrm{Sn} \text {, Annealed }\end{array}$ & 65 & 23,000 & 45 & 130 & 180 & 150 & 210 \\
\hline 536 & \multirow{18}{*}{$\begin{array}{l}\text { Ti.6Al.4V, } \\
\text { Annealed }\end{array}$} & 55 & 50,000 & $100^{+}$ & 920 & 1100 & 1100 & $500^{+}$ \\
\hline 540 & & 65 & 53,000 & - & - & 640 & 52.8 & $500^{+}$ \\
\hline 644 & & 55 & 23,000 & 20 & 40 & 210 & 80 & 110 \\
\hline 645 & & 65 & 39,000 & 80 & 230 & 220 & 125 & 230 \\
\hline 547 & & 65 & 71,000 & 45 & - & 80 & - & - \\
\hline 551 & & 55 & 92,000 & 100 & 540 & 720 & 484 & $500^{+}$ \\
\hline 552 & & 65 & 64,000 & 35 & - & - & - & - \\
\hline 563 & & 56 & 61,000 & 80 & 40 & - & - & - \\
\hline 654 & & 55 & 71,000 & 65 & 180 & - & 110 & - \\
\hline 555 & & 65 & 61,000 & 30 & 50 & - & - & -- \\
\hline 559 & & 56 & 52,000 & 80 & 320 & 350 & 200 & 350 \\
\hline 560 & & 55 & 54,000 & 100 & 680 & - & 170 & 300 \\
\hline 562 & & 65 & 76,000 & 40 & 120 & - & 100 & 180 \\
\hline 576 & & 55 & 108,000 & 20 & -- & 100 & -. & $\ldots$ \\
\hline 579 & & 55 & 116,000 & 15 & - & - & - &.- \\
\hline 580 & & 65 & 63,000 & 75 & 400 & 638 & 440 & 500 \\
\hline 589 & & 65 & 163,000 & - & - & - & - & - \\
\hline 646 & & 80 & 23,000 & 85 & 180 & - & 150 & 190 \\
\hline 740 & \multirow{5}{*}{$\begin{array}{l}\text { Ti.6Al.6V. } \\
\text { 2Sn, Annealed }\end{array}$} & 56 & 43,000 & 70 & 370 & 264 & 200 & 170 \\
\hline 754 & & 55 & 46,000 & 85 & 650 & 374 & 280 & 230 \\
\hline 758 & & 56 & 72,000 & 38 & 100 & 143 & 110 & 140 \\
\hline 816 & & 55 & 31,000 & - & - & - & - & - \\
\hline 187 & & 65 & 32,000 & - & - & . & $\cdots$ & - \\
\hline
\end{tabular}


out of the holes. Each hole was scanned along its entire depth at least it times. A typical crack response is illustrated in Figure 105. Sinusoidal-type CRT displays were found to be indicative of irregular surface contour in the holes attributable to the flutes of the reamers used. It was noted, however, that after the holes had been tested by five different operators that the holes appeared to be burnished and a stainless steel coating remalned in the holes. No significant wear on the probe was noticed; however, before any further tests with an absolute probe, the holes had to be chemically cleaned due to the changes in apparent conductivity of the hole surfaces. Testing of the holes was approximately 10 times faster with the Circograph as with the other systems investigated.

The test labeled "ED 520-Uncomp" was performed using a Magnaflux ED 520 eddy current instrument with an absolute probe. This particular instrument uses continuously variable frequencies (from 55 to $200 \mathrm{KHz}$ ) which are fixed by the probe coil and the lift-of $i$ compensation. Lift-off compensation was negative and the test frequency was $134 \mathrm{KHz}$. The operating point was selected to give the maximum response to the difference in conductivity from the two pieces of titanium in the reference standard. The absolute probe was the sume as before. The sensitivity of the instrument was set to yield a 110 microamp difference between the piece of T1-6AI-6V-2Sn and T1-8Al-IMO-IV in the sensitivity standard. Again a Moseley 680 strip chart recorder was used as an aid for crack detection and a scan index fixture was used for the $1 / 16$ inch scan index.

More indications wer obtained using the Circograph than with the other instruments. Since none of the cracks were fractured to confirm their existance, it is not known how many of the indications were from discontlnulties other than cracks. It also appeared that, among the other methods, the methods using absolute hole probes were less sensitive to cracks ocuirring near the edges of the holes than was the method employing the differential probe. In comparison, the Circograph was the moat sensitive method for cracks cccurring near the edges of the holes aince it was easy to maintain probe normality and there was virtually no edge effect. Also, the high probe $\mathrm{rpm}$ allows inspections at very small index values with little loss in test time. 

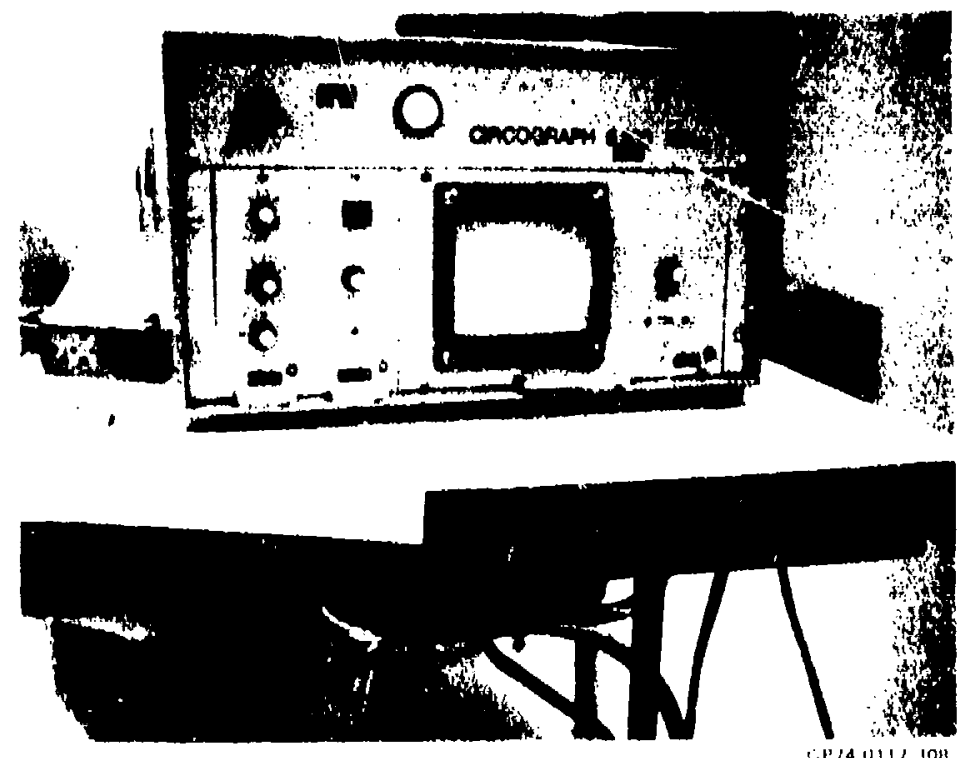

FORSTER CIRCOGRAPH 6.23

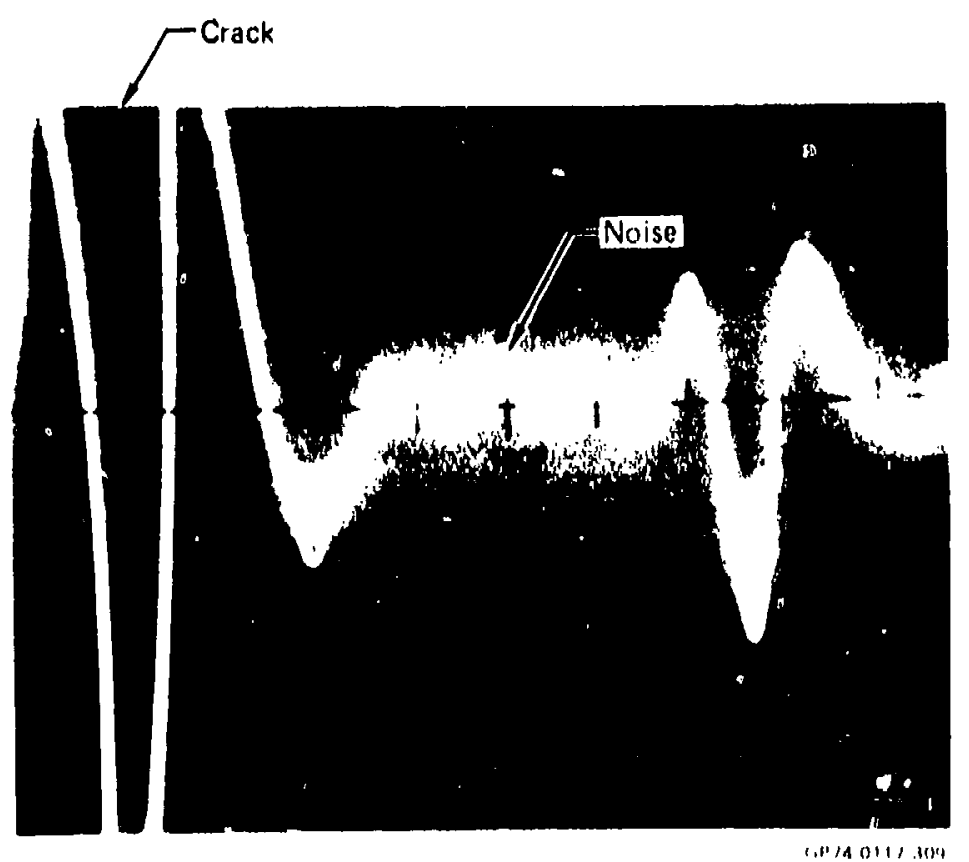

FIGURE 105

CATHODE RAY TUBE PRESENTATION OF CRACK RESPONSE 


\section{Verification of Surface Crack Size}

Several of the tension-tension fatigue and bending fatigue surface connected cracks used in the program were intentlonally exposed in order to measure their actual length and depth. Sawcuts were made adjacent to the crack and the specimen was intentionally failed by overload. The fracture surfaces of the original fatigue cracks were examined and the actual length and depth of each were measured. The actual crack dimensions are listed in Table 82 and photographs of typical fracture surfaces are shown in Figure 106.

Several of the specimens were examine intact at a magnification of $400 x$ in order to measure the width of the cracks. The average crack width was .0005 inch.

\section{FORDSITY}

Several hand forged billets ( $T 1-6 \mathrm{Al}-6 \mathrm{~V}-2 \mathrm{Sn}$ ) contalning porosity have been collected during past internal programs. The billets sections were 4-1/2 $\times 4-1 / 2$ inches, $4-1 / 2 \times 6$ inches, and $4-1 / 2 \times 5-3 / 4 \times$ varying lengths. The porosity in each of the billets is positioned as shown in Figure 107. A program was conducted using these pleces to measure the diameter of typical pores which are detectable during a penetrant inspection.

\section{a. Ultrasonic Method}

The billets had been eertified as ultrasonically acceptable at a Class A level (similar to class A described in MIL-I-8950B - Inspection, Ultrasonic, Wrought Metal, Process for). Subsequently these same billets were submitted to mechanical properties testing and failed at a level below mininum allowable 1 imits for tensile strength and ductility. As a result of the fallure, a section of the failed billet was submitted to a metallographic evaluation. An unacceptable porous condition was tound within the biliet, with the heaviest concentration of stringer type porosity lying near the outside of the billet. Figure 107 illustrated the distribution of porosity in a typical billet.

With the discovery of the porosity, ultrasonic reinspection of the blilets was undertaken. The following setup was used:

(1) Parts were fmmersed and a $21 / 2$ inch wates path was used.

(2) A $5.0 \mathrm{MHz}$ flat $3 / 4^{\prime \prime} 11$ thium sulphate transducer with a 194721 with a 105 pulser was used for scanning.

(3) A "diatarice-amplitude correction" curve baged on 3/64" diameter flat bottom holes with metal travels of $1.25,2.25,3.25$, and 4.75 inches was established by plotting it on the face of the sathode ray tube.

With this test setup, a great deal of nolse uppeured on the cathode ray tube wherever the billet was examined. This nolse fell below the $3 / 64$ inch "distance anplitude correction" curve in 111 cases except for one or two small areas where individual indicutions appeared above $1 t$. These were not rejectable indlcations for Class $A$. Consurrent with these indications, it was noted that there was a $50 \%$ or more $103 \mathrm{~s}$ of back reflection in the areas of the billet where the indications were the greatest. This latter observation Lis a normal rejectable condition. It was noted that the back reflection is normally in saturation when "DAC" curve is established by using tho proper 
TABLE 82

ACTUAL SIZE OF SURFACE CRACKS

\begin{tabular}{|c|c|c|c|}
\hline $\begin{array}{c}\text { Specimen } \\
\text { No. }\end{array}$ & $\begin{array}{l}\text { Targat } \\
\text { Crack Longth } \\
\text { (in.) }\end{array}$ & $\begin{array}{c}\text { Actual } \\
\text { Crack Langth } \\
\text { (in.) }\end{array}$ & $\begin{array}{c}\text { Actual } \\
\text { Crack Depth } \\
\text { (in.) }\end{array}$ \\
\hline $\begin{array}{l}33 \\
.7 \\
45 \\
75\end{array}$ & $0.025-0.050$ & $\begin{array}{l}0.074 \\
0.040 \\
0.010 \\
0.060\end{array}$ & $\begin{array}{l}0.014 \\
0.015 \\
0.005 \\
0.015\end{array}$ \\
\hline $\begin{array}{l}38 \\
82 \\
39 \\
56 \\
59\end{array}$ & $0.050 \cdots 0.100$ & $\begin{array}{l}0.070 \\
0.059 \\
0.060 \\
0.080 \\
0.090\end{array}$ & $\begin{array}{l}0.025 \\
0.013 \\
0.040 \\
0.020 \\
0.030\end{array}$ \\
\hline $\begin{array}{r}3 \\
11 \\
15 \\
25 \\
56 \\
66\end{array}$ & $0.100-0.250$ & $\begin{array}{l}0.119 \\
0.200 \\
0.200 \\
0.150 \\
0.125 \\
0.105\end{array}$ & $\begin{array}{l}0.019 \\
0.070 \\
0.070 \\
0.020 \\
0.035 \\
0.030\end{array}$ \\
\hline $\begin{array}{r}8 \\
21 \\
30\end{array}$ & $0.250-0.500$ & $\begin{array}{l}0.430 \\
0.410 \\
0.480\end{array}$ & $\begin{array}{l}0.160 \\
0.170 \\
0.180\end{array}$ \\
\hline
\end{tabular}

QP74.011722 


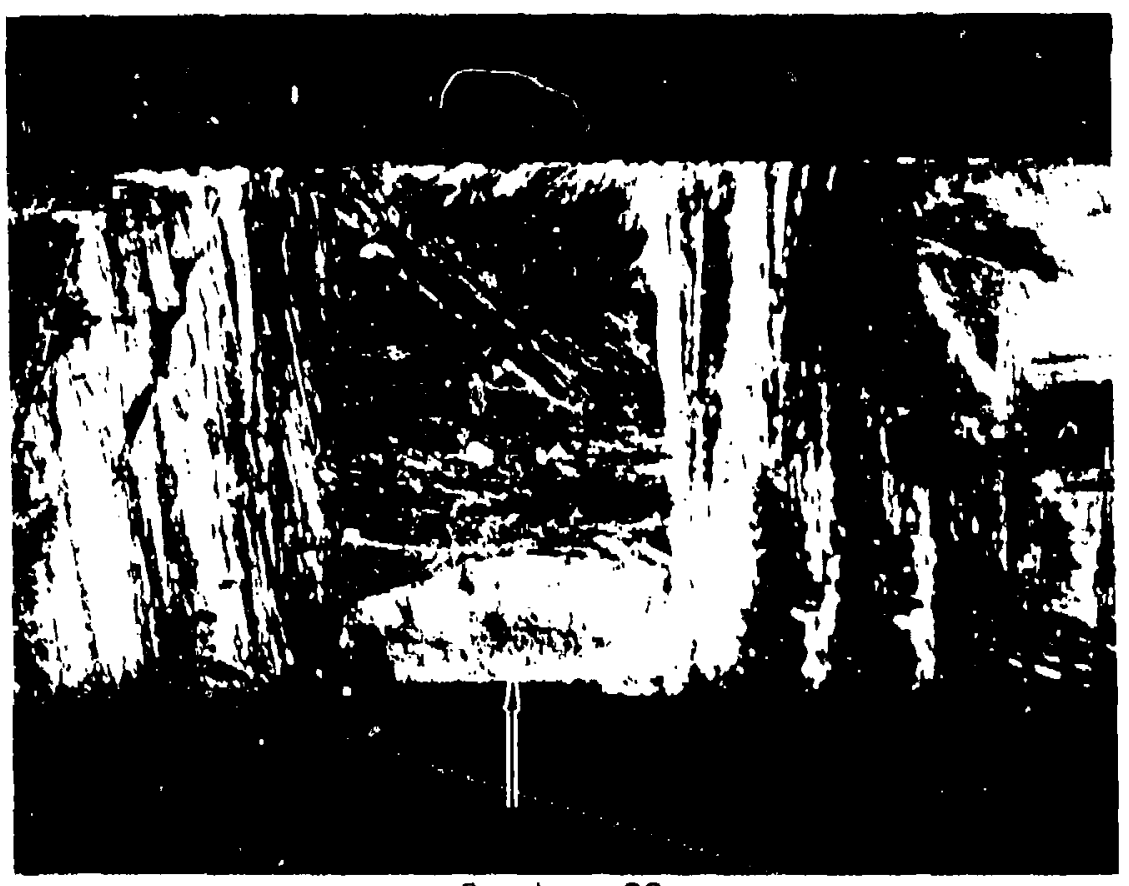

Specimen 33

$0.070 \mathrm{ln}$. Lonly $\times 0.014 \mathrm{ln}$. Deep
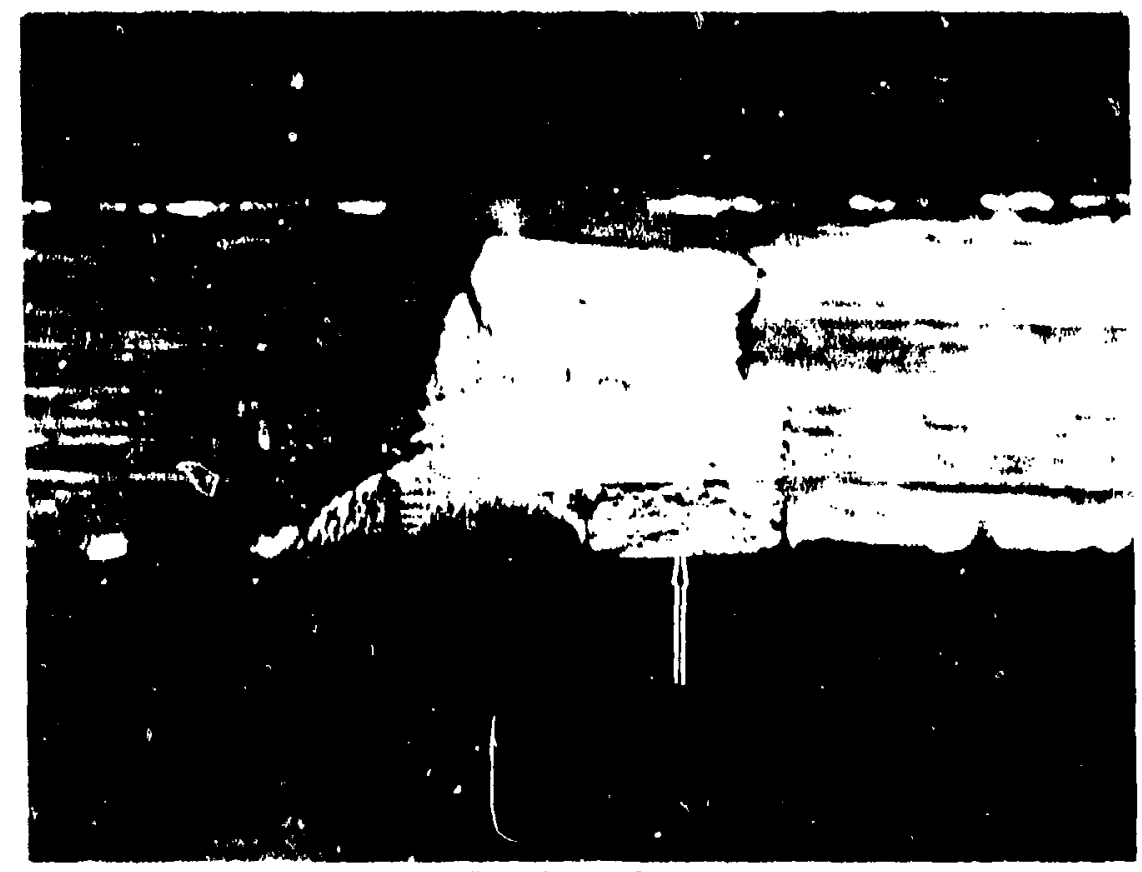

specimen 3

$4 x$

$0.119111 .1 .0110 \times 10.01911$, Deep

FI.jURE 106

PHIOTOGRAPHIS OF FRACTURE SURFACE OF SURFACE CRACKS 


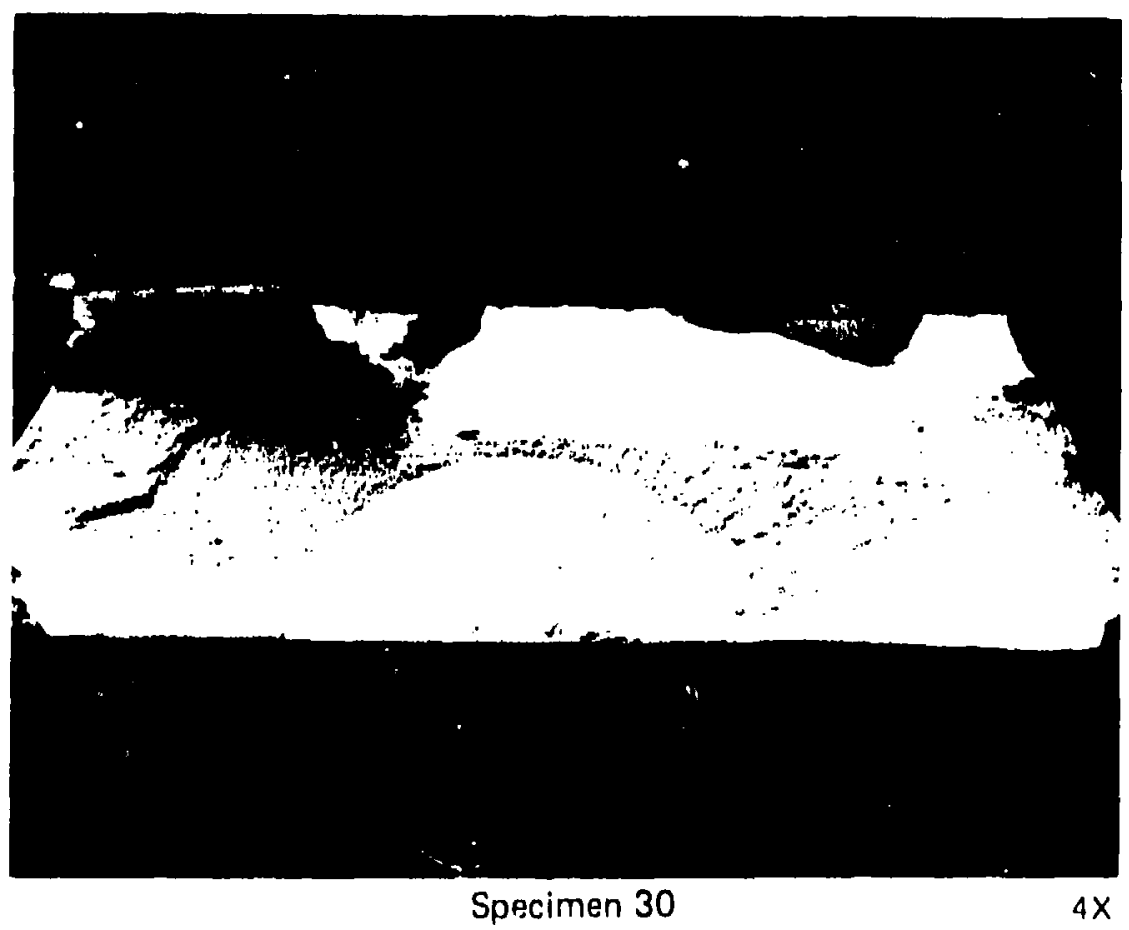

$0.48 \mathrm{In}$. Long $\times 0.18 \mathrm{In}$. Deep

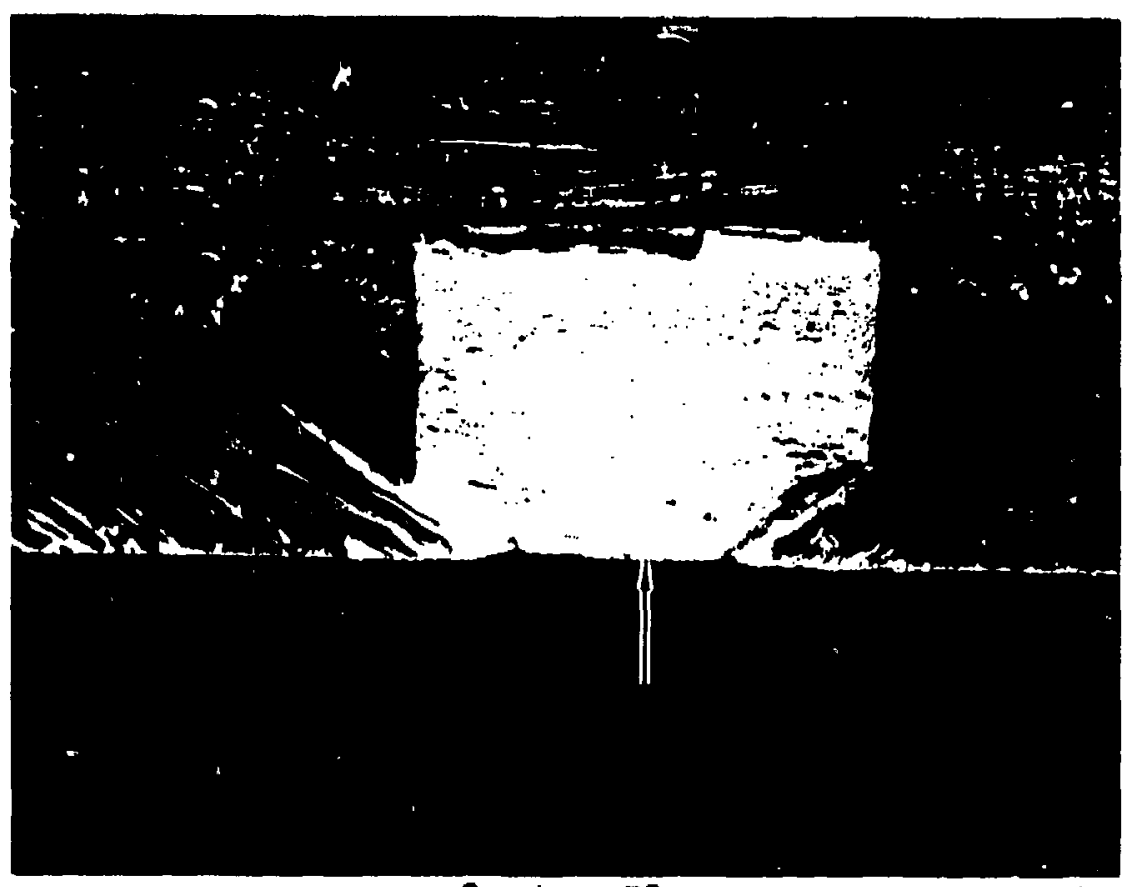

Specimen 59

$0.090 \mathrm{ln}$. Long $\times 0.030 \mathrm{ln}$. Deep

FIGURE 106 (Continued)

PHOTOGRAPHS OF FRACTURE SURFACE OF SURFACE CRACKS 


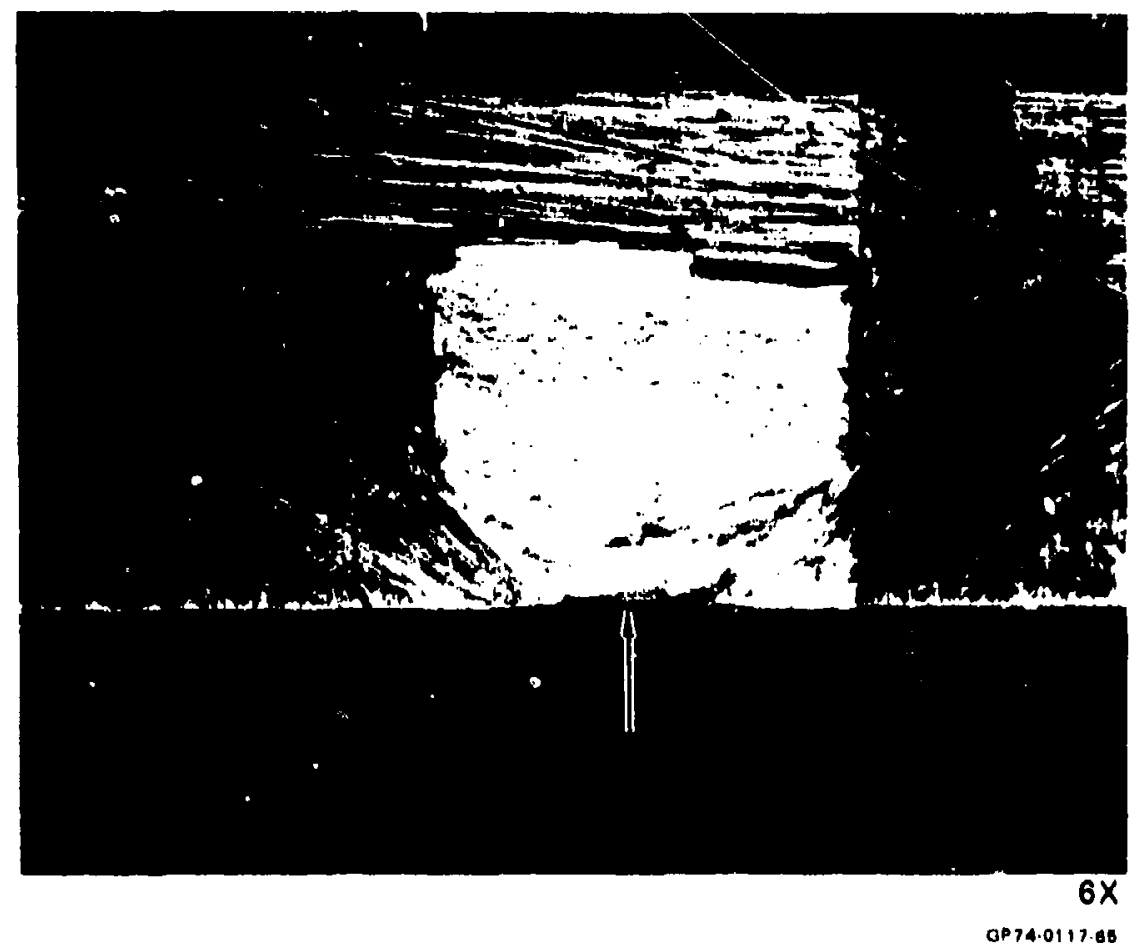

Specimen 39

$0.040 \mathrm{ln}$. Lony $\times 0.015 \mathrm{In}$. Deep

FIGURE 106 (Continued)

PHOTOGRAPHS OF FRACTURE SURFACE OF SURFACE CRACKS 


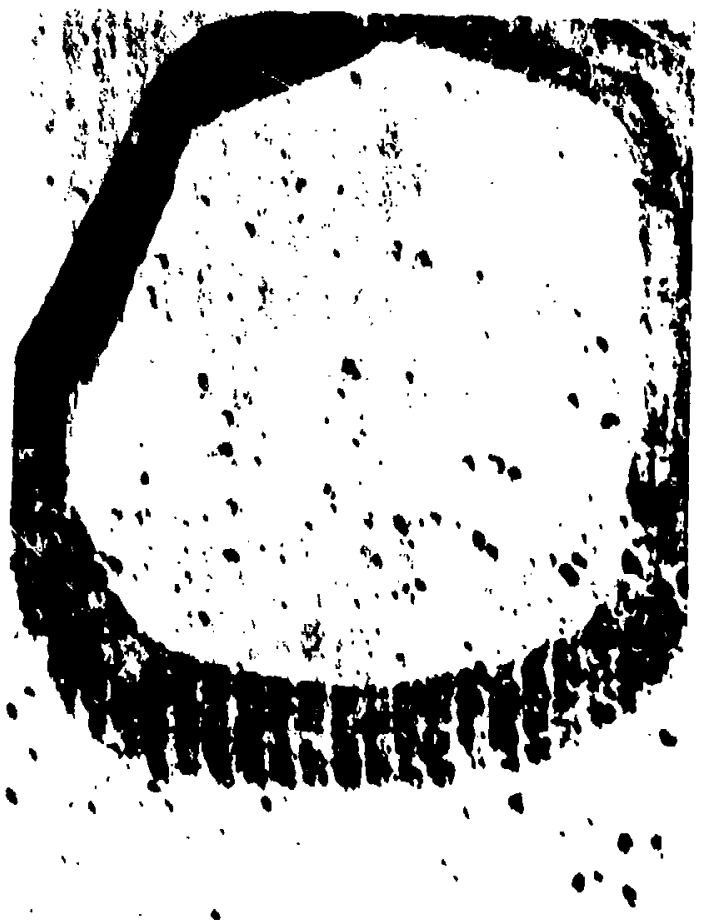

View A
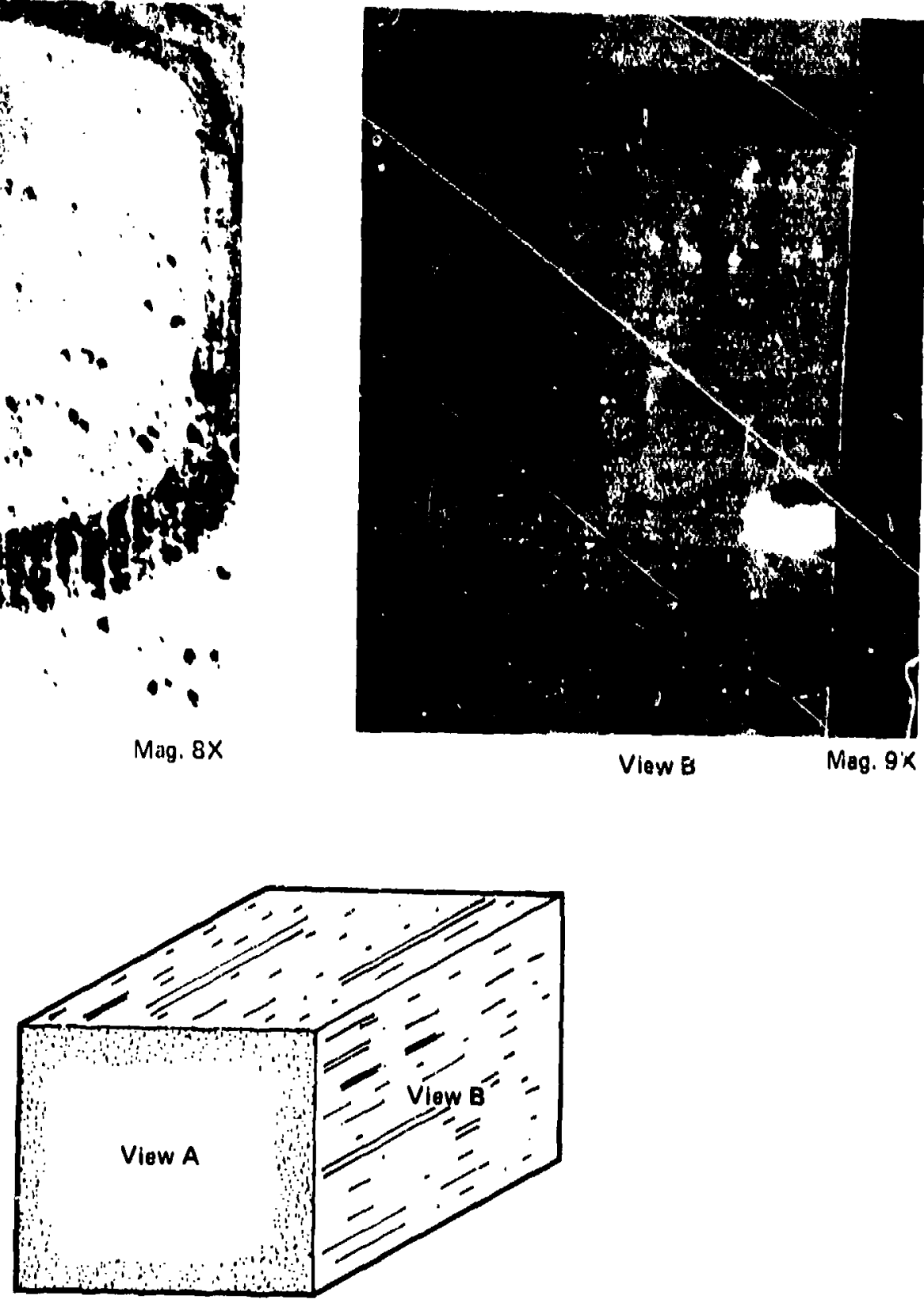

FIGURE 107

(i\$) 40113$)$

TYPICAL POROSITY IN HAND FORGED BILLETS 
test blocks. With this circumstance, it is impossible to judge a true $50 \%$ loss of back reflection unless one of the back surface multiples that is not in saturation is observed. Observation of a multiple back reflection requires compression of the scope picture, which in itself is undesirable, or taking into account the geonetric progression of loss on the multiples of the first back reflection is a possibility. Another method for eliminating the problem of the saturated back reflection is to make a separate back reflection test scan of the part. At least part of the industry feels a $50 \%$ loss of back reflection is significant only when related to a $50 \%$ reduction in height of the observed iack reflection on the cathode ray tube for a setup whicn has been made on the proper $\Lambda S T M$ reference biocks. Since, in this case, the back reflection is nomally in saturation, the observed $50 \%$ loss will amount to an actual $80 \%$, $90 \%$, or more, loss of back reflection. Surface conditions of the billet influence the loss of back reflection to a great extent and a slight shift of the part will often eliminate what appeared to a large loss of back reflection. The fact casts doubt on the ability to correctly evaluate potential porous conditions in parts with nonparallel surfaces. Significant losses in back reflection, at least for a porous condition, must always be accompanied by an increase in the noise level between the front and back surface.

An additional 10 Mi6Al-6V-2Sn billets were ultrasonically inspected using the same method of calibration and equipment as used for the first lot, except that additional ASTM type reference standards having metal travels of $1 / 4,1 / 2$ and $3 / 4$ inch were also use to establish the DAC. The sound entry ond back surfaces of the billets had surface finishes from 125 to 350 RHR. Special attention was given to any loss of back raflection and also significant indications betwern the front and back surface indications. One billet of the 10, in particular, appeared to have rejectable indications $1 / 2$ " to $I^{\prime \prime}$ below the front surface. These indications were thought to be too far from the frout surface to be due to surface condition, and risually the surface seemed satisfactory for an ultrasonic test. Nevertheless, it was decided that a test should be made to definitely establish that the indications were not die to surface imperfections. The following test was made:

(1) The billet with the greatest $r \epsilon_{i}$,ctable indications between front and back surface was seleated. The areas in question on the billet were pinpointed by marking the billet with a steel stamp.

(2) The suriace of the billet was machined (without entirely removing the steel stamping) to a 32 RHR surface finish.

(3) The billet was retested ultrasonically and the original rejectable indications between the front and back surface had disappeared.

As a result of this special test, all bijlets of the lot of 10 billets were routed to the machine shop for clean-up of the surface to a finisin of 32 to $63 \mathrm{RHR}$. After surface improvemert, the billets were again tusted ultrusonically and fourd to be acceptable if the brak reflection was monitored in saturation, but were rejectable if a second test for back reflection me surement only was performed w: ih the br :k reflection at a reduced luvel. In the second test. the back reflection in the center of the billets was set at 90 to $9 \% \%$ of full CRT height; and as the search 
unit removed toward the enge of the billets, the back surface response dropped to below $45 \%$ of fu.!I CRT height. No single indications were rejectable. Because porosity had previously escaped detection by ultrasonics, it was decided to send one billet from the lot of 10 to the ciremical milling department for a ten sacond surface etch. (On the previous lot of billets, surface etching had been used to expose porosity). This ttch did bring out a porous condition in the billet; and this condition was considered unacceptable.

A subsequent stidy of the amount of etching required resulted in the following conclusions. If visual methods were to be employed in evaluation, an etch removing about 0.010 inches optimum. If a fluorescent dye penetrant evaluation is to be performed, then a 0.002 inch metal removal is satisfactory for detecting the porosity.

\section{b. Radiographic Method}

Radiographic techniques using $\Lambda S T M$ Class I fillm and low kilovoltage/ high contrast techniques were also used to try and detect the porosity in selected $41 / 2$ inch thick billets. It was assumed that since the porosity was concentrated along the edeses of the billots, the part's radiographic image would indicate an area of prouler part density in the center of the billets. No measurable film density difforence was obtained, however, in the resulting radiographs. Image quality of $2-1 T$ was insufficient "or detecting individual pores. Nota that for a $41 / 2$ inch thick section, a $2 \%$ contrast only implies a resoluiion of a 0.090 inch thickness change. The pores were less than 0.020 inches diancter. The evaluation of a $?$ inch billet sertion containing, porosity al so did not reveal any radiographic indication of changes in density or presence of pores.

\section{c. Penetrant Method}

Each section from the three billets was etched to remove .010 inch from each surface to ensure removal of any disturbed surface metal resulting from the sawcutting operation. Next, the sections were trichlorethylene vapor degreused for 16 hours and penetrant inspected in the laboratory using Tracer-'Iech P-1.33 fluorescent water washable penetrant and Tracer-Tech $1499 \mathrm{C}$ nonaqueous wet developer. This penetrant system is equivalent in sensitivity to a MIL-I-25135, Group VI System. A penetrant uwell time of 10 minutes was used. Excess penetrant was removed using a hand held Tri-Con 400501 water spray nozzle with the spray directed normal to the surfice; the wash water temperature was approximately $70^{\circ} \mathrm{F}$ and the wash water pressure was approximately $40 \mathrm{psi}$. The specimens were wished until clean under $200 \mathrm{~m}\lrcorner$ crowatts $/ \mathrm{cm}^{2}$ of ultraviolet light. Next, the specimens were dried for 20 minutes in a circulating air oven at $170^{\circ} \mathrm{F}$. Arter a bleed-out time of 5 minutes, the penetrant indications were photographed (see figure 111) using the following parumclers: approximateiy 1000 microwatts per $\mathrm{cm}^{2}$ of ultraviolet light, 25 second exposure at f9, Royal Pan Film, Tiffin Yellow No. 2 filter. Next, severul of the porosity indications were examined at $200 x$ under a lirht microscope (Unitron 'IMD 3370) and the diameters of the pores were masured. The measured diameters are listed in Trable 83. The diameter of those pores which were detectable by penetrant inspection varied from 0.0025 to 0.016 Inch. As can be seen in View $B$ of Figure 1.10\%, several of the pores had considerable depth. At a masnification of $200 x$, the depth was measiured to vary from 0.033 to 0.106 inch long. 


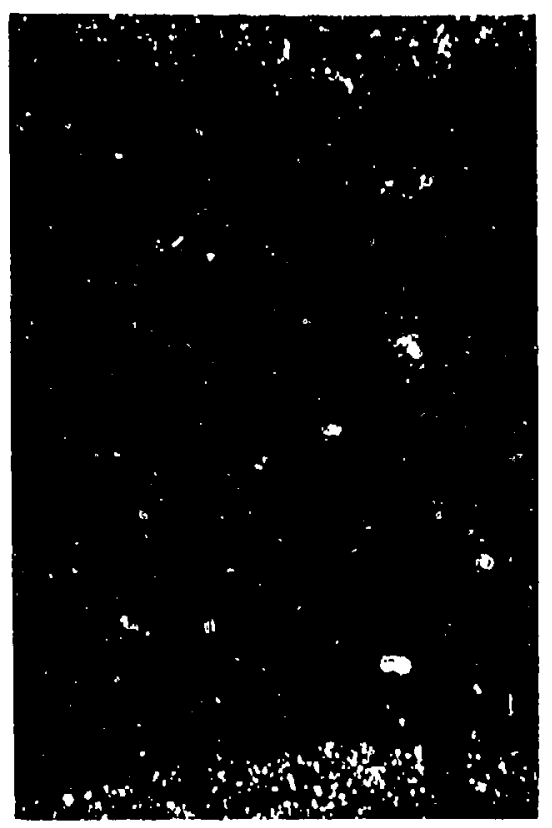

$\mathrm{S} / \mathrm{N} 4$

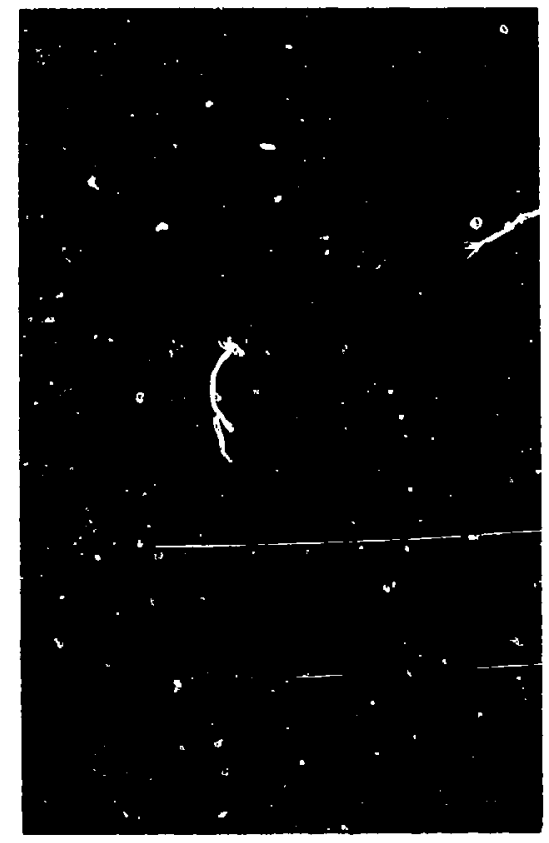

S/N5

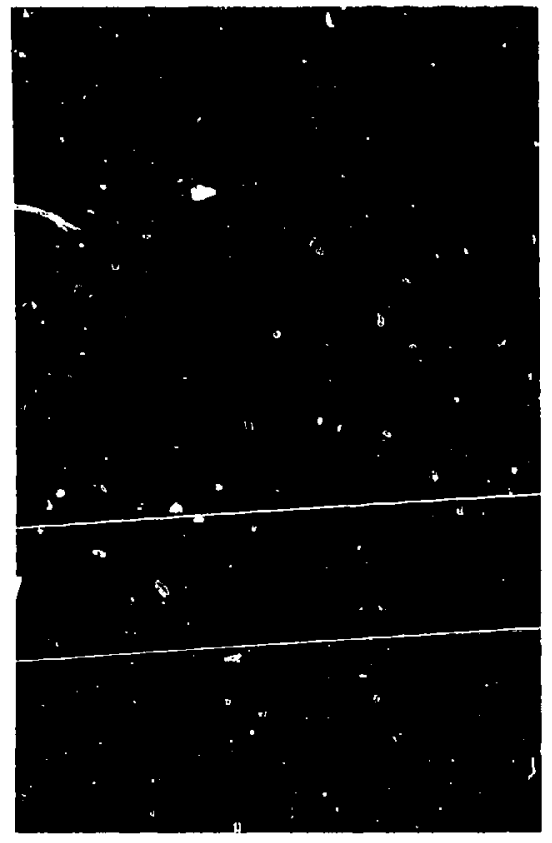

$\mathrm{S} / \mathrm{N} 6$

TIGURE 168

(GP740117230

PENETRANT INDICATIONS OF POROSITY

TABLE 83

POROSITY DIAMETERS

\begin{tabular}{|c|c|c|c|c|c|}
\hline Specimen & Porosity Diameter (in.) & Specinien & Porosity Diameter (in.) & Specimen & Porosity Diameter (in.) \\
\hline \multirow{6}{*}{ S/N4 } & 0.0025 & & 0.0045 & & 0.0025 \\
& 0.003 & & 0.005 & & 0.0043 \\
& 0.005 & & 0.005 & & 0.0045 \\
& 0.006 & & 0.005 & & 0.0045 \\
& 0.006 & S/N5 & 0.006 & S/N6 & 0.0045 \\
& 0.0065 & & 0.007 & & 0.0045 \\
& 0.012 & & 0.009 & & 0.008 \\
& 0.013 & & & & 0.008 \\
& 0.016 & & & & 0.009 \\
\hline
\end{tabular}

(1) 14011$)$ 11 


\section{INTERNAL CRACKS}

\section{a. Specimen Fabrication}

Each specimen was fabricated by initially cutting $2 \times 5$ inch blanks from 1 inch thick Ti-6AI-4V plate and grinding the $2 \times 5$ inch face on each to a $16 \mathrm{rms}$ finish. Rectangular EDM slous were then located on the ground $2 \times 5$ inch faces with the long dinension of the slot jarailel. to the 2 inch dimension. The slots serve as crack initiation sites and varied from .005 deep $\times .015$ long to .010 deep $x .100$ long depending upon the size of the crack desired. A fatigue crack was generated f'rom each EDM slot by fatiguing in 3 point bending with 67,000 psi stress at the block surface. The crack growth was monitored optically and was cuintiolied to the desired length. Next, the FDM slot was removed by grinding, leaving only the fatigue craci. The length of the fatigue crack was again mescurea at nigh magnification. A cap, $1 \times 2 \times 5$ inches, was mated to tho cracked specimen and the two were diffusion bonded together (see Figure 109). Prior to diffusion bonding, the ground face of each block wos etched to clean the mating surlaces in preparation for bonding. The two blocks were initially joined by electron beam welding in a vacuum as shown in Figure 109. The crucked block and the cap were diffusion bonded together in a vacuum at 1710-174 F for approximately $?$ hour under a load chat was s.lowly increased from zero to approximateiy 2.5 tons. Die blocks were used to restrict the reduction in thickness to .060 inch.

A list of the specinens with the crock Jentihs prior to bonding is presented in T'uble $8 l_{4}$.

TABLE 84

CRACK LENGTHS BEFORE BONDING IN INTERNALLY CRACKED SPECIMENS

\begin{tabular}{|l|ll|c|}
\hline Specimen & Elox Size (in.) & $\begin{array}{c}\text { Crack Length } \\
\text { (in.) }\end{array}$ \\
\hline$A 1$ & 0.030 Decp $\times 0.100$ Long & 0.231 \\
$A 4$ & 0.010 & $\times 0.030$ & 0.059 \\
$A 6$ & 0.008 & $\times 0.020$ & 0.032 \\
$A 8$ & 0.025 & $\times 0.080$ & 0.123 \\
$A 11$ & 0.030 & $\times 0.100$ & 0.505 \\
$A 14$ & 0.030 & $\times 0.100$ & 0.368 \\
26 & 0.005 & $\times 0.015$ & 0.020 \\
27 & 1.010 & $\times 0.030$ & 0.048 \\
7 & 0.010 & $\times 0.030$ & 0.054 \\
8 & 0.010 & $\times 0.030$ & 0.050 \\
10 & 0.010 & $\times 0.030$ & 0.055 \\
11 & 0.010 & $\times 0.060$ & 0.104 \\
13 & 0.010 & $\times 0.060$ & 0.124 \\
\hline
\end{tabular}

\begin{tabular}{|c|cc|c|}
\hline Specimen & Elox Size (i i.) & $\begin{array}{c}\text { Crack Length } \\
\text { (in.) }\end{array}$ \\
\hline 12 & 0.010 Deep $\times 0.060$ Lorrg & 0.12 \\
14 & 0.010 & $\times 0.060$ & 0.114 \\
28 & 0.010 & $: 0.060$ & 0.108 \\
16 & 0.010 & $\times 0.100$ & 0.286 \\
17 & 0.010 & $\times 0.100$ & 0.281 \\
18 & 0.010 & $\times 0.100$ & 0.269 \\
29 & 0.010 & $\times 0.109$ & 0.268 \\
20 & 0.010 & $\times 0.100$ & 0.285 \\
21 & 0.010 & $\times 0.100$ & 0.536 \\
22 & 0.010 & $\times 0.100$ & 0.561 \\
24 & 0.010 & $\times 0.100$ & 0.632 \\
27 & 0.010 & $\times 0.100$ & 0.598 \\
& & & \\
\hline
\end{tabular}




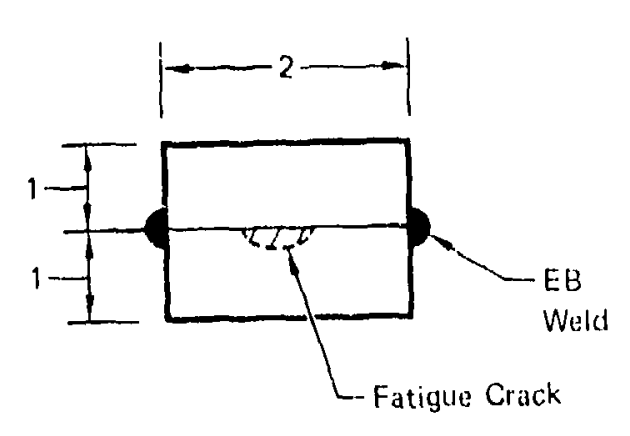

EB Welding Prior to Bondung

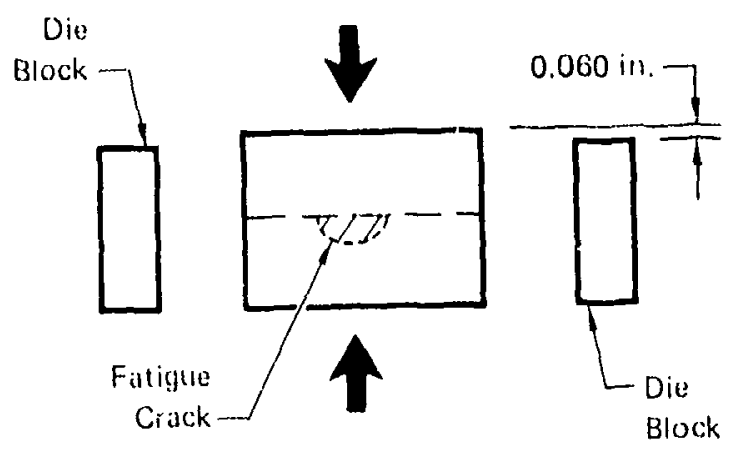

Diffusion Bonding

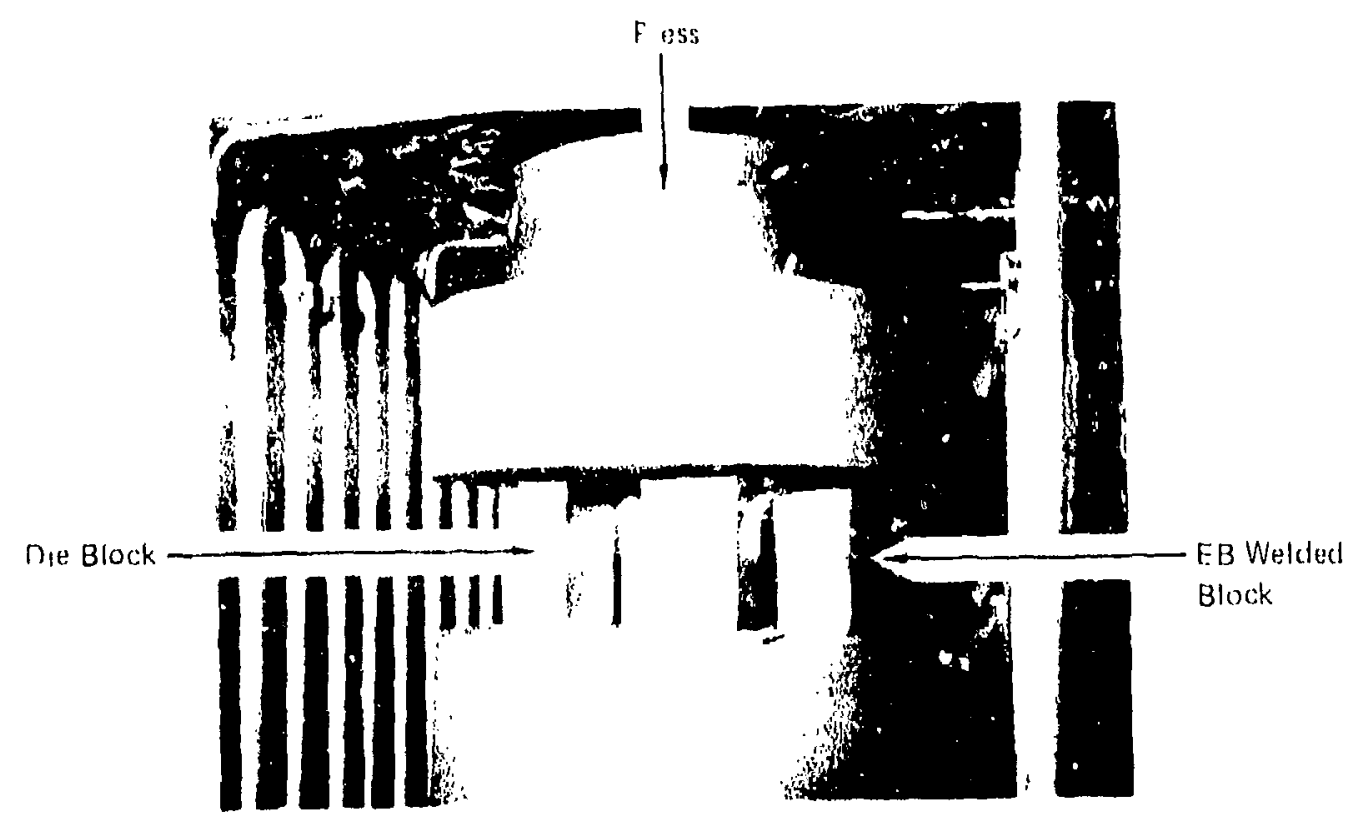

Photograph of Diffusion Bonding Set-Up

FIGURE 109

DIFFUSION BONDING OF INTERNALLY CRACKED SPECIMENS 


\section{b. Ultrasonic Testing}

The specimens containing internal cracks were subjected to the test program summarized in Table 85. Initially, Specimen Numbers Al, A4, $A 6, A 8, A I 7$, and AI 4 were along with 3 uncracked dumy specimens immersion angle beam and immersion straight beam inspected by General Electric in their laboratory. A $3 / 4$ inch diameter focused lithium sulfate $15 \mathrm{MHz}$ search unit with a focal length of approximately 7 inches in water was used. A Branson 600 ultrasonic instrument was used to pulse the search unit at a frequency of $5 \mathrm{MHz}$. The water path was 6 inches and the scan index was $1 / 8$ inch. For the angle beam inspection a sound beam angle of 45 degrees in the metal was used. The scanning was manilal using a scan index or" .090 inch.

An evaluation was made of the difference in sound transmission characteristics between the reference standard and a representative test specimen by monitoring vack surface reflections. Since the gain setting at a particular amplitude in the reference standard was within 30 percent of the same amplitude back reflection in the test speciman, no correction was made during the actual testing.

The first series of tests were performed at a scanning gain established with the Ti-6Al-4V reference standard shown in Figure 110 . The search unit was adjusted such that the responses from the side drilled holes at $3 / 8$ and $1-1 / 2$ inch metal travels were equal. Next, these responses were acjusted to 80 percent of saturation and the test specimens were scanned at that gain level. The amplitude of all discontinities at that scanning gain were recorded. The sound beam angles for the various tests at that scanning gain are shown in Figure 111.

A second series of tests were performed by adding 12 d.B of ge.in to the original gain level. For each discontinuity found, the search unit was manipulated to maximize the response and the signal ampititude was recorded. The results of the testing is shown in Table E6. Only Angle Beam l'est No. 1 was successful among the angle beam tests in detecting cracks. This probably indicates, that, for the other tests, the cracks were not oriented favorably with respect to the sound beam such that the sound was not reflected back to the receiving search unit.

In addition, the straight beam testing was successful in detecting three of the cracks. 'The response from several of the cracks was relatively small. For example, the amplitude of the response from the .123 inch long crack was 15 percent of saturation with the straight beam test. Such smal1 responses may result in acceptabjiljty of production parts, dependine upon the acceptance criteria used. One explanation for the small response from such a relatively large crack is that, during the fabrication of the specimens, partial healing of the crack may have occurred during diffusion bonding and the actual crack length may be less than the expected crack length. There were no false indications recorded during the inspections. It should be pointed out that the small amplitudes recorded in Table 86 are approximations since it is not possible to accurately measure such small amplitudes from the CRT screen. 
TABLE 85

SUMMARY OF ULTRASONIC TESTING OF INTERNAL'-Y CRACKED SPECIMENS

\begin{tabular}{|c|c|}
\hline $\begin{array}{c}\text { Testing } \\
\text { Group }\end{array}$ & \multicolumn{1}{c|}{ Test Method } \\
\hline Jet Engine & $\begin{array}{l}\text { Lab - Straight Beam Immersion } \\
\text { Lab - Angle Beam Immersion } \\
\text { Production - Straight Beam Immersion } \\
\text { Production - Angle Beam Immersion }\end{array}$ \\
\hline $\begin{array}{l}\text { Air Force Materials } \\
\text { Laboratory }\end{array}$ & Lab - Angle Beam Immersion \\
\hline Airframe & $\begin{array}{l}\text { Lab - Straight Beam Immersion } \\
\text { Lab - Straight Beam Contact }\end{array}$ \\
\hline
\end{tabular}

OP/A 01/150

TARIEE 20

ENGINE ULTRASONIC INSPECTION (LABORATORY) RESULTS FOR INTERNAL CRACKS

\begin{tabular}{|c|c|c|c|c|c|}
\hline \multirow{3}{*}{$\begin{array}{c}\text { Specimen } \\
\text { No. }\end{array}$} & \multirow{3}{*}{$\begin{array}{c}\text { Crack } \\
\text { Length } \\
\text { (in.) } \\
4\end{array}$} & \multicolumn{4}{|c|}{ Amplitude of Response (\% of Saturation) } \\
\hline & & \multicolumn{2}{|c|}{$\begin{array}{l}\text { Straight Beam } \\
\text { Test No. } 1\end{array}$} & \multicolumn{2}{|c|}{$\begin{array}{l}\text { Angle Beam } \\
\text { Test No. } 1\end{array}$} \\
\hline & & 1 & 2 & 1 & 2 \\
\hline A1 & 0.231 & No Response & No $R_{1}$ sponse & No Response & 3 \\
\hline A4 & 0.059 & No Response & No Resp onse & No Response & No Response \\
\hline A6 & 0.032 & No Response & No Respori.e & No Response & No Response \\
\hline$A B$ & 0.123 & $15 \%$ & $60 \%$ & 3 & $21 \%$ \\
\hline A11 & 0.505 & $23 \%$ & $100 \%$ & $40 \%$ & $100 \%$ \\
\hline. .14 & 0.368 & $45 \%$ & $100 \%$ & $65 \%$ & $100 \%$ \\
\hline
\end{tabular}

1. Scanning gain was establishod by setting the ininimum resworiso to $80 \%$ of full saturation.

A Scanning gain was astablighed as above excont $12 \mathrm{~dB}$ was addad.

(3) Response vas too small to bo measurect.

A. Actual irack langth may bo less than shown due to

GPI4 $011 ;$ : partial healing during diffusion bonding 


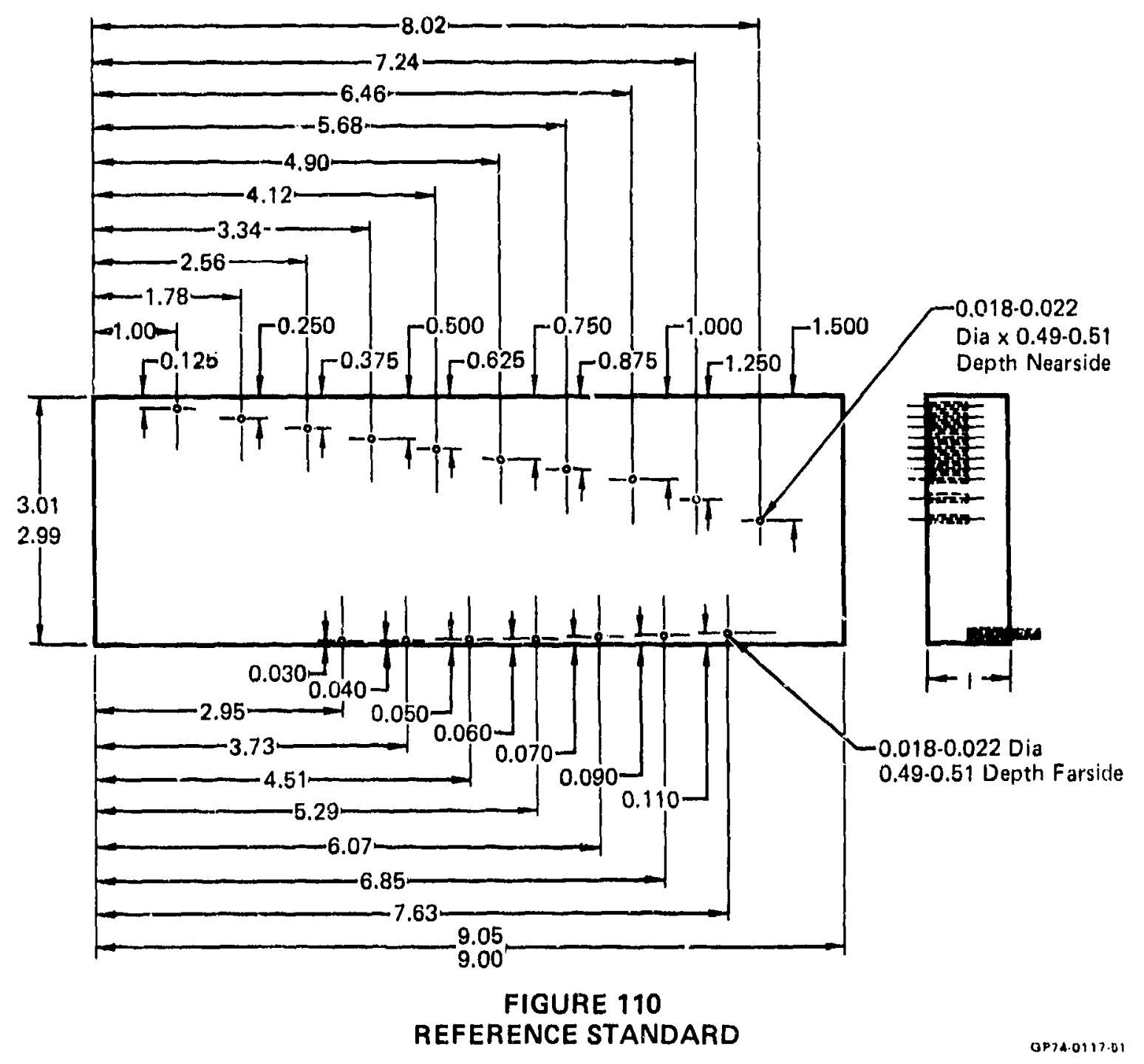



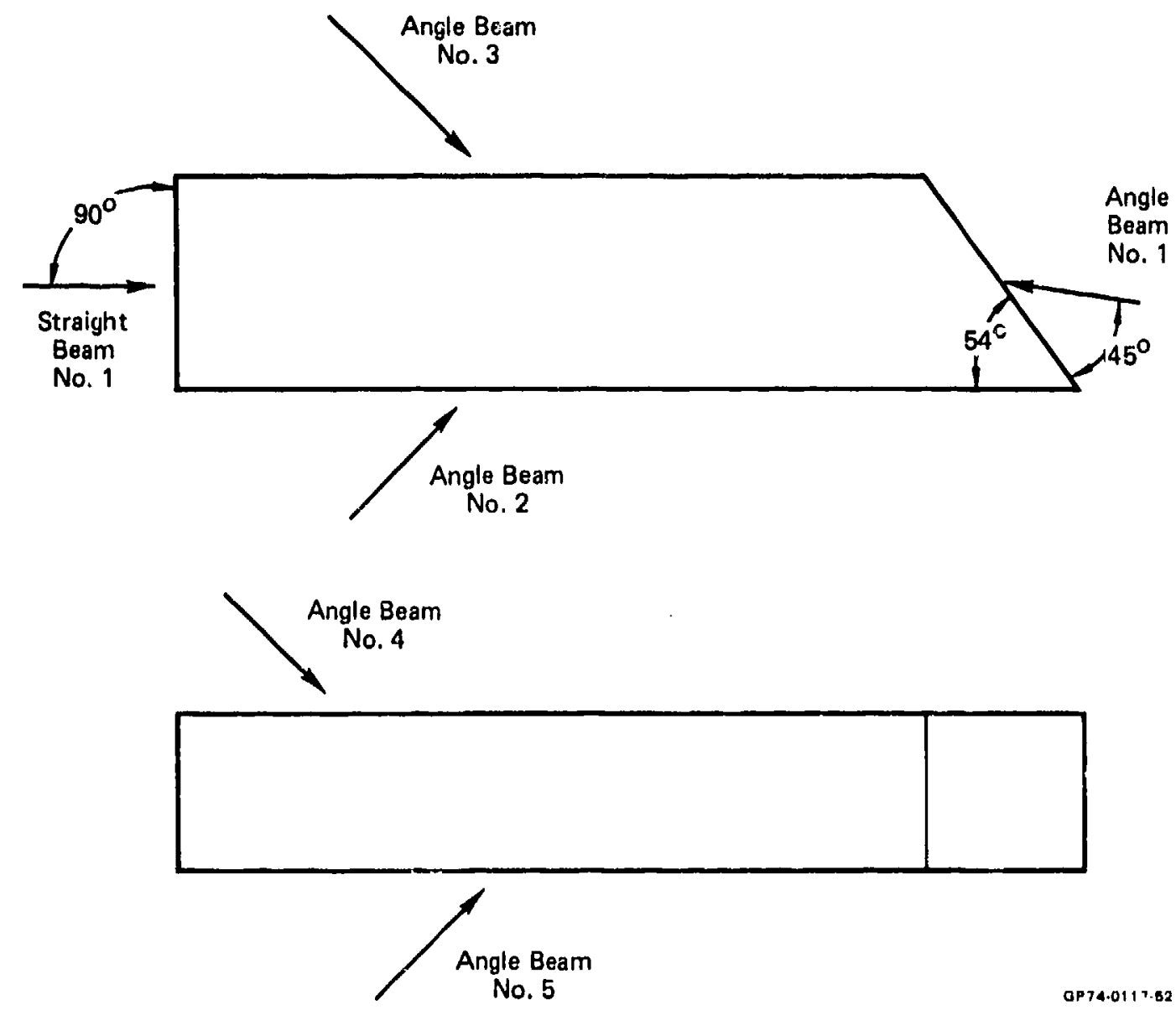

FIGURE 111

SOUND BEAM ANGLE FOR GE LABORATORY INSPECTION OF INTERNAL CRACKS 
Following the laboratory inspection of the internal cracks, production ultrasonic inspections were made on the 6 cracked specimens and the 3 uncracked specimens using the normal production inspection f'acilities and personnel. The sound beam directions were the same as for the laboratory insfections. Each specimen was inspected 3 times by each of 3 inspections. The results of the testing was shown in Tables 87 and 88 . of the angle: beam tests, only Angle Beam No. 1 was successful.

In some cases, there was a large variation in response amplitude as recorded from one test to another for the same inspector. For example, for specimen Al 4 which has an original crack length of .368 inch. Inspector A recorded response amplitudes of $12 \%, 78 \%$ and $100 \%$ of saturation in 3 tests. In other cases, however, the 3 response amplitudes were approximately the same. As with the laboratory inspections, there were no false indications recorded.

For comparison purposes, the 6 cracked specimens and the 3 uricracked dumny specimens were ultrasonically inspected at the Air Force Materials Laboratory. A $1 / 2$ inch diameter, lead zirconate titanate, $7 \mathrm{MHz}$ search unit was used. This search unit was focused and had a focal length in water of approximately 6 to 9 inches. The test frequency was $5 \mathrm{MHz}$ and a Branson 600 ultrasonic instrument was used. The water path was 2-1/2 inches and the scan index was $0.020-0.040$ inches. The inspection procedure and reference standard was the same as used by the engine manufacturer. T'wo independent inspectors were used. A summary of the results is in Table 89. Of the angle beam tests, orily Angle Beam No. I wa successful. 
TABLE 87

RESULTS OF ENGINE PRODUCTION STRAIGHT BEAM IMMERSION TESTS $\_$

\begin{tabular}{|c|c|c|c|c|c|c|c|c|c|c|}
\hline \multirow{3}{*}{ Specimen } & \multirow{3}{*}{$\begin{array}{c}\text { Crack } \\
\text { Longth } \\
\text { (in.) }\end{array}$} & \multicolumn{9}{|c|}{ Response Amplitude ( $\%$ of Saturation) } \\
\hline & & \multicolumn{3}{|c|}{ Inspector A } & \multicolumn{3}{|c|}{ Inspector B } & \multicolumn{3}{|c|}{ Inspector C } \\
\hline & & 1 & 2 & 3 & 1 & 2 & 3 & 1 & 2 & 3 \\
\hline$A 6$ & 0.032 & - & - & - & - & - & - & - & - & - \\
\hline A4 & 0.059 & - & - & - & - & - & - & - & - & - \\
\hline$A 8$ & 0.123 & 15 & 12 & 8 & 8 & 5 & 8 & 12 & 12 & 10 \\
\hline A1 & 0.231 & - & - & - & - & - & - & - & - & - \\
\hline A14 & 0.368 & 12 & Sat. & 78 & Sat. & 18 & 50 & 35 & 30 & 32 \\
\hline A11 & 0.505 & 18 & 40 & 60 & 8 & 15 & 23 & 25 & 35 & 35 \\
\hline
\end{tabular}

1. Scanning gain wos established by sutting the minimum

\begin{tabular}{|c|c|c|c|c|c|c|c|c|c|c|}
\hline \multirow{3}{*}{ Specimen } & \multirow{3}{*}{$\begin{array}{c}\text { Crack } \\
\text { Length } \\
\text { (in.) }\end{array}$} & \multicolumn{9}{|c|}{ Pesponse Amplitude (\% of Saturation) } \\
\hline & & \multicolumn{3}{|c|}{ Inspector A } & \multicolumn{3}{|c|}{ Inspector B } & \multicolumn{3}{|c|}{ Inspector C } \\
\hline & & 1 & 2 & 3 & 1 & 2 & 3 & 1 & 2 & 3 \\
\hline A6 & 0.032 & & & & & & & & & \\
\hline A4 & 0.059 & & & & & & & & & \\
\hline$A 8$ & $0.1 \div 3$ & 65 & 65 & 35 & 48 & 43 & 45 & 60 & 65 & 60 \\
\hline A1 & 0.231 & & & & & & & & & \\
\hline A14 & 0.368 & 59 & Sat. & Sat. & Sat. & 80 & Sat. & Sat. & Sat. & 95 \\
\hline A11 & 0.505 & 75 & Sat. & Sat. & 37 & 70 & Sat. & 90 & Sat. & Sat. \\
\hline
\end{tabular}

Scanning gain was astablished by setting the minimum response to $80 \%$

of saturation and sub racting $12 \mathrm{~dB}$ of attenuation. 
TABLE 88

RESULTS OF ENGINE IMMERSION ANGLE BEAM TESTS $\uparrow$

\begin{tabular}{|c|c|c|c|c|c|c|c|c|c|c|}
\hline \multirow{3}{*}{ Specimen } & \multirow{3}{*}{$\begin{array}{c}\text { Crack } \\
\text { Length } \\
\text { (in.) }\end{array}$} & \multicolumn{9}{|c|}{ Response Amplitude (\% of Saturation) } \\
\hline & & \multicolumn{3}{|c|}{ Inspestor A } & \multicolumn{3}{|c|}{ Inspector B } & \multicolumn{3}{|c|}{ Inspector C } \\
\hline & & 1 & 2 & 3 & 1 & 2 & 3 & 1 & 2 & 3 \\
\hline$A 6$ & 0.032 & & & & & & & & & \\
\hline A4 & 0.059 & & & & & & & & & \\
\hline$A B$ & 0.123 & 10 & 10 & 12 & 5 & 9 & 5 & 5 & 12 & 13 \\
\hline A1 & 0.231 & & & & & . & & & & \\
\hline $\mathrm{A} 14$ & 0.368 & 61 & 46 & 60 & 57 & 62 & 10 & Sat. & Sat. & Sat. \\
\hline A11 & 0.505 & 25 & 30 & 30 & 33 & 47 & 60 & 72 & 70 & 75 \\
\hline
\end{tabular}

\begin{tabular}{|c|c|c|c|c|c|c|c|c|c|c|}
\hline \multirow{3}{*}{ Specimen } & \multirow{3}{*}{$\begin{array}{c}\text { Crack } \\
\text { Length } \\
\text { (in.) }\end{array}$} & \multicolumn{9}{|c|}{ Response Amplitude (\% of Saturation) } \\
\hline & & \multicolumn{3}{|c|}{ Inspector A } & \multicolumn{3}{|c|}{ Inspector B } & \multicolumn{3}{|c|}{ Inspector C } \\
\hline & & 1 & 2 & 3 & 1 & 2 & 3 & 1 & 2 & 3 \\
\hline A6 & 0.032 & & & & & & & & & \\
\hline A4 & 0.059 & & & & & & & & & \\
\hline A8 & 0.123 & 47 & 55 & 62 & 35 & 50 & 28 & 30 & 65 & 65 \\
\hline A1 & 0.231 & & & & & & & & & \\
\hline A14 & 0.363 & Sat. & Sat. & Sat. & Sat. & Sat. & 40 & Sat. & Sat. & Sat. \\
\hline A 11 & 0.505 & Sat. & Sat. & Sat. & Sat. & Sat. & Sat. & Sat. & Sat. & Sat. \\
\hline
\end{tabular}

(1) Scanning gain was detablishod by adjusting the minimum response to $80 \%$ of saturation and subtracting $12 \mathrm{~dB}$ of attenuation. 
TABLE 89

RESULTS OF AFML LABORATORY ULTRASONIC :NISPECTIONS

\begin{tabular}{|l|c|c|c|c|c|}
\hline \multirow{2}{*}{ Specimen } & \multirow{3}{*}{$\begin{array}{c}\text { Crack } \\
\text { iength } \\
\text { (in.) }\end{array}$} & & \multicolumn{4}{|c|}{ Response Amplitude (\% of Saturation) } \\
\cline { 3 - 6 } & & \multicolumn{2}{|c|}{ Inspector 1 } & \multicolumn{2}{|c|}{ Angle Beam } \\
\cline { 3 - 6 } & & Inspector 2 \\
\hline A6 & 0.032 & 0 & 0 & 0 & 0 \\
A4 & 0.059 & 0 & 0 & 0 & 0 \\
A8 & 0.123 & 0 & 50 & 0 & 70 \\
A1 & 0.231 & 0 & 0 & 0 & 0 \\
A14 & 0.368 & 63 & Saturation & 32 & Saturation \\
A11 & 0.505 & 48 & Saturation & 20 & 80 \\
\hline
\end{tabular}

1) Scanning gain was established by setting the minlmum response to $80 \%$ of saturation. 2. Scanning gain was astablished by setting the minlmum response to $80 \%$ of seturation
and subtracting 12 dB of attenuation. 
A11 the specimens listed in Table 84 were straight beam immersion inspected in the laboratory at the airframe manufacturer. A flat $3 / 4$ inch diameter, $5 \mathrm{MHz} S I$ 'z search unit ( $\mathrm{S} / \mathrm{N}$ 21269) was used in conjunction with a Branson 600 ultrasonic instrument and a 623Ts pulse/receiver. A 3 inch water path was used and this water path was maintainec to $\pm 1 / 8$ inch between the reference standards and the test parts, th $\geqslant$ reference standards used were typical ASTM-type standards with $3 / 64$ inch diameter flat bottom holes as reflectors. The reference standard material was Ti-6Al- 45 . $\mathrm{Ar}_{\mathrm{r}}$ adjustment was made for the difference in sound tras.smission characteristics between the reference standard and the test pit?e by comparing the $\mathrm{AB}$ difference in back reflection through the 5 inches of metal in the test specimen and through the 5 inch metal travel reference standard. It; was found that the difference was $1 \mathrm{CB}$ per inch of metal travel. Next, the metal travel of each reference standard was multiplied by 1 aB per inch in order to arrive at the required correction factors. Next, the 3.64 inch diameter flat bottom hole in the reference standard exhibiti:1g the maximum response in the set was adjusted to $80 \%$ of saturation. The responses from the other reference standards were mathematical. Iy adjusted using the correction factors and marked on the CRT screen to form a DAC curve. For scanning purposes, an additional $6 \mathrm{~dB}$ of attenuation was subtracted for greater sensitivity.

The scan index used was $0.25 \mathrm{inch}$. The scan index was shecked on the reference standard to determine that at the extreme ends of the scan index, the response was greater than 50 percent of the maximum response from the 3/64 inch diameter flat bottom hole in the relerence standurd at a 3 inch metal travel. Each test part was manually scanned as shown in Figure 112. For all discontinuities with amplitude greater than $50 \%$ of the DAC, the search unit was manipulated to maxinize the response, the scanning gain was reduced by $6 \mathrm{~dB}$ and the amplitude was recorded as a percentage of the DAC curve height. In a normal production inspection, only those discontinuities whose amplitude equalled or exceeded the DAC curve woulu be rejected.

The results of the laboratory inspection is shown in Table 90 . Photographs of typical cathode ray tube presentations are shown in Figurs 113. As had occurred in some ol the previous testing, there were cases where the ultrasonic response versus crack length bofnre bonding did not follow the xpected pattern. For example, in Specimen 9 the response was 50\% of the DAC and in Specimen 12 the response was $20 \%$ of the DAC, even thour ${ }^{1}$ the crack length prior to bonding was twice that in Specimen 9. This could occur if partial healing of the cracks took place during diffusion sonding. Subsequent destructive analysis of the cracks in Specimen Number: : $: A 1$, and $A 4$ failed to reveal any eridence that the cracks survived At $\therefore$ ' ision bonding peration. The smallest crack detected during the toritiaj nad a crack length prior to bonding of .048 inch (Specimen 27).

Following the straight beam imnersion tests, a laboratory straight beam contact test was performed upon each specimen. A $3 / 4$ inch diameter, $5 \mathrm{MIz}$, SFZ search unit (S/N 1.2356 ) was used along, with a Branson 600 instrument. The specimens were checked for difference in sound transmission characteristics from the reference standards as before. The ditference was small enouph to ifnore. The specimens were scanned with the 


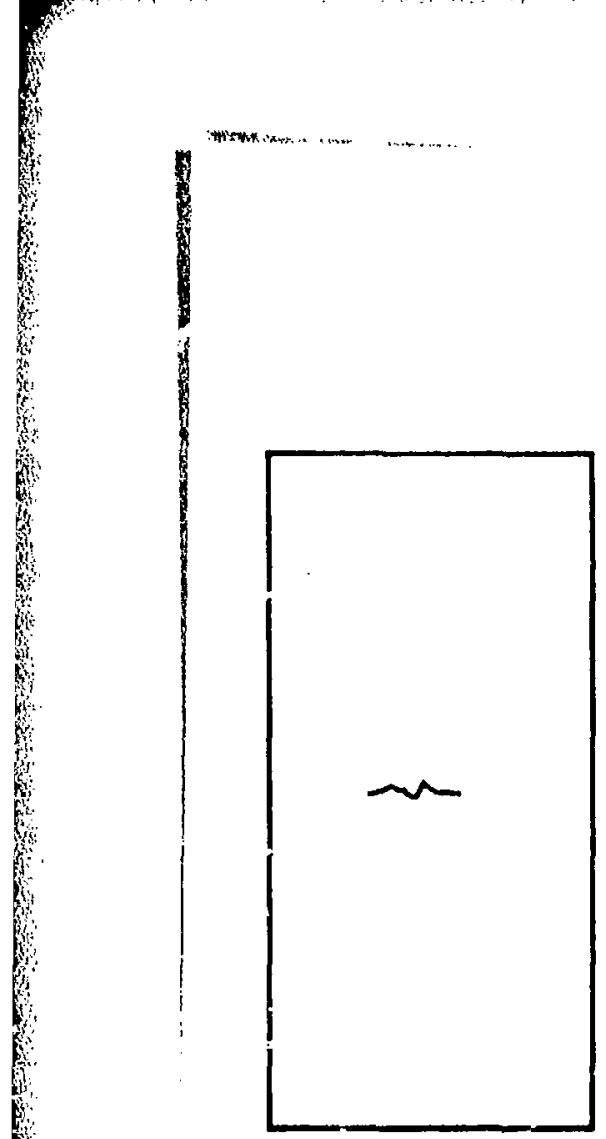

Type A Specimen

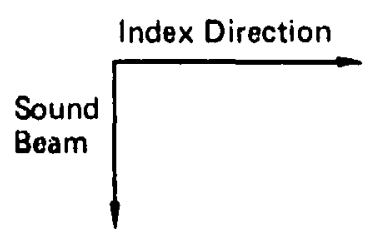

Type B Specimen

FIGURE 112

SETUP FOR STRAIGHT BEAM IMMERSION TESTING OF INTERNALLY CRACKED SPECIMENS

279 
TABLE 90

ULTRASONIC INSPECTION RESULTS (AIRFRAME) FOR INTERNAL CRACKS

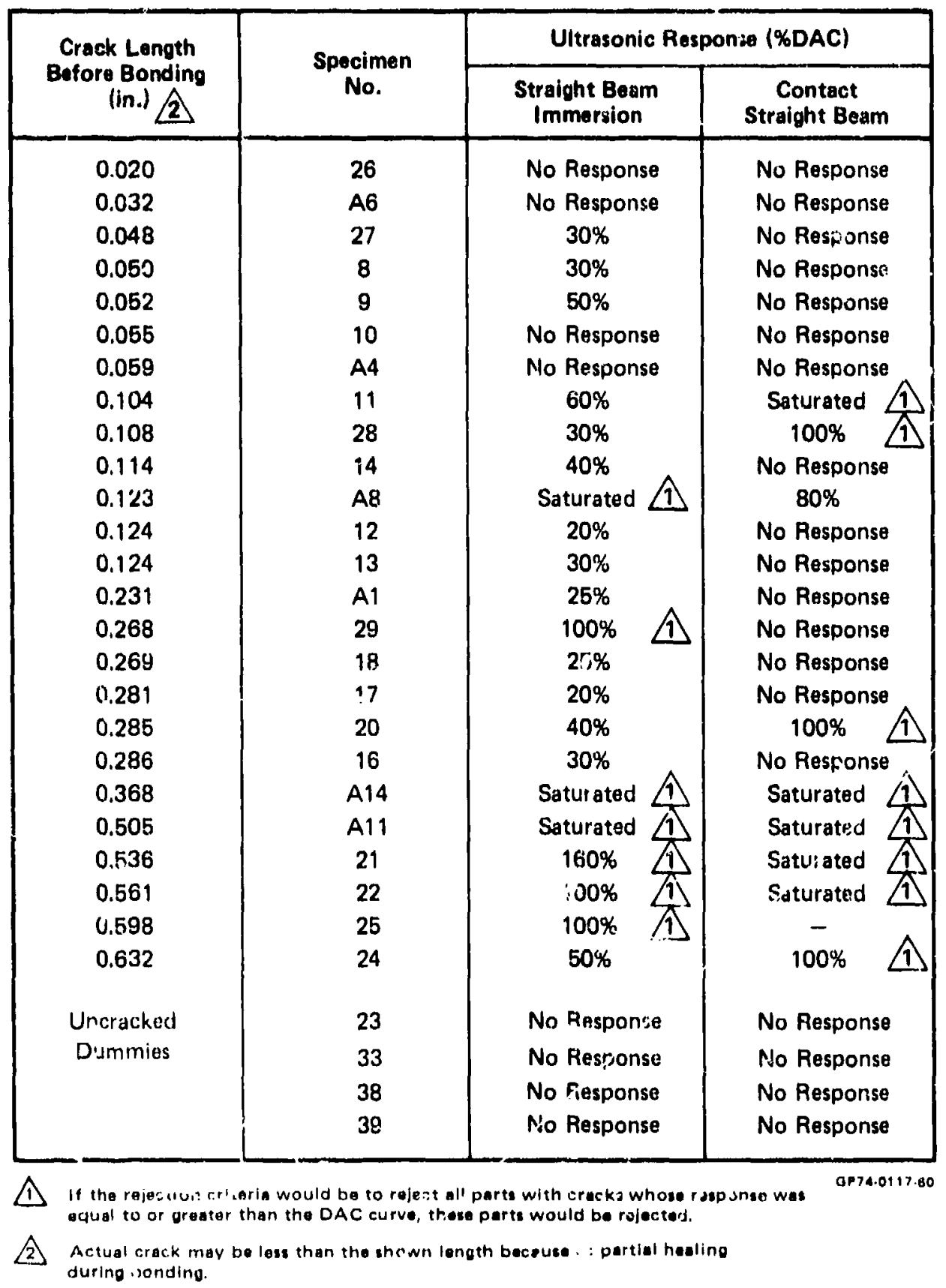




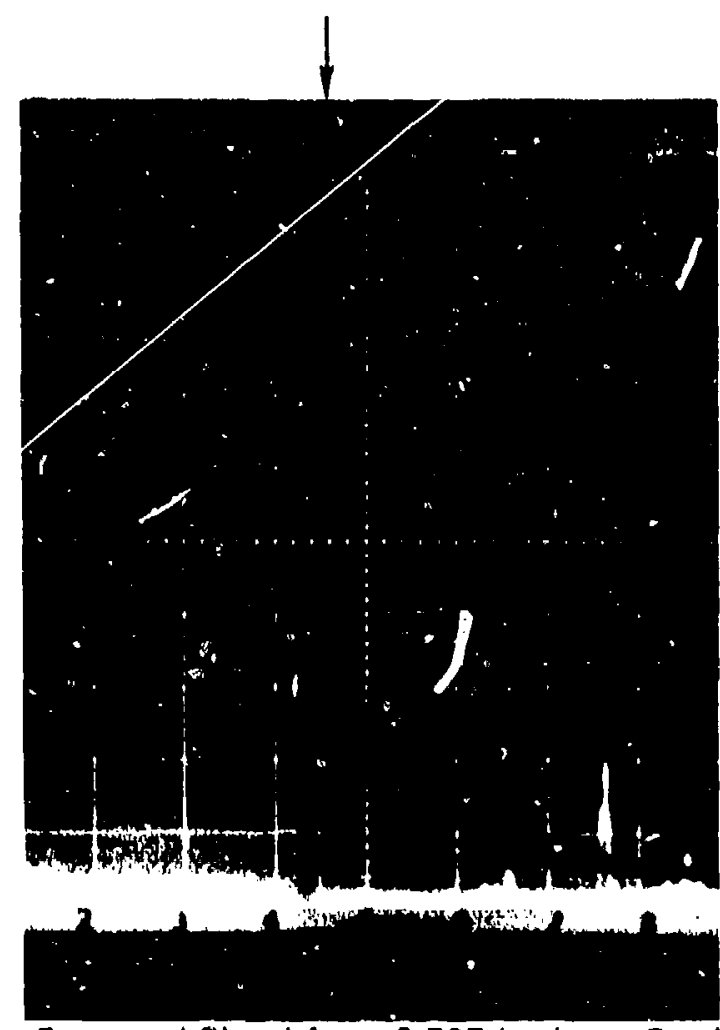

Saturated Signal from $0.505 \mathrm{In}$. Long Crack (Specimen A11)

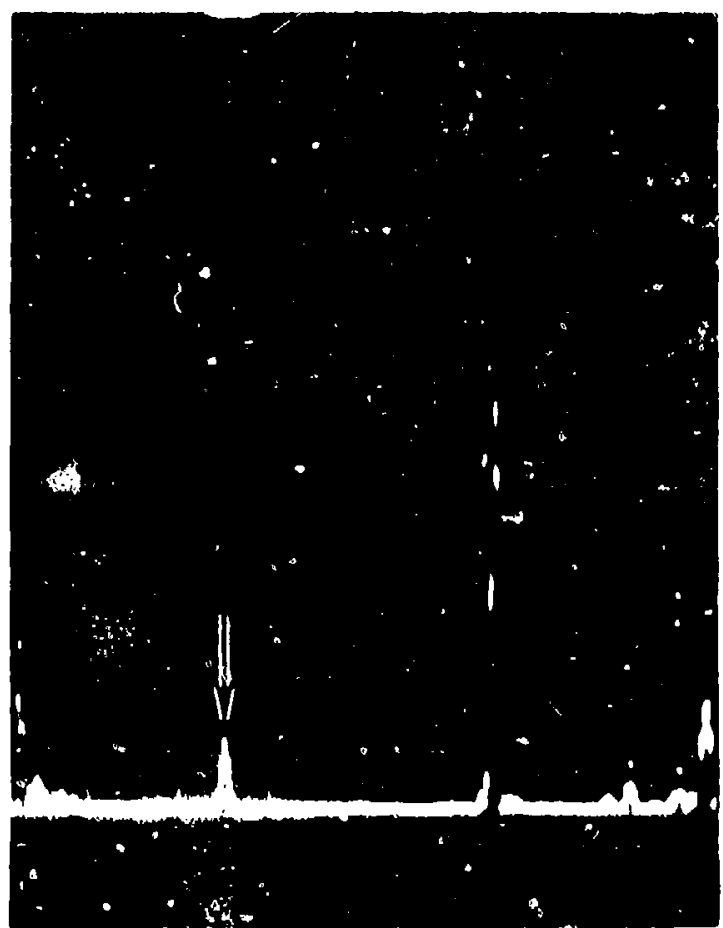

Signal trom $0.23 \mathrm{In}$. Long Crack in Specimen A 1 (Signal is $25 \%$ of DAC Curve)

FIGURE 113

TYPICAL RESPONSES FROM INTERNAI CRACKS DURING STRAIGHT BEAM IMMERSION TESTS 
sound beam direction the same as in the immersion tests. The couplant was "Lubriplate" grease. The results of the testing is shown in Table 90. As can be seen, the contact tests were not as effective as the immersion tests for detecting the cracks. Eleven cracks detected by the immersion method were not detected by the contact method. These cracks ranged in length (prior to diffusion bonding) from .048 to .286 inches. Of course, the present length of these cracks may be less than the length pitor to bonding.

\section{c. Veriftcation of Internal Crack Size}

I'wo of the internal cracks used in the norgram were intentionally exposed in order to measure their actual size. Saw cuts were tade adjacent to the cracks and the specimens were intentionally failed $1 ; \%$ overload. The fracture surfaces were examined and the actual length and depth of each fatigue crack was measured. The measured crack dimensions are recorded below and representative photographs appear in Figure 114.

\begin{tabular}{cccc}
$\begin{array}{c}\text { Specimen } \\
\text { ivo }\end{array}$ & $\begin{array}{c}\text { Target } \\
\text { Crack Length } \\
\text { (Inches) }\end{array}$ & $\begin{array}{c}\text { Actual } \\
\text { Length } \\
\text { (Inches) }\end{array}$ & $\begin{array}{c}\text { Actual } \\
\text { Depth } \\
\text { (Inches) }\end{array}$ \\
\cline { 2 - 3 } & $\begin{array}{c}.285 \\
20\end{array}$ & .376 & .075 \\
21 & .536 & .56 & .140
\end{tabular}

"Hroe other sircimons containine internal cracks were cross sectioned and examined metallographically to locate the cracks. These specimens, Numbers $12, \mathrm{Al}$, and $\mathrm{A} 4$, were selected because the ultrasonic response from the cracks were quite low or zero and it was desired to letermine if partlal healing of the cracks had occurred during diffusion bonline. litch cross section was polished several times and there was no evidence of crucks in any of the cross sections. Based on this, it aprear's that these cracks either partially or totally healed during dif'fusion bonding which explains the lack of significant ultrasonic response from these specimene. 


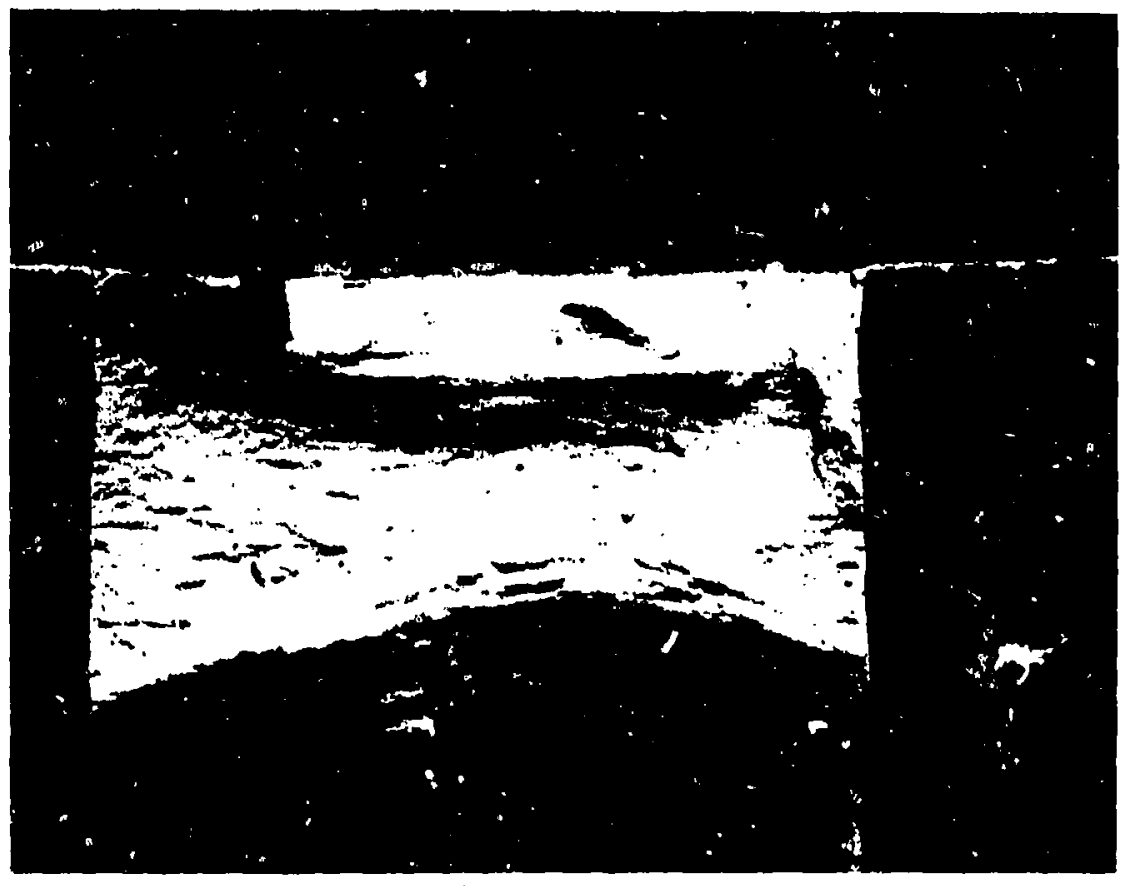

Specimen 20

$4 x$

$0.37 \mathrm{ln}$. Long $\times 0.075 \mathrm{ln}$. Deep

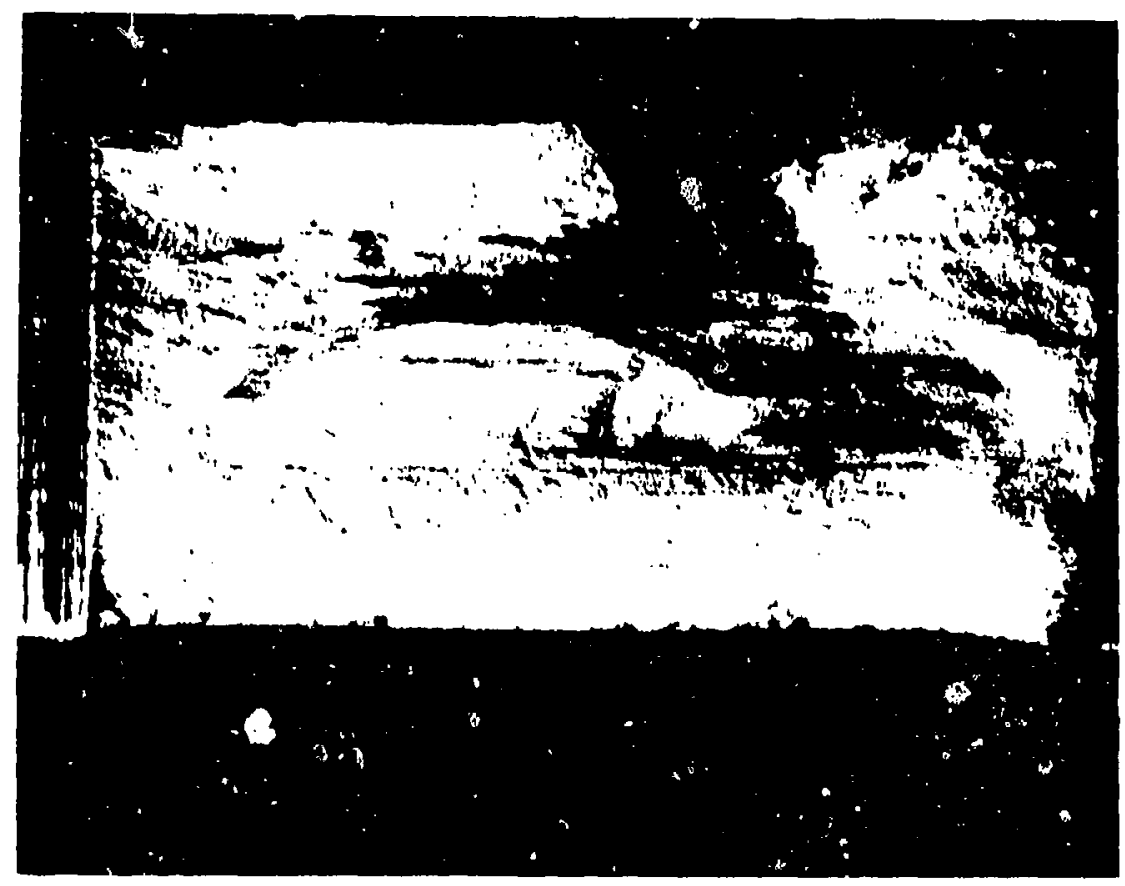

Specimen 21

$4 \times$

0.56 In. Long $\times 0.140$ In. Drep

FIGURE 114

PHC OGRAPHS OF FRACTURE SURFACE OF INTERNAL CRACKS 
4. SEGREGATES - JET ENGINE DISK FORGINGS

a. Radiographic Inspection

Disk forging No's 4, 5, and 6 from the ingot bottom and No's $\%, 8$, and 9 from the ingot top were inspected radiographically by the engine manufacturer. Production $X$-ray interpreters, qualified to MIL-SIL-453, - re used to interpret the film. 'The forgings had been machined to a 125 rms or better finish. liist, two exposures were made of each forging with a U.E. OX.-250 X-ray machine to examine the $23 / 4$ inch thick area. The parameters shown in lable 91 were used. MIL-STD-453 2 percent thickness titanjum penetrameters were used as image quality indi-. cators and were piaced on the source side of the forgings (see Figure 11.5). Hach exposure was made with the $x$.r.ay beam centered at the forging center. The film was processed meunully. The geometric insharpness was $.385 \mathrm{~mm}$. Fxamination of the GAF $100 \mathrm{f} i \mathrm{~lm}$ indicated that the $1 . T$ hole in the $1 \mathrm{~L} / 2$ ? inch penet dameter was visiule resulting in an. equivalent sarsitivity of 2.4 percent. When the GAF 100 and GAF 400 film wera placid bogether and examined, the l'l hole was visiole in the 1 1/: inch peretrameter. Tho overall f'ilm density was 2.4 to 2.6 H and D when the two flims were viewed together and 1.9 to 2.111 and $D$ where the GAr 400 film was viewed separmtels. For the NDT 55 film, the over... all. dersity was 2.3 to 2.5 If and 1 and the IT hole was visible. When these films were examined for evidence of discontinuities, the rim section was not examined. Two additional exposurt's vere made to examine? the rim section and the thin section in the center of the forging. (see lable $9 \mathrm{l}$ ). Agajn a G.E. OX-250 X-ray machine was used. One lnch titanium penetrameters were placei on the rim fo: lixposure 1. Exposurs 2 , made at a separate f'acility, was made wich $n 3$ inch titaniur penetrameter since a 1 inch penetrameter was not available. The overali. film density ranged from $1.5 \mathrm{H}$ and $\mathrm{L} \mathrm{at}^{\mathrm{t}}$, the $3 . j \mathrm{n}$ to 3.2 in the conter section for the GAF 400 Film and 1.9 in tho rim sectich for the NDI 5; film. The $2 \mathrm{~T}$ penetrameter hole was visjble on the car 400 film and the L'T hole was visible on the JD' 55 film resulting, in an equivalent sensitivity of 1.4 percent.

Finally, an exposure was made ol the entire forging using a vander.. eraf' in order to examine the entire forging on one raliograph. 'ilhe overali film density varied from 2.8 t, 3.1 . II and $D$ and the geometric unsharpness was $0.155 \mathrm{~mm}$.

There was no evidence of segretates discornible in any of the films.

Following the radiographic inspections, forging No's 4, 5, 8, and 9 were sent to the Air Force Materlals luboratory for radiographic inspection. One exposure was made of anch toritig with a Norelco

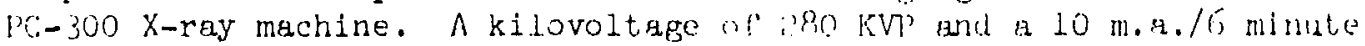
exposure were used. 'ihe film was Korluk $M$ and a . OlO inch thisk lead

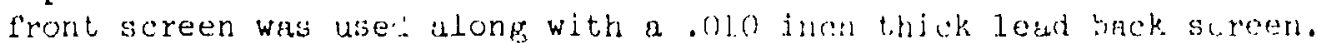
The source-to-film distance was 43 inches and the peometric unshapress

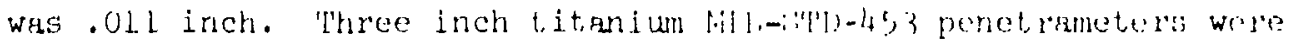

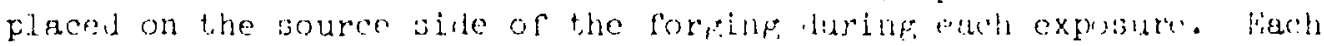




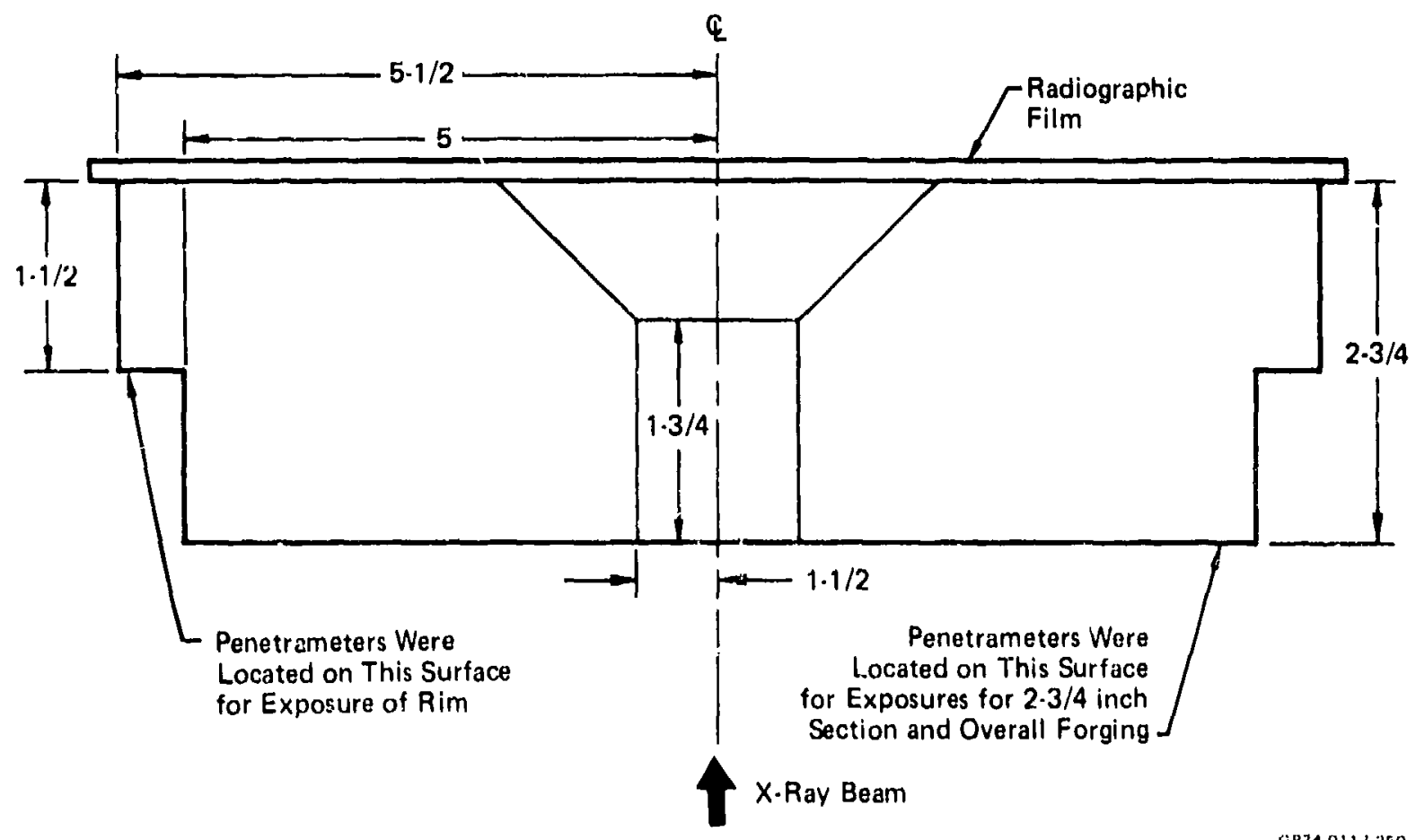

FIGURE 115

RADIOGRAPHY OF DISK FORGINGS

TABLE 91

JET ENGINE MANUFACTURER LABORATORY DISK X-RAY INSPECTION PARAMETERS

\begin{tabular}{|c|c|c|c|c|c|}
\hline & \multicolumn{2}{|c|}{$2 \cdot 3 / 4 \mathrm{in}$. Suction } & \multicolumn{2}{|c|}{ Aim Section } & \multirow{2}{*}{$\begin{array}{l}\text { Entire } \\
\text { Forging }\end{array}$} \\
\hline & Exposure 1 & Exposure 2 & Exposure 1 & Exposure 2 & \\
\hline KVP $\ldots \ldots \ldots \ldots$ & $\ldots .250$ & 250 & 250 & 250 & 1500 \\
\hline MA $\ldots \ldots \ldots \ldots$ & $\ldots 10$ & 10 & 10 & 10 & 10 \\
\hline Time $(\min ) \ldots \ldots \ldots \ldots \ldots \ldots$ & $\ldots . .8$ & 6 & 3 & $2 \cdot 1 / 6$ & $2 \cdot 5 / 1 "$ \\
\hline Film $\ldots \ldots \ldots$ & $\begin{array}{l}\text { GAF } 100 \\
\text { and } 400\end{array}$ & NDT 55 & GAF 400 & NDT 55 & NDT 55 \\
\hline $\begin{array}{ll}\text { Screens (Lead) Front (min).... } & \text { Eack (min) .... } \\
& \end{array}$ & $\begin{array}{l}\ldots .005 \mathrm{in} . \\
\ldots .010 \mathrm{in} .\end{array}$ & $\begin{array}{l}0.010 \mathrm{in} \\
0.010 \mathrm{in}\end{array}$ & $\begin{array}{l}0.005 \mathrm{in} \\
0.010 \mathrm{in}\end{array}$ & $\begin{array}{l}0.010 \mathrm{in.} \\
0.010 \mathrm{in} .\end{array}$ & $\begin{array}{l}0.010 \mathrm{in.} \\
0.010 \mathrm{in.}\end{array}$ \\
\hline Scurce-to Film D.stance ........ & $\ldots .3611$. & $36 \mathrm{in.}$ & $36 \mathrm{in.}$ & $48 \mathrm{in.}$ & $42 \mathrm{in.}$ \\
\hline Developing $(\min ) \ldots \ldots \ldots \ldots$ & .... 8 & 5 & 8 & 5 & 7 \\
\hline
\end{tabular}


film was processea manially and examined by ar. interpreter qualified to MIL-STD-453. The overall film density was approximately $2.0 \mathrm{H}$ and $D$ density units and the IT hole was visible in the peretrameter image or through the $23 / 4$ inch thickness resuliing in an equivalent sensitivity of 1.53 percent.

As in the case of the investigation by the engine manufacturer, there was no evidence of any segregates discernible.

\section{b. Penetrant Inspection}

A laboratory fluorescent penetrant inspection was carried out on the 6 aisk forgings at the engine manufacturer. The' specimens were swabbed with alcohol as a cleaning method prior to application of the penetrant. The penetrant, Magnaflux " $-22 \mathrm{~A}$ which is a MIL-I-25.35, Group VI post-emulsifiable penetrent, was allowed to dwell on the forgings for 30 minutes. Excess penetrant was washed from the forgings by a water spray at $45 \mathrm{psi}$ and the water temperature varied from $78^{\circ} \mathrm{F}$ to $85^{\circ} \mathrm{F}$ and the washing time varied from 55 seconds to 105 seconds. Next, the forgings were oven dried at $136^{\circ} \mathrm{F}-168^{\circ} \mathrm{F}$ for 10 minutes prior to application of the Magnaflux ZP-4A ary powder developer. A minimum of 5 minutes was allowed for development. The forgings were examined in a darkened booth with 1,100 microwatts per $\mathrm{cm}^{2}$ of ultraviolet lighi intensity at the forging surface.

A second penetrant inspection was performed on the forgings with Magnaflux ZL-30A post emulsifiable penetrant. Prior to the srcond inspection, the forgings were again cleaned by swabbing with alcohol. A penetrant dwell time of 30 minutes was used prior to emulsification with Magnaflux ZE-4A for 1 minute. Excess pentetrant was removed by spray washing at $50 \mathrm{psi}$ and a water temperature of $70^{\circ} \mathrm{F}-91^{\circ} \mathrm{F}$. The washing time was 10 seconds. After washing, the forgings were oven dried at $140^{\circ} \mathrm{I}-150^{\circ} \mathrm{F}$ for 10 minutes before application of the Magnaflux 2P-4A dry powder developer. A minimum of 5 minutes was allowed for development. The forgings were examined in a darkened booth with 1,100 microwatts per $\mathrm{cm}^{2}$ of ultraviolet lisht intensity at the inspection surface.

There were no relevant penetrant indications detect..1 : : ing the two inspections. The only indication was from burrs and mis ine tears.

Next, the forgingo were sent to the Air Force Materials wat matcry for penetrant inspection. The forgings were cleaned by trichlor, ci... ylene degreasing, for 1 hour prior to immersion in Magnaslux ZL-22S. fluorescent penetrani for 30 minutes. Emulsification with ZL-3 war perlormed for 30 secunds. After excess penetrant was washed from the surfaces, the forgings were dried for 5 minutes at $180^{\circ} \mathrm{F}$. Next, Sherwin D-1.00 nonaqueous wet developer was applied for a ininimit 5 minutes. As in the case of the enpine inslections, there wero no relevant penetrant indications.

\section{c. Ultriasnic Inspetion}

Prior to ultrasonic inspection, the disk torgings were machined to a las rms or betier surface finish as shown in Figure lizi. Alter 


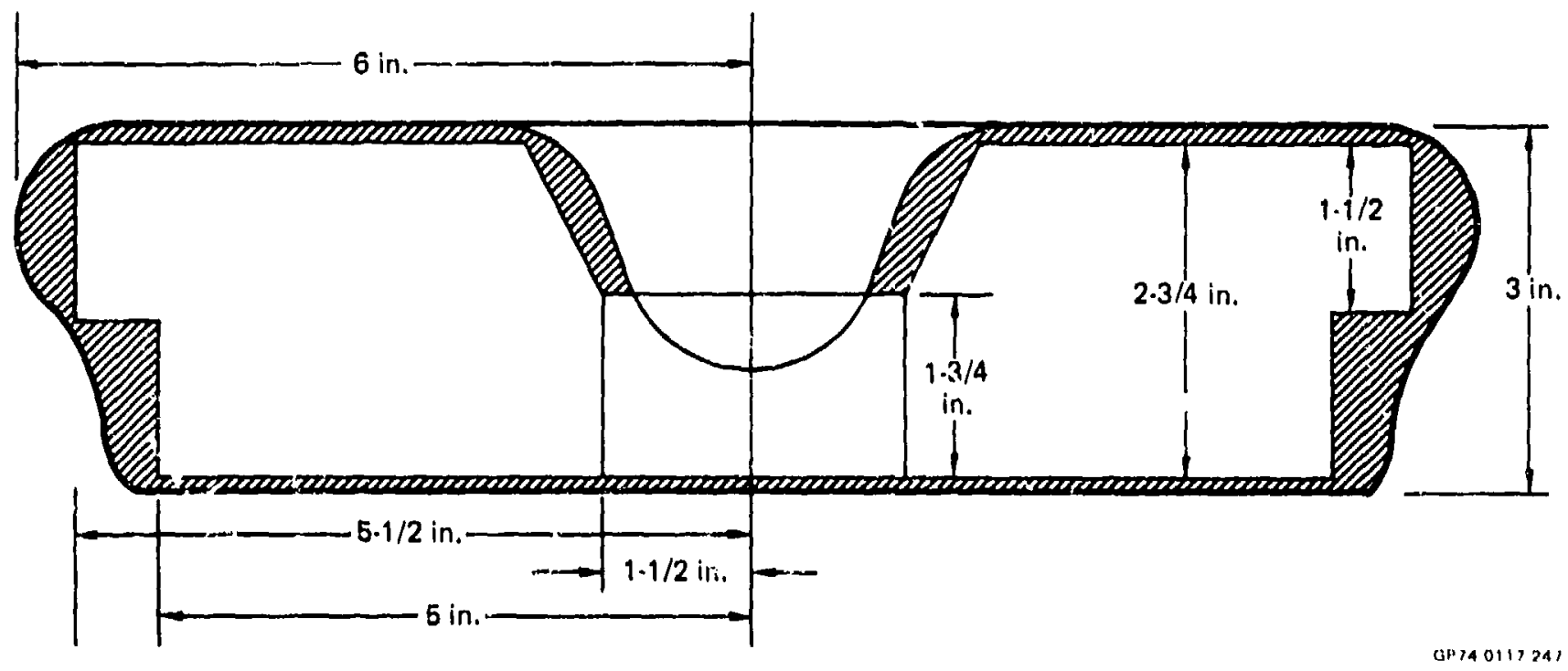

FIGURE 116

AREAS MACHINED ON DISK FORGING 
the machining operation, the forgings were subjected to ultrasonic inspections at the engine manufacturer and also at the Air Force Materials Laboratory (see Table Y'2).

Production inspection of the forgings at the engine munufacturer consisted of several straight and angle beam immersion inspections. A . $.5 \mathrm{MHz} 3 / 4$ inch diameter litinium sulfate focused search unit with a focal length of 6 to 9 inches in water was used. The search unit was pulsed at 5Miz using a Branson 600 ultrasonic instrument. A waterpath of 6 inches was lised for both the struight beam and angle beam inspections and a $1 / 8$ inch scan index was chosen as a typical production inspection scan index. The indexing was automatic while the scanning was manual. The refracted sound beam argle in the metal was 45 degrees for the angle beam inspections.

Production Angle Beam Immersion Inspection

The search unit position with respect to the reference standard was adjusted so that the sound bean angle was 45 degrees in the metal. Next, the water path was adjusted to 6 inches to bring the focal point of the sound beam to the .020 inch diameter hole with the greategt metal travel. During calibration, the gain was adjusted to bring the hole response to 80 percent of saturation, $12 \mathrm{~dB}$ of attenuation was removed and the gain setting was recorcled. Then, the search unt was moved to obtain responses from each of the other holes and their response was adfusted to 80 percent of saturation, $12 \mathrm{~dB}$ of attenuation was removed, and the gain seiting was recorded. The scanning gain for the inspection of the test specimens was the highest recorded gain setting plus an additional $22 \mathrm{~dB}$.

During the scanning of the test parts, all discontindities with amplitudes greater than 40 percent of the corresponding reference standard response at the same metal travel distance were evaluated further by manipulating the search unit. If the response, at the "plus 12 aB" gain, exceeded 60 percent of the corresponding reference response, the discontinuity was recorded.

The reference standard used had similar sound transmission characteristics as compared to the forgings. The gain setting at a particular back reflection amplitude in the reference standard was within 30 percent of the saile amplitude back reflection in the forging at the same metal travel.

The sound beam angles used in the angle beam inspection are shown in Figures 117 and 118 . As can be seen, circumferential, axial, and radial shear were used. If, during initial calibration, it was found that it was not possible to inspect through the entire thickness oi the forging, inspections were performed from opposite sulfaces to ensure 100 percent inspection. 
TABLE 92

SUMMARY OF ULTRASONIC INSPECTIONS OF DISK FORGINGS

\begin{tabular}{|c|c|c|c|c|c|}
\hline \multirow{2}{*}{$\begin{array}{c}\text { Forging } \\
\text { No. }\end{array}$} & \multirow{2}{*}{$\begin{array}{l}\text { Location } \\
\text { in } \\
\text { Original } \\
\text { Ingot }\end{array}$} & \multicolumn{2}{|c|}{$\begin{array}{l}\text { CE Production } \\
\text { Inspection }\end{array}$} & \multicolumn{2}{|c|}{$\begin{array}{c}\text { AFML } \\
\text { Inspection }\end{array}$} \\
\hline & & A & B & A & B \\
\hline 4 & Bottom & $x$ & $x$ & & \\
\hline 5 & & $x$ & $x$ & $x$ & $x$ \\
\hline 6 & & $x$ & $x$ & & \\
\hline 7 & Top & $x$ & $x$ & & \\
\hline 8 & & $x$ & $x$ & & \\
\hline 9 & & $x$ & $x$ & $x$ & $x$ \\
\hline
\end{tabular}

QP 74.0117.248
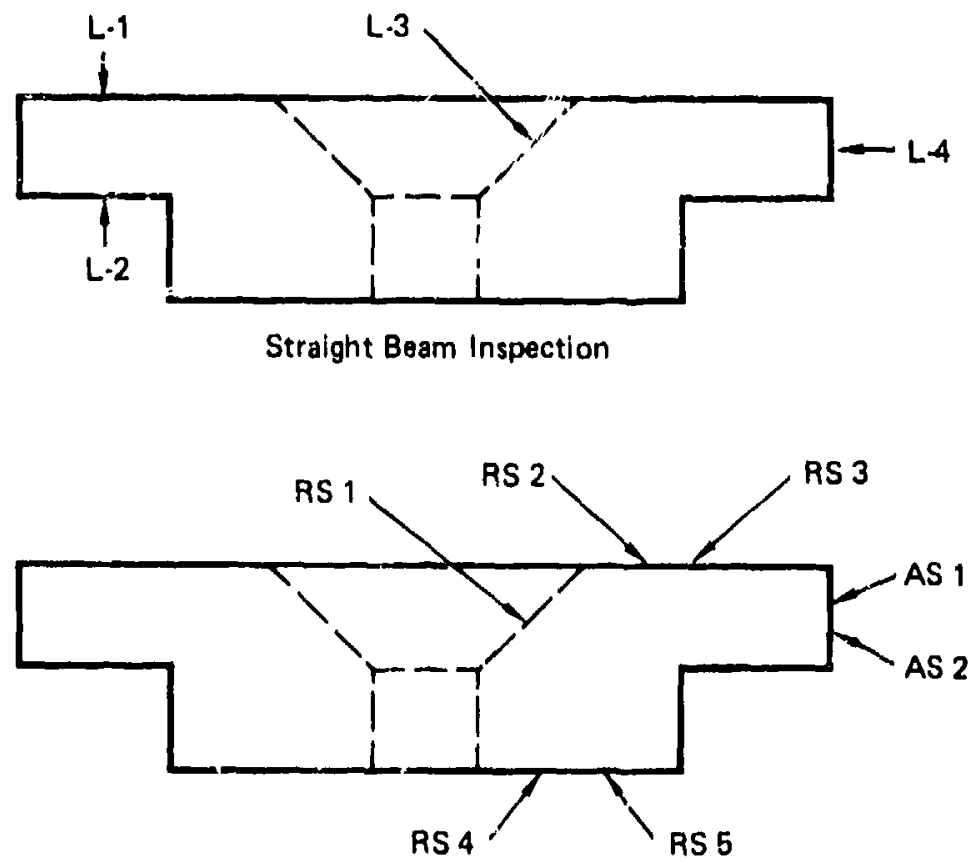

Radial and Axial Shear Inspections

FIGURE 117

SOUND BEAM DIRIECTIONS FOR DISK FORGING INSPECTIONS 
CS 1

(Clockwiss)

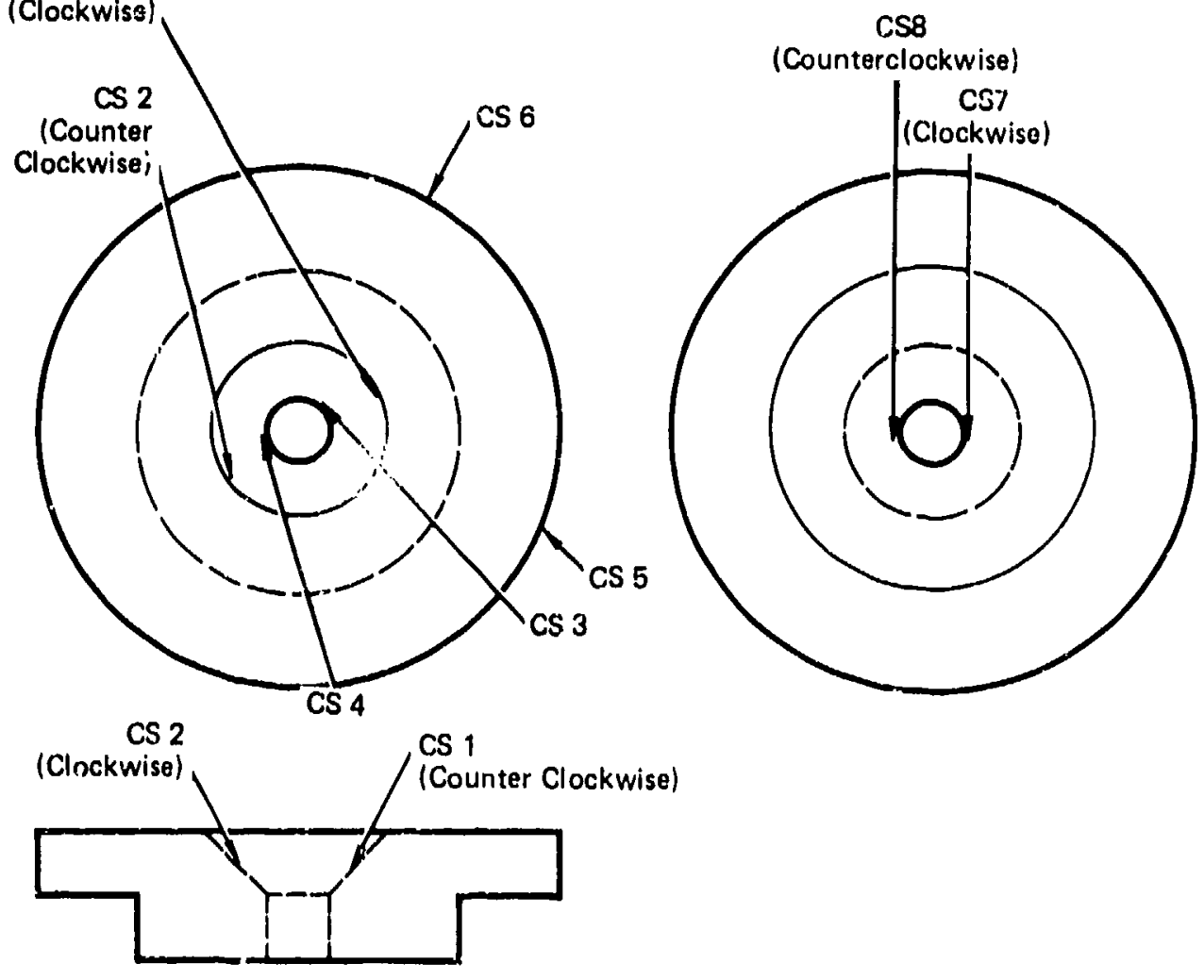

FIGURE 118

CIRCUMFERENTIAL SHEAR INSPECTION

OPra 0520 12 
roduction Straight Beam Immersion

Initially, the search unit was manipulated to maximize the response from the .020 inch diameter hole at a metal travel of $1 / 8$ inch in the reference standard. Next, the water path was ajusted in order to produce an approximately equal response from the .020 inch diameter holes at $3 / 8$ und $11 / 4$ metal travels. The gain control was adjusted to bring the two responses to 80 percent of saturation, $12 \mathrm{~dB}$ of attenuation was removed, and the gain setting was recorded. The search unit was positioned over the remaining holes in the reference standard and the response was adjusted to 80 fercent of saturation. Next, $12 \mathrm{~dB}$ of attenuation was removed and the gain setting was recorded. Finally, the scanning gain was obtained by adjusting the smallest hole response to 80 percent of saturation and renoving an additional $12 \mathrm{~dB}$ of atienuation.

During the scanning of the test parts all discontinuities with amplitudes greater than 40 percent of the corresponaing amplitude of the reference hole at the same metal travel were evaluated further by manipulating the search unit for maximum response. If the response, at the "plus $12 \mathrm{~dB}$ " gain, exceeded 60 percent of the corresponding reference response, the discontinuity was recorded.

The results of the inspections are shown in Figures 119 and 120 . A combined total for each inspector is presented in Figure 121.

As can be seen, there were only 2 indications as a result of the lungitudinal wave irspection but maly indications as a result of the shear wave inspections. This is true for both inspectors. This is similar to the results of the ultrasonic inspection of the ingot and 9 inch diameter billet where several indications were found using a shear wave that was not found using a longitudinal wave. 'These results may stem from the orientation of the discontinuities within the forgings. Also, since the wave length of shear waves is less than that of longitudinal waves (for a constant frequency), the resolution capability of shear waves is probably greater than with longitudinal waves. An examination of the cata indjcates that many more indications were lucated using radial shear than were located with axial or circumferential shear.

A conparison of the results for each inspector to shown in Figure 121. In each disk forging, Inspector B located more ultrasonic indications than did Inspector A. For example, for Disk Forging No 5, Inspector A located a total of 32 indications whereas Inspector $B$ located a total of 183. It should be pointed out, however, that all 6 disk forglngs would have been rejected by both inspectors according to the G.F. production acceptance criteria since rejection is not bisec on the quantity of dissontinuities.

\section{AFM Inspection}

Disks No 5 and 9 were straight beam immergion and anple beam immersion inspected at the Air Force Materials Laboratory using AFML personnel and equipment. For these inspections, a $1 / 2$ inch diameter, Branson lead zirconate titanate $7 \mathrm{MHz}$ search unit was used. This search 


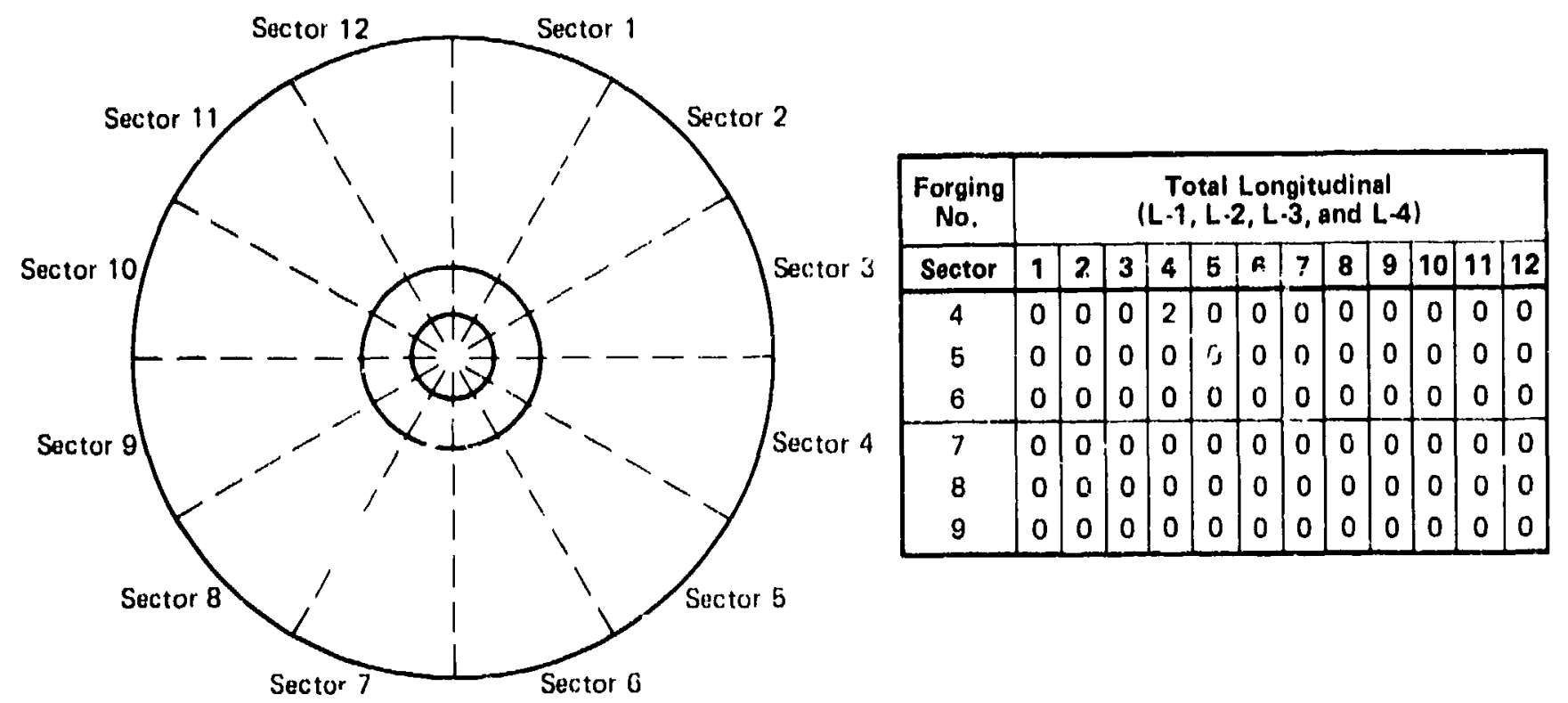

\begin{tabular}{|c|c|c|c|c|c|c|c|c|c|c|c|c|c|c|c|c|c|c|c|c|c|c|c|c|c|}
\hline \multirow{2}{*}{$\begin{array}{l}\text { Forging } \\
\text { No. } \\
\text { Sector }\end{array}$} & \multicolumn{13}{|c|}{$\begin{array}{l}\text { Total Radial Shear } \\
\text { (RS 1, RS } 3 \text { and RS 5) }\end{array}$} & \multicolumn{12}{|c|}{$\begin{array}{l}\text { Total Radial Shear } \\
\text { (RS } 2 \text { and RS 4) }\end{array}$} \\
\hline & 1 & 2 & 3 & 4 & 5 & $\varepsilon$ & i & 8 & & & & & 12 & 1 & 2 & 3 & 4 & 5 & 6 & 7 & 8 & {$[9$} & 10 & & 12 \\
\hline 4 & 0 & 0 & 2 & 2 & 1 & 0 & & 0 & & & & 1 & 0 & 0 & 0 & 0 & 0 & 0 & 0 & 0 & 0 & 1 & 0 & 0 & 0 \\
\hline 5 & 1 & 2 & 0 & 0 & b & 2 & & 4 & & & & 0 & 4 & 0 & 0 & 0 & 0 & 0 & 0 & 0 & 0 & 0 & 10 & 0 & 0 \\
\hline 6 & 15 & 8 & 3 & 9 & 8 & 3 & 2 & 1 & & & & 9 & 6 & 0 & 0 & 0 & 0 & $0 \mid$ & 0 & 0 & 0 & 0 & 0 & 0 & 0 \\
\hline 7 & 1 & 17 & 17 & 0 & 2 & 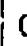 & & & & & & 41 & 13 & 0 & 0 & 0 & 0 & 0 & 0 & 0 & 0 & 0 & 0 & 0 & 0 \\
\hline 8 & 6 & 1 & 3 & 6 & 2 & C & 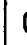 & 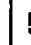 & & & & & 10 & 0 & 0 & 0 & 0 & 0 & 1 & 0 & 0 & 0 & 0 & 0 & 0 \\
\hline 9 & 0 & 1 & 10 & 0 & & & & & & & & & & 0 & 0 & & 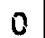 & & & 0 & & 0 & & & \\
\hline
\end{tabular}

\begin{tabular}{|c|c|c|c|c|c|c|c|c|c|c|c|c|c|c|c|c|c|c|c|c|c|c|c|c|}
\hline \multirow{2}{*}{$\begin{array}{c}\begin{array}{c}\text { Forging } \\
\text { No. }\end{array} \\
\text { Sector } \\
\end{array}$} & \multicolumn{12}{|c|}{$\begin{array}{l}\text { Total Circumferential Shear } \\
\text { (CS } 1, \operatorname{CS} 2, \operatorname{CS} 3, \operatorname{CS~} 4, \operatorname{CS} 5 \text {, and CS 6) }\end{array}$} & \multicolumn{12}{|c|}{$\begin{array}{l}\text { Total Axial Shear } \\
\text { (AS } 1 \text { and AS 2) }\end{array}$} \\
\hline & 1 & 2 & 3 & 4 & & 6 & 7 & 8 & 9 & 10 & & 12 & 1 & 2 & 3 & 4 & 5 & 6 & 7 & 8 & $\theta$ & 101 & & 12 \\
\hline & & & 0 & 0 & & 0 & 0 & & 1 & 0 & 0 & U & 1 & 0 & 1 & 0 & 0 & 1 & 0 & 0 & 0 & & 0 & 0 \\
\hline & 2 & c & 0 & 0 & 0 & 0 & 0 & 0 & 0 & 0 & 0 & 0 & 1 & 0 & 0 & 0 & 0 & 0 & 0 & 0 & 0 & 0 & 0 & 0 \\
\hline & & c & 0 & 0 & 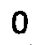 & 0 & 0 & 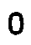 & 0 & 0 & 0 & & 6 & 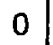 & 0 & U & 1 & 0 & 1 & 0 & 1 & 0 & 0 & 0 \\
\hline & & & 0 & $\sigma$ & & 0 & 0 & & & 0 & 0 & & 0 & 0 & 0 & 0 & 0 & 0 & 0 & 0 & 0 & 0 & 0 & 0 \\
\hline & 0 & 0 & 0 & 0 & 0 & 0 & 0 & 0 & 0 & 0 & 0 & 0 & 0 & 0 & 0 & 0 & 1 & 1 & 0 & 0 & 0 & 0 & 0 & 0 \\
\hline & & & & 2 & & & 1 & 1 & & & 0 & & $=$ & 0 & 0 & 0 & 0 & 0 & & 0 & 0 & 0 & 01 & \\
\hline
\end{tabular}

FIGURE 119

DEFECT LOCATION SUMMARY FOR ENGINE INSPECTOR A 


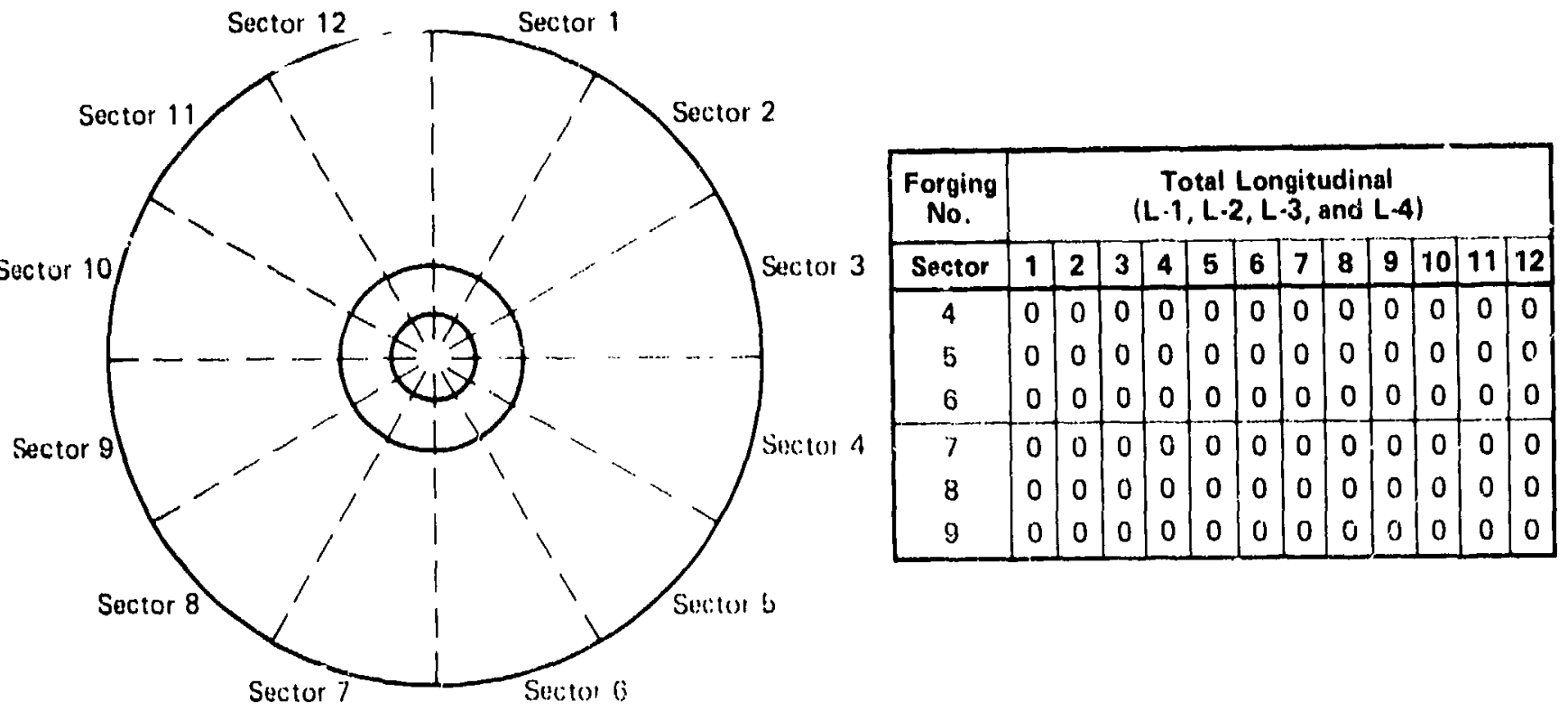

\begin{tabular}{|c|c|c|c|c|c|c|c|c|c|c|c|c|c|c|c|c|c|c|c|c|c|c|c|c|}
\hline $\begin{array}{l}\text { Forging } \\
\text { No. }\end{array}$ & \multicolumn{12}{|c|}{$\begin{array}{l}\text { Total Radial Shear } \\
\text { (RS 1. RS } 3 \text { and RS } 5 \text { ) }\end{array}$} & \multicolumn{12}{|c|}{$\begin{array}{l}\text { Total Radial Shear } \\
\text { (RS } 2 \text { and RS 4) }\end{array}$} \\
\hline Sector & 1 & 2 & 3 & 4 & 5 & 6 & 7 & 8 & 9 & 10 & 11 & 12 & 1 & 2 & 3 & 4 & 5 & 6 & 7 & 91 & $\therefore$ & 10 & 11 & 12 \\
\hline 4 & 8 & 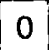 & 7 & 3 & 4 & 10 & 2 & 4 & 19 & 20 & 5 & 2 & 0 & 0 & 0 & 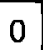 & 0 & 0 & 0 & 0 & 0 & 0 & 0 & 0 \\
\hline 5 & 3 & 12 & 3 & 8 & 19 & 5 & 4 & 26 & 50 & 12 & 35 & 6 & 0 & 0 & 0 & 0 & 0 & 0 & 0 & 0 & 0 & 0 & 0 & 0 \\
\hline 6 & 29 & 24 & 23 & 42 & 18 & 8 & 52 & 47 & 29 & 40 & 36 & 19 & 0 & 1 & 0 & $\ldots$ & 0 & 0 & 2 & 1 & 0 & 0 & 0 & 0 \\
\hline 7 & 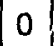 & 6 & 5 & 1 & 4 & 21 & 1 & 25 & 39 & 2 & 6 & 20 & 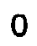 & 0 & 0 & 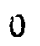 & 0 & 0 & 0 & 0 & 0 & 0 & 0 & 0 \\
\hline 0 & 11 & 10 & 16 & 4 & 3 & 4 & 3 & 6 & 18 & 23 & 36 & 16 & 0 & 0 & C & $u$ & 0 & 0 & 0 & 0 & 0 & 0 & 0 & 0 \\
\hline 9 & 10 & 32 & 4 & 1 & 27 & 5 & 15 & 22 & 23 & 12 & 24 & 11 & 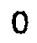 & 0 & 0 & 0 & 0 & 0 & 0 & 0 & 0 & 0 & 1 & 1 \\
\hline
\end{tabular}

\begin{tabular}{|c|c|c|c|c|c|c|c|c|c|c|c|c|c|c|c|c|c|c|c|c|c|c|c|c|}
\hline $\begin{array}{c}\text { Forging } \\
\text { No. }\end{array}$ & & & & & & & & & & & & & & & & & & & & & & & & \\
\hline Sector & 1 & 2 & 3 & 4 & 5 & 6 & 7 & 8 & & 10 & 11 & 12 & 1 & 2 & 3 & 4 & 5 & 6 & 7 & 8 & 9 & 10 & 111 & 12 \\
\hline 4 & 0 & 0 & 0 & 0 & 0 & 0 & 0 & 0 & & U & 0 & 0 & 0 & 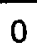 & 0 & $\mathbf{u}$ & 01 & 0 & 0 & 0 & 0 & 0 & 0 & 0 \\
\hline 5 & 0 & 0 & 0 & 0 & 0 & 0 & 0 & 0 & $u$ & 0 & 0 & 0 & 0 & 0 & 0 & 0 & 0 & 0 & 0 & 0 & 0 & 0 & 0 & 0 \\
\hline 6 & 0 & 0 & 0 & 0 & 0 & 0 & 0 & 0 & 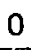 & 0 & 0 & 0 & 0 & 0 & 0 & 0 & 0 & 0 & 0 & 0 & 0 & 0 & 0 & 0 \\
\hline 7 & 0 & $v$ & $\sigma$ & 0 & $\mathbf{v}$ & 0 & 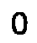 & 0 & 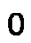 & v & 0 & 0 & 0 & 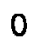 & 2 & 1 & 0 & 1 & 0 & 1 & 2 & 2 & 0 & 0 \\
\hline 8 & 0 & 0 & 0 & 0 & 0 & 0 & 0 & 0 & 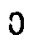 & 0 & 0 & 0 & 0 & 0 & 0 & 0 & 0 & 0 & 0 & 0 & $\mathrm{C}$ & 0 & 0 & 0 \\
\hline 9 & 0 & 0 & 0 & 0 & 0 & 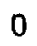 & 0 & 0 & & 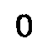 & 0 & 0 & 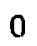 & 0 & 0 & 0 & 0 & 0 & 0 & 0 & 0 & 0 & 0 & 0 \\
\hline
\end{tabular}

FIGURE 120

DEFECT LOCATION SUMMARY FOR ENGINE INSPECTOR B 

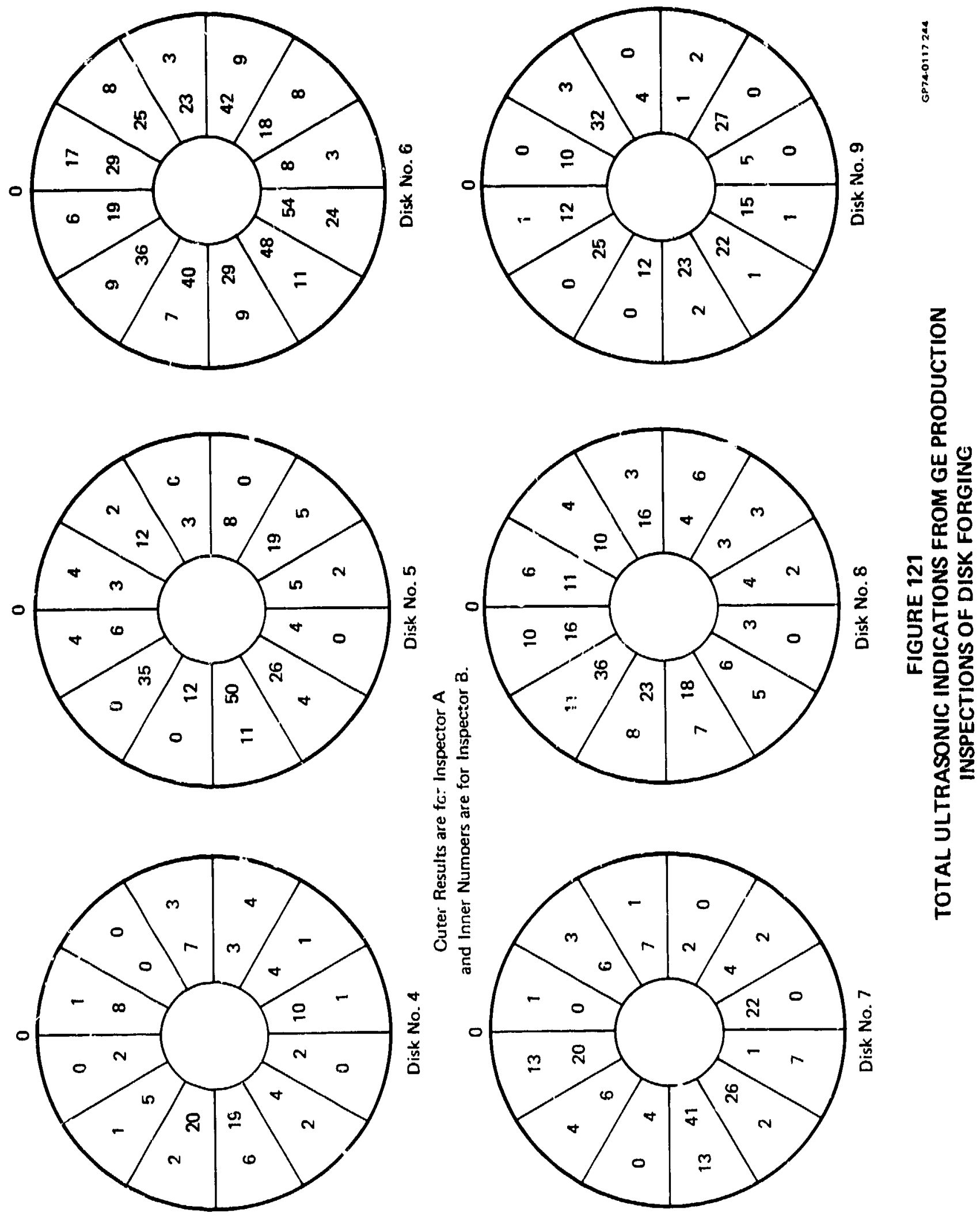
unit was focused and had a focal length in water of approximately 5 inches. The test frequency was $5 \mathrm{MHz}$ and Branson 600 ultrasontc instmment was used. During the inspections, the disks were lisiated on c turntable and C-scan recordings were made of the indications. The scan rate was 17 revolutions per minute. For the angle bean inspections, the lefracted soind beam anglu in the metal was 45 degrees.

The Coneral Electric reference standard, used by G.E. in their disk forging inspection, was also used in the AFML inspections. The search unit was positioned over the reference standard in order to odfust the sound beam angle in the metal to 45 degrees for the angle beam inspection. The water path establlshed during the stralgint beam calibration was used. Then, gain settingn were oitained for an 80\% response from each hole 1 in the reference standard. Next, the response from the .020 inch diameter reference hole at a 1.25 inch metal travel was adjuste , to 80 percent of saturation. The scanning gain was increased by removing an additional $12 \mathrm{~dB}$ of attenuation and the C-scan was set to print-out any discontinuities whose amplitude exceeded 60 percent of seduration. It was found, however, that it was not always possible to interpret the results at this high. gain since there was a myriad of indications printed out on the C-scan. This can be explained by the fact that very small. discontinulties near the sound entry surface were beins inspected at an effective sensitivity level in excess of the "plus $12 \mathrm{~dB}$ " level by virtue of their short metal travels. In order to evaluate tha o.sk forgings, then, separate scans were made of each at lower gain levels of "plus $5 \mathrm{~dB}^{\prime \prime}$ and "plus $8 \mathrm{~dB}$ "; as a result, approximate distarice amplitude corrections were obtained for discontinulties at the shorter metal travels. The C-scans were used to locate tha discontinulties. Each discontinuity was then evaluated by direct comparison of their response with the response from the reference hole at the same metal travel. If the discontinuity responge at the "p?us $12 \mathrm{~dB}$ " gain exceeded 60 percent of the corresponding reference response, the discontinuity was documented.

The straight beam imersion tests were set-up by adjusting the water path (2 11/16 inches) until the response from the $3 / 8$ and $11 / 4$ inch deep reference holes were 1dentical. Next, the responses were a ted to 80 percent of saturation, and the sensitivity was increased $t$. L.: $\mathrm{dB}$. No indications were recorded on the C-scans. 
Two independent AFML technicians were used and the Figures 117 and 118 scan plans were reproduced by Inspector A whereas, for Inspector B, L-3, L-4, C.S. 3, C.S.4, C.S.5, and C.S. 6 were omitted.

A summary of the test results appear in Figure 122. Listed are those indications whose amplitude equalled or exceeded 60 percent of the reference hole response at the "plus $12 \mathrm{~dB}$ " level. A compar1son of the inupection results from G.E. and AFLL for disk forging No's 5 and 9 are shown in Table 93.

TABLE 93

COMPARISON OF TOTAL GE ULTRASONIC INDICATIONS WITH TOTAL AFML ULTRASONIC INDICATIONS

\begin{tabular}{|c|c|c|c|c|c|c|c|c|c|c|c|c|c|}
\hline \multicolumn{14}{|c|}{ Sector (in degrees) } \\
\hline Inspactor & 0 & 30 & 60 & 90 & 120 & 150 & 180 & 210 & 240 & 270 & 300 & 330 & Total \\
\hline \multicolumn{14}{|c|}{ Disk No. 5} \\
\hline GE $A$ & 4 & 2 & 0 & 0 & 5 & 2 & 0 & 4 & 11 & 0 & 0 & 4 & 32 \\
\hline GE B & 3 & 12 & 3 & 8 & 19 & 5 & 4 & 26 & 50 & 12 & 35 & 6 & 183 \\
\hline AFMLA & 1 & 0 & 3 & 6 & 5 & 6 & 14 & 8 & 8 & 6 & 6 & 8 & 71 \\
\hline AFML B & 2 & 2 & 3 & 7 & 8 & 6 & 8 & 9 & 6 & 11 & 7 & 5 & 75 \\
\hline \multicolumn{14}{|c|}{ Disk No. 9} \\
\hline GEA & 1 & 3 & 0 & 2 & 0 & 0 & 1 & 1 & 2 & 0 & 0 & 1 & 11 \\
\hline GE B & 10 & 32 & 4 & 1 & 27 & 5 & 15 & 22 & 23 & 12 & 25 & 11 & 187 \\
\hline AFML A & 3 & 6 & 3 & 1 & 1 & 13 & 4 & 7 & 12 & 9 & 6 & 7 & $* 72$ \\
\hline AFML B & 4 & 1 & 1 & 0 & 3 & 6 & 5 & 9 & 6 & 6 & 3 & 2 & $* 46$ \\
\hline
\end{tabular}

- 5 indlcations foulli hy AFML Inspecior A on testing not completed by AFML Inapector $B$. - 10 indicatlons found by AFML inepector A un tenting not complated by AFML Inepector $B$. 


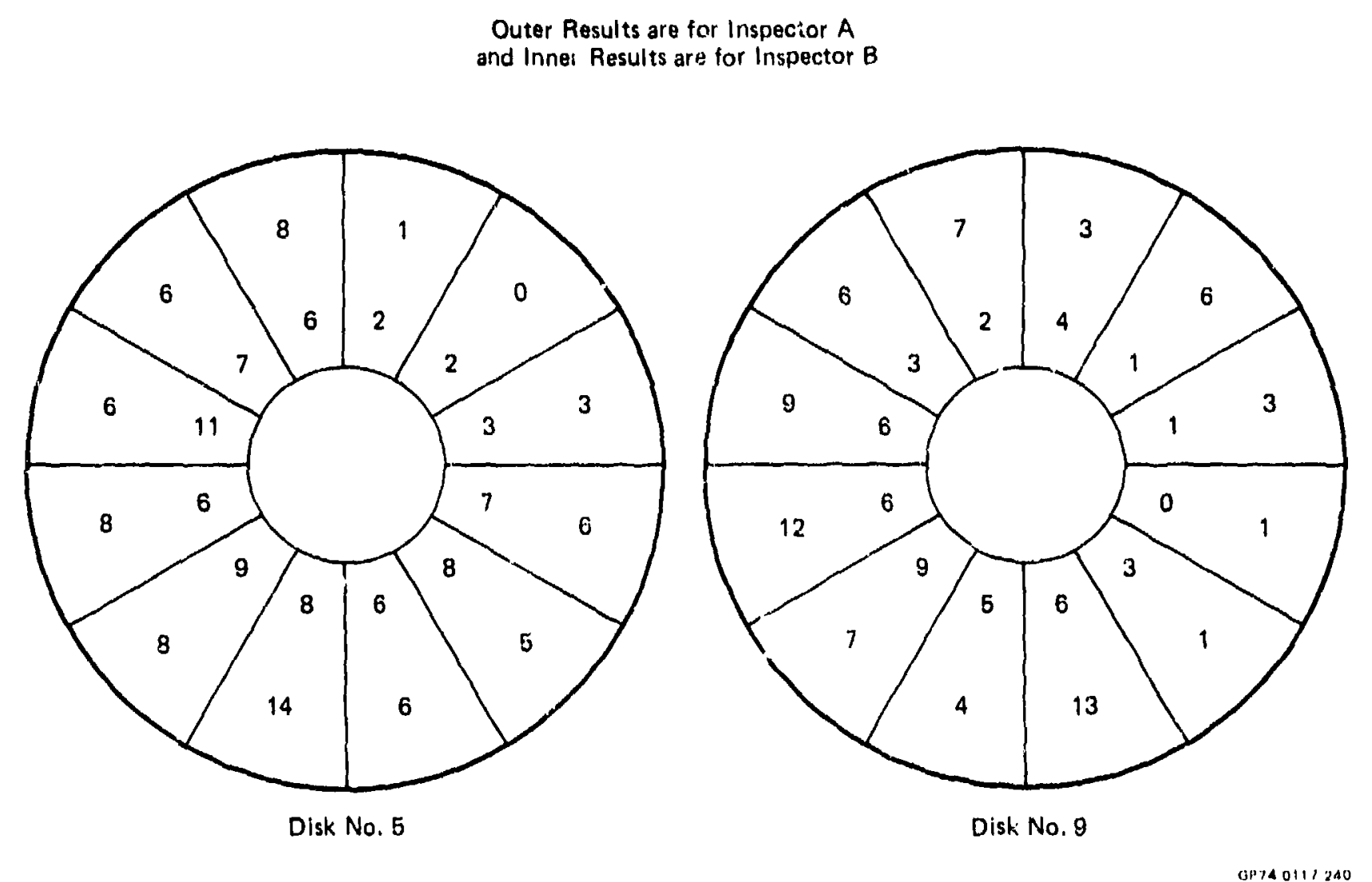

FIGURE 12:

TOTAL ULTRASONIC INDICATICNS FROM AFML INSPECTIONS OF DISK FORGINGS 
5. PLATE

a. Ultrasonic Inspection

The production ultrasonic inspection was carried out on the plate using the straight beam immersion method. A 3/4 inch diameter, $5 \mathrm{MHz}$ SIZ flat search unit (S/N 18650) was used along with a Sperry UM77I (s/N 66720) and a IOS $\mathrm{dB}$ pulser/receiver (s/N 66727). The vertical and horizontal linearity of the electronic system had been checked within 4 months of the inspection according to the procedures given in ASTM E317-68. A 3 inch water path was chosen for the inspections. This water path was maintained constant for the reference standards and the plate to $\pm 1 / 8$ inch.

Ti-6Al-4V reference standards with $3 / 64$ inch diameter flat bottom holes at metal travels of $3 / 8,1 / 2,3 / 4,1$, and $1-1 / 4$ inches were used for callbration. These reference standards were commercially purchased Ti-6AI-4V ASTM-type straight beam reference standards. Initially, a distance-amplitude curve (DAC) was constructed by positioning the search unit for maximum response from that $3 / 64$ inch diameter flat bottom reference hole which exhibired the largest amplitude signal. The signal amplitude then was adjusted to 80 percent of saturation on the cathode ray tube (CRT). Without changing the gain control, the search unit was positioned over the remaining reference standards and the amplitudes were marked on the CRI screen. The points were joined by a smooth curve. In order to increase the test sensitivity, an attempt was made to inspect the plate at a higher scanning gain. First, $19 \mathrm{~dB}$ of attenuation was removed which is apjroximately equivalent to calibrating with a $1 / 64$ inch diameter flat bottom. However, at this gain level, the ultrasonic noise in the plate was so high (exceeded $25 \%$ of the DAC curve) as to prevent effective inspection (see Figure 123). Next, a total of $7 \mathrm{~dB}$ was subtracted (equivalent to a $2 / 64$ inch diameter hole calibration) but again the noise in the plate exceeded 25\% of the DAC curve was too high (see Figure 12.4). Finally, the gain was reset for the original $80 \%$ of saturation from the highest amplitude reference standard. The rational of increasing sensitivity by a specific amount rather than attempting to drill and use exceedingly small reference standard holes is valid within certain limits and should be mentioned at this time. On a previous internal program using aluminum AS'T'M type blocks, it was found that the relationship between the search uni, diameter and f'requency effects the response from the holes. Both contact and immersion type search units were used. Frequencies and diameters of the uctive areas were varied and the responses were measured from several holes. The table following iists the average results obtained. 


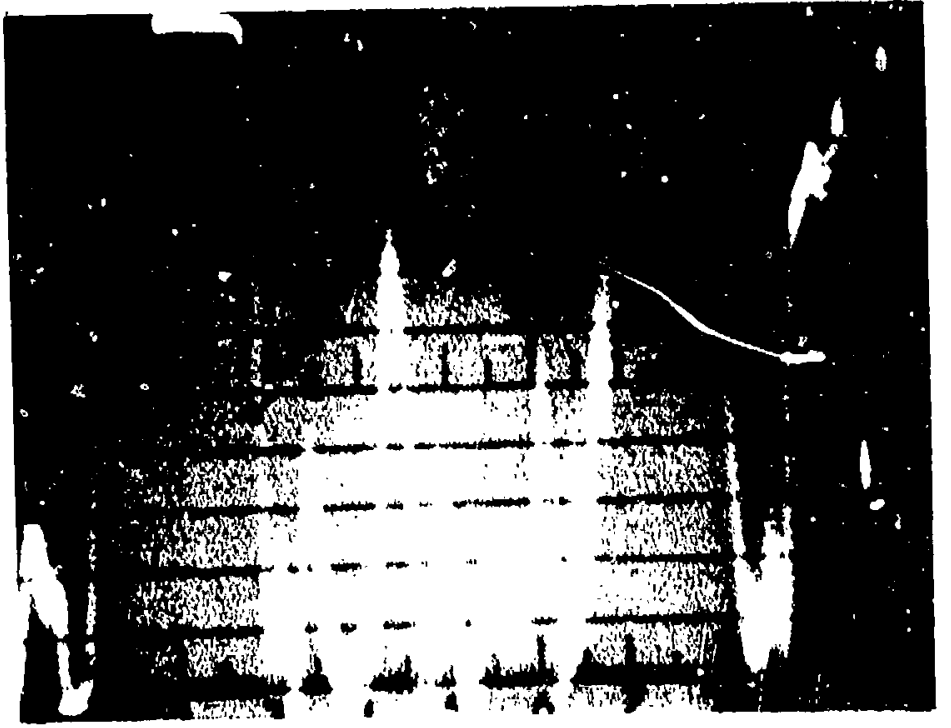

FIGURE 123

HIGH NOISE LEVEL IN PLATE AFTER SUBTRACTION OF 19 dB

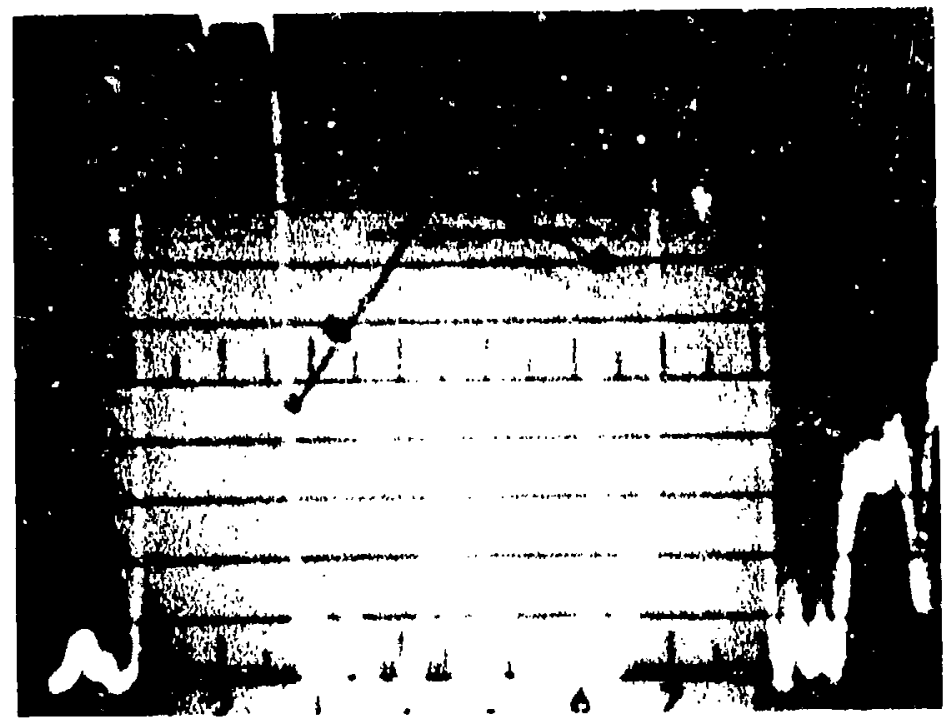

FIGURE 124

HIGH NOISE LEVEL IN PLATE AFTER SUBTRACTION OF $7 \mathrm{~dB}$ 


\begin{tabular}{|l|l|l|l|r|r|r|r|}
\cline { 2 - 8 } \multicolumn{2}{c|}{} & \multicolumn{6}{c|}{ Response Variations, (dB) } \\
\hline \multirow{2}{*}{ Frequency, MHz } & \multicolumn{2}{|c|}{$2-1 / 4$} & \multicolumn{2}{|c|}{5} & \multicolumn{2}{|c|}{10} \\
\hline Hole Dia. (Inches) & 5 to 3 & 5 to 8 & 5 to 3 & 5 to 8 & 5 to 3 & 5 to 8 \\
\hline \multirow{2}{*}{$\begin{array}{c}\text { Dia. } \\
\text { inches) }\end{array}$} & $1 / 4 "$ & -10 & +8 & -14 & +18 & -12 & +19 \\
\cline { 2 - 8 } & $1 / 2 "$ & -7 & +6 & -10 & +8 & -12 & +10 \\
\cline { 2 - 8 } & $3 / 4 "$ & -8 & +7 & -9 & +9 & -10 & +7 \\
\hline
\end{tabular}

It is obvious that at the normal test conditions using $5 \mathrm{MHz} 3 / 4$ inch diameter search units, the ratio of hole areas between a $3 / 64$ inch, a $5 / 64$ inch, and an 8/64 inch diameter flat bottom hole varies directly with the $\mathrm{dB}$ gain or loss required to obtain identical CRT resoonse amplitude. (i.e. If the ratio of areas between an $8 / 64$ and $a "-164$ is $64 / 9$ or 7.1 , then the $\mathrm{dB}$ ratio should be about $17 \mathrm{~dB}$ if area/amplitude is the only variable.) However, as the frequency is increased or the search unit dianeter is reduced, the area/amplitude relationship no longer holds as can be seen in the values obtained using a $10 \mathrm{MHz}$ $1 / 4$ inch diameter search unit. This can be explained using the hole diameter to wave length ratio and the reradiation concept discussed in the Nondestructive Testing Handbook by McMaster (Reference 5 ).

In addition, the responses from standard drilled holes (no flat bcttom) were compared to ASTM type holes described above and the results listed in the following table were obtained.

\begin{tabular}{|l|c|c|c|c|}
\cline { 2 - 5 } \multicolumn{1}{c|}{} & \multicolumn{3}{c|}{ Response Variations (dB) } \\
\hline \multicolumn{2}{c|}{ Frequency, Mliz } & $2-1 / 4$ & 5 & 10 \\
\hline \multirow{3}{*}{$\begin{array}{l}\text { Hole } \\
\text { Size } \\
(64 \text { ths })\end{array}$} & $\# 3$ & -1 & -5 & -12 \\
\cline { 2 - 5 } & $\# 5$ & -2 & -.24 & -18 \\
\cline { 2 - 5 } & $\# 8$ & -8 & -18 & -28 \\
\hline
\end{tabular}


Variations in hole bottom flatness had less effect as the frequency and hole size were reduced. The behavior of this data also can be described by the hole diameter to wavelength ratio. Plotting the Log $D / \lambda$ ratio versus the difference in $d B$ from one hole diameter to the next (in the range of $3 / 64$ to $8 / 54$ : mater) proved that a straight line relationship exists and showed but the flat bottom hole response will equal the response from any surface of the sume diameter when the $D / \lambda$ ratio is equal to or less than 0.5 .

This data, although performed on aluminum, should be directly applicable to titanium since the contour surface block results as well as the transinission data discussed in this section demonstrates the transferability of results from one material to the other. Note, however, whether material transiniasion characteristics or surface orientation (both front and back surfaces) or both resulted in differences in back reflection responses of at least $16 \mathrm{~dB}$ from one area of the bar to another.

A check was made for the difference in sound transmission characteristics between the reference standards and the $1-1 / 2$ inch thick plate. At the gain established as described above, the decibel (dB) difference was noted between the back surface response in the plate and in a reference standard with the same metal travel. It was found in the case of the two plates that there was no dB difference between the plate and reference standard so that no correction was necessary.

As shown in Figure 125, the plate was scanned manually from two sides. In each case, the scan index was 0.25 inch. This was chosen using the scanning gain by determining the total traversing distance across the reference standards through which no less than $50 \%$ of the DAC curve is obtained.
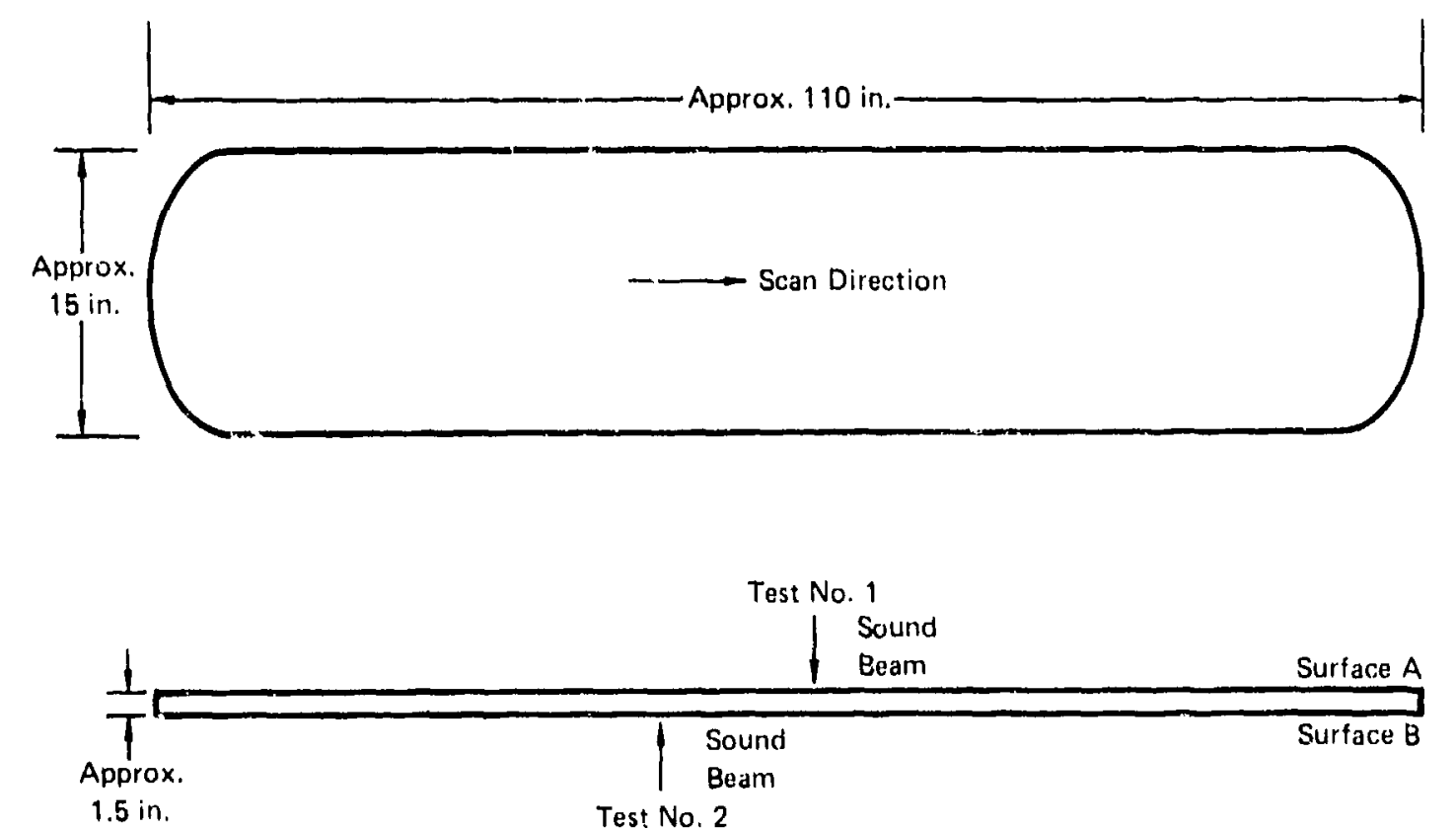

FIGURE 125

QP140111.24

SCAN PLAN FOR PLATE 
A.11 discontinuities with amplitule greater than $50 \%$ of the MAC carve wore evaluaced for acceptance or rejection. Each discontinuity rosponse was directly compared to the flat bottom hole response in a roference standard of appropriate metal travel. Whe location and size of cuch lujectable discontinuity was marked on the plate and, upon completion or the inspection, the information was transferred to mylar overlay. Finally, all. the markings were removed from the plate.

Upon completion of the 5 MHz strajght, beam inanersion touting, Whe plates were reinspected using a $10 \mathrm{Mlz}, 1 / 2$ inch diameter, leal a reonute titanate search unit ( $\mathrm{S} / \mathrm{N}$ 15384). The remaining equipmun, firmution inspector, and procedure was as for the 5 MHz inspection.

A typical CRT photograph of a discontialuity in the plate is shown in Figure 136.

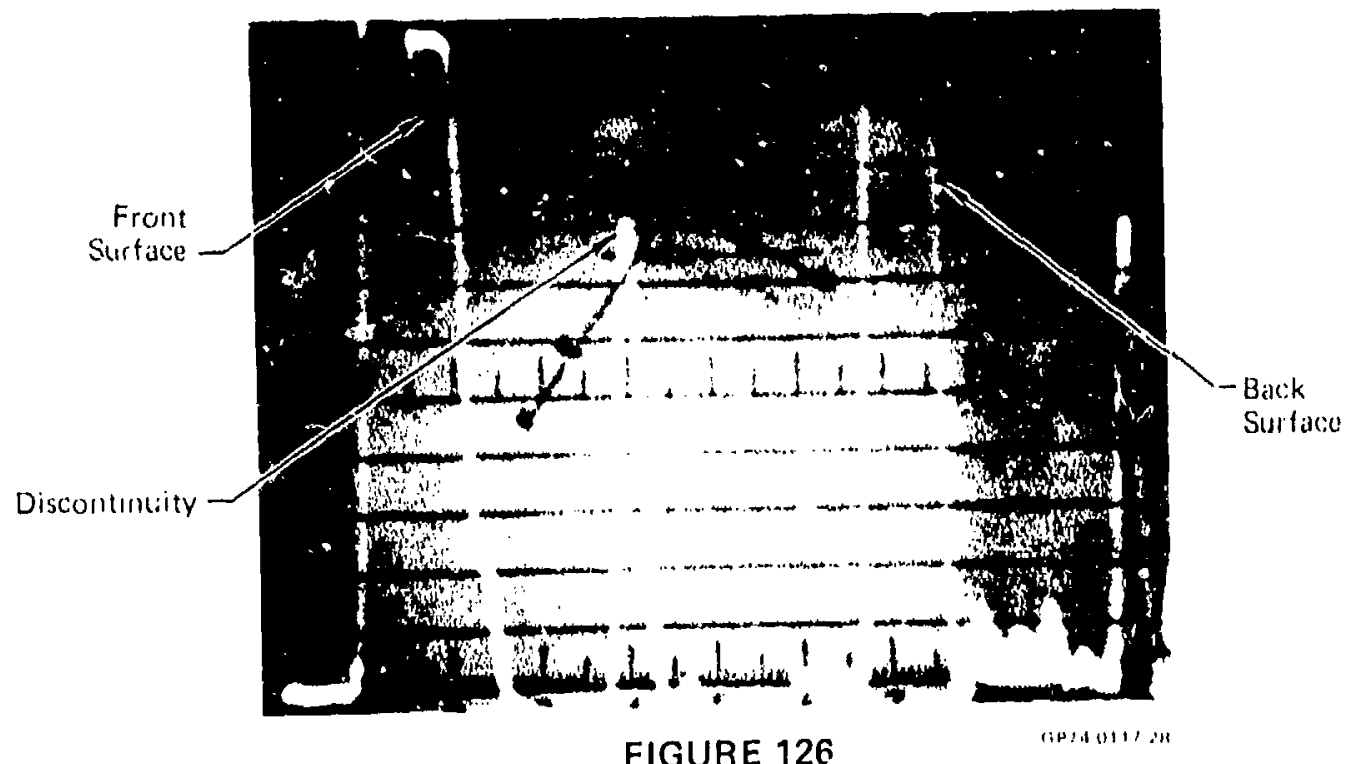

FIGURE 126

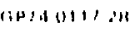

TYPICAL RESPONSE FROM DISCONTINUITY IN PLATE

'Ihe resulta of the two straight bean inspection ia shown in 'I'bles: 94 and 95. The approximate location of cach discontinuit, in allown in lhe?

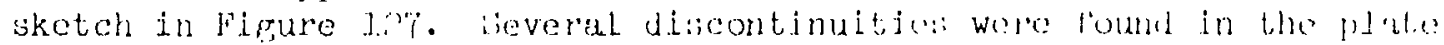

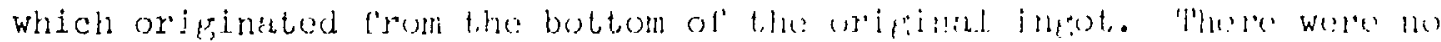

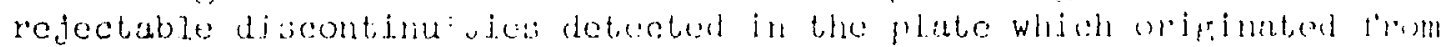

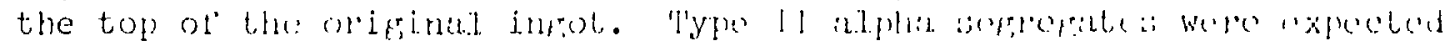
in this material irom the inrot top. 
TABLE 94

SIJMMARY OF STRAIGHT BEAM TESTING OF PLATE FROM INGOT BOTTOM (SURFACE "A" WAS THE SOUND ENTRY SURFACE)

\begin{tabular}{|c|c|c|c|c|c|c|}
\hline \multirow{2}{*}{$\begin{array}{c}\text { Dofact } \\
\text { No. }\end{array}$} & \multicolumn{2}{|c|}{ Approximate Length } & \multicolumn{2}{|c|}{ Approximate Dopth } & \multicolumn{2}{|c|}{ Pesponse Amplitudo } \\
\hline & $6 \mathrm{MHz}$ & $10 \mathrm{MHz}$ & $5 \mathrm{MHz}$ & $10 \mathrm{MHz}$ & $5 \mathrm{MHz}$ & $10 \mathrm{MHz}$ \\
\hline 1 & $\Delta$ & 0.5 & 0.6 & 0.6 & No. 3 & $<$ No. 2 \\
\hline 2 & 5.0 & 5.5 & 0.7 & 0.6 & $>$ No. 5 & $>$ No. 5 \\
\hline 3 & 仓 & 0.5 & 0.6 & 0.6 & $>$ No. 5 & $>$ No. 3 \\
\hline 4 & 1.6 & 1.6 & 0.9 & 0.9 & $>$ No. 5 & No. 5 \\
\hline 5 & 0.5 & 0.75 & 0.75 & 0.8 & $>$ No. 5 & $>$ No. 3 \\
\hline 6 & $\triangle$ & 1 & 0.9 & 0.8 & $<$ No. 3 & $>$ No. 2 \\
\hline 7 & $\Delta$ & A & 0.8 & 0.8 & No. 3 & $<$ No. 2 \\
\hline 8 & 3.25 & 3.75 & 0.6 & 0.8 & $>$ No. 5 & $>$ No. 5 \\
\hline 9 & 2 & 2 & 2 & 2 & 2 & 2 \\
\hline 10 & (1) & (1) & 0.6 & 0.6 & No. 3 & $>$ No. 2 \\
\hline 11 & 1 & 0.75 & 0.4 & 0.8 & $>$ No. 3 & $>$ Nu. 2 \\
\hline 12 & 1) & $\hat{1}$ & 0.9 & 0.6 & No.? & $<$ No. 2 \\
\hline 13 & 0.75 & 0.75 & 0.5 & 0.5 & $>$ No. 3 & No. 2 \\
\hline 14 & 1.0 & 0.5 & 0.6 & 0.6 & $>$ No. 3 & $>$ No. 2 \\
\hline 16 & 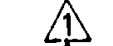 & 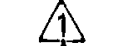 & 0.6 & 0.6 & $>\mathrm{No} .3$ & $<N_{0}, 2$ \\
\hline 16 & 2 & (2) & 2 & 2 & 2 & 2 \\
\hline
\end{tabular}


TABLE 95

SUMMARY OF STRAIGHT BEAM TESTING OF PLATE FROM INGOT BOTTOM (SURFACE " $B$ " WAS THE SOUND ENTRY SURFACE)

\begin{tabular}{|c|c|c|c|c|c|c|}
\hline \multirow{2}{*}{$\begin{array}{c}\text { Dofoct } \\
\text { No. }\end{array}$} & \multicolumn{2}{|c|}{ Approximate Length } & \multicolumn{2}{|c|}{ Approximute Depth } & \multicolumn{2}{|c|}{ Response Amplituds } \\
\hline & $5 \mathrm{MHz}_{2}$ & $10 \mathrm{MHz}$ & $5 \mathrm{MHz}$ & $10 \mathrm{MHz}$ & $5 \mathrm{MHz}$ & $10 \mathrm{MHz}$ \\
\hline 1 & 0.4 & 0.75 & 0.9 & 0.9 & No. 3 & $>$ No. 2 \\
\hline 2 & 5.5 & 5.5 & 0.8 & 0.8 & $>$ No. 5 & $>$ No. 5 \\
\hline 3 & 0.5 & 0.76 & 0.9 & 0.9 & No. 3 & No. 3 \\
\hline 4 & 1.75 & 1.6 & 0.6 & 0.6 & $>$ No. 5 & $>$ No. 6 \\
\hline 5 & 0.75 & 0.75 & 0.8 & 0.8 & $>$ No. 5 & $>$ No. 3 \\
\hline 6 & & & 0.8 & 0.5 & $>$ No. 3 & No. 2 \\
\hline 7 & 1 & 1 & 0.6 & 0.7 & $>$ No. 3 & $>$ No. 2 \\
\hline 8 & 3.5 & 3.5 & 0.9 & 0.9 & $>$ No. 5 & $>$ No. 5 \\
\hline $\mathcal{G}$ & & 2 & 1.2 & 2 & No. 3 & 2 \\
\hline 10 & $\Delta$ & $\hat{i}$ & 0.9 & 0.9 & No. 3 & $>$ No. 2 \\
\hline 11 & 0.5 & 4 & 1.2 & 0.6 & No. 3 & $>$ No. 2 \\
\hline 12 & 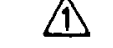 & 1 & 0.6 & 0.8 & $<$ No. 3 & $>$ No. 2 \\
\hline 13 & 0.75 & 0.5 & 1.0 & 1.2 & $>$ No. 3 & $>$ No. 2 \\
\hline 14 & $0.70^{\circ}$ & 0.5 & 0.9 & $(i, 9$ & No. 3 & $<$ No. 2 \\
\hline 15 & 4 & 0.75 & 0.9 & 1.0 & No. 3 & $>$ No. 3 \\
\hline 16 & 11 & (1) & 1.2 & 1.1 & $>$ No. 3 & $<$ No. 2 \\
\hline
\end{tabular}
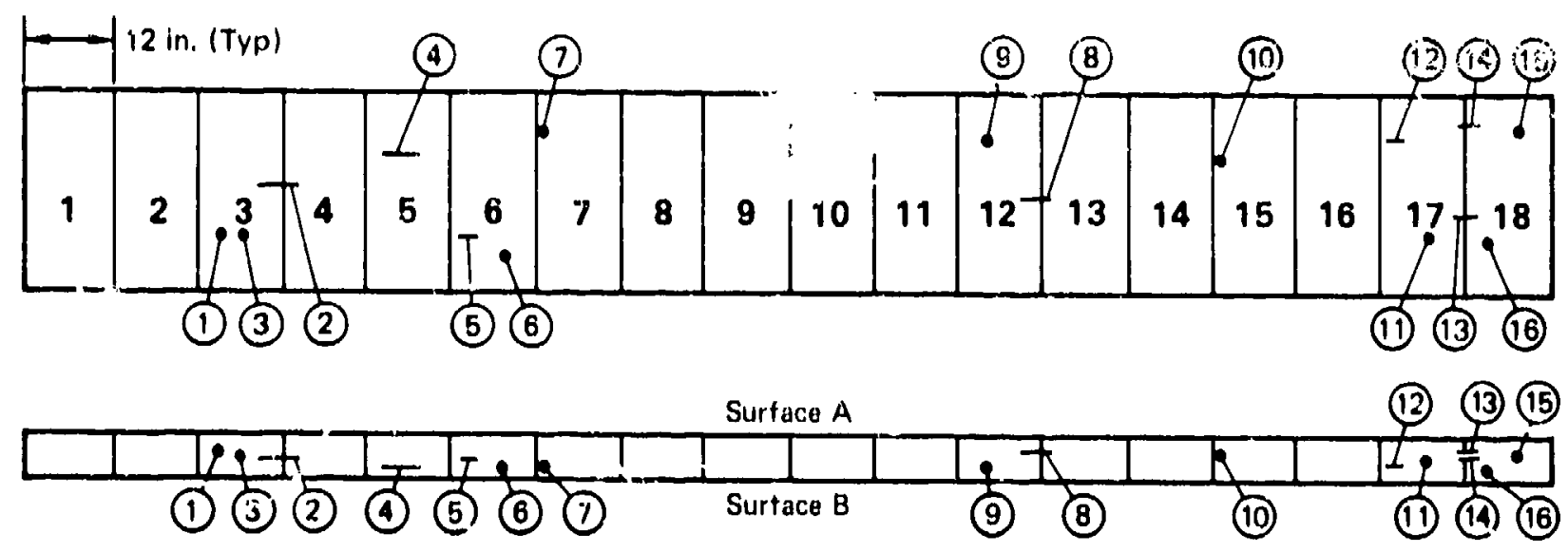
The discontinuities found in the plate from the ingot bottom varied in length from zero (non-linear) to 5.5 inches. The amplitude response varted from less than a 2/64 inch diameter flat bottom hole to greater then a 5/64 inch diameter flat bottom hole.

The test results indicate that greater resolution was achieved with the $10 \mathrm{MHz}$ frequ.ncy than the $5 \mathrm{MHz}$ frequency. For example, several of the discontinuities which appeared to be non-linear using $5 \mathrm{MHz}$ were found to have length when tested with $10 \mathrm{MHz}$ (see Table 94).

b. Radiographic Inspection

The plate material was radiographically inspected using production radiographic facilities. The exposures were made with a siefert Isovolt $400 \mathrm{X}$-ray machine having a $4.0 \mathrm{~mm}$ focal spot. The exposures were made at $150 \mathrm{KV}$ and 10 millamperes for 15 minutes. A NIL-STD- 453 - 3 penetrameter was used as an image quality indicator and was placed on the source side of the plate. The front screen was .005 inch thick lead and the back screen was .010 inch thick 1sad. Cardboard cassettes were used with 14 x 17 inch Geveart D4 film (ASTiv Iype I) and a $1 / 8$ inch thick I 3 ad sheet was used to back up the film casseite. The focal spot-tof'ilm distance was 45 inches and ihe direction of the central beam was aligned to be perpendicular to the film surface. Twelve inch wide areas were exposed using the $14 \times 17$ inch $11 \mathrm{~lm}$ to provide for overlapping of exposures. The exposed fllm was processed in a Kodak Model B X-Omat automatic processor using Geveart G135N developer and G334N f'Ixer. The density of each radiograph was between 2.0 and $2.5 \mathrm{H}$ and $\mathrm{D}$.

None of the segregates which were detected ultrasonically were observed on the radiographs. A second examination of the films was made in the area of ultrasonic indications but, again, there was no evidence of discontinuities on the films. From this, it can be concluded that the Type I stabilized alpha detects in plate are more easily detected using ul.trasonic techriques than radiography. 
6. BAR

a. Ultrasonic Inspection

The initial production straight beam inspection of the bar was performed using the same $5 \mathrm{MHz}$ search unit as was used for the plate inspection. All the equipment for the bar insyection was the same as for the plate inspection. Ti-6A1-4V reference standards with 3/64 inch diameter flat bottiom holes at $1 / 2,3 / 4,1,1-1 / 4$, and $1-3 / 4$ inch metal travels were used to establish the DAC curve as described for the plate inspection. As with the plate inspection, an attempt was made to increase the scanning gain by subtracting $19 \mathrm{~dB}$ and then $7 \mathrm{~dB}$ but gain the ultrasonio noise level was greater than $25 \%$ at the DAC curve level (see Figure 128). As in the zase of the plate inspection, the gain was reset at ths original DAC curve level. The scan index was .25 inch.

Correction was made for the difference in sound transmission characteristics between the reference standards and the bar using the same procedure as for the plate inspection. It was found that there was a wide variation in the sound transmission characteristics along each bar. Consequently, each bar was divided into 12 inch segments and correction was made for the average attenuation within each segment. The variation in average $a B$ difference between each segmert of the bar and the reference standards is shown in Table 96. As can be seen the variation was as great as zero to 13 dB within a single bar. A portion of the $d B$ difference may be due to surface irregularities.

TABLE 96

VARIATION IN! AVERAGE SOUND TRANSMISSION CHARACTERISTICS BETWEEN BAR AND REFE.RENCE STANDARDS FOR $5 \mathrm{MHz}$ STRAIGHT BE.AM TESTING

\begin{tabular}{|c|c|}
\hline $\begin{array}{c}\text { Bar } \\
\text { No. }\end{array}$ & $\begin{array}{c}\text { Variation in Average dB Difference Botween } \\
\text { Bar and Reference Standard }\end{array}$ \\
\hline $1-2 \mathrm{~A} 2 \mathrm{~A}$ & 0 to $13 \mathrm{~dB}$ \\
$1-2 \mathrm{~A} 2 \mathrm{~B}$ & 0 to $6 \mathrm{~dB}$ \\
$1.2 \mathrm{~A} 2 \mathrm{C}$ & 3 to $12 \mathrm{~dB}$ \\
$1-2 \mathrm{~A} 2 \mathrm{D}$ & 0 to $7 \mathrm{~dB}$ \\
$1.2 \mathrm{~A} 2 \mathrm{E}$ & 1 to $10 \mathrm{~dB}$ \\
$1-\mathrm{iA2A}$ & 0 to $7 \mathrm{~dB}$ \\
$1.1 \mathrm{~A} 2 \mathrm{~B}$ & 0 to $8 \mathrm{~dB}$ \\
$1.1 \mathrm{~A} 2 \mathrm{C}$ & 2 to $9 \mathrm{~dB}$ \\
$1.1 \mathrm{~A} 2 \mathrm{D}$ & 3 to $8 \mathrm{~dB}$ \\
$1.1 \mathrm{~A} 2 \mathrm{E}$ & 0 to $7 \mathrm{~dB}$ \\
\hline
\end{tabular}

(,P) (1) $11,: 11$ 


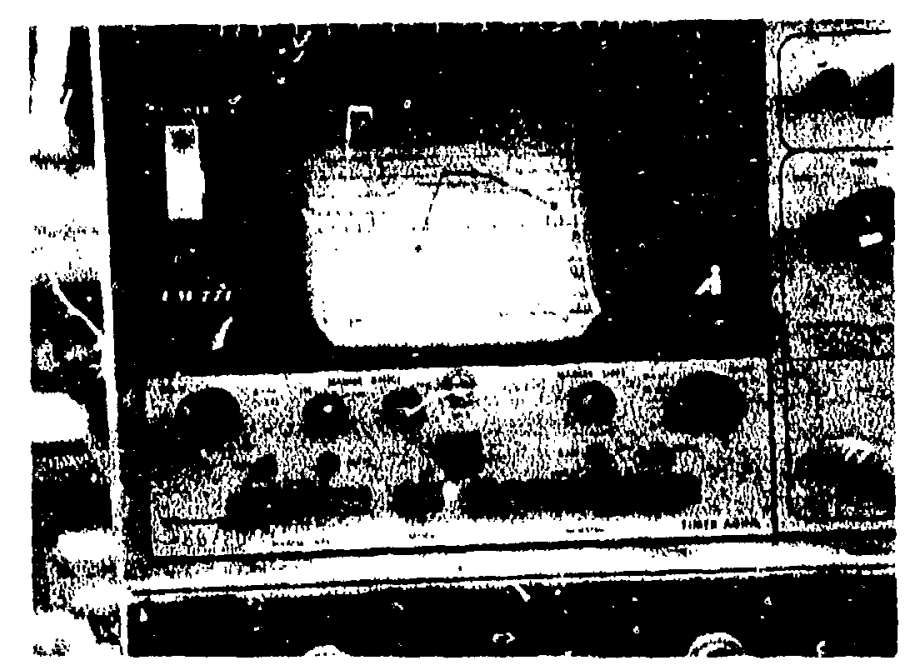

Actual Scamninẹ Gain Used for lnspertion of Bar

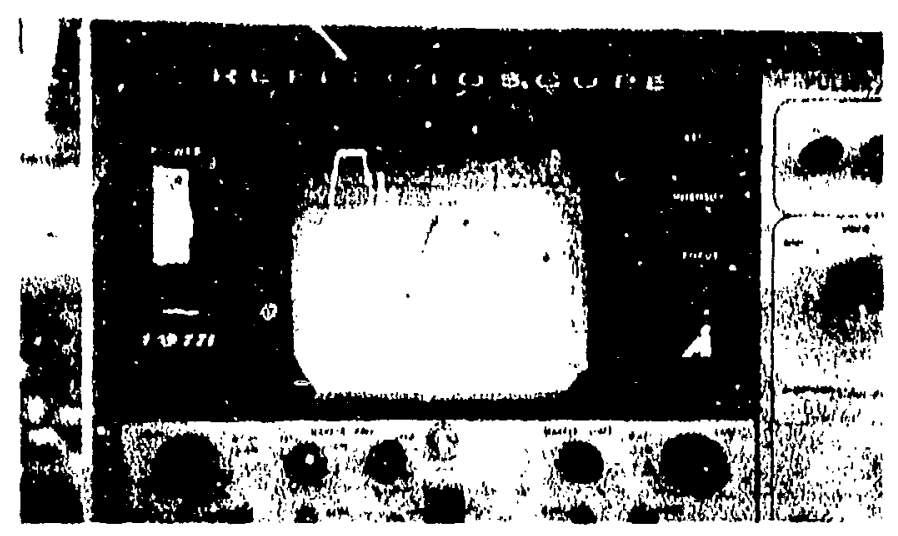

19 dB Subtracted (Cruimalent o a 1/64 Flat Bottom Hole Response)

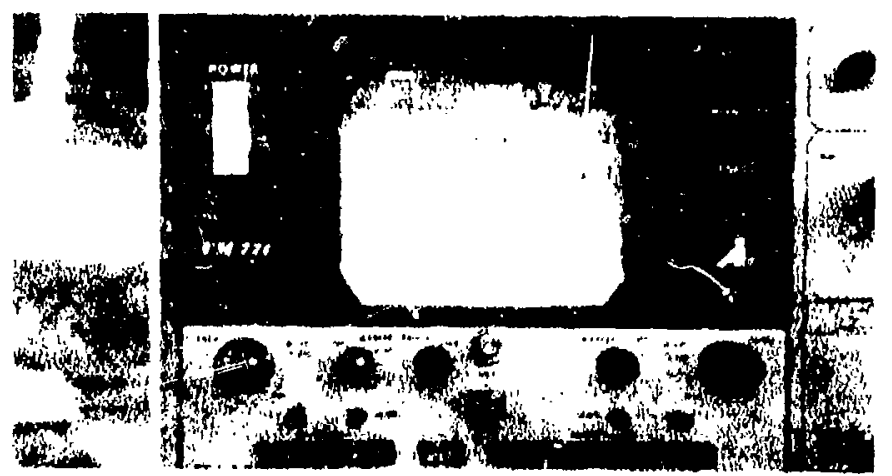

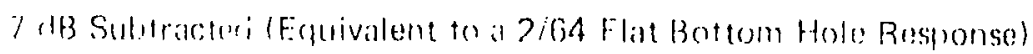

FIGURE 128

PHOTOGRAPHS OF CATHODE RAY TUBE PRESENTATION

OF BACK SURFACE RESPONSE AND NOISE IN BAR AT SEVERAL GAIN LEVEIS 
As with the plate inspection, the waterpath was 3 inches $\pm 1 / 8$ inch. Many of the bars were warped and twisted. Consequently, it was not possible to scan them automatically and still maintain a $+1 / 8$ inch water path. Therefore, the scanning bridge was moved by hand by the cperator. The bars were scanned as shown in Figure 129.

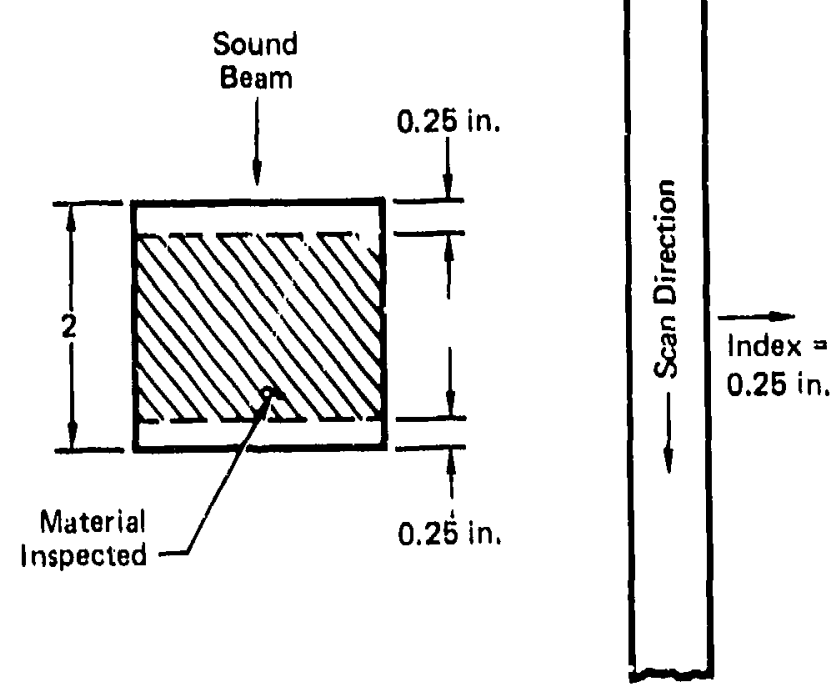

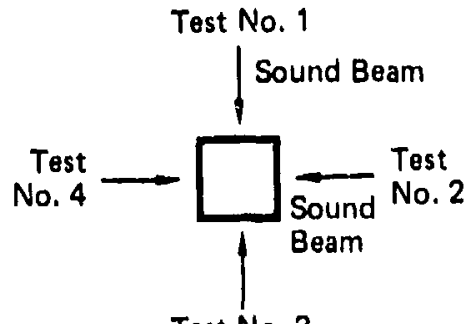

Test No. 3

\section{FIGURE 129}

SCAN PLAN FOR BAR

Each bar was inspected in 4 mutual] y perpendicular directions to overcome detection difficulties that might arise from the orientation of discontinuities.

As with the plate, all discontinuities with amplitude greater than $50 \%$ of the DAC on the cathode ray tube were evaluated further to determine acceptance or rejection. Each discontinuity was evaluated by manipulating the search unit to maximize the response from the discontinuity.

The location and size of each discontinuity whose response exceeded the DAC curve was marked on the bar surface. After completion of the inspection, the information was transferred to mylar overlays and the markings vere removed from the surface of the bar.

For comparative purposes, a second strat $t$ beam immersion inspection was performed using a $10 \mathrm{MHz}, 1 / 2$ inch diameisr, lead zirconate titanate search unit ( $\mathrm{S} / \mathrm{N}$ 15384). The remaining equipment, production inspector, and procedure was as for the $5 \mathrm{MHz}$ inspection. 
Figure 130 is used to explain the results of the straight beam immersion tests and Figure 131 is a schematic showing the section layout. The inspection data is presented in Figure 132.

As can be seen, several discontinuities are present in the bars which originated from the bottom of the original ingot. There were no rejectable discontinuities detect,ed in the bars which originatad from the top of the original ingot. Type II alpha segregates were expected in this lnaterial from the ingot top. It is not known if these segregates oxdst in the bar at this point or if the ultrasonic inspections were not successful in detecting them.

The discontinuities found in the bars from the ingot bottom varied in length from zero (non-linear) to 9.3 inches. The amplitude response varied from less than a $2 / 64$ inch diameter flat bottom hole to greater than a $5 / 64$ inch diameter flat hottom hole.

The teat results indicate that greater resolution was achieved with the $10 \mathrm{MHz}$ frequency than the $5 \mathrm{MHz}$ frequency. For example, the $5 \mathrm{MHz}$ inspection of Bar 1-2A2A, Section 7 indicated the presence of 2 separate discontinuities, where as, the $10 \mathrm{MHz}$ inspection revealed one continuous discontinuity. In addition, there were a few point discontinuties detected at $10 \mathrm{MHz}$ which were not detected at $5 \mathrm{MHz}$.

The imporiance of correcting for differences in sound transmission characteristics between the bar and the reference standard, can be seen from the test results. For example, in one area of Bar 1-2A2A, a difference of $13 \mathrm{~dB}$ was encountered. Without correction, the response amplitude would be reduced to approximately 2.5 percent of 1 ts amplitude after correction and it is douotful that discontinuities equivalent to a $2 / 64$ inch diameter flat bottom hole would have been detected.

Following the straight beam irspections, several of the bars were inspected using angle beam immersion techniques. The following bars were inspented:

$1-2 A 2 A, 1-2 \mathrm{~A} 2 \mathrm{~B}, 1-2 \mathrm{~A} 2 \mathrm{D}, 1-1 \mathrm{~A} 2 \mathrm{~A}, 1-1 \mathrm{~A} 2 \mathrm{~B}, 1-2 \mathrm{~A} 2 \mathrm{C}$

Eash bar was inspected using a $3 / 4$ inch diameter, $5 \mathrm{MHz}$, flat Aerotech Gamma search unit (S/N 11232?) and a Sperry UM 771 U1trascric instrument with a $103 \mathrm{~dB}$ pulser/receiver. The reference standard was a 2 inch thick as-rolled plate, machined to the conflguration previoualy describer in Figure 48. The difference in sound transmission between the bar and the reference standard was measured using the straight team inmeraion method. A $1 / 2$ inch diameter, 10MHL, Aerotech Garma search unit was used. A frequency of $10 \mathrm{MHz}$ was choser to keep the wave length the same as with for $5 \mathrm{MHz}$ shear mode sound beam. The search unit was positioned over the reference standard and the back reflection through the 2 inches of metal was adjusted to 30 percent of saturstion. Next, without changing the gain control, the search unit was positioned over the 2 inch thick bar. The search unit was moved to several nositions on each bar and, in this manner, an average $d B$ difference betwten the bar and reference standard was arrived at. 

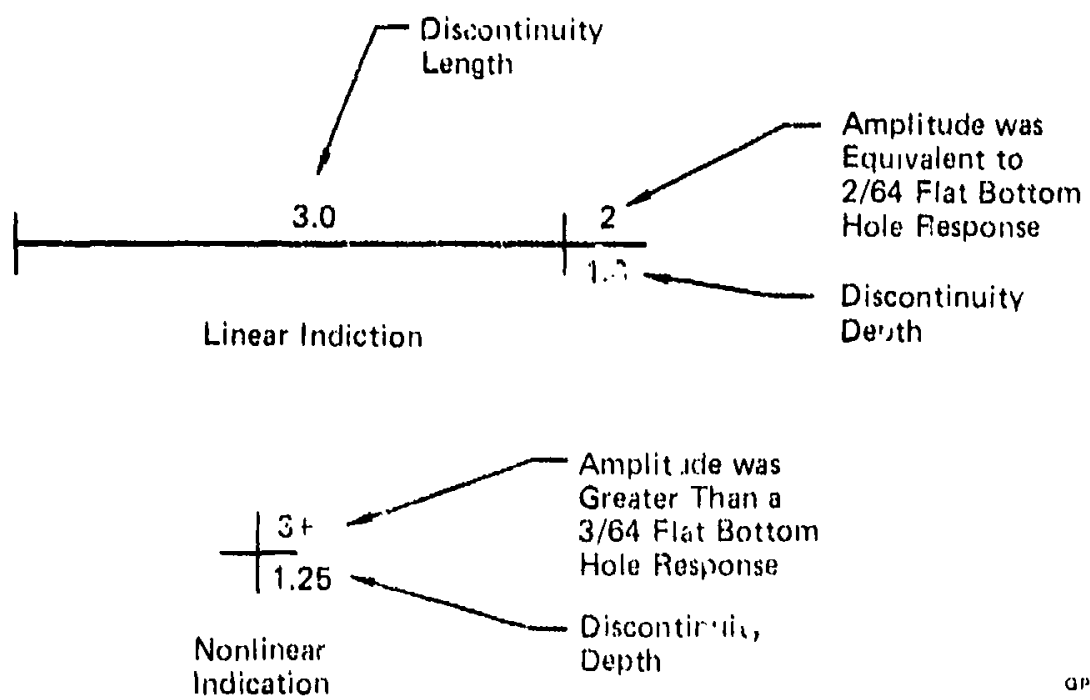

FIGUAE 130

DATA PRESENTATION
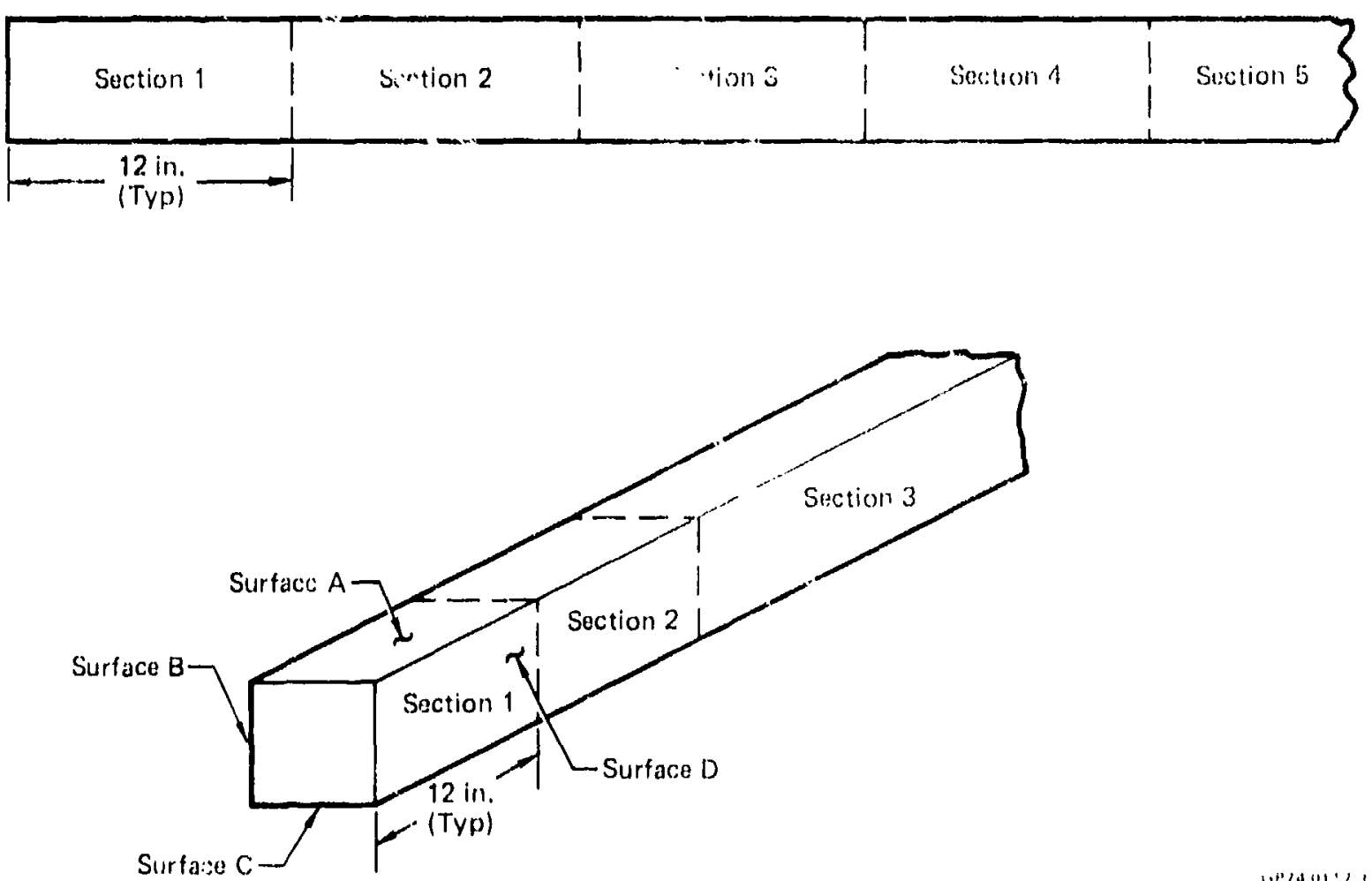

FIGURE 131

LAYOUT OF BARS FOR ULTHASONIC INSPECTION 
Bar No. 1-2A2A

$10 \mathrm{MHz}$

Section 1

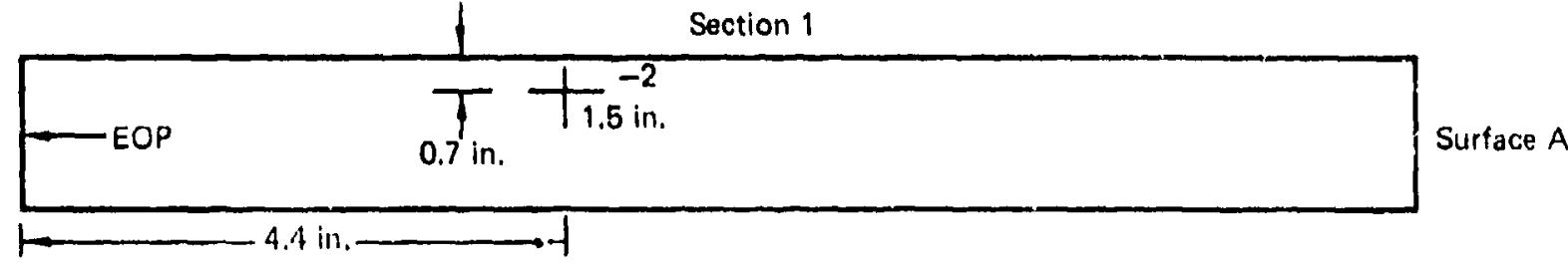

Surface B
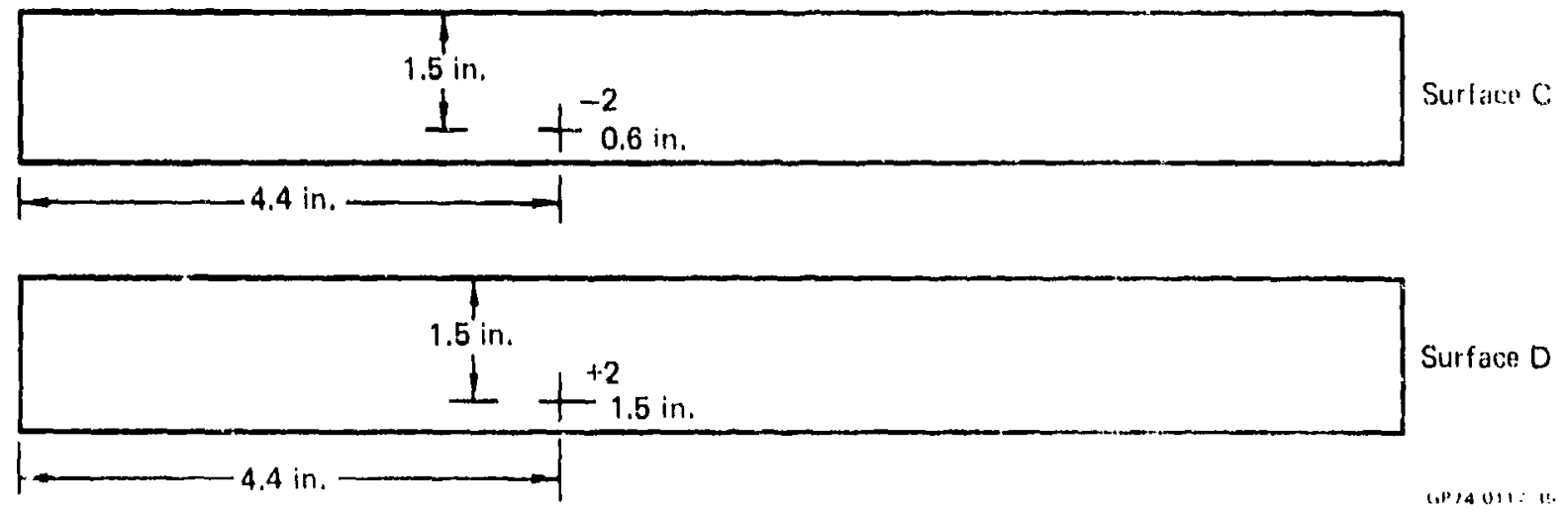

FIGURE 132

LOCATION OF DEFECTS IN BAR 



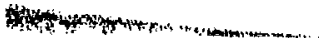

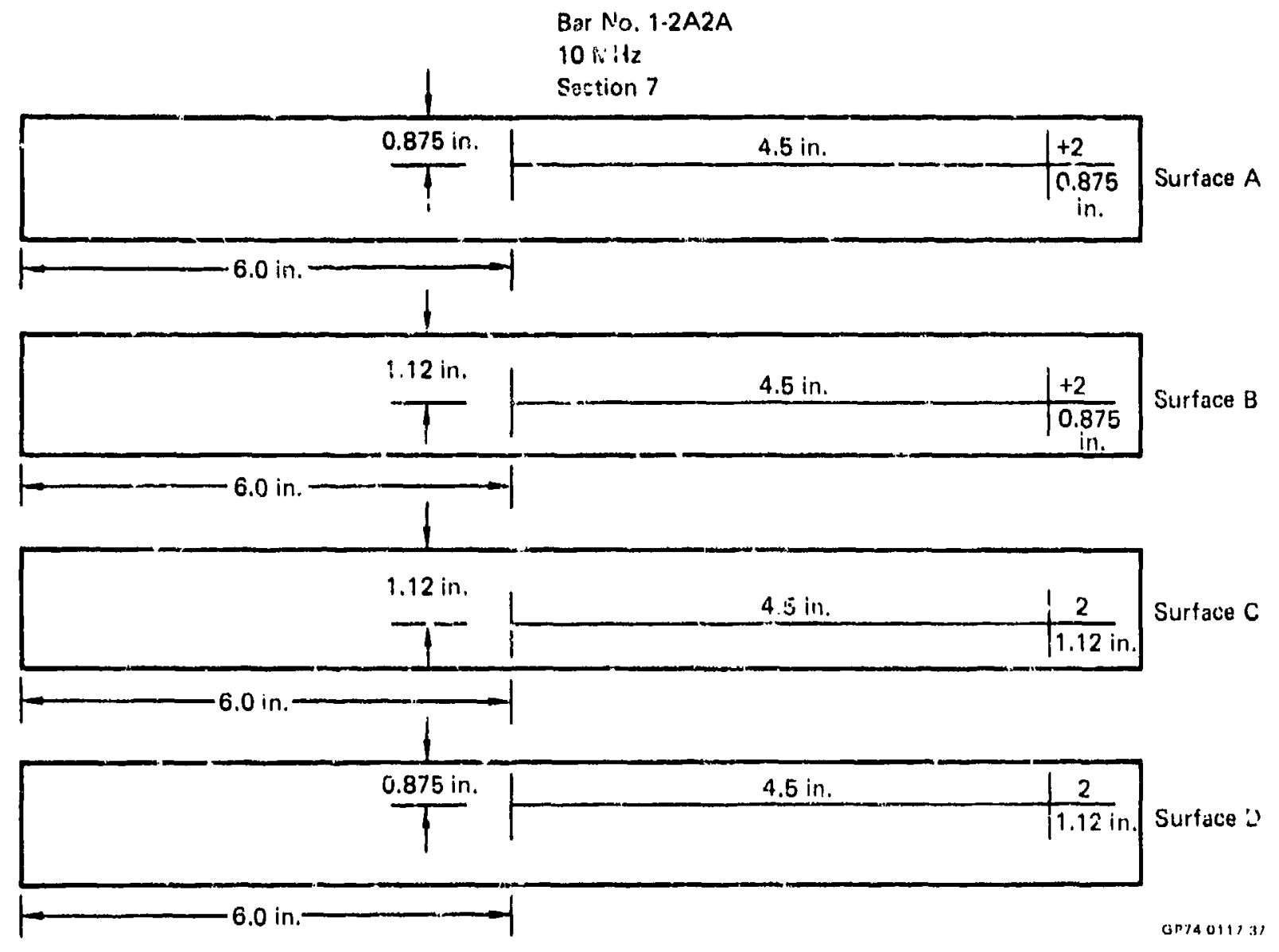

FIGURE 132 (Continued)

LOCATION OF DEFECTS IN BAR 
Bar No. 1.2A2B

$5 \mathrm{MHz}$

Section 1
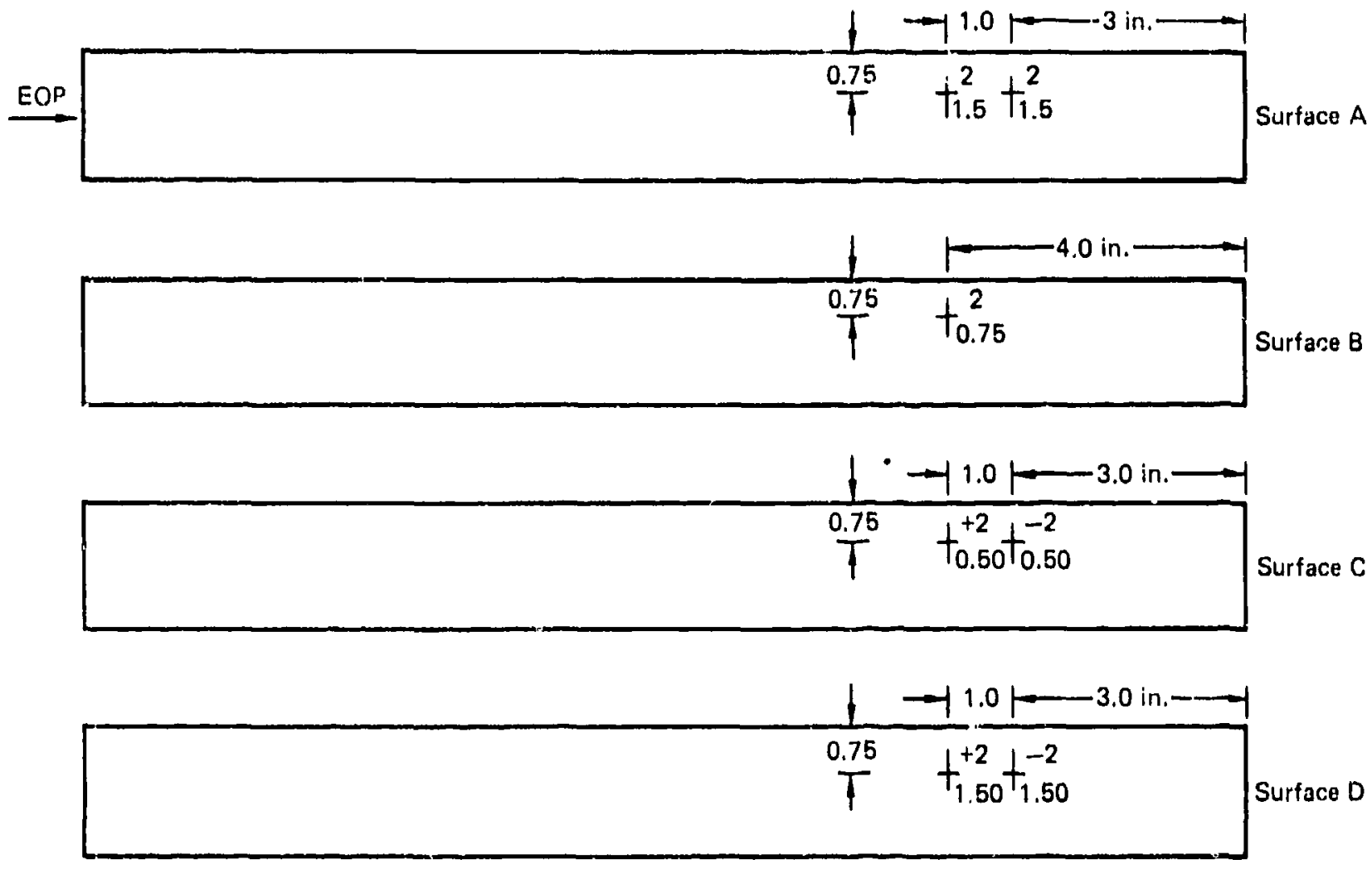

FIGURE 132 (Continued)

LOCATION OF DEFECTS IN BAR 


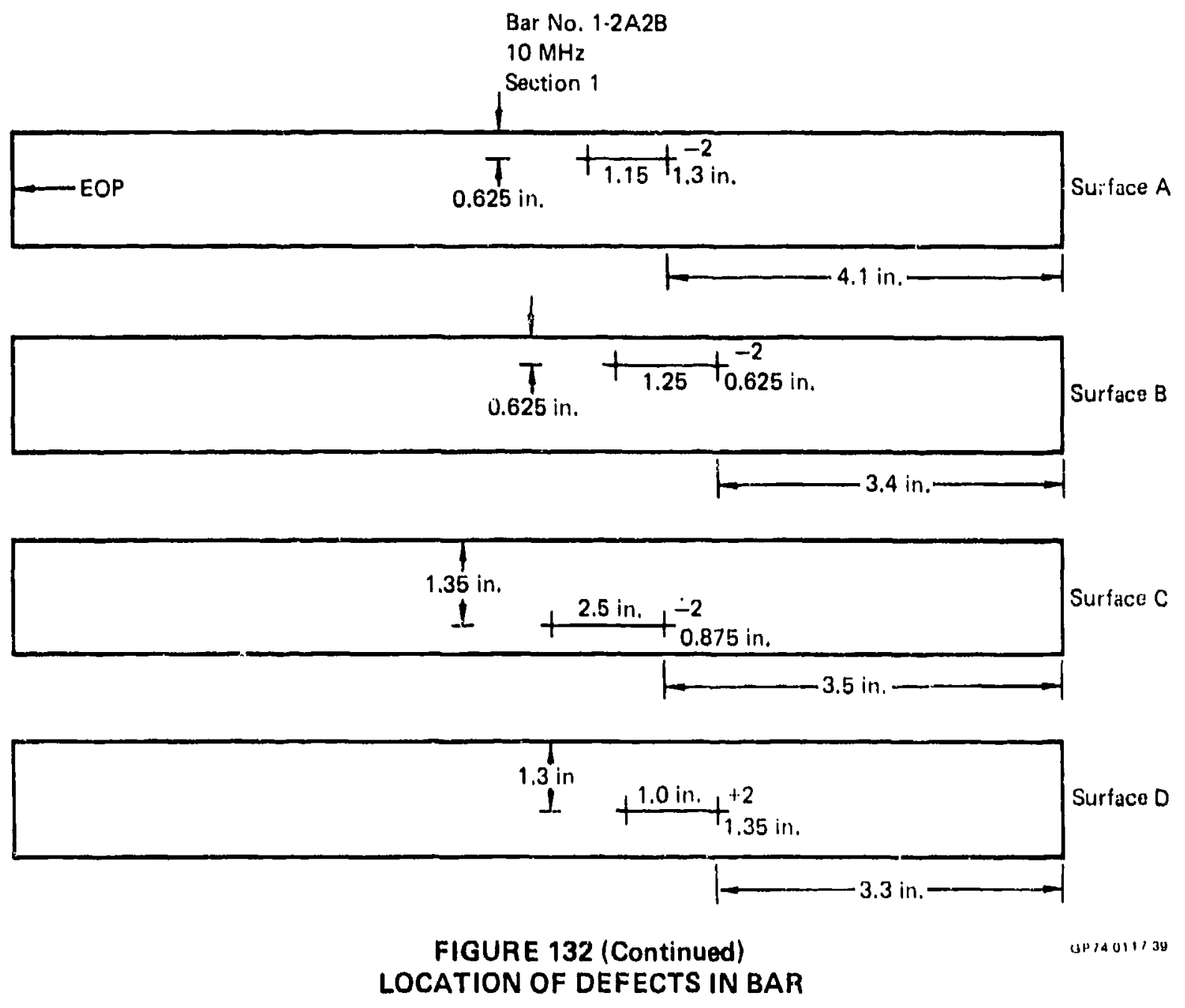


Bar No. 1-2A2B

$5 \mathrm{MHz}$

Section 6

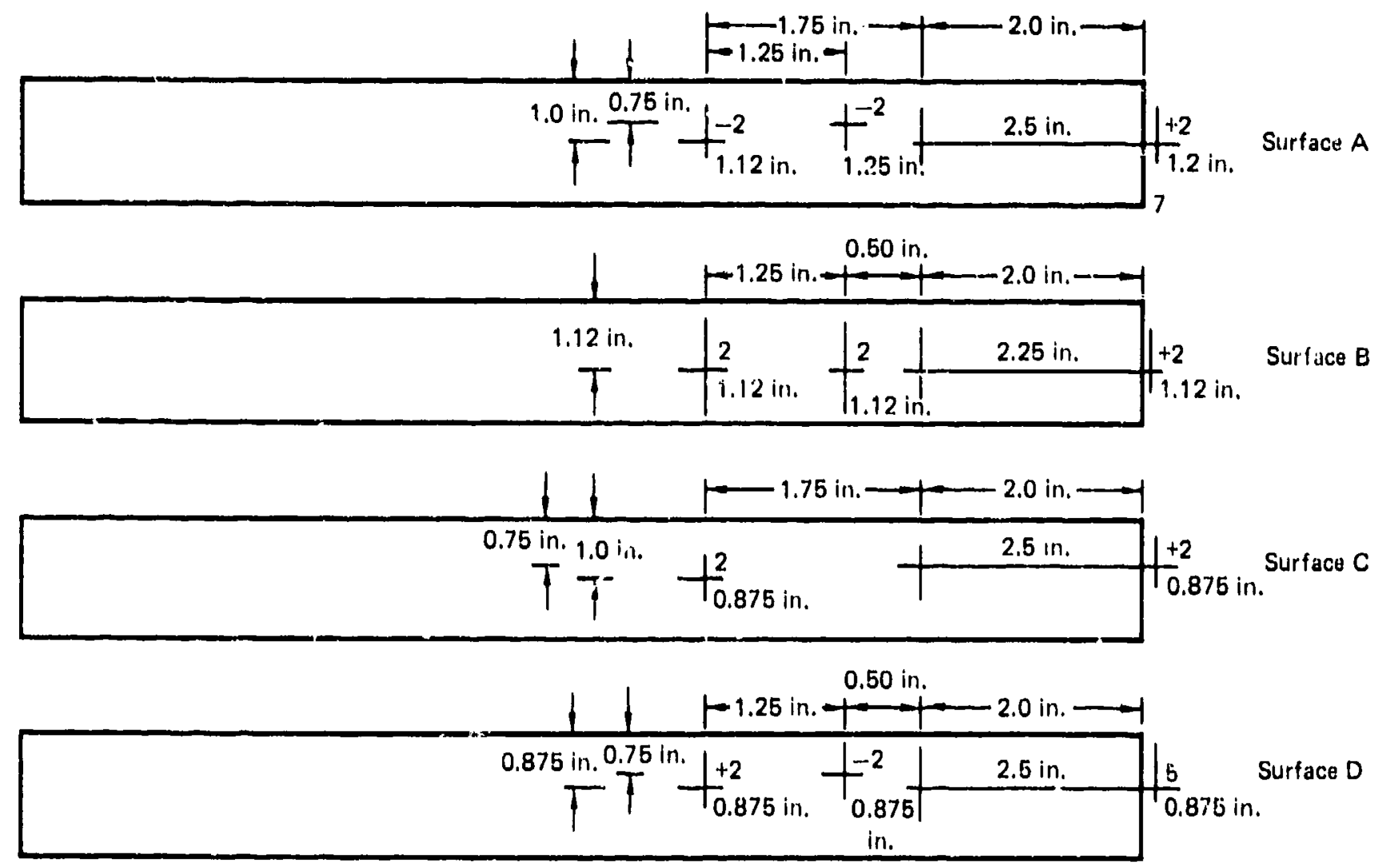

FIGURE 132 (Continued)

LOCATION OF DEFECTS IN BAR 
Bar No. 1.2A2B

$10 \mathrm{MHz}$

Section 6

$1.15 \mathrm{in.} 7$

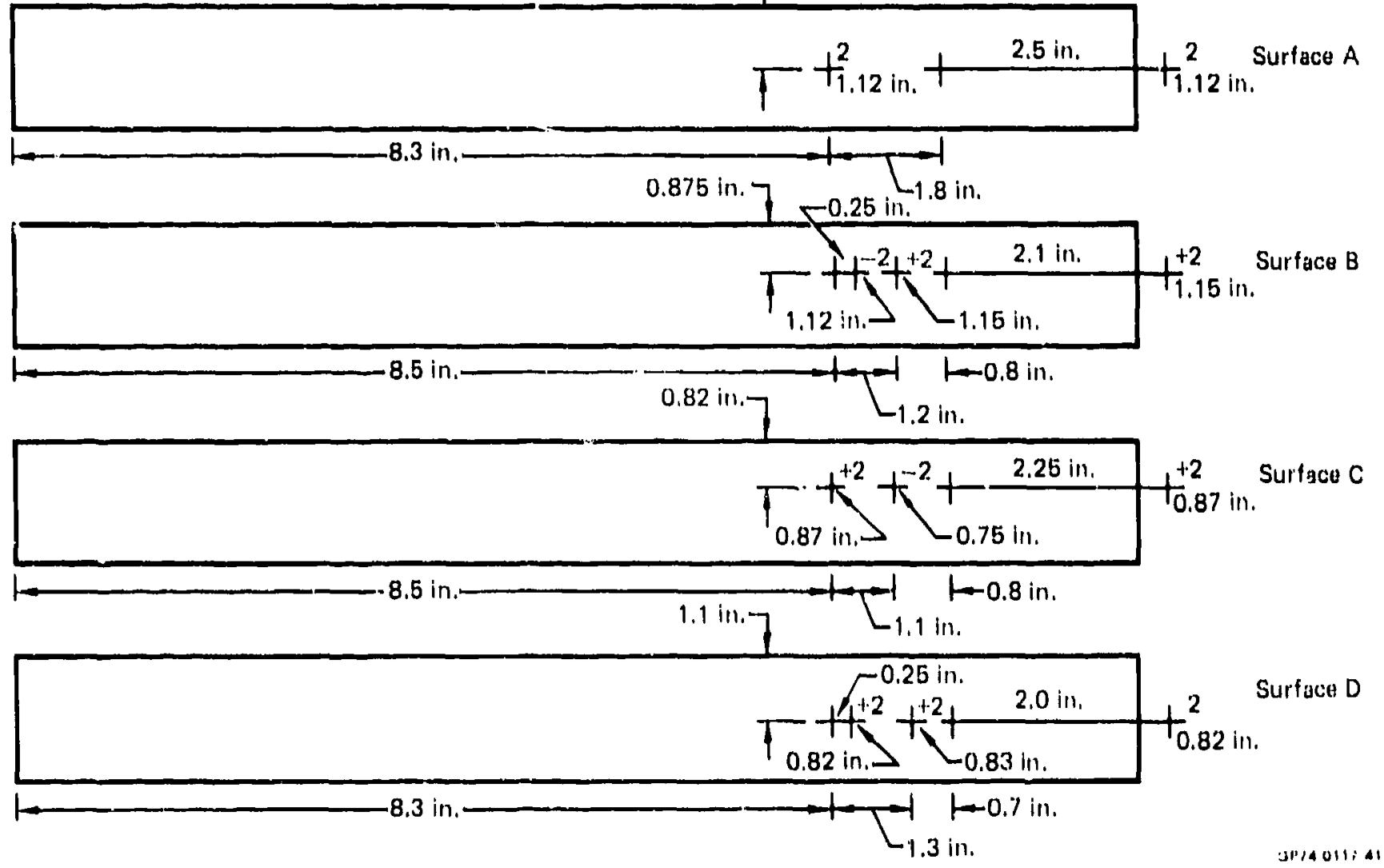

FIGURE 132 (Continued)

LOCATION OF DEFECTS IN BAR 
Bar No. 1.2A2D

$5 \mathrm{MHz}$

Section 1

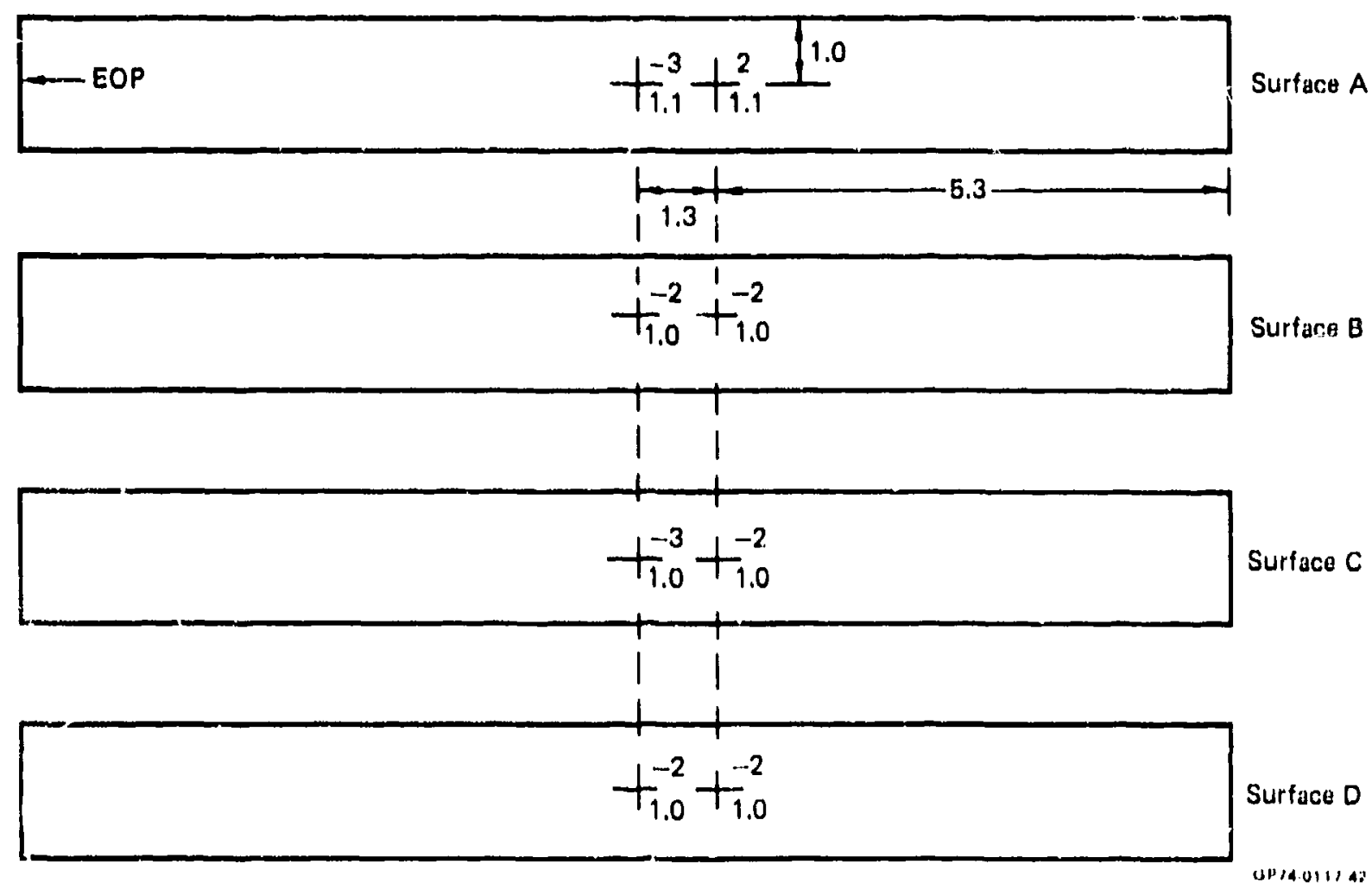

FIGURE 132 (Continued)

LOCATION OF DEFECTS IN BAR 
Bar No. 1.2A2D

$10 \mathrm{MHz}$

Section 1

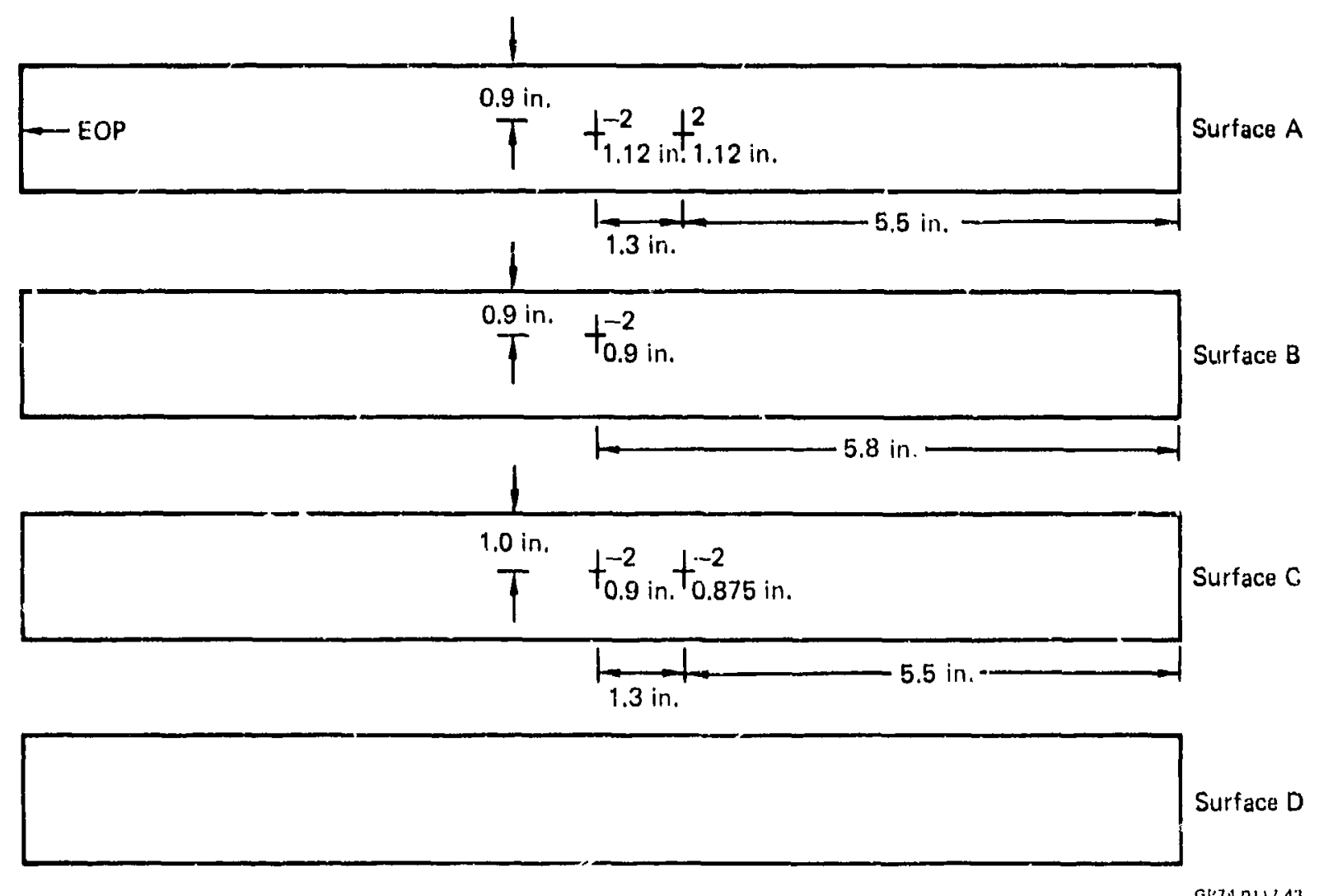

:IGURE 132 (Continued)

I.UCATION OF DEFECTS IN BAR 
Bar No. 1-2A2E

$5 \mathrm{MHz}$

Saction 4

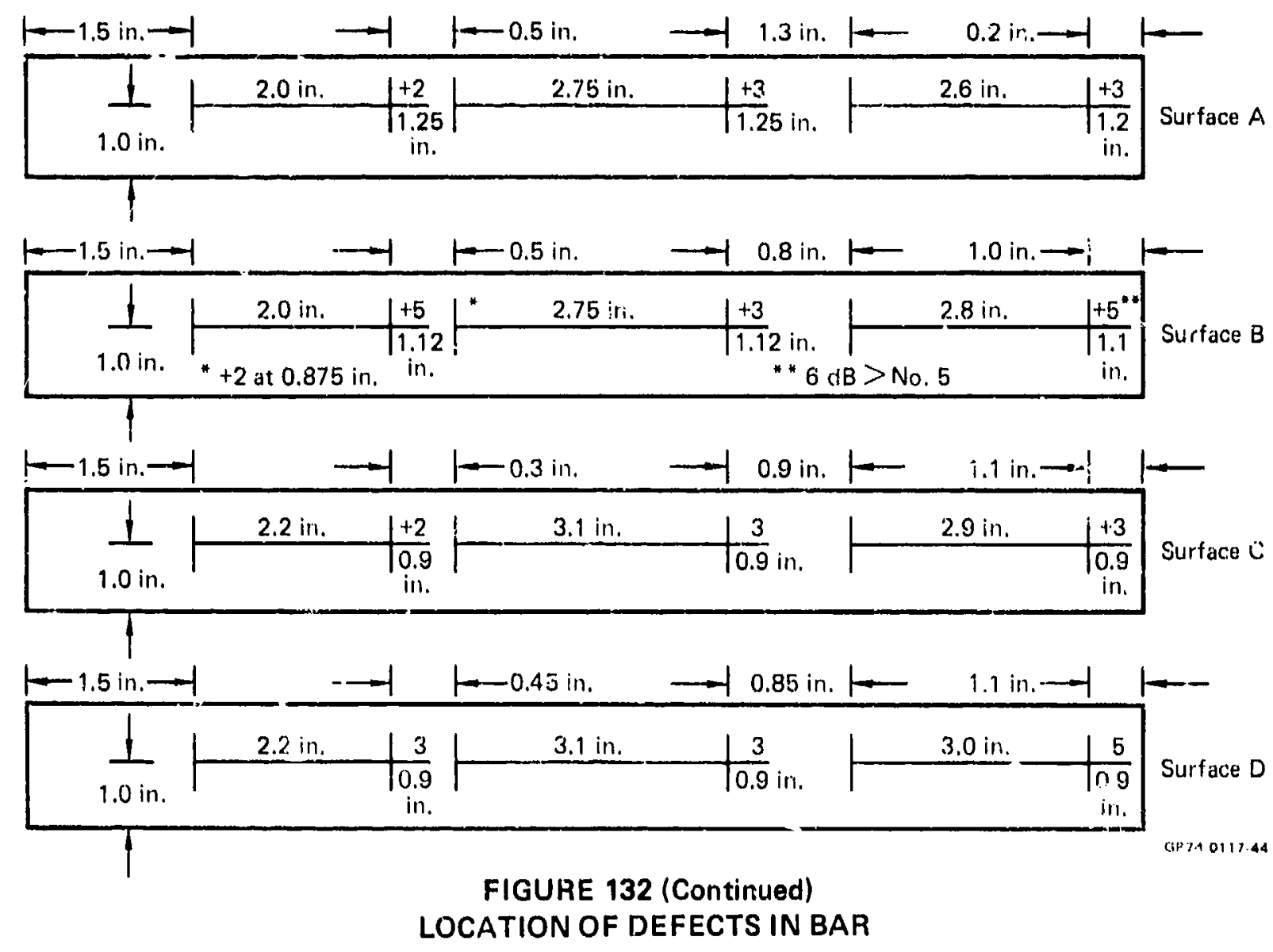




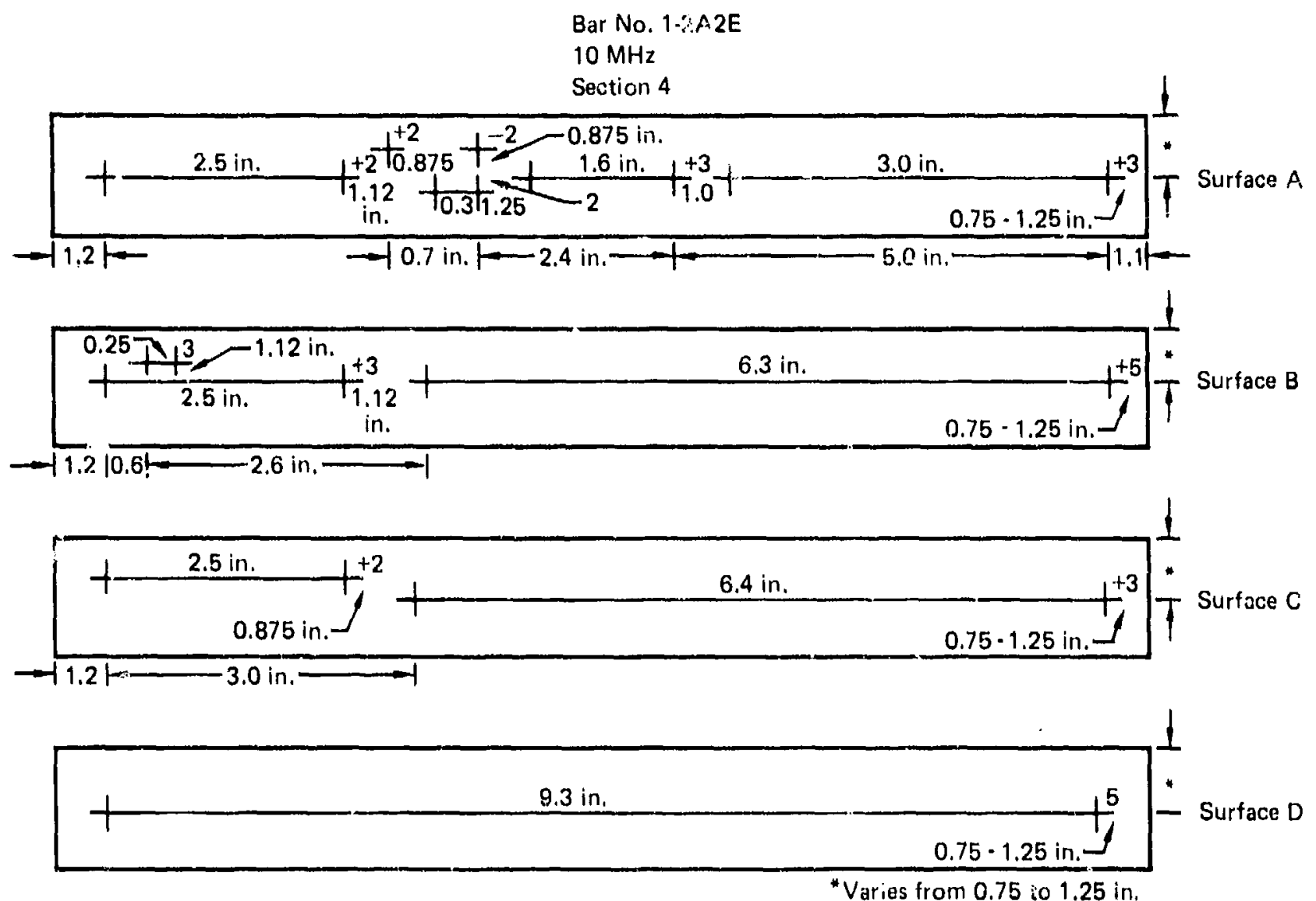

FIGURE 132 (Continued)

LOCATION OF DEFECTS IN BAR 
Bar No. 1-2A2E

$5 \mathrm{MHz}$

Section 5

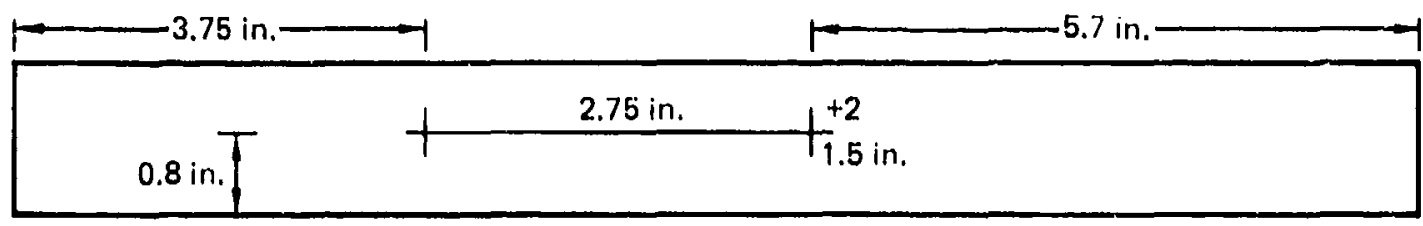

Surface $A$

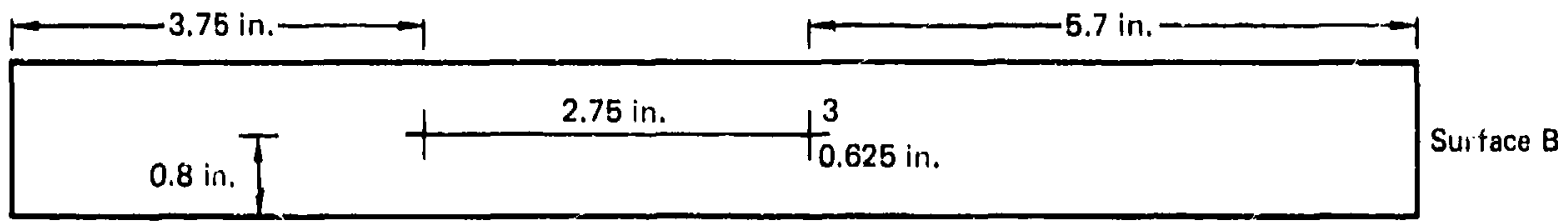

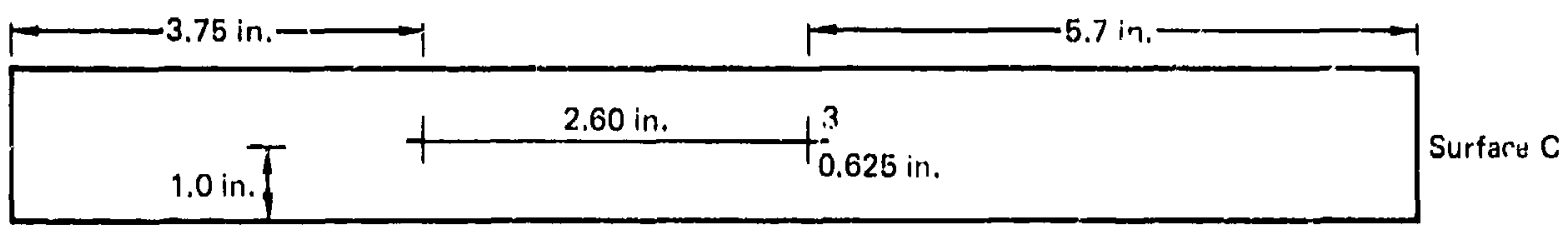

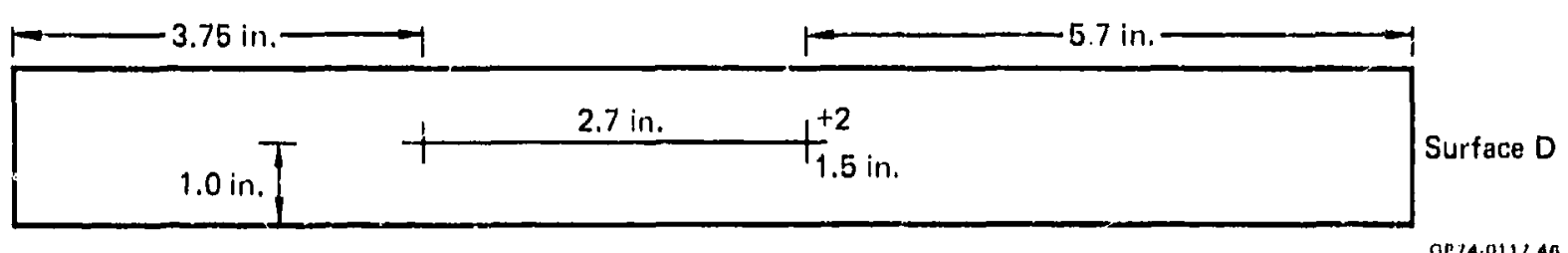

FIGURE 132 (Continued) LOCATION OF DEFECTS IN BAR 


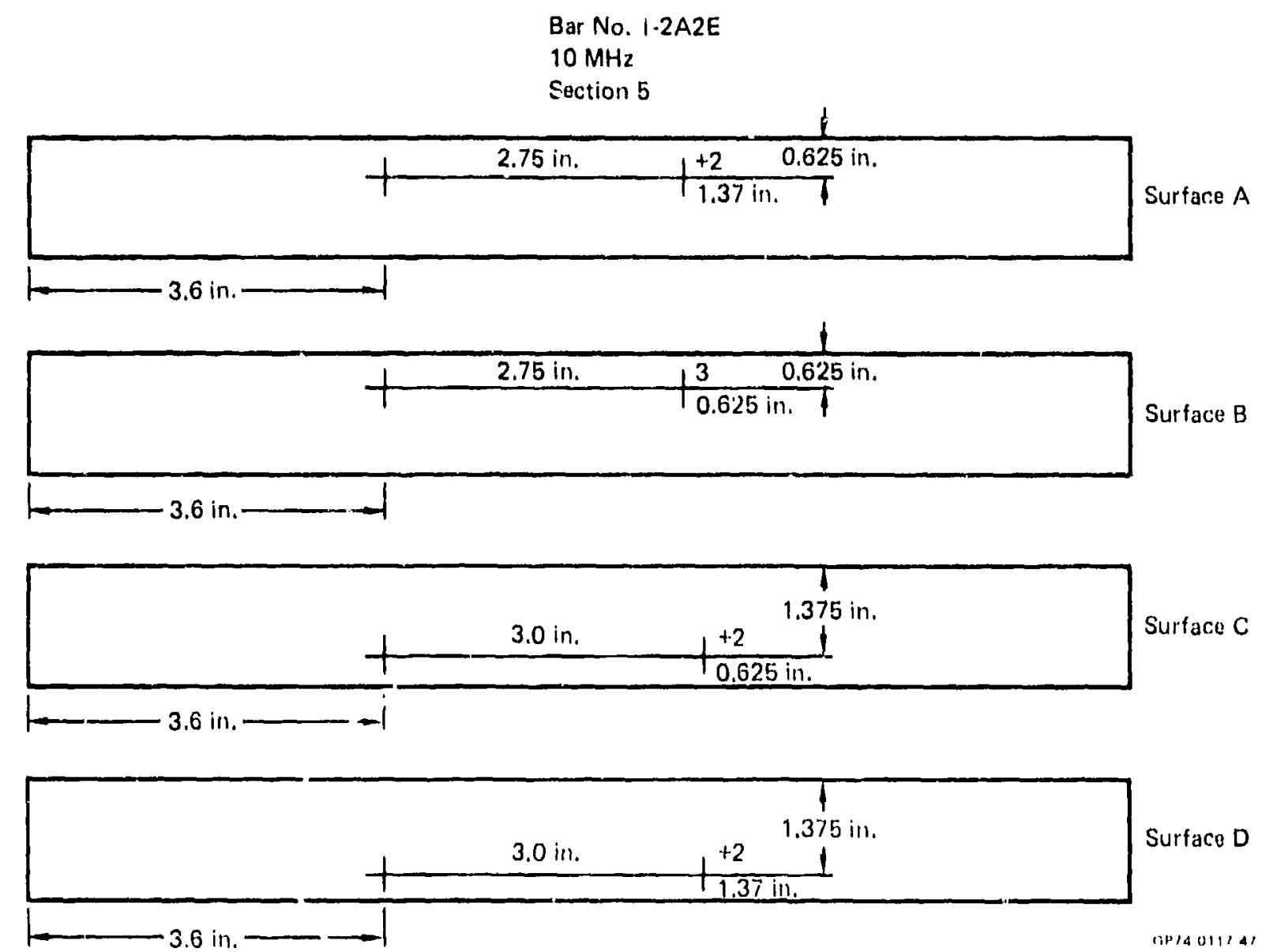

FIGURE 132 (Continued)

LOCATION OF DEFECTS IN BAR 
Next, the $5 \mathrm{MHz}$ search unit was attached and adjusted for a 3 inch water path and a refracted sound beam angle in the bar of 45 degrees \pm 5 degrees. A distance - amplitude correction (DAC) curve was developed using the side-drilled 5/64 inch diameter holes in the reference standard. The search unit was located for solund entry points $1,2,3,4$, and 5 shown in Figure 133. The signal amplitude was adjusted to 80 percent of saturation at whichever point gave the highest amplitude signal. Without changing the gain control, the search unit was positioned at the other points, the signel amplitudes were marked on the cuthode ray tube (CRT), and the points were joined by a smooth curve. Then, the search unit was located at Position 6 and the iastrument gain was adjusted to bring the response from the $2 / 64$ inch diameter hole to colncide with Point 2 on the DAC curve.

The scan injex was .25 inch. This index was chosen using the scanning gain by determining the total traversing distance across the reference standard through which no less than 50 percent of the DAC curve response is obtained. Each oar was scanned using Surface $A$ as the sound entry surface. The scauning direction was parallel to the 7 foot length of each bar. All discontinuities whose amplitude exceeded 50 percent of the DAC curve were evaluated further for reject or accept status.

None of the bars exhibited ultrasonic responses which exceeded 50 percent of the DAC curve, however. This was true even for those areas where discontinuities were detected previously by straight beam testing. Subsequent metallographic examination of the discontinuities detected by the straight beam tests indicated that most of the segregates were somewhat planar and oriented parallel to the sound entry surface. Such an orientation would favor detection by straight beam techniques but, apparently, would be unfavorable for an angle beam test.

\section{RADIOGLAPHIC INSPECTION}

The bar was radiographically inspected using the production radiographic facilities. The procedure was the same as for the plate except the exposures were made at $210 \mathrm{KV}$ and $10 \mathrm{milliamps}$ for 15 minutes.

As with the plate, none of the Type I alpha segregates detected ultrasonically were observed on the radiographs.

\section{SEGREGATES - AIRFRAME FORGINGS}

a. Ultracilic Inspection

Each of the airframe forgings were inspected using the straight beam immersion method. A $3 / \delta$ inch diameter, $10 \mathrm{MHz}$ lithium sulfate search unit ( S,'N 15384) was used with a Sperry IJM721 ultrasonic instrument and a $10 \mathrm{~S} \mathrm{~dB}$ pulser/receiver. The water path was 3 inches $\pm 1 / 3$ inch.

Cunmercially produced $\mathrm{Ti}-6 \mathrm{Al}-4 \mathrm{~V}$ reference standards with $3 / 64$ inch diameter flat bottom holes at metal travels of $1 / 8,1 / 4,1 / 2,3 / 4,1$, $1-1 / 4$, and $1-3 / 4$ inches were used for calibration. These reference standards were ASTM - type straight beam reference standards. 
(6)

(2) (1) (5)

(3)

(4)
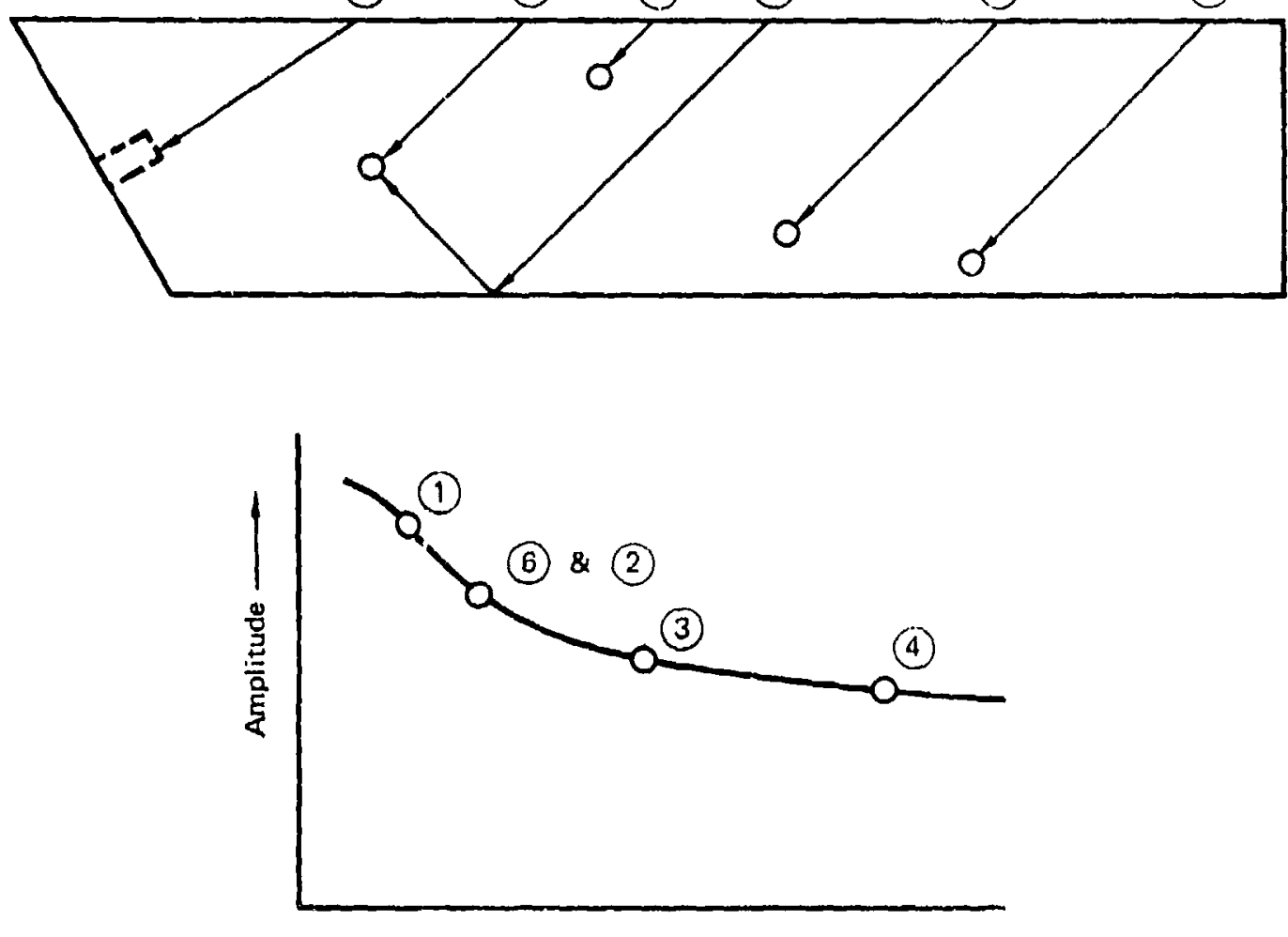

Metal Travel Distance

FIGURE 133

SOUND ENTRY POINTS USED TO ESTABLISH THE DAC CURVE 
Initially, a distance-amplitude correction (DAC) curve was constructed by positioning the search unit for maximum response from the $3 / 64$ inch diameter flat botton hole which exhibited the largest amplitude signal. The signal amplitude was adjusted to 80 percent of saturation on the cathode ray tube (CRT). Without changing the gain control, the search unit was positioned over the remaining reference standards and the amplitudes were marked on the CRT screen. The points were joined by a smooth curve.

In order to increase the test sensitivity, an attempt was made to inspect the forgings at a higher scanning gain. A total of $7 \mathrm{~dB}$ of attenuation was removed which is equivalent to calibrating with a $2 / 64$ inch diameter flat bottom hole. At this goin level, the ultrasonic noise in the forgings was less than 25 percent of the DAC curve.

A check was inade for the difference in sound transmission characteristics between the reference standards and the forgings. At the gain level established above, the decibel ( $d B$ ) difference was noted between the back surface response in the forging and in a reference standard with the same metal travel. This was done at approximately 10 locations in each of 4 of the forgings. The average $\mathrm{dB}$ difference was $2 \mathrm{~dB}$. It was decided that this difference was insignificant and no corrections were made for it.

The scal index was 0.25 inch. This was chosen using the scanning gain by determining the total traversing distance across the reference standards through which no less than 50 percent of the DAC curve is obtained.

The scan plan for the forgings is shown in Figure 134. As can be seen the thin sections were scanned from opposite sides to improve the inspectability near the sound entry surface. Each discontinuity whose amplitude exceeded 50 percent of the DAC curve was evaluated further. The search unit was manipulated to maximize the response from the discontinuity and, if the maximized response equalled or exceeded the DAC curve, the location of the discontinuity was marked on the surface of the forging. A summary of the results in shown in Figure 135. As can been seen, ultrasonic indications were found in Forging No. 1 which is from the bottom of the original ingot and Forging No's 5 and 7 from the top of the original ingot. 

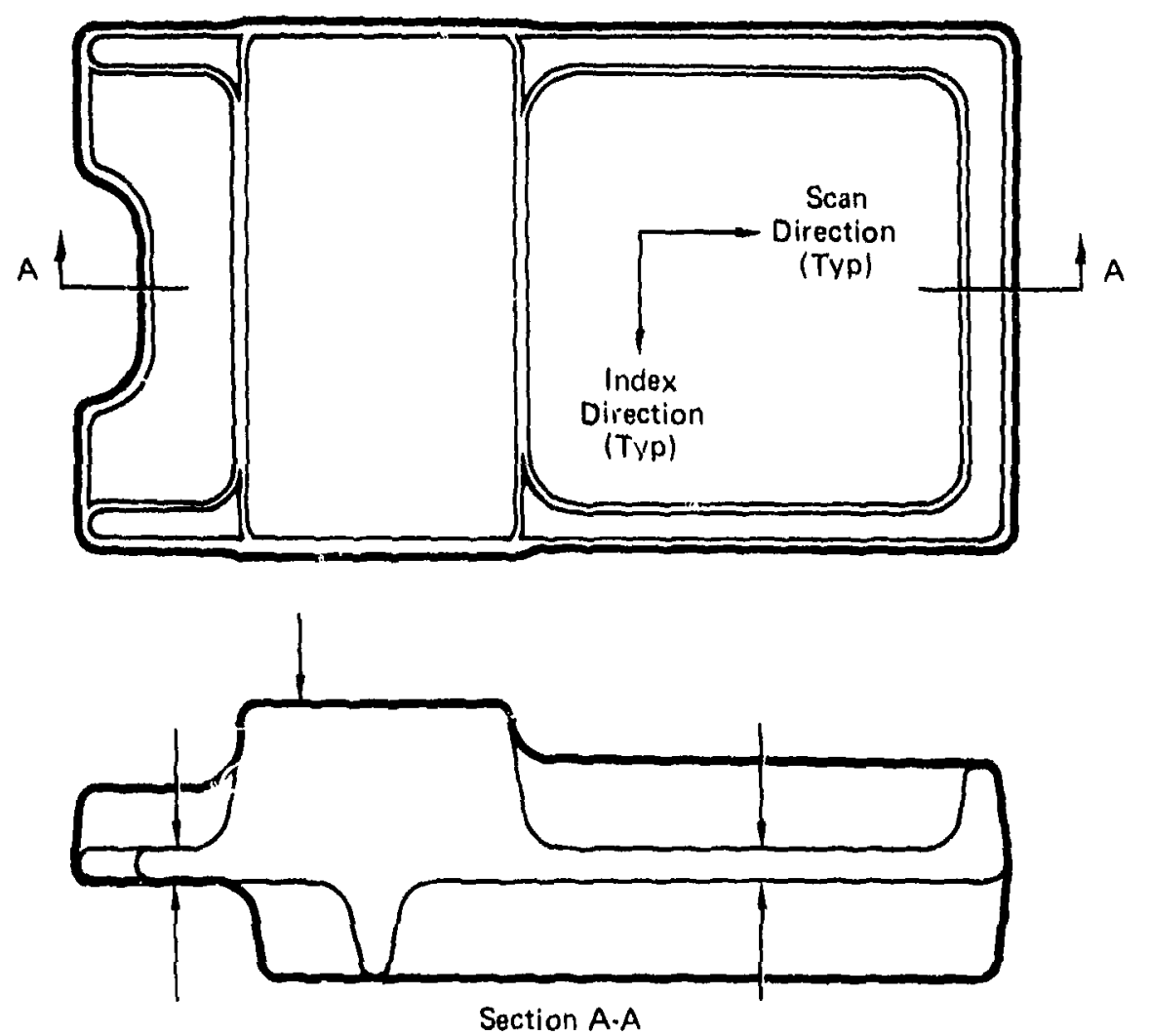

FIGURE 134

QP74011/230 SCAN PLAN FOR AIRFRAME FORGINGS 

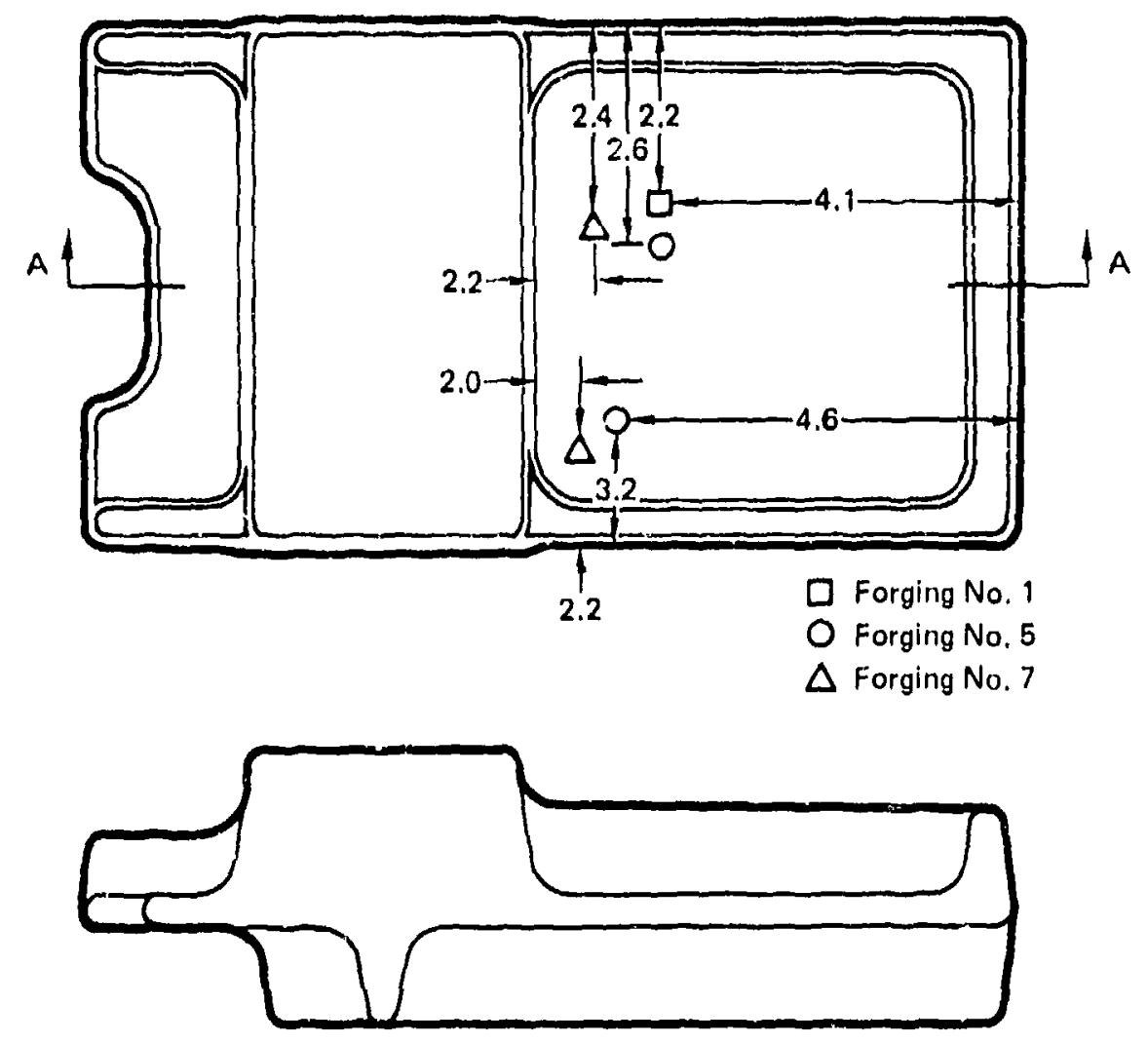

Section A.A

FIGURE 135

ULTRASONIC INDICATIONS IN AIRFRAME FORGINGS 
8. METALIOGRAPHIC EXAMINATION OF SEGREGATES IN BAR, PLATE, AIND FORGIN 1 S

Several discontinuities which were detected during the ultrasonic inspections were sectioned and examined metallographicaliy. Those discon tinuities which were examined are listed below.

Part No U1trasonic Response As Length (Inches) Depth (Inches)

\begin{tabular}{|c|c|c|c|}
\hline $\begin{array}{l}\text { Bar } 1-2 A 2 B \\
\text { Section } 1\end{array}$ & $\begin{array}{l}\text { Less than No } 2 \text { flat } \\
\text { bottom hole }\end{array}$ & 1.15 & 1.30 \\
\hline $\begin{array}{l}\text { Bar 1-2A2B } \\
\text { Section } 6\end{array}$ & $\begin{array}{l}\text { No } 2 \text { flat bottom } \\
\text { hole }\end{array}$ & 2.50 & 1.12 \\
\hline $\begin{array}{l}\text { Bar } 1-2 \mathrm{~A} 2 \mathrm{E} \\
\text { Section } 4\end{array}$ & $\begin{array}{l}\text { Greater than No } 5 \\
\text { flat bottom hole }\end{array}$ & 9.3 & 0.75 \\
\hline $\begin{array}{l}\text { Bar 1-2A2E } \\
\text { Section } 5\end{array}$ & $\begin{array}{l}\text { Greater than No } 2 \\
\text { flat bottom hole }\end{array}$ & 3.0 & 1.37 \\
\hline $\begin{array}{l}\text { Plate A - } \\
\text { Skction } 3\end{array}$ & $\begin{array}{l}\text { Greater than No } 5 \\
\text { flat bottom hole }\end{array}$ & 5.0 & 0.63 \\
\hline $\begin{array}{l}\text { Plate A - } \\
\text { Section } 17\end{array}$ & No 2 flat bottom hole & 0.75 & 0.50 \\
\hline $\begin{array}{l}\text { Plate A - } \\
\text { Skction } 18\end{array}$ & No 2 flat bottom hole & 0.50 & 0.63 \\
\hline $\begin{array}{l}\text { Airframe } \\
\text { Forging No } 7\end{array}$ & $\begin{array}{l}\text { Greater than No } 2 \text { flat } \\
\text { bottom hole }\end{array}$ & & \\
\hline $\begin{array}{l}\text { Airframe } \\
\text { Forging No } 4\end{array}$ & - & - & - \\
\hline $\begin{array}{l}\text { Engine Disk } \\
\text { Forging No } 4\end{array}$ & - & - & - \\
\hline $\begin{array}{l}\text { Engine Disk } \\
\text { Forging No } 6\end{array}$ & - & - & - \\
\hline $\begin{array}{l}\text { Engine Disk } \\
\text { Forging No } 7\end{array}$ & - & - & - \\
\hline
\end{tabular}

(1) Results of $10 \mathrm{MHz}$ straight beam immersion test 
Photomicrographs of the discontinuities found metallographically in the bar and plate are shown in Figures 136 through 142. A sumary of the size of each is documented in Table 97.

TABLE 97

DIMENSIONS OF TYPE I ALPHA STABILIZED DEFECTS

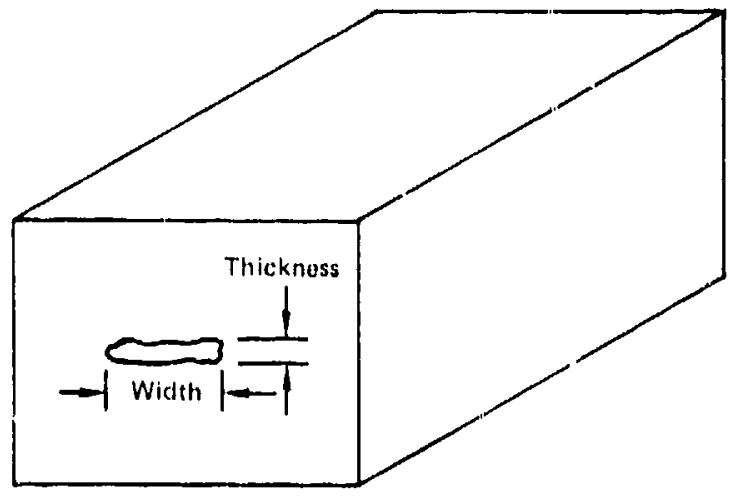

\begin{tabular}{|c|c|c|}
\hline $\begin{array}{l}\text { Location } \\
\text { of } \\
\text { Segregate }\end{array}$ & $\begin{array}{l}\text { Width } \\
\text { (in.) }\end{array}$ & $\begin{array}{l}\text { Thickness } \\
\text { (in.) }\end{array}$ \\
\hline $\begin{array}{l}\text { Bar } 1.2 A 2 B \\
\text { Section } 1\end{array}$ & 0.20 & 0.03 \\
\hline $\begin{array}{l}\text { Bar } 1.2 A 2 B \\
\text { Section } 6\end{array}$ & 0.02 & 0.01 \\
\hline $\begin{array}{l}\text { Bar 1.2A2E } \\
\text { Section } 4\end{array}$ & 0.09 & 0.02 \\
\hline $\begin{array}{l}\text { Bar } 1.2 \mathrm{~A} 2 \mathrm{E} \\
\text { Section } 5\end{array}$ & 0.18 & 0.03 \\
\hline Plate A - Section 3 & 0.28 & 0.006 \\
\hline Platte A - Section 17 & 0.23 & 0.05 \\
\hline Plate A-Section 18 & 0.21 & 0.03 \\
\hline
\end{tabular}

GP1401144

The discontinuities in the bar and plate all were from material which originated from the bottom of the ingot. This area had been seeded with nitrided sponge to induce Type I alpha stabilized defects. The detected discontinuities all had the cheracteristics of Type I segregates as described in "Characterization of Alpha Segregation Defects In 'Iitanium GAl-4V Alloy" by li. H. Crala in AFMT TR 68-304. In each, there was evidence of crack:; and/or volds associated with alpha stabilized phase.

'The cross acction.; taken trrough Airframe Forging No 7 were taken through both of the ultrasonile indications. The cross sections taken through Airframe fiorgink No /, were taken through two random areas since there were no ultrasonic indications in thiu forging.

There was no evidence of segregates or cracks and voids in the cross sections throush Nirframe Forging No 7 . At this point, it is not known if the ultrasonic indications were false indications or if the segregates were present but not detacied during the metallographic examination. Since there were no ultrasonic indications in the forgings from the top of the ingot, two random cross sections were taken through Airframe Forging No 4 to determine if there were type II segregates present which were not detected ultrasonically. 'i'here was no evidence of Type II segregates and, therefore, the testing was inconclusive. A typical photonicrogruph of the airframe forgine microstructure is shown in Figure 14.3. 

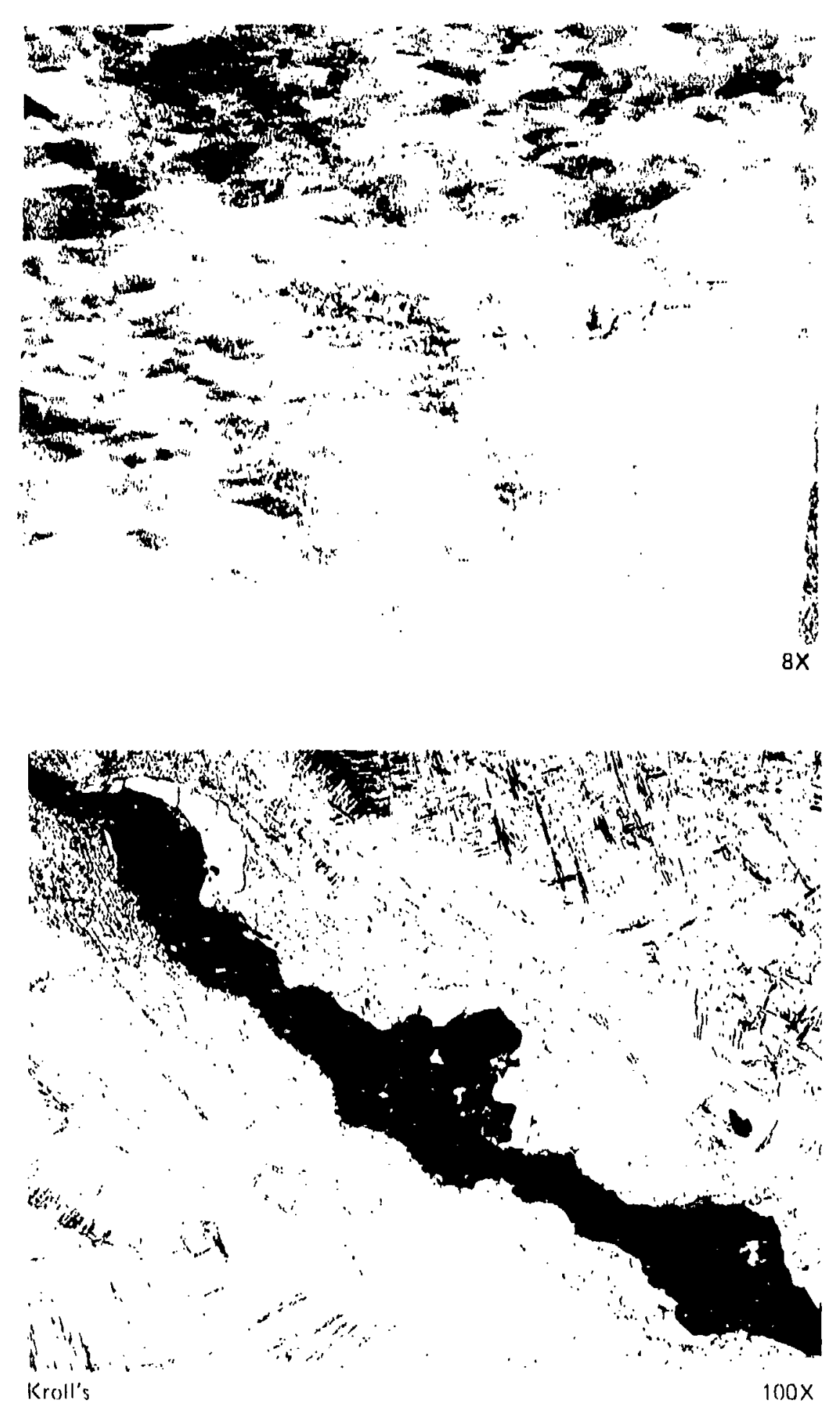

FIGURE 136

PHOTOMICROGRAPHS OF SEGREGATE IN PLATE A, SECTION 3 (RESPONSE WAS GREATER THAN NO. 5 FLAT BOTTOM HOLE) 

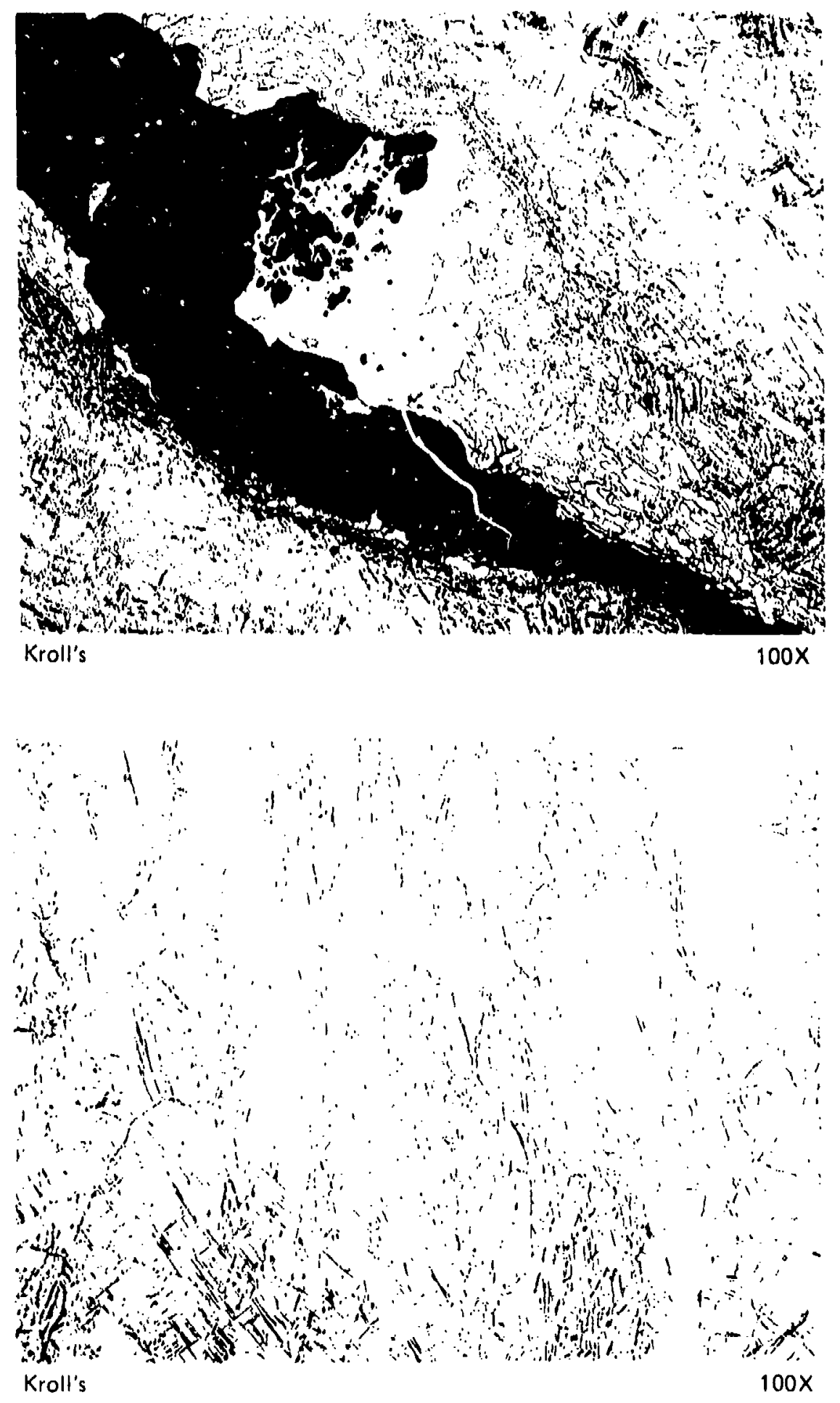

Matrix

(in) 14011101

FIGURE 136 (Continued

PHOTOMICROGRAPHS OF SEGREGATE IN PLATE A, SECTION 3 (RESPONSE WAS GREATER THAN NO. 5 FLAT BOTTOM HOLE) 

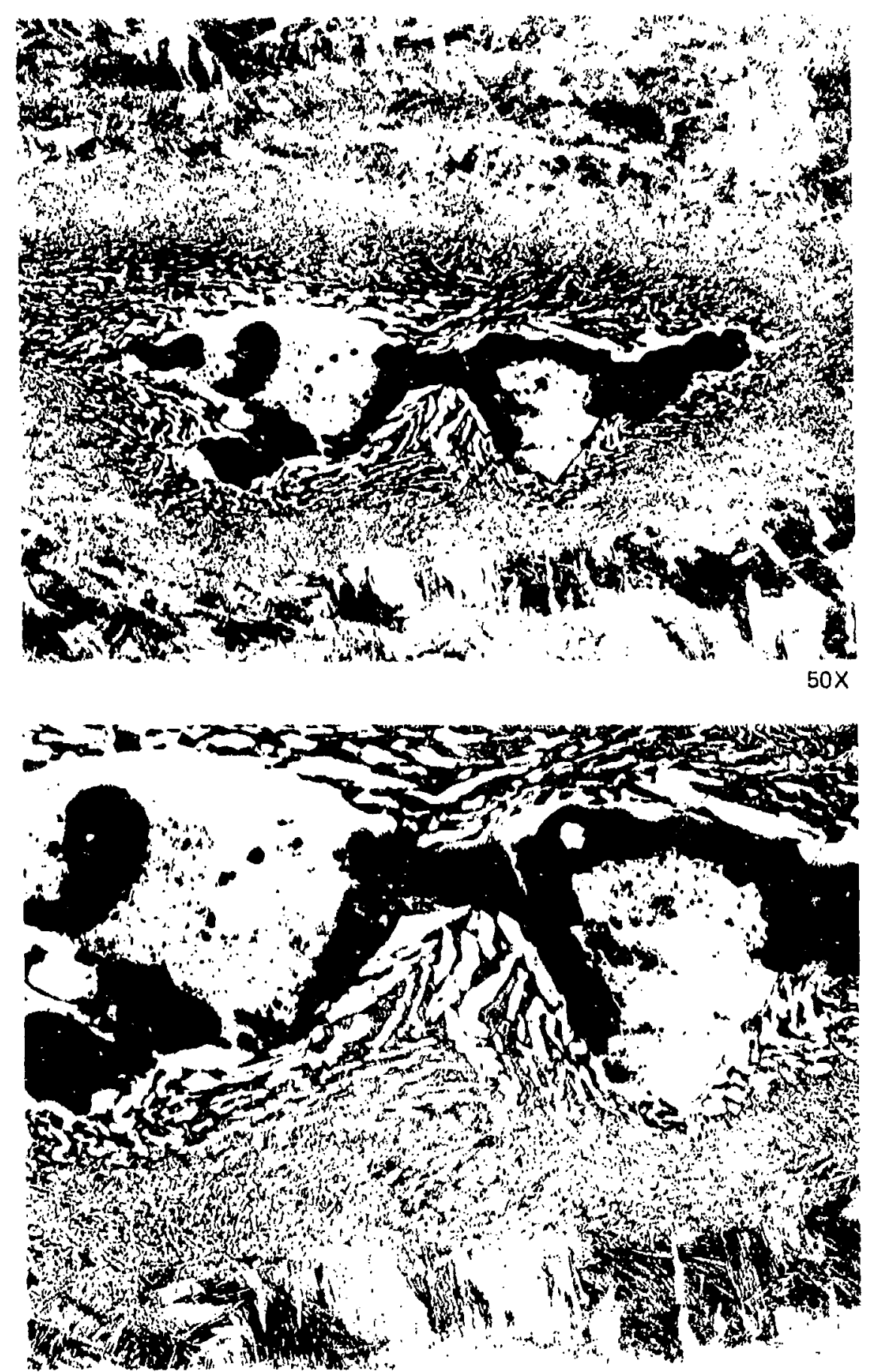

FIGURE 137

PHOTOMICROGRAPHS OF SEGHEGATE IN PLATE A, SEC YION TI IIIGONSE WAS EQUAL TONO. 2 FIAAT BOTTOM HOLEI 

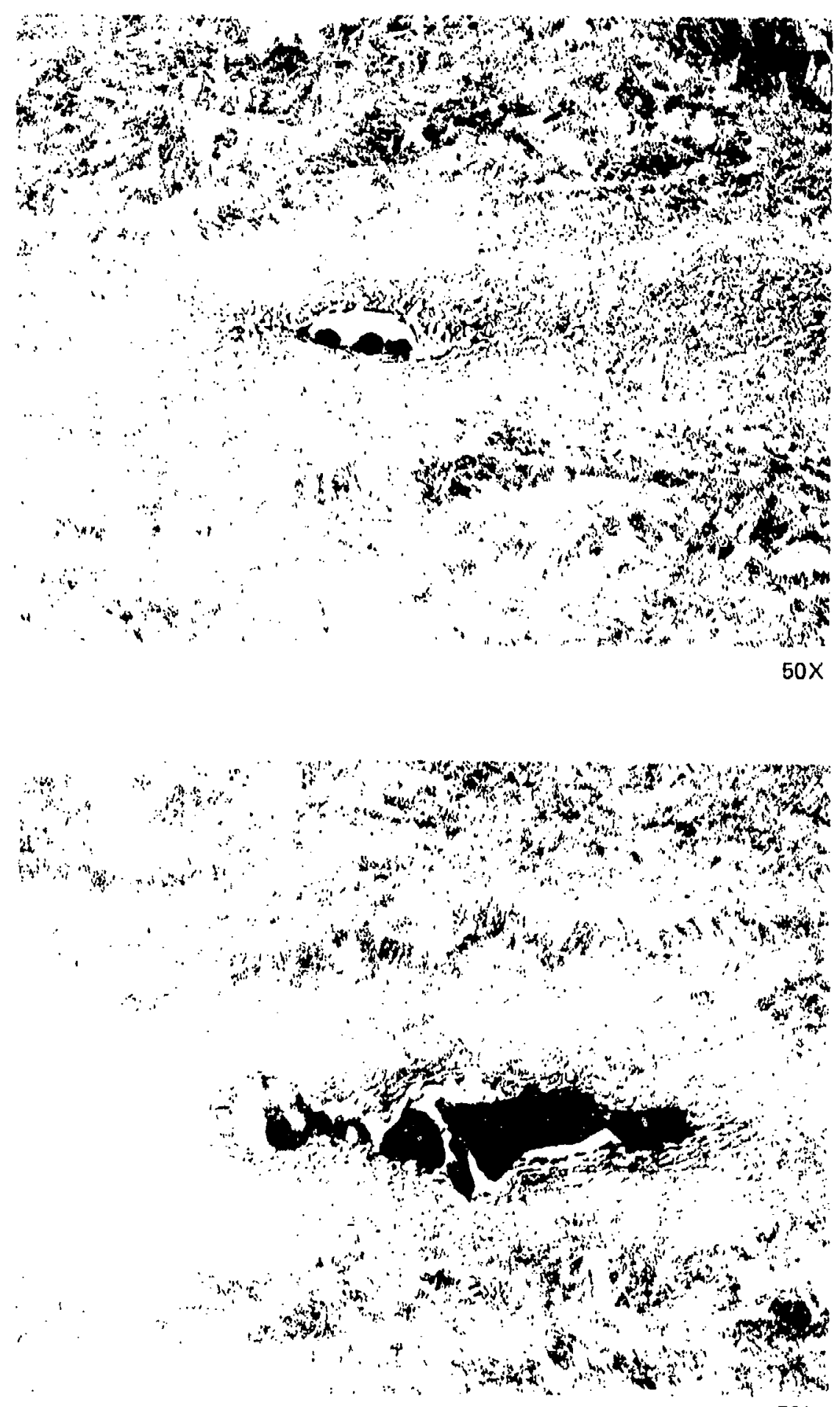

$50 x$

FIGURE 138

PHOTOMICROGRAPHS OF SEGREGATES IN PLATE A, SECTION $1 E$ (RESPONSE WAS EQUAL TO A NO. 2 FLAT BOTTOM HOLE) 


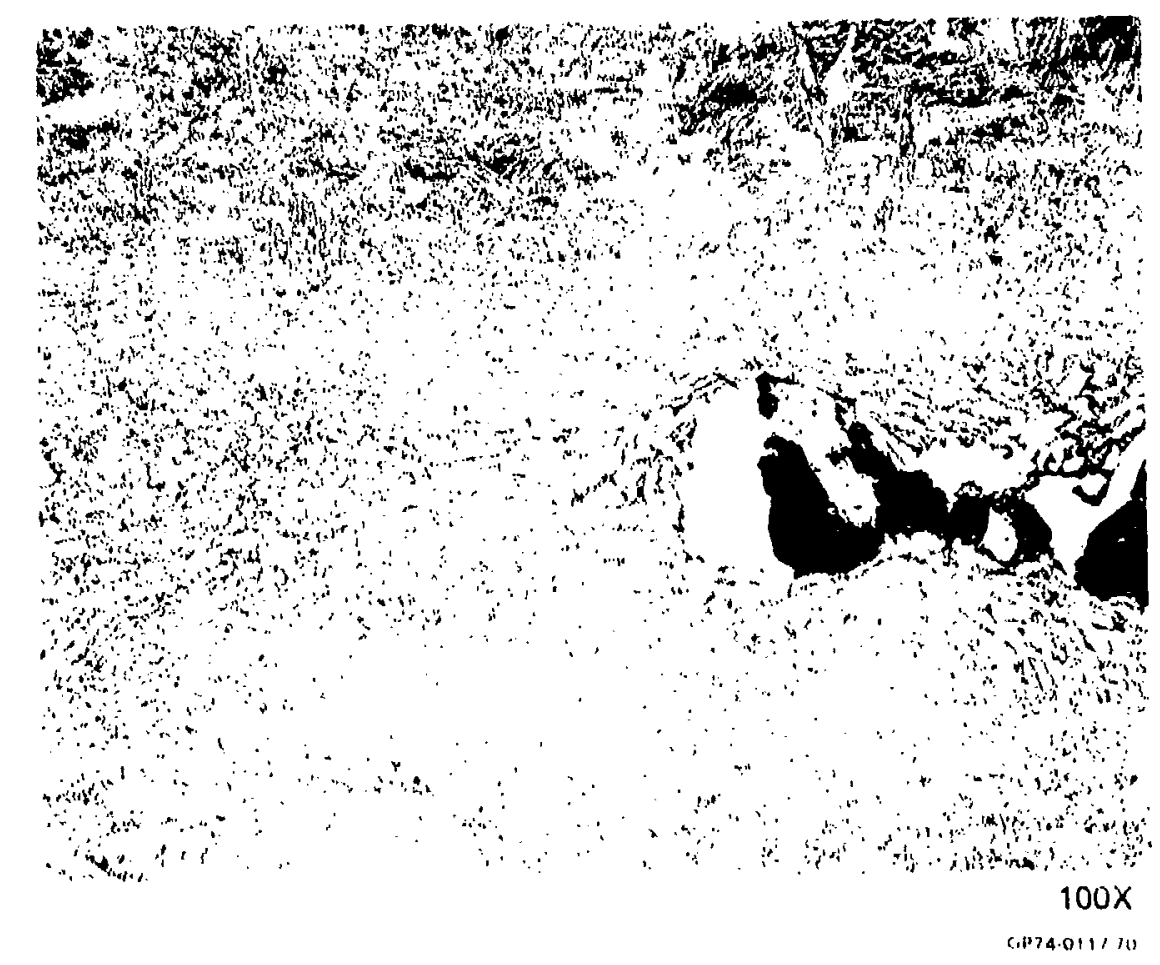

FIGURE 138 (Continued)

PHOTOMICROGRAPHS OF SFGKEGATES IN PLATE A, SECTION 18 (RESPONSE WAS EQUAL. TO A NO. 2 (FLAT BOTTOM HOLE) 


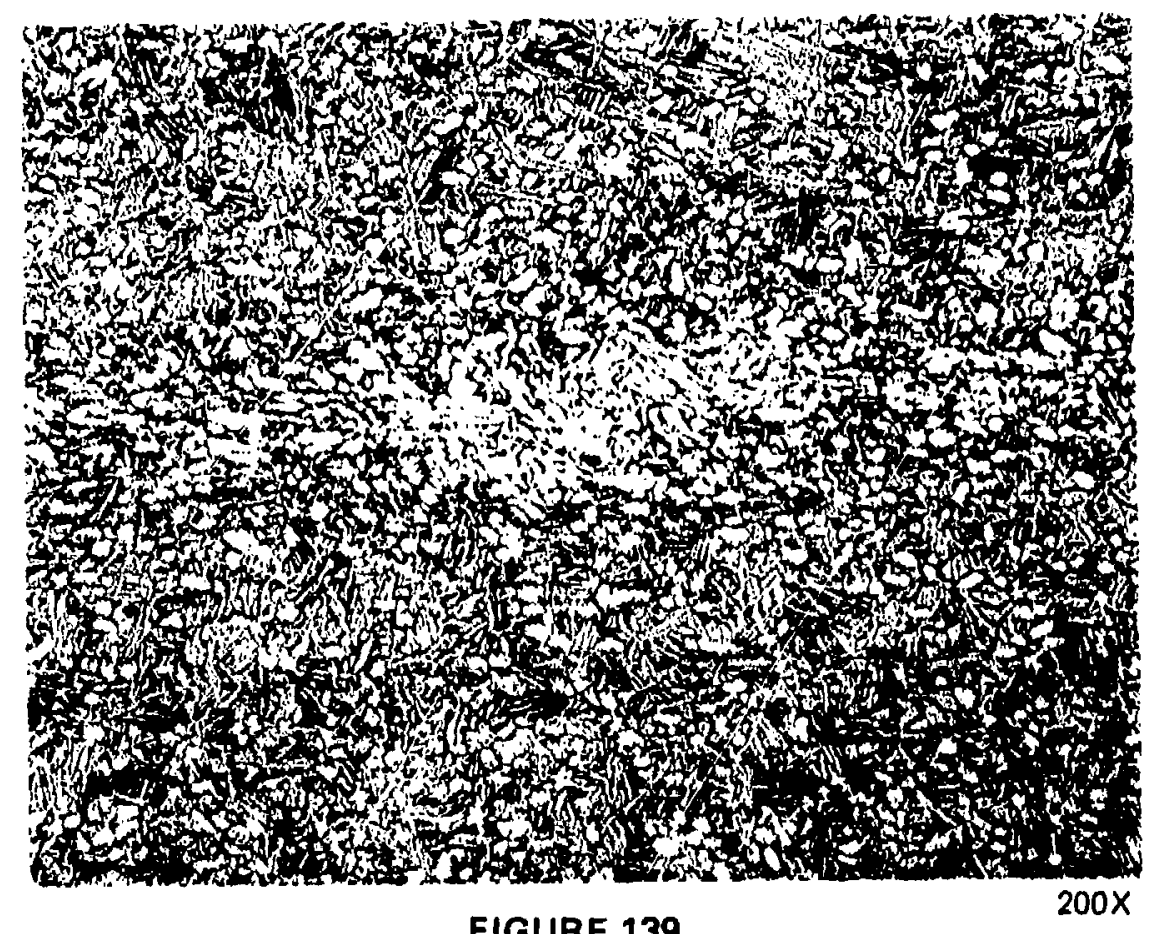

FIGURE 139

$200 x$

PHOTOMICROGRAPHS OF SEGREGATE IN BAR 1.2A2B, SECTION 1 (RESPONSE WAS LESS THAN NO. 2 FLAT BOTTOM HOLE) 


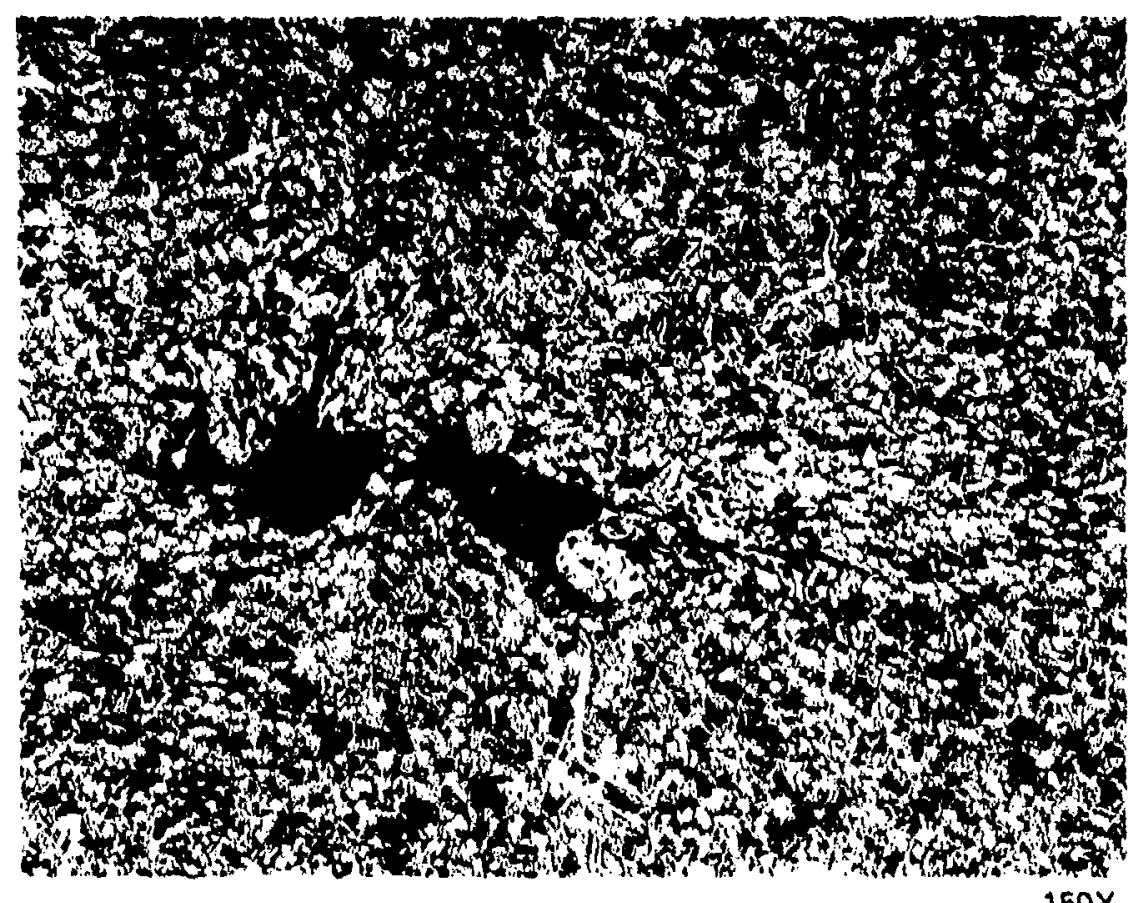

$150 x$

OP74.0111.73

FIGURE 140

PHOTOMICROGRAPHS OF SEGREGATE IN BAR 1-2A2B, SECTION 6 IRESPONSE WAS EQUAL TO NO. 2 FLAT BOTTOM HOLE) 


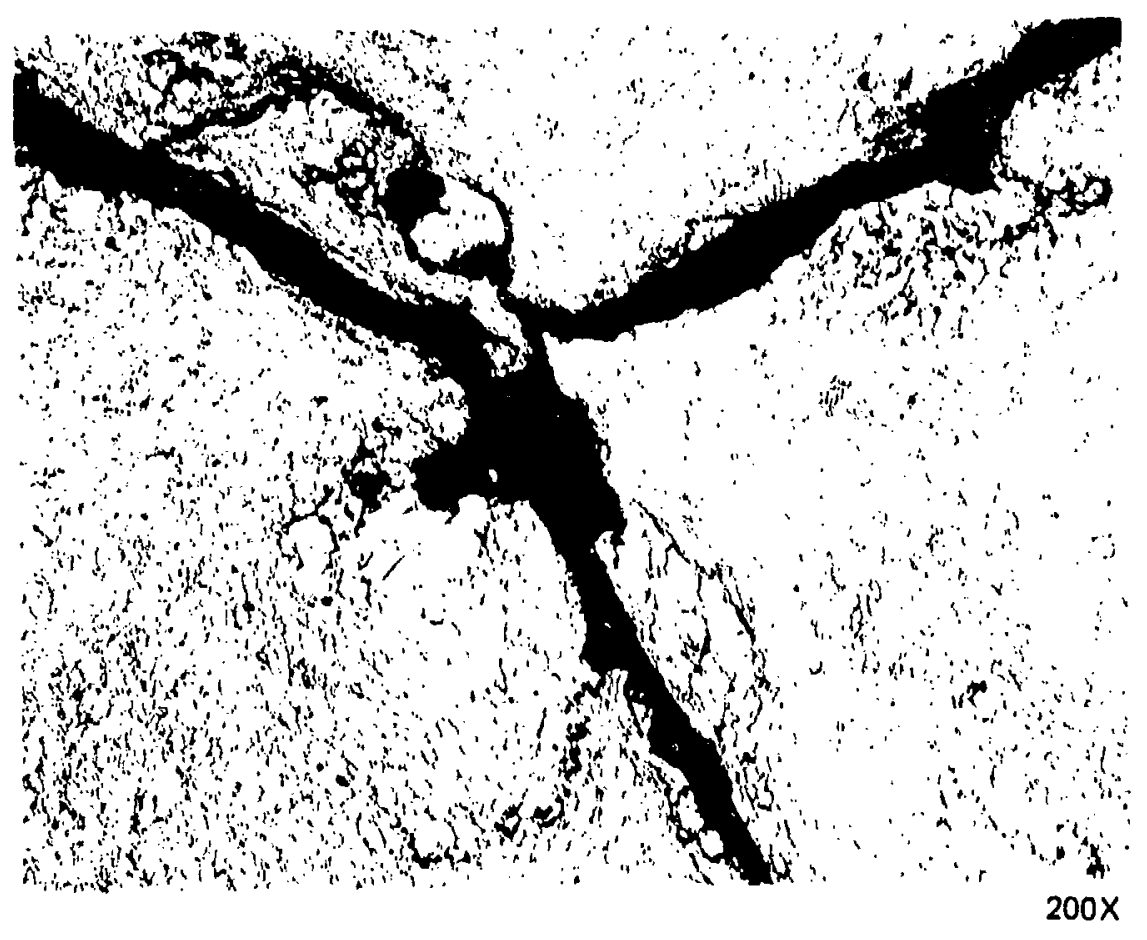

FIGURE 141

PHOTOMICROGRAPHS OF SEGREGATE: IN BAR 1-2A2E, SECTION 4 (RESPONSE WAS GREATER THAN NO. 5 FLAT BOTTOM HOLE) 


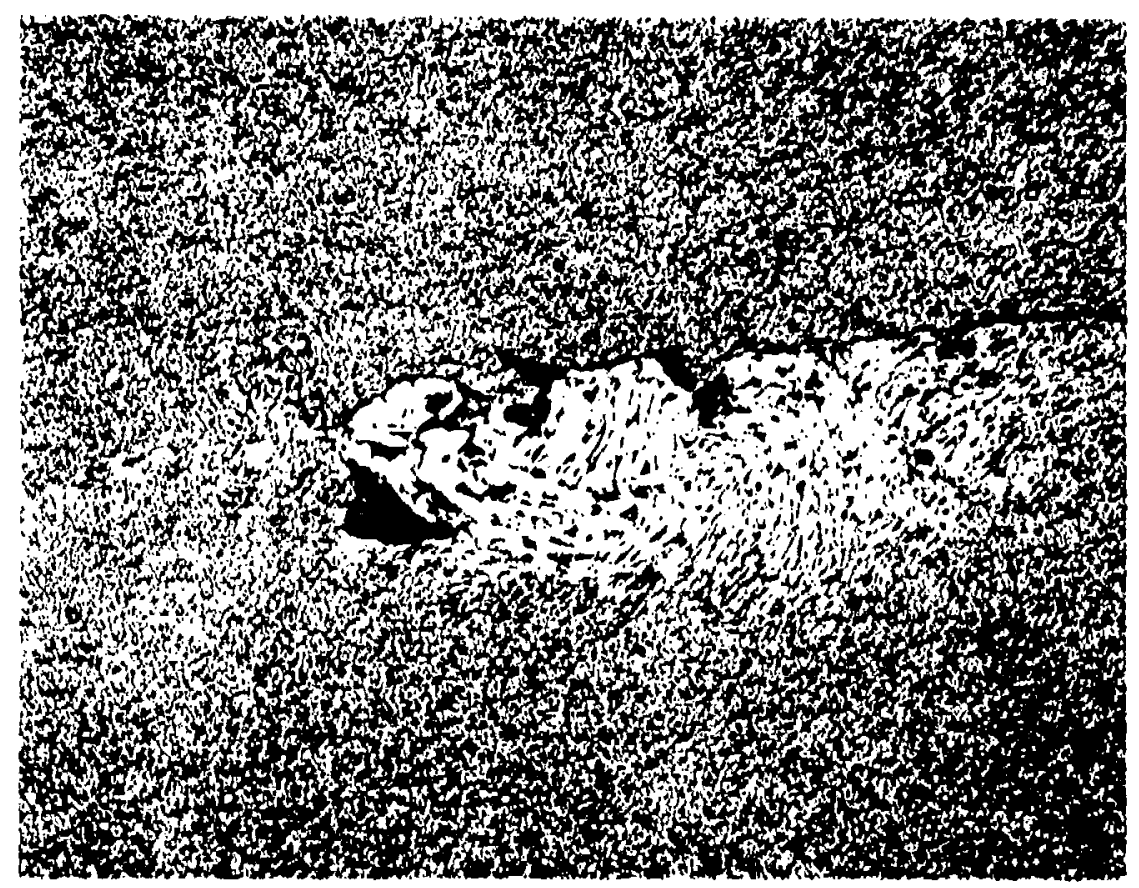

$50 x$

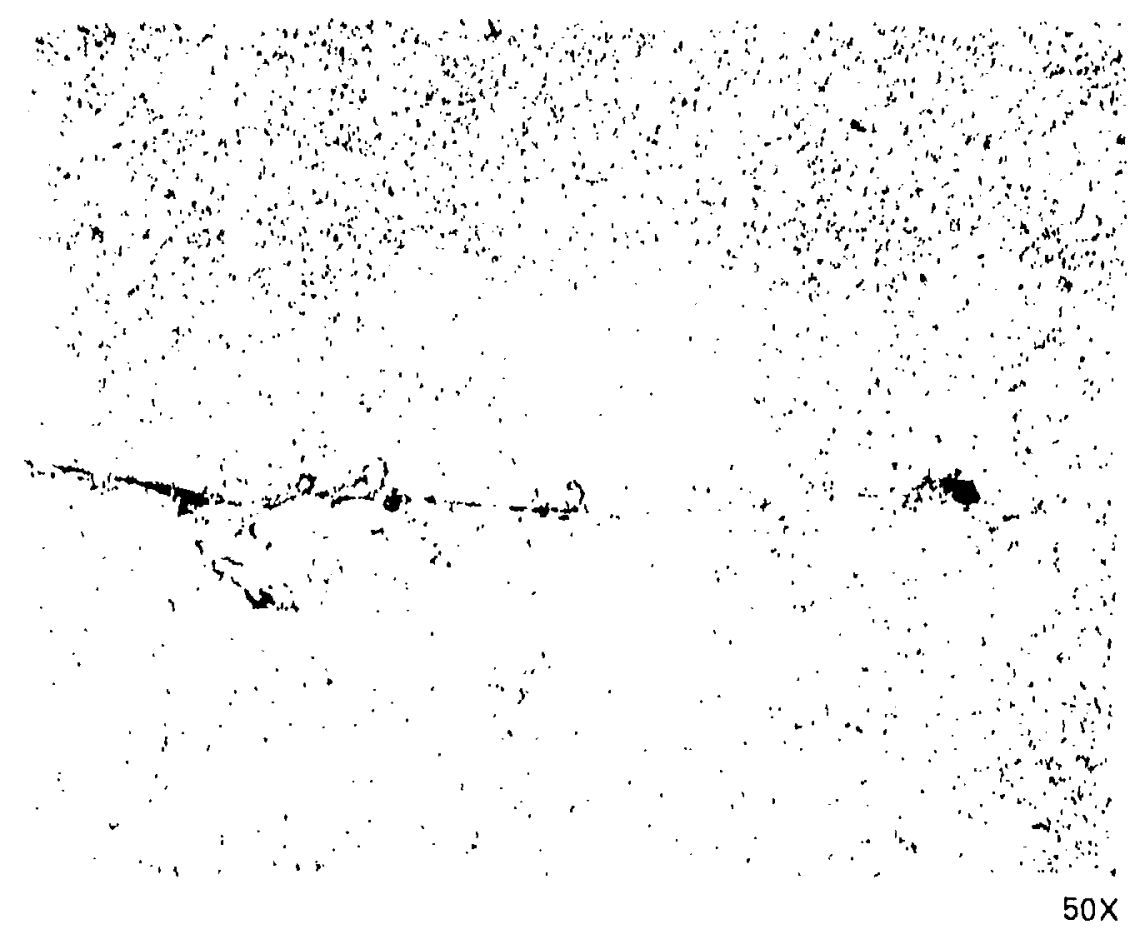

FIGURE 142

PHOTOMICROGRAPHS OF SEGREGATE IN BAR 1-2A2E, SECTION 5 (RESPONSE WAS GREATER THAN NO. 2 FLAT BOTTOM HOLE) 


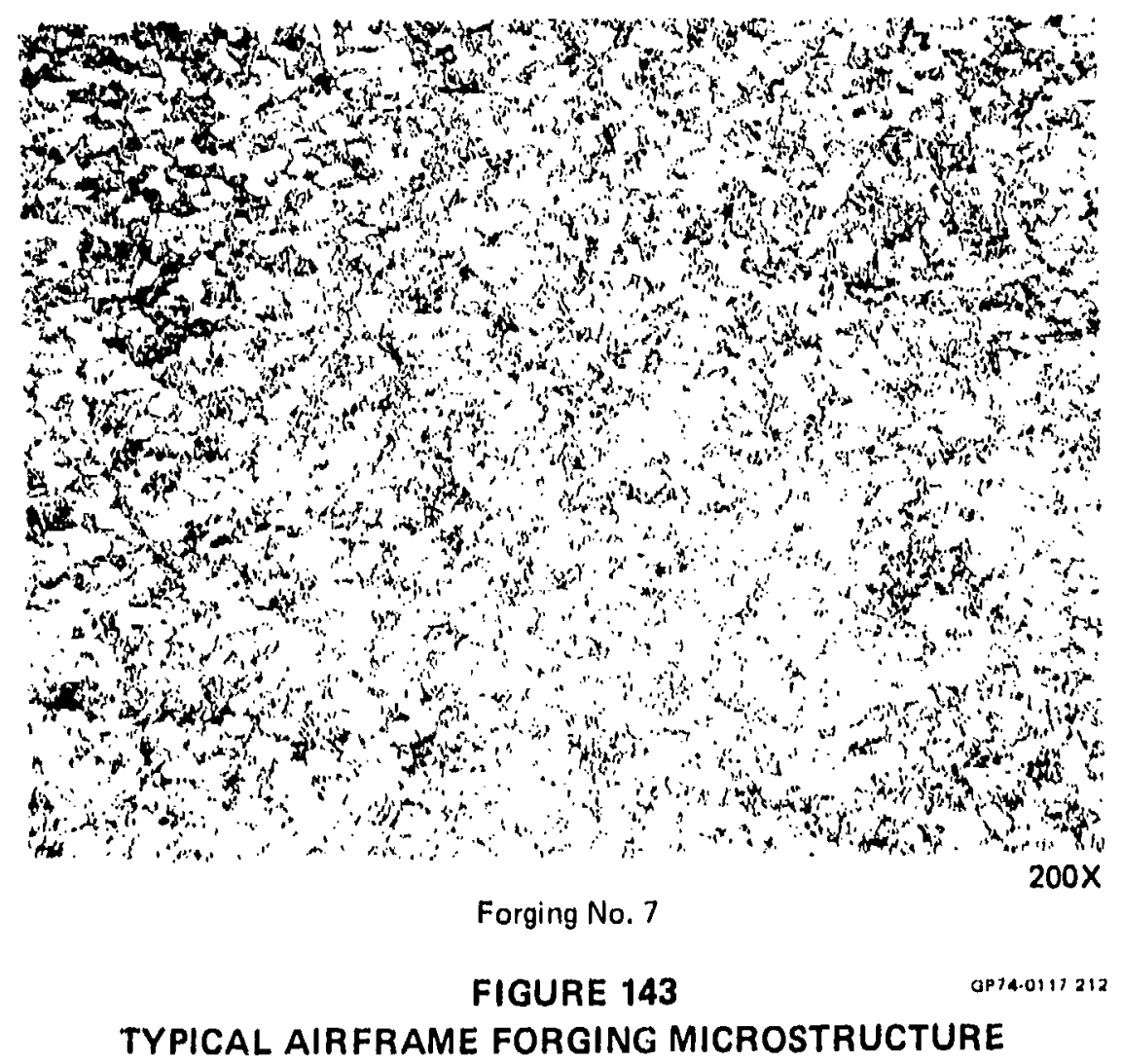


Prior to sectioning Disk Forging No's 4, 6, and 7, an immersion angle beam laboratory ultrasonic inspection was performed to precisely locate several discontinuities detected during the production inspections. A $3 / 4$ inch diameter long focused lithium sulfate search unit was used along with an Immerscope RI pulser/receiver. The test frequency was $15 \mathrm{MHz}$. A water path of 5 inches was used and the sound beam angle in the forgings was 45 degrees. The scan index was .050 inch and the scan rate was 2.25 revolutions per minute. Calibration was performed in the same manner as for the production ultrasonic inspestion of the forgings described previously. An X-Y recording was prepared for all the scans used in the production ultrasonic inspection from an analog signal provided by the ultrasonic equipment. The locations of the subsequent sections for metallographic purposes were based on these results.

Finally, a manual scan inspection was performed using the same equipment except for a Sperry HFN pulser/receiver. An additional $12 \mathrm{~dB}$ of attenuation was used for this inspection.

A comparison of the results of the original C-scan, analog-ecan, and manual scan Disk Forgings No 6 and 7 is shown in Tables 98 and 99 As can be seen, there is a high degree of reproducibility among these three methods.

The locations of the sections taken through the disk forgings are shown in Figure 144. Each section was polished and then macroetched with a 5 percent $\mathrm{HF}-95$ percent water solution for 5 to 10 minutes. Followint this, selected areas were prepared metallographically and examined at high megnification. The etchant used was 10 percent HF-90 percent water for a few seconds. Photomicrographs of the discontinuities in the disk forgings are presented in Figures 145 and 146.

The discontinuity in Disk Forging No 4 appears to be a Type I alpha stabilized defect in appearance. This defect was detected by both shear wave and longitudinal wave ultrasonic inspection during the General Electric production ultrasonic inspection. During that inspection, the ultrasonic amplitude response was 25 percent of saturation in the longitudinal wave inspection and 40 percent of saturation in the radial and circumferential shear wave inspections.

The defect was examined with a Cambridge Sterossan Model Mark IIA scanning eleciron microscope and an aluminum analysis was made in several areas. The aluminum content was 3.9 percent adjacent to the void and 6.0 percent in the matrix away from the void. The aluminuin content in an alpha phase area was 1.5 percent. These compositional differences compare favorably with the previous results reported in "Characterization of Alpha Segregation Defects In Titanium 6Al-4V Alloy" by E. M. Grata in AFML TR 68-304 for Type I alpha stabilized defects. 
TABL'́̃ y8

COMPARISON OF THREE METHODS USED IN FINDING DEFECTS FOR EVALUATION (DISK NO. 6)

Top Circumferential Shear O.D. to I.D.

\begin{tabular}{|c|c|c|c|c|}
\hline Defuct & Type Scan & $\begin{array}{c}\text { Angular Position * } \\
\text { (deg) }\end{array}$ & $\begin{array}{l}\text { Depth } \\
\text { (in.) }\end{array}$ & $\begin{array}{c}\text { Amplitude } \\
(\%)\end{array}$ \\
\hline \multirow[t]{3}{*}{$A$} & C-Scan & 40 & 0.625 & NA \\
\hline & Analog-Scan & 40 & 0.687 & 77 \\
\hline & Manual-Scan & 40 & 0.600 & 44 \\
\hline \multirow[t]{3}{*}{ B } & C.Scan & 320 & 0.750 & NA \\
\hline & Analog-Sican & 320 & 0.687 & $62-75$ \\
\hline & Manual-Scan & 320 & 0.850 & 30 \\
\hline \multirow[t]{3}{*}{ C } & C.Scan & 300 & 1.000 & NA \\
\hline & Analog-Scan & 298 & 0.750 & 68 \\
\hline & Manual-Scan & 300 & 0.900 & 20 \\
\hline \multirow[t]{3}{*}{$H$} & C-Scan & 170 & 0.750 & NA \\
\hline & Analog-Scan & 168 & 0.875 & 60 \\
\hline & Manual-Scan & 170 & 0.800 & 30 \\
\hline \multirow[t]{3}{*}{1} & C.Scan & 355 & 1.000 & NA \\
\hline & Analog.Scan & 355 & NA & 50 \\
\hline & Mariual-Scan & 355 & 0.700 & 50 \\
\hline \multirow[t]{3}{*}{ J } & C-Scan & $255-258$ & 0.250 & NA \\
\hline & Analog-Scan & $265-258$ & 0.312 & 89 \\
\hline & Manual-Scan & 255 & 0.300 & 40.45 \\
\hline \multirow[t]{3}{*}{$J_{2}$} & C.Scan & $262-266$ & 0.250 & NA \\
\hline & Analog-Scan & 265 & 0.250 & 80 \\
\hline & Manual-Scan & 265 & 0.300 & 65 \\
\hline
\end{tabular}

- Enrering point of beam glven - circumforential moda

Note: Depch glven for C-scan is the gate conter depth - actual deptl

can be $\pm 1 / 16$ - also, the ampltude calnot be glven as

reference; grav-scale was not made at the time of the scon.

N.A. ... Not Applicable 
TABLE 98 (Continued)

COMPARISON OF THREE METHODS USED IN FIP.DING

DEFECTS FOR EVALUATION (DISK NO. 6)

Bottom Radial Shear OD to ID

\begin{tabular}{|l|l|c|c|c|}
\hline Defect & Type Scan & $\begin{array}{c}\text { Angular Position } \\
\text { (deg) }\end{array}$ & $\begin{array}{c}\text { Depth } \\
\text { (in.) }\end{array}$ & $\begin{array}{c}\text { Amplicude } \\
(\%)\end{array}$ \\
\hline E & C-Scan & 15 & 1.000 & NA \\
& Analog-Scan & $14-16$ & 0.937 & $79 \cdot 90$ \\
& Manual-Scan & 15 & 1.000 & 70 \\
F & C-Scan & 200 & 1.000 & NA \\
& Analog-Scan & $204 \cdot 206$ & 1.000 & 90 \\
& Manual-Scan & 200 & 1.000 & 80 \\
G & C-Scan & 313.315 & 1.000 & NA \\
& Analog-Scan & $306 \cdot 308$ & 1.062 & 85 \\
& Manual-Scan & 315 & 0.950 & 60 \\
G2 & C-Scan & 330 & 1.250 & NA \\
& Analog-Scan & 342 & 0.812 & 75 \\
& Manual-Scan & 330 & 1.100 & 60 \\
D & C.Scan & 155 & 1.250 & iNA \\
& Analog-Scan & 155 & 0.937 & 85 \\
& Manual-Scan & 155 & 0.950 & 50 \\
\hline
\end{tabular}


TABLE 99

COMPARISON MANUAL AND ANALOG SCANS FOR DISK NO. 7

\begin{tabular}{|c|c|c|c|c|}
\hline Indic. & Type Scan & $\begin{array}{c}\text { Angular Position } \\
\text { (dfeg) }\end{array}$ & $\begin{array}{c}\text { Distance from CD } \\
\text { (in.) }\end{array}$ & $\begin{array}{l}\text { Dopth } \\
\text { (in.) }\end{array}$ \\
\hline & & \multicolumn{2}{|c|}{ Bottom Radial Shear In } & \\
\hline A & Analog & $1 ; 6$ & $0.9-1.2$ & 1 \\
\hline A & Manual & 176 & 0.9 & 1.1 \\
\hline B & Analog & 224 & $0.4-0.5$ & $1 \cdot 1.1$ \\
\hline B & Mianual & 224 & $0.4 \cdot 0.5$ & 1.1 \\
\hline C & Analog & 240 & $0.8 \cdot 0.9$ & $0.95 \cdot 1.0$ \\
\hline C & Manual & 240 & $0.8-0.9$ & 0.95 \\
\hline$D$ & Analog & 192 & $1.35 \cdot 1.45$ & $0.85-1.0$ \\
\hline$D$ & Manual & 192 & 1.4 & 0.9 \\
\hline F. & Analog & 350.355 & $1.45 \cdot 1.6$ & $1.02 \cdot 1.1$ \\
\hline E & Manual & 350.355 & 1.5 & 1.05 \\
\hline$F$ & Analog & 250 & $1.9-1.95$ & 0.3 \\
\hline $\mathbf{F}$ & Manual & 250 & $i .9$ & 0.3 \\
\hline G & Analog & $98-100$ & $1.25-1.25$ & $1.15 \cdot 1.17$ \\
\hline $\mathbf{G}$ & Manual & 100 & $1.25-1.3$ & 1.15 \\
\hline$H$ & Analog & 22 & $0.9-1.0$ & 1.15 \\
\hline$H$ & Manual & 22 & 1.0 & 1.15 \\
\hline$N$ & Analog & 84.86 & 2.250 & 0.4 \\
\hline $\mathbf{N}$ & Manual & \multicolumn{2}{|c|}{ Top Radial Shear In } & 0.4 \\
\hline 1 & Analog & $124 \cdot 126$ & $0.25-0.3$ & $0.7 \cdot 0.75$ \\
\hline 1 & Manual & 124 & 0.3 & 0.75 \\
\hline J & Analog & $98 \cdot 102$ & $0.85-0.95$ & $0.8 \cdot 0.9$ \\
\hline J & Manual & 100 & 0.850 & 0.9 \\
\hline$K$ & Analog & 278 & $0.45 \cdot 0.5$ & $0.7 \cdot 0.75$ \\
\hline $\mathrm{K}$ & Manual & 278 & 0.5 & $0.7 \cdot 0.75$ \\
\hline$L$ & Analog & $140 \cdot 144$ & $2.1-2.2$ & $1+$ \\
\hline L & Manual & 140 & 2.15 & $1+$ \\
\hline M & Analog & 92 & $1.3-1.35$ & 0.95 \\
\hline$M$ & Manual & $\theta 2$ & 1.3 & 0.95 \\
\hline
\end{tabular}




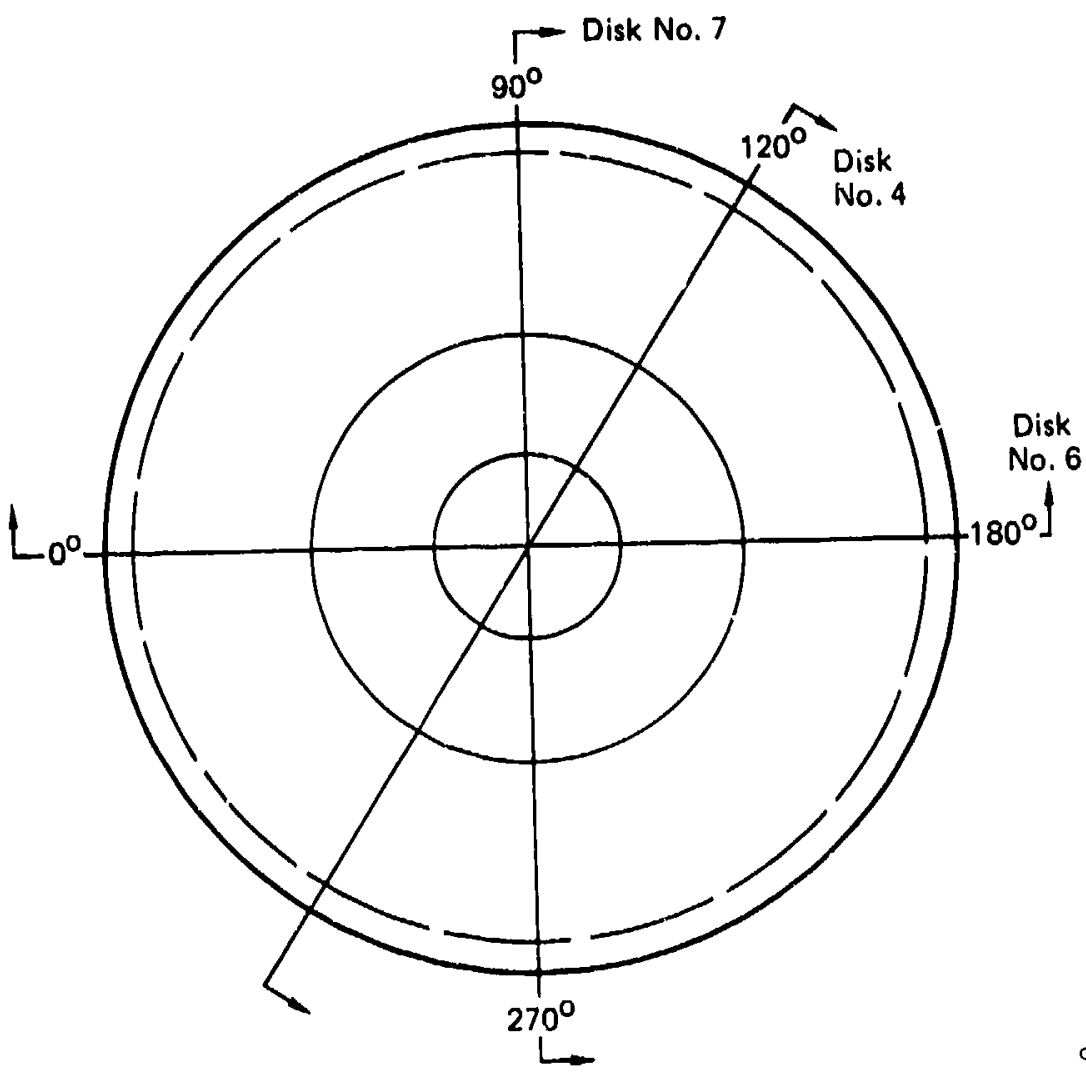

370117239

FIGURE 144

LOCATION OF METALLOGRAPHIC CROSS SECTIONS IN DISK FORGINGS 


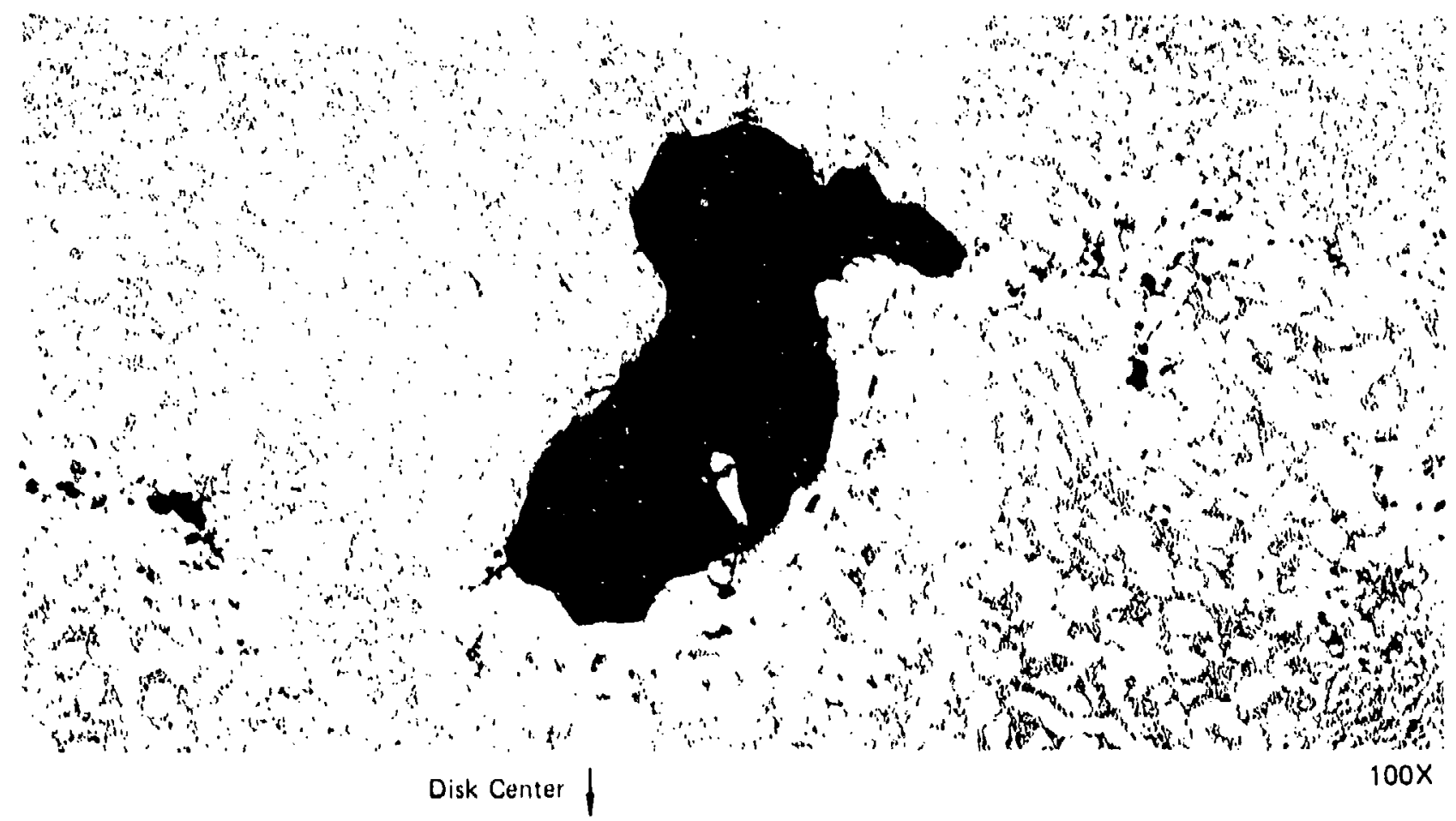

Disk Forging No. 4

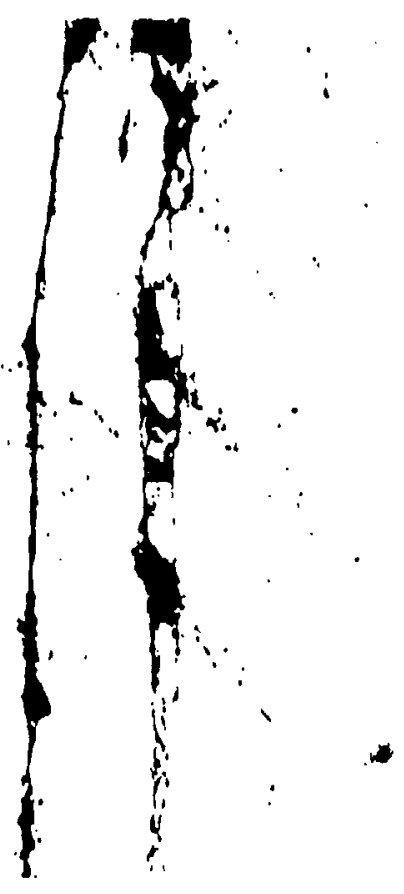

Disk Forging No. 6

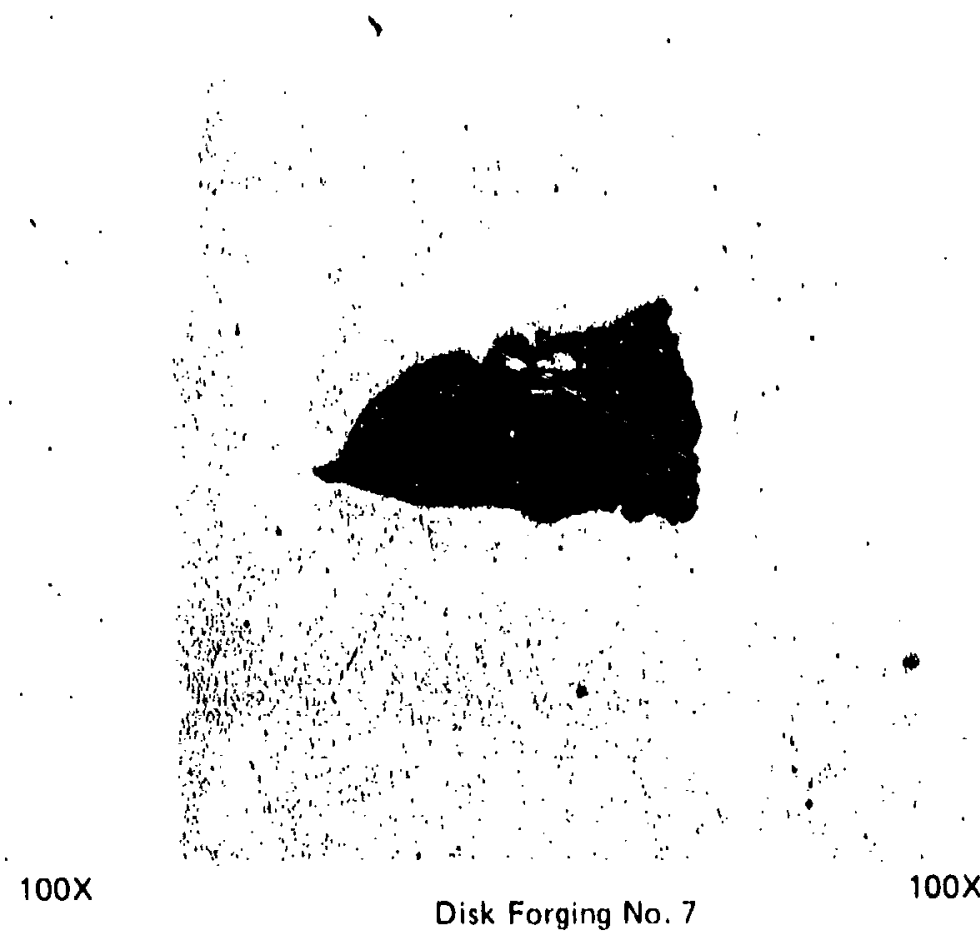

FIGURE 145

$(3+14.011721 .5$ DISCONTINUITIES IN DISK FORGINGS 

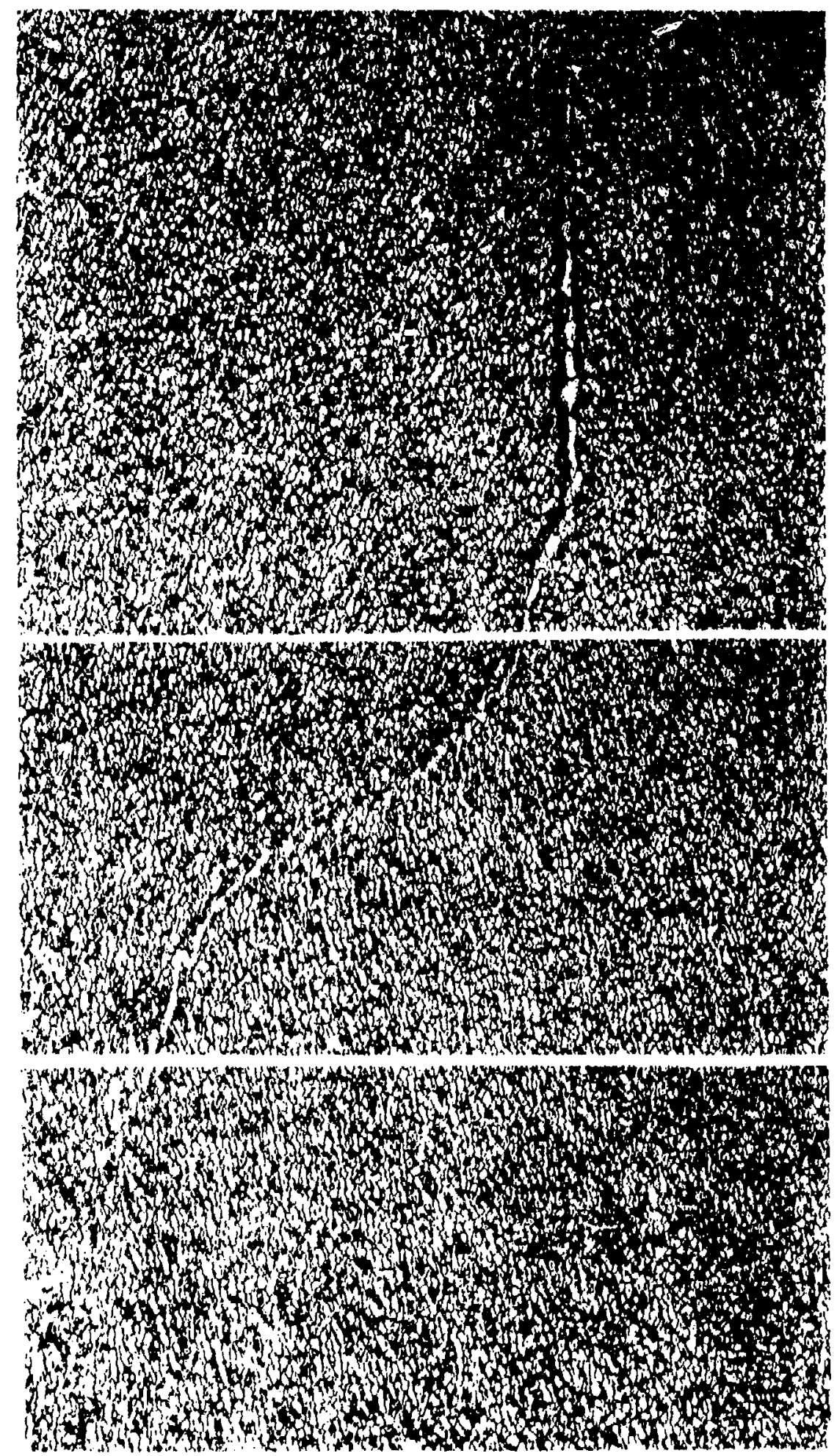

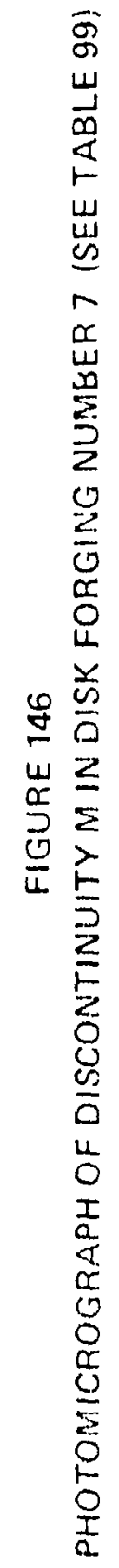


SECTION VI

CONCLUSIONS

The following conclustons may be drawn from the results reported here:

(1) To most effectively detect a wide variety of crack and porosity sizes with a production penetrant inspection, several parameters must be carefully controlled. These parameters include the penet.rint dwell and bleed-out times, the emulsification time, the temperature and pressure of the water used to iemove the excess penetrant, the type of developer uged, and the ultraviolet/white light intensity in the inspection. Some manufacturing operations performed prior to penetrant inspection, such as glass bead peenting and shot peenting, can reduce the effectiveness of subjequent penetrant inspection. Removal of material by chemical etching prior to the penetrant inspection can improve the effectiveness of the penetrant inspection.

(2) Surface connected cracks with lengths of approximately .050 to .10 Inch can be detected with a high probability at a 95 percent confidence level in a production penetrant inspection. Smaller cracks can also be detected, but with a lower probabllity of detection. The overall capability for crack detection in a particular production part is related to the chosen NDT plan. For example, a penetrant inspection followed by a surface wave and - gle beam ultrasonic inspection will substantially increase the p.obability of crack detection.

(3) The offectiveness of ultrasondc inspection of titanium ingot, biller, and forgings can be increased by using the shear wave mode as well as the longttudinal wave node.

(4) Macroetching and anodic etching of the random billet sections are ineffective techniques for establishing the exdstence of Type I stabilized areas.

(5) Ultrasonic ingpection of titanium ingot and billet material could be signiflcantly improved by implementation of such developed inspection techniques as the use of proper reference standards, proper preparation of the billet surfaces, and crmpensation for sound transutssion differences.

(6) A significant difference in sound transmission characteristics can exist between the part to be inspected and the reference used when inspecting titanium bar, plate, and forgings. When these differences are large, compensation must be made to conduct on effective ultrasonic inspection.

(7) Contour sound entry surfaces can significantly effect the resilts of a straight beam immersion ultrasontc inspection and compensation shoulo be made for this effect. The amount of compensation required varies as a function of radius of curvature, metal travel distance and search undt. Aluminum contour reference standards can be used for inspecting titantum if adjustments are made for differences in sound transmission characterist1cs. One contour reference standard can he used to inspect a contour surface with a range of radil. 
(8) The effectiveness of immersion angle beam inspection of internal cracks in machined thick sect,on titanium is highly dependent upon the orientation of the crack with respect to the sound beam. Crack detection capability is very poor with the sound beam at 45 degrees to the crack surface.

(9) Discontinuities, which are ortented perpendicular to the sound entry surface, are more easily detected in thin section parts than thick section parts when using angle beam uitrasonics. Discontinulties, which are oriented parallel to the sound entry surface, can be detected in thin section parts using straight beam ultrasonics.

(10) A multiple inspection NDT approach, such as a penetrant inspection followed by both a surface wave and contact angle beam ultrasonic inspection, is highly effective in detecting surface cracks. At least 98 percent (95 percent confidence level) of all cracks with lengths .050 to 0.10 inch can be detected with such in inspection approach.

(11) The radiographic method does not appear to be an effective method for the detection of Type I or Type II alpha stabilized defects in titanium bar, plate, and forgings, whereas the ultrasonic method can be effective in detecting Type I alpha stabilized defects in titanium ingot and billet as well as bar, plate, and forgings.

(12) Eddy current methods potentially can detect fatigue cresks with depths of approximately .025 inch in unfilled fastener holes. Higher frequency eddy current inspection may be capable of detecting smalier cracks, 
Section VII

Recommendations

The following recommendations are made based on the results reported here:

(1) The processing parameters for other penetrant systems need to be investigated to establish the variations to le expected from one system to another.

(2) The crack detection capability of other penetrant systems need to be measured to determine the variation within one MIL-I-25135 group.

(3) The quantitative effect of varlous mechanical processes upon penetrant crack detection capability needs further definition.

(4) Further work should be done in the area of ultrasonic inspection of contour surfaces to determine at which radius the contour effect becomes negligible.

(5) The crack detection capability of surface wave ultrasonics should be measured for subsurface cracks at various depths below the surface.

(6) Several aspects of ultrasonic inspection of titanium inpot and billet, such as controlling search unit characteristics and usinf proper reference standards, need to be implemented by the titanium producers.

(7) Several aspects of radioiraphic inspection need to be improved. Improvements in the plaque-type imare quality indicators are necessary to achieve reproducible radiography. Imare quality indicators are needed for material thicknesses of $1 / 4$ inch or less. A need exists for low $\mathrm{kV}$, hlgh milliamperage $X$-ray equipment to improve subject contrast while maintaining reasonable exposure time. A method is needed to measure the actual KV of an X-ray machine.

(8) The minimum detectable crack depth in titanium fastener holes with hign frequency eddy current reeds to be determined.

(9) The effect of the alpha segregates, detected in this program, upon the mechanical properties of $\mathrm{TI}-6 \mathrm{Al}-4 \mathrm{~V}$ needs to be established.

(10) Military nondestructive testing specifications shuuld be revised to include data developed during this program such as penetrant dwell times for high sensitivity water washable penetrants and ultrasonic inspection procedurss for contour surfaces. 


\section{REFERENCES}

(1) i. S. Abbott, "Effect of Mechanical Processing Unnn Penetrant Inspection Eingitivity", TIS Number CPO2OGFO12.20, Peport MDC Al181, McDonnell Aircraft Company, 24 June 1971.

(2) Sattler, F. J. and Matay, I. M., "Advanced Nondestructive Testing Techniques for Titanium Billets and Ingots", AFML TR-70-118, June 1970.

(3) E. M. Grala, "Characterization of Alpha Segregation Defects in Titanium 6AI-4V Alloy", AFNL TR-68-304.

(4) F. W. Wood, "Improvement of Ritanium Alloy Ingot Consolidation", AFML-TR-72-46, May 1972.

(5) R. C. McMaster, Fd., Nondestructive Testing Handbook, Vol. 2, Soclety for Nondestructive Testing, Ronald Press, 1963. 